$$
\begin{aligned}
& 0 \\
& 2 \\
& w \\
& 1 \\
& n \\
& u \\
& 3
\end{aligned}
$$



NILS S. BORCHERS, SELMA GÜNEY, UWE KRÜGER \& KEREM SCHAMBERGER (HRSG.)

\section{Transformation der Medien - Medien der \\ Transformation}

Verhandlungen des Netzwerks

Kritische Kommunikationswissenschaft 
Mehr über unsere Autoren und Bücher:

www.westendverlag.de

Die Deutsche Nationalbibliothek verzeichnet diese Publikation in der Deutschen Nationalbibliografie; detaillierte bibliografische Daten sind im Internet über http://dnb.d-nb.de abrufbar.

Dieser Band ist im Nachgang der 3. Jahrestagung des Netzwerks Kritische Kommunikationswissenschaft entstanden, die unter dem Titel "Transformation der Medien - Medien der Transformation« vom 21. bis 22. November 2019 an der Universität Leipzig stattfand, und wird gefördert von der Universität Leipzig mit Mitteln aus dem Publikationsfond für OA-Monographien und -Sammelbände.

Die Beiträge in diesem Buch erscheinen unter der Creative-Commons-Lizenz CC BY-ND 3.0 DE:

https://creativecommons.org/licenses/by-nd/3.0/de/

DOI: https://doi.org/10.53291/GFNG8688

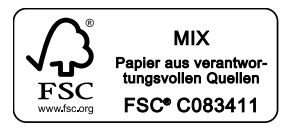

ISBN: 978-3-86489-845-7

(C) Westend Verlag GmbH, Frankfurt / Main 2021

Umschlaggestaltung: Buchgut, Berlin

Satz: Publikations Atelier, Dreieich

Druck und Bindung: CPI - Clausen \& Bosse, Leck

Printed in Germany

Lektorat: Philipp Müller 


\section{Inhalt}

Nils S. Borchers, Selma Güney,

Uwe Krüger \& Kerem Schamberger

Einleitung

Medien-Transformation in der DDR und in Ostdeutschland

Mandy Tröger

Die vergessenen Medienreformen des letzten

Jahres der DDR

Judith Kretzschmar \& Rüdiger Steinmetz

Abbruch, Umbruch, Aufbruch: Programme des

sächsischen Lokalfernsehens in der Nachwendezeit

1990-1995

Antje Glück

Kalter Krieg oder innere Einheit? Der Wandel des

Mediendiskurses über Ostdeutschland durch

ostdeutsche Journalist*innen in Die Zeit

\section{Digitale Transformation in der neoliberalen Globalisierung}

Klaus Dörre

Kampf um Öffentlichkeit. Kapitalistische Landnahme

und die Zerstörung von Vernunft

Holger Pötzsch

Kapitalismus, Big Data und die neue Rolle der Archive:

Anmerkungen zu kritischer Medienkompetenz in Zeiten

digitaler Transformation 
Johannes Gemkow

Wikipedia und die Transformation der Wissensaushandlung

Hanan Badr

Zehn Jahre nach den Arabischen Umbrüchen:

Kritische Reflektionen zu Medien und Transformation

in Ägypten und Tunesien

Sebastian Köhler

Transformation und Transparenz:

Warum im Journalismus das »Quellen-W « wichtiger wird

Michael Haller

Transformationen im Online-Medienmarkt:

Was wird aus den journalistischen Kompetenzen?

Natalie Berner

Motherhood in Transition - Who Cares?

Eine qualitative Analyse medialer Anerkennungsstrukturen von Mutterschaft und Care-Arbeit

\section{Kommunikation für eine sozial-ökologische Transformation}

Sigrid Kannengießer

Sozial-ökologische Transformationsforschung: Desiderata der Kommunikations- und Medienwissenschaft

Thomas Pleil, Sandra Müller \& Lea Matusiak

Public Relations in der transformativen Wissenschaft:

Der Beitrag Strategischer Kommunikation zum Gelingen

eines transformativen Forschungsparadigmas

Melanie Malczok

Strategische Devianz: Potenziale und Risiken ungehorsamer Ästhetik in der Kommunikation sozialer Bewegungen 
Moritz Clauß

Der Index der Eliten? Politische und mediale Perspektiven auf die nachhaltige Entwicklung in Deutschland

Torsten Schäfer \& Stella Lorenz

Wo steht der deutschsprachige Nachhaltigkeits-

journalismus? Ein Überblick

Uwe Krüger

Geburtshelfer für öko-soziale Innovationen:

Konstruktiver Journalismus als Entwicklungskommunikation für westlich-kapitalistische Gesellschaften in der Krise

Thomas Wiedemann

Filmförderung als Transformationsbremse.

Die politische Gestaltung der Kinospielfilmproduktion in Deutschland

\section{Visionen für transformative Kommunikationsverhältnisse}

Nils S. Borchers \& Sebastian Jürss

Wird die Große Transformation geteilt? Zum Einfluss

der Geschäftsmodelle von Sharing-Plattformen auf das transformative Potenzial der Sharing Economy

401

Heiko Hilker

Für ein neues duales System: Der öffentlich-rechtliche Rundfunk als Ausgangspunkt für datensparsame Plattformen - Plädoyer eines Medienpolitikers

Florian Zollmann

Gegen die Zwänge des Marktes: Konturen eines demokratischeren Mediensystems 



\section{Einleitung}

\section{Nils S. Borchers, Selma Güney, Uwe Krüger \& Kerem Schamberger}

Nils S. Borchers, Selma Güney, Uwe Krüger \& Kerem Schamberger: Einleitung. In: Nils S. Borchers, Selma Güney, Uwe Krüger und Kerem Schamberger (Hrsg.): Transformation der Medien - Medien der Transformation. Verhandlungen des Netzwerks Kritische Kommunikationswissenschaft. Frankfurt am Main: Westend 2021. DOI: https://doi.org/10.53291/MWNT3828.

\section{Hintergrund und Idee des Bandes}

Wir stehen vor großen Herausforderungen: Die menschengemachte Erderwärmung scheint, trotz regelmäßiger Klimagipfel und ausgerufener Klimaziele, bislang kaum aufhaltbar. Das Eigentum ist - weltweit und innerhalb der westlichen Demokratien - immer ungleicher verteilt; das führt zu Migrationsbewegungen in den globalen Norden, die dort zum Teil erheblichen Protest erregen. Wir erleben hierzulande, in Europa und den USA einen rasanten Aufstieg rechter Kräfte, demokratische Grundprinzipien werden in Frage gestellt, das Vertrauen in gesellschaftliche Institutionen erodiert, und die erreichten Erfolge emanzipativer Bewegungen, beispielsweise in Hinblick auf Geschlechterverhältnisse und Antirassismus, werden öffentlichkeitswirksam negiert - eine Entwicklung, die insbesondere die Bereiche Medien und Journalismus berührt. Es wird immer deutlicher, dass angesichts der multiplen Krisen, mit denen sich heutige Gesellschaften konfrontiert sehen, ein »Weiter so« nicht möglich ist. Nötig sind tiefgreifende Veränderungen statt bloßer Feinanpassungen, mit anderen Worten: eine umfassende gesellschaftliche Transformation.

Dieser Sammelband geht zurück auf die 3. Jahrestagung des Netzwerks Kritische Kommunikationswissenschaft (KriKoWi), die unter dem Titel »Transformation der Medien - Medien der Transformation« vom 21. bis 22. November 2019 am Institut für Kommunikations- und 
Medienwissenschaft (IfKMW) der Universität Leipzig stattfand. Thema, Ort und Zeit waren nicht zufällig gewählt, jährte sich doch zum 30. Mal der Fall der Berliner Mauer, dem die Montagsdemonstrationen in Leipzig vorangegangen waren. In der damaligen Noch-DDR markierte der November 1989 den Beginn einer grundlegenden politischen, wirtschaftlichen, sozialen und kulturellen Umwälzung, bei der Medien sowohl im Vorfeld als auch im Verlauf eine wichtige Rolle spielten und von der sie selbst natürlich auch betroffen waren.

Bei »Transformation« im Sinne von grundlegendem Wandel handelt es sich einerseits um einen Prozess - um nicht zu sagen: Dauerzustand -, in dem sich die Medien seit spätestens den 1990er Jahren weltweit befinden und den man mit »digitalem Strukturwandel der Öffentlichkeit« (Eisenegger 2021) umreißen könnte. Die technologische Revolution der »Digitalisierung «, im engeren Sinne verstanden als »die Wandlung analoger Informationen in eine diskrete, stufige (Daten-) Form « (Sühlmann-Faul und Rammler 2018, 29), wird dabei begleitet von und ist verschränkt mit anderen Megatrends wie Globalisierung, Ökonomisierung und Individualisierung. So ist Digitalisierung »als ganzheitlicher, radikaler und lange dauernder gesamtgesellschaftlicher Umbruchsprozess (oder als ssoziotechnische Transformation`) zu verstehen « (ebd., 31). Neuen Medientechnologien wie dem Internet wird oftmals das Potenzial zugeschrieben, gesellschaftliche Transformationsprozesse auszulösen und zur Demokratisierung beizutragen; genauso häufig werden die in sie gesetzten Hoffnungen allerdings enttäuscht. Denn die Art und Weise ihres Gebrauchs hat - nicht zuletzt aufgrund bestehender kapitalistischer Besitz- und Machtverhältnisse immer wieder dazu geführt, dass sie Herrschaftsstrukturen reproduzieren. Auch digitalisierungsgetriebene Transformationsprozesse und die mit ihnen zusammenhängende Globalisierung unter neoliberalen Vorzeichen sind in diesem Sammelband Thema kritischer Betrachtung.

Andererseits wird »Transformation « in diesem Band in einem weiteren Sinn verwendet: als eine neue »Große Transformation « zu einer nachhaltig wirtschaftenden und sozial sowie intersektional gerechten Weltgesellschaft. Eine solche tiefgreifende Umgestaltung erscheint unserem Netzwerk KriKoWi im Angesicht von Klima- und Ökokrise, exorbitanten sozio-ökonomischen Ungleichheiten und Ungerechtigkeiten sowie Diskriminierungen in Sachen class, race und gender nicht nur wünschenswert, sondern dringend notwendig. ${ }^{1}$ Ein Schlüsselkon-

1 Siehe das Selbstverständnis des Netzwerks Kritische Kommunikationswissen- 
zept in dieser Debatte um eine sozial-ökologische Transformation ist die Nachhaltigkeit, die als »moralische Revolution « verstanden werden kann und als »eine systematische Erweiterung der Idee der Menschenrechte « zu denken ist, da sie »ein wachsendes Verständnis des Respekts gegenüber anderen Menschen, global und intergenerationell« (Schneidewind 2018, 26) markiert: Alle heutigen und zukünftigen Menschen auf der Erde sollen die gleichen Entwicklungsmöglichkeiten haben. Außerdem muss eine Große Transformation für die Interessen der Tiere wie auch der Natur insgesamt einstehen und ihnen unveräußerliche Rechte zugestehen (Freeman et al. 2011; Perlo 2002). Für einen solchen Wertewandel sind Medien und öffentliche Kommunikation entscheidend, da über sie Wissensbestände, Normen und Ideologien transportiert und (re-)produziert werden, die eine sozial-ökologische Transformation entweder begünstigen oder behindern können.

Aus unserer Sicht kommt der Kommunikations- und Medienwissenschaft eine wesentliche Rolle bei der Erforschung der medialen Bedingungen dieser Transformationen zu (Kannengießer 2020; Krüger und Meyen 2018) - eine Verantwortung, der sich das Fach bislang nur bedingt gestellt hat. Im Rahmen einer Öffentlichen Kommunikationswissenschaft sollte sich die Disziplin zudem nicht damit begnügen, diese Transformation »bloß« zu erforschen, sondern darüber hinaus Fragestellungen emanzipatorischer gesellschaftlicher Bewegungen aufnehmen, ihre Expertise in den öffentlichen Diskurs einspeisen und an gesellschaftlichen Entscheidungsprozessen mitwirken.

So handelt dieses Buch von drei Transformationen - einer politischen, einer technologischen und einer moralischen - und den mit ihnen verbundenen gesellschaftlichen Wandlungsprozessen mit besonderem Fokus auf Kommunikationsverhältnissen, Medienlandschaften und Öffentlichkeitsstrukturen. In den Beiträgen werden zugleich immer wieder die Berührungspunkte dieser drei Umwälzungen deutlich. Das Buch ist kritisch, weil die hier versammelten Autor*innen Bezug nehmen auf Gesellschaftstheorien und Kapitalismusanalyse, weil sie auf Eigentumsverhältnisse, Herrschaftsformen, Machtungleichgewichte sowie die sie stützende(n) Ideologie(n) blicken und weil sie einen Beitrag dazu leisten möchten, die Gegenwart in ihrer historischen Gewordenheit zu verstehen und in Richtung einer sowohl gerechteren als auch zukunftsfähigeren Welt für kommende Generationen zu transformieren.

schaft unter: https://krikowi.net/netzwerk/. 


\section{Aufbau des Bandes}

Die Wechselwirkungen von Transformation und Medien werden in diesem Band in vier Kapiteln verhandelt, die wir im Folgenden kurz vorstellen.

\section{Medien-Transformation in der DDR und in Ostdeutschland}

30 Jahre nach der Friedlichen Revolution an der Universität Leipzig über Medien, Öffentlichkeit und Journalismus zu sprechen, ist alles andere als konfliktfreier Stoff. Denn während in den späten 1980er Jahren eine relativ kleine Gruppe überwiegend junger Leipziger*innen mit Rückendeckung einiger evangelischer Pfarrer beharrlich daran arbeitete, Öffentlichkeit für Missstände in der DDR herzustellen und illegale Proteste zu organisieren, bildete die personell gut ausgestattete Sektion Journalistik der Karl-Marx-Universität angehende Journalist*innen als Propagandist*innen, Agitator*innen und Organisator*innen der SED aus. Auf der einen Seite wurden heimlich Flugblätter auf Schreibmaschinen getippt, per Wachsmatritzenmaschinen vervielfältigt und unter Gefahr verbreitet sowie Informationen per Westmedien »über Bande gespielt«, um die DDR-Bevölkerung über oppositionelle Aktivitäten zu informieren und Inhaftierte freizubekommen (Wensierski 2017; Krüger 2015). Auf der anderen Seite wurden im sogenannten »Roten Kloster« unter professoraler Anleitung Diplomarbeiten geschrieben wie »Der sozialistische Journalismus als Tribüne der sozialistischen Demokratie« oder »Formen und Methoden der wirkungsvollen journalistischen Darstellung von Erfahrungen der Werktätigen beim Ringen um den wissenschaftlich-technischen Fortschritt« - beides Schriften aus dem Jahr 1989.

Nachdem die SED vor der Macht der Straße eingeknickt war, wurde die Sektion Journalistik abgewickelt und mit Wissenschaftler*innen aus der Bundesrepublik, unter der Leitung des Münchner Ordinarius Karl-Friedrich Reimers, als »Institut für Kommunikations- und Medienwissenschaft « neu gegründet. Die Entscheidungen, wer bleiben durfte, wer gehen musste und wie mit dem durchaus vielfältigen und widersprüchlichen Erbe der Leipziger Journalistik umzugehen ist, fielen dabei nicht immer auf nachvollziehbare Weise. Was damals gut lief und was hätte besser und gerechter laufen können, verhandelten die damals beteiligten Akteur*innen aus Ost und West in einer span- 
nungsgeladenen Podiumsdiskussion unter dem Titel »Der Abriss des Roten Klosters - Wie die Journalistenausbildung in Leipzig verwestlicht wurde« auf der Tagung. Der Impulsvortrag von Hans Poerschke, 1989/90 letzter gewählter Direktor der Sektion Journalistik, sowie die Diskussion zwischen ihm, Heike Schüler, Michael Haller und Horst Pöttker unter der Moderation von Melanie Malczok sind im Netz nachzuerleben und -zulesen. ${ }^{2}$ In diesem Band wird das Thema »MedienTransformation in der DDR und in Ostdeutschland « von anderen Seiten beleuchtet.

Die Medien-Wende in der DDR beschreibt Mandy Tröger aus Sicht von ostdeutschen Akteur*innen, die ihre neugewonnene Freiheit nach dem Mauerfall von der SED für eigenständige medienpolitische Reformen nutzten und der Noch-DDR eine eigenständige demokratisch-pluralistische Medienordnung geben wollten. Diese visionierte Ordnung unterschied sich in einigen Punkten durchaus von der in der Bundesrepublik bestehenden. Die schnelle Wiedervereinigung 1990 mit der Durchsetzung westdeutscher Partei- und Konzerninteressen machte ihre Bemühungen jedoch bald obsolet. Dennoch lohnt es sich, ihr Erbe nachzuvollziehen: Vor allem die Betonung der »inneren Pressefreiheit«, also der Autonomie der Journalist*innen von Vorgesetzten und Medieneigentümer*innen, sollte heute angesichts steigender Medienkonzentration und Ökonomisierungstendenzen wieder ins medienpolitische Gedächtnis gerufen werden.

Während die einen demokratische Medienpolitik zu gestalten versuchten, machten die anderen Lokalfernsehen von unten: Judith Kretzschmar und Rüdiger Steinmetz beschäftigen sich mit den Strukturen und dem Output von rund 40 sächsischen TV-Sendern zwischen 1990 und 1995, welche die unmittelbare Nachwendezeit hautnah dokumentierten. Ohne öffentlich-rechtliche Anstalten oder Konzernstrukturen im Rücken besorgten Pfarrer, Kleinunternehmer*innen, Videokünstler*innen und Hobbyjournalist*innen Berichterstattung aus der Nachbarschaft. Was dort zu sehen war und wie sich bei Wiederaufführungen vor sächsischen Bürger*innen deren Träume und Trau-

2 Über den YouTube-Kanal des Netzwerks KriKoWi ist ein Mitschnitt der Veranstaltung verfügbar: https://www.youtube.com/watch?v=gwVBhfo8aJE $\& \mathrm{t}=4399$ s. Ein Transkript findet sich im »Biographischen Lexikon der Kommunikationswissenschaft« von Michael Meyen: http://blexkom.halemverlag. de/landnahme/. 
mata der frühen 1990er Jahre re-aktualisieren, beschreibt der Beitrag anschaulich in Text und Bild.

Wie gestaltet sich der mediale Diskurs über Ostdeutschland und Ostdeutsche heute und welche Veränderungen sind hier festzustellen? Antje Glücks Beitrag widmet sich der Transformationskraft der neuen Wende- und Post-Wende-Generation von Journalist*innen mit einem besonderen Blick auf das Büro der Zeit im Osten. Mithilfe einer kritischen Diskursanalyse der westdeutschen Wochenzeitung Die Zeit arbeitet sie heraus, wie negative Stereotype, die den Osten essentialistisch und marginalisierend darstellen, in der Berichterstattung zwar weiterhin fortbestehen, sich aber auch - unter anderem als Reaktion auf den Aufstieg der AfD - Entwicklungen hin zu einem integrativeren Mediendiskurs erkennen lassen. Darin kommt es (zwar nicht dauerhaft, jedoch deutlich erkennbar) zu emanzipierenden Diskursen, in denen ostdeutsche Identität ausgehandelt wird.

\section{Digitale Transformation in der neoliberalen Globalisierung}

In den 1980er Jahren ging es mit der »überschaubaren alten Medienwelt, in der eine recht kleine Zahl privater Print-Verlage und öffentlichrechtlicher Rundfunkanstalten innerhalb professioneller Strukturen Inhalte für große, weitgehend passive Publika in einem fast ausschließlich nationalen Rahmen produzierte (Krüger 2018, 13), langsam zu Ende: Die Zulassung des privaten Rundfunks und die Einführung von Satelliten- und Digitaltechnik sowie schließlich der Durchbruch des Internets als Massenmedium um das Jahr 2000 führte zu einem tiefgreifenden Strukturwandel der Öffentlichkeit, der noch längst nicht abgeschlossen ist. Klar dürfte allerdings schon einmal sein: »Die gestiegenen Teilhabemöglichkeiten für den Einzelnen sind wiederum erkauft für den Preis tendenziell gesunkener Reichweite in einem digitalen Universum mit inflationären, teils personalisierten bzw. privaten Teilöffentlichkeiten in Sozialen Medien « (ebd.). Zu wenigen reichweitenstarken Medien sind eine Vielzahl reichweitenschwacher als »Long Tail« des Öffentlichen hinzugekommen (Brosda 2013, 179).

Doch ein Mehr an Demokratie oder kommunikativer Vernunft (siehe Trump und Twitter) ist damit nicht zwangsläufig verbunden. Im Auftaktbeitrag des Abschnitts »Digitale Transformation in der neoliberalen Globalisierung « weist Klaus Dörre eindringlich auf die anhaltende oder sogar steigende Machtkonzentration der großen Medienkonzerne hin. 
Aktuell sieht er einen neuen Schub kapitalistischer »Landnahme«: Ein auf Wachstum basierendes Wirtschaftssystem muss stetig Externes okkupieren und monetarisieren. Wir erleben eine verstärkte Landnahme von lebendigem Wissen, Erfahrung, Information und Öffentlichkeit, die auch Arbeits- und Beschäftigungsverhältnisse im Medienbereich neu (nämlich: prekärer) strukturiert. Von dieser Diagnose ausgehend fordert Dörre »einen digitalen Infrastruktur- und Mediensozialismus, der den Zugang zu demokratischen Öffentlichkeiten als öffentliches Gut betrachtet« und schützt.

Holger Pötzsch geht auf die Rolle digitaler Datenbanken ein, die immer stärker in gesellschaftliche Machtverhältnisse eingebettet sind. Er führt dabei ihren doppelten Charakter aus: Zum einen erlauben sie Menschen, über digitale Netzwerke sichtbar und erreichbar zu werden. Zum anderen ermöglichen sie neue Formen von Überwachung und riesige Datenansammlungen, »mit dem Ziel vorgreifender staatlicher Kontrolle und der Kapitalisierung menschlicher Identitäten«. Um diese Ambivalenz begreifbar zu machen, schlägt Pötzsch die Unterscheidung zwischen Oberflächen- und Tiefenarchiven vor und plädiert für die Verbreitung einer kritischen Medienkompetenz, die den Menschen die Mittel an die Hand gibt, Widerstand im Zeitalter digitaler Transformationen leisten zu können.

Auch Johannes Gemkow beschäftigt sich in seinem Beitrag mit der Bedeutung von Medienkompetenz in Transformationsprozessen. Wichtig für seine Überlegungen ist das mit Foucault gedachte Konzept der produktiven Macht, die sich in einem konkreten Handlungskontext aus dem Kräfteverhältnis von Akteur*innen und Strukturen ergibt. Anhand der Wikipedia als Paradebeispiel für kollaborative Wissensproduktion arbeitet Gemkow die Aufgabe der Medienkompetenz heraus, Machtstrukturen erkennen und produktiv mit ihnen umgehen zu können.

Einen Fokus auf die Rolle der Digitalisierung in nicht-westlichen Kontexten legt der Beitrag von Hanan Badr. In ihrer Untersuchung der Arabischen Umbrüche in Ägypten und Tunesien in den Jahren 2010 und 2011 argumentiert sie, dass die dortigen Transformationsprozesse weder auf die (digitalen) Medien noch auf die Politik allein zurückzuführen sind. Vielmehr entwickeln sie sich laut Badr dadurch, dass widerständige Akteur*innen counter-issues - von Gegeneliten problematisierte sozioökonomische und politische Missstände - in hybriden Mediensystemen nicht nur über digitale, sondern auch nicht-digitale Medien in die Öffentlichkeit tragen. Sie plädiert einerseits für ein soziopolitisch und regional kontextualisiertes Verständnis von counter-issues und anderer- 
seits für mehr regional vergleichende Forschung insbesondere unter Miteinbezug von nicht-westlichen Staaten.

Von den arabischen Umbrüchen hin zur Ukraine-Krise und den geopolitischen Spannungen zwischen Russland und dem Westen: In seinem Beitrag »Transformation und Transparenz« kritisiert Sebastian Köhler, dass unter den Bedingungen beschleunigter Themenzyklen in der digitalen 24/7-Öffentlichkeit bei außenpolitischen Konfliktthemen allzu oft die Quelle von Informationen nicht oder nicht prominent genug angegeben wird. Anhand der Fälle Babtschenko, Skripal und Nawalny zeigt er, dass durch mangelnde Quellentransparenz in der Tendenz zwischenstaatliche Spannungen geschürt werden, und fordert mehr Sorgfalt in den Redaktionen.

Den Verlust journalistischer Kernkompetenzen im Zuge des digitalen Wandels und der Ökonomisierung von Medienprodukten beklagt Michael Haller. In der Aus- und Weiterbildung von Journalist*innen werde immer stärker Wert auf technisches Know-how, Management-Skills und ContentMarketing-Methoden gelegt, die eine stärkere Anpassung an die Zwänge des Marktes ermöglichen. Vor allem privatwirtschaftlich organisierter Onlinejournalismus ist für Haller ein »Gefangener der Vermarktungszwecke« und bleibt »insofern seiner öffentlichen Aufgabe entfremdet«. Daher fordert er eine Dekommerzialisierung von Diskursräumen und auch eine verstärkte Vermittlung von Medien- und Informationskompetenz an jene Menschen, die früher einmal Publikum genannt wurden.

Auf Kommerzialisierung und Kommodifizierung verweist auch der Beitrag von Natalie Berner über die Konstruktion von Mutterschaft in den Medien. Mittels einer Diskursanalyse untersucht sie die mediale Darstellung dieser Form der Care-Arbeit. Vor allem in Sozialen Medien wie Instagram werde Mutterschaft zur Ware gemacht: Sogenannte »Momfluencer « monetarisieren ihre Selbstinszenierung als Mütter, während sie gleichzeitig verschiedene andere Rollen erfüllen müssen. Anerkennung wird ihnen nur zugeschrieben, wenn sie sich neben der Care-Arbeit zugleich selbst verwirklichen und erfolgreich sind (\#WorkingMom). Ein Zeit- und Ressourcenkonflikt, der in einer gesellschaftlichen Transformation unbedingt aufgelöst werden muss.

\section{Kommunikation für eine sozial-ökologische Transformation}

Die Dysfunktionalitäten des neoliberal geprägten globalen Kapitalismus in sozialer und ökologischer Hinsicht sind nicht zu übersehen. 
Dennoch fällt es gegenwärtig schwer, sich - vor allem angesichts des Versagens des Etatismus im ehemaligen Ostblock (Kovel 2007) - eine andere Welt vorzustellen. Und doch: Auch unsere lange Gegenwart ist historisch gewachsen. Sie ist ein Produkt der letzten »Großen Transformation« (Polanyi 1944), nämlich des Übergangs von der feudalen Agrargesellschaft zur kapitalistischen Industrie- und Marktgesellschaft, als Aufklärung und wirtschaftsliberales Denken die Gewinnerzielung als Motiv des Wirtschaftens an die Stelle der Subsistenz setzten und von der kirchlichen Verdammung als Gier befreiten. Trotzdem ist die Welt veränderbar. Eine Reihe von Akteur*innen aus der Wissenschaft, allen voran der Wissenschaftliche Beirat der Bundesregierung Globale Umweltveränderungen (WBGU), fordern eine neue Große Transformation hin zu einer klimaverträglichen, gerechten und nachhaltigen Weltwirtschaftsordnung. Ein solcher Übergang »ist hinsichtlich der Eingriffstiefe vergleichbar mit [...] der Neolithischen Revolution, also der Erfindung und Verbreitung von Ackerbau und Viehzucht, sowie der Industriellen Revolution « (WBGU 2011, 5). Angesichts der existenzbedrohenden Trends des Erdsystems im Anthropozän müsse er jedoch wesentlich schneller vorangetrieben werden.

Der Begriff der Nachhaltigkeit ist ein wirkmächtiger Herausforderer des gegenwärtigen Systems, der zahlreiche Akteur*innen in Journalismus, PR, (Kommunikations-)Wissenschaft, sozialen Bewegungen, Politik und Wirtschaft inspiriert - oder strategisch von diesen genutzt wird. Selbst die Vereinten Nationen haben ihn als Leitbild für eine gute Entwicklung von Wirtschaft und Gesellschaft konsentiert. Diese Popularität bildet sich im Abschnitt »Kommunikation für eine sozial-ökologische Transformation«ab.

Das Konzept der Nachhaltigkeit ist der zentrale Bezugspunkt für die Arbeit von Sigrid Kannengießer. Zwar beschäftigt sich die Kommunikationswissenschaft ihr zufolge lebhaft mit Wandel, viel zu selten allerdings mit dem konkreten Wandel hin zu einer nachhaltigen Gesellschaft. Sie schlägt der Disziplin daher vor, die Frage zu stellen, wie Medien zur Großen Transformation beitragen können. Dabei nutzt sie einen holistischen Medienbegriff, der nicht nur Medienorganisationen, sondern auch Inhalte und Technologien umfasst. Aus dieser Perspektive identifiziert Kannengießer Fragestellungen, anhand derer sich die Kommunikationswissenschaft in eine interdisziplinäre Transformationsforschung einbringen sollte.

Thomas Pleil, Lea Matusiak und Sandra Müller fordern in ihrem Beitrag, dass nicht nur die Journalismusforschung (Krüger und Meyen 
2018), sondern alle Felder der Kommunikationswissenschaft und damit auch die Public-Relations-Forschung zu einer Großen Transformation beitragen. Die Autor*innen argumentieren daher, dass die PR nicht allein Organisations- und damit Einzelinteressen, sondern eben auch Interessen der Gesellschaft vertreten und damit zur Lösung bestehender (Transformations-)Probleme beitragen soll. Sie sehen die Funktion der PR-Praxis, im Verbund mit der PR-Forschung, maßgeblich in einer Vermittlerrolle, indem sie öffentlich die Relevanz und Zielsetzung einer transformativen Wissenschaft darstellt. An einem konkreten Projekt zu Systeminnovationen für nachhaltige Entwicklung, an dem die Autor*innen beteiligt sind, führen sie exemplarisch aus, wie die PR diese Rolle ausfüllen kann.

Auch Melanie Malczok thematisiert die Möglichkeiten Strategischer Kommunikation, in den Dienst einer gesellschaftlichen Transformation zu treten. Sie konzentriert sich in ihrer Untersuchung auf soziale Bewegungen, die mit geringen Ressourcen öffentliche Aufmerksamkeit und Unterstützung für ihre Belange gewinnen müssen. Malczok entwickelt dabei das Konzept der strategischen Devianz als zentrales Instrument für die Kommunikation solcher Initiativen. Darunter versteht sie die Inszenierung normenabweichender Handlungen, da diese einen hohen Nachrichtenwert besitzen. Allerdings bergen sie das Risiko, so Malczok, als »systemzersetzend « wahrgenommen zu werden und somit die Legitimität der sozialen Bewegung zu gefährden. Die Kunst bestehe darin, diese Normenabweichungen strategisch als »progressive Herausforderung geltender Normen« zu inszenieren. Am Beispiel der Rodungsarbeiten im Hambacher Forst veranschaulicht Malczok, wie dieser Balanceakt gelingen kann.

Von sozialen Bewegungen hin zum politischen und medialen Establishment: Wie der Begriff der Nachhaltigkeit hier benutzt wird, zeigt Moritz Clau $\beta$ in seinem Beitrag. Mit der kritischen Indexing-These im Hinterkopf, der zufolge Leitmedien oftmals lediglich den Elitendiskurs abbilden, untersucht er eine Bundestagsdebatte zu nachhaltiger Entwicklung aus dem Jahr 2017 sowie die entsprechenden journalistischen Beiträge. Er findet große Überschneidungen zwischen den politischen und medialen Darstellungen, allerdings zeigten sich die Medien kritischer gegenüber dem Thema »Greenwashing « und thematisierten auch den politisch unbeliebten »Verzicht« als Alternative zum nachhaltigen Konsum.

»Wo steht der deutschsprachige Nachhaltigkeitsjournalismus?«, fragen dann Torsten Schäfer und Stella Lorenz. Sie geben einen Überblick 
über das Segment der Publikumszeitschriften mit Nachhaltigkeits- und Achtsamkeitsbezug, berichten von Projekten, Plattformen, Netzwerken, Vereinen, Stiftungen, Studiengängen und Weiterbildungsmöglichkeiten, die den Schutz der natürlichen Lebensgrundlagen als journalistischen Gegenstand fördern. Das Thema Nachhaltigkeit, so scheint es, ist auf dem Weg in den medialen Mainstream. Allerdings zeigt ihre Bestandsaufnahme auch auf: Viele Angebote sind nur prekär finanziert und werden von einer geringen Zahl engagierter Akteur*innen getragen.

Weiter geht es mit dem Themenkomplex um Journalismus und Nachhaltigkeit: Uwe Krüger verhandelt in seinem Beitrag, ob das journalistische Rollenverständnis (Stichworte: Objektivität, Neutralität und Kritik) mit einem Engagement für eine Große Transformation zur Nachhaltigkeit vereinbar ist. Dazu vergleicht er die Strömung des »Konstruktiven Journalismus« mit dem Konzept des »Development Journalism« aus dem Globalen Süden und postuliert einen »Transformativen Journalismus«, für den neben der klaren Wertentscheidung zugunsten der Nachhaltigkeit vor allem eines essenziell ist: die institutionelle und mentale Unabhängigkeit der Journalist*innen von den politischen und wirtschaftlichen Akteur*innen einer solchen Transformation.

Thomas Wiedemann beschäftigt sich mit den Strukturen der Kinospielfilmlandschaft in Deutschland und inwiefern diese der filmischen Kommunikation einer gesellschaftlichen Transformation entgegenstehen. Er fragt nach den Mechanismen des politischen Gestaltungswillens der Filmförderung und findet heraus, dass Kinofilme in Deutschland keine transformative Kraft entwickeln können, weil Regisseur*innen oft an Bestehendes andocken müssen, um öffentliche Finanzierung zu erhalten. Zudem konstatiert Wiedemann eine »Elitisierung der Branche«, was bedeutet, dass Drehbuchautor*innen, Regisseur*innen und Produzent*innen fast ausnahmslos aus der oberen Mittelschicht stammen und vom Status quo profitieren. Er erwartet deshalb seitens der nationalen Kinospielfilmproduktion mittelfristig keine nennenswerten Impulse für die transformativen Herausforderungen der Gesellschaft.

\section{Visionen für transformative Kommunikationsverhältnisse}

Eines ist klar: Für eine andere Welt braucht es nicht nur Kritik am Bestehenden, sondern auch Ideen und Vorstellungskraft, Visionen und Utopien. Damit sind keine geschlossenen Gesellschaftsentwürfe gemeint, keine von oben zu oktroyierenden Masterpläne, aber Schritte in 
die richtige Richtung - der Weg entsteht im Gehen. Im Sinne einer »transformativen Kommunikationswissenschaft« (Krüger und Meyen 2018), einer die Wirklichkeit transzendierenden »Möglichkeitswissenschaft« (Eurich 2002, 131) oder auch der »Critical Future Studies« (Goode und Godhe 2017) versammelt der letzte Abschnitt »Visionen für transformative Kommunikationsverhältnisse«.

Den Einstieg in den Abschnitt besorgen Nils S. Borchers und Sebastian Jürss mit einer Arbeit zur Sharing Economy. Die Autoren fragen, wie die entsprechenden Plattformen beschaffen sein müssen, damit sie die transformativen Versprechen der Sharing Economy einlösen können. Anhand einer Analyse verschiedener Dimensionen der Geschäftsmodelle entwickeln sie einen Idealtyp, der unter anderem auf Plattformkooperativen, Peer-to-Peer-Transaktionen und missionsgetriebene Geschäftsansätze setzt. Um die Sharing Economy in eine relevante Transformationsagentin zu verwandeln, müssen Plattformen, die diesen Idealtyp adaptieren, gezielt aufgebaut, unterstützt und regulativ bevorteilt werden.

Mit dem Online-Angebot der Öffentlich-Rechtlichen platziert Heiko Hilker ein weiteres Medienfeld im Zentrum einer transformativen Vision. Dabei macht er sich für die Werte des Datenschutzes und der Datensparsamkeit stark, auf die er die Mediatheken der öffentlich-rechtlichen Sender verpflichten möchte. Auf diese Weise, so argumentiert Hilker, kann deren Online-Angebot als eine relevante Alternative zu populären Streamingdiensten etabliert werden.

Im finalen Beitrag dieses Bandes macht Florian Zollmann konkrete Vorschläge für eine umfassende Medienreform. Fünf Bereiche sind für ihn dabei zentral: Konzentrationskontrolle, unabhängige Aufsicht und Überwachung journalistischer Standards, Demokratisierung der Presse- und Rundfunkräte, Aufbau und Finanzierung unabhängiger Nachrichtenmedien, öffentliche Kontrolle und journalistische Selbstverwaltung. Diese Punkte könnten nur durch eine breite Medienreformbewegung umgesetzt werden, und somit stellt das Ende dieses Buches zugleich einen Aufruf an die Leser*innen dar, sich im Sinne einer solchen Bewegung zu engagieren. 


\section{Entstehung des Bandes und Dank}

Die hier versammelten Beiträge wurden im Vorfeld einer mehrstufigen Qualitätssicherung unterzogen: In einem offenen (nicht anonymen) Peer-Review-Verfahren sichteten jeweils zwei Gutachter*innen die Einreichungen zur Tagung; die Vortragenden bekamen dann in Leipzig von den insgesamt rund 100 Konferenzteilnehmer*innen lebhaftes fachliches Feedback. Die für diesen Band ausformulierten Manuskripte wurden anschließend von jeweils mindestens zwei Herausgeber*innen oder weiteren Gutachter*innen gelesen und mit Überarbeitungsvorschlägen an die Autor*innen zurückgegeben. Lockdowns an Schulen und andere mit der Corona-Pandemie verbundene Einschränkungen haben den Mitwirkenden viel Einsatz und Flexibilität bei der Arbeit an diesem Band abverlangt. An dieser Stelle möchten wir allen Autor*innen und allen Gutachter*innen für die produktive Zusammenarbeit herzlich danken.

Verbunden sind wir weiterhin dem Westend Verlag, der nach dem ersten KriKoWi-Tagungsband Ideologie, Kritik, Öffentlichkeit (Krüger und Sevignani 2020) nun auch diesen zweiten publiziert. Große Unterstützung erfuhren wir (wieder) von den Geschäftsführern Markus J. Karsten und Andreas Horn, vom Pressechef Rüdiger Grünhagen und von Lea Mara Eßer, die aktuell die neue Wissenschaftssparte im Westend Verlag entwickelt; für das Lektorat zeichnete wieder der scharfsichtige Philipp Müller verantwortlich. Dass der Band nicht nur auf Papier, sondern auch wieder online in einer Open-Access-Variante unter der Lizenz CC BY-ND 3.0 DE erscheinen kann (abzurufen unter der DOI https://doi.org/10.53291/GFNG8688), hat die Universitätsbibliothek Leipzig mit einer Förderung aus dem Publikationsfonds für OA-Monographien und Sammelbände ermöglicht. Ein Dank geht daher an die Mitarbeiter*innen des Open Science Office der UBL, insbesondere an Dr. Henriette Rösch und Dr. Adriana Slavcheva. Und schließlich gäbe es diesen Sammelband nicht ohne die Leipziger Tagung, die 2019 von Dr. Sevda Can Arslan, Dr. Nils S. Borchers, Marlen van den Ecker, Nadja Enke, Dr. Charlotte Knorr, Dr. Uwe Krüger, Melanie Malczok, Aljoscha Paulus, Juliane Pfeiffer, Thomas Rakebrand, Kerem Schamberger, Dr. Sebastian Sevignani und Dr. Mandy Tröger mit viel Herzblut organisiert und von Prof. Dr. Siegfried Lokatis (als Schirmherr der Veranstaltung) sowie von Prof. Dr. Patrick Donges (als Geschäftsführendem Direktor des IfKMW) und Prof. Dr. Markus Beiler (Gebäudemanagement IfKMW) unterstützt wurde. 


\section{Literatur}

Brosda, Carsten. 2013. Digitale Chancen für das gesellschaftliche Zeitgespräch. In Medien, Netz und Öffentlichkeit: Impulse für die digitale Gesellschaft, herausgegeben von Marc Jan Eumann, Frauke Gerlach, Tabea Rößner und Martin Stadelmaier, 171-181. Essen: Klartext.

Eisenegger, Mark. 2021. Dem digitalen Strukturwandel der Öffentlichkeit auf der Spur: Zur Einführung. In Digitaler Strukturwandel der Öffentlichkeit: Historische Verortung, Modelle und Konsequenzen, herausgegeben von Mark Eisenegger, Marlis Prinzing, Patrick Ettinger und Roger Blum, 1-14. Wiesbaden: Springer VS.

Eurich, Claus. 2002. Kritik und Utopie: Vorüberlegungen zur Zukunftsfähigkeit der kritischen Theorie. In Gesellschaftstheorie und Mediensystem. Interdisziplinäre Zugänge zur Beziehung von Medien, Journalismus und Gesellschaft, herausgegeben von Claus Eurich, 121-137. Münster: Lit.

Freeman, Carrie Packwood, Marc Bekoff, und Sarah M. Bexell. 2011. Giving Voice to the »Voiceless «: Incorporating Nonhuman Animal Perspectives as Journalistic Sources. Journalism Studies 12 (5): 590-607. DOI: https://doi.org/ 10.1080/1461670X.2010.540136.

Goode, Luke, und Michael Godhe. 2017. Beyond Capitalist Realism: Why We Need Critical Future Studies. Culture Unbound: Journal of Current Cultural Research 9 (1): 109-129.

Kannengießer, Sigrid. 2020. Nachhaltigkeit und das »gute Leben«: Zur Verantwortung der Kommunikations- und Medienwissenschaft in digitalen Gesellschaften. Publizistik 65 (1): 7-20.

Kovel, Joel. 2007. The Enemy of Nature: The End of Capitalism or the End of the World? 2. Auflage. London: Zed Books.

Krüger, Uwe. 2015. Ex-Lukaspfarrer Wonneberger: »Leipziger Osten war Keimzelle der Friedlichen Revolution«. Neustädter Markt Journal 2: 12-21, http://www. neustaedtermarkt-leipzig.de/wp-content/uploads/2017/12/2-2015.pdf. Zugegriffen: 9. März 2021.

Krüger, Uwe. 2018. Der neue Strukturwandel der Öffentlichkeit und die German Angst. In Die neue Öffentlichkeit. Wie Bots, Bürger und Big Data den Journalismus verändern, herausgegeben von Gabriele Hoofacker, Wolfgang Kenntemich und Uwe Kulisch, 9-25. Wiesbaden: Springer VS.

Krüger, Uwe, und Michael Meyen. 2018. Auf dem Weg in die Postwachstumsgesellschaft: Plädoyer für eine transformative Kommunikationswissenschaft. Publizistik 63 (3): 341-357. DOI: https://doi.org/10.1007/s11616-018-0424-2.

Krüger, Uwe, und Sebastian Sevignani (Hrsg.). 2020. Ideologie, Kritik, Öffentlichkeit: Verhandlungen des Netzwerks Kritische Kommunikationswissenschaft. Frankfurt am Main: Westend sowie Universität Leipzig. DOI: https://doi.org/ 10.36730/ideologiekritik.2019.0.

Perlo, Katherine. 2002. Marxism and the Underdog. Society \& Animals 10 (3): 303318. DOI: https://doi.org/10.1163/156853002320770092. 
Polanyi, Karl. 1944. The Great Transformation: The Political and Economic Origins of Our Time. New York: Farrar \& Rinehart.

Schneidewind, Uwe. 2018. Die Große Transformation: Eine Einführung in die Kunst gesellschaftlichen Wandels. Frankfurt am Main: S. Fischer.

Sühlmann-Faul, Felix, und Stephan Rammler. 2018. Der blinde Fleck der Digitalisierung: Wie sich Nachhaltigkeit und digitale Transformation in Einklang bringen lassen. München: Oekom.

WBGU. 2011. Welt im Wandel. Gesellschaftsvertrag für eine Große Transformation. Hauptgutachten des Wissenschaftlichen Beirats der Bundesregierung Globale Umweltveränderungen. Bonn. https://www.wbgu.de/fileadmin/user_ upload/wbgu/publikationen/hauptgutachten/hg2011/pdf/wbgu_jg2011.pdf. Zugegriffen: 9. März 2021.

Wensierski, Peter. 2017. Die unheimliche Leichtigkeit der Revolution: Wie eine Gruppe junger Leipziger die Rebellion in der DDR wagte. München: Deutsche Verlags-Anstalt.

\section{Open Access}

Dieser Beitrag erscheint unter der Creative-Commons-Lizenz CC BY-ND 3.0 DE: https://creativecommons.org/licenses/by-nd/3.0/de/. 



\section{Medien-Transformation in der DDR und in \\ Ostdeutschland}





\title{
Die vergessenen Medienreformen des letzten Jahres der DDR
}

\author{
Mandy Tröger
}

Keywords: DDR, Medientransformation, alternative Reforminitiativen

\section{Abstract}

Misst man den Erfolg der Medientransformation in Ostdeutschland nach 1990 an der Umsetzung der medienpolitischen Ziele des Jahres 1989, so muss man zum Schluss kommen, dass diese gescheitert ist. Der Reformrahmen wurde früh von westdeutschen (partei)politischen und wirtschaftlichen Interessen gesteckt und orientierte sich entsprechend eng am BRDStandard. Vor allem ressourcenstarke Medienorganisationen aus dem Westen, die von den bestehenden Strukturen einer expandierenden BRDMedienordnung profitierten, konnten ihre Interessen erfolgreich durchsetzen. Politische Initiativen und Reformziele ressourcenärmerer DDR-Organisationen und -Akteur*innen gerieten ins Hintertreffen, da sie dieser Ordnung nicht entsprachen. Der vorliegende Beitrag greift drei Medienreform-Initiativen der Jahre 1989 und 1990 wieder auf: 1) die Arbeit an einem umfassenden Mediengesetz, 2) die Idee und Tätigkeit des Medienkontrollrats und 3) die Ausgestaltung der inneren Pressefreiheit. Die Wirkungslosigkeit dieser Bemühungen macht sie nämlich keineswegs irrelevant. Vielmehr ist die Frage, warum sie sich nicht durchsetzen konnten, wichtig für gegenwärtige und künftige Transformationsprozesse. Angesichts aktueller Krisen (Finanzierung des Journalismus, Legitimation des öffentlich-rechtlichen Rundfunks) lohnt es sich zudem, damals verfolgte alternative Visionen zum Funktionieren freier Medien neu zu bewerten und herauszuarbeiten, ob sich deren Reformpotenzial für derzeitige Herausforderungen nutzbar machen lässt. 
Mandy Tröger: Die vergessenen Medienreformen des letzten Jahres der $D D R$. In: Nils S. Borchers, Selma Güney, Uwe Krüger und Kerem Schamberger (Hrsg.): Transformation der Medien - Medien der Transformation. Verhandlungen des Netzwerks Kritische Kommunikationswissenschaft. Frankfurt am Main: Westend 2021. DOI: https://doi.org/10.53291/NXTH6381.

Mandy Tröger, PhD I Ludwig-Maximilians-Universität München I mandy. troeger@ifkw.Imu.de

\section{Einführung}

Geschichtsschreibung ist die Konstruktion vergangener Realitäten unter gegenwärtigen Bedingungen. Da letztere sich ständig ändern, entwickeln sich auch die Perspektiven weiter, aus denen wir uns der Geschichte nähern, wie wir sie erzählen und welche Fragen wir an sie stellen. Zum 30-jährigen Jubiläum der deutschen Einheit rückt das letzte Jahr der Deutschen Demokratischen Republik (DDR), also vom Herbst 1989 bis zum Herbst 1990, zunehmend in den Blick der Forschung. Anfangs nur eine »Fußnote der Geschichte« (Stuhler 2010) zwischen Mauerfall und deutscher Einheit, werden heute vermehrt Fragen nach den Leistungen der Regierungen Modrow und de Maizière (Bahrmann und Links 2009; Stuhler 2010), nach Reformzielen und Initiativen der DDRBürger*innen- und Arbeiter*innenbewegungen (Kowalczuk 2015; Gehrke und Hürtgen 2001) sowie nach unterschiedlichen Wendeerfahrungen aus ost- und westdeutscher Perspektive (Brückweh, Villinger und Zöller 2020; Links, Nitsche und Taffelt 2009) gestellt. Dieses Interesse ist nicht zuletzt aktuellen Entwicklungen in Ostdeutschland geschuldet. Das »Erstarken populistischer Bewegungen« oder die »abnehmende Akzeptanz politischer Parteien « führen in der Ursachensuche letztlich zu der Frage, welche Weichen diesbezüglich während der Transformationsprozesse Anfang der 1990er gestellt wurden (vgl. KAS 2020).

Ähnliches gilt auch für die DDR-Medienreform. Denn im Zuge aktueller »Lügenpresse«-Debatten und einer weiterhin existierenden deutsch-deutschen »medialen Spaltung «, die auch auf eine »erstickte Medienrevolution« (vgl. Mükke 2021, 6) nach dem Mauerfall zurückzuführen sei, werden Fragen danach lauter, welche der ursprünglichen Reformbestrebungen umgesetzt und in die vereinigte Bundesrepublik eingebracht werden konnten. Zwar behauptete der letzte DDR-Ministerpräsident Lothar de Maizière (CDU) noch vor seiner Wahl am 18. März 
1990, die CDU-Ost werde »einen bedingungslosen Beitritt [der DDR zur BRD] nicht zulassen. Das können wir unseren Leuten nicht antun« (zitiert in Fehrle 1990). Aber, so fügte er hinzu, der Beitritt nach Artikel 23 des Grundgesetzes sei »eine Notwendigkeit der Zeit« (ebd.). Damit war auch die Übernahme der BRD-Medienordnung - also einer privatwirtschaftlich organisierten Verlagspresse und eines dualen Rundfunksystems im Osten Deutschlands - als Teil der deutschen "SchnellkleberEinheit« (taz 1990) am 3. Oktober 1990 beschlossene Sache.

In der Fachliteratur wurde diese Übernahme lange nicht in Frage gestellt (vgl. Machill et al. 2010; Schneider 2002); für Gunter Holzweißig (2002; 2008) ist sie logische Konsequenz der deutschen Einheit. In 40 Jahren deutscher Teilung, unterstreicht er, standen die freien Medien der BRD der DDR-Propaganda entgegen. Die Übernahme westdeutscher Strukturen im Osten nach 1990 führte demnach zu einer pluralistisch parlamentarischen Demokratie und folglich auch zur Etablierung freier Medien auf einst unfreiem Boden.

Dass die Realität weitaus komplexer war, zeigen Studien zur deutschdeutschen Mediengeschichte (vgl. Bösch und Classen 2009; Horton 2016) sowie zur Transformation der DDR-Presse (Kapitza 1997; Haller und Mükke 2010; Schneider 1992; 2002; Tröger 2019a), des Pressevertriebs (Klammer 1998; Tröger 2019b), des Fernsehens und Radios (Tichy und Dietl 2000) und des Buchmarktes (Links 2010) sowie zum Aufbau ostdeutscher Landesmedienanstalten (Rummel 1993). In ihrer Gesamtheit zeichnen diese Veröffentlichungen ein vielschichtiges Bild deutsch-deutscher Medienbeziehungen sowie einer heiß umstrittenen »Medienwende«. Von ost- und westdeutschen (partei)politischen Interessen und frühem Wirtschaftsdruck geprägt, war der Reformrahmen einer sich transformierenden DDR-Medienlandschaft eng nach BRDStandard gesetzt. Die Interessen von DDR-Akteur*innen - beispielsweise der Buch- und Zeitungsverlage oder der DDR-Reformgruppen wurden übergangen oder schlechtweg ignoriert (Links 2010; Machill et al. 2014; Tröger 2019b).

Mit diesen Analysen problematisieren empirische Studien die "grundsätzliche Wirklichkeitsblindheit« (Segert 2019, 66) theoretischer Diskussionen in der Transformationsforschung zum Übergang von Diktaturen zu Demokratien. Vor allem durch die angelsächsischen Debatten der »Transition-to-Democracy«-Schule geprägt, bleiben deren Beiträge laut dem Politikwissenschaftler Dieter Segert nicht selten »blind für politische Konsequenzen von wirtschaftlichen Prozessen« (ebd.). Demzufolge werden gesellschaftliche und ökonomische Phäno- 
mene und Prozesse aus den Transformations- und Demokratieanalysen postsozialistischer Gesellschaften ausgeklammert. Der Begriff »Transition« suggeriert zudem, dass Reformen in einem linearen Prozess des Fortschritts aus sich selbst heraus erfolgten (vgl. Hamilton 1990; Siebert 1992; Conradt 1995).

Aus diesem Defizit erklären sich bis heute auch die unzureichenden Erklärungsansätze für die Langzeitfolgen der »medialen Landnahme« (Becker 2007), also der Erschließung des ostdeutschen Medienmarktes durch BRD-Interessengruppen ab Anfang 1990. Für diesen hieß das unter anderem: die Übernahme ungebrochener Monopolstrukturen ehemaliger SED-Bezirkszeitungen durch westdeutsche Großverlage und eine dadurch bedingt steigende Pressekonzentration seit Anfang der 1990er Jahre (vgl. Schneider 1992; Mohl 2010; Tröger 2019a). In der Literatur werden diese generell als logische, wenn auch bedauernswerte Erscheinungen neuer kapitalistischer Marktdynamiken gesehen (Schneider 2002; Haller et al. 1994). Fragen nach medienpolitischen Alternativen des Zeitraums 1989 bis 1990 kamen bisher nur selten auf (vgl. von Törne und Weber 1995; von Törne 1995; Mohl 2011). Auch DDR-Medienreforminitiativen, kritisiert die Historikerin Morgan Guzman $(2015,212)$, führen in der Forschungsliteratur als »fehlgeschlagen[e] Relikt[e] einer kurzen Phase des reformativen Optimismus« ein Schattendasein. Zu Unrecht: Denn Wirkungslosigkeit ist nicht gleichbedeutend mit Irrelevanz und die Frage, warum sich diese Initiativen nicht durchsetzen konnten, ist nicht nur von akademischem Interesse, sondern durchaus auch wichtig für gegenwärtige und künftige Transformationsprozesse. Im Folgenden wird daher die Erinnerung an drei Reforminitiativen des letzten Jahres der DDR wiederbelebt: 1) die Arbeit an einem umfassenden Mediengesetz, 2) die Idee und Tätigkeit des Medienkontrollrats und 3) die Ausgestaltung der inneren Pressefreiheit. Dabei sollen Konzepte und Ziele sowie die Umstände, die zu ihrem Scheitern führten, im Mittelpunkt der Betrachtung stehen.

\section{Die Initiative für ein umfassendes Mediengesetz}

Nur zwei Tage nach der deutschen Einheit am 3. Oktober 1990 forderte Gerhard Bächer, Mitglied der Grünen (Ost), seine Parteikolleg*innen zu medienpolitischem Widerstand auf. »Unterschätzt bitte die Bedeutung dieses Bereichs nicht«, mahnte er, »es ist doch ein großer Unterschied, ob die Medienpolitik - und damit der Prozeß der öffentlichen 
Meinungsbildung - von Privatinteressen bzw. den Interessen einzelner Parteien dominiert wird, oder nicht « (Bächer 1990). Anlass seines Drängens war parteipolitischer und wirtschaftlicher Druck in der Mediengesetzgebung der neuen Bundesländer.

Konzeptionell helfen hier Studien, die sich mit der Institutionalisierung von Medienmärkten in Demokratien beschäftigen und beispielsweise die Beeinflussung von Gesetzgebungsprozessen durch Medienorganisationen untersuchen (Buschow 2012), die institutionelle Interessenvertretung durch Medienlobbyisten in den Blick nehmen (Dogruel et al. 2017) oder die Rolle der Parteipolitik beim Aufbau von Rundfunkinfrastrukturen offenlegen (Rummel 1993). Diese Veröffentlichungen zeigen, dass die politischen und rechtlichen Rahmenbedingungen in demokratisch-pluralistischen Medienordnungen einfach nicht gegeben beziehungsweise von Medienorganisationen und Parteipolitik beeinflusst sind. Das wiederum heißt, dass die »strategische Institutionalisierung von Interessen« (Buschow 2012) eine maßgebliche Rolle für die ordnungspolitische Ausgestaltung von Medienlandschaften spielen. Gleiches galt für die Transformation der DDR-Medien im Wendejahr und danach. Allerdings geschah die strategische Interessendurchsetzung hier im Zeitraffer und in einem weitgehend »rechtsfreien Raum « (Runder Tisch 1990b, 4), gerahmt durch eine sich abzeichnende Durchsetzung der BRD-Medienordnung im Presse- (vgl. Tröger 2019b) und Rundfunkwesen (Tichy und Dietl 2000).

In der Bundesrepublik Deutschland liegt die Rechtshoheit im Rundfunk- und Pressebereich bei den Ländern. ${ }^{1}$ In der DDR, wo diese zentralistisch organisiert waren, wurde bereits ab Mai 1990 an einem Rundfunküberleitungsgesetz gearbeitet. Dessen Ziel bestand darin, den DDR-Rundfunk in das föderale Rundfunksystem der BRD zu integrieren. Allerdings galten die Arbeiten an diesem Gesetz ursprünglich nicht dem Rundfunk allein. Anfänglich bezweckte man ein umfassendes und »komplexe[s] Mediengesetz (Bischof 1990) - also ein Gesetz, das auf alle Medien anwendbar sein und eine Reihe von Freiheiten gewährleisten sollte.

Schon am 31. Oktober 1989, zehn Tage vor dem Fall der Berliner Mauer, hatte der Vorsitzende des Verbandes der Journalisten der DDR (VJD) und erste Sekretär des Verbandes der DDR-Film- und Fernseh-

1 Ende der 1980er (bis zum Inkrafttreten der Föderalismusreform im Jahr 2006) lag die Rahmengesetzgebungskompetenz im Pressebereich allerdings beim Bund. 
schaffenden (VFF), Eberhard Heinrich, eine Arbeitsgruppe gegründet, um »den sofortigen Beginn und die exakte Durchführung der für die Ausarbeitung eines Mediengesetzes der DDR notwendigen Arbeiten zu sichern« (Vereinbarung 1989, 1). »Alle, die es angeht, werden zur Mitarbeit aufgefordert« (ebd.), schrieb Heinrich und meinte damit Ministerien, Universitäten und Journalist*innen. Ziel war ein Gesetzentwurf, »der demokratisch erarbeitet und breit diskutiert [...] Konsensfähigkeit erlangt« (ebd., 2). Die rechtliche Unterstützung kam von Dr. Anselm Glücksmann, dem einzigen »Rechtswissenschaftler, der sich in der DDR mit Presse- und Medienrecht beschäftigt hat« (Glücksmann 1989). Dieser begrüßte am 5. November 1989 das Reformstreben, mahnte aber auch zu Bedacht: »In keinem sozialistischen Land«, so Glücksmann, gebe »es bisher ein Gesetz, das uns als Vorbild dienen kann«, und eine Fertigstellung bis Ende des Jahres sei daher »irreal, wenn wir nicht oberflächlich und damit verantwortungslos herangehen wollten« (ebd.). Glücksmann schlug eine Kommission bestehend aus Journalist*innen, Mitgliedern aller Parteien sowie Vertreter*innen mehrerer Organisationen vor, die »vom Vertrauen des Volkes getragen« (ebd.) sofort mit der Arbeit an einem umfassenden Gesetz beginnen sollte.

Bereits am 18. Dezember verabschiedete die Arbeitsgruppe des VJD und des VFF ein Zehn-Punkte-Thesenpapier für ein zukünftiges Mediengesetz. Es sollte der neu zu gründenden Gesetzgebungskommission Mediengesetz unter dem neuen Ministerrat Hans Modrows zugesandt werden. Bestehend aus circa 60 Mitgliedern (Vertreter*innen des Runden Tisches, ${ }^{2}$ zuständige Ministerien und publizistische Berufsverbände) war das Ziel der Kommission, unter Leitung des Justizministers ein Mediengesetz der DDR zu erarbeiten. Es sollte öffentlich diskutiert und dann von einer frei gewählten Volkskammer (basierend auf einer neuen Verfassung) verabschiedet werden (Wiedemann 1995, 90).

Als Zwischenschritt legte die Kommission dem Ministerrat am 9. Januar 1990 einen Gesetzentwurf vor, der die Meinungs-, Informations- und Medienfreiheit bis zur Einführung eines umfassenden Mediengesetzes gewährleisten sollte. Der Entwurf stützte sich auf einen Vorschlag der SPD (Ost) vom 3. Januar und legte in 15 Punkten dar, wie genau sich diese Freiheiten definierten. Er erklärte, dass die DDR im Einklang mit dem internationalen Pakt über bürgerliche und politische

2 Dem oppositionellen Runden Tisch (gegründet am 7. Dezember 1989) gehörten Vertreter*innen von zwölf Parteien, politischen Gruppierungen und Organisationen an. 
Rechte (1966), der KSZE-Schlussakte (1975) und der UNESCO-Mediendeklaration (1978) »einen freien Informationsaustausch und eine breite internationale Zusammenarbeit im Bereich von Information und Kommunikation« (Runder Tisch 1990a) fördere.

Jeder Bürger hat das Recht auf freie Meinungsäußerung. Dieses Recht schließt die Freiheit ein, sich um Informationen und Ideen aller Art, ungeachtet der Grenzen mündlich, schriftlich oder gedruckt, in Form von Kunstwerken oder durch jedes andere Mittel seiner Wahl zu bemühen, diese zu empfangen und mitzuteilen. (Zitiert in ebd.)

Massenmedien sollten öffentlich und ungehindert den bestehenden Meinungspluralismus abbilden und alle staatlichen Institutionen, politischen Parteien und zivilgesellschaftlichen Organisationen hierfür einen angemessenen Zugang zu Medien erhalten. Konkret wurde der Ministerrat aufgefordert, »im Interesse der Chancengleichheit« aller politischen Gruppen »einen öffentlich kontrollierten gesellschaftlichen Fonds « zu schaffen, um deren Presseprodukte zu unterstützen und zusammen mit dem Runden Tisch eine landesweite unabhängige Tageszeitung zu gründen (ebd.). Jegliche Art der Zensur sollte verboten sein. Medien seien frei, solange sie nicht »für Kriegshetze, Aufruf zur Gewalt, die Bekundung von Glaubens-, Rassen- und Völkerhaß sowie militaristische, faschistische, revanchistische und andere antihumanistische Propaganda « missbraucht würden. Zudem sollte jede natürliche und juristische Person in der DDR das Recht zur Veröffentlichung und zum Vertrieb von Printmedien haben. Niemandem dürften durch die Inanspruchnahme dieser Rechte negative Konsequenzen entstehen.

Der Gesetzentwurf enthielt zudem zwei wichtige Elemente: Zum einen machte er Medienschaffende, deren Arbeit öffentlich erschien, persönlich für diese verantwortlich. Die »Mitarbeiter der Medien« hatten aber auch »das Recht, die Ausarbeitung eines Materials zu verweigern, wenn Themenstellung und Auftrag ihren persönlichen Überzeugungen widersprechen« (ebd.). Dieser aus der DDR-Erfahrung gespeiste Fokus auf die journalistische Autonomie (innere Pressefreiheit) unterschied sich vom westdeutschen Modell des Tendenzschutzes für Verleger*innen (dem Vorrang institutioneller Autorität und dem Recht der Medieneigentümer*innen, die politische Linie festzulegen). Zum anderen sollte zur Gewährleistung der Umsetzung des Mediengesetzes ein beratender Medienkontrollrat gegründet werden.

Diese Gesetzesvorlage wurde am 15. Januar 1990 vom Runden Tisch ratifiziert und kurz darauf, am 5. Februar, von der Volkskammer be- 
schlossen. Der Beschluss über die Gewährleistung der Meinungs-, Informations- und Medienfreiheit gab vor allem den neu gegründeten Medien (beispielsweise Zeitungen, lokalen Radiosendern und Buchverlagen) rechtliche Sicherheit. Jeder konnte nun Printmedien produzieren und vertreiben; die Lizenzierung wurde abgeschafft, nur eine Registrierung war nötig. Der Beschluss liberalisierte zudem den Pressevertrieb, indem er das Monopol des Postzeitungsvertriebs (PZV) aufhob. Das löste letztlich einen Zeitungsboom aus (Tröger 2020), war aber auch das Signal für BRD-Verlage, die DDR zu erobern (Herkel 1990).

Doch auch wenn, wie das Bundesministerium des Innern (BMI) in Bonn einige Tage darauf unterstrich, der Beschluss zweifellos einen wichtigen Schritt in die richtige Richtung darstellte, entsprach er nicht vollständig den Überzeugungen der Bundesregierung (Bachmann 1990). Das allgemeine Mediengesetz, die Einrichtung des Medienkontrollrats (MKR) oder die Ausgestaltung der inneren Pressefreiheit widersprachen westdeutscher Praxis. Während eines Treffens mit westdeutschen Verlagsvertreter*innen am 14. Februar unterstrich das BMI, dass für »ein künftig vereintes Deutschland « in der DDR »dafür Sorge zu tragen « sei, dass »Strukturen gebildet würden, [...] die kompatibel seien« mit denen der BRD (BMI Protokoll 1990, 3). Nichts, was im Osten geschehe, dürfe bestehende Strukturen in der BRD gefährden. Damit war ein allgemeines Mediengesetz auf bundespolitischer Seite vom Tisch; der Beschluss vom 5. Februar sollte bis zum Ende der DDR medienpolitische Grundlage bleiben.

Die zugrundeliegende Idee blieb trotz Einheitsdruck und Rundfunküberleitungsgesetz bis Juli 1990 bestehen. Noch zu Beginn des Vormonats wirkte die Arbeitsgruppe Grundsatzfragen unter dem Volkskammer-Ausschuss für Presse und Medien darauf hin, den Beschluss vom 5. Februar zu einem »umfassenden und selbstständigen Mediengesetz der DDR « (in ADN 1990) auszubauen. Ziel war es laut dem Ausschussvorsitzenden Jürgen Schwarz, mit dem Mediengesetz einen Teil zur »hoffentlich ganz neuen Medienordnung für ganz Deutschland « (in Transkript 1990) beizutragen. Denn die Einheit beider deutscher Staaten bedeute nicht zwangsläufig, dass die DDR die BRD-Medienordnung übernehmen müsse. Vielmehr gab es »unvorstellbar viele Vorstellungen, was aus den Medien der DDR noch werden kann« (ebd.).

Ähnlich argumentierte die Kommission Medienpolitik der PDS. Zu ihrem Treffen am 14. Juni 1990 entwarf sie ebenfalls eigene Richtlinien. Da die DDR noch für einen absehbaren Zeitraum existieren werde, gelte es Reformen zeitnah durchzusetzen. Mit Blick auf aktuelle Entwick- 
lungen war ihre Sorge, dass »[a]lle grundlegenden Veränderungen [...] negiert « würden, da die »Medienmechanismen, die Markt- und Machtverhältnisse der bundesdeutschen Medienlandschaft « künftig auch im Osten Deutschlands »ungehemmt wirken« (PDS-Entwurf 1990, 1). Deren Vorboten seien bereits jetzt sichtbar. Jede »demokratische Neugestaltung der Medienstruktur und der Medienkultur « (ebd.), betonte die PDS-Kommission, mache aber eine grundlegende Reform und demokratische Verfassung (wie vom Runden Tisch entworfen) notwendig. Diese solle künftig »jegliche ökonomische und politisch bedingte Monopolisierung von öffentlicher Meinung verhinder[n] (ebd.).

So entwarfen verschiedene Gruppen Vorlagen, die am 26. Juli 1990 letztlich von der Arbeitsgruppe Grundsatzfragen unter der Kommission Mediengesetz im Ministerium für Medienpolitik (MfM) diskutiert wurden. 23 Teilnehmer*innen verschiedener DDR-Institutionen (wie Parteien, Verlage und Gewerkschaften) nahmen an diesem Treffen teil. Man diskutierte, ob eine überarbeitete Gesetzesvorlage, für die »die Gesetzgebungskommission sich stets mit voller Energie eingesetzt hat « (Protokoll 1990, 3), tatsächlich von Nutzen war. Das Treffen endete mit dem Fazit, dass »das immer schneller werdende Tempo der Vereinigung der beiden deutschen Staaten « eine weitere Überarbeitung »nicht sinnvoll erscheinen läßt« (ebd., 4). »[J]etzt noch eine Gesetzgebung mit Geltung für das heutige Gebiet der DR [sic] in Angelegenheiten anzustreben, die sowieso in einem vereinten Deutschland Zuständigkeit der Länder sein werden und es in den Ländern der heutigen Bundesrepublik von jeher sind « (ebd.) machte die Arbeit inhaltslos. Damit war das Gesetz endgültig vom Tisch.

Stattdessen sollte eine neu zu gründende Kommission die künftigen Bundesländer in der Vorbereitung ihrer jeweiligen Landesmediengesetze unterstützen. Die Teilnehmer*innen des Treffens wurden gebeten, hierfür Ideen und Vorschläge bis Mitte August an das MfM zu senden. Das Ministerium wurde so zum »Anwalt der Länder, die es noch gar nicht gibt« (Brüning, 1990), und vertrat deren zukünftige Interessen.

\section{Der Medienkontrollrat}

Am 13. Februar 1990 gründete sich der Medienkontrollrat (MKR). Einzigartig in der deutschen Geschichte, hatte er kein Gegenstück in der Bundesrepublik, wo 1956 der Deutsche Presserat als Selbstkontrollgremium der großen Verleger- und Journalistenverbände in Reaktion auf 
ein geplantes Bundespressegesetz entstanden war. Der MKR hingegen bildete ein unabhängiges, überparteiliches Beratungsgremium, das die Durchsetzung des Mediengesetzes begleiten sollte. Ihm gehörten Vertreter*innen des gesamten ostdeutschen politischen Spektrums an: Parteien, Verbände, Kirchen, des DDR-Presse- und Informationsdienstes und viele andere (Claus 1991; Guzman 2015).

Der MKR hatte weder legislative noch exekutive Gewalt, weshalb er mit einem »Wolf ohne Zähne« (Theon 1990) verglichen wurde. Laut MKR-Mitglied Dr. Wolfgang Kleinwächter traf diese Beschreibung »in der Tat« zu, aber »das ist nicht zu bedauern, sondern das ist gewollt« (in Claus 1991, 10). »Der Medienkontrollrat muß bellen, beißen muß dann die Exekutive, also der Ministerrat, der Minister oder andere Gremien, die für die Durchführung von Verordnungen zuständig sind « (ebd.), unterstrich Kleinwächter im Frühling 1990. Dem Beschluss vom 5. Februar verpflichtet, sah sich der Rat als »eine moralisch-appellative Instanz einzig der Aufgabe verpflichtet, die Meinungsvielfalt und Auswahlfreiheit für den mündigen Bürger vor erneuter Vermachtung ebenso zu schützen wie vor deformierter Vermarktung« (MKR 1990a). Hierfür hielt der MKR öffentliche Anhörungen mit verschiedenen Interessengruppen des Mediensektors und wurde so zu einem Schauplatz, auf dem »in kleinem Maßstab jene größeren Kräftedynamiken « wirkten, »die 1990 das Schicksal der DDR prägten« (Guzman 2015, 213). Dabei verkörperte der Rat »die Hoffnung, dass die ostdeutschen Medien bei entsprechendem Schutz und Aufsicht ihren eigenen Reformprozess anführen und eigene demokratisch und wirtschaftlich tragfähige Medieninstitutionen und -unternehmen schaffen« (ebd., 211) könnten. So bedurfte beispielsweise jede »Eigentumsbeteiligung an Medien der DDR durch Ausländer« einer Zustimmung des MKR, womit die »Eigenständigkeit der Medien« gewährleistet werden sollte (Runder Tisch 1990a). Diese Regelung schloss Investor*innen aus der BRD ein. Denn um die »Informationsfreiheit und Meinungspluralismus auf dem Gebiet der DDR garantieren zu können«, so der Rat, seien »alle Schritte zu unterlassen, die zu Monopolstellungen sowohl der DDR - als auch ausländischer Verlage führen können« (MKR 1990b, 1). Da Kooperationsbestrebungen bundesdeutscher Verlage mit DDR-Verlagen, -Redaktionen und -Druckereien bereits Anfang 1990 rasant anstiegen, galt diese Regelung vor allem BRD-Investor*innen.

Allerdings kämpfte der Rat von Beginn an mit Arbeitsüberlastung und seinem Mangel an Autorität. Er übernahm Aufgaben, die eigentlich der Exekutive zugekommen wären. Laut Gottfried Müller, Minister für 
Medienpolitik in der Regierung de Maizière, sei »aber niemand sonst dagewesen, der im befürchteten Chaos hätte Eckpfeiler aufstellen können« (in Brüning 1990). Der Rat füllte diese Lücke, war mit der langen Liste an Problemen aber überfordert, besonders dann, wenn sie Legislativ- oder Exekutivmaßnahmen erforderten. Dazu zählten Papierknappheit, Dumpingpreis-Strategien und Steuerschulden westdeutscher Verlage, wachsende Joint-Venture-Aktivitäten und offene Fragen bezüglich Werbung und Radiofrequenzen für private Rundfunkveranstalter. Bereits auf seiner konstituierenden Sitzung sollte er grundlegende Probleme zum Pressevertrieb und zu Joint-Venture-Aktivitäten entscheiden. Zu diesem Zeitpunkt hatte der Rat weder ein eigenes Statut noch interne Strukturen und Verfahren. Die technische Grundausstattung fehlte, und drei feste Planstellen sowie Räumlichkeiten und Möbel mussten noch beantragt werden. Die volle Ausstattung des MKR sollte bis Ende März dauern, ab diesem Zeitpunkt war er voll funktionsfähig (vgl. Tröger 2019b).

Trotz langer Aufgabenliste und hohem Arbeitspensum war die Bilanz des Rates am Ende seiner acht Monate düster. Zwar hatte er es, laut Müller, als »Konstante in der unruhigen Medienlandschaft « (zitiert in Brüning 1990) geschafft, »konzeptionelle Linien« festzulegen und unerwünschte Entwicklungen zu stoppen (zitiert in Regierungspressedienst 1990, 5). In der Gestaltung der DDR-Medienwende blieb er aber weitgehend wirkungslos. Zum einen, da seine Arbeit mit Übernahme der BRD-Medienordnung, wie MKR-Mitglied Bächer (2016) im Sommer 1990 erkannte, »für die Katz« war. Zum anderen, und darauf verwies Kleinwächter im April 1990, weil er konsequent ignoriert wurde. Auf dem Pressemarkt beispielsweise machten »sich BRD-Verlage breit, als gäbe es gar keinen Medienkontrollrat! (in BZ 1990). MKR-Sekretär Andreas Graf fügte hinzu, er würde »viel lieber beißen als bellen dürfen bei allem, was man so sieht « (in journalist 1990). Der Rat hatte den aggressiven Verlagsstrategien, denen gegenüber auch Selbstkontrollversuche der Verlagsverbände wirkungslos waren (vgl. Fürstner 1990), wenig bis nichts entgegenzusetzen.

\section{Innere Pressefreiheit und Landesmediengesetze}

Bis August 1990 erhielt das MfM eine Vielzahl an Vorschlägen für die Ausgestaltung künftiger Landesmediengesetze, die sich meist sowohl auf den Rundfunk als auch auf die Presse bezogen. So hatte auch die 
Gesetzgebungskommission für ein allgemeines Mediengesetz Rahmenvorschläge gemacht. Demnach sollten in Bezug auf die Presse Regelungen zur Verantwortlichkeit von Journalist*innen, zum Pressevertrieb und zum strukturellen Aufbau der Presse festgeschrieben werden, um nur einige zu nennen (Protokoll 1990, 4).

Letztlich lieferte die Initiative Sächsisches Landesmediengesetz die Vorlage für die Pressegesetze der künftigen Länder. Der Gesetzentwurf »über die Freiheiten, Rechte und Pflichten der Presse in Sachsen« war am 13. August 1990 in Leipzig erarbeitet worden (Halbach 1990). Dieser hatte mehrere Punkte aus BRD-Landespressegesetzen übernommen (wie das Recht auf Gegendarstellung, Regelungen bezüglich der Beschlagnahme von Medien oder strafrechtlicher Haftung), enthielt aber auch eigens erarbeitete Bestimmungen. So bot die Vorlage etwa eine zweiseitige Definition der Pressefreiheit und dazu eine dreiseitige Erläuterung. Darin hieß es:

Der Missbrauch wirtschaftlicher und politischer Machtstellung ist zu verhindern. [...] Herausgeber, Verleger und redaktionelle Mitarbeiter sind in besonderer Weise dem humanistischen Kultur- und Bildungsauftrag verpflichtet. (Entwurf 1990, 1)

Anders als in der Bundesrepublik üblich, verlagerte die Vorlage den Fokus von Medienorganisationen auf die Rechte und Pflichten einzelner Medienakteur*innen, wie Journalist*innen und Redakteur*innen. Sie unterstrich, dass die im Pressesektor Beschäftigten persönlich für die Erfüllung ihrer öffentlichen Pflichten verantwortlich seien. Das bedeutete:

[Sie] haben das Recht, die Ausarbeitung eines Beitrages oder eine entsprechende Mitwirkung zu verweigern, wenn Inhalt und Herstellungsweise ihren persönlichen Überzeugungen widersprechen. Sie können auch durch kein Arbeitsverhältnis verpflichtet werden, in Veröffentlichungen Ansichten zu vertreten, die ihrer persönlichen Meinung zuwiderlaufen. Aus ihrer Weigerung darf den Mitarbeitern kein Nachteil erwachsen. (ebd., 3)

Teile dieser Klausel stammten aus dem frühen Vorschlag der SPD (Ost) vom 3. Januar 1990, war vom Runden Tisch ratifiziert und in den Beschluss vom 5. Februar aufgenommen worden.

Auch der Medienausschuss der Volkskammer gab Grundsatzempfehlungen für die Mediengesetzgebung der künftigen Bundesländer, die bis nach der deutschen Einheit im Umlauf blieben. Er definierte Medienfreiheit zum einen als das Recht der Bürger*innen »auf wahrhaftige, 
umfassende, vielfältige und ausgewogene Informationen durch die Massenmedien «, um sich eine eigene Meinung zu bilden (Grundsatzempfehlungen 1990, 2), und zum anderen als die Freiheit der Massenmedien, ihrer Eigentümer*innen und ihrer Beschäftigten, unabhängig Meinungen und Informationen in Druck, Ton und Bild zu verbreiten. Dies müsse »unter Wahrung der demokratischen und humanistischen Prinzipien der Freiheit und Verantwortung, Vielfalt und Wahrhaftigkeit, internationalen Verbundenheit und nationalen Eigenständigkeit und Offenheit im Informationsleben [geschehen] (ebd., 2-3).

Diese Definition, wie auch die der Initiative Sächsisches Landesmediengesetz, fasste die Medien- und Pressefreiheit weit und gestaltete sie dann konkret aus. »Zur Realisierung der inneren Pressefreiheit in den Medien«, unterstrich der Ausschuss, »wird empfohlen, Redaktionsstatute abzuschließen« (ebd., 4). So sollte ein »arbeitsrechtliches Verhältnis zwischen Verleger, Intendant und Redakteur« (ebd.) geregelt und Journalist*innen explizite Freiheiten, aber auch Verantwortung zugeschrieben werden.

Letztendlich fanden einige, wenn auch nicht viele dieser Ideen ihren Weg in ostdeutsche Landesgesetze. Das Pressegesetz für Brandenburg beispielsweise umfasste die Gewährleistung von Redaktionsstatuten, was der Verein Deutscher Zeitschriftenverleger (VDZ) sogleich als Einschränkung der Pressefreiheit und Versuch der staatlichen Kontrolle interpretierte (Protokoll F.D.P. Medienbeirat 1993).

\section{$5 \quad$ Fazit}

Bereits Mitte 1990 bemängelten Kritiker*innen, der »Funke der DDRReformbewegungen - auf dem Gebiet der Medien« sei "schon so gut wie erloschen « (Briefs, 1990). Denn mit der wachsenden Dominanz westdeutscher Verlags- und Politikinteressen waren die Diskussionen zum Mediengesetz aussichtslos, die Etablierung eigenständiger Medien und das Wirken eines souveränen Medienrates illusorisch und die Festschreibung der inneren Pressefreiheit unerwünscht. Misst man also den Erfolg der Herbstrevolution 1989 an der Umsetzung der Ziele ostdeutscher Akteur*innen, die sich aus der DDR-Erfahrung speisten, dann ist der Transformationsprozess gescheitert. Nicht umsonst drängte der Runde Tisch auf seiner letzten Sitzung am 12. März 1990, es brauche schnelle und konsequente Reformen, um eine vertraglich geregelte Vereinigung beider Staaten zu erreichen. Vor allem aber müssten mit der 
Einheit die Erfahrungen von Gruppen und Einzelpersonen in »konsequenter Demokratiegestaltung « rechtlich fixiert und die basisdemokratische Arbeit institutionalisiert werden, um Bürgergruppen, Parteien und Minderheiten einzubinden, die sonst keine Vertretung im Parlament fänden (Runder Tisch 1990c, 9).

Dieses Ziel fiel der Übernahme der bundesdeutschen politischen Ordnung zum Opfer. Gleiches galt für Initiativen, die Änderungen in der gesamtdeutschen Medienlandschaft anstrebten. So waren es vor allem ressourcenstarke westdeutsche Medienorganisationen, die ihre Interessen erfolgreich durchsetzten, da sie von den bereits bestehenden Strukturen einer expandierenden BRD-Medienordnung profitierten. Politische Initiativen und Reformziele ressourcenärmerer DDR-Organisationen und -Akteur*innen gerieten ins Hintertreffen, weil sie dieser Ordnung nicht entsprachen. Angesichts aktueller Krisen (Finanzierung des Journalismus, Legitimation des öffentlich-rechtlichen Rundfunks) lohnt es sich aber, damals verfolgte alternative Visionen zum Funktionieren freier Medien neu zu bewerten und herauszuarbeiten, ob sich deren Reformpotenzial für derzeitige Herausforderungen nutzbar machen lässt.

\section{Literatur}

ADN. 1990. Medienbeschluß der Volkskammer soll noveliert werden, 7. Juni 1990. BArch DC9/1033 (1/2), Hefter 3.

Bächer, Gerhard. 2016. Interview mit Autorin, Berlin, 27. Juni 2016.

Bächer, Gerhard. 1990. Brief, Gerhard Bächer an Landesverbände Grüne Partei, 5. Oktober 1990. Archiv Grünes Gedächtnis / B. V.3 - Grüne Partei DDR, Box 2730, Akte 30.

Bachmann, Ralf. 1990. Kurzinformation über Expertengespräche DDR-BRD zur Zusammenarbeit im Bereich Presse, Funk und Fernsehen, Berlin, 10. Februar 1990. BArch DC9/1052.

Bahrmann, Hannes, und Christoph Links. 2009. Chronik der Wende. Die Ereignisse in der DDR zwischen 7. Oktober 1989 und 18. März 1990. 12. Auflage. Berlin: Christoph Links Verlag.

Becker, Jörg. 2007. Mediale Landnahme in Osteuropa. Medienimpulse 61: 25-26.

BMI Protokoll. 1990. Protokoll einer Besprechung im Bundesinnenministerium am 14.02.1990 in Bonn zum Thema Pressevertrieb in der DDR, Bonn, 16. Februar 1990. BArch DM3/21121 (1/3).

Bösch, Frank, und Christoph Classen. 2009. Bridge over troubled water? Deutschdeutsche Massenmedien. In: Geteilte Geschichte: Ost- und Westdeutschland 19702000, herausgegeben von Frank Bösch, 449-487. Göttingen: Vandenhoeck und Ruprecht. 
Briefs, Ulrich. 1990. Das Jahrzehnt der Goldgräber. Revier, April 1990. Archiv Grünes Gedächtnis / B. V.3 - Grüne Partei DDR, Box 27-30, Akte 21.

Brückweh, Kerstin, Clemens Villinger, und Kathrin Zöller (Hrsg). 2020. Die lange Geschichte der »Wende«. Geschichtswissenschaft im Dialog. Berlin: Christoph Links Verlag.

Brüning, Jens. 1990. Anwalt der Länder, die es noch gar nicht gibt. DDR-Medienminister Müller vor dem Kontrollrat. Süddeutsche Zeitung, 27. April 1990. BArch DC 9/1033 (1/2).

Buschow, Christopher. 2012. Strategische Institutionalisierung durch Medienorganisationen. Der Fall des Leistungsschutzrechtes. Köln: Herbert von Halem.

BZ. 1990. Mit beschränkten Vollmachten. Gespräch mit dem Mitglied des Medienkontrollrates Prof. Kleinwächter. BZ, 19. April 1990. IISG/ID-Archiv MKR, Akte $35 \mathrm{a}-\mathrm{b}$.

Claus, Werner (Hrsg.). 1991. Medien-Wende, Wende-Medien? Dokumentation des Wandels im DDR-Journalismus, Oktober '89 - Oktober'90. Berlin: Vistas.

Conradt, David (Hrsg.). 1995. Germany's new politics. Parties and issues in the 1990s. Providence RI: Berghahn Books.

Dogruel, Leyla, Lavinia Wolf und Hannah Knox. 2017. Interessenvertretung auf Medienmärkten aus Akteursperspektive. Tätigkeitsfelder und berufliches Selbstverständnis von Medienlobbyisten. Publizistik 2: 179-196.

Entwurf. 1990. Gesetz über die Freiheiten, Rechte und Pflichten der Presse in Sachsen, Leipzig, 13. August 1990. Archiv Grünes Gedächtnis / B. V.3 - Grüne Partei DDR, Box 27-30, Akte 30.

F.D.P.-Leitlinien. 1993. Leitlinien liberaler Medienpolitik, Antrag zum F.D.P.-Bundesparteitag 11.-13. Juni in Münster, 11.-13. Juni 1993. Archiv des Liberalismus, FDP Medienkommission/24549.

Fehrle, Birgit. 1990. »Einen Beitritt ohne Bedingungen macht die CDU nicht mit«Interview mit Lothar de Maizière, Vorsitzender der CDU (taz vom 07.03.1990), taz - DDR Journal Nr. 2, Die Wende der Wende, 146-147, Archiv Grünes Gedächtnis / B.V.3 - Grüne Partei DDR, Box 31-38, Akte 33.

Fürstner, Wolfgang. 1990. »Die Worte veralten im Mund«. Eine Dokumentation zum Pressevertrieb in der DDR. textintern, DDR extra, Nr. 13, 21. März 1990, 11-14. Archiv Grünes Gedächtnis / B. V.3 - Grüne Partei DDR, Box 27-30, Akte 29.

Gehrke, Bernd, und Renate Hürtgen (Hrsg.). 2001. Der betriebliche Aufbruch im Herbst 1989. Die unbekannte Seite der DDR-Revolution. Diskussion - Analyse Dokumente. Berlin: Bildungswerk Berlin der HBS.

Glücksmann, Anselm. 1989. Brief, Dr. Anselm Glücksmann an Manfred Flegel, Betr: Schaffung eines Medien- und Pressegesetzes, 5. November 1989. BArch DC9/1051.

Grundsatzempfehlungen. 1990. Mediengesetzgebung in den Ländern Berlin, Brandenburg [etc.], Volkskammerausschuss, [o.D.]. Anlage zu Bächer (1990).

Guzman, Morgan Morille Schupbach. 2015. East German Journalists and the Wende: A history on the collapse and transformation of socialist journalism in Germany. PhD Dissertation. University of California, Los Angeles.

Halbach, Heinz. 1990. Brief und Anlage, Prof. Halbach an das Ministerium für Me- 
dienpolitik, 14. August 1990. Archiv Grünes Gedächtnis / B. V.3 - Grüne Partei DDR, Box 27-30, Akte 30.

Haller, Michael, und Lutz Mükke (Hrsg.). 2010. Wie die Medien zur Freiheit kamen. Zum Wandel der ostdeutschen Medienlandschaft seit dem Untergang der DDR. Köln: Herbert von Halem.

Haller, Michael, Johannes Ludwig, und Hartmut Weßler. 1994. Entwicklungschancen und strukturelle Probleme der Zeitschriftenpresse in den neuen Bundesländern. Forschungsbericht für den Bundesminister des Inneren, Band I: Der Zeitschriftenmarkt Ost. Institut für Kommunikations- und Medienwissenschaft der Universität Leipzig.

Hamilton, Daniel. 1990. After the revolution. The new political landscape in East Germany. Washington, D. C.: American Institute for Contemporary German Studies.

Herkel, Günter. 1990. Marketing in ausgehungerten Märkten. Publizistik und Kunst 5: 50-54. IISG/ID-Archiv MKR, Akte 35a-b.

Holzweißig, Gunter. 2002. Die schärfste Waffe der Partei. Eine Mediengeschichte der DDR. Köln: Böhlau.

Holzweißig, Gunter. 2008. Wandel der DDR-Medien durch die Wende. In: Deutschland und die »Wende « in Literatur, Sprache und Medien. Interkulturelle und kulturkontrastive Perspektiven. Dokumentation eines Expertenseminars für Internationale Alumni der Georg-August-Universität Göttingen vom 8. bis 13. Juli 2007, herausgegeben von Hiltraud Casper-Hehne und Irmy Schweiger, 141-160. Göttingen: Universitätsverlag Göttingen.

Hörschelmann, Kathrin. 2002. Media networks in transition: The politics of cultural production in post-unification Germany. Social \& Cultural Geography, 3 (2): 155-174.

Horton, Gerd. 2016. The Impact of Hollywood Film Imports in East Germany and the Cultural Surrender of the GDR Film Control in the 1970s and 1980s. German History 34 (1): 70-87.

Journalist. 1990. Druck aus dem Westen. journalist Special-DDR 7, 23.

Kapitza, Arne. 1997. Transformation der ostdeutschen Presse: »Berliner Zeitung, « »Junge Welt« und »Sonntag/Freitag« im Prozeß der deutschen Vereinigung. Studien zur Kommunikationswissenschaft. Opladen: Westdeutscher Verlag.

KAS. 2020. Promotionskolleg »Demokratien in Europa - Transformationen nach 1990«. Konrad-Adenauer-Stiftung. https://www.kas.de/en/web/begabtenfoer derung-und-kultur/promotionskolleg-demokratien-in-europa-transformatio nen-nach-1990-. Zugegriffen: 6. Januar 2021.

Klammer, Bernd. 1998. Pressevertrieb in Ostdeutschland. Die wirtschaftlichen und politischen Interessen beim Aufbau eines Pressegroßhandelssystems nach der Oktoberwende 1989. Dortmunder Beiträge zur Zeitungsforschung. München: Saur.

Kowalczuk, Ilko-Sascha. 2015. Endspiel. Die Revolution von 1989 in der DDR. München: C.H. Beck.

Kuschel, Franziska. 2016. Schwarzhörer, Schwarzseher und heimliche Leser: Die DDR und die Westmedien. Göttingen: Wallstein Verlag.

Links, Christoph. 2010. Das Schicksal der DDR-Verlage. Die Privatisierung und ihre Konsequenzen. Berlin: Christoph Links Verlag. 
Links, Christoph, Sybille Nitsche, und Antje Taffelt. 2009. Das wunderbare Jahr der Anarchie. Von der Kraft des zivilen Ungehorsams 1989/90. Berlin: Christoph Links Verlag.

Machill, Marcel, Markus Beiler, und Johannes R. Gerstner (Hrsg). 2010. Medienfreiheit nach der Wende. Entwicklung von Medienlandschaft, Medienpolitik und Journalismus in Ostdeutschland. Konstanz: UVK.

Machill, Marcel, Markus Beiler, und Johannes R. Gerstner. 2014. Systemwechsel Die Transformation des DDR-Fernsehens 1989. Bundeszentrale für politische Bildung, 6. Oktober 2014. https://www.bpb.de/gesellschaft/medien-und-sport/ medienpolitik/172174/die-transformation-des-ddr-fernsehens-1989? $\mathrm{p}=$ all. Zugegriffen: 6. Januar 2021.

MKR. 1990a. Ergebnisprotokoll der letzten Medienkontrollratssitzung am 19.09.1990, Erklärung, Berlin, 30. September 1990. Archiv Grünes Gedächtnis / B. V.3 - Grüne Partei DDR, Box 27-30, Akte 30.

MKR. 1990b. Presseerklärung, Medienkontrollrat der DDR, 21. März 1990. Archiv Grünes Gedächtnis / B. V.3 - Grüne Partei DDR, Box 27-30, Akte 30.

Mohl, Ariane. 2011. Personelle und institutionelle Übergänge im Bereich der brandenburgischen Medienlandschaft, Gutachten für die Enquête-Kommission 5/1 des Brandenburger Landtags. https://www.landtag.brandenburg.de/media_ fast/5701/Gutachten_Mohl_Medienlandschaft\%2020.pdf. Zugegriffen: 6. Januar 2021.

PDS-Entwurf. 1990. Medienpolitische Grundlinien der PDS mit Blick auf die Einheit Deutschlands, Vorlage für das Präsidium, Kommission Medienpolitik, Berlin, 14. Juni 1990. ADS/PDS-PV-349 (Januar-November 1990, Band II).

Protokoll. 1990. Protokoll über die Beratung der Arbeitsgruppe »Grundsatzfragen« der Gesetzgebungskommission »Mediengesetz« im Ministerium für Medienpolitik am 26. Juli 1990. Archiv Grünes Gedächtnis / B. V.3 - Grüne Partei DDR, Box 27-30, Akte 30.

Protokoll F. D.P. Medienbeirat. 1993. Protokoll der Sitzung des F. D.P. Medienbeirats am 19./20. Mai 1993 in München, 19. bis 20.Mai 1993. Archiv des Liberalismus, FDP Medienkommission/24549.

Regierungspressedienst. 1990. Für fairen Wettbewerb aller Medien, DDR-Regierungspressedienst, 14/90, 7. Mai 1990. BArch DC 9/1033 (1/2).

Rummel, Andreas. 1993. Die Rolle der Parteipolitik beim Aufbau des Mitteldeutschen Rundfunks. Diplomarbeit. LMU München.

Runder Tisch. 1990a. 7. Sitzung, Gesetzgebungskommission Mediengesetz, Entwurf vom 09.01.1990, Beschluß der Volkskammer über die Gewährleistung der Meinungs-, Informations- und Medienfreiheit, 15. Januar 1990. BArch DA3/7.

Runder Tisch. 1990b. Sitzungsprotokoll, 12. Februar 1990. BArch DM3/21121 (1/3). Runder Tisch. 1990c. Ergebnisse der 16. Sitzung des Rundentischgespräches am 12. März 1990, Abschlußerklärung des Zentralen Runden Tisches. Archiv Grünes Gedächtnis / B. V.3 - Grüne Partei DDR, Akte 7.

Schneider, Beate. 1992. Pressemarkt Ost II. Nur die Konzentration macht Fortschritte. In: Pressemarkt Ost. Nationale und internationale Perspektiven, herausgegeben von Walter A. Mahle, 35-46. München: Ölschläger. 
Schneider, Beate. 2002. Die Wende auf dem Medienmarkt. Historisch-PolitischeMitteilungen 9: 217-225.

Segert, Dieter. 2019. Erfolgreicher Theorie-Eklektizismus und blinde Flecken. WeltTrends (Potsdam) 155: 65-67.

Siebert, Horst (Hrsg.). 1992. The Transformation of Socialist economies. Symposium, 1991. Tübingen: J. C.B. Mohr.

Stuhler, Ed. 2010. Die letzten Monate der DDR. Die Regierung de Maizière und ihr Weg zur deutschen Einheit. Berlin: Christoph Links Verlag.

Taz. 1990. Infokasten 17./18.02.1990. taz - DDR Journal Nr. 2, Die Wende der Wende, Januar bis März 1990, Von der Öffnung des Brandenburger Tores zur Öffnung der Wahlurnen, 104.

Tichy, Roland, und Sylvia Dietl (Hrsg.). 2000. Deutschland einig Rundfunkland? Eine Dokumentation zur Wiedervereinigung des deutschen Rundfunksystems 1989-1991. München: Verlag Reinhard Fischer.

Theon, Ute. 1990. Medienkontrollrat - ein Wolf ohne Zähne. taz, 3. April 1990. BArch DC 9/1033 (2/2).

Transkript. 1990. Rundfunk der DDR, Redaktion Monitor, DS Kultur, 8.05 Uhr, v. 20.06.1990, Medienausschuß der Volkskammer in Bonn (Interview mit Hr. Schwarz), 6. Juni 1990. BArch DC9/1033 (1/2), Hefter 2.

Tröger, Mandy. 2020. On Unregulated Markets and the Freedom of Media: The Transition of the East German Press after 1989. DGPuK-Preisbeitrag. Medien und Zeit 2: 6-10.

Tröger, Mandy. 2019a. Die Treuhandanstalt und die Privatisierung der DDR-Presse. Aus Politik und Zeitgeschichte 35/37: 34-39.

Tröger, Mandy. 2019b. Pressefrühling und Profit. Wie westdeutsche Verlage 1989/1990 den Osten eroberten. Köln: Herbert von Halem.

Vereinbarung. 1989. Vereinbarung zwischen dem Verband der Journalisten (VDJ) und dem Verband der Film- und Fernsehschaffenden (VFF), o. D. [31. Oktober 1989]. BArch DC9/1051.

von Törne, Lars. 1995. Mühlfenzl oder Eine westdeutsche Medienpolitik nach Gutsherrenart. In: Kolonialisierung der DDR. Kritische Analysen und Alternativen des Einigungsprozesses, herausgegeben von Wolfgang Dümke und Fritz Vilmar, 299-317. Münster: Agenda.

von Törne, Lars, und Patrick Weber. 1995. Zeitungslandschaft Ost - Monopolitistische Medienkonzentration oder pluralistischer Pressemarkt? In: Kolonialisierung der DDR. Kritische Analysen und Alternativen des Einigungsprozesses, herausgegeben von Wolfgang Dümke und Fritz Vilmar, 276-298. Münster: Agenda.

Wiedemann, Jasmin. 1995. Mitgefangen, mitverkauft. Zur Situation ostdeutscher Frauenzeitschriften nach der Wende. Münster: Waxmann.

\section{Open Access}

Dieser Beitrag erscheint unter der Creative-Commons-Lizenz CC BY-ND 3.0 DE: https://creativecommons.org/licenses/by-nd/3.0/de/. 


\title{
Abbruch, Umbruch, Aufbruch: Programme des sächsischen Lokalfernsehens in der Nachwendezeit 1990-1995
}

\author{
Judith Kretzschmar \& Rüdiger Steinmetz
}

Keywords: Transformation, Sattelzeit 1990-1995, Lokalfernsehen, Identität, Ostdeutschland, Vereinigungsprozess

\section{Abstract}

Von 1989/90 bis 1995 kam es in Deutschland zu einem Zusammenprall der Kulturen West versus Ost, bei dem die Macht ungleich verteilt war. Die etwa 40 sächsischen Lokalfernsehprogramme aus dieser Zeit stellen - mit dem »Blick von unten «- einzigartige Quellen für das kulturelle Gedächtnis eines der wichtigsten historischen Einschnitte im 20. Jahrhundert dar. Eine Untersuchung der Programme und deren heutige Wiederaufführung tragen zur Revision etablierter Darstellungen, Positionen und Beurteilungen dieser Zeit bei. In diesem Beitrag wird auf Zwischenergebnisse zweier Untersuchungskategorien eingegangen: einerseits auf Umbrüche im Arbeitsleben und deren - als teilweise bis heute fortdauernde Ängste-erlebte Auswirkungen sowie andererseits auf die Begegnung mit Westdeutschen. Aus den im Projekt realisierten Wiederaufführungen von Lokal-TV-Beiträgen in ganz Sachsen lassen sich heute bei den Zuschauer*innen Lebenserfahrungen sowie verschüttete, verdrängte beziehungsweise (nur) gelernte, erworbene Kontexte und Gefühle dieser Sattelzeit re-aktualisieren. Außerdem können dadurch Erklärungen für die Wurzeln gegenwärtiger sozialer Probleme und politischer Diskurse im vereinigten Deutschland gegeben werden.

Judith Kretzschmar \& Rüdiger Steinmetz: Abbruch, Umbruch, Aufbruch: Programme des sächsischen Lokalfernsehens in der Nachwendezeit 19901995. In: Nils S. Borchers, Selma Güney, Uwe Krüger und Kerem Scham- 
berger (Hrsg.): Transformation der Medien - Medien der Transformation. Verhandlungen des Netzwerks Kritische Kommunikationswissenschaft. Frankfurt am Main: Westend 2021. DOI: https://doi.org/10.53291/THLT5265.

Dr. Judith Kretzschmar I Leipziger Institut für Heimat- und Transformationsforschung (LIHT) I jkretz@uni-leipzig.de

Prof. Dr. Rüdiger Steinmetz I Leipziger Institut für Heimat- und Transformationsforschung (LIHT) I rstein@uni-leipzig.de

\section{Einführung}

Im Zeitraum der Niederschrift dieses Beitrags, im Oktober 2020, erreichten uns ständig Interviewanfragen von »Qualitätsmedien«, die Expertise aus unserem vor mehr als zehn Jahren abgeschlossenen und breit veröffentlichten DFG-Forschungsprojekt über die Programmgeschichte des DDR-Fernsehens wollten: ${ }^{1}$ Zur Aktuellen Kamera, zum Fernsehballett, zur ostalgischen Unterhaltungsorientierung des MDR, zum medizinischen Beratungsformat Visite - und wir erwarten noch Fragen zu Karl-Eduard von Schnitzler (Der Schwarze Kanal), also »Sudel-Ede«, »Pittiplatsch« und zum Sandmann mit dem Spitzbart. Weil das Internet nichts vergisst, finden einfallslose, klischee-orientierte und an wiederkehrender Jubiläumsberichterstattung interessierte Journalist*innen von heute immer wieder dieselben Themen. Ihre eigenen Recherchen ergeben nur wenig zu medialen Vereinigungsbilanzen, den neuen biographischen Selbstreflexionen der »Wende- $\ll^{2}$ und der »Nachwende-Generation« und schon gar nichts zu neuen medialen Quellen, die im Folgenden dargestellt werden.

1 Vgl. Steinmetz und Viehoff (2008). Judith Kretzschmar war eine der Ko-Autor*innen. Aus diesem DFG-Projekt gingen mehr als 30 Publikationen in der Reihe »MAZ. Materialien, Analysen, Zeitzeugen« im Universitätsverlag Leipzig hervor.

2 Die deutsche Geschichte des 20. Jahrhunderts ist voller Brüche, beispielsweise in den Jahren 1918, 1933, 1945 oder 1989. Doch nur für den gewaltigen Umbruch in der DDR bürgerte sich der belanglose Begriff »Wende « ein. Zurückzuführen ist dies auf Egon Krenz, den Nachfolger Erich Honeckers. Dieser sprach in seiner Antrittsrede am 18. Oktober 1989 in Anlehnung an die sowjetische Perestroika von einer nötigen »Wende« durch die SED. Allerdings ist »Wende« kein überzeugender Terminus für diesen fundamentalen Systemwechsel, da er das Ausmaß der Veränderungen überhaupt nicht abdeckt (vgl. Jesse o. J.; Richter 2007a; 2007b; Eckert 2007). 
Dieser Beitrag präsentiert Zwischenergebnisse des noch laufenden Forschungsprojekts »Heimat heute - oder: Jeder hat sein Nest im Kopf «. ${ }^{3}$ In dessen Mittelpunkt steht die Analyse eines einzigartigen Bestandes an audiovisuellen Quellen, die das kulturelle Gedächtnis der Menschen in Ostdeutschland in der Sattelzeit ${ }^{4}$ zwischen 1989/90 und 1995 bewahren und den Vereinigungsprozess abbilden: die Programme von bis zu 40 lokalen Fernsehsendern in Sachsen. Sie sind bis heute weder von der Forschung noch von der Politik, den staatlichen Archiven oder den öffentlich-rechtlichen Qualitätsmedien in größerem Umfang beachtet worden.

Zum ersten Mal in der Geschichte wird mit diesem singulären Fundus an lokalen Fernsehprogrammen ein wichtiger deutscher und europäischer Transformationsprozess kontinuierlich durch bewegte Bilder festgehalten, und zwar in einem Bottom-up-Produktionsprozess sich selbst medial professionalisierender Bürger*innen und nicht in einem staatlichen Top-down-Verlautbarungsprozess einer Machtelite. Wir orientieren uns an den von Ilko-Sascha Kowalczuk $(2019,213-214)$ formulierten Desideraten: „Wir brauchen eine kritische Auseinandersetzung mit den sozialen, wirtschaftlichen und kulturellen Ursachen und Folgen der Transformation. In dieser Aufarbeitung müssen alle Erfahrungsräume Platz finden.«

Von folgender Annahme wird dabei ausgegangen: Analysen der Programme der lokalen Fernsehsender in den neuen Bundesländern am Beispiel Sachsens (1990 bis 1995) sowie die re-aktualisierte Erfahrung aus heutiger Sicht (Fokusgruppen) können verschüttete, verdrängte beziehungsweise (nur) gelernte, erworbene Kontexte und Gefühle aufdecken sowie Erklärungen für die Wurzeln gegenwärtiger sozialer und politischer Diskurse im vereinigten Deutschland bieten.

Daraus wurden folgende Forschungsfragen entwickelt:

1. Inwieweit lassen sich aus der Begegnung mit diesen historischen Programmen Lebenserfahrungen sowie verschüttete beziehungsweise verdrängte Kontexte und Gefühle dieser Sattelzeit bei heutigen Seher*innen re-aktualisieren?

2. Inwieweit können dadurch gegenwärtige soziale und politische

3 Leipziger Institut für Heimat- und Transformationsforschung (LIHT), https:// www.heimat-und-transformation.de/en/.

4 Der Begriff der »Sattelzeit« wird in diesem Beitrag in Anlehnung an Reinhart Koselleck in seinen Geschichtlichen Grundbegriffen verwendet, der ihn in Bezug auf eine idealtypische Beschreibung des Übergangs von der alteuropäischen zur modernen Geschichtsauffassung, also den Umbruch vom Ende des 18. zum 19. Jahrhundert prägte (vgl. Koselleck 1972, XIII-XXIII). 
Diskurse im vereinigten Deutschland auf ihre Ursprünge zurückgeführt und erklärt werden?

\section{Die Große Transformation und ihr audiovisuelles Gedächtnis}

\subsection{Die Neue Große Transformation}

Die Jahre 1989 und $1990^{5}$ stellen neben 1918 und 1945 die dritte große Zäsur im 20. Jahrhundert dar. Sie markieren den Beginn einer tiefgreifend und zeitrafferartig vor sich gehenden Transformation des politischen, ökonomischen wie gesellschaftlichen Systems und damit des Alltags von Millionen Menschen. Dies ist von Ther (2019) in Anlehnung an den Wirtschaftshistoriker Karl Polanyi (2019 [1944]) die »Neue Große Transformation « genannt worden. »Große Transformation« bedeutet dabei eine tiefgreifende Umformung ohne revolutionäre Prozesse, also eine gewaltlose Veränderung verfestigter Formen in diversen Subsystemen (Staatlichkeit, Wirtschaft, Kultur und Gesellschaft) sowie grundlegende Strukturbrüche und -wandlungen (vgl. Buchholz 1968).

Dieser Prozess umspannt mehrere übergreifende Themenkomplexe, die der Forschung als analytische Kategorien zugrunde gelegt werden, nämlich der politische Systemwandel mit der Etablierung und Konsolidierung von Demokratie, Partei- und Verwaltungsstrukturen; dann der ökonomische Umbau: Kapitalismus statt Staatssozialismus, der neoliberale Umbau des Wirtschaftssystems durch Abwicklung oder Privatisierung bisher staatlicher Betriebe, unter anderem mit (zunächst) hoher Arbeitslosigkeit und späterer Prosperität als eine Folge dieser Entwicklungen (vgl. Ther 2016, 26, 28; Ther 2019, 166; Milev 2020, $23-40)^{6}$

5 1989: Fall der Mauer und anderer militärisch hoch bewehrter Grenzen in Mitteleuropa; 1990: Vereinigung Deutschlands, zunehmende Autonomie mittel-osteuropäischer Staaten, allmählicher Zerfall der Sowjetunion, Ende des Kalten Krieges.

6 Internationale Kontexte wie der Zusammenbruch des Staatssozialismus und seine Rückwirkungen auf die Europäische Gemeinschaft und die Europäische Union sowie auf die weltweiten politischen Koordinaten sind von hoher Wichtigkeit, werden aber in dem hier dargestellten Projekt noch nicht berücksichtigt. 
Diese Große Transformation war und ist nicht auf die DDR und die anderen postsozialistischen Staaten beschränkt, sondern umfasste, wie Philipp Ther (2019, 91-95) es bezeichnet, in einem ko-transformativen Prozess die »alte Bundesrepublik« und - mindestens - die Europäische Gemeinschaft sowie (ab 1992) die Europäische Union. Aus ihrer Geschwindigkeit ergaben sich aber folgende Besonderheiten der deutschen Transformation im Unterschied zu anderen postsozialistischen Staaten:

1. Der paritätische Umtauschkurs von einer D-Mark für eine DDRMark (statt real 1:4) ${ }^{7}$ bei der Währungsunion am 1. Juli 1990 bedeutete für die ostdeutsche Wirtschaft eine vierfache Verteuerung ihrer Ausfuhren gegenüber 1988. Er ermöglichte Produktionsverlagerungen nach Mittel- und Osteuropa an Ostdeutschland vorbei, wovon zum Beispiel Tschechien profitierte (vgl. Ther 2019, 79).

2. Ein »Zweiter Schock für die ostdeutsche Wirtschaft [war] die rasche Liberalisierung des Außenhandels« (ebd., 80). Wegen der EG fielen »sämtliche Handelsschranken nach Westeuropa - diesem Konkurrenzdruck war die ostdeutsche Wirtschaft nicht gewachsen « (ebd.).

3. Zwischen 1990 und 1992 wurden im Rahmen der »radikalen Privatisierung « (ebd.) mehr als 10000 ostdeutsche Betriebe verkauft. Dies führte zu einem drastischen Verfall der Preise für die Betriebe und zu einem Treuhand-Verlust von 270 Milliarden DM statt erwarteter Gewinne von 600 Milliarden DM (ebd., 80-81). Nur jeder vierte Arbeitsplatz blieb erhalten, was einen »Strukturbruch« vor allem für Städte mittlerer Größe bedeutete und einen »Bruch im Leben von Millionen von Menschen, die arbeitslos wurden, umschulen mussten, oft trotzdem keine dauerhafte Stelle fanden und durch Frühverrentung aufs Altenteil geschoben wurden« (ebd.).

4. Der Austausch der Eliten in Ostdeutschland war im Ergebnis radikaler als die Entnazifizierung in Westdeutschland nach 1945 (vgl. Weber 2020, 1129).

7 Der Umtauschkurs war gestaffelt und variierte je nach Alter: Ein Verhältnis 1:1 galt bei Bürger*innen ab 60 Jahren für bis zu 6000, zwischen 14 und 59 Jahren für bis zu 4000 und bei Kindern bis 14 Jahren für bis zu 2000 DDR-Mark, außerdem für regelmäßige Zahlungen wie Löhne, Gehälter, Stipendien, Renten, Mieten und Pachten. Höhere Sparguthaben und Schulden wurden 2:1 umgetauscht. Der Durchschnitt lag bei 1,8:1 (vgl. Neubert 2008, 386-387). 
Jeder Ostdeutsche hatte sein Leben »in einem Maße umstellen müssen, als wäre er in ein anderes Land gezogen. Fast alle wechselten den Arbeitsplatz, mit Phasen der bis dahin unbekannten Arbeitslosigkeit. Umlernen mussten alle, am Arbeitsplatz, in der Politik, in der Verwaltung, im privaten Bereich« (Schröder 2007, 13).

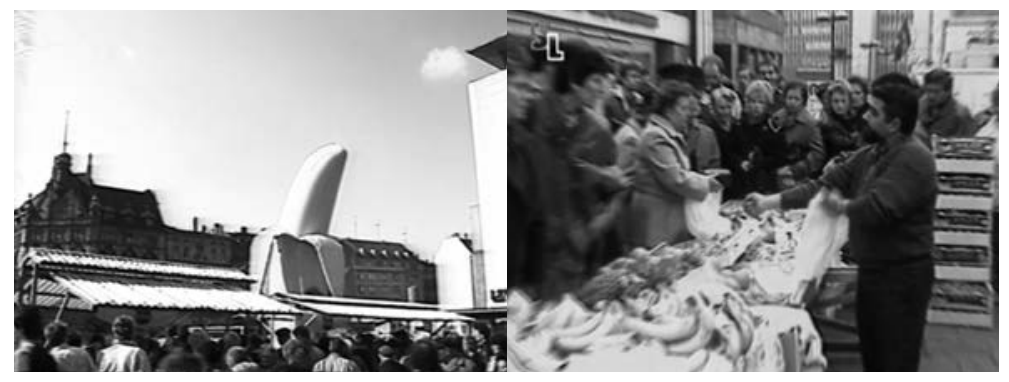

Abb. 1 und 2: März 1990 auf dem Leipziger Marktplatz: Marktschreier und eine überdimensionale Banane symbolisieren die westliche Übernahme öst-

licher Märkte. (C) Stadtfernsehen / Studio Leipzig, März 1990.

Die Große Transformation nahm allerdings nicht erst am 9. November 1989 oder am 3. Oktober 1990 ihren Anfang, und sie mündete nicht irgendwann am Ende der 1990er Jahre in eine vollendete Vereinigung, sondern hatte ihren Vorlauf in den 1980ern: Niedergang der DDR-Ökonomie, mediale Öffnung nach Westen, Entstehen und Erstarken einer oppositionellen Zivilgesellschaft, die sich die seit Anfang der 1980er Jahre aufkommenden, modernen elektronischen Medien zunutze machte (Satellitenfernsehen, Kabelnetzwerke, Antennengemeinschaften, Videokameras). Die Große Transformation ist ein bis heute andauernder, Generationen überspannender Prozess.

\subsection{Eingrenzungen und Ausprägungen des Projekts}

Das hier vorgestellte Forschungsprojekt konzentriert sich auf die Sattelzeit des Übergangs von einem staatssozialistischen in ein demokratisches und kapitalistisches System, auf die erste Phase der Transformation in ein gemeinsames Deutschland 1990 bis 1995. Diese ist unter anderem gekennzeichnet durch politische und mediale Maßnahmenund Ereignisbündel, nämlich »die Delegitimierung und Abschaffung der sozialistischen Staatsmacht in der DDR, [den] kurzzeitige[n] Ver- 
such des Aufbaus eines pluralistischen politischen Systems in der DDR, [den] zur Beendigung der deutschen Zweistaatlichkeit hinführende[n] Prozess sowie die politisch-administrative Übergangsperiode für das ostdeutsche Siedlungsgebiet« (Pasternak 1998, 21).

In diesem Zeitraum, Anfang 1995, endeten auch die ökonomischen Maßnahmen zur Übergangsfinanzierung der deutschen Einheit, und die öffentliche Finanzwirtschaft des vereinigten Deutschlands wurde weitgehend von Sonder- und Ausnahmeregelungen befreit (vgl. Wollmann 1997, 74; vgl. Einigungsvertrag 1990). Zwei weitere Gründe für den Zeitrahmen 1990 bis 1995 sind technischer Natur und von dem bisher Genannten weitgehend unabhängig: Zum einen datieren die audiovisuellen Quellen, die frühesten analogen Videobänder der ersten Gründungswelle der Lokalfernsehveranstalter, genau auf den Zeitraum von 1990 bis 1995 und sind von technischem Verfall bedroht. Zum anderen traf die Entfaltung gleich mehrerer für das Entstehen von Lokalfernsehen zentraler technologischer Entwicklungen mit den oben angeführten Entwicklungen zusammen, quasi als Conditiones sine qua non: tragbare Videokameras (Fernsehen für Jedermann) sowie Glasfaser- und Kupfer-Kabelnetzwerke.

Seit einigen Jahren ist, teilweise in einer jüngeren Generation, teilweise auch unter den ehemaligen Akteur*innen, ein Diskurs entstanden, der etliche der damaligen politischen und ökonomischen Entscheidungen kritisch daraufhin hinterfragt, ob sie tatsächlich so »alternativlos« waren, wie es vor 25 und 30 Jahren erschien. Jörg Schweinitz, Hilde Hoffmann und Tobias Ebbrecht postulierten bereits 2009 in Bezug auf das »abgeschlossene Sammelgebiet « DDR eine abgeklärte Haltung und ein nüchternes wissenschaftliches Urteil auf dem Feld der Transformationsforschung, um sich gar nicht erst in die Kämpfe der ehemaligen Protagonist*innen einzumischen (vgl. Schweinitz et al. 2009, 16-17). ${ }^{8}$ Hieraus leiten wir drei theoretisch-methodologische Momente ab:

8 Persönliche Anmerkungen dazu: Wir beide, als Autor*innen dieses Beitrags und als Forscher*innen heute, 30 Jahre nach diesem weitreichenden historischen Ereignis, versuchen einen solchen »frischen Blick« in der Forschung selbst einzunehmen. Den Fall der Mauer und die folgende Sattelperiode haben wir als reflektierende Erwachsene durchlebt: Judith Kretzschmar, die ihre prägenden politischen, kulturellen, sozialen und medialen Erfahrungen in der DDR gemacht hat, und Rüdiger Steinmetz in der Bundesrepublik Deutschland. Außerdem hat unser Thema seine Wurzeln in den Zeiten des Kalten Krieges zweier deutscher 
1. Heute stimmt es umso mehr, dass sich, frei von den Kämpfen der »heißen« Transformationszeit, eine abgewogenere Analyse anstellen lässt. Dies kann und muss (auch) eine jüngere Forscher*innengeneration leisten, gemeinsam mit Zeitzeugen und auf der Basis neuer, eben auch audiovisueller Quellen.

2. Vieles von dem, was heute aufbricht und sich in Wahlergebnissen niederschlägt, wurde vor 25 bis 30 Jahren unterschätzt oder falsch bewertet, in der Hektik des Umbruchs missachtet, liegengelassen, unter den Teppich gekehrt und überdeckt durch allzu viele, gleichzeitig auf Politik wie auf Bürger*innen einstürzende Herausforderungen, Verheißungen und Möglichkeiten. Heute stellen sich die damals unbeantworteten, verdrängten Fragen neu.

3. Gleichzeitig wirft die heutige Perspektive ein Licht auf die geronnenen Erfahrungen, Gefühle, Hoffnungen und Enttäuschungen, die in diesen frühen lokalen Fernsehprogrammen zu finden sind. Der Soziologe Michael Hofmann $(2016,7)$ betont: »Wir können heute noch gar nicht ermessen, wie wichtig und wertvoll die in der Transformation gewonnenen Lebenserfahrungen für die nachfolgenden Generationen sein werden.«

\subsection{Lokalfernsehen als Speicher audiovisuellen, kulturellen Gedächtnisses}

Spätestens seit Anfang der 1970er Jahre versteht man die Programme und Inhalte audiovisueller Massenmedien auch wissenschaftlich als geronnene Erinnerungen ihrer jeweiligen Zeit, als Bewegungen des »Zeitgeists « und als historische Quellen (vgl. Albrecht 1969; McCreary 1972). Auf der Produktebene werden die bewegten Bilder von Film und Fernsehen in ihrer synergetischen Einheit aus Ton, Montage und anderen untrennbaren ästhetischen Komponenten als zu analysierende historische und kulturelle Quellen immer mehr anerkannt und durch die Analyse der Bedingungen ihrer Produktion und Rezeption kontextualisiert. In modernen Gesellschaften sind die jeweiligen Mediensysteme auf (inter-)nationaler, regionaler und lokaler Ebene als komplexe, selbstreferentielle Kommunikationssysteme anzusehen, die eine »Sprache sprechen«. Auf der anderen Seite basieren die Inhalte dieser Pro-

Staaten, die jeweils in einen der gegnerischen Blöcke integriert waren und unsere Lebens- und Denkweisen beeinflusst haben. 
gramme auf lokalen und (sub-)regionalen Grundlagen; sie haben spezifische Wurzeln in Kultur und Geschichte. Diese klassischen Medien drücken einerseits gesellschaftliche Erfahrungen, Ideen und individuelle Phantasien aus und formen sie andererseits.

Massenmedien sind "Systeme der Beobachtung sowie der Selbstbeobachtung der Gesellschaft« (vgl. Gerhards 1994) und sie sorgen für die Integration in und die Teilhabe von Menschen an der Gesellschaft. Sie vermitteln und übersetzen durch ihre audiovisuelle Repräsentation und Distribution zwischen der individuellen und der soziokulturellen Dimension des kollektiven Gedächtnisses (vgl. Erll 2017, 135). Die Kulturanthropologin Aleida Assmann (2018) untersuchte in ihrem Werk Der lange Schatten der Vergangenheit die Erinnerungskultur einschließlich der Rolle der Medien darin. Medien wie fiktionale und dokumentarische Filme oder im hier diskutierten Fall lokale Fernsehprogramme bilden Quellen lebendiger Erinnerungen, die diese in ein kulturelles Gedächtnis überführen:

Die Massenmedien schaffen wichtige Impulse und Auslöserreize für das kulturelle Gedächtnis, ohne selbst eines zu produzieren. Sie sind unentbehrlich, um es zu aktivieren, doch es bedarf anderer Instanzen, um es zu bilden. Der größte Teil der Medienangebote geht unwiederbringlich verloren; ein kleiner Teil landet im kulturellen Speichergedächtnis, ein winziger Ausschnitt davon wird Bestandteil des kulturellen Funktionsgedächtnisses (Assmann 2018, 242). ${ }^{9}$

Assmann unterscheidet grundsätzlich zwischen einem »inkarnierten Erlebnisgedächtnis« der Zeitgenoss*innen und einem »exkarnierten Mediengedächtnis« der Gesellschaft (Assmann 2018, 210-213), die sich gegenseitig beeinflussten und beeinflussen. Hinzugefügt sei: Im Laufe der Zeit, etwa bei Neuinterpretationen und der Wiederverwendung in verschiedenen Bildungskontexten, aber auch bei Neukompila-

9 Das »Speichergedächtnis« ist laut Assmann $(2018,55)$ der »Fundus und Hintergrund für latente Erinnerungen, die ihre Stunde hinter sich oder noch vor sich haben«, weil sie eben, wie es in dem hier vorgestellten Projekt geschieht, dem Vergessen durch Re-Aktualisierung entrissen und dem aktiven Erinnern im Funktionsgedächtnis zugeführt werden. »Im Funktionsgedächtnis herrscht notorischer Platzmangel. Was dort hineingelangt - vom Kanon biblischer Texte bis zum Kanon der Klassiker - ist durch rigorose Verfahren der Auswahl hindurchgegangen. [...] Was einen Platz im Funktionsgedächtnis einer Gesellschaft hat, hat Anspruch auf immer neue Aufführung, Ausstellung, Lektüre, Deutung, Auseinandersetzung.« (ebd., 56) 
tionen und Interpretationen in neuen Fernsehsendungen, hat dieses exkarnierte Mediengedächtnis das Potenzial, wieder in die Erfahrungserinnerungen gegenwärtiger und zukünftiger Individuen, Gruppen und Generationen zurückzufließen und diese damit neu zu »inkarnieren « bei denen, die als Zeitzeug*innen an den Ereignissen teilgenommen hatten, aber auch bei denen, die zur Zeit der Ereignisse gerade erst oder noch gar nicht geboren waren. Assmann (ebd., 215) spricht in diesem Zusammenhang von der zweiten und dritten Generation, die in der konsequenten Genealogie derjenigen Ereignisse steht, die ihre Identität geprägt haben, aber außerhalb der Reichweite ihrer bewussten und selbstgewonnenen Erfahrung. So sind die Erinnerungen an die 1990er Jahre allgegenwärtig, als Teil eines Erfahrungs- und eines Generationengedächtnisses. Assmann $(2014,14)$ definiert diese Omnipräsenz als »Noch-Gegenwart der Vergangenheit«.

Darüber hinaus spielt, so ist hinzuzufügen, bei der DDR- und Vereinigungserfahrung eine »Zwischen- und Zwittergeneration « eine Rolle, nämlich ostdeutsche Jugendliche, die im Alter von 12 bis 15 Jahren die deutsche Wiedervereinigung erlebten, in ihrer frühen Sozialisation mit Ost-Identität ausgestattet wurden, die noch von antifaschistischen Helden, kommunistischen Ritualen und SED-Insignien geprägt waren (vgl. Wolfrum 2006, 495) und dann plötzlich die »ersten Wessis aus Ostdeutschland« wurden, wie es die Autorin Jana Hensel (2017 [2002], 166) formulierte.

In dieser Arbeit wird folglich unterschieden zwischen drei Generationen: der Generation der (damals erwachsenen, aktiven) heutigen Zeitzeug*innen, der »Wende- oder Zwischengeneration« und der beziehungsweise den »Nach-Wende-Generation(en)«.

\subsection{Entwicklung lokaler Fernsehsender in der DDR und in Sachsen}

Während die Grundstrukturen des staatlichen DDR-Fernsehens bis zum 31. Dezember 1991 bestanden, hatten die ab 1990 entstandenen lokalen Fernsehsender eine dreifache Genese: a) Ihre technischen und teilweise auch personellen Wurzeln lagen im letzten Jahrzehnt der DDR, in den sogenannten »Antennengemeinschaften $« ;{ }^{10} \mathrm{~b}$ ) sie gingen

10 Die Kabelnetze der Antennengemeinschaften verbanden in der Endphase der DDR hunderte, tausende und mitunter bis zu 50000 Haushalte in Wohnblöcken 
teilweise aus der Bürgerrechtsbewegung in der DDR und der unmittelbaren Phase nach dem Fall der Mauer hervor; c) diese beiden Wurzeln waren teilweise miteinander verflochten.

Einige Beispiele für diese Wurzeln sollen nun näher dargestellt werden: In den hügeligen Regionen Sachsens, insbesondere im Erzgebirge, in der Sächsischen Schweiz, im Vogtland und im Zittauer Gebirge, erlaubte die Topographie nicht einmal den Empfang eines oder gar beider DDR-Fernsehprogramme. So war es etwa seit Mitte der 1980er Jahre ein staatlich akzeptiertes Verfahren, eine Höhenlage für eine »Antennenkopfstation « technisch zu vermessen und zu verorten, von der aus die Bürger*innen in unbezahlter Arbeit selbst Kabelnetze errichteten. Die Deutsche Post lizenzierte diese Stationen. Als Beispiel sei die Antennengemeinde Chemnitz/Ebersdorf genannt, die bereits zu Weihnachten 1984 stolz war, West-TV zu empfangen (vgl. Antennengemeinschaft Chemnitz/Ebersdorf, Chronik o. J.). Neben der Möglichkeit, das DDR-Fernsehen auch in abgelegenen und in Bergregionen zu bekommen, war es ein willkommener Nebeneffekt, manchmal sogar der Hauptgrund, dass man öffentlich-rechtliche oder kommerzielle Fernsehprogramme aus Westdeutschland sehen konnte (vgl. Antenne Meuselwitz).

Viele noch heute bestehende örtliche Kabelanlagen stammen daher aus DDR-Zeiten. Um eine Genehmigung zu erhalten, musste lediglich nachgewiesen werden, dass das DDR-Fernsehen irgendwo in der Kommune nicht optimal zu empfangen war (vgl. Staud 1996). Ein weiterer Hintergrund der geduldeten Kabelsysteme bestand auch darin, dass der Empfang der West-Programme so besser kontrolliert werden und man gegebenenfalls ganze Dörfer relativ leicht abschalten konnte.

Eine wesentliche Rolle für die Entwicklung des Lokalfernsehens in Sachsen spielten vier internationale technische Entwicklungen zu Beginn der 1980er Jahre: erstens die Entwicklung von Personal Computern (Apple II ab 1977, IBM 5150 ab 1981) und Spielekonsolen (Commodore $64 \mathrm{ab}$ 1982), zweitens die magnetische Bild- und Tonaufzeichnung per „Camcorder« (ab 1983) auch in Händen von Amateur*innen, die das »Fernsehen von nebenan« ermöglichen und befruchten sollten, drittens die Verkabelung per Kupfer- und Glasfaserkabel (seit Mitte der 1980er

mit Fernseh- und Radioempfang. Dies waren nichtstaatliche Einheiten und ihre Mitglieder waren durch einen sozialen, gemeinschaftlichen und technischen Pioniergeist motiviert. 
Jahre) und viertens die Entwicklung des Satellitenfernsehens seit 1987 (TV-Sat 1) und 1989 (TV-Sat2 sowie DFS Kopernikus).

Auf der Grundlage dieser Technologien und der dispersen, lokalen Netz-Infrastruktur entwickelten sich in der DDR örtliche Antennengemeinschaftsanlagen, aus denen Lokal-TV-Stationen entstanden. Hier zwei Beispiele: Bereits 1986 sollen nach unserem jetzigen Erkenntnisstand in Marienberg-Goldkindstein im Erzgebirge die ersten selbstproduzierten lokalen Programme mit Stand- und Bewegtbildinhalten begonnen haben. 1979 wurde der erste Antrag gestellt, Anfang 1981 war Marienberg im Erzgebirge auf private Initiative einer Antennengemeinschaft verkabelt, 1984 wurde die Antennenanlage (Kabel-Kopfstation) auf dem Mühlberg aufgebaut, und am 3. August 1984, mehr als fünf Jahre vor dem Fall der Mauer, stellte Günter Rötzer beim Rat des Kreises Marienberg einen Antrag auf »Kabelrundfunk in der Region Marienberg«, der nie abgelehnt oder genehmigt wurde (vgl. Rötzer 1984). Er fand dabei tolerierende Unterstützung vom Rat des Kreises Marienberg und des VEB Federnwerk Marienberg. Seit 1986 wurde im Kabelnetz der Stadt Marienberg auf Sat.1 eine Art elektronische Zeitung oder Teletext mit lokalen Inhalten ausgestrahlt. ${ }^{11}$ Diese Inhalte erzeugte man auf einer umprogrammierten Spielkonsole (Laser 210-BK, seit 1984 auf dem Markt). ${ }^{12}$ Aber die Einrichtung eines eigenen Kabelkanals dauerte bis November 1989, wobei nur wenige Videoproduktionen im Rahmen von Videotextnachrichten, Veranstaltungsankündigungen und lokaler Werbung stattfanden. Bis 1991 wurde das Lokalfernsehen, das zum größten Teil ein als Schleife gesendetes Teletext-»Programm« und nur wenige Videos enthielt, in etwa 15 sächsischen Gemeinden verbreitet. Die Zulassung durch die Sächsische Landesmedienanstalt (SLM) erfolgte 1992; heute ist das Programm der Regionalfernsehen Mittelerzgebirge MEF $\mathrm{GmbH}$ nahezu im gesamten Mittleren Erzgebirgskreis zu empfangen.

Eine ähnlich interessante Entwicklung durchlief die Großantennengemeinschaft Burgstädt. Ab 1980 entwickelten sich im Stadtgebiet von Burgstädt, etwa 20 Kilometer von Chemnitz (damals Karl-Marx-Stadt) entfernt, und den angrenzenden Nachbargemeinden aus Bürgerinitiativen fünf Antennengemeinschaften, die sich 1984 unter einem Dach zusammenschlossen und Ende 1989 auf die Herausgabe der »Burgstädter Kabelzeitung« einigten. Diese »Kabelzeitung« erhielt eine Sendelizenz

11 Teletext beziehungsweise Videotext befand sich seit 1980 in der Bundesrepublik im Regelbetrieb von immer mehr ARD-Anstalten (vgl. Chronik der ARD 1978).

12 https://www.mef-line.de/über-uns/entwicklung.html 
von der DDR-Regierung unter Hans Modrow und wurde ab Februar 1990 ausgestrahlt. Ein Rechtsnachfolger, »RG Regional-TV«, existiert bis heute. ${ }^{13}$

Das Lokalfernsehen in Burgstädt und das Beispiel des heutigen »MittelErzgebirgsFernsehens « in Marienberg zeigen die Kontinuität von einer DDR-Kabelnetzgemeinschaft in einigen großen Wohnblöcken zu den frühesten Lokalfernsehsendern im vereinten Deutschland (vgl. Großantennengemeinschaft Burgstädt und Großgemeinschaftsantennenanlage Marienberg-Goldkindstein 2020). Die späten DDR-Jahre und die frühe Transformationszeit ermöglichten kleineren und größeren Bürgerinitiativen - wenn man die Antennengemeinschaften auch als solche bezeichnen will - unterhalb des staatlichen Radars Rundfunk $\mathrm{zu}$ veranstalten. Bis zur Etablierung einer neuen Zulassungsbehörde kann man diese Initiativen als »Piratensender« bezeichnen (vgl. auch Kretzschmar und Steinmetz 2020, 89).

Die Sächsische Landesanstalt für privaten Rundfunk und neue Medien (SLM) wurde Ende 1991 gegründet, nahm am 2. Januar 1992 in Dresden ihre Tätigkeit auf und vergab seit Spätsommer 1992 die ersten lokalen Rundfunklizenzen (vgl. Kühn 2003, 95-98), die erste am 27. August 1992 an das »Kabeljournal« in Röhrsdorf bei Chemnitz. Bis Ende 1995 hatte die SLM Lizenzen für etwa 68 lokale Fernsehsender vergeben, davon um die 40 für Kabelgemeinschaftsanlagen mit »Telezeitung $\ll \cdot{ }^{14} \mathrm{Als}$ Indikator für einen dann beginnenden Konsolidierungsprozess dieses kurzzeitigen Gründungsbooms liefen bis 1999 bereits wieder 21 Sendelizenzen aus oder wurden zurückgegeben.

\subsection{Programm-Dimensionen}

In Sachsen entstand in der ersten Hälfte der 1990er Jahre die reichhaltigste lokale Fernsehlandschaft in ganz Deutschland. Diese Programme bestanden in weiten Teilen aus lokalen und subregionalen Teletext-Informationen, von ihnen auch als »Fernseh-Zeitung « bezeichnet, und lokaler Videotext-Werbung. Ein geringer Teil des meist in Endlosschleifen laufenden 24-Stunden-Angebots bestand aus klassischen bewegten Fernsehbildern, manchmal mit werktäglich aktualisierten Magazinen,

13 https://gag-burgstaedt.de/history.html

14 Eigene Berechnungen, basierend auf N.N. (Richter). Veranstalterübersicht Fernsehen - Erstzulassung bis 1995. SLM, interne Quelle, undatiert. 
meist aber mit nur einmal wöchentlich aktualisierten Beiträgen. In den ersten Jahren gehörten auch PR-Videos westdeutscher Unternehmen, internationale Musikvideos, Animationsfilme und Werbung für lokale Geschäfte und Händler zum Bewegtbild-Programm.

Eine genaue Berechnung der Programmdimensionen in Stunden oder Kassetten in der ersten Hälfte der 1990er Jahre in Sachsen ist meist mangels einer archivarischen Erfassung schwierig. In den Jahren 1990, 1991 und drei Viertel des Jahres 1992, also in der Zeit vor der Lizenzierung, gab es weniger als zehn lokale Stationen, bis Ende 1995 etwa 40. Eigene vorsichtige Berechnungen gehen von bis zu 1000 Programmstunden Bewegtbild von 1990 bis 1995 aus.

In Sachsen wurden zwischen 1990 und 1999 zahlreiche lokale Fernsehsender gegründet und auf einer zeitlich und räumlich sehr unterschiedlichen Basis betrieben. Zudem wandte man professionelljournalistische und westliche kommerzielle Programmformate sehr unterschiedlich an. Alle Programme waren - mehr oder weniger Learning-by-doing-Projekte, sowohl aus journalistischer als auch aus technischer und fernseh-ästhetischer Sicht. Gerade die dahingehende »Unbedarftheit« vieler ostdeutscher Macher*innen und ihrer überlieferten Programme trägt heute ganz wesentlich zur Authentizität und zum historischen Quellenwert des Materials bei. Manchmal sind hier Direct-Cinema-Berichte im besten Sinne zu finden, die kaum eine Differenz zwischen den »Macher*innen« als Nachbar*innen und den Dargestellten erkennen lassen. In den Kleinstädten und ländlichen Gemeinden ist ein sehr freier Umgang mit der Programmzeit festzustellen. Im Hinblick auf den kulturellen Wert der Programme und ihren Beitrag zum authentischen Bild des Alltags und seiner Veränderungen bildet all dies ein wesentliches Unterscheidungs- und Qualitätsmerkmal gegenüber den Programmen des öffentlich-rechtlichen Fernsehens.

\subsection{Auswahl sächsischer Lokalfernsehsender}

Im Folgenden werden Struktur und Geschichte der Sender kurz erläutert, deren Programme genauer untersucht wurden und die mit Programmausschnitten Eingang in die im Projekt realisierten Wiederaufführungen von Lokal-TV-Beiträgen gefunden haben. 
Tab. 1: Ausgewählte sächsische Lokalfernsehsender (Zusammenstellung auf Basis des gegenwärtigen Kenntnisstandes der Autor*innen).

\begin{tabular}{|c|c|c|}
\hline Name & Sendezeitraum & Besonderheiten \\
\hline $\begin{array}{l}\text { Stadtfernsehen } \\
\text { Leipzig }\end{array}$ & $\begin{array}{l}\text { März } 1990 \text { bis } \\
1993\end{array}$ & $\begin{array}{l}\text { Ältestes Lokalfernsehen in Leipzig. Das Nachrichten- } \\
\text { magazin »Studio Leipzig « wurde in einem gläsernen } \\
\text { Studio mitten in der Stadt präsentiert, als Zeichen für } \\
\text { Medientransparenz - in ausdrücklichem Gegensatz zu den } \\
\text { DDR-Medien. }\end{array}$ \\
\hline $\begin{array}{l}\text { Regionalfern- } \\
\text { sehen Mittel- } \\
\text { erzgebirge MEF } \\
\text { GmbH }\end{array}$ & 1986 bis heute & Siehe Abschnitt 2.4 . \\
\hline $\begin{array}{l}\text { Hoy-TV, später } \\
\text { Elsterwelle } \\
\text { TV (2000 bis } \\
\text { 2018), heute } \\
\text { Lausitzwelle TV }\end{array}$ & $\begin{array}{l}\text { Januar } 1993 \text { bis } \\
\text { heute }\end{array}$ & $\begin{array}{l}\text { Sendete zunächst für die ostsächsische Stadt Hoyers- } \\
\text { werda, dann auch für die Stadt Kamenz. Tägliche, viertel- } \\
\text { stündige Nachrichten folgten ab September 1993. Dazu } \\
\text { kamen drei Magazine am Montag, Mittwoch und Freitag } \\
\text { mit Themenschwerpunkten. Betreibergesellschaft war und } \\
\text { ist die SGS Rundfunkgesellschaft GmbH. }\end{array}$ \\
\hline LTV & 1992 bis 1994 & $\begin{array}{l}\text { Gegründet von Peter Vonstein, in der DDR Leiter des } \\
\text { Leipziger Bezirkskabinetts für Kulturarbeit und Anfang der } \\
\text { 1990er Jahre Produzent (»Stein-TV «) der Hallervorden- } \\
\text { Show auf Sat.1. Vonstein gründete die Produktionsfirma } \\
\text { Neues aus Sachsen GbR als Muttergesellschaft für das } \\
\text { dritte Leipziger Lokalfernseh-Programm LTV. Dieses bekam } \\
\text { ein Fenster auf der Frequenz von Vox zwischen } 17 \text { und } 20 \\
\text { oder } 21 \text { Uhr. Programmschwerpunkte waren Kultur (bei- } \\
\text { spielsweise Kirchenporträts), Live-Diskussionen zu Politik- } \\
\text { und Kulturthemen, Sport und Nachrichten. }\end{array}$ \\
\hline $\begin{array}{l}\text { E-R-tv / } \\
\text { Erzgebirge } \\
\text { Regional TV, } \\
\text { Marienberger } \\
\text { Fernsehen }\end{array}$ & $\begin{array}{l}\text { Beginn unbe- } \\
\text { kannt, SLM-Lizenz } \\
\text { von März } 1994 \text { bis } \\
\text { März } 2007\end{array}$ & $\begin{array}{l}\text { Der Sender produzierte alle } 14 \text { Tage ein dreistündiges, } \\
\text { nicht formatiertes Programm, das in Endlosschleife in } \\
\text { Kabelanlagen in Ansprung, Lengefeld, Zschopau und } \\
\text { Zöblitz lief. } 1995 \text { ließ der Zschopauer Bürgermeister das } \\
\text { Programm wegen »Unstimmigkeiten « mit dem Programm- } \\
\text { chef abschalten und verwies Letzteren mit seiner Kamera } \\
\text { aus dem Stadtrat. Die SLM musste gegen die Abschaltung } \\
\text { des Programms einschreiten. }\end{array}$ \\
\hline
\end{tabular}




\begin{tabular}{|c|c|c|}
\hline Name & Sendezeitraum & Besonderheiten \\
\hline $\begin{array}{l}\text { Laubuscher } \\
\text { Heimatkanal }\end{array}$ & $\begin{array}{l}\text { März } 1992 \text { bis } \\
2009\end{array}$ & $\begin{array}{l}\text { Betreiber war der evangelische Pfarrer Gerd Simmank. Er } \\
\text { realisierte ein Fernsehprogramm, das Ereignisse in der } \\
\text { kleinen Lausitzer Gemeinde Laubusch (gehört heute zur } \\
\text { Stadt Lauta) ungeschnitten und unformatiert abbildete, } \\
\text { um Öffentlichkeit herzustellen und Bürger*innenbetei- } \\
\text { ligung zu ermöglichen. Zusätzlich strahlte er rund } 3600 \\
\text { Morgenandachten aus. Pfarrer Simmank finanzierte alles } \\
\text { aus eigener Tasche (mehr in Kretzschmar und Steinmetz } \\
\text { 2020, 93). }\end{array}$ \\
\hline Kanal X & $\begin{array}{l}\text { März } 1990 \text { bis } \\
\text { Anfang } 1991\end{array}$ & $\begin{array}{l}\text { Gegründet in Leipzig von den westdeutschen Videokünst- } \\
\text { Iern Ingo Günther und Norbert Meissner sowie den ost- } \\
\text { deutschen Anja-Christin Remmert (Autorin) und Jörg Seyde } \\
\text { (Kunsthistoriker). Eingetragen als gemeinnütziger Verein. } \\
\text { Beim Runden Tisch Leipzig beantragte der Verein in der } \\
\text { Endphase der DDR eine Sendelizenz, die ihm der Medien- } \\
\text { kontrollrat aber nicht erteilte. }\end{array}$ \\
\hline $\begin{array}{l}\text { RFV / VRF } \\
\text { Vogtland } \\
\text { Regional } \\
\text { Fernsehen }\end{array}$ & $\begin{array}{l}\text { Januar } 1994 \text { bis } \\
\text { Dezember } 2015\end{array}$ & $\begin{array}{l}\text { Sendete in Kabelanlagen in Plauen, Auerbach, Klingenthal, } \\
\text { Markneukirchen, Reichenbach und dem Oberen Vogtland } \\
\text { wöchentlich drei Stunden aktuelles Programm mit Schwer- } \\
\text { punkten auf Sport, Wirtschaft und Regionalkultur. Seine } \\
\text { Kulturprogramme, unter anderem die Rubrik»Geschichte } \\
\text { aus Stein «, waren ebenso beliebt wie »Der Blumenstrauß } \\
\text { der Woche« für »verdiente VogtländerInnen « und »Vogt- } \\
\text { länder filmen selbst«. Das Programm wurde für seine } \\
\text { Qualität mit vielen Preisen ausgezeichnet. }\end{array}$ \\
\hline Torgau-TV & $\begin{array}{l}\text { April } 1995 \text { bis } \\
\text { heute }\end{array}$ & $\begin{array}{l}\text { Verbreitet in den Kabelnetzen Torgau, Beilrode, Arzberg } \\
\text { und Zinna. Das Programm bestand aus einer wöchent- } \\
\text { lichen einstündigen Sendung mit einem langen Beitrag, } \\
\text { einer »Wochenschau« und einem »Polizeireport«. Es } \\
\text { enthielt auch Reportagen, Dokumentationen, Interviews, } \\
\text { Kommentare, Ratgebersendungen und Veranstaltungs- } \\
\text { tipps. }\end{array}$ \\
\hline $\begin{array}{l}\text { eff3 Frei- } \\
\text { berg (Erstes } \\
\text { Freiberger } \\
\text { Fernsehen - } \\
\text { 3. Kanal) }\end{array}$ & $\begin{array}{l}\text { Juni } 1994 \text { bis Juni } \\
2015\end{array}$ & $\begin{array}{l}\text { Kabel-Fernsehprogramm für Freiberg, Conradsdorf, Naun- } \\
\text { dorf, Hilbersdorf, Halsbrücke, Krummenhennersdorf, Klein- } \\
\text { waltersdorf, Zug, Weißenborn und Großschirma. Täglich } \\
\text { zu jeder ungeraden Stunde konnten die angeschlossenen } \\
\text { Haushalte das 40-minütige, wöchentlich aktualisierte } \\
\text { Programm empfangen. Wie bei anderen lokalen Fernseh- } \\
\text { programmen wechselten sich in der Programmschleife } \\
\text { Fernseh- und Videotext-Teile ab. }\end{array}$ \\
\hline
\end{tabular}




\begin{tabular}{|c|c|c|}
\hline Name & Sendezeitraum & Besonderheiten \\
\hline $\begin{array}{l}\text { Euro-Regional- } \\
\text { TV / eRtv } \\
\text { Görlitz }\end{array}$ & 1992 bis 2017 & $\begin{array}{l}\text { Programm für die Landkreise Görlitz, Bautzen und } \\
\text { Zgorzelec (Polen), das von Beginn an grenzüberschreitend } \\
\text { konzipiert war. Die technische Reichweite lag bei bis zu } \\
300000 \text { Zuschauer*innen, davon etwa } 80000 \text { in Polen. } \\
1992 \text { Beginn als »Bildschirmzeitung « (Videotext). Später } \\
\text { kamen das deutsch-polnische Magazin »Nachbarn « und } \\
\text { das Wirtschaftsregionenmagazin »Zukunft Heimat« dazu. }\end{array}$ \\
\hline Eilenburg-TV & $\begin{array}{l}\text { Februar } 1995 \text { bis } \\
\text { Februar } 2016\end{array}$ & $\begin{array}{l}\text { Wurde von der im Oktober } 1994 \text { von Karl-Heinz Hempel } \\
\text { und Andrea Heyn gegründeten Media Concept GmbH für } \\
\text { zunächst } 6000 \text { Kabelhaushalte in der nordsächsischen } \\
\text { Kleinstadt (knapp } 20000 \text { Einwohner*innen) veranstaltet; } \\
\text { Sendelizenz der SLM am 8. Februar 1995. Sendestart im } \\
\text { Juli } 1995 \text { zunächst mit Videotext-Schleifen, dann ab dem } \\
\text { Mulde-Hochwasser im September } 1995 \text { auch mit Video- } \\
\text { berichterstattung. Hempels Erfahrungen resultierten aus } \\
\text { dem alteingesessenen Fernsehgeschäft seines Vaters und } \\
\text { Heyn war eine komplette Seiteneinsteigerin als Diplom- } \\
\text { ingenieurin für Betontechnologie. }\end{array}$ \\
\hline
\end{tabular}

\section{$3 \quad$ Methoden der Untersuchung}

Entsprechend den in der Einleitung aufgeworfenen Forschungsfragen, 1) die Relevanz für eine heutige Reaktivierung direkter sowie indirekter, mediatisierter Erfahrungen zu untersuchen und 2) die Wurzeln heutiger aus der Transformation resultierender Problemthemen aufzuspüren und die bisherige »Nachwende«-Geschichtsschreibung kritisch zu hinterfragen, wurde für dieses Projekt ein Methodenmix entwickelt. Darin bekommen heutige Zuschauer*innen (drei Generationen) Programme aus der Sattelzeit kontextualisiert vorgeführt. Dann werden die heutigen Nutzer*innen zur (Re-)Aktivierung ihrer Erinnerungen und inzwischen gemachten Erfahrungen befragt. Aus historischer, politischer, soziologischer, medienwissenschaftlicher und Oral-HistoryFachliteratur wurden zuvor thematische Kategorien entwickelt, die der teilweise quantifizierenden, überwiegend aber qualitativen Analyse von Programmen und Reaktionen auf die Programme zugrunde liegen.

Es handelt sich wegen seines noch nicht gänzlich überschaubaren Umfangs um ein Projekt in progress. Es befindet sich auf dem Weg zwischen einerseits deduktiv abgeleiteten Kategorien und Subkategorien wie auch andererseits induktiv aus dem Gesprächs- oder Interviewma- 
terial gewonnenen Ergebniskategorien und Themenclustern. Hinzu kommt, dass die beiden Autor*innen implizite Hypothesen haben - bedingt durch ihre Ost- beziehungsweise Westsozialisation, Innen- oder Außensicht und -Erfahrung sowie ihre Geschlechts- und Generationenunterschiede -, die erst im Laufe des Forschungsprozesses explizit werden. Das Projekt ist in der gegenwärtigen Phase in seiner Abfolge und seinem Aufbau weiterhin auf Offenheit und Hypothesengewinnung angelegt.

Folgende Methoden wurden angewandt:

- Deduktion von zwölf Themenkategorien für die Analyse der Programme aus der Literatur. ${ }^{15}$

- Quantitative und qualitative Analyse lokaler sächsischer Fernsehprogramme der Jahre 1990 bis 1995.

15 1. System-Transformation übergreifend: Überführung sozialistischer Strukturen in kapitalistische; 2. Politische Transformation: Aufbau neuer politischer, demokratischer und rechtsstaatlicher Strukturen; 3. Ökonomische Transformation: Währungsaufwertung und Einkommensangleichung - dann aber der Kollaps der Wirtschaft und die Bedürftigkeit nach Alimentation, Anpassung der Realitäten unter dem Druck erhöhter Ansprüche und verschlechterter Bedingungen; 4. Kulturelles Leben: Schließung und Neu-Etablierung von Bildungs-, Kultur- und Sozialeinrichtungen; 5. Arbeitsleben: Schließung (»Abwicklung«) von Industrie-, Landwirtschafts- und Handelsbetrieben, Arbeitsplatzverlust, Neu-Orientierung auf Arbeitsstrukturen und -profile, Konkurrenz, Leistungsanforderungen, erste Streiks, Arbeitsemigration nach Westdeutschland; 6. Soziale und allgemeinmenschliche Lage: Verlust erworbener sozialer und ethischer Standards und Ziele, Neuorientierung, Rollen von Familie, Freundeskreis, Nachbarschaft und Arbeitskolleg*innen, Übernahme von mehr Eigenverantwortung, Generationen-Sichtweisen; 7. Umgang mit der (eigenen) Vergangenheit: Entdecken, Aufdecken, Diskutieren; altes und neues (politisches) Personal, Schuldfragen; 8. Heimat: Traditionen, Brauchtum, Feste; regionale/lokale Dialekte und Speisen; 9. (Verkehrs-)Infrastruktur, (Landschafts-)Architektur: Verkehrsentwicklung, Stadtplanung und Restaurierung, Ökologie und Umweltschutz, Wandel der Dörfer, Städte und Landschaften, Freizeit und Tourismus; 10. Das Eigene und das Fremde: neue Reisemöglichkeiten, Entdecken »fremder« Länder und Kulturen, neue Erfahrungen und alte Vorurteile; neue ausländische Restaurants, Speisen und Getränke; Ausländerfeindlichkeit, »Besser-Wessis« - »JammerOssis«; 11. Phasen der Erfahrung mit der Vereinigung: Euphorie, Ernüchterung und Desillusionierung, falsche und enttäuschte Hoffnungen, Integration und Pragmatik; 12. Neue Medien-Strukturen und -Erfahrungen: West-Dominanz im Mediensektor, Nachahmung westdeutscher Programmformate und Medienpraktiken, neue Medienmöglichkeiten und -freiheiten. 
- Kontextualisierende Präsentationen ausgewählter Programme an mehr als zwölf Standorten in Sachsen mit anschließenden Fokusgruppen-Gesprächen.

- Qualitative Analyse der Fokusgruppen-Gespräche entsprechend den thematischen Kategorien und Unterkategorien.

- Macher*inneninterviews.

Bisher (Stand: März 2021) wurden etwa 250 Programmstunden von zwölf Lokalfernsehsendern untersucht und Fokusgruppen-Gespräche mit etwa 200 Teilnehmer*innen sowie zehn Macher*inneninterviews geführt.

\section{Einige Zwischenergebnisse}

Aus den zwölf Untersuchungskategorien werden im Folgenden zwei ausgewählt, die sich besonders klar aus der Auswertung der bisherigen Fokusgruppen-Gespräche an den über Sachsen verteilten Veranstaltungsorten ergaben: erstens die Umbrüche im Arbeitsleben und deren erlebte Auswirkungen und zweitens das Eigene und das Fremde (OstWest). Diese Fokusgruppen-Gespräche wurden leitfadengestützt durch zwei Moderator*innen jeweils im Anschluss an einen einleitenden Vortrag und die Präsentation einer teilweise regionalspezifischen Auswahl von Programmclips geführt und anonymisiert aufgezeichnet. ${ }^{16}$ Bei der Auswertung der Fokusgruppen-Gespräche wurde auf die interpretativreduktive Methode von Lamnek (1995; 1998; vgl. Lamnek und Krell 2016) zurückgegriffen.

\subsection{Umbrüche im Arbeitsleben und deren erlebte Auswirkungen (als Ängste)}

Durch die Fernsehclips wurden bei den Teilnehmer*innen sowohl damalige, aber auch gegenwärtige Zukunfts- und Existenzängste, Traumatisierungen sowie die Gefühle der Selbst- und Fremdscham re-aktualisiert.

16 Die Transkriptionen wurden auf Basis digitaler Tonmitschnitte und Videoaufzeichnungen zur Zuordnung eventuell wiederkehrender Sprecher*innen angefertigt. Der mündliche Sprachduktus wurde beibehalten, aber behutsam in eine lesbare Fassung redigiert. 
Diese wurden generell ausgelöst durch den abrupten Bruch mit den eingespielten Gewohnheiten des Alltags, speziell aber vor allem durch gravierende Einschnitte im Arbeitsleben nahezu eines und einer jeden. Ein erheblicher Teil dieser Gefühle ist heute noch virulent, unabhängig davon, ob die Zeitzeug*innen eher eine positive oder negative Bilanz der Vereinigung für sich ziehen. Es wurde deutlich, dass die genaue lokale Provenienz der Clips zwar eine gewisse Rolle spielte; aber es zeigte sich vor allem, dass die primären, »inkarnierten « Erfahrungen der Zeitgenoss*innen, an welchem Ort auch immer gewonnen, durch die mediatisierten, »exkarnierten« Erfahrungen mit den ausgewählten Clips aus anderen Orten Sachsens revoziert, aktualisiert und (quasi auf einem zweiten methodischen Weg) bestätigt, beglaubigt und verfestigt wurden. Das ließe sich entweder damit begründen, dass die Forscher*innen eine »typische«, repräsentative Programmauswahl getroffen hatten oder dass diese inkarnierten Erfahrungen eben überall in Sachsen, wenn nicht darüber hinaus in ganz Ostdeutschland, gemacht wurden. Wir vermuten Letzteres.

Hier einige Zitate aus den Gesprächen, die sich auf die zuvor gesehenen Beispiele beziehen:

Die Angst, die Angst, die dann gerade in den ersten Jahren nach der Wende war: »Was wird denn jetzt? « Also ich habe mich gefragt, und viele andere, »wie geht es denn weiter? « Die Westmark war erst einmal schön und dass man in den Urlaub, vielleicht, fahren konnte. Aber, was wird? Es hatte sich dann angedeutet, erst die Betriebe haben so eine Übergangsgesellschaft gemacht, dann wurden Lehrgänge angeboten, dann ABM. ${ }^{17}$

Ich habe schon zu DDR-Zeiten mit geistig und mehrfach behinderten Kindern gearbeitet und bin jetzt 41 Jahre an der gleichen Stelle. [...] Wir haben eigentlich insofern, naja, den Umbruch relativ still erlebt. Nur, dass die Ängste immer sehr geschürt waren, und die Ängste waren ähnlich wie in dem Film. [...] Behalten wir unseren Arbeitsplatz? [...] Wir [haben] ganz oft zusammengesessen, wenn irgendwelche Anbieter kamen, die sagten: "Wir übernehmen in einem halben Jahr die Schule, und dann seid ihr alle entlassen." Also solche Phrasen haben wir durch. Es hat sich eigentlich immer wieder gezeigt, dass am Ende das gar keiner so umsetzen konnte wie geplant. [...] Das war immer ganz beängstigend, doch am Ende sieht man, dass die wirkliche Arbeit dann eben gezählt hat. Aber man hat im Grunde genommen die Ängste damals gesehen, und heute sind sie eigentlich immer noch da, nur anders, aber immer noch präsent. Und von Zeit zu Zeit kommt

17 Sprecher im Mehrgenerationenhaus Zwönitz (Erzgebirge) am 6. März 2020. $\mathrm{ABM}=$ Arbeitsbeschaffungsmaßnahme. 


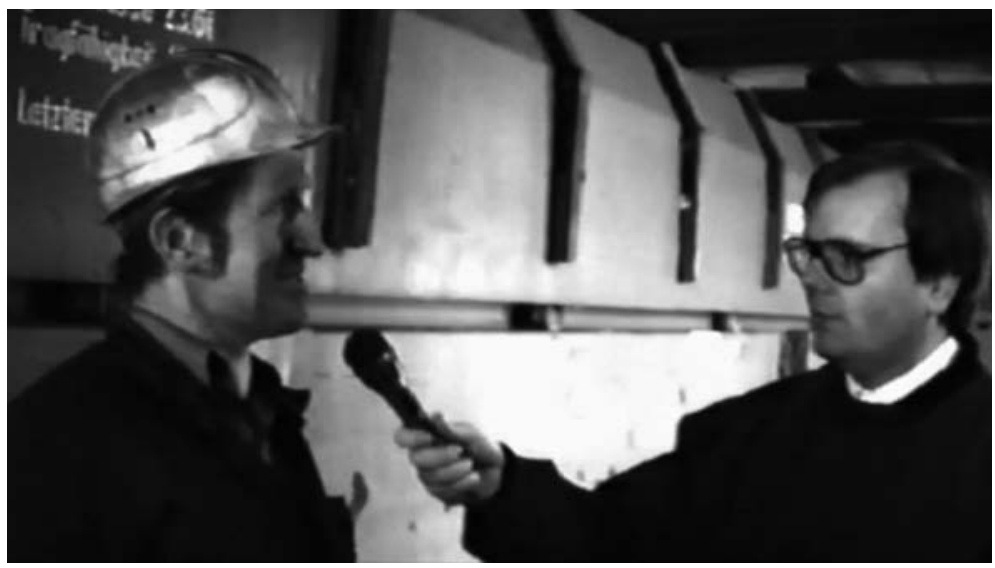

Abb. 3: Etwa 1000 Arbeitsplätze fallen weg, als Ende 1993 die Brikettfabrik in Laubusch (Lausitz) geschlossen wird. Unter den Arbeiter*innen herrscht Zukunftsangst. ( Laubuscher Heimatkanal, 19. November 1993.

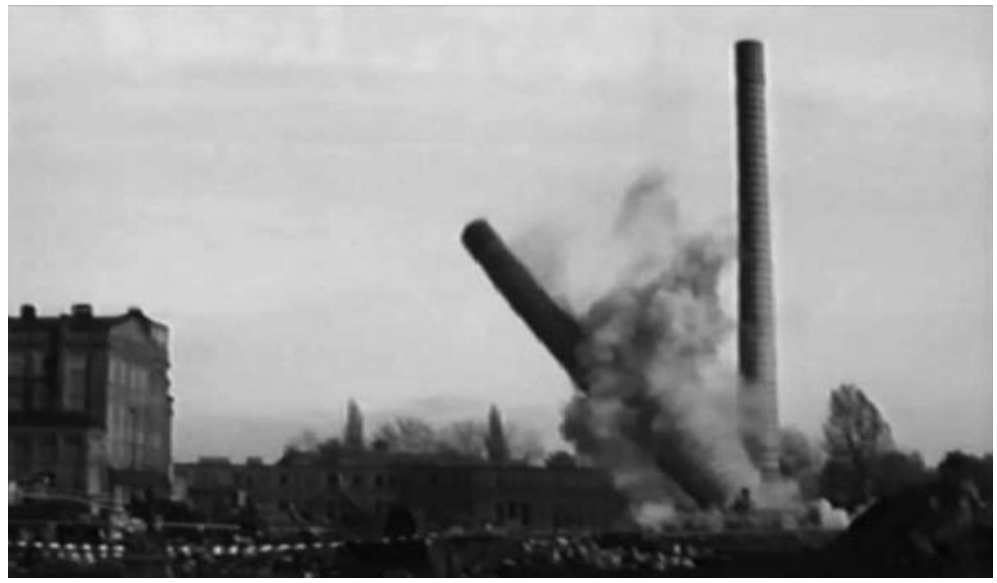

Abb. 4: Ikonisches Bild des Abbruchs: Sprengung auf dem Gelände der Brikettfabrik. (C) Laubuscher Heimatkanal, 19. November 1993.

dann irgend so ein Schatten, der irgendwas möchte, und den müssen wir dann immer wieder neu bekämpfen. ${ }^{18}$

Ich schätze das natürlich, jetzt die Welt bereisen zu können, was früher mal nicht möglich war. Aber ich habe halt so in Erinnerung, dass doch auch sehr

18 Sprecherin in der Stadtbibliothek Chemnitz am 11. Oktober 2019. 


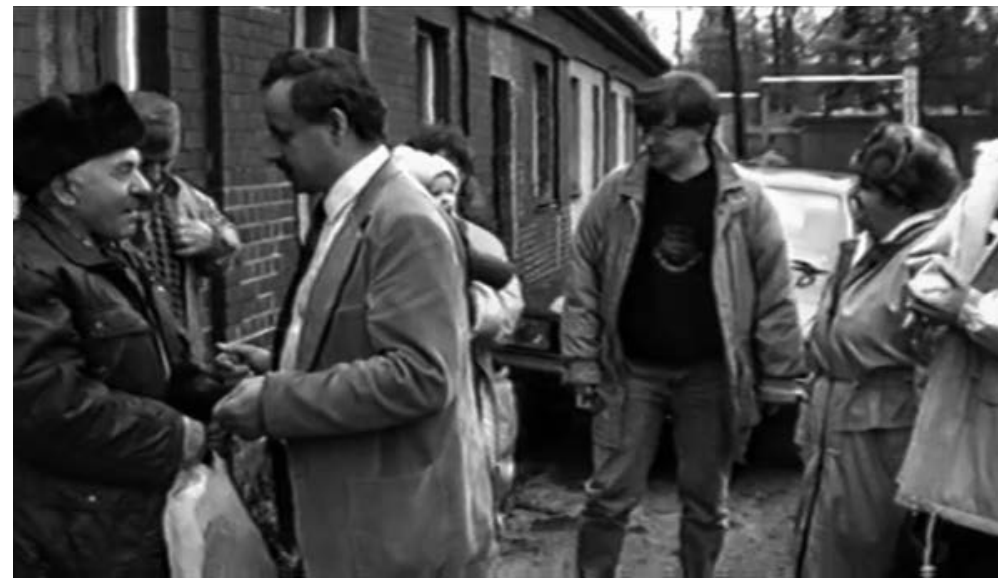

Abb. 5: Sozialer Sprengstoff im Laubuscher Lokalfernsehen: Dem kleinen Ort (etwa 5000 Einwohner) werden 1992 deutschstämmige Aussiedlerfamilien aus Kasachstan und der Ukraine zugewiesen, während kurz danach die Brikettfabrik geschlossen wird und knapp 1000 Menschen ihre Arbeit verlieren. (C) Laubuscher Heimatkanal, 6. November 1992.

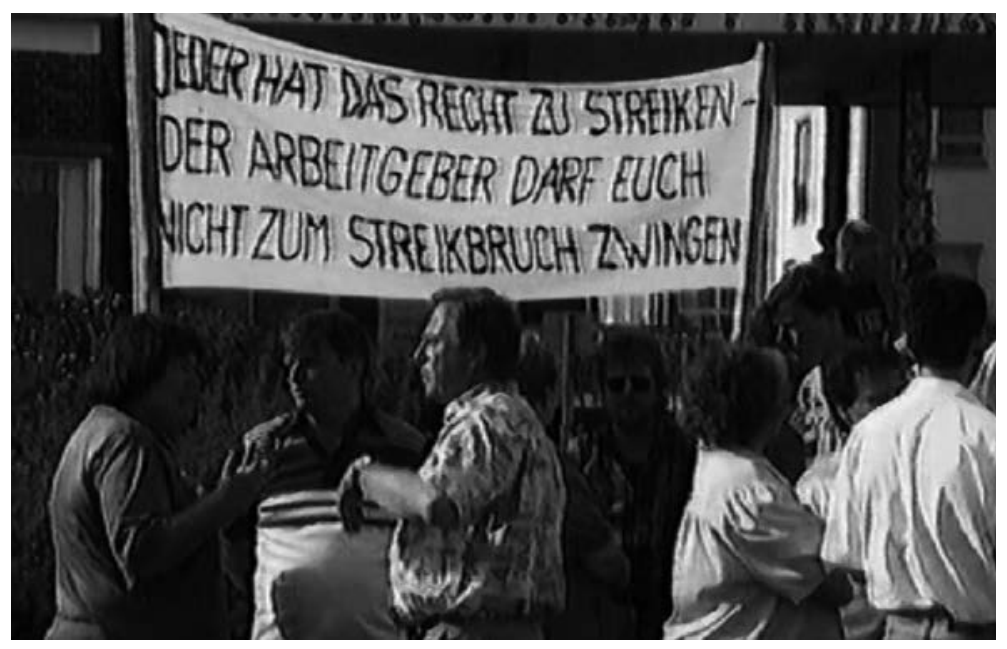

Abb. 6: Nach der Euphorie kam die Ernüchterung: Erste Streiks für Tarifverträge in Sachsen fanden im Frühjahr 1993 statt, hier am 4. Mai 1993 beim Druckmaschinenwerk MAN-Plamag in Plauen. Arbeiter*innen bekamen nur die Hälfte des Lohns bayerischer Metallfacharbeiter*innen. (c) RFV/VRF Vogtland Regionalfernsehen, 4. Mai 1993. 


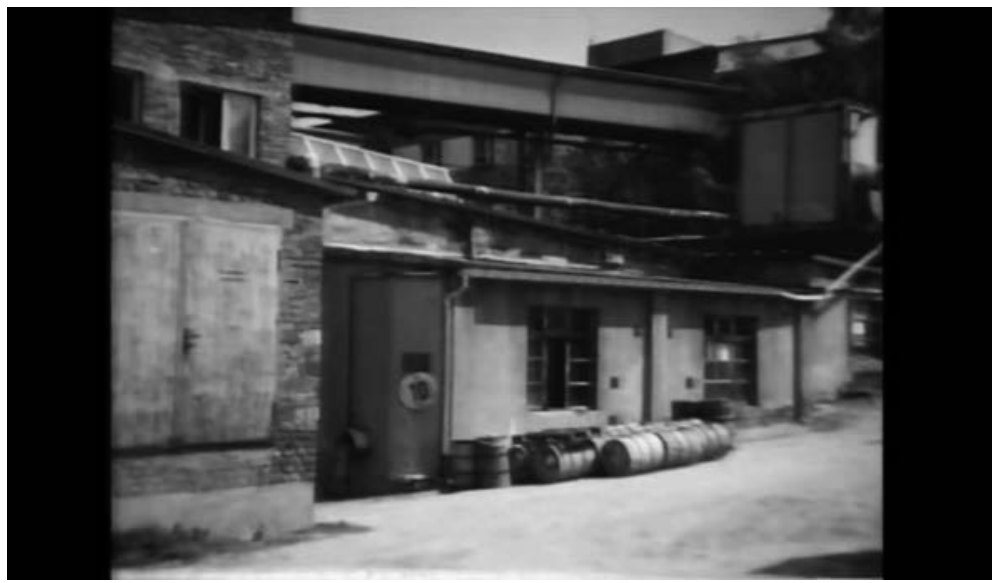

Abb. 7: Abbruch, Umbruch und Aufbruch in Auerbach (Vogtland): Aus dem »Suppina«-Werk wird »Knorr«-Suppen. (C) RFV / VRF Vogtland Regionalfernsehen, Februar 1993.

viel Verlustängste [...] und Existenzängste bestanden. Also, das ist das, was ich [...] aus dieser Zeit mitgenommen habe. ${ }^{19}$

Die folgenden Äußerungen beziehen sich auf Programmausschnitte, die den damals - nach Übernahme durch die großen westdeutschen Energiekonzerne - hoffnungsvollen Umgestaltungsprozess des Lausitzer Braunkohlereviers durch umweltfreundlichere Technik in Beziehung setzen zu der heutigen grundlegenden Umwandlung der Lausitz weg von der Braunkohle hin zu einer Hightechregion:

Da könnte einer ein Déjà-vu erleben. Wenn der mit 18 als Lehrling bei der LAUBAG dabei war und jetzt in »Schwarze Pumpe« arbeitet, sagt der: »Werde ich jetzt wieder arbeitslos, wie damals? $«^{20}$

[Dazu:] Es haben hier [in Hoyerswerda] über 70000 Menschen gewohnt, und jetzt sind es, glaube ich, in der Kernstadt nur noch 30000 . Das ist eben schon ein Schrumpfungsprozess, der geht parallel mit der wirtschaftlichen

19 Sprecher im Mehrgenerationenhaus Zwönitz (Erzgebirge) am 6. März 2020.

20 Sprecher im »studio eins« Hoyerswerda am 2. Juli 2020. Äußerung zum Thema "Schwarze Pumpe « und Braunkohletagebau damals sowie den Auswirkungen des Kohleausstiegsgesetzes vom Januar 2020 und der Digitalisierungsförderung in der Lausitz. Auf dem Areal des 1955 errichteten VEB Gaskombinats »Schwarze Pumpe« arbeitet heute ein 1992 errichtetes Braunkohle-Großkraftwerk. 
Entwicklung der Region einher. Falls es jetzt nicht gelingt, irgendeinen Ersatz zu schaffen, dann wird es noch wirklich schlimm kommen. Und insofern kann man schon die Ängste der Menschen verstehen. Also das ist bei uns natürlich auch, egal ob in der Zeitung oder halt auch Thema: Was wird passieren ${ }^{21}$

Die hier ausgewählten Beispiele belegen zwei durchgehende Trends in den Fokusgruppen-Gesprächen: zum einen, dass die in den Erinnerungen der Angehörigen der Zeitzeugen-Generation tief verwurzelten Erinnerungen und Gefühle durch die Fernsehclips reaktiviert wurden; und zum anderen, dass diese scheinbar verschütteten Kontexte auf die eigene Gegenwart bezogen und durchaus auch von einer Region auf die andere übertragen, also verallgemeinert werden.

\subsection{Das Eigene und das Fremde: Ost- und Westdeutsche}

Die zweite untersuchte Kategorie »Das Eigene und das Fremde«nimmt die scheinbaren Gewissheiten und Argumentationsmuster (im Sinne verfestigter Topoi) der letzten Jahrzehnte auf, nach denen sich die Welt des vereinten Deutschlands in »Besser-Wessis« und »Jammer-Ossis« einteilen ließe. Auch hier ging es darum, inkarnierte Erfahrungen anhand von historischen audiovisuellen Quellen überprüfen, bestätigen oder widerlegen zu lassen und damit als exkarnierte Erfahrungen entweder zu beglaubigen oder zu falsifizieren.

Hier wieder Beispiele aus den Fokusgruppen-Gesprächen, die sich auf die gerade zuvor gesehenen Fernsehclips beziehen und durchaus unterschiedliche reaktivierte Erfahrungen und heutige Positionen verdeutlichen:

Der einzige Gedanke, der mir jetzt beim Anschauen dieser Videoclips gekommen ist: dass einige Gedanken, die wir damals schon hatten, sich bestätigen im Rückblick. Gerade diese Konfrontation. Ich nenn' es jetzt mal »Konfrontation«, vielleicht ist es nicht immer eine Konfrontation im wahrsten Sinne des Wortes gewesen, aber es sind doch Welten aufeinandergeprallt, die sich im persönlichen Bereich zusammenfinden mussten oder auch nicht zusammengefunden haben, wenn wir Auseinandersetzungen mit Investoren [...] hatten. Ich denke manchmal, manche Sachen, die man uns Ossis als Vorurteile vorgeworfen hat, die bewahrheiten sich im Nachhinein eigentlich schon. In vielen Bereichen muss man im Nachhinein sagen:

21 Sprecher im »studio eins« Hoyerswerda am 2. Juli 2020. 


\section{Abb. 8: Verteilung von Schokorie-}

geln auf dem Leipziger Marktplatz, Mitte März 1990. Der Beitrag heißt "Test the West.« (C) Stadtfernsehen / Studio Leipzig, März 1990.

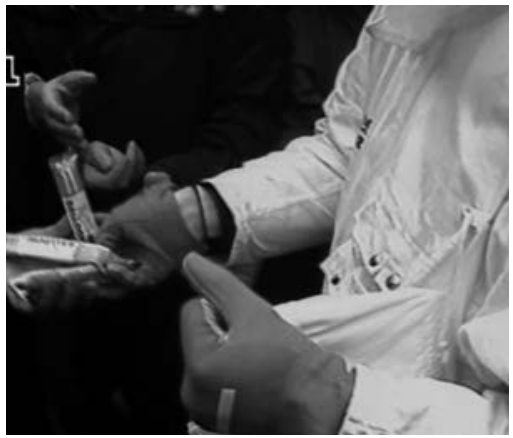

Ja, wir hatten vielleicht doch bewusst richtige Vorurteile beziehungsweise waren skeptisch. ${ }^{22}$

Das [die gezeigten Clips] spricht die Gefühle an. Ich bin eine Görlitzerin und auch schon etwas älter, ich hab' das alles miterlebt. Das ist unglaublich, was das bei mir ausgelöst hat. [...] Ich musste auch viel lachen hier, ich hab' auch geweint; das ist so, das betrifft einen ja selber. [...] Was ich erlebt hab' [...]: Wie die einzelnen kleinen Leute vor Ort im Westen hilfsbereit waren, wie die uns auch unterstützt haben, gegenseitig auch respektiert haben. Ich denke immer, die Kleinen, die miteinander zu tun hatten, die ohne wirtschaftliche Interessen irgendwas taten, damit konnte man ganz viel anfangen. [... $]^{23}$

Wie man damals auch umgegangen ist miteinander: Ich hab' das selbst erlebt auf dem Marienplatz [in Görlitz], wie dort dieser riesige LKW von Milka stand und kostenlos diese Schokoladentafeln verteilt haben an unsre Görlitzer Bürger. Und wenn da eine runterfiel, die Leute sind auf allen v-ie-r-e-n gekrochen und haben das aufgehoben. Da hab' ich mir gedacht, was ist denn mit den Leuten los? Was geht hier vor sich? Wieso erniedrigen wir uns so? Wieso lassen wir uns so vereinnahmen? ${ }^{24}$ (Vgl. Abb. 8).

Mich hat es peinlich berührt, muss ich sagen, mit dem Wissen von heute natürlich. Wie wir da so nach so Zeitungen, so einem Mist da angestanden haben und uns die Bananen um die Ohren hauen haben lassen, furchtbar. Muss ich jetzt echt so sagen, das ist schlimm eigentlich. Aber gut, das war damals die Zeit. ${ }^{25}$ (Vgl. Abb. 9)

Wir haben dem Westen viel zu verdanken. Was wäre denn die Alternative gewesen, wenn der Westen gesagt hätte, wir nehmen euch nicht? Unser

22 Sprecherin in der Stadtbibliothek Chemnitz am 11. Oktober 2019.

23 Sprecherin in der Stadtbibliothek Görlitz am 10. Oktober 2019.

24 Sprecherin in Stadtbibliothek Görlitz am 10. Oktober 2019.

25 Sprecher im »studio eins« Hoyerswerda am 2. Juli 2020. 
Abb. 9: Verkaufvon West-Zeitungen auf dem Leipziger Marktplatz im März 1990. Im Beitrag findet vor allem die Bild-Zeitung reißenden Absatz. (C) Stadtfernsehen/Studio Leipzig, 16. März 1990.

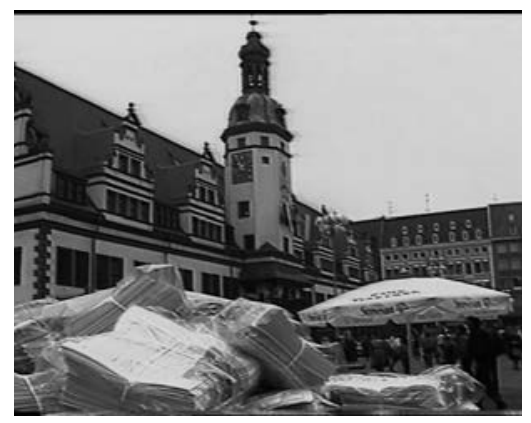

Geld war in der Welt wenig wert. Wir hatten wenig Rohstoffe; das Uran hat der Russe abgegriffen [...], weil das Uran eben ganz wertvoll war. Ich bin ein Kind des Erzgebirges und ich bin heute noch sehr dankbar, dass meine Kinder ihre Meinung sagen dürfen, dass sie, ohne Parteibuch und ihre Meinung nach dem Wind zu richten, aufs Gymnasium durften. ${ }^{26}$

Ich musste wie viele arbeitslos Gewordene nach der Wende aus dem Beruf ganz raus, vollkommen was Neues gemacht: Umschulung zum Altenpfleger, [...] die sogenannten Wessis als Ausbilder. [...] Ich war insofern sehr beeindruckt: Denen war zum Beispiel auch ganz wichtig, dass sie uns mit unserer Mentalität verstehen [...]: »Ich will von euch lernen, und wir wollen uns austauschen.« [...] Also die haben sich, glaub' ich, reingekniet. Haben sogar Wochenenden mit uns verbracht, einfach um uns mal kennenzulernen. Man kann sagen: fast Familie. Das war für mich beeindruckend, das war ein gutes Miteinander. Wir hatten auch viel Spaß mit dem »viertel vor« und »viertel nach«. Ich habe das sehr positiv in Erinnerung. ${ }^{27}$

Auch heute noch, glaube ich, man würde ähnliche Antworten bekommen. [...] Das ist so eine Blaupause auch auf die aktuelle Situation auch. [...] Man sagt zwar immer, Geschichte wiederholt sich nicht, aber [...] manche Verhaltensweisen ändern sich eben nicht. ${ }^{28}$

Ich denke, dass es wichtig ist, ins Gespräch zu kommen. Miteinander reden. Was mir da immer wieder auffällt, wer im Westen gelebt hat und keinerlei Kontakt in die DDR hatte, den hat es nie interessiert, der hatte keine Brüche. Der hat keinen Bruch erlebt, sondern konnte so weiterleben, als wenn nichts passiert wäre, und hier in der DDR ist alles passiert. [...] Jeder, der hier in Görlitz gewesen ist, hat eine Geschichte zu erzählen, wo ein Betrieb

26 Sprecher im Mehrgenerationenhaus Zwönitz (Erzgebirge) am 6. März 2020.

27 Sprecherin in der Thomaskirche Leipzig am 28. Oktober 2019.

28 Sprecher in Stadtbibliothek Görlitz am 10. Oktober 2019. 
zugemacht worden ist, wo die Kinder weggegangen sind, und das spüren wir ja bis heute. Das ist die Nachwende. ${ }^{29}$

Die Wendezeit war für mich verbunden mit dem persönlichen beruflichen Anfang, insofern hab' ich nicht innerhalb einer Struktur eine Veränderung erlebt, sondern ich hab' eigentlich eine Auflösung erlebt. [...] Auf der anderen Seite war das auch eine wunderbar anarchische Zeit, und man hat einfach, weil man ja keinen fragen konnte, der einem gesagt hat, was man machen soll oder wie man es machen soll, da hat man halt einfach gemacht. Manchmal sehnt man sich ein bisschen zurück nach so einer Zeit. Und dann will ich auch nicht immer so dieses Bashing »der West-Mensch, der uns betrogen hat «. Da gab es halt, [...] schwarze Schafe, vielleicht auch viele schwarze Schafe. Aber man wollte auch eine neue Ordnung haben und brauchte halt einfach Fachleute. Es wurde ja beschlossen, dass das eine Land in dem anderen aufgeht, und dann musste man sich eben sozusagen dem unterordnen. ${ }^{30}$

Zuzuhören, verschiedene Perspektiven und Haltungen zuzulassen und zu tolerieren, in einer »coolen« Distanz zur heißen ersten Phase die Transformation und ihre Ausprägungen und Auswüchse zu analysieren und zu bewerten, das wären (als Ergebnis unserer Forschungen) probate Mittel, auf dem Weg der Vereinigung voranzukommen. Die gegenwärtig junge und die mittlere, die »Wende«-Generation haben hierfür die nötige Offenheit und ihr geht der mentale Vereinigungsprozess zu langsam voran.

Ich fand auch den Clip mit den Jugendlichen spannend, weil das tatsächlich dieselben Themen sind, auf die man auch stößt, wenn man heute mit Schülern, Studenten und allen möglichen jüngeren Leuten in der Stadt sich unterhält. [...] Wir haben ja nur die Erfahrungen durch unsere Eltern gemacht. Aber viele Einstellungen, auch dieses Ost-West-Ding, haben sich noch gar nicht so stark verändert. Die sind zum Teil stagniert irgendwie [...], so Klischees, dass die sich jetzt über 30, 40, 50 Jahre eigentlich nicht verändert haben. In der Gesellschaft und wir selbst in unserer Generation [haben] quasi Teile dieser Klischees übernommen [...] und auch so bestimmte Meinungen gelernt $[\ldots] .^{31}$

Ich glaub', es geht extrem langsam voran. Ich hab' halt selbst die Erfahrung gemacht, wenn ich in westdeutschen Bundesländern bin, dass einem viele

29 Sprecher in der Stadtbibliothek Görlitz am 10. Oktober 2019.

30 Sprecher in der Stadtbibliothek Chemnitz am 11. Oktober 2019.

31 Sprecher in der Stadtbibliothek Görlitz am 10. Oktober 2019, Nach-Wende-Generation, Ostdeutschland. 
Fragen gestellt werden. sJa, wie ist denn das bei euch, wie ist denn das und wie ist der Akzent, und wie reden die Leute, und wir sind so ..., und die Arbeitsbedingungen sind so unterschiedlichヶ, und so ganz viele Themen. Gemeingesellschaftlich denkt man, da sind wir schon lange drüber, und die beiden deutschen Staaten gibt es gar nicht mehr, aber irgendwie gibt es sie doch, weil sie in den Köpfen noch existieren. ${ }^{32}$

\section{$5 \quad$ Fazit}

Die Sicherung, Erschließung und Analyse der 40 sächsischen lokalen Fernsehprogramme als audiovisuelles Kulturgut und dessen heutige Wiederaufführung vor Angehörigen der »Vor-Wende-«, der »Wende-« und der »Nach-Wende-Generationen« trägt zur Revision vertrauter Darstellungen, Positionen und Beurteilungen dieser Sattelzeit bei: Dies zeigen erste Programmanalysen und die Auswertungen von Fokusgruppen-Gesprächen. 30 Jahre nach dem Beginn des Vereinigungsprozesses sind ein guter zeitlicher Abstand, aus dem heraus diese drei Generationen sowohl in Ost als auch in West aus kühler Distanz besser verstehen, wie ihre Identität durch das historische Schlüsselereignis des Falls der Berliner Mauer und des Endes des Kalten Krieges verändert beziehungsweise neu geprägt wurde. Und dieser zeitliche Abstand wird der heutigen jüngeren Generation sowie denen nach ihnen helfen nachzuvollziehen und zu verstehen, woher ihre Identitäten kommen und wie sie geformt wurden.

Programmanalysen, regional unterschiedlich gewichtete Präsentationen und Kontextualisierungen der audiovisuellen Quellen entsprechend den oben genannten Kategorien werden das exkarnierte Gedächtnis gegenwärtiger und künftiger Generationen als kulturelles Speichergedächtnis, wenn nicht gar kanonisiertes Funktionsgedächtnis, wesentlich mitgestalten. Weit mehr als schriftliche Quellen, aber auch als Fotografien sind diese bewegten Fernsehbilder und -töne geeignet, Erinnerung und Anschauung eines entscheidenden Abschnitts der jüngsten Zeit-, Sozial- und Kulturgeschichte hervorzurufen, zu reaktivieren, in Lehr- und Bildungspaketen und in Ausstellungen zu erhalten.

Zur Beantwortung der beiden Forschungsfragen:

32 Sprecher in der Stadtbibliothek Görlitz am 10. Oktober 2019, Nach-Wende-Generation, Ostdeutschland. 
1. Inwieweit lassen sich aus der Begegnung mit diesen historischen Programmen Lebenserfahrungen sowie verschüttete beziehungsweise verdrängte Kontexte und Gefühle dieser Sattelzeit bei heutigen Seher*innen re-aktualisieren?

Hier ist zu differenzieren zwischen den drei Generationengruppen. Bei den Zeitzeug*innen wurden (damalige, aber auch gegenwärtige) Zukunfts- und Existenzängste, Traumatisierungen sowie die Gefühle der Selbst- und Fremdscham re-aktualisiert. Ost-WestVorurteile werden erinnert, aber unterschiedlich bewertet. Ein erheblicher Teil dieser Gefühle ist heute noch virulent, unabhängig davon, ob die Zeitzeug*innen eher eine positive oder eher eine negative Bilanz der Vereinigung für sich ziehen. Für die beiden jüngeren Generationen können die Autor*innen wegen deren relativ geringen Anteils an den Fokusgruppen nur vorläufig festhalten: Ängste und Traumatisierungen sind hier nicht anzutreffen; stattdessen ein begieriges, dankbares Aufsaugen von audiovisuell induzierten Anschauungen des damaligen Alltags, der ohne die Fernsehbeiträge aus dem Nahbereich allenfalls aus Kindeserinnerungen, Erzählungen oder erlebten Erziehungsmaßstäben der Eltern sowie aus Schule und Hochschule bestand.

2. Inwieweit können dadurch Erklärungen für die Wurzeln gegenwärtiger sozialer und politischer Diskurse im vereinigten Deutschland gegeben werden?

Bis heute treffen bei Ost- und Westdeutschen zwei unterschiedliche kulturelle, soziale Arbeits- und Erfahrungswelten aufeinander. Aufgrund des gemeinsamen Zeitraums von immerhin drei Jahrzehnten existiert die Polarisierung »Ost versus West« nicht mehr in der Reinform wie noch während der Sattelzeit. Vielerlei Differenzierungen, Mischungen und gemeinsame Erfahrungen sind eingetreten. Doch erhoffte und erfahrene Veränderungen waren nicht immer kongruent, und trotz beiderseitigen Bemühens: Die »Große mentale Transformation « - und damit die Vollendung der Vereinigung - ist ein bis heute und darüber hinaus anhaltender, unvollendeter Prozess. 


\section{Literatur}

Albrecht, Gerd. 1969. Nationalsozialistische Filmpolitik. Eine soziologische Untersuchung über die Spielfilme des Dritten Reichs. Stuttgart: Enke.

Antennengemeinschaft Chemnitz/Ebersdorf. Chronik. http://www.antenneebersdorf.de/index.php/geschichte.html. Zugegriffen: 17. März 2021.

Antenne Meuselwitz (Sendestart 1986). http://www.antenne-meuselwitz.de/ gesch.htm. Zugegriffen: 17. März 2021.

Assmann, Aleida. 2014. Geschichte im Gedächtnis. Von der individuellen Erfahrung zur öffentlichen Inszenierung. München: C. H. Beck.

Assmann, Aleida. 2018. Der lange Schatten der Vergangenheit. Erinnerungskultur und Geschichtspolitik. München: C.H. Beck.

Buchholz, Arnold. 1968. Die große Transformation. Stuttgart: Deutsche Verlags-Anstalt.

ARD. o.J. Chronik der ARD 1978. http://web.ard.de/ard-chronik/index/ 2190? year=1978. Zugegriffen: 17. März 2021.

Eckert, Rainer. 2007. Gegen die Wende-Demagogie - für den Revolutionsbegriff. Anmerkungen zu: Michael Richter, Die Wende. Plädoyer für eine umgangssprachliche Benutzung des Begriffs. Deutschland Archiv 6: 1084-1086.

Einigungsvertrag. 1990. Vertrag zwischen der Bundesrepublik Deutschland und der Deutschen Demokratischen Republik über die Herstellung der Einheit Deutschlands. EinigVtr. Ausfertigungsdatum: 31.08.1990. https://www.gesetze-im-internet. de/einigvtr/EinigVtr.pdf. Zugegriffen: 17. März 2021.

Erll, Astrid. 2017. Kollektives Gedächtnis und Erinnerungskulturen. Stuttgart: J.B. Metzler. DOI: 10.1007/978-3-476-05495-1_1.

Gerhards, Jürgen. 1994. Politische Öffentlichkeit. Ein system- und akteurstheoretischer Bestimmungsversuch. Kölner Zeitschrift für Soziologie und Sozialpsychologie, Sonderheft Öffentlichkeit und soziale Bewegungen: 77-105.

Großgemeinschaftsantennenanlage Marienberg-Goldkindstein. 202040 Jahre Antennengemeinschaft Marienberg-Goldkindstein. Interview mit Günter Rötzer. MittelErzgebirgsFernsehen (MEF) vom 1. Februar, https://www.youtube.com/ watch? $v=$ mkcSNbOSZLk. Zugegriffen: 17. März 2021.

Hensel, Jana. 2017 [2002]. Zonenkinder. Reinbek bei Hamburg: Rowohlt.

Hofmann, Michael. 2016. Einführung. In: Helden im Wilden Osten. Ostdeutschland in den Neunzigerjahren. Begleitheft zur Ausstellung, herausgegeben von Christian Schmidt und Aiko Wulf. Leipzig.

Jesse, Eckhard. o. J. Der Begriff »Wende« in der Diskussion. Erfurt: Gesellschaft für Zeitgeschichte e.V. http://www.gesellschaft-zeitgeschichte.de/dokumente/aktuelle-dokumente/der-begriff-wende/. Zugegriffen: 17. März 2021.

Koselleck, Reinhart. 1972. Einleitung. In: Geschichtliche Grundbegriffe. Historisches Lexikon zur politisch-sozialen Sprache in Deutschland, herausgegeben von Otto Brunner, Werner Conze und Reinhart Koselleck, XIII-XXVII. Stuttgart: KlettCotta.

Kowalczuk, Ilko-Sascha. 2019. Die Übernahme. Wie Ostdeutschland Teil der Bundesrepublik wurde. München: C.H. Beck. 
Kretzschmar, Judith und Rüdiger Steinmetz. 2020. „Wir hatten immer Sendezeit, wie wir wollten.« Rundfunkhistorisches Gespräch mit Gerd Simmank (Laubuscher Heimatkanal). Rundfunk und Geschichte 46 (1-2): 86-101.

Kühn, Detlef. 2003. Den Privaten eine Anstalt: Gründung und erste Jahre der SLM. In: Rundfunk in Ostdeutschland. Erinnerungen - Analysen - Meinungen, herausgegeben von Gerlinde Frey-Vor und Rüdiger Steinmetz, 91-107. Konstanz: UVK.

Lamnek, Siegfried. 1995. Qualitative Sozialforschung. 2 Bände. Weinheim: Beltz PVU.

Lamnek, Siegfried. 1998. Gruppendiskussion. Theorie und Praxis. Weinheim: Beltz PVU.

Lamnek, Siegfried, und Claudia Krell. 2016. Qualitative Sozialforschung. Weinheim: Beltz PVU.

Milev, Yana. 2020. Das Treuhand-Trauma: Die Spätfolgen der Übernahme. Berlin: Das neue Berlin.

McCreary, Eugene C. 1972. Zeitgeschichte im Film- und Tondokument: 17 historische, pädagogische und sozialwissenschaftliche Beiträge, herausgegeben von Günter Moltmann und Karl Friedrich Reimers. 1970. Göttingen: Musterschmidt. Rezension in The American Historical Review 77(2): 473-474. DOI: https://doi. org/10.1086/ahr/77.2.473-a.

Neubert, Erhart. 2008. Unsere Revolution. Die Geschichte der Jahre 1989/90. München, Zürich: Piper.

Pasternack, Peer. 1998. »Demokratische Erneuerung«. Eine universitätsgeschichtliche Untersuchung des ostdeutschen Hochschulumbaus 1989-1995. Mit zwei Fallstudien: Universität Leipzig und Humboldt-Universität zu Berlin. Dissertation. Carl von Ossietzky-Universität Oldenburg. https://www.hof.uni-halle.de/web/dateien/Demokratische-Erneuerung.pdf. Zugegriffen: 17. März 2021.

Polanyi, Karl. 2019 [1944]. The Great Transformation. Politische und ökonomische Ursprünge von Gesellschaften und Wirtschaftssystemen. Frankfurt am Main: Suhrkamp.

Richter, Michael. 2007a. Die Wende. Plädoyer für eine umgangssprachliche Benutzung des Begriffs. Deutschland Archiv 5: 861-868.

Richter, Michael. 2007b. Replik auf Rainer Eckerts Anmerkungen. Deutschland Archiv 6: 1086-1087.

Rötzer, Günter. 1984. An den Rat des Kreises Marienberg (Erzgebirge): »Kabelrundfunk im Gebiet Marienberg«, 3. August 1984. https://www.mef-line.de/ über-uns/entwicklung.html. Zugegriffen: 17. März 2021.

Schröder, Richard. 2007. Die wichtigsten Irrtümer über die deutsche Einheit. Freiburg im Breisgau: Herder.

Schweinitz, Jörg, Hilde Hoffmann und Tobias Ebbrecht. 2009. Zur Einleitung. Die Erinnerung an die DDR, der Dokumentarfilm und die Filmgeschichtsschreibung. In: DDR erinnern vergessen. Das visuelle Gedächtnis des Dokumentarfilms, herausgegeben von Jörg Schweinitz, Hilde Hoffmann und Tobias Ebbrecht, 7-19. Marburg: Schüren.

Staud, Toralf. 1996. Fernsehen von nebenan. Die Zeit Nr. 34 vom 16. August.

Steinmetz, Rüdiger, und Reinhold Viehoff (Hrsg.). 2008. Deutsches Fernsehen Ost. 
Eine Programmgeschichte des DDR-Fernsehens. Potsdam: Verlag für Berlin-Brandenburg.

Ther, Phillipp. 2016. Die neue Ordnung auf dem alten Kontinent. Eine Geschichte des neoliberalen Europa. Berlin: Suhrkamp.

Ther, Phillipp. 2019. Das andere Ende der Geschichte. Über die Große Transformation. Berlin: Suhrkamp.

Weber, Petra. 2020. Getrennt und doch vereint. Deutsch-deutsche Geschichte 19451989/90. Berlin: Metropol.

Wolfrum, Edgar. 2006. Die geglückte Demokratie. Geschichte der Bundesrepublik Deutschland von ihren Anfängen bis zur Gegenwart. Stuttgart: Klett-Cotta.

Wollmann, Hellmut. 1997. Transformation der politisch-administrativen Strukturen in Ostdeutschland. Wiesbaden: Springer VS.

\section{Open Access}

Dieser Beitrag erscheint unter der Creative-Commons-Lizenz CC BY-ND 3.0 DE: https://creativecommons.org/licenses/by-nd/3.0/de/. 


\title{
Kalter Krieg oder innere Einheit? Der Wandel des Mediendiskurses über Ostdeutschland durch ostdeutsche Journalist*innen in Die Zeit
}

\author{
Antje Glück
}

Keywords: Marginalisierung, Journalismus, Ostdeutschland, Diskursanalyse, Transformation

\section{Abstract}

In den vergangenen drei Jahrzehnten fiel die mediale Darstellung Ostdeutschlands oft negativ aus. Ostdeutsche wurden stereotyp als rechtsradi$\mathrm{kal}$, passiv und exotisierend dargestellt, und der Osten selbst als ein "fremdes Land« konstruiert. Dies betraf fast alle überregionalen, im Westen verankerten Nachrichtenmedien. Zeitgleich zum Aufstieg der rechtspopulistischen AfD vor allem im Osten kam es jedoch auch journalistisch zu einer Wende: Mit Zeit im Osten eröffnete das erste Redaktionsbüro, das ausschließlich mit Ostdeutschen besetzt ist. Wie wirkte sich das auf den Diskurs in der Zeit aus? Dieser Beitrag untersucht diskursanalytisch den Zeitraum von 2015 bis 2019. Als treibende Kraft tritt hier eine neue Generation von jungen selbstbewussten Journalist*innen hervor: die Wendeund Post-Wende-Kinder, geboren im Osten, aufgewachsen in Gesamtdeutschland. Der Beitrag untersucht, inwieweit ein journalistischer Wandel und integrativerer Mediendiskurs durch diese Generation realisiert wird.

Ich danke den Kollegen Armin Scholl und Michael Higgins sowie den Herausgeber*innen dieses Bandes für Kritik und Hinweise zum Beitrag. Ebenfalls danke ich meinen Eltern. 
Antje Glück: Kalter Krieg oder innere Einheit? Der Wandel des Mediendiskurses über Ostdeutschland durch ostdeutsche Journalist*innen in Die Zeit. In: Nils S. Borchers, Selma Güney, Uwe Krüger und Kerem Schamberger (Hrsg.): Transformation der Medien - Medien der Transformation. Verhandlungen des Netzwerks Kritische Kommunikationswissenschaft. Frankfurt am Main: Westend 2021. DOI: https://doi.org/10.53291/AAMU5370.

Dr. Antje Glück | Bournemouth University (UK) | AGlueck@bournemouth.ac.uk

\section{Einführung}

Mit den Feiern zum 30. Jahrestag des Beitritts der DDR zur BRD scheint die Deutsche Einheit längst vollzogen. Umso auffälliger erschien jedoch eine Reihe von Kommentaren zum Osten Deutschlands, die in den letzten fünf Jahren in politischen und medialen Diskursen auftauchten. Mal ging es um »Dunkeldeutschland«, wie es der ehemalige Bundespräsident Joachim Gauck nach einem Anschlag auf ein Flüchtlingsheim im sächsischen Heidenau formulierte, bewusst oder unbewusst anknüpfend an eine lang etablierte westdeutsche Wende-Rhetorik (Ondreka 2015). Ein andermal wurde sogar die provokante Idee eines »innerdeutschen Kolonialismus« aufgeworfen, bei der Westdeutschland eine Kolonialisierung des Ostens zugeschrieben wurde (Oberender 2017).

In diesem Beitrag argumentiere ich, dass sich zwar mit dem Beitritt der DDR zur BRD im Oktober 1990 die politisch-topographischen Grenzen der Bundesrepublik erweitert haben, dass dies jedoch nicht gleichermaßen für die räumliche Grenzziehung im Journalismus gelten muss. Die Erweiterung der politischen Grenzen deckt sich nicht unbedingt mit dem diskursiven Raum der bundesdeutschen Öffentlichkeit.

Der Nachrichtenjournalismus spielt in diesem Gefüge eine entscheidende Rolle, denn er dient nicht nur als Primärvermittler konstruierter sozialer Wirklichkeiten, sondern auch als zeitgenössisches Gedächtnis und Träger von Erinnerung. Gerade im ostdeutschen Fall spielt diese in welcher Form sie auch vorliegt - als Nachfolgeprodukt des Kalten Krieges eine unterschwellige Rolle. Über die letzten drei Jahrzehnte hinweg prägte eine distinkte Tendenz das Bild von Ostdeutschland, denn die Berichterstattung über das Territorium der ehemaligen DDR war über lange Zeit negativ geprägt.

Im Folgenden wird untersucht, ob die Berichterstattung über Ostdeutschland nach drei Jahrzehnten diesen Negativ-Bias behalten hat oder 
ob inzwischen ein Wandel zu verzeichnen ist. Offenbart sich vielleicht eine Transformation hin zu einem Journalismus, der eine Integrationsleistung zu erbringen vermag, die über Jahrzehnte defizitär war? Am Beispiel der Ost-Berichterstattung der meinungsführenden (west)deutschen Wochenzeitung Die Zeit werden Perspektiven von Transformation in journalistischen Diskursen und Praktiken aufgezeigt und bewertet.

\section{Deutsch-deutsche Erinnerungslandschaften}

Eine empirische Analyse der medialen Wahrnehmung von Ostdeutschland ist kaum möglich ohne eine tiefere Kenntnis der Struktur von gegenwärtigen deutsch-deutschen Erinnerungsdiskursen. Konkurrierende Erinnerungsentwürfe sind gegenwartsaktuell, denn sie strukturieren sowohl die Identität von Gruppen als auch soziale Realitätsentwürfe (Halbwachs 1992). Hierbei kann davon ausgegangen werden, dass in der heutigen Wahrnehmung des Ostens einerseits frühere Wahrnehmungsmuster fortwirken, sowohl aus der Zeit des Kalten Krieges als auch der Wende- und Nachwendezeit, sich diese Muster jedoch andererseits transformiert haben oder neu gebildet wurden. Sie aufzudecken ist das Ziel der vorliegenden Analyse.

Hilfreich dafür ist die Orientierung an Martin Sabrows (2009) Ausführungen zu den gegenwärtig miteinander konkurrierenden Erinnerungslandschaften an die DDR. Der Kampf darum, wie die DDR also (nicht) erinnert wird oder werden soll, spielt auch unweigerlich in die mediale Wahrnehmung des Ostens mit hinein - und dies wirkt bis in die Gegenwart fort. Sabrow unterscheidet drei primäre Gedächtnisstränge: Diktatur-, Arrangement- und Fortschrittsgedächtnis. Diese Modi Operandi des Gedenkens formen ein »tripolare[s] Kräftefeld« (ebd., 20) und greifen teilweise auf dominante Wahrnehmungsmuster des Kalten Krieges zurück.

Das Diktaturgedächtnis konzentriert sich auf die DDR als Unterdrückungs- und Unrechtsstaat. Es hält insbesondere Erinnerungen an "Schreckensorte der kommunistischen Herrschaft [...] bis zum Bespitzelungssystem der Staatssicherheit« (ebd., 18) wach und betont den Täter-Opfer-Gegensatz sowie individuelles Leid. Die DDR wird hier als negatives Kontrastbild zum Rechtsstaat präsentiert. Dieses Narrativ hat vornehmlich den staatlichen und öffentlichen Diskurs bis in die Gegenwart hinein dominiert. Vor allem in Ostdeutschland verbreitet ist hingegen das Arrangementgedächtnis, das »vom richtigen Leben im falschen 
weiß und die Mühe des Auskommens mit einer mehrheitlich vielleicht nicht gewollten, aber doch als unabänderlich anerkannten oder für selbstverständliche Normalität gehaltenen Parteiherrschaft« erinnert (ebd., 19). Diese Perspektive schaut auf die private Lebenswelt und -realität der DDR-Bürger*innen. Es betont den Stolz auf das Erreichte und Geschaffene, an glückliche Zeiten und einstige Werte. Unter diese Gedächtnisform fällt auch Ostalgie. Die dritte Form ist schließlich das Fortschrittsgedächtnis. Dieses erinnert an die DDR als idealistische legitime Alternative zu einer kapitalistischen Gesellschaftsordnung. Hierunter fallen beispielsweise Diskussionen um sozialistische Bauten und antifaschistische Gedenkorte, soziale Sicherheit und Gerechtigkeit, ein fortschrittliches Gesundheits- und Bildungssystem sowie die staatlich durchgesetzte Gleichstellung der Frau.

Ein Abgleich dieser drei Erinnerungsdiskurse mit der aktuellen überregionalen Berichterstattung macht deutlich, dass diese vor allem vom ersten Narrativ, dem Diktaturgedächtnis, geformt wird (siehe Abschnitt 4 zum Stand der Forschung weiter unten). Passende Erklärungsansätze finden sich in Ansätzen zu medialem Elitenbias und -konsens. Generell ist hier eine Nähe des Journalismus zur Politik anzunehmen. Diese äußert sich beispielsweise durch Indexing (Bennett 2011) sowie über Faktoren wie Nachrichtenselektionsroutinen und die Macht institutionalisierter Quellen (vgl. Krüger in diesem Band). Eine weitere Rolle spielt die Objektivitätsnorm, der zufolge Ansichten, die keine politische Rückendeckung haben, als Bias interpretiert werden können. Hinzu kommt, dass politische Eliten in der Lage sind, Vergangenheiten selektiv zu thematisieren und somit zu manipulieren, um die eigene Macht zu sichern (Hobsbawm und Ranger 1983).

Es kann jedoch nicht davon ausgegangen werden, dass Viktimisierung durch den Staat eine universale oder Mehrheitserfahrung in der DDR war (Hogwood 2013). Aus diesem Grund lässt eine journalistische Berichterstattung, die primär auf das Diktaturgedächtnis ausgerichtet ist, andere Wahrnehmungen und Erinnerungen an die DDR und die Nachwendezeit außen vor. (Westdeutsche) Elitendiskurse und heterogene ostdeutsche Erinnerungsnarrative weichen stark voneinander ab. ${ }^{1}$ Damit wird die Heterogenität und Multidirektionalität ostdeutscher

1 Jedoch gibt es auch innerhalb der westdeutschen Diskurslandschaft gravierende Unterschiede, so zum Beispiel der Mythos der Befreiung des Ostens durch Westdeutschland versus die Kolonialisierung des Ostens durch die ideologisch anders ausgerichtete BRD (Hogwood 2013, 41). 
Erinnerungskonstruktionen unzureichend abgebildet. Dies kann problematische Auswirkungen auf die Identität von Ostdeutschen haben, da soziale Gruppen Erinnerung über die Definition von Vergangenheit bilden (Halbwachs 1992).

Letztendlich ist es schwierig zu definieren, was eigentlich 30 Jahre nach dem Ende der beiden deutschen Staaten genau ost- und was westdeutsch ist. Beide Identitäten sind geschichtlich jung und gründeten sich auf die Nachkriegszeit nach dem Zusammenbruch Hitlerdeutschlands. Hier wurden je nach politischer Blockzugehörigkeit im Kalten Krieg zwei unterschiedliche Identitäten geformt, die miteinander in direkter Konkurrenz standen. Das Zusammenspiel der Betonung negativer Erinnerungen an die DDR durch die bundesdeutsche Politik soll zusammen mit der Abwertung positiver Erinnerungen idealerweise zu einer gesamtdeutschen Identität führen, die auf rein westdeutschen soziopolitischen Normen beruht (Hogwood 2013, 42). Dies bildet den Rahmen für eine asymmetrische Machtkonstellation.

Der nachfolgende Abschnitt entwickelt genauer, wie aktueller Meinungsjournalismus und gesellschaftliche Erinnerung zusammenhängen.

\section{Journalismus als Träger gesellschaftlicher Erinnerung}

Journalismus verstanden als »culturally constructed narratives « (Bird und Dardenne 1988, 67) besitzt die Wirkmächtigkeit, durch die Herstellung von Öffentlichkeit gesellschaftliche Diskurse zu definieren und damit überindividuell gültige soziale Wirklichkeiten zu schaffen. Der Informationsjournalismus erfüllt hier eine wichtige Funktion: Er ermöglicht potenziell Teilhabe und Mitbestimmung aller gesellschaftlichen Akteur*innen, indem er »Orientierung in einer komplexen Welt« bietet (Meier 2018, 14). Diesem Potenzial steht jedoch entgegen, dass Journalismus am vollständigen Beschreiben der Realität nur scheitern kann - jedoch liegt seine Stärke im Erzählen von Geschichten über die Realität (Köhler 2009).

In diesem Sinne lassen sich für den Gegenwartsjournalismus zwei grundlegende Charakteristiken identifizieren: Zum einen erscheint Berichterstattung allgemein als institutionalisierte Erzählerin von Geschichten auf gesamtgesellschaftlicher Ebene, zum anderen erlaubt ein interdisziplinärer Rückgriff auf Memory Studies das Verständnis von 
Journalismus als kollektiver Erinnerungsträger von Vergangenheit, als Geschichtserzähler oder Chronist.

Journalismus als Institution gesellschaftlichen Geschichtenerzählens vermittelt Wirklichkeiten, darunter »chronicles« als Darstellungen von Ereignissen und »stories« als Einordnung und Kontextualisierung des Zeitgeschehens (Bird und Dardenne 1988). Journalistische Medien können in diesem Sinn als Plattformen sozialer Praxis gedacht werden. Sie bieten Referenzrahmen an, die strukturieren und bestimmen, ob ein Thema als relevant und ein Framing oder ein Narrativ als gültig anzunehmen ist.

Narrative umfassen hier verbale wie visuelle, rationale wie emotionale Anteile; sie sind im Sinne von Langers (1965) »präsentativer Symbolik« erfassbar als Ganzheit einer Situationserfahrung und sinnliche Unmittelbarkeit. Gruppen können dabei einen konjunktiven Erfahrungsraum teilen (Mannheim 1980, 220), verbunden durch ein geteiltes Schicksal und Gemeinsamkeiten im biographischen Erleben. Dies bestärkt eine kollektive Dimension der Wissensgenerierung. Dabei ist es wichtig hervorzuheben, dass es nicht allein um den Austausch von bereits gemachten (kollektiven) Erfahrungen geht, sondern sich auch über zukunftsbezogene Erwartungshaltungen verständigt wird. Zusammengefasst geht es beim Gegenstand dieses Beitrags also um einen konjunktiven deutsch-deutschen Erfahrungs- und Erwartungszusammenhang.

Nachrichtenmedien haben eine zentrale Stellung in diesem Verständigungsprozess inne, denn, wie Tenenboim-Weinblatt (2011) ausführt, gilt auch Journalismus als Träger von »prospective memory«. Unter diesem Konzept kann die Herleitung der Zukunft aus der Vergangenheit verstanden werden, quasi als »vorausschauende Erinnerung«. Eine solche Konzeptualisierung von Medien als zentrale Instanzen gesellschaftlicher Erinnerungen basiert auf zwei Annahmen. Erstens gibt es kein Zeitalter ohne Erinnerungskonstruktion - Vergangenheiten werden in jeder Gegenwart konstruiert. Sie bilden das kommunikative Gedächtnis einer Gesellschaft (Belke 2009, 175). Zweitens sind retroaktive (vergangene) und prospektive Erinnerung eng miteinander verbunden. Mediale Diskurse geben Vergangenheit nicht einfach in der Gegenwart wieder, sondern nutzen sie als Erfahrung für die Zukunft: »In this way, memory can be perceived as mediating between historical experience and contemporary behaviours." (Hogwood 2013, 36) Die medialen Diskurse über den Osten definieren das im vereinigten Deutschland gültige Wissen über Ostdeutschland und die Ostdeutschen. 


\section{Forschungsstand: Das Medienbild Ostdeutschlands}

Die medienwissenschaftliche Forschung hat sich intensiv mit medialem Strukturwandel in Transformations- und Zerfallsprozessen beschäftigt. Jedoch fanden Prozesse, in denen ein Staat einen anderen komplett eingliedert oder übernimmt, wenig Beachtung.

Analysiert man die Hintergründe der Medienberichterstattung über Ostdeutschland in den letzten Jahrzehnten, fallen zunächst zwei strukturelle Ungleichheiten im bundesdeutschen Mediensystem ins Auge. Westdeutsche Medien behielten auch nach dem Mauerfall die Autorität, das Bild des Ostens, eingeschlossen dessen realsozialistischer DDR-Vergangenheit, zeichnen zu dürfen. Dass diese Macht lange unangetastet blieb, liegt zuvorderst in der Etablierung spezifischer bundesdeutscher Medieneigentumsstrukturen begründet. Fast alle ostdeutschen Medien wurden bereits kurz nach der Wende in westdeutsche Hände (sprich: Verlagskonzerne) übergeben, wodurch die Entwicklung eines eigenständigen ostdeutschen Medienmarktes weitgehend ausblieb (Tröger 2019). Somit fehlten dezidiert ostdeutsche Stimmen innerhalb der bundesdeutschen überregionalen Öffentlichkeit von Anfang an. ${ }^{2}$ Aufgrund der homogenen (westdeutschen) Eigentümerstruktur sahen sich viele eingesessene bundesdeutsche Massenmedien auch in den Folgejahrzehnten kaum einer ernstzunehmenden ostdeutschen Konkurrenz - sprich: einem alternativen oder gegenläufigen Diskurs beziehungsweise Öffentlichkeit - ausgesetzt. Parallel dazu wurden mediale Elitepositionen selbst in Medien, die ostdeutsche Leser*innen- und Rundfunklandschaften bedienen, mit westdeutschem Führungspersonal besetzt (vgl. Mükke 2021).

Vor diesem Hintergrund erscheint eine marginalisierende Darstellung des Ostens aus einer dezidiert westdeutsch geprägten Perspektive als logische Konsequenz. Selbige folgt neben den Kriterien von Marktgängigkeit und Zielgruppenorientierung ebenso einer politischgesellschaftlichen Agenda. Der Osten dient der Funktion der Selbstversicherung - als Alter ist er gleichzeitig Vergleichs- und Kontrastfolie des bundesdeutschen Selbstverständnisses. Dadurch dient der in den

2 Ausnahmen bilden hier die ehemaligen DDR-Zeitungen Junge Welt und Neues Deutschland, die als Zeitungen mit regionaler Wirkung vor allem im Osten weiterbestanden, sowie der Lokalfernsehmarkt bis Mitte der 1990er Jahre (siehe dazu Kretzschmar und Steinmetz in diesem Band). 
Medien oft porträtierte Alteritätsdiskurs zur Re-Etablierung westdeutscher Identität (Ahbe 2009, Tenenboim-Weinblatt 2011).

Die kommunikations- und medienwissenschaftliche Forschung seit den 1990er Jahren arbeitet recht übereinstimmend ein eher negatives Bild der bundesdeutschen Nachrichtenberichterstattung über den Osten heraus. Es sind wenige, aber aussagekräftige Studien, die von Zeit zu Zeit empirische Bestandsaufnahmen wiedergeben. Dazu zählen Früh et al. (1999), Abhe (2009), Kolmer (2009), Früh et al. (2011), Kollmorgen et al. (2011) und zuletzt Ruhrmann (2016) oder der Mitteldeutsche Rundfunk (2018). Grob verallgemeinernd lässt sich sagen, dass diese Studien drei wiederkehrende Trends identifizieren: erstens die Unterrepräsentation und Marginalisierung Ostdeutschlands in der Nachrichtenberichterstattung, zweitens die Abwesenheit ostspezifischer Themen und drittens einen Sprach- und Bildergebrauch, der »regionsbasiertes Othering (Matejskova 2013, 35) als stets präsentes Framing des Ostens betont.

Zentral dabei ist das Grundverständnis über die Kontinuität der westdeutsch geprägten Berichterstattung. Abhe $(2009,59)$ zeigt auf, wie seit dem Wendejahr 1989/90 kontinuierlich »Wahrheiten über die Ostdeutschen, ihre Vergangenheit und ihre Sitten in Umlauf gesetzt« wurden, welche die Basis dafür schufen, »Stereotype und Deutungsmuster zu gültigem Wissen « werden zu lassen. Die Tendenz, die in bundesdeutschen Leitmedien wie beispielsweise der Süddeutschen Zeitung oder der FAZ zu finden ist, habe »wenig mit dem zu tun, was sich die Zeitzeugen heute über die Vergangenheit erzählen - vor allem, wenn sie damals im Osten Deutschlands gelebt haben« (Meyen 2013, 225). Das gleichzeitige Fehlen authentischer Eindrücke aus den fünf neuen Bundesländern im öffentlichen Diskurs trug dazu bei, die Geschichte des Ostens und der DDR im breiten Maße abzuwerten, unter anderem durch Gleichsetzung mit dem Nationalsozialismus als »totalitäre Staaten « (Wippermann 2009, 8). Pauschale Stigmatisierungen wie diese ließen neue spezifisch ostdeutsche politische Entwicklungen (wie zum Beispiel die Partei Die Linke) eher außen vor oder betteten diese in bestehende Diskurse ein.

Besonders problematisch erscheint die unterschwellige Tendenz, Ost-West-Differenzen zu hierarchisieren. Ostdeutsche werden dabei routinehaft als Kontrast zur westdeutschen Norm gesehen, als eine schwer verständliche Minderheit eines »fremden Territoriums (Wedl 2009), die es kaum in die Alltagswelt des Westens schaffe. Diese »hierarchisch konstruierte« Differenz schreibt dem Westen ein deutsches 
»genealogisches Erbe« zu, während ehemalige Ostdeutsche als geringwertiger eingestuft werden (Hörschelmann 2001, 986). Die Erwartungshaltung an die "Neuen « aus dem Osten ist hier Nachahmung und Anpassung an die »proper citizens « des Westens (Matejskova 2013, 34-35). ${ }^{3}$ Der Westen fungiert dabei als »Normal Null« (Roth 2008), und der Osten bildet die Abweichung und Differenz dazu (Ahbe 2009).

In der Folge müssen Ostdeutsche mit einem permanenten medialen Fremdblick leben. Damit einher geht auch die Homogenisierung der sehr heterogenen Gruppe der Ostdeutschen. ${ }^{4}$ Wedl (2009) zeigte mit einer Analyse von Zeit-Artikeln auf, wie dies diskursiv umgesetzt wird: Zum einen werden Ostdeutsche entindividualisiert als Masse dargestellt; zum anderen fungiert »ostdeutsch « weiterhin als essentialistische Eigenschaft und funktionales Alteritätskonstrukt westdeutscher Identität.

Die Abwesenheit von ostdeutschen Stimmen im Mediendiskurs ist dann besonders auffällig, wenn westdeutsche Expertise den Osten zu erklären versucht: Es wird über anstatt mit Ostdeutschen gesprochen. Jedoch zeigt sie sich dabei wenig erfolgreich, wenn es um die Popularität rechtsradikaler Bewegungen in Ostdeutschland geht. Pauschale öffentliche Verurteilungen wie die »Dunkeldeutschland«-Bemerkung des damaligen Bundespräsidenten Joachim Gauck (Ondreka 2015) gießen zusätzlich Öl ins Feuer.

Diese jahrzehntelange, allgegenwärtige diskursive Marginalisierung hat Auswirkungen auf ostdeutsche Identitätskonstruktionen und die Selbstverortung innerhalb einer gesamtdeutschen Medienöffentlichkeit. Jüngst wurde dem Westen »kultureller Kolonialismus« vorgeworfen (Krüger in Decker 2017) und das Konzept getestet, Ostdeutsche als Migrant*innen zu betrachten (Ergin 2018; Foroutan et al. 2019; Köpping 2018). Ebenso meldeten sich ostdeutsche Prominente öffent-

3 An dieser Stelle ist Kimmels $(2009,57)$ Hinweis auf die Entstehung eines unterschwelligen westdeutschen Überlegenheitsgefühls interessant. Er verweist auf den Stolz von Westdeutschen, sich nach der Aufteilung des Deutschen Reiches unter den »besseren « Besatzer*innen zu wähnen, später »das Gefühl, als `bessere ¿ Deutsche im `besseren« Deutschland zu leben«. Dieses subjektive Empfinden wurde durch die Massenfluchtbewegungen aus Ostdeutschland 1989 re-aktualisiert.

4 Die Sondersituation von Ostdeutschen als äußerst heterogene »Gruppe« macht sogar explizite Antidiskriminierungsbemühungen rechtlich kompliziert (Liebscher 2019). 
lich zu Wort mit Aufrufen wie »Integriert doch erst mal uns!« (Köpping 2018) oder »Hört endlich zu! (Richter 2018).

Selbst die Bilanz der Bundesregierung zu 30 Jahren deutscher Einheit erwähnt, dass sich die Mehrheit der Ostdeutschen als »Bürger zweiter Klasse« wahrnimmt (Presse- und Informationsamt der Bundesregierung 2020, 14; Foroutan et al. 2019) - eine Selbstwahrnehmung, die sich seit 20 Jahren wenig geändert hat (Neues Deutschland 2001).

Interessant erscheint hier die zugespitzte Formulierung Ahbes, dass »Ostdeutsche latent als eine Spezies konstruiert [werden], die politisch als demokratieunfähig, autoritätsgläubig und ausländerfeindlich gilt, kulturell als provinziell, spießig-piefig und unselbständig « (Ahbe 2001, 793). Diese und andere empirische Ergebnisse liegen jedoch zwei Jahrzehnte zurück.

Die dargestellten Momentaufnahmen über die diskursive Konstruktion des Ostens nehme ich zum Anlass, eine kursorische Bestandsaufnahme der medialen Gegenwartsdiskurse zu unternehmen - drei Jahrzehnte nach dem Mauerfall. Anlass hierfür sind veränderte politische Gegebenheiten, darunter ab 2015 die Proteste gegen die Pro-Immigrationspolitik der Bundeskanzlerin Angela Merkel sowie die deutlichen Wahlerfolge der rechtspopulistischen AfD. Diese Ereignisse führten zu einer sehr negativ geprägten Berichterstattung über den Osten, ohne jedoch notwendigerweise Erklärungen für den »fremden Osten« zu liefern.

Zentral bleiben die von Abhe (2009) aufgeworfenen Fragen an den gesamtdeutschen Mediendiskurs: Wer prägt gültige Vorstellungen über eine Bevölkerungsgruppe? Welche Rolle spielen meinungsführende Medien? Und wie interagieren tradierte Identitäten und neue Konfliktlinien mit den bereits aufgezeigten etablierten Diskursmustern? Schließlich: Braucht Journalismus einen anderen Ansatz und normativen Begründungszusammenhang?

\section{Kritische Diskursanalyse als Annäherung an Medienbilder}

Als Material für dieses Projekt wurde das Print- und Onlineangebot der überregionalen Wochenzeitung Die Zeit ausgewählt. Das Medium gilt als meinungsführend und bietet durch die nicht-tagesgebundene Berichterstattung tiefere Reflexionsmomente über den Status quo. Von Interesse für die vorliegende Untersuchung sind vor allem die subjekti- 
ven Darstellungsformen Leitartikel, Kommentar, Feuilleton oder Reportage. Die Diskursanalyse soll einen Einblick geben, wie der Osten Deutschlands innerhalb eines relevanten gesamtdeutschen Medienbildes verankert ist.

Zur Erstellung des Textkorpus wurde in die Datenbank LexisNexis eine Suchsyntax ${ }^{5}$ eingegeben. Diese filterte alle Artikel mit expliziter Erwähnung der Suchwörter »Osten« oder »Ostdeutschland« heraus. Alle Artikel mit Syntaxbezug vom 1. Januar 2015 bis 7. Mai 2019 (Ende der Datenerhebung) gingen in die Auswahl ein. Anschließend wurde eine manuelle Feinauswahl vorgenommen, denn von Interesse waren nicht punktuelle Ereignisse oder Themen, sondern der breitere Blick auf den Osten, die Darstellung von dessen Lebensrealität und Geschichte sowie Diskussionen um ostdeutsche Identität. Ein Artikel wurde dann ausgewählt, wenn sein thematischer Schwerpunkt auf Ostdeutschland lag. Nach Anwendung dieser Kriterien und Entfernung von Dopplungen verblieben $\mathrm{N}=296$ Beiträge. $^{6}$

Dass hier der Fokus auf der Zeit liegt, hat einen weiteren Grund: Das Büro von Zeit im Osten war (und ist) wegweisend für die gesamtdeutsche Zeitungslandschaft. In Dresden 2009 gegründet, etablierte sich die Redaktion ab 2015 in Leipzig. Unter der Leitung von ehemals Martin Machowecz und seit März 2021 Anne Hähnig bearbeitet heute eine recht junge Redaktion ostdeutsche Themen aller Art. Diese bedient die nationale Ausgabe der Zeit inklusive aller Supplements sowie die Regionalausgabe Zeit im Osten. Letztere ist zwar vollständig online zugänglich, gedruckt jedoch nur in der Regionalausgabe für Ostdeutschland. Dem Leipziger Zeit-Büro folgten Spiegel und Süddeutsche Zeitung mit kleineren »Ost«-Besetzungen ebenfalls nach - diese produzieren jedoch keine eigenständigen Ost-Ausgaben.

Zugang zur Analyse des Materials bietet die Kritische Diskursanalyse. Dieses Verfahren legt Wert auf das Sichtbarmachen unterliegender Ideologien und Machtverhältnisse oder in den Worten von Machin und Mayr: "Since language can (re)produce social life, what kind of world is being created by texts and what kinds of inequalities and interests might this seek to perpetuate, generate or legitimate?« $(2012,24)$ Der

5 Die verwendete Suchsyntax für Die Zeit lautete: »(ostdeutschland or ostdeutsch or ostdeutscher or ostdeutsche or ostdeutschem or ostdeutschen) and publication(Die Zeit)«

6 Eine weitere Quelle ist der Sonderband der Zeit 》Guter Osten, böser Osten« (Schwarz 2019), der eine Auswahl der in der Zeit veröffentlichten Beiträge über das Ost-West-Verhältnis vereint. 
Sprachgebrauch in Diskursen erscheint dabei weder als neutral noch als apolitisch, sondern als Ausdruck einer Menge von Überzeugungen (Fairclough 1989).

Diese Analyse soll primär Fragen nach den Textinhalten und möglichen Diskursveränderungen im Laufe des Untersuchungszeitraums unter zeit- und kontextsensitiven Gesichtspunkten beantworten: Welche Themen und Argumente werden angesprochen, welche nicht? Was bleibt ungesagt? Verändern sich Argumente und wenn ja, warum (»critical discourse moments«; siehe Carvalho 2008)? Diskurstransformationen werden an ausgewählten Texten illustriert. Ein weiteres Interesse liegt auf der Autor*innenschaft (Ost gegenüber West). Die Analyse prüft außerdem, inwieweit empirisch belegte Diskursmuster (siehe oben) aus den vergangenen Jahrzehnten weiterhin aktuell sind.

\section{Analysiert: Der »0sten« im Zeit-Mediendiskurs}

Der folgende Überblick beleuchtet mittels Themen- und Diskursanalyse, wie Ostdeutschland in der Zeit dargestellt wird. Sofort ins Auge fällt die ungleiche Verteilung der 296 Beiträge über den Untersuchungszeitraum hinweg. Für die Jahre 2015 und 2016 wurden insgesamt 45 Beiträge ermittelt. Allein im Jahr 2018 waren es bereits mehr als 100. Das erste Jahresdrittel 2019 enthielt bereits 66 Beiträge (siehe Tab. 1).

Tab. 1: Häufigkeiten der Beiträge in der Zeit zum Thema »ostdeutsch/ Ostdeutschland« Januar 2015 bis Mai 2019 (bereinigte Auswahl).

\begin{tabular}{|l|c|c|c|c|c|c|}
\hline "ostdeutsch* \\
pro Jahr
\end{tabular}

Während frühere medienwissenschaftliche Studien regelmäßig die Unterrepräsentation Ostdeutschlands im Diskurs nachgewiesen hatten, ist das bei der Zeit nur bis 2016 der Fall. Ab 2017 nehmen die Beiträge rapide zu. Eine mögliche Ursache dafür bilden parallele politische Entwicklungen: Die Pegida-Proteste und der Wahlerfolg der rechtspopulis- 
tischen AfD bei den Bundestagswahlen im September 2017 lenkten die Aufmerksamkeit auf den Osten. ${ }^{7}$

\subsection{Kontext: Das Leipziger Büro Zeit im Osten und Autor*innenbiographien}

Das Jahr 2017 steht auch für eine zweite journalistische Entwicklung. Zu diesem Zeitpunkt war das Zeit-im-Osten-Redaktionsbüro in Leipzig bereits fest etabliert. Innerhalb weniger Jahre entwickelte sich diese Redaktion zu einer festen Stütze des Hamburger Hauptbüros mit einer enormen Bandbreite an Themen und einer großen Anzahl von Beiträgen aus dem Osten. Beim zehnjährigen Jubiläum am 5. September 2019 in Leipzig war die Rede von »einem anderen Blick auf Ostdeutschland«. Den Redakteur*innen geht es vor allem darum, den »Osten anders zu erzählen« und zu fragen, wie dieser »zu einem selbstverständlichen Stück dieser Republik werden« kann (Freunde der Zeit 2019). Diese andere Stimme soll integrativ sein und bildet die Leitvision für den Journalismus aus, im und für den Osten - Journalismus mit einer gewissen Mission also.

Das Leipziger Büro stellt bis heute eine Anomalie in der gesamtdeutschen Presselandschaft überregionaler Zeitungen dar. Denn eine Vielzahl seiner festen und freien Autor*innen sind im Osten geboren meist kurz vor oder nach der Wende. Dazu zählt der Redaktionskern um Martin Machowecz (bis März 2021 Büroleiter von Zeit im Osten, *1988 in Meißen), Anne Hähnig (*1988 in Freiberg), Valerie Schönian (jetzt freie Autorin, *1990 in Gardelegen), aber auch weitere Autor*innen wie Caterina Lobenstein (*1983 in Jena) oder Carolin Würfel (*1986 in Leipzig). Diese letzte Generation der DDR-Geborenen kennt das frühere Gesellschaftssystem aus eigener Erfahrung kaum oder gar nicht, sondern lediglich durch die Erzählungen der eigenen Familie (neben der Schule und den Medien). Sie gelten als Wendekinder- und Post-Wende-Generation mit ostdeutscher Identität, aber unterbrochener oder keiner Sozialisation in der DDR (Ahbe und Gries 2006; Kubiak und Weinel 2016). Weitere Autor*innen erlebten als »Wendejugend « Kindheit und Jugend in der DDR (darunter Jana Simon, Jana Hensel, Christian Bangel, Evelyn Finger und Maike Nedo) und haben dadurch

7 Die AfD erreichte in Sachsen überraschend die größte Stimmenanzahl, während sie in allen anderen vier ostdeutschen Bundesländern auf dem zweiten Platz lag. 
einen realen Bezug zur DDR-Geschichte des Ostens. Nur ein einziger ostdeutscher Zeit-Autor im Sample - Christoph Dieckmann (*1956) blickt auf eine geteilte persönliche Biographie in beiden deutschen Staaten zurück.

Diese Redaktionszusammenstellung erlaubt zwei Schlussfolgerungen über Merkmale, die den Mediendiskurs über den Osten prägen. Zum einen sticht die Abwesenheit einer potenziell »belastenden« historischen Vergangenheit unter den meisten Ost-Autor*innen ins Auge, da es kaum Interaktionen mit dem Staatsapparat gegeben hat. Damit beschränkt sich reflexive DDR-Erfahrung auf Sekundärerzählungen des sozialen Umfelds, während die eigene erwachsene Identität in einem gesamtdeutschen Zusammenhang erlebt und gestaltet wurde. Zum anderen geht es um die Suche nach einer klar definierten eigenen Identität innerhalb des deutsch-deutschen Gesamtgefüges. Hier fallen durch die Abwertung der DDR ältere Ost-Generationen als Rollenvorbilder weitgehend aus und ein ausschließlich westdeutsch ausgerichteter Diskurs erscheint unzureichend. Die eigenständige Identität des Ostens rückt in den Blickpunkt (siehe Göring-Eckardt 2018 und die Initiative »Wir sind der Osten $\ll^{8}$ ). Dies kommt auch im Journalismus der Zeit deutlich zum Ausdruck - Biographie als Story - und wird nachfolgend im Abschnitt 6.6 diskutiert.

Die nächsten Abschnitte widmen sich inhaltlichen Aspekten von besonderen Diskurskonstellationen um Ost-West mit folgenden fünf Bereichen: Negativ-Stereotypisierungen, Ost und West als unterschiedlich, aber gleichberechtigt, Positivnachrichten und Emanzipation des Ostens, Thematisierung von Ungerechtigkeiten und ostdeutsche Identität.

\subsection{Diskursformation 1: Negative Ost-Stereotype}

Unreflektierte Negativstereotype, wie sie in früheren empirischen Studien aufgezeigt wurden, finden sich indirekt wieder - vor allem in Beiträgen zum Rechtsextremismus, zur DDR-Vergangenheit und zum Osten als fremdem Land, das es zu entdecken gilt.

Die überregionale Vorliebe der Themenkombination »Ostdeutschland, Rechtsextremismus und AfD« ist auffällig (20 von 24 Beiträgen). Adressiert werden Fremdenfeindlichkeit in Bautzen, Chemnitz, Dresden oder Tröglitz. Während 2015 noch ein westdeutscher Experte

8 https://wirsindderosten.de/ 
(Soziologe Heinz Bude, »Fremdenfeindlichkeit: 'Existenzieller Neid««, 05.02.2015) Pegida im Osten zu erklären versucht, finden sich hier parallel bereits Perspektiven von innerhalb der ostdeutschen Gesellschaft - so beispielsweise der Artikel von Machowecz über »Busen, Bier und Islamismus « (23.04.2015), in dem er das politische Aktivwerden von Pegida-Gründer Lutz Bachmann und seines Freundeskreises abseits von Klischees darstellt. Bei Carolin Würfel (»Ein schreckliches Heim-Weh«, 27.01.2017) vermischt sich die politische Analyse mit privaten Erfahrungen bei der Rückkehr in den persönlichen Bekanntenkreis nach Leipzig. Doch es sind vor allem die rassistischen Vorfälle in Chemnitz, über die vorrangig ostdeutsche Reporter*innen berichten. Zwar beschreibt der westdeutsche Autor Gunther Schnabl den Osten als »Leeres Land«, das die Toleranz aufgrund von Abwanderung und Armut »längst verloren« hätte (27.09.2018), doch bilden anderswo ostdeutsche Autor*innenteams eine differenzierte Alltagsrealität ab. Kreativer Widerstand gegen Rechtsextremismus wird genauso beleuchtet (»Wie klingt linke Heimatmusik? «, 11.01.2018; »Die Mitte muss brummen«, 10.09.2018) wie die Emotionen von Ostdeutschen oder der Zusammenhang von Rechtsextremismus mit Geschlecht (»Die Wut der Frauen«, 09.03.2017) oder Unternehmern (»AfD: Chef sucht ein Zuhause«, 29.01.2015). Ein Negativbeispiel ist hier allerdings Evelyn Fingers polemischer Beitrag »Stolz der Verlierer « (14.09.2017), der Ostdeutsche gleich zu Beginn dreifach auf primitive Emotionen reduziert: »Sie brüllen ihren Hass gegen die Politik hinaus«; »als die Ostdeutschen brüllten, wir seien ein Volk«; »das Gebrüll der Ossis«.

Als zweite große Dimension spielt die DDR-Vergangenheit des Ostens eine Rolle. Diese scheint oft in negativem oder bestenfalls ambivalentem Licht. So wertet man an sich positive Akte der DDR negativ um (Gedenken an die Bombardierung Dresdens: „Bomben aufs Abendland «, 13.02.2015; Internationale Solidarität: »Sie hassen die Moral der Eliten«, 25.02.2018). In »Jugendarrest: SSie fühlen sich abgehängt« (25.05.2016) beschreibt die Autorin, wie strafgefährdete Jugendliche durch Konfrontation mit einer repressiven DDR-Vergangenheit für positive Aspekte der Demokratie gewonnen werden sollen. Einige Beiträge fügen sich in das oben erklärte »Diktaturgedächtnis« ein. Jedoch gibt es auch Gegenbeispiele, die eine positiv Lebensrealität in der DDR vermitteln. Dazu zählen beispielsweise die Ermahnung zur Würdigung der Lebensleistungen Ostdeutscher (»Helden der Arbeit«, 19.09.2018) oder erfolgreiche Biographien vor und nach der Wende (Karl Döring rettet einen Betrieb in Eisenhüttenstadt über die Wende: »Bei uns war nichts 
marode«, 08.10.2015). Beide Beiträge zeigen Normalität in der DDR und bedienen damit eher Diskurse des Arrangementgedächtnisses.

Die dritte Dimension ist die partielle Exotisierung des Ostens als (weiterhin) »fremdes Land «, das durch einen Nicht-Ostdeutschen »entdeckt « wird. Dieses fortbestehende Motiv fand sich im Untersuchungszeitraum mehrfach. So besuchte Moritz von Uslar sowohl Görlitz als auch den Weihnachtsmarkt in Chemnitz nach den Gewaltvorfällen im Sommer 2018 (»Morgens halb zehn in Deutschland«, 02.09.2016; »Innere Einkehr auf Sächsisch«, 05.12.2018). In ersten Artikel wird zwar viel über Görlitz, aber nicht mit den Görlitzern gesprochen. Der Chemnitzer Artikel schildert zunächst von Uslars eigene Eindrücke, bevor er später Chemnitzer interviewt. Etwas kurios erscheint vielleicht die Überschrift als Essenz der Beobachtungen eines südafrikanischen Fotografen, der zum ersten Mal den Osten bereist, in »Land ohne Lächeln« (20.09.2017).

Die Abwertung des Ostens erfolgt im Untersuchungszeitraum zumeist indirekt über Themenkarrieren (Rechtsextremismus, AfD), die fortgesetzte Herabstufung des staatlich-institutionellen DDR-Erbes mit gleichzeitiger Anerkennung individueller Lebensleistungen und der Darstellung des Ostens als »fremdes Anderes«. Diese sind Fortführungen von etablierten Tropen mit Entstehungshintergrund im Kalten Krieg, als Wettbewerb der Selbstverständnisse darum, welches das »bessere und demokratischere Deutschland«sei.

\subsection{Diskursformation 2: Diskurse von Gleichheit}

Ein integrativer Diskurs würde theoretisch die (historisch bedingten) Unterschiede von Ost und West anerkennen und beide als gleichwertig einstufen. Dies ist im Untersuchungszeitraum gelegentlich zu beobachten. »Normalisierte Unterschiede « werden etabliert bei Frauen in Führungspositionen (so gibt es im Osten mehr »Frauen im Fußball«, 14.09.2017), bei den anderen Wünschen eines ostdeutschen Publikums der Öffentlich-Rechtlichen (»Das gestörte Programm«, 07.12.2017) und bei der Analyse zum Rechtsstatus des Schwangerschaftsabbruchs (die DDR war liberaler: »Der West-Paragraf«, 14.02.2019). Diese Diskursart erlaubt es, faktische Unterschiede zwischen Ost und West wahrzunehmen und bereitet den Boden für eine integrative Berichterstattung. 


\subsection{Diskursformation 3: Emanzipierende Diskurse}

Diese Diskurse finden sich überwiegend in Zeit im Osten, die in ihrer gedruckten Form vorrangig auf eine ostdeutsche Leser*innenschaft ausgerichtet ist. Hier wird der Osten als positiv und als Vorbild dargestellt. Beispiele dafür stammen einerseits aus einer positiven Bewertung von DDR-Gegebenheiten, andererseits aus der Gegenwart. So heißt es »Ja zur Platte« (05.11.2015) in einem Artikel über Beschränkungen in Wohnstandards, und es wird darauf verwiesen, dass die DDR-Bevölkerung weniger an Allergien litt (»Gab es vor der Wende in der DDR weniger Allergien als im Westen?«, 19.04.2017).

Für die Gegenwart dominieren positive Städtebeschreibungen, das Ostprodukt Nudossi als ökologisch vorbildlicher Brotaufstrich (»Die Zukunft aufs Brot«, 07.09.2017), RB Leipzig als erste ostdeutsche Mannschaft in der Champions League (»Auftritt der Diebe«, 08.06.2017) oder der Aufstieg von Ostdeutschen in westdeutschen Institutionen (so bei den Grünen: »Out of Guben«, 03.02.2017; oder als Vorstand der Deutschen Börse: »Immer schön flexibel«, 09.08.2018). Noch deutlicher wird dies in »Ostfrauen« (07.03.2019), des Reviews einer MDR-Serie, »die endlich zeigt, wie sehr sie dieses Land verändert haben«.

In das Bild des Ostens als positiv und »empowered « passt vor allem auch der Beitrag des Philosophen Peter Neumann (»Bitter enttäuschte Hoffnungen, nagelneue Utopien«, 17.04.2019). Anlässlich des bevorstehenden 30. Jahrestags des Mauerfalls schlug er vor, mit der Erinnerung der DDR auf eine vierte Art umzugehen - der »ostdeutsche Umbruch als europäische Utopie«. In diesem Sinne wird der Osten ein Experimentierfeld für zukünftige Gesellschaftsmodelle, ein Labor für kreative Problemlösungen, ein Ort für Innovation. Die doppelte deutsch-deutsche Erfahrung ist dabei nichts, was behindert, sondern eine wirkmächtige Ressource.

\subsection{Diskursformation 4: Artikulation von Benachteiligungen des Ostens}

Die realen Ungleichheiten zwischen Ost und West in nahezu allen Gesellschaftsbereichen finden sich nicht unbedingt im medialen Diskurs wieder. Zumindest ist die abwertende Bezeichnung »Jammerossi« (siehe Wedl 2009) aus der Zeit komplett verschwunden. 
Nach den politischen Wahlerfolgen der AfD im Osten wurde auch die Artikulation von Ungleichheit lauter. Deutlich trat dies in der Debatte um eine »Ost-Quote« (2017) und gleich zweifach 2019 hervor - einerseits beim Vergleich von Ostdeutschen mit Migrant*innen und bei Vorwürfen, dass der Osten kolonialisiert wurde (»Ostquote: Verhilft sie Ostdeutschen zu mehr Chancengleichheit?«, 21.03.2019; »Ostdeutschland: Wer das Sagen hat «, 11.04.2019), andererseits bei datenjournalistischen Darstellungen zu Migrationsbewegungen (Abwanderungen) Ostdeutscher, deren Ursachen und potenziellen Rückkehrtrends (Zeitim-Osten-Special, 02.05.2019).

Gleichzeitig setzen sich Ostdeutsche mit kontinuierlicher Diskriminierung reflektiv auseinander, beispielsweise bei der Debatte um Vornamen (»Vorurteile bei Vornamen«, 03.10.2018), Doppelnamen (»Doppeldeutschland«, 07.03.2019) oder die Scham aus dem jahrzehntelangen Verstecken der Ost-Identität aus Angst vor Repressalien (»Ich bin damals abgerutscht«, 31.01.2019). Diese Momente markieren die ostdeutsche Zugehörigkeit als Thema bei einigen der Autor*innen.

Der Wandel im Diskurs ist hier bemerkenswert. Während diese Art von offenen Bekundungen und Stellungnahmen zum Einfordern von »mehr Gleichheit 2015 nicht existierte, stellen sie inzwischen einen relevanten Teil der Artikulationen über ostdeutsche Erwartungshaltungen dar. Spätestens hier wird deutlich, dass sich Ostdeutsche nicht mehr schamvoll verstecken oder zurückziehen, sondern spürbar an Stimme gewonnen haben.

\subsection{Diskursformation 5: »Ostdeutsch sein«- Wer verhandelt die Identität?}

Dieser letzte Diskurs ist ebenso spannend wie neu. »Der Osten ist nicht totzukriegen«, schreibt der Zeit-im-Osten-Gründer Schwarz (2019b, 14) und meint damit nicht die »Alten« mit ihrer Sorge, für die eigene Biographie Spott zu ernten, sondern die Jungen, die ihre Ost-Identität teils spät für sich entdecken. Und genau dieser Punkt ist ungewöhnlich für den sonst distanziert-faktizierenden Journalismus - hier fallen plötzlich gleich mehrfach die persönliche Biographie der Zeit-Autor*innen und die journalistische Story zusammen. Es ist gerade die bewusst ausgedrückte Subjektivität, die einen Einblick in die Normalität des ostdeutschen Lebens ermöglicht - Alltagsgeschichten, die überall im Osten passieren könnten. 
Beispiele für diese autobiographischen Geschichten des Entdeckens der eigenen ostdeutschen Identität finden sich bei Caterina Lobenstein (»Deutsche Wiedervereinigung: Was blüht denn da?«, 22.06.2017), Valerie Schönian (»Heimat Ostdeutschland: Jahrgang 1990«, 14.12.2017), Martin Machowecz (»Auf der Tanne«, 14.12.2017), Maike Nedo (»Ich hab mich getarnt«, 20.12.2017; »Was wurde aus Rocco«, 15.11.2018), Sophie Herwig (»Immer auf Safari«, 28.12.2017) und - als Antwort einer anderen Ost-Generation darauf - Christoph Dieckmann (»Ostdeutschland: Jahrgang 1956«, 28.12.2017). Diese Selbstzeugnisse und offenen Beobachtungen beziehungsweise Reflektionen können Verarbeitungsstrategien von Identitätskonflikten darstellen. Doch dabei bleibt zu bedenken, dass diese generationsspezifisch sind und nicht ältere ostdeutsche Generationen repräsentieren.

Bedauerlich ist, dass ab Oktober 2017 (nach der Bundestagswahl) viele dieser so wichtigen Diskurse um ostdeutsche Identität lediglich in Zeit im Osten erscheinen, nicht jedoch in der überregionalen Printausgabe. Damit stehen Debatten um das ostdeutsche Selbstverständnis nur begrenzt einer gesamtdeutschen Leser*innenschaft zur Verfügung.

Der übrige Ost-Identitätsdiskurs bewegt sich fort von reduzierenden AfD-Assoziationen hin zum Nachdenken, was der Osten in einem gemeinsamen Deutschland sein kann und sollte. Es geht aber auch darum, wie die Wende verlaufen ist und wie wenig Westdeutsche teilweise den Osten bewusst und mit Interesse wahrnehmen (»Manche kennen den Osten der USA besser als den Osten Deutschlands«, 04.04.2019).

Diskussionen um potenziellen Kolonialismus, Parallelen zu Migrant*innen und das dynamische Aufbrechen des Ostens (»Das musste mal gesagt werden«, 14.02.2019) mündeten zwei Jahre später in der Frage, »wie viel Identitätspolitik [...] die Debatte über Ostdeutschland [verträgt] « (»Identitätspolitik. Wer wir sind. Sind wir wer?«, 14.03.2021). Die Debatte um ostdeutsche Identität ist damit nicht mehr auf den Osten beschränkt, sondern hat ein gesamtdeutsches Medium erreicht.

\section{$7 \quad$ Fazit}

Der US-amerikanische Journalismusforscher Michael Schudson (2011) schrieb, dass unabhängiger Journalismus die Grundbedingung jeder Demokratie sei. Im Vergleich zu anderen Transformationen im postsozialistischen Europa hatte der Zusammenbruch der DDR die Besonder- 
heit, dass bereits kurz nach dem Mauerfall die Presse - und später auch die Rundfunklandschaft - unter westdeutschen Eliten aufgeteilt war. Damit entstand eine Ausnahmesituation: Ostdeutsche besaßen seit 1990 nur wenig Chancen auf das ungehinderte Ausdrücken - und Verarbeiten - der eigenen Identität und der erlebten Transformationsprozesse.

Diese notwendige Arbeit leisten nun ausgerechnet die Nachgeborenen - junge ostdeutsche Journalist*innen, welche die DDR selbst nur noch vage oder gar nicht mehr miterlebt haben. Sie bringen Glaubwürdigkeit, Selbstbewusstsein und Transparenz mit, um als Mediator*innen und verspätete Integrationshelfer*innen der deutschen Einheit zu wirken, und zeigen auf, wie differenziert und innovativ der Osten sein kann. Das Negativbild steht nicht mehr allein im Vordergrund.

Unbefangen und sprachgewaltig tritt diese jüngere Generation auf. Sie kennt die DDR nur aus Geschichten, aber sie hört den jüngeren und älteren Generationen im Osten zu. Es steht zur Vermutung, dass diese Generation an Ost-Journalist*innen durch ihre geschichtliche »Unschuld « in ihren Positionen weniger angreifbar ist. Sie ringen durch das Bewusstsein der biographischen Andersartigkeit um eine Neudefinition ihrer eigenen Identität im deutsch-deutschen Gesamtgefüge. Deswegen werden Diskurse zur Emanzipation des Ostens verstärkt geführt, während jedoch elitennahe Diskurse bezüglich des negativen Erbes des DDR-Systems relativ unangetastet bleiben.

Mit dem Mauerfall 1989 wurden DDR-bezogene Identitätskonstruktionen auf dem metaphorischen »Müllhaufen der Geschichte« entsorgt - bis zum Aufstieg der AfD, die einen gesamtdeutschen Diskurs dazu animierte, doch etwas genauer auf den Osten zu schauen. Zeit im Osten ist ein Produkt eben jenes Prozesses. Der Beitrag hat gezeigt, dass es mehr als 25 Jahre gebraucht hat, bis sich die früher dokumentierten medialen Diskurse in der Öffentlichkeit verändern sollten. Diese Transformation ist gegenwärtig in vollem Gange - durch praktizierte Diversität in einer Redaktion, dem Büro von Zeit im Osten.

\section{Literatur}

Ahbe, Thomas. 2001. »Ostalgie« als Laienpraxis in Ostdeutschland. Ursachen, psychische und politische Dimensionen. In: Die DDR in Deutschland. Ein Rückblick auf 50 Jahre, herausgegeben von Heiner Timmermann, 781-802. Berlin: Duncker \& Humblot. 
Ahbe, Thomas. 2009. Die Ost-Diskurse als Strukturen der Nobilitierung und Marginalisierung von Wissen. Eine Diskursanalyse zur Konstruktion der Ostdeutschen in den westdeutschen Medien-Diskursen 1989/90 und 1995. In: Die Ostdeutschen in den Medien. Das Bild von den Anderen nach 1990, herausgegeben von Thomas Ahbe, Rainer Gries and Wolfgang Schmale, 59-112. Leipzig: Leipziger Universitätsverlag.

Ahbe, Thomas, und Rainer Gries. 2006. Die Generation der DDR und Ostdeutschlands. Ein Überblick. Berliner Debatte Initial 17 (4): 90-109.

Ahbe, Thomas, Rainer Gries, und Wolfgang Schmale. 2009. Die Ostdeutschen in den Medien. Das Bild von den Anderen nach 1990. Leipzig: Leipziger Universitätsverlag.

Belke, Julia. 2009. Das Bild der Ostdeutschen im öffentlich-rechtlichen Fernsehen. Eine Diskursanalyse des ARD-Politmagazins Kontraste in der Zeit von 19872005. In: Die Ostdeutschen in den Medien. Das Bild von den Anderen nach 1990, herausgegeben von Thomas Ahbe, Rainer Gries und Wolfgang Schmale, 135180. Leipzig: Leipziger Universitätsverlag.

Bennett, W. Lance. 2011. News: The politics of illusion. New York: Longman.

Bird, S. Elizabeth, und Robert W. Dardenne. 1988. Myth, Chronicle, and Story. Exploring the Narrative Qualities of News. In: Media, Myths, and Narratives. Television and the Press, herausgegeben von James W. Carey, 67-86. Newbury Park u. a.: Sage.

Carvalho, Anabela. 2008. Media(ted) Discourse and Society. Journalism Studies 9 (2): 161-177. DOI: 10.1080/14616700701848162.

Decker, Markus. 2017. bpb-Chef über westdeutsche Dominanz: „Es fehlen Übersetzer kultureller Differenzen«. Interview mit Thomas Krüger. Berliner Zeitung vom 31. Oktober, https://www.berliner-zeitung.de/politik-gesellschaft/bpb-chefueber-westdeutsche-dominanz-es-fehlen-uebersetzer-kultureller-differenzenli.12448. Zugegriffen: 25. März 2021.

Ergin, Yasmine. 2018. Sind Ostdeutsche auch Migranten? NDR Online vom 11. Juni, https://www.ndr.de/kultur/Sind-Ostdeutsche-auch-Migranten,migranten150.html. Zugegriffen: 1. Oktober 2018.

Fairclough, Norman. 1989. Language and Power. London: Longman.

Foroutan, Naika, Frank Kalter, Coşkun Canan, und Mara Simon. 2019. Ost-Migrantische Analogien I. Konkurrenz um Anerkennung. Stereotype, Abwertungsgefühle und Aufstiegskonflikte. Berlin: Deutsches Zentrum für Integrations- und Migrationsforschung (DeZIM).

Freunde der Zeit. 2019. Hinter der Geschichte: Der andere Blick auf Ostdeutschland. https://verlag.zeit.de/freunde/rueckblick/hinter-der-geschichte/10jahre-zeit-im-osten/. Zugegriffen: 15. März 2021.

Früh, Werner, Uwe Hasebrink, Friedrich Krotz, Christoph Kuhlmann, und HansJörg Stiehler. 1999. Ostdeutschland im Fernsehen. Erfurt: Thüringer Landesmedienanstalt.

Früh, Werner, Hans-Jörg Stiehler, Hannah Früh, und Claudia Böttcher. 2011. Mediale Vereinigungsbilanzen. Ost- und Westdeutschland im Fernsehen: Event- und Alltagsberichterstattung. Berlin: Vistas. 
Göring-Eckardt, Katrin. 2018. Bleibende Unterschiede. Deutschlands Osten ist anders. Wirtschaftswoche vom 22. September, https://www.wiwo.de/my/politik/ deutschland/bleibende-unterschiede-deutschlands-osten-ist-anders/23089018.html?ticket=ST-653181-Vt71Q51fgjXvQFB9Gu1h-ap2. Zugegriffen: 25. März 2021.

Halbwachs, Maurice. 1992. On Collective Memory. Chicago, London: University of Chicago Press.

Hobsbawm, Eric, und Terence Ranger. 1983. The Invention of Tradition. Cambridge: Cambridge University Press.

Hogwood, Patricia. 2013. Selective Memory. Channeling the Past in Post-GDR Society. In: Remembering and Rethinking the GDR. Multiple Perspectives and Plural Authenticities, herausgegeben von Anna Saunders and Debbie Pinfold, 34-48. Houndmills, Basingstoke, New York: Palgrave Macmillan.

Hörschelmann, Kathrin. 2001. Breaking ground-marginality and resistance in (post) unification Germany. Political Geography 20 (8): 981-1004. DOI: https:// doi.org/10.1016/S0962-6298(01)00041-5.

Köhler, Sebastian. 2009. Die Nachrichtenerzähler. Zu Theorie und Praxis nachhaltiger Narrativität im TV-Journalismus. Baden-Baden: Nomos / Edition Reinhard Fischer.

Kollmorgen, Raj, Frank-Thomas Koch, und Hans-Liudger Dienel. 2011. Diskurse der deutschen Einheit. Kritik und Alternativen. Wiesbaden: VS Verlag für Sozialwissenschaften.

Kolmer, Christian. 2009. Nachrichten aus einer Krisenregion. Das Bild Ostdeutschlands und der DDR in den Medien 1994-2007. In: Die Ostdeutschen in den Medien. Das Bild von den Anderen nach 1990, herausgegeben von Thomas Ahbe, Rainer Gries und Wolfgang Schmale, 181-214. Leipzig: Leipziger Universitätsverlag.

Köpping, Petra. 2018. Integriert doch erstmal uns! Eine Streitschrift für den Osten. Berlin: Christoph Links Verlag.

Kubiak, Daniel, und Martin Weinel. 2016. DDR-Generationen revisited - Gibt es einen Generationszusammenhang der »Wendekinder«? In: Die Generation der Wendekinder. Elaboration eines Forschungsfeldes, herausgegeben von Adriana Lettrari, Christian Nestler and Nadja Troi-Boeck, 107-129. Springer VS.

Langer, Susanne K. 1965. Philosophie auf neuem Wege. Das Sympol im Denken, im Ritus und der Kunst. Frankfurt am Main: S. Fischer.

Liebscher, Doris. 2019. »Wir sind ein Volk«? Warum wir Rechtsschutz gegen die Diskriminierung als »Ossi« brauchen. Humboldt Law Clinic, Grundundmenschenrechtsblog vom 17. Oktober, http://grundundmenschenrechtsblog.de/ wir-sind-ein-volk-warum-wir-rechtsschutz-gegen-die-diskriminierung-als-ossibrauchen/. Zugegriffen: 18. Januar 2021.

Machin, David, und Andrea Mayr. 2012. How To Do Critical Discourse Analysis. A Multimodal Introduction. Los Angeles, London u. a.: Sage.

Mannheim, Karl. 1980. Strukturen des Denkens. Frankfurt am Main: Suhrkamp.

Matejskova, Tatiana. 2013. The Unbearable Closeness of The East: Embodied MicroEconomies of Difference, Belonging, and Intersecting Marginalities in Post-Socialist Berlin. Urban Geography 34 (1): 30-52. DOI: 10.1080/02723638.2013.778630. 
MDR. 2018. Analyse zur TV-Doku »Wer braucht den Osten?« Ostdeutschland in der Presse. Mitteldeutscher Rundfunk vom 9. Juni, https://www.mdr.de/zeitreise/ wer-braucht-den-osten-datenanalyse-der-osten-in-den-medien-100.html. Zugegriffen: 17. März 2021.

Meier, Klaus. 2018. Journalistik. 4. Auflage. Konstanz: UTB.

Meyen, Michael. 2013. »Wir haben freier gelebt«. Die DDR im kollektiven Gedächtnis der Deutschen. Bielefeld: Transcript.

Mükke, Lutz. 2021. 30 Jahre staatliche Einheit - 30 Jahre mediale Spaltung. Schreiben Medien die Teilung Deutschlands fest? OBS Arbeitspapier. Frankfurt am Main: Otto-Brenner-Stiftung, https://www.otto-brenner-stiftung.de/fileadmin/user_ data/stiftung/02_Wissenschaftsportal/03_Publikationen/AP45_Mediale_Spaltung.pdf. Zugegriffen: 26. März 2021.

Neues Deutschland. 2001. Ostjugend: In: DDR war es nicht schlechter. Neues Deutschland vom 8. Februar, https://www.neues-deutschland.de/artikel/899447.ostjugend-in-ddr-war-es-nicht-schlechter.html. Zugegriffen: 26. März 2021.

Oberender, Thomas. 2017. Deutsche Einheit: Die Mauer ist nicht gefallen. Die Zeit vom 3. Oktober, https://www.zeit.de/2017/40/ddr-mauerfall-kinderbetreuung-west-ost-deutschland. Zugegriffen: 14. Februar 2021

Ondreka, Lukas. 2015. Joachim Gauck, die Ossis und Dunkeldeutschland. Süddeutsche Zeitung vom 26. August, https://www.sueddeutsche.de/politik/bundespraesident-joachim-gauck-die-ossis-und-dunkeldeutschland-1.2622780. Zugegriffen: 14. Februar 2021.

Presse- und Informationsamt der Bundesregierung. 2020. 30 Jahre Deutsche Einheit. Schwarzrotgold. Das Magazin der Bundesregierung, Heft 2, https://www. bundesregierung.de/resource/blob/975232/1779314/e933561f3e0a91ce366a cccc392632aa/download-pdf-data.pdf?download=1. Zugegriffen: 14. Februar 2021

Richter, Frank. 2018. Hört endlich zu! Weil Demokratie Auseinandersetzung bedeutet. Berlin: Ullstein.

Roth, Kersten Sven. 2008. Der Westen als »Normal Null«. Zur Diskurssemantik von »ostdeutsch« und »westdeutsch«. In: Diskursmauern. Aktuelle Aspekte der sprachlichen Verhältnisse zwischen Ost und West, herausgegeben von Kersten Sven Roth and Markus Wienen, 69-89. Bremen: Dr. Ute Hempen Verlag.

Ruhrmann, Georg. 2016. Das Bild Ostdeutschlands in den Medien. Von der Unterrepräsentation zur »Stigmatisierung«? In: Empirische Medienökonomie. Reflexionen der Arbeiten von Wolfgang Seufert, herausgegeben von Jörg Müller-Lietzkow and Felix Sattelberger, 138-160. Baden-Baden: Nomos.

Sabrow, Martin. 2009. Vorwort. Die DDR erinnern. In: Erinnerungsorte der DDR, herausgegeben von Martin Sabrow, 11-27. München: C. H. Beck.

Schudson, Michael. 2011. The Sociology of News. New York, London: W. W. Norton \& Company.

Schwarz, Patrik. 2019a. Guter Osten, böser Osten. Bonn: Bundeszentrale für politische Bildung.

Schwarz, Patrik. 2019b. Nicht wegen der Alten, sondern wegen der Jungen gibt es 
den Osten noch. In: Guter Osten, böser Osten, herausgegeben von Patrik Schwarz, 14-15. Bonn: Bundeszentrale für politische Bildung.

Tenenboim-Weinblatt, Keren. 2011. Journalism as Agent of Prospective Memory. In: On Media Memory. Collective Memory in a New Media Age, herausgegeben von Motti Neiger, Oren Meyers und Eyal Zandberg, 213-225. Basingstoke: Palgrave Macmillan.

Tröger, Mandy. 2019. Pressefrühling und Profit: Wie westdeutsche Verlage 1989/1990 den Osten eroberten. Köln: Herbert von Halem.

Wedl, Juliette. 2009. Ein Ossi ist ein Ossi ist ein Ossi ... Regeln der medialen Berichterstattung über »Ossis« und »Wessis« in der Wochenzeitung Die Zeit seit Mitte der 1990er Jahre. In: Die Ostdeutschen in dem Medien. Das Bild von den Anderen nach 1990, herausgegeben von Thomas Ahbe, Rainer Gries und Wolfgang Schmale, 112-134. Leipzig: Leipziger Universitätsverlag.

Wippermann, Wolfgang. 2009. Dämonisierung durch Vergleich: DDR und Drittes Reich. Berlin: Rotbuch.

\section{Open Access}

Dieser Beitrag erscheint unter der Creative-Commons-Lizenz CC BY-ND 3.0 DE: https://creativecommons.org/licenses/by-nd/3.0/de/. 


\section{Digitale Transformation in der neoliberalen Globalisierung}





\title{
Kampf um Öffentlichkeit. Kapitalistische Landnahme und die Zerstörung von Vernunft
}

\author{
Klaus Dörre
}

Keywords: Landnahme, Strukturwandel der Öffentlichkeit, digitalisierter Kapitalismus, öffentlich-rechtlicher Rundfunk, Journalismus, Nachhaltigkeitsziele, Mediensozialismus

\section{Abstract}

Gegenwärtig erleben wir eine kapitalistische Landnahme des Öffentlichen und der Öffentlichkeit, die auf eine Zerstörung kommunikativer Vernunft hinausläuft. So lautet die These des Beitrags, der das Ringen um Öffentlichkeit als eine neue Form des Klassenkampfs begreift. Ausgehend von einer Theorie kapitalistischer Landnahmen werden die Dynamiken einer Kommodifizierung von Wissen und Erfahrung analysiert, die einen tiefgreifenden Wandel demokratischer Öffentlichkeiten mit sich bringen. Öffentlichrechtliche Medien werden als positive Externalitäten begriffen, die es gegen den Zugriff privater Verwertungsinteressen zu verteidigen und auszubauen gilt. Mediensozialismus umschreibt die Zielkoordinaten einer solchen Politik, die Nachhaltigkeitsziele als ihre normative Grundlage nutzen kann.

Klaus Dörre: Kampf um Öffentlichkeit. Kapitalistische Landnahme und die Zerstörung von Vernunft. In: Nils S. Borchers, Selma Güney, Uwe Krüger und Kerem Schamberger (Hrsg.): Transformation der Medien - Medien der Transformation. Verhandlungen des Netzwerks Kritische Kommunikationswissenschaft. Frankfurt am Main: Westend 2021. DOI: https://doi. org/10.53291/TMQ05163.

Prof. Dr. Klaus Dörre I Friedrich-Schiller-Universität Jena I klaus.doerre@ uni-jena.de 


\section{Einleitung}

Wenige Tage nach dem bewaffneten Sturm auf das Capitol sperrte Twitter das private Konto des damals noch amtierenden US-Präsidenten Donald Trump. Jahrelang hatte er die mediale Öffentlichkeit mit seinen Tweets vor sich hergetrieben. Um die eigene Anhängerschaft zu erreichen, schienen ihm die einstigen Leitmedien wenn nicht überflüssig, so doch als nachrangige Teilöffentlichkeit, die allenfalls als Instrument politischer Polarisierung taugten. Über Jahre warteten Tausende Journalist*innen auf die Kurzbotschaften Trumps, stets getrieben von der Sorge, andere Medien könnten die Erstmeldung für sich reklamieren. Nach einer Rede, die rechtsradikale Demonstrant*innen zum Sturm auf das Parlamentsgebäude animiert hatte, war zunächst das Ende dieses Twitter-Regimes gekommen. Endlich, so möchte man meinen. Doch die Reaktion der deutschen Kanzlerin zeugte keineswegs von Erleichterung. Sie halte die Sperrung des privaten Twitter-Kontos von Donald Trump für problematisch, ließ Angela Merkel verlauten. Und sie hat recht! Maßt sich doch ein privates Unternehmen an, darüber zu entscheiden, wem Meinungsfreiheit zusteht und wem nicht.

Der Vorgang zeigt exemplarisch, was sich seit geraumer Zeit ereignet und nun verstärkt zum Gegenstand öffentlicher Auseinandersetzungen wird. Der Klassenkampf, so die hier vertretene These, ist auch zu einem Kampf um Öffentlichkeit geworden. Mehr noch: zu einem Kampf wider die Zerstörung der Vernunft. Er berührt die Grundfesten liberaler Demokratien und ist, aus einer emanzipatorischen Perspektive betrachtet, nur zu gewinnen, indem demokratische Öffentlichkeiten als ein nichtkapitalistisches Anderes begriffen werden, das es gegen jedwede Spielart marktgetriebener Landnahmen zu verteidigen gilt. Weit davon entfernt, den vielschichtigen Prozess der Kommodifizierung und Zerstörung von Öffentlichkeit auch nur annähernd beschreiben zu können, beschränke ich mich an dieser Stelle auf erste Überlegungen zu dieser Problematik. Ich beginne mit einigen konzeptuellen Anmerkungen zum Kampf um Öffentlichkeit (2), skizziere sodann die Grundidee des Landnahmetheorems (3) und widme mich nachfolgend der konkurrenzgetriebenen Landnahme von Wissen, Erfahrung und Öffentlichkeit (4), um abschließend Möglichkeiten zu einer demokratischen Gegenlandnahme auszuloten (5). 


\title{
2 Zerstörung von Öffentlichkeit
}

Das Phänomen eines gesellschaftlichen Kampfs um Öffentlichkeit ist alles andere als neu. Jürgen Habermas (1990 [1962]) hatte es bereits in seinem zum Klassiker gewordenen Strukturwandel der Öffentlichkeit systematisch behandelt und den Antagonisten »Proletariat« im übergreifenden Kontext seiner Theorie in gewisser Weise durch die korrigierende Kraft öffentlicher Diskurse und der in ihnen wirkenden kommunikativen Vernunft ersetzt. Wie er selbst in einem Vorwort zu einer späteren Ausgabe seines Werks einräumt, unterschätzte seine Stilisierung bürgerlicher Öffentlichkeit jedoch die Einflüsse konkurrierender Öffentlichkeiten. Solche Kommunikationskanäle entstehen durch Ausschluss aus der hegemonialen bürgerlichen Öffentlichkeit, notierte der Philosoph:

\begin{abstract}
Von »Ausschluß « kann in einem »Foucaultschen« Sinne die Rede sein, wenn es sich dabei um Gruppen handelt, deren Rolle für die Formierung einer bestimmten Öffentlichkeit konstitutiv ist. »Ausschluß « gewinnt einen anderen, weniger radikalen Sinn, wenn sich in denselben Kommunikationsstrukturen gleichzeitig mehrere Arenen bilden, wo neben der hegemonialen bürgerlichen Öffentlichkeit andere subkulturelle oder klassenspezifische Öffentlichkeiten unter eigenen, nicht ohne weiteres kompromissfähigen Prämissen auftreten. Den ersten Fall habe ich seinerzeit gar nicht berücksichtigt, den anderen Fall habe ich im Vorwort erwähnt, aber nicht behandelt. (Habermas 1990, 15)
\end{abstract}

In den Zeiten von Trump und Twitter gesellt sich ein dritter Fall hinzu. Die oft nur vermeintlich Ausgeschlossenen konstituieren über das Internet Öffentlichkeiten, die sich demokratischer Kontrolle weitgehend entziehen und so der bürgerlichen Öffentlichkeit samt ihren Leitmedien die hegemoniale Positionierung mehr und mehr streitig machen. Der Effekt ist ein mehr als zwiespältiger. Einerseits handelt es sich bei der bürgerlichen Öffentlichkeit um eine vermachtete Struktur, die Abweichungen vom Basiskonsens allenfalls in begrenztem Ausmaß gestattet, andererseits kann sie ihre normativ-regulative Funktion nur erfüllen, wenn sie für neue, vom Basiskonsens abweichende Entwicklungen in der Gesellschaft offen ist. Erst dann wirkt sie als ein Organ, das vernünftige Argumente in welch begrenztem Ausmaß auch immer zum Zuge kommen lässt.

Die Methode Trump steht indes für eine Spielart kapitalistischer Landnahmen, die nicht nur auf die Okkupation demokratischer Öf- 
fentlichkeit, sondern auf eine Zerstörung der Vernunft hinausläuft. Dies freilich in einem anderen Sinne, als der Anklang an Georg Lukács gleichnamige Schrift nahelegen könnte (dazu kritisch Bermbach und Trautmann 1987; Rücker 1976). Den »Weg Deutschlands zu Hitler auf dem Gebiet der Philosophie« lässt Lukács $(1954,6)$ bereits beim deutschen Idealismus beginnen und den Einbezug von Elementen Marx'scher Theorie in die deutsche Soziologie kritisiert er letztendlich als Legitimation eines Irrationalismus, der dem Faschismus den Weg bahnt. Ideologischer Maßstab ist ein kanonischer Marxismus, der allein nach Lukácz gegen das Virus des Irrationalen zu immunisieren vermag.

Ein derart enges Interpretationsschema ignoriert schon mit Blick auf die Vorgeschichte des deutschen Faschismus, dass das Hitler-Regime in vielerlei Hinsicht um die Zerstörung von Wissenschaftlichkeit schlechthin bemüht war. Genau das ist, sicher in anderen Formen und Ausprägungen, auch heute wieder der Fall. Trump und Twitter sind diesbezüglich nur die Spitze eines Eisbergs. Rechtspopulist*innen und -radikale ernten allerdings nur, was mit der Kommodifizierung des Öffentlichen und der Öffentlichkeit bereits vorbereitet wurde. Genauer: Die eingehegte, geschützte bürgerliche Öffentlichkeit ist zu einem Objekt kapitalistischer Landnahmen geworden, die sich in Etappen vollziehen und mit dem jüngsten Digitalisierungsschub einen Punkt erreicht haben, an dem statt von Strukturwandel eher von einer Zerstörung des Öffentlichen und der Öffentlichkeit gesprochen werden muss.

\section{Mechanismen kapitalistische Landnahme}

Beginnen wir mit dem Begriff der Landnahme, einer zentralen Kategorie für Theorien, die den Kapitalismus als expansives System analysieren und kritisieren. Ungeachtet ihrer sonstigen Heterogenität teilen entsprechende Konzepte die Annahme, dass sich kapitalistische Gesellschaften nicht ausschließlich aus sich selbst heraus reproduzieren können. Kapitalistische Dynamik beruht auf einer komplexen Innen-Außen-Bewegung. Stets beinhaltet sie die Internalisierung von Externem, die Okkupation eines nicht oder nicht vollständig kommodifizierten Äußeren. Land steht in diesem Zusammenhang nicht allein, ja nicht einmal in erster Linie für Grund und Boden. Der Begriff ist ein Synonym für Territorien, Produktionsweisen, Lebensformen und nicht zuletzt für Wissensbestände, die zuvor nicht oder nicht vollständig in den kapitalistischen Warentausch integriert waren. Sofern es kein funktio- 
nales Anderes zu entdecken gibt, das in Besitz genommen, in Wert gesetzt, kommodifiziert und profitabel genutzt werden kann, geraten Gesellschaften mit eingebautem Expansionsdrang an die Grenzen ihrer Entwicklungsfähigkeit. Sie stagnieren und zerfallen.

Die Landnahmekategorie verweist somit auf ein Expansionsparadoxon. Kapitalistische Produktionsweisen müssen sich ausweiten, um zu existieren. Dabei absorbieren und ruinieren sie allmählich, was für ihre Reproduktion benötigt wird. Je erfolgreicher die Akkumulations-, Wachstums- und Kommodifizierungsmaschine arbeitet, desto wirkungsvoller untergräbt sie die Selbstreproduktionsfähigkeit sozialer und natürlicher Ressourcen, ohne die moderne kapitalistische Gesellschaften nicht überlebensfähig sind. Fortgesetzte Landnahmen bewirken dennoch keinen automatischen Zusammenbruch des Kapitalismus. Vielmehr zwingen sie die dominanten kapitalistischen Akteure zur Kreation, Institutionalisierung und ständigen Modifikation von Selbststabilisierungsmechanismen. Hierzu gehören auf der makrogesellschaftlichen Ebene die moderne Kredit- und Finanzwirtschaft, das Innovationssystem, der Wohlfahrtsstaat, die organisierten Arbeitsbeziehungen, die Institutionen sozialer Reproduktion, die Regulationen der Naturverhältnisse, aber auch - wie wir noch sehen werden - die Schutzmechanismen für Informationen, Wissensbestände und selbst persönliche Erfahrungen. Auch die bürgerlich-demokratische Öffentlichkeit lässt sich als ein aktiv hergestelltes Außen kapitalistischer Marktvergesellschaftung begreifen. Ihre fortschreitende Kommodifizierung läuft auf die Internalisierung einer - positiven - Externalität ${ }^{1}$ hinaus. Grundsätzlich gilt: Ohne marktbegrenzende Institutionen und soziale Regeln, die den Warentausch mit Hilfe von Selbststabilisierungsmechanismen in die Gesellschaft einbetten, wäre die expansive Marktvergesellschaftung, die moderne Kapitalismen in all ihren Varianten auszeichnet, gar nicht denkbar.

Die Grundzüge des Landnahmetheorems habe ich an anderer Stelle ausführlich dargestellt (Dörre 2009; 2015). Nachfolgend beschränke ich mich deshalb auf einige Überlegungen, mit deren Hilfe sich das Konzept für die Interpretation des Strukturwandels von Öffentlichkeit

1 Die Kategorie der Externalität verwende ich hier als Synonym für das nichtkapitalistische Andere. Externalitäten entstehen nicht ausschließlich durch die - negative - Externalisierung von Kosten. Sie sind, etwa in Gestalt von NonProfit-Organisationen, in gemischten Ökonomien immer vorhanden, können neu geschaffen werden, eignen sich aber auch als Landnahme-Objekte. 
fruchtbar machen lässt. Nach Burkart Lutz $(1984,62)$, dem Nestor der deutschen Industriesoziologie, kann jeder Wachstumsschub als eine Phase je spezifischer Landnahmen durch den expandierenden industriell-marktwirtschaftlichen Teil der Volks- und Weltwirtschaft beschrieben werden. Lutz, der den Landnahmebegriff in die soziologische Debatte eingebracht hat, bezieht sich auf einen Theoriestrang, der bis zu Marx' Analyse der sogenannten ursprünglichen Akkumulation zurückreicht. Im ersten Band von Das Kapital veranschaulicht Marx (1973 [1867]), wie Staat, politischer Zwang und Akkumulation durch gewaltsame Enteignung (Bauernlegen), Raub von Kirchengütern sowie die Einhegung und private Nutzung von zuvor im Kollektivbesitz befindlichem Gemeindeland zu Geburtshelfern des Kapitalismus werden. Die Scheidung von Produzent*innen und Produktionsmitteln als zentrale Voraussetzung für die Entstehung doppelt freier Lohnarbeiter*innen und damit des Kapitalismus ist »in die Annalen der Menschheit eingeschrieben mit Zügen von Blut und Feuer« (ebd., 743).

Entscheidend ist jedoch nicht die von Marx sicher überzeichnete Gewaltträchtigkeit (Kocka 2013, 41) dieser ersten kapitalistischen Landnahme. Als weitaus wichtiger muss gelten, dass es sich bei der ursprünglichen Akkumulation von Beginn an um einen politischen, auf Staatsintervention beruhenden Prozess handelt. Weder die Veränderung der Eigentumsverhältnisse und die Expropriation des Landvolks noch die Disziplinierung der freigesetzten Arbeitskräfte für die neue Produktionsweise sind ohne Staatsintervention und außerökonomischen Zwang möglich (Marx 1973 [1867], 765). Marx vertritt allerdings die Ansicht, das politisch verfügte Zwangsmoment werde eine Episode in der Frühgeschichte des Kapitalismus bleiben. Im historischen Verlauf entstehe eine Arbeiterschaft, die »aus Erziehung, Tradition, Gewohnheit die Anforderungen jener Produktionsweise als selbstverständliche Naturgesetze anerkennt« (ebd.). Gewalt werde nur noch ausnahmsweise eingesetzt, die Arbeitenden könnten im Normalfall den Naturgesetzen der Produktion überlassen bleiben. Der stumme Zwang der ökonomischen Verhältnisse besiegele die Herrschaft des Kapitalisten über den Arbeiter.

In diesem Punkt hat sich Marx geirrt, wie Rosa Luxemburg (1975a [1913]) zu Recht kritisiert. Gravierende Strukturveränderungen des Kapitalismus vor Augen, lautet Luxemburgs zentrales Argument, dass sich die kapitalistische Dynamik als systemischer Zwang zu einer sich periodisch wiederholenden ursprünglichen Akkumulation interpretieren lässt. Erst durch Einverleibung von nichtkapitalisierter Arbeitskraft 
und Erde serwirbt das Kapital eine Expansionskraft, die ihm erlaubt, die Elemente seiner Akkumulation auszudehnen jenseits der scheinbar durch seine eigene Größe gesteckten Grenzen« (ebd., 305). Auf der sachlichen Ebene bleibe die Akkumulation des Kapitals an »nichtkapitalistische Kreise gebunden« (ebd., 306).

Obwohl sich Rosa Luxemburgs Theorie der externen Mehrwertrealisierung, mit der sie den Imperialismus ihrer Zeit erklären will, nicht halten lässt (dazu ausführlich Dörre 2018), bleiben ihre Überlegungen in mindestens dreierlei Hinsicht bedeutsam:

Erstens zeigt Luxemburg überzeugend, dass die kapitalistische Dynamik eine Doppelgestalt besitzt. Die eine Bewegung setzt sich in den Produktionsstätten des Mehrwerts, in den Fabriken, der durchkapitalisierten Landwirtschaft und auf den Warenmärkten durch. Hier reproduziert sich der Kapitalismus weitgehend auf seinen eigenen Grundlagen. Ausbeutung beruht in dieser Sphäre des kapitalistischen Warentauschs, den »inneren Märkten «, ${ }^{2}$ auf dem Äquivalenzprinzip.

Das heißt, die Lohnabhängigen werden, vermittelt über soziale Kämpfe und konjunkturelle Schwankungen, entsprechend der Grenzen entlohnt, die der historisch variable Wert ihrer Arbeitskraft setzt. Die andere Entwicklung bricht sich in Austauschbeziehungen zwischen der Kapitalakkumulation einerseits und nichtkapitalistischen Produktionsweisen, Schichten und Territorien andererseits Bahn. In diesen »äußeren«, weil nicht kapitalistischen Märkten, die es auch innerhalb nationaler Gesellschaften gibt, gilt das Prinzip des Äquivalententauschs auch in der Zirkulationssphäre allenfalls eingeschränkt. Hier herrschen Willkür, außerökonomische Disziplinierung, Dominanz, vor allem aber Überausbeutung ${ }^{3}$ und ungleicher Tausch. Landnahmen verschieben die

2 Die Unterscheidung zwischen Innen und Außen ist keine der "politischen Geographie«, sondern eine »der sozialen Ökonomie«: »Innerer Markt vom Standpunkt der kapitalistischen Produktion ist kapitalistischer Markt, ist diese Produktion selbst als Abnehmerin ihrer eigenen Produkte und Bezugsquelle ihrer eigenen Produktionselemente. Äußerer Markt ist die nichtkapitalistische soziale Umgebung, die seine Produkte absorbiert und ihm Produktionselemente und Arbeitskräfte liefert.« Daher vollziehen sich Eigentumsbildung und Freisetzungen nicht nur »auswärts«, in Kolonien und vorkapitalistischen Gesellschaften; als Proletarisierung von ländlichen und städtischen Mittelschichten, Handwerker*innen und kleinen Warenproduzent*innen finden sie ebenso im Inneren industriekapitalistischer Gesellschaften statt (Luxemburg 1975a, 311, 315).

3 Primäre Ausbeutung beruht in der Sphäre des Warentauschs auf dem Äquivalenzprinzip; das heißt die Lohnabhängigen werden, vermittelt über soziale 
Grenzen zwischen inneren kapitalistischen und äußeren nichtkapitalistischen Märkten. Es handelt sich dabei keineswegs um eine lineare Inwertsetzung von »neuem Land «. Vielmehr trägt jede Landnahme stets die Möglichkeit zu gesellschaftlicher Regression durch autoritär verfügte Disziplinierung in sich. Das ist unter anderem deshalb bedeutsam, weil der digitalisierte Kapitalismus mit seinen diversen Teilöffentlichkeiten keineswegs mit Fortschritt identifiziert werden muss.

Der beständige, systemisch unverzichtbare Stoffwechsel zwischen inneren und äußeren kapitalistischen Märkten läuft zweitens auf ein zeitlich lang gestrecktes »Zernagen« und »Assimilieren « (Luxemburg 1975a [1913], 364) nichtkapitalistischer Milieus hinaus. In diesem Prozess entstünden, so Luxemburg, die »seltsamsten Mischformen zwischen modernem Lohnsystem und primitiven Herrschaftsverhältnissen « (ebd., 312). Beispiele für solche Amalgamierungen seien das »Zerbröckeln« traditioneller Natural- und Bauernwirtschaften, etwa die »planmäßige, bewusste Vernichtung und Aufteilung des Gemeineigentums« (ebd., 328), welche die französische Kolonialpolitik in ihren arabischen Kolonien vornahm, oder die »Zwangslohnarbeit« (Luxemburg 1975b, 670), die spanische Eroberer zur Ausbeutung der indigenen Bevölkerung Lateinamerikas einführten. Landnahme bedeutet demnach, dass unterschiedliche Formen unfreier, prekärer und nur teilweise kommodifizierter Arbeit über längere historische Perioden hinweg konserviert, neu kombiniert und so als Arbeit für das Kapital genutzt werden. Es bilden sich hybride Verbindungen aus Lohnarbeit und unfreien, vorkapitalistischen oder prekären Arbeitsformen in unterschiedlich strukturierten Märkten heraus, deren »Stoffwechsel « dominanten Akteuren Extragewinne verspricht. Im Kontrast zur marxistischen Orthodoxie ihrer Zeit hat Luxemburg damit »eine völlig eigenständige Betrachtungsweise von Gesellschaftsformationen « begründet, die »im Gegensatz zu den linearen und evolutionistischen Auffassungen von >Fortschritt《 (Löwy 2013, 54) steht. Diese impliziert die gleichgewichtige Anerken-

Kämpfe, in etwa entsprechend des Wertes ihrer Arbeitskraft entlohnt. In äußeren, nichtkapitalistischen Märkten gilt das Prinzip des Äquivalententauschs allenfalls eingeschränkt. Hier herrschen Disziplinierung, rassistische und sexistische Abwertung, Willkür und zum Teil offene Gewalt. Ausbeutung beruht hier auf diversen Formen eines ungleichen Tauschs; das heißt, die durchschnittlichen gültigen Standards für die Reproduktion der Arbeitskraft werden durch außerökonomischen Zwang systematisch unterboten. Weil solche Aneignungsformen auch schon vor dem Kapitalismus existiert haben, bezeichne ich sie als Varianten sekundärer Ausbeutung (vgl. Dörre 2017). 
nung einer begrenzten Pluralität an Antagonismen und Ausbeutungsverhältnissen. Ein solches Nebeneinander diverser Ausbeutungs- und Herrschaftsformen finden wir, wie sich zeigen wird, auch im zeitgenössischen Kapitalismus.

Strukturprägend für die kapitalistische Dynamik ist drittens ein sozialer Mechanismus, den der Sozialgeograph David Harvey (2014, 32) in Anlehnung an Rosa Luxemburg als Kapitalüberschuss-Absorptionsproblem bezeichnet hat. Damit ist gemeint, dass eine Ökonomie, die während einer Produktionsperiode wächst, in der nachfolgenden Periode absorptionsfähige Märkte für das zusätzliche Mehrprodukt schaffen muss, was ohne markterweiternde Investitionen nicht möglich ist. Je höher das Reichtumsniveau von Gesellschaften und je größer das Wirtschaftswachstum, desto schwerer wird es, neue Märkte für das anlagesuchende Kapital zu erschließen. Dieses Kapitalüberschuss-Absorptionsproblem ist die zentrale makroökonomische Triebkraft hinter kapitalistischen Landnahmen. Es erklärt, weshalb der Akkumulationsprozess des Kapitals »die unumschränkte Verfügungsmöglichkeit« über »alle Produktivkräfte der Erde« (Luxemburg 1975a, 312) benötigt, soweit diese in den Schranken der Mehrwertproduktion mobilisierbar sind. Und es macht vor allem deutlich, weshalb kapitalistische Dynamik immer wieder auf Marktexpansion, auf die Ausdehnung alter und die Entdeckung neuer Märkte hinausläuft. Der Kapitalismus ist demnach ein »einzigartiges System der Marktabhängigkeit«; er verallgemeinert »die Imperative des Wettbewerbs, der Akkumulation und der Profitmaximierung « und muss in einem Grade expandieren, »wie es mit keiner anderen Gesellschaftsform vergleichbar ist« (Wood 2015, 115). Dieser Anforderung kann sich auch der zeitgenössische Kapitalismus nicht entziehen. Es sind allerdings besondere Märkte, in denen sich ein neuer Modus Operandi von Landnahmen zu bewähren hat und diejenigen, auf denen Wissen, Daten und Informationen vermarktet werden, sind für ihn von besonderer Bedeutung.

Kapitalistische Landnahmen, so können wir festhalten, generieren eine stets auf außerökonomischen Zwang angewiesene und mitunter gewaltträchtige Innen-Außen-Dialektik. Diese Bewegungsform ist immer mit der Absorption eines nicht marktförmigen Anderen verbunden. Landnahme bedeutet Kommodifizierung, Monetarisierung und Kommerzialisierung dieses Außen und damit zugleich dessen allmähliche Assimilation und Zerstörung. Deshalb sind Landnahmen endlich. Ist ein nichtkapitalistisches Anderes absorbiert, schwächt sich die 
expansive Dynamik ab, bis sich ein neues Anderes findet, das in Besitz genommen werden kann.

Landnahmen, die von der privaten Verfügung über Produktivkapital als dynamischem Prinzip angetrieben werden, erweiterte Reproduktion und Marktexpansion zum Ziel haben und unterschiedliche Modi von Ausbeutung und Dominanz durchsetzen, sind nicht nur umkämpft, sondern stets mit Landpreisgabe, präziser: mit Repulsionen, das heißt mit Bewegungen verbunden, die in gewisser Weise auf das Gegenteil von Kommodifizierung hinauslaufen. In der Akkumulation von bürokratisch-politischer Macht finden marktgetriebene Landnahmen ein expansives Pendant, das sich in spannungsvoller Ko-Evolution zur erweiterten Reproduktion des Kapitals, aber auch abgelöst von ökonomischer Expansion entfalten kann. ${ }^{4}$ Jede raum-zeitlich begrenzte und deshalb historisch einmalige Landnahme beruht auf einem besonderen Modus Operandi, der wiederum eine Vielzahl an Transformationsmechanismen ausbildet. Wird dieser dysfunktional, kann es zu großen Krisen von Kapitalakkumulation und gesellschaftlicher Reproduktion kommen. Derartige Ereignisse sind etwas völlig anderes als jene periodischen Ungleichgewichte, die mit dem Konjunkturzyklus verbunden sind. Sie erfassen das gesamte Ensemble gesellschaftlicher Verhältnisse und können deshalb nur überwunden werden, wenn die Beziehungen zwischen Akkumulationsregime, Regulationsweisen, Produktionsmodellen, Konsummustern, Lebensstilen und Reproduktionsformen völlig neu strukturiert werden. Es gilt, in den Worten von Burkart Lutz (1984, 62), geeignete »Strukturparameter « zu finden und zu institutionalisieren, die für eine gewisse Zeit die soziale Kohärenz kapitalistischer Gesellschaften sicherstellen.

\section{Landnahme von Wissen, Information und Öffentlichkeit}

Diese Grundidee gilt für die Landnahme des Sozialen, deren Modus Operandi die Dynamik des finanzialisierten Kapitalismus bestimmt hat, freilich nur in modifizierter Form. Eine solche Landnahme setzt mit ih-

4 Diesen Gedanken hat Hannah Arendt $(2006,312)$ in die Debatte eingebracht: »Durch eine unbegrenzte Akkumulation von Macht, das heißt von Gewalt, die kein Gesetz begrenzt, konnte eine unbegrenzte oder jedenfalls erst einmal unbegrenzt scheinende Akkumulation von Kapital vonstatten gehen.« 
ren komplexen Transfermechanismen und Bewährungsproben gewissermaßen an den marktbegrenzenden Institutionen und Regulationen an, die der wohlfahrtsstaatliche Kapitalismus hervorgebracht hat. Die Grundrichtung dieser Landnahme »zweiter Ordnung « habe ich an anderer Stelle ebenfalls ausführlich beschrieben (Dörre 2009; 2015), so dass auch hier eine knappe Bemerkung genügen soll. Zugespitzt formuliert, betrachten die Protagonist*innen dieser Landnahme, die finanzkapitalistischen Eliten und die ihnen funktional zugeordneten Klassenfraktionen, die Selbststabilisierungsmechanismen kapitalistischer Dynamik und die durch sie geschützten Bereiche als Verwertungsobjekte. Das gilt auch und gerade für den sozialen Raum von Wissen, persönlicher Erfahrung und die mit beiden korrespondierenden Öffentlichkeiten.

\section{Landnahme von »lebendigem Wissen« und Erfahrung}

Öffentlichkeit ist in gewisser Weise die politische Form gesellschaftlichen Bewusstseins (vgl. Gerhardt 2012). Sie beruht auf Wissen um Belange, die einer kollektiven Bearbeitung bedürfen und deshalb nach kommunikativem Austausch verlangen. Kapitalistische Landnahme bedeutet in diesem Zusammenhang, dass jenes Wissen, das in Informationen verwandelt - Öffentlichkeit konstituiert, zum Objekt privater Verwertungsinteressen wird. Dieser Prozess der Kommodifizierung von Öffentlichkeit hat lange vor der Digitalisierung begonnen; mit der Erfindung und Weiterentwicklung von Massenmedien setzt er sich in immer neuen Schüben durch. Digitale Technologie eröffnet dem markt- und gewinngetriebenen Zugriff auf solche Wissensbestände jedoch ungeahnte Möglichkeiten. Allerdings erfordert die Landnahme von Wissen besondere Transfermechanismen, von denen André Gorz (2004) einige in einem bemerkenswerten Essay kurz nach der Jahrtausendwende treffend analysiert hat. Die besondere Qualität der Landnahme von Wissen und in der Folge auch des öffentlich-rechtlichen Raums wurzelt in der Gegenwart vor allem darin, dass ihre Protagonist*innen mit Hilfe digitaler Technik Wissen und Erfahrung extrahieren, also von menschlichen Körpern und Gehirnen trennen, sie auf Universalmaschinen übertragen und gewinnbringend in die kapitalistische Warenform zwängen. Nun stellt Wissen jedoch keine Ware wie jede andere dar, sondern entsteht als ein Produkt nicht nur der Erwerbsarbeit, sondern der gesamten Lebens- 
tätigkeit von und der Interaktionen zwischen Personen. Im Unterschied zu »totem «, formalisiertem Wissen ist »lebendiges Wissen« (ebd., 45, 129) ${ }^{5}$ stets an die Person und hinsichtlich der Öffentlichkeit an den Homo publicus, an seine politischen Präferenzen, Werturteile und Weltsichten gebunden. Deshalb können sich weder Intelligenz an sich noch öffentliche Vernunft völlig »menschenfrei« entfalten. Wird das Wissen von lebendigen Körpern abgetrennt, verwissenschaftlicht und verwertet, nimmt es eine formalisierte Gestalt an. In diesem Aggregatzustand lässt es sich, ähnlich wie »tote Arbeit«, auch in digitalisierter Form als »totes Wissen« in den Kapitalkreislauf einbeziehen.

Zu den Eigenschaften von Wissen gehört aber, dass seine Produktivkraft dann am größten ist, wenn es von allen oder doch möglichst vielen genutzt werden kann. Es hat zunächst einen Wahrheitswert, der seinem - fiktiven - Warenwert vorausgesetzt ist. Um Wissen in die kapitalistische Form zu bringen, muss es künstlich verknappt und mit Eigentumstiteln versehen werden. ${ }^{6}$ In anderen Worten, wird es zu »neuem Land «, das es aus der Perspektive von Tech-Konzernen und unterstützenden Staaten zu extrahieren, zu kommodifizieren und profitabel zu nutzen gilt. Dadurch gerät Wissen zu einem der wichtigsten Objekte kapitalistischer Landnahme. Das Problem ist nur: Je besser diese Landnahme gelingt, desto stärker wird der eigentliche Gebrauchswert von Wissen, werden sein Wahrheitswert und seine Fähigkeit zur Reichtumsproduktion eingeschränkt. Die sogenannte Wissensökonomie enthält daher »im Grunde eine Negation der kapitalistischen Warenökonomie. Wenn man sie als neue Form des Kapitalismus behandelt, verschleiert man ihr Negativitätspotenzial«, denn nicht alles Wissen ist gleichwertig, und der Kapitalismus wertet und verwertet vor allem dasjenige Wissen, »dessen instrumentelles Potenzial offensichtlich oder vorhersehbar ist« (ebd., 74-75).

Formalisiertes digitales Wissen »[...] kann komplexe Interaktionen zwischen einer Vielzahl von Akteuren und Variablen organisieren und regeln. Es kann Maschinen, Anlagen und flexible Fertigungssysteme

5 Gorz (2004) grenzt das an menschliche Körper und persönliche Erfahrungen gebundene »lebendige« von formalisierbarem »toten« Wissen ab. Damit gewinnt er ein Kriterium, das ihm eine fundierte Kritik der sogenannten künstlichen Intelligenz erlaubt. Intelligenz kann es nach Gorz' Auffassung nur in ihrer Verknüpfung mit »lebendigem Wissen« geben, als rein maschinelle ist Intelligenz nicht herstellbar.

6 »Um als Ware verkäuflich und als Kapital verwertbar zu sein, muss Wissen folglich in Privateigentum verwandelt und verknappt werden.« (Gorz 2004, 11) 
entwerfen und lenken. Kurz, es kann die Rolle eines Fixkapitals spielen, indem es akkumulierte stote Arbeit der lebendigen, materiellen oder immateriellen Arbeit substituiert. Da die Grenzkosten der Software äußerst gering sind, kann sie sehr viel mehr Arbeit einsparen, als sie kostet und das in gigantischen, noch vor kurzem unvorstellbaren Ausmaßen. Das bedeutet, dass das formale Wissen unermesslich viel mehr 'Werts zerstört, als es zu schöpfen erlaubt. Anders gesagt, es erspart Unmengen von bezahlter gesellschaftlicher Arbeit und verkleinert folglich den (monetären) Tauschwert einer wachsenden Anzahl von Produkten und Dienstleistungen.« (ebd., 48, Hervorhebung im Original)

Man kann sicher darüber streiten, ob das in dieser von Gorz behaupteten Linearität zutrifft. Dagegen lässt sich etwa einwenden, dass er die Fähigkeiten kapitalistischer Akteure zur Wissensextraktion und -verwertung unterschätzt. So geht beispielsweise das Forscherteam um Andreas Boes (2015) davon aus, dass der »Informationsraum« eine wahre Fülle an möglichen neuen Geschäftsmodellen bietet, die sich für eine Revitalisierung des Kapitalismus geradezu aufdrängen. Mit »Informationsraum« ist gemeint, dass das Internet einen sozialen Handlungs- und Interaktionsraum konstituiert, der vielfältigsten Nutzungsformen offensteht. Mit seiner Hilfe bilde sich »eine lebendige globale Informations- und Kommunikationsumgebung « heraus, deren Zwecke und Veränderungsmöglichkeiten sich durch aktive Nutzung beständig veränderten und erweiterten: „Weil so geistige Tätigkeiten in neuer Qualität aneinander anschlussfähig werden, entsteht hier ein ganz neues Potenzial der Nutzung geistiger Produktivkraft.« (ebd., 85) Bisher, so sei hinzugefügt, sind die neuen Geschäftsmodelle allerdings relativ übersichtlich geblieben. Häufig verdrängen sie nur, was es in anderer Form auch schon zuvor gegeben hat.7 Ungeachtet der unterschiedlichen Einschätzungen über das Wachstumspotenzial der digitalen Ökonomie hat André Gorz den Aneignungsmodus der digitalen Landnahme von Wissen präzise rekonstruiert. Rohstoff dieser Landnahme sind nicht allein Daten und Informationen; »lebendiges Wissen « und an die Person gebundene Erfahrung bilden zunehmend die Quelle, auf die Verwertungsinteressen zugreifen. Damit wird künstlich, also mit Hilfe privat- oder staatskapitalistischer

7 »In digital capitalism capital aims to appropriate digital machines as instruments for political control, economic accumulation, and ideological manipulation«, beschreibt der Kommunikationswissenschaftler Christian Fuchs (2018, 287) eine Haupttendenz der digitalen Landnahme. 
Eigentumstitel, verknappt, was am produktivsten zu nutzen wäre, wenn Wissen als digitale Allmende allen zur Verfügung stünde.

\section{Austausch zwischen »inneren« und »äußeren« Märkten}

Was bedeutet all das nun für die bürgerliche Öffentlichkeit und die durch sie geleistete Informationsarbeit? Betrachten wir die Landnahme von Wissen, Information und Öffentlichkeit anhand der drei sozialen Mechanismen, die sich schon in Rosa Luxemburgs Akkumulationstheorie finden.

Beispiele für einen Stoffwechsel zwischen »inneren« und »äußeren« Märkten lassen sich im für die öffentliche Meinung konstitutiven Medienbereich leicht finden. Die kapitalistische Landnahme beginnt in der Bundesrepublik mit der Zulassung von privaten Radio- und Fernsehsendern neben den öffentlich-rechtlichen Anstalten Anfang der 1980er Jahre sowie einer fortschreitenden Kommerzialisierung von Zeitungen und Printmedien. Anders formuliert: Der öffentlich-rechtliche Rundfunk und seine TV-Sender werden als funktionales Anderes betrachtet, das sich dem Wettbewerb mit gewinngetriebenen Privatsendern aussetzen muss. Eigner dieser Sender sind wiederum überwiegend Konzerne, die zugleich einen erheblichen Teil der Printmedien kontrollieren.

Am weitesten fortgeschritten ist die Landnahme von Öffentlichkeit in den USA, wo der öffentlich-rechtliche Sektor allerdings eine deutlich andere Struktur aufweist als in Deutschland und anderen europäischen Staaten. Nichtkommerzielle TV-Sender und Rundfunkstationen sind gewissermaßen das Resultat von Gegenlandnahmen. Das Ende der 1960er Jahre gegründete National Public Radio (NPR) versammelt unter seinem Dach Radiostationen, die sich über eine Mischform aus staatlichen Geldern und Spenden finanzieren. Mit dem Public Broadcasting System, einem Netzwerk öffentlicher Fernsehsender, verhält es sich ähnlich. Die 1967 geschaffene Corporation of Public Broadcasting verteilt staatliche Gelder zu gleichen Teilen an beide Netzwerke (Neumann 2018).

Landnahme bedeutet in diesem schon immer von privaten Unternehmen dominierten Sektor vor allem Intensivierung von Konkurrenz und Regeländerung. Der Staat steuert vor allem über die Vergabe von Sendelizenzen; Kabelfernsehen und Streamingdienste sind dagegen kaum reguliert. Dadurch ist auch den privaten Sendern eine Konkurrenz erwachsen, die zur Minderung von Werbeeinnahmen geführt hat, 
mit einer enormen Konzentration von Medienmacht als Konsequenz. In den USA kontrollierten 1983 die 50 größten Unternehmen 90 Prozent der Medien. Gegenwärtig sind es nur noch sechs Konzerne, die über 90 Prozent dessen verfügen, was US-Bürger*innen über die Medien zu sehen, zu hören und zu lesen bekommen. 2010 erzielten diese Unternehmen - Comcast, News Corp, Disney, Viacom, Time Warner und CBS - einen Umsatz von insgesamt 275 Milliarden US-Dollar (Sanders 2017, 444); eine Summe, die davon zeugt, dass der Mediensektor zu einem hochgradig zentralisierten »inneren« kapitalistischen Markt geworden ist. ${ }^{8}$

Dieser »innere Markt« und seine Regeln bestimmen sukzessive die Themen, die Qualität der Berichterstattung, die Formate von Sendungen - kurzum: Sie entscheiden darüber, was eine Nachricht ist und was nicht, was in die Öffentlichkeit gehört und was nicht, was gesendet wird und was nicht. Selbiges geschieht selbstverständlich nicht in jenem trivialen Sinne, den Verschwörungsmythen unterstellen. Milliardär*innen, denen Zeitungen und Privatsender gehören, müssen nicht zum Telefon greifen, um Journalist*innen zu instruieren. Die Formierung der öffentlichen Meinung erfolgt über weitaus subtilere Mittel. Man kann von der Redaktionslinie einer Tageszeitung abweichen - zehn Prozent nach links, zehn Prozent nach rechts, ein Mehr an oppositionellem Geist hat keine Chance und schadet dem eigenen Renommee. Das jedenfalls glauben Qualitätsjournalist*innen auch hierzulande sicher zu wissen (vgl. Ulrich 2019).

Wo die Konzentration der Medienlandschaft weiter fortgeschritten ist als in Deutschland und anderen europäischen Staaten, sind die Folgen für das Nachrichtenwesen und die öffentliche Meinung entsprechend stärker offensichtlich. Der demokratische Sozialist Bernie Sanders hat dies am Beispiel seiner ersten Präsidentschaftswahlkampagne eindrucksvoll beschrieben. Zwei seiner Erfahrungen seien exemplarisch hervorgehoben. Als eine Art »Daumenregel« habe er gelernt, »dass eine Frage den Medienkonzernen umso unwichtiger erscheint, je mehr sie arbeitende Menschen betrifft, und dass die Aufmerksamkeit der Medien größer wird, je geringer die Relevanz für normale Leute ist« (Sanders 2017, 421). Die Hauptursache für diese Entwicklung sieht

8 Sanders bezieht sich auf Daten von https://www.freepress.net/. Der Mediensektor in den USA hat sich seither verändert, 2020 ist jedoch noch immer die Rede von sechs Konzernen, die $\$ 90 \%$ of the media outlets in America (Louise 2020) kontrollieren. 
Sanders darin, dass Politik in den medialen Öffentlichkeiten mehr und mehr zu Unterhaltung verkommt. Dazu passt, dass unter anderem allerlei Spektakel, Skandale, die Beleidigung von Gegner*innen und Intimitäten den Rang von öffentlichen Ereignissen eingeräumt bekommen.

Entertainer vom Schlage eines Donald Trump wissen, wie man einen derart umgestalteten öffentlichen Raum für eigene Zwecke ausnutzen kann:

Trump gewann die republikanischen Vorwahlen [vor seiner ersten Präsidentschaft; KD) mit Hilfe einer massiven Medienberichterstattung, die er mit seinen Tweets und scharfen persönlichen Angriffen auf seine Konkurrenten befeuerte. Bis Ende Februar hatte er nach Angaben des Economist in den Abendnachrichten zehnmal so viel Aufmerksamkeit erhalten wie der republikanische Senator Rubio aus Florida. Für die Medienkonzerne sind Beleidigungen und persönliche Attacken ein gefundenes Fressen. (ebd., 426)

Heute sehen wir, was daraus geworden ist - eine fatale Präsidentschaft, gestützt auf ein Verbiegen, Ignorieren und Umdeuten von Fakten, das an Georg Orwells 1984 erinnert. In diesem Roman indoktriniert ein Ministerium für Wahrheit die Menschen mit Hilfe einer eigenen Sprache, dem sogenannten »Neusprech «, nach dem Motto: »Krieg ist Frieden. Freiheit ist Sklaverei. Unwissenheit ist Stärke.« (Orwell 1949, 23)

So weit sind wir hierzulande noch lange nicht. Doch die Theatralisierung und Trivialisierung von Politik als Unterhaltung ist längst in Deutschland angekommen. Auch hier sieht sich der öffentliche Rundfunk dem Wettbewerb mit Privatsendern ausgesetzt, die von Werbung leben und denen sowohl die Werbeeinnahmen der öffentlich-rechtlichen Sender als auch der Rundfunkbeitrag ein Dorn im Auge sind. Nicht zufällig richten sich Attacken der radikalen Rechten und ihrer Unterstützer in bürgerlichen Parteien gegen Beitragserhöhungen; in Sachsen-Anhalt löste das Nein der christdemokratischen Regierungspartei zu einer minimalen Steigerung des Rundfunkbeitrags eine veritable Koalitionskrise aus. Gravierender ist jedoch, dass die großen Medienkonzerne, allen voran das Murdoch-Imperium, die Konzentration der Medienlandschaft auch in Deutschland weiter vorantreiben wollen. So greift der Murdoch-Konzern nach einigen Privatsendern, die sich in finanziellen Schwierigkeiten befinden. Was das im Erfolgsfall bedeuten könnte, hat Bernie Sanders unmissverständlich klargemacht: »In einer Zeit, in der Wissenschaftler immer eindringlicher vor der planetarischen Klimakrise warnen, bemüht sich Murdoch gemeinsam mit 
der fossilen Energiewirtschaft um die Widerlegung der Wissenschaft « (Sanders 2017, 439; vgl. auch Waterson 2020). Man beginnt zu ahnen, dass Wissenschaftsfeindlichkeit und Verschwörungstheorien keineswegs ausschließlich spontan entstehen. Es ist aber keineswegs allein der Murdoch-Konzern, der den Rechtspopulismus medial fördert. In Deutschland ist die Bild-Zeitung mit ihren Zusatzangeboten aus dem Hause Springer längst dabei, die Funktion einer »rechten Apo mit medialer Macht« zu erfüllen (Lucke 2021).

\section{Neukombinationen von »künstlerischer« Tätigkeit und prekärer Beschäftigung}

Wirkung können Verschwörungsmythen auch deshalb entfalten, weil die Landnahme von Wissen und Öffentlichkeit die Arbeits- und Beschäftigungsverhältnisse im Mediensektor neu strukturiert, worunter die Qualität der Berichterstattung leidet. Im journalistischen Bereich bringt diese Landnahme einen Arbeits- und Arbeitertypus hervor, dessen Wert vornehmlich auf Spezialkenntnissen und -qualifikationen beruht, die sich im Grunde nicht messen oder vergleichen lassen. Für die Spitzen in der Hierarchie von Journalist*innen, Redakteur*innen, Publizist*innen, Zeitungs-, Rundfunk- und Fernsehmacher*innen wird es immer schwerer, den Wert der Ware Arbeitskraft zu berechnen. Beschäftigte im wissensintensiven Medienbereichen agieren wie Künstler*innen oder Profifußballer*innen, in dem Sinne, dass ihre Einzigartigkeit und Besonderheit den nur schwer messbaren Wert der Arbeitskraft bestimmen.

Wenn er überhaupt irgendwo zu einer realen Figur geworden sein sollte, dann findet sich der Typus des Selbstunternehmers im Mediensektor, betraut mit der Arbeit an Öffentlichkeit und öffentlicher Meinung. Doch wie André Gorz richtig feststellt: Je mehr innerhalb eines Arbeits- und Beschäftigungsverhältnisses an das Selbst-Produzieren appelliert wird, desto stärker tendieren die Arbeitenden dazu, auch mehr sein zu wollen, als sie eigentlich sind. Journalist*innen betätigen sich als Schriftsteller*innen oder Wissenschaftler*innen und sie schreiben Bücher, um ihren eigentlichen Wert darzustellen. Werbegraphiker*innen erzeugen Kunstwerke und dergleichen mehr. Dies kann dazu führen, dass die Nebentätigkeit zur eigentlichen Quelle des Selbstbewusstseins wird: „Um einen Teil ihres Lebens dem totalen Verwertungszwang zu entziehen, messen die >Arbeiter des Immateriellen< schließlich ihren spielerischen, sportlichen, kulturellen und assoziativen Aktivitäten, bei 
denen das Sich-selbst-Produzieren ein Selbstzweck ist, eine größere Bedeutung bei als der Arbeit.« (Gorz 2004, 27)

Die Spitzen der Zunft haben mit flexiblen, befristeten Beschäftigungsverhältnissen keine Probleme. Am unteren Ende sieht das hingegen völlig anders aus. Die Arbeit an der Öffentlichkeit wird selbst bei öffentlich-rechtlichen Sendern von Journalist*innen verrichtet, die sich in Freie, feste Freie und Festangestellte ausdifferenzieren. Für einen erheblichen Teil der Journalist*innen gelten Arbeitsbedingungen, die der »Künstlerprekarität« ähneln. Einkommen und Beschäftigungsverhältnisse reichen lediglich für ein unsicheres Leben; allein das inhaltliche Interesse an der Tätigkeit bindet und integriert. Dem angesehenen Meinungsbildner in der Redaktion einer überregionalen Tageszeitung steht der freie Journalist einer Regionalzeitung gegenüber, der mit unsicherem Einkommen gemeinsam mit zwei Kolleg*innen als »Mädchen für alles« die Lokalberichterstattung eines großflächigen Landkreises besorgt. Solche Journalist*innen kann man auch jenseits ihrer eigentlichen beruflichen Tätigkeit treffen - etwa als Mitbesitzer*innen und Aushilfen in einem Kiosk, das bevorzugt Badegäste und Radwander*innen bewirtet, ${ }^{9}$ oder - weit häufiger und auch bedenklicher - als PR-Arbeiter*innen für private Auftraggeber (vgl. Obermaier und Koch 2015).

Im Journalismus markiert das regulierte, vertraglich geschützte und wohlfahrtsstaatlich eingehegte Beschäftigungsverhältnis einen Standard, der qua Enteignung oder Vorenthaltung von Sozialeigentum mit Beschäftigungsverhältnissen kombiniert wird, die sich durch Unsicherheit, Überausbeutung und ungleichen Tausch auszeichnen. Folgerichtig ist die Welt des Journalismus eine gespaltene. Die Grenzen zwischen freier Tätigkeit, wie es sie im Journalismus schon immer gab, und prekärer Beschäftigung fließen ineinander über. Auf der prekären Seite sind die Einkommen niedrig, die Arbeitsbedingungen schlecht, und auch die Reputation ist nicht sonderlich groß. Journalismus wird deshalb mehr und mehr zu einem Beruf, den man sich leisten können muss. Der Journalist Thomas Schnedler, der zu diesem Thema promoviert hat (Schnedler 2017), erläutert in einem Interview mit Deutschlandfunk Kultur:

Das ist tatsächlich eine große Gefahr, dass der Journalismus noch mehr als ohnehin schon zu so einer Art Elitenjob wird, den man sich leisten können muss, weil man entweder selber über die nötigen Mittel verfügt oder weil

9 Es handelt sich um ein reales Beispiel, das jedoch kein Ausnahmefall ist. 
man eben solche Sicherheitsgaranten und andere Unterstützer hat, die einem das dann erst ermöglichen. Und es würde schon zu einer großen Schieflage führen im Beruf, und auch dazu, dass bestimmte Wahrnehmungen und Erfahrungen gar nicht mehr in dem Berufsstand sich irgendwie wiederfinden. (Schnedler 2018)

Ob und wie sich die Prekarisierung des Journalismus auf die Qualität der Arbeit und damit auch auf das öffentliche Bewusstsein auswirkt, ist noch weitgehend unerforscht. Dass soziale Unsicherheit die Qualität der Berichterstattung negativ beeinflusst, die regulative Kraft bürgerlicher Öffentlichkeit beschädigt und so den Irrationalismus fördert, ist jedoch eine starke Hypothese, deren Untersuchung lohnenswert ist.

\section{Vom Überschuss-Absorptions- zum Verhaltensvorhersage-Problem}

Mit dem Internet wird alles besser, könnte man meinen. Schließlich bietet das Netz jedem und jeder die Möglichkeit, mit geringem Aufwand eigene Öffentlichkeiten jenseits institutionalisierter Formen zu kreieren und zu betreiben. Das demokratische Versprechen des Internets ist jedoch zum gegenwärtigen Zeitpunkt kaum mehr als ein schöner Schein. Tatsächlich treiben die Netzkonzerne die Konzentration von Datennutzung, Informationsgewinnung und -verbreitung weiter voran. Einerseits erscheinen die Zugänge niedrigschwellig. Zumindest in reichen Gesellschaften verfügen nahezu alle über die Produktionsmittel, die eine Teilhabe an der digitalen Ökonomie erlauben. Häufig genügt ein Notebook mit entsprechender Ausstattung, um geschäftsfähig zu sein. Die scheinbare Demokratisierung des Zugangs zu Produktionsmitteln korrespondiert jedoch andererseits mit einem hochgradig vermachteten Feld. In ihrem Atlas der digitalen Welt vermitteln die Autoren Martin Andree und Timo Thomsen (2020) einen Eindruck von Konzentrationsprozessen, die sich spontan keineswegs erschließen. Das hängt auch damit zusammen, dass niemand genau zu sagen vermag, wie groß der Anteil der GAFAM-Gruppe ${ }^{10}$ und vergleichbarer ITKonzerne am digitalen Aufmerksamkeitsmarkt tatsächlich ist.

10 Die GAFAM-Gruppe umfasst mit Google, Apple, Facebook und Microsoft einige der reichsten Unternehmen der Welt. Diese Konzerne verwerten die Verhaltensdaten von Milliarden Menschen. Herausgefordert werden sie gegenwärtig 
Um einen Eindruck von den Konzentrationsprozessen zu vermitteln, wählen die Autoren ein einprägsames Bild. Sie nutzen den Gini-Koeffizienten als Analogie, um das Ausmaß der Konzentration in einer Zahl auszudrücken. Ein Gini-Koeffizient von 1 würde bedeuten, dass eine Person alles besitzt; ein Wert 0 steht hingegen für maximale Gleichverteilung. Andree und Thomsen $(2020,30)$ haben nun die Verteilung der gemessenen Aufmerksamkeit auf das von ihnen erhobene Spektrum an 131000 Angeboten errechnet und kommen auf einen Wert von 0,988; das heißt ein winziges Spektrum an Angeboten zieht den Großteil der Aufmerksamkeit auf sich. Als Vergleichsmaßstab ziehen die Genannten die Vermögensverteilung heran. Würde man die Konzentration des Internet-Traffic darin übersetzen, besäßen die 500 wohlhabendsten Personen in Deutschland etwas über 85 Prozent des Vermögens, dem großen Rest blieben ganze 14,2 Prozent. Die Ungleichheit in der Aufmerksamkeitsverteilung ist damit noch weitaus größer als in der Vermögensverteilung (ebd., 19-20).

Von dieser Konzentration bekommen gewöhnliche Internetnutzer*innen in der Regel gar nichts mit. Eine große Vielfalt an Angeboten lässt den Gedanken an Konzentrationsprozesse gar nicht erst aufkommen. Damit entsteht eine Grundproblematik für jede Spielart regulatorischer Politik im Netz. Was, etwa beim Schutz von Urheberrechten, auf Unternehmen zielt, die den Traffic beherrschen, kann unter Umständen als staatlicher Eingriff in die Freiheiten der Internetnutzer*innen verstanden werden. Hinzu kommt, dass oft gar nicht klar ist, wie und auf welche Wissensbestände, Erfahrungen und Tätigkeiten zugegriffen wird. Medien, die für die bürgerlich-demokratische Öffentlichkeit lange Zeit konstitutiv waren, erwächst daraus eine existenzielle Bedrohung. Sie konkurrieren mit Suböffentlichkeiten im Netz, die sich der moralisch-regulativen Kraft bürgerlicher Öffentlichkeit weitgehend entziehen. Zugleich verlieren sie Werbeeinnahmen an die Internetkonzerne und deren Filialen. In dem Maße, wie sie sich für digitale Angebote öffnen, machen sie sich jedoch vom Wissen der Tech-Oligopole abhängig, oft, ohne mit den neuen Formaten kostendeckende Einnahmen generieren zu können. Die Großunternehmen der digitalen Ökonomie benötigen »proprietäre Märkte« (Dolata 2019, 182). ${ }^{11}$ Diese nicht frei zugänglichen Märkte entstehen, indem künst-

allenfalls durch chinesische IT-Konzerne, die ebenfalls monopolartige Organisationsformen aufweisen.

11 »Massive Konzentrationsprozesse, die Herausbildung von Winner-takes-all- 
lich verknappt wird, was eigentlich im Überfluss vorhanden ist. Unternehmen schaffen und verteidigen also mit staatlicher Unterstützung Wissens- und Technologiemonopole, die es überhaupt erst erlauben, den digitalen Kapitalismus zu einer gewinnbringenden Veranstaltung zu machen (Staab 2019).

\section{Zum Schluss: Für Mediensozialismus!}

Die großen Internetgiganten werden alles daransetzen, ihre Wissensund Marktmonopole zu erhalten - auch zu Lasten unabhängiger Medien. Doch es kommt eine weitere Gefahr hinzu, die Shoshana Zuboff (2019) in brillanter Weise analysiert hat. Sie spricht von einem aus dem Ruder gelaufenen »Überwachungskapitalismus«, der es gelernt habe, seine »historischen Bedingungen raffiniert auszubeuten und seinen Erfolg zu verteidigen« (ebd., 33). »Überwachungskapitalismus« bedeutet, dass sich die großen Internetkonzerne unsere Datenspuren im Netz als Gratisressource aneignen, um sie in Verhaltensvorhersageprodukte zu verwandeln, die sie daraufhin an Dritte verkaufen können. Die Nutzung solcher Daten für Interventionen in den US-Präsidentschaftswahlkampf zeigt, wie weit die Zerstörung demokratischer Öffentlichkeit bereits vorangeschritten ist. Der »Überwachungskapitalismus« läuft darauf hinaus, Verhaltenstendenzen nicht nur zu ermitteln, sondern erwünschtes Verhalten möglichst auch herbeizuführen - eine Dystopie, deren Realisierung bereits begonnen hat.

Fassen wir zusammen: Die Kommodifizierung von Medien bedingt, dass große gesellschaftliche Gruppen samt der sie betreffenden Themen aus der bürgerlichen Öffentlichkeit ausgeschlossen werden. Das wiederum macht die Medien, die Redaktionen und die Journalist*innen angreifbar. Nur vor diesem Hintergrund ist zu erklären, dass Teilöffentlichkeiten, die das Internet bietet, zum Katalysator einer Öffentlichkeitsrebellion geworden sind. Suböffentlichkeiten lassen die Leitmedien bei ihrer Kommunikation weitgehend außen vor. Das öffnet dem Irrationalismus Tür und Tor, weil gemeinsame Diskursstandards und -regeln in diesen Suböffentlichkeiten nicht mehr gelten. Die Inter-

Märkten und die Etablierung neuer natürlicher Quasi-Monopole, die das Web heute sowohl in ökonomischer als auch in sozialer Hinsicht prägen, sind die weithin sichtbaren Folgen dieser großflächigen Landnahme«, beschreibt Ulrich Dolata $(2019,182)$ die zurückliegende Digitalisierungsetappe. 
nalisierung des funktionalen Außen »Öffentlichkeit« in den kapitalistischen Verwertungsprozess hat eine Gegenbewegung im Netz ausgelöst, die jedoch kaum mehr als eine imaginäre Revolte ist, weil auch sie in den Bahnen kapitalistischer Landnahmen gefangen bleibt und der Zerstörung demokratischer Öffentlichkeit zusätzliche Schubkraft verleiht. Die Folgen sind in den USA zu besichtigen: Wahrheit wird zu Fake News, Wissenschaft zur Lüge, eine Wahlniederlage zum Sieg und der Sturm auf das Capitol zu einer verständlichen Reaktion vermeintlich Betrogener.

Lässt sich dieser Zerstörung von Vernunft etwas entgegensetzen? Ich weiß es nicht, aber ich hoffe es. Drei Maßnahmenbündel halte ich für zentral. Erstens benötigen wir einen digitalen Infrastruktur- und Mediensozialismus, der den Zugang zu demokratischen Öffentlichkeiten als öffentliches Gut betrachtet, das es zu schützen gilt. Die Verteidigung wissenschaftlicher Standards muss zwingender Bestandteil entsprechender Politiken sein. Wissenschaft dient der Wahrheitssuche. Sie beruht auf institutionalisiertem Selbstzweifel. Deshalb kann jede wissenschaftliche Erkenntnis potenziell mit einer wissenschaftlichen Gegenthese konfrontiert werden. Dies zu verdeutlichen ist jedoch etwas völlig anderes als die Verbreitung sogenannter alternativer Fakten. Ein öffentlich finanzierter Mediensektor muss der Wahrheitssuche Raum geben. Er darf nicht primär von Einschaltquoten und Zielgruppendiagnosen abhängen; seine Hauptinhalte müssen neben Unterhaltung und Zerstreuung seriöse Informationsangebote sein. Zweitens bedeutet dies, dass Leitmedien - allen voran der öffentlich-rechtliche Rundfunk - finanziell abgesichert, aber in ihrer Qualität verbessert und demokratisiert werden müssen. Ihre Kontrolle sollte Transformations- und Nachhaltigkeitsräten übergeben werden, die sich an den Sustainable Development Goals (SDGs) als normativer Grundlage orientieren und sicherstellen, dass die großen gesellschaftlichen Krisen und Probleme in geeigneter Weise zu Themen, Informationen und Nachrichten werden. Drittens schließlich bedarf es einer demokratischen Netz- und Medienpolitik, die Pluralismus garantiert und die Verteidigung der Meinungsfreiheit nicht privaten Unternehmen überlässt. Die Zerschlagung von Wissens- und Medienmonopolen ist dafür eine unabdingbare Voraussetzung.

Bringt man diese Überlegungen auf eine einfache Formel, dann sehen wir uns tatsächlich mit einer Entscheidungssituation konfrontiert, in der die Zurückdrängung des medial gestützten Irrationalismus und die Zerstörung von Vernunft nur noch mittels eines Übergangs zu ratio- 
naleren, nachkapitalistischen Gesellschaften möglich scheinen (Dörre und Schickert 2019; Dörre 2020). Diese Gesellschaften hätten sich des systemischen Zwangs zu fortgesetzten Landnahmen zu entledigen. Der Weg dorthin führt über den Ausbau positiver Externalitäten, zu denen an erster Stelle demokratische Öffentlichkeiten gehören.

\section{Literatur}

Andree, Martin, und Timo Thomsen. 2020. Atlas der digitalen Welt. Frankfurt am Main, New York: Campus.

Arendt, Hannah. 2006. Elemente und Ursprünge totaler Herrschaft. Antisemitismus, Imperialismus, totale Herrschaft. 11. Auflage. München: Piper.

Bermbach, Udo, und Günter Trautmann. 1987. Georg Lukács. Opladen: Westdeutscher Verlag.

Boes, Andreas, Tobias Kämpf, Barbara Langes, und Thomas Lühr. 2015. Landnahme im Informationsraum. Neukonstituierung gesellschaftlicher Arbeit in der »digitalen Gesellschaft«. WSI Mitteilungen 2: 77-85.

Dolata, Ulrich. 2019. Plattform-Regulierung. Koordination von Märkten und Kuratierung von Sozialität im Internet. Berliner Journal für Soziologie 29: 179-206.

Dörre, Klaus. 2009. Die neue Landnahme. Dynamiken und Grenzen des Finanzmarktkapitalismus. In: Soziologie - Kapitalismus - Kritik. Eine Debatte, herausgegeben von Klaus Dörre, Stephan Lessenich und Hartmut Rosa, 21-86. Frankfurt am Main: Suhrkamp.

Dörre, Klaus. 2015. Social Capitalism and Crisis: From the Internal to the External Landnahme. In: Sociology - Capitalism - Critique, herausgegeben von Klaus Dörre, Stephan Lessenich und Hartmut Rosa, 247-277. London, New York: Verso.

Dörre, Klaus. 2017. Ausbeutung und Leistungsgerechtigkeit - eine Forschungsheuristik. In: Leistung und Gerechtigkeit - Das umstrittene Versprechen des Kapitalismus, herausgegeben von Brigitte Aulenbacher, Maria Dammayr, Klaus Dörre, Wolfgang Menz, Birgit Riegraf und Harald Wolf, 174-190. Weinheim: Beltz Juventa.

Dörre, Klaus. 2018. Rosa Luxemburg, Die Akkumulation des Kapitals (1913). In: Geschichte des politischen Denkens. Das 20. Jahrhundert, herausgegeben von Manfred Brocker, 1. Auflage, 80-95. Berlin: Suhrkamp.

Dörre, Klaus. 2020. Die neue Lust am Sozialismus. Option für eine Nachhaltigkeitsrevolution? In: Sozial-ökologische Utopien. Diesseits oder jenseits von Wachstum und Kapitalismus?, herausgegeben von Benjamin Görgen und Björn Wendt, 249-272. München: Oekom.

Dörre, Klaus, und Christine Schickert (Hrsg.). 2019. Neosozialismus. Solidarität, Demokratie und Ökologie vs. Kapitalismus. München: Oekom.

Fuchs, Christian. 2018. Industry 4.0. The Digital German Ideology. TripleC: Communication, Capitalism \& Critique 16 (1): 280-289. 
Gerhardt, Volker. 2012. Öffentlichkeit. Die politische Form des Bewusstseins. München: C.H. Beck.

Gorz, André. 2004. Wissen, Wert und Kapital. Zur Kritik der Wissensökonomie. Zürich: Rotpunktverlag.

Habermas, Jürgen. 1990 [1962]. Strukturwandel der Öffentlichkeit. Neuauflage. Frankfurt am Main: Suhrkamp.

Harvey, David. 2014. Das Rätsel des Kapitals entschlüsseln. Hamburg: VSA.

Kocka, Jürgen. 2013. Geschichte des Kapitalismus. München: Beck.

Löwy, Michael. 2013. Westlicher Imperialismus gegen Urkommunismus. Eine neue Lesart von Rosa Luxemburgs ökonomischen Schriften. In: Rosa Luxemburgs »Akkumulation des Kapitals«. Die Aktualität von ökonomischer Theorie, Imperialismuserklärung und Klassenanalyse, herausgegeben von Ingo Schmidt, 53-62. Hamburg: VSA.

Louise, Nickie. 2020. These 6 corporations control 90\% of the media outlets in America. The illusion of choice and objectivity. TechStartups vom 18. September, https://techstartups.com/2020/09/18/6-corporations-control-90-mediaamerica-illusion-choice-objectivity-2020/. Zugegriffen: 5. Februar 2021.

Lucke, Albrecht von. 2021. Rechte APO mit medialer Macht. Blätter für deutsche und internationale Politik 3: 89-89.

Lukács, Georg. 1954. Die Zerstörung der Vernunft. Berlin: Aufbau.

Lutz, Burkart. 1984. Der kurze Traum immerwährender Prosperität. Frankfurt am Main, New York: Campus.

Luxemburg, Rosa. 1975a [1913]. Die Akkumulation des Kapitals. Ein Beitrag zur ökonomischen Erklärung des Imperialismus. In: Gesammelte Werke, Band 5, 5-411. Berlin: Dietz.

Luxemburg, Rosa. 1975b. Einführung in die Nationalökonomie. In: Gesammelte Werke, Band 5, 524-778. Berlin: Dietz.

Marx, Karl. 1973 [1867]. Das Kapital. Erster Band. In: Marx-Engels-Werke 23. Berlin: Dietz.

Neumann, Mario. 2018. So werden öffentliche Sender in den USA finanziert. Neue Zürcher Zeitung vom 10. Februar, https://www.nzz.ch/feuilleton/medien/oeffentliches-us-radio-helfen-sie-uns-ld.1354508. Zugegriffen: 5. Februar 2021.

Obermaier, Magdalena, und Thomas Koch. 2015. Mind the gap. Consequences of inter-role conflicts of freelance journalists with secondary employment in the field of PR. Journalism 16 (5): 615-629. DOI: 10.1177/1464884914528142.

Orwell, George. 1949. 1984. London: Secker and Warburg.

Rücker, Silvie. 1976. Irrationalismus. In: Historisches Wörterbuch der Philosophie, Band 4, herausgegeben von Joachim Ritter und Karlfried Gründer. Basel, Stuttgart: Schwabe.

Sanders, Bernie. 2017. Unsere Revolution. Berlin: Ullstein.

Schnedler, Thomas. 2017. Prekäre Arbeit im Journalismus. Dissertation. Universität Hamburg, https://ediss.sub.uni-hamburg.de/bitstream/ediss/6133/1/Dissertation.pdf. Zugegriffen: 5. Februar 2021.

Schnedler, Thomas. 2018. Prekäres Arbeiten in den Medien »Gefahr, dass Journalismus noch mehr Elitenjob wird«. Thomas Schnedler im Gespräch mit Isabelle 
Klein. Deutschlandfunk vom 11. September, https://www.deutschlandfunk.de/ prekaeres-arbeiten-in-den-medien-gefahr-dass-journalismus.2907. de.html?dram:article_id=427828. Zugegriffen: 5. Februar 2021.

Staab, Philipp. 2019. Digitaler Kapitalismus. Markt und Herrschaft in der Ökonomie der Unknappheit. Berlin: Suhrkamp.

Ulrich, Bernd. 2019. Alles wird anders. Das Zeitalter der Ökologie. Köln: Kiepenheuer \& Witsch.

Waterson, Jim. 2020. James Murdoch criticises father's news outlets for climate crisis denial. The Guardian vom 14. Januar, https://www.theguardian.com/ media/2020/jan/14/james-murdoch-criticises-fathers-news-outlets-for-climate-crisis-denial. Zugegriffen: 4. März 2021.

Wood, Ellen Meiksins. 2015. Der Ursprung des Kapitalismus. Eine Spurensuche. Hamburg: Laika.

Zuboff, Shoshana. 2019. Das Zeitalter des Überwachungskapitalismus. Frankfurt am Main, New York: Campus.

\section{Open Access}

Dieser Beitrag erscheint unter der Creative-Commons-Lizenz CC BY-ND 3.0 DE: https://creativecommons.org/licenses/by-nd/3.0/de/. 


\title{
Kapitalismus, Big Data und die neue Rolle der Archive: Anmerkungen zu kritischer Medienkompetenz in Zeiten digitaler Transformation
}

\author{
Holger Pötzsch
}

Keywords: Digitaler Kapitalismus, digitale Archive, kritische Medienkompetenz

\section{Abstract}

Dieser Beitrag behandelt das Thema kritische Medienkompetenz in Zeiten digitaler Transformation. Zunächst etabliere ich einige Prämissen, die diesen Text von businessorientierten Diskursen abgrenzen, bevor ich genauer auf neue Rollen digitaler Archive eingehe. Ich argumentiere, dass es wichtig ist, technische Errungenschaften nicht nur auf ihre Funktionalitäten hin korrekt zu beschreiben, sondern diese auch in weitere gesellschaftliche Rahmen einzubetten, um ihre variierenden politischen Implikationen korrekt ausleuchten zu können. Als nächsten Schritt führe ich dann die Begriffe explizite Oberflächenarchive und implizite Tiefenarchive ein, um einige soziotechnische Dynamiken heutiger Transformationen zu einem digitalen Überwachungskapitalismus greifbar zu machen. Abschließend argumentiere ich für die Wichtigkeit eines umfassenden Medienkompetenzbegriffes, der auch einer kritischen Kontextualisierung digitaler Technologie in einem weiteren gesellschaftlichen und wirtschaftlichen Rahmen Rechnung zu tragen vermag.

Holger Pötzsch: Kapitalismus, Big Data und die neue Rolle der Archive: Anmerkungen zu kritischer Medienkompetenz in Zeiten digitaler Transformation. In: Nils S. Borchers, Selma Güney, Uwe Krüger und Kerem Schamberger (Hrsg.): Transformation der Medien - Medien der Transformation. Verhandlungen des Netzwerks Kritische Kommunikationswissenschaft. Frankfurt am Main: Westend 2021. DOI: https://doi.org/10.53291/JARS9423. 
Holger Pötzsch, PhD I Universität Troms $\varnothing$ - Norwegens Arktische Universität I holger.potzsch@uit.no

\section{Einführung}

In diesem Beitrag geht es um Implikationen neuer Technologien des Archivierens und Kuratierens digitaler Daten in kommerziellen Sozialen Medien. Das Problem, so meine Prämisse, ist so gut wie nie die Technik an sich, sondern ihr Gebrauch in gesellschaftlichem Rahmen. Wie Timo Daum $(2019,144)$ es in seinem Buch über Kapitalismus und künstliche Intelligenz ausdrückt: »Die kapitalistische Anwendung von Technologie ist das Problem: Das Verwertungsinteresse des Kapitals lässt jegliche moralischen und ethischen Ansprüche an Grenzen stoßen.« Was man mit Technologie zu erreichen hofft, ist daher oft weniger relevant als das, was bei faktischem Gebrauch derselben in situierten Kontexten herauskommt.

Vor diesem Hintergrund gehe ich im Folgenden der veränderten Rolle von Archiven in digitalen Zeiten nach. Wie unter anderem von Manoff (2004) dargelegt, wird das Konzept oft zur staatlichen Kontrolle über gesellschaftliche Erinnerung in Bezug gesetzt. Archive, so die Autorin, sind Orte, an denen als wichtig erachtete Dokumente gelagert und eingesehen werden können. Daher war ihre Kontrolle schon immer eine zentrale Frage in der Organisation und Begrenzung staatlicher Machtausübung (siehe auch Derrida 1995; Joyce 1999; Carter 2006). Aber die konkreten Lagerstätten für physische Dokumente haben sich im Zuge technologischer Entwicklungen mehr und mehr in dynamische Vernetzungen digitaler Datenbanken verwandelt (Ernst 2013; Hogan 2015). Die politischen und gesellschaftlichen Konsequenzen solcher Transformationsprozesse sind das Thema dieses Beitrages.

Ich lege das theoretisch fundierte Argument vor, dass digitale Archive, wie digitale Technologie im Allgemeinen, von einer Doppelbödigkeit gekennzeichnet sind, die zwischen den Polen von Freiheit und Kontrolle oszilliert (siehe beispielsweise Galloway 2004; Chun 2006). Digitale Technologie erlaubt es Menschen einerseits, einfach und schnell für andere sichtbar und erreichbar zu sein. Daher hilft sie sowohl bei oftmals notwendiger öffentlicher Selbstdarstellung als auch beim Koordinieren kollektiver Aktivitäten. Andererseits jedoch ermöglichen digitale Archive auch neue Formen von Überwachung und das Sammeln von Daten über sowohl Gruppen als auch Individuen in bisher 
ungeahnten Größenordnungen - mit dem Ziel vorgreifender staatlicher Kontrolle sowie der Kapitalisierung menschlicher Identitäten und Relationen (Gehl 2014; Harcourt 2015; Mau 2017; Pötzsch 2018).

Um diese inhärente Ambivalenz digitaler Netzwerke beschreibbar zu machen, unterscheide ich hier zwischen expliziten Oberflächenarchiven, die von Nutzer*innen kontrolliert und instrumentalisiert werden können (beispielsweise Profil- oder Gruppenseiten auf Facebook), und impliziten Tiefenarchiven, die, von selbigen weitgehend unbemerkt, kommerziellen und staatlichen Akteur*innen das Sammeln und Verwerten umfassender Datensets ermöglichen (beispielsweise die Profilierung von Nutzer*innen durch Google, Facebook, TikTok oder variierende Streamingdienste). Beide Technologien, so mein Argument, verquicken sowohl Unterdrückung und Ausbeutung als auch Mobilisierung und Widerstand miteinander. Sie stehen in einem dialektischen Verhältnis, das Widersprüche über Zeit in einer höheren Ordnung auflösen kann. Die derzeit dominierende kapitalistische Organisationsform privilegiert allerdings diejenigen gesellschaftlichen Kräfte, die Tiefenarchive zu erstellen und in staatliche sowie Kapitalmacht umzuwandeln verstehen. Daher verbleibt die politische Rolle der Oberflächenarchive zumeist eine nur potenziell befreiende (vgl. Galloway 2004; Morozov 2013; Gehl 2014; Pötzsch 2018; Daum 2019). Eine Transformation der Medien schafft nicht automatisch Medien der Transformation.

Abschließend stelle ich die Frage, wie mit diesem gesellschaftlichen Zustand umgegangen werden kann. Als konkreten Lösungsansatz fordere ich eine kritische digitale Kompetenz (critical digital literacy; Pangrazio 2016) als vorrangiges Bildungsziel ein, die nicht nur auf praktische Fertigkeiten im Gebrauch von digitalen Netzwerken und Oberflächenarchiven abzielt. Stattdessen versteht sie, diese Technologien im Kontext gesellschaftlicher Zustände und Machtverhältnisse kritisch zu bewerten und ermöglicht, falls notwendig, aktiven Widerstand oder Re-appropriation. Damit wird digitale Medienkompetenz mehr als nur ein quantifizierbarer Standard in der schulischen Produktion instrumentellen Humankapitals (Pötzsch 2019). Im Gegenteil sieht sie die Erziehung des kritisch-reflektierenden Subjektes auch ohne oder gegen Technologie als zentrales Element heutiger Bildungsanstrengungen (vgl. Simanowski 2018). 


\section{Technologie, Transformation und Gesellschaft: Eine Prämisse}

Die digitale Transformation Deutschlands und der Welt schreitet scheinbar unaufhaltsam voran. Wie ein von Microsoft gesponsertes IDC White Paper (Hopp et al. 2017, 2) es formuliert, findet »[d]ie digitale Transformation [...] derzeit in allen Branchen und Märkten stat «; sie wird so »immer mehr zur Quelle echter Innovation und neuer Geschäftsmodelle. Das Business der Zukunft ist ohne Frage digital«. Jetzt gelte es nur, die »Reifegradstufe « deutscher Unternehmen entsprechend zu erhöhen, um sie vom unbrauchbaren und altmodischen »digital resister in den experimentierfreudigen und risikobereiten »digital disruptor « umzumodeln (ebd., 4).

Die Bevölkerung steht solchen Änderungen offenbar positiv gegenüber, titelt doch eine von PricewaterhouseCoopers finanzierte Studie (pwc 2018) an prominenter Stelle: »44\% >I don't mind digitisation affecting every part of my life «.« Also alles in bester Ordnung? Um diese Frage zu beantworten, muss man herausarbeiten, wer genau sich in diesen Studien denn überhaupt so einig ist und für wen die neuen Geschäftsmodelle und Effektivitätsgewinne digitaler Disruptoren eigentlich von Vorteil sind.

Das Problem sowohl mit wirtschaftsfinanzierten Hochglanzbroschüren (Hopp et al. 2017; pwc 2018) als auch mit Fachbeiträgen betriebswirtschaftlicher oder technologischer Ausrichtung (beispielsweise Kilkki et al. 2018; Skog 2018) ist eine gewisse Selektivität des Ansatzes und der Datengrundlage. So stellt sich bei zweitem Hinsehen schnell heraus, dass etwa die Studie von PricewaterhouseCoopers (2018) nur die Meinung von 44\% der Befragten vermitteln kann. Diese Gruppe wiederum setzt sich aus Teilnehmer*innen einer Onlineumfrage zusammen - Menschen also, die bereits über die Mittel verfügen, an Studien dieser Art teilzunehmen. Alle Befragten kommen aus Deutschland oder den USA, 82 Prozent leben in urbanen Zentren, 59 Prozent sind zwischen 18 und 26 Jahren alt und über 82 Prozent haben mindestens einen Bachelorgrad - eine Gruppe also, die für ein Überleben unter der Bedingung einer umfassenden digitalen Disruption mehr als gut gerüstet erscheint. Ähnliches gilt für das IDC White Paper (Hopp et al. 2017). Gefragt wird nicht, wie eine Gesellschaft, die zu 100 Prozent der Wunschdemographie der digitalen Disruptor*innen angehört, eigentlich aussehen soll, ob und wie diese lebenswert erscheint und wer genau in ihr und von ihr profitieren kann. Stattdessen werden dieje- 
nigen, deren Arbeitsplätze und -bedingungen durch digitale Disruptionen am meisten bedroht sind - ungelernte Lohnarbeiter*innen und Menschen in prekären Arbeitsverhältnissen - als Teil von Belegschaften und Zielgruppen von Effektivitätssteigerungen im Namen globaler Konkurrenz nicht in ausreichendem Maße in die Studien und Modelle einbezogen.

Ähnliches gilt für eine Reihe von Fachbeiträgen. So enthalten die digitalen Transformations- und Disruptionsmodelle etwa von Kilkki et al. $(2018,277)$ und Skog et al. $(2018,435)$ keine Variablen für Lohnarbeiter*innen oder prekär Beschäftigte und rekurrieren ausschließlich auf finanzielle und technische Faktoren. Damit schreiben sich diese Studien reibungslos in eine lange Reihe apologetischer Beiträge zur Digitalisierung ein, die nur die Weltsicht einer privilegierten Minderheit als relevant ansehen und alles, was dieser entgegenspricht, mit Schweigen quittieren. Die Opfer einer «schöpferischen Zerstörung« im Sinne Schumpeters (1993) zählen in neoliberalen Kapitalismus eben nicht (vgl. Daum 2017, 31-32).

Man muss allerdings nicht viel Zeit mit der Suche nach Studien verbringen, welche die vielen Kehrseiten einer scheinbar unaufhaltsamen digitalen Transformation kritisch ausleuchten und hinterfragen. So stellt Cathy O'Neil (2016) überzeugend die vielfältigen Probleme und Ungerechtigkeiten heraus, die mit der raschen Verbreitung digitaler Technologien verbunden sind. Mit Blick vor allem auf die USA zeigt sie auf, wie Hochschulzulassungen (ebd., 50), Marketing (ebd., 68), das Justizwesen (ebd., 84), Arbeitsvermittlung und Arbeitsalltag (ebd., 105) bis hin zur Vermittlung von Versicherungen und Krediten (ebd., 141) immer mehr von undurchschaubaren Algorithmen gesteuert werden, deren Entscheidungen kaum noch nachvollziehbar und daher schlecht kontrollierbar sind (vgl. Pasquale 2016; Eubanks 2018).

Aus ähnlicher Sicht warnte Aneesh bereits 2009 vor einer »Algokratie«, in der Algorithmen über Arbeitsbedingungen und -organisation in globalen Wertschöpfungsketten entscheiden, während Gehl (2014), Harcourt (2015) und Pötzsch (2018) die oft negativen Folgen algorithmischer Identitätskonstruktion und -kommodifizierung in kommerziellen Sozialen Medien herausarbeiten. Andere hinterfragen Entwicklungen in Richtung einer digitalisierten »scoring society (Dencik et al. 2019; vgl. Pasquale 2016), die Lebenschancen und Möglichkeiten von Bürgern*innen in abstrahierte Datensets zerlegt, auf diese Weise digital prozessierbar und damit planbar macht (vgl. Mau 2018; Kitchin 2017; Eubanks 2018; Mejias und Couldry 2019). Wieder andere 
kritisieren Fehler und Ungerechtigkeiten in prädiktiver Polizeiarbeit (Kaufmann et al. 2019), digitaler Politikausformung und Meinungsbildung (Treré 2016), automatisierter Kinderfürsorge (Redden et al. 2020) oder eines digitalisierten Schulwesens (Williamson 2017; Golden 2017; Williamson und Hogan 2020). Auch negative Effekte der Digitalisierung für Arbeitsbedingungen und die Umwelt wurden bereits mehrfach ausgeleuchtet (Qiu 2016; Maxwell und Miller 2012; Notley 2019; Global E-Waste Monitor 2017; China Labor Watch 2018). All diesen Studien ist gemein, dass sie differenziertere Sichtweisen auf digitale Transformationen und Disruptionen einfordern, die sowohl Vorteilen als auch klar negativen Effekten technologischer Änderungen offen gegenüberstehen.

Die Digitalisierung ist ein ambivalentes Phänomen. Wie unter anderem Galloway (2004) und Chun (2006) schreiben, oszillieren digitale Technologien (wie andere Technologien auch) zwischen den Polen von Freiheit und Kontrolle. Welche politischen, sozialen, wirtschaftlichen, ökologischen und kulturellen Folgen technische Innovationsarbeit zeitigt, ist durch den spezifischen gesellschaftlichen Kontext bedingt, in dem sie erfolgt und in der ihre Errungenschaften zur Anwendung kommen. Unterschiedliche Interessen sind in Technologie eingeschrieben und bedingen ihre Anwendung und Effekte (Winner 1980). Daher die Warnung Morozovs (2013), digitale Technologie werde von kommerziellen Akteur*innen als notwendige (und oft kostspielige) Lösung für Probleme angepriesen, die bei näherem Hinsehen schlecht definiert oder völlig irreal erscheinen.

Dieser Beitrag folgt einem pragmatischen Verständnis von Technologieentwicklung, das eine Positionierung im wissenschaftlichen Feld als entweder Technologiedeterminist*in oder -konstruktivist*in vermeidet. Stattdessen folge ich einem Ansatz, der Technologie und Gesellschaft als eng miteinander verquickt und gegenseitig konstitutiv denkt (Orlikowski 2007; Hayles 2012; Daum 2019). Wie Dafoe (2015, 1050) es ausdrückt:

[T] he question should not be a dichotomous one of whether technological determinism is right or wrong, but a set of questions of degree, scope, and context: [...] to what extent, in what ways, and under which scope conditions are particular groups of people able to shape sociotechnical systems?

Die Erfassung von spezifischen »scope conditions« derzeitiger Digitalisierungstendenzen erscheint somit als ein wichtiger und produktiver Zweig kritischer wissenschaftlicher Arbeit. 


\section{Archive in Zeiten digitaler Transformation}

\subsection{Internet, Wirtschaft und Politik}

Die gegenwärtige kapitalistische Organisationsform der meisten Gesellschaften hat spezifische »scope conditions« geschaffen, die es einer engen Vernetzung von privatwirtschaftlichen und staatlichen Akteur*innen ermöglichen, globale Kommunikationsnetzwerke für ihre Zwecke auszubauen und auszunutzen. Zu Beginn war die Internetära eine staatliche Angelegenheit. Beim öffentlich finanzierten Ausbau des amerikanischen ARPANET ab Ende der 1950er Jahre flossen militärische Interessen, Profitdenken, wissenschaftlicher Forschungsdrang sowie gegenkulturelle Strömungen zusammen. Die neue Technologie wurde genutzt, um damals noch sehr große Mainframecomputer zu vernetzen und deren Ressourcen für Wissenschaftler*innen, die nicht vor Ort sein konnten, zugänglich zu machen. Gleichzeitig koordinierte das Netzwerk die Raketenabwehr des US-amerikanischen Militärs und ermöglichte es gegenkulturellen Bewegungen anonym mit neuen Identitäten und Lebensformen zu experimentieren (für eine detailreiche Studie zum Thema vgl. Abbate 1999).

Heute, 50 Jahre nach diesen Anfängen, hat sich das Internet weitgehend in eine techno-kapitalistische Dystopie verwandelt, in der alles und alle konstant überwacht, quantifiziert, analysiert und vermarktet werden (Andrejevic 2007; Zuboff 2019). Menschliche Beziehungen verarmen und kommen mehr und mehr denen programmierbarer Bots gleich (Gehl 2014; Harcourt 2015), während sowohl Militär, Sicherheitsapparate als auch Großkapital neue Potenziale für Machterweiterung, Einflussnahme und Profit identifizieren und für sich nutzbar machen. Solche Faktoren sind die dunkle Kehrseite der oft oberflächlich bejubelten digitalen Transformation aller Lebensbereiche.

Neuen Formen von Ausbeutung, Kommodifizierung, Überwachung und Kontrolle wurzeln allerdings nicht in der Technologie an sich, sondern sind den gesellschaftlichen und politischen Kontexten ihrer Entwicklung und Anwendung geschuldet (siehe Daum 2019). So ließen sich Konturen eines alternativen Computernetzwerkes, das für Menschen und nicht ausschließlich für Staat oder Profit arbeiten sollte, im Projekt Cybersyn der sozialistischen Regierung von Präsident Allende in Chile erkennen (Schmidt und Funk 2020). Wie viele andere progressive Errungenschaften wurden jedoch auch diese Ansätze unter 
den Stiefeln US-gestützter Generäle um Augusto Pinochet zermalmt (Medina 2006). Auch heute gibt es aber noch Nischen, in denen sich nichtkommerzielle und kooperativ organisierte Alternativen zu einem »corporate internet« entwickeln (Gehl und Synder-Julie 2016; Gehl 2020). Verglichen mit den Giganten des digitalen Kapitalismus haben diese jedoch nur geringen Einfluss und Durchschlagkraft (Fuchs 2017; Zuboff 2019).

\section{2 (Digitale) Archive}

Wie beeinflussen nun solche Entwicklungen die Rollen und Funktionsweisen von Archiven und Praktiken des Archivierens und Kuratierens in digitalen Zeiten?

Traditionell werden Archive in engem Zusammenhang mit staatlicher Organisation von Wissensmacht gesehen. Derrida (1995, 1-2), beispielsweise, geht etymologisch vor, wenn er Archiv auf den griechischen Terminus arkhe zurückführt und erläutert, dass dieser von Anfang an die Begriffe »Ursprung « und »Autorität« eng miteinander verknüpfte. Gleichzeitig, so Derrida, stellen der freie Zugang zu Archiven und öffentliche Kontrolle über dort aufbewahrte Dokumente und Artefakte wichtige Grundpfeiler demokratischer Gesellschaftsordnungen dar.

Archiv-Macht-Konstellationen wurden auch aus postkolonialer Sicht kritisch beleuchtet. Richards (1993) zum Beispiel zeigt auf, wie das britische Imperium in seinen Archiven Daten und Fakten zu eroberten und kolonialisierten Völkern sammelte, die wenig mit den faktischen Lebenswelten der Beschriebenen zu tun hatten. Da diesen jedoch der Zugang zu den Zentren der Wissensproduktion und -vermittlung weitgehend verwehrt blieb, begannen eine Reihe von Falschheiten und Missverständnissen - »the fantasy of the imperial archive « (Richards 1993, 6) - ein Eigenleben zu führen und sich über Generationen von Lehrenden und Lernenden weiter zu verbreiten. Said (1978) hat die bisher vielleicht umfassendste Studie zu den Praktiken und diskursiven Machverhältnissen von kolonialer Wissensproduktion vorgelegt.

Andere kritische Arbeiten haben auf Lücken und Auslassungen in gesammelten Materialen hingewiesen und ihre Auslegungen an Analysen solcher »blind spots « geknüpft (Carter 2006), das oftmalige Fehlen mündlicher Überlieferungen bemängelt (Haebich 2016) oder die Wichtigkeit einer Öffnung der Archive für Demokratisierungsprozesse 
hervorgehoben (Joyce 1999). Osborne (1999) wiederum richtet Aufmerksamkeit auf Praktiken des Archivierens, um so einem als zu statisch angesehenen Verständnis von Dokumentsammlungen entgegenzuwirken.

Die digitale Transformation hat heute auch die Archive erreicht. Neue Technologien schaffen entsprechende Möglichkeiten wie auch Probleme und ziehen neue Dynamiken nach sich. So freut sich etwa Cook $(2013,97)$ darüber, dass die digitale Ära Bürger*innen »new agency and a new voice« gäbe und es ihnen ermögliche vor allem über Soziale Medien "all kinds of new and potentially exciting and potentially archival traces of human life, of what it means to be human« zu sammeln und zu kuratieren. Er übersieht dabei jedoch, dass die neuen digitalen Archive kommerzieller Sozialer Medien den Nutzer*innen nur Zugang zu einem verschwindend kleinen Teil der weitgehend automatisch zusammengestellten Datensammlungen gewähren. Der Rest ist ihnen unzugänglich und wird seitens multinationaler Gesellschaften und staatlicher Agenturen in privatwirtschaftlichen Profit und politische Kontrollmacht umgemünzt (Gehl 2014; Harcourt 2015; Poitras 2014; Pötzsch 2018; Zuboff 2019).

So werden Nutzer*innendaten von kommerziellen Akteuren wie Facebook, Google oder TikTok gesammelt, zu Profilen verdichtet und dann an Werbekunden oder andere Interessenten, wie beispielsweise Versicherungen, weiterveräußert (Fuchs 2017). Staatliche Agenturen wiederum rekurrieren in wachsendem Ausmaß auf digitale Analyseinstrumente, um Gesellschaften effektiv verwalten zu können. Staatsbürger*innen werden zunehmend automatisch profiliert, um etwa Sozialhilfe zu allokieren oder geeignete Arbeitsstellen zu finden. Dies geschieht häufig ohne das Wissen und ohne Mitspracherecht der Betroffenen (O'Neill 2016). Das Resultat ist eine »black box society (Pasquale 2016), in der es Entscheidungsfindungen an Transparenz weitgehend fehlt und Beschlüsse oft nicht ausreichend nachvollzogen oder hinterfragt werden können (Eubanks 2018).

Digitale Archive helfen also, staatliche und privatwirtschaftliche Macht zu konsolidieren. Gleichzeitig schaffen sie jedoch auch neue Möglichkeiten, diese herauszufordern. Schon vor der Jahrtausendwende schrieb Lynch $(1999,75)$ : »The recent proliferation of electronic means for reproducing and disseminating documents and entire archives has begun to disrupt the tradional exclusiveness of scholarly access«. Was er schreibt, gilt allerdings nicht nur für den forschungsorientierten, sondern im höchsten Grad auch für den politisch motivierten 
Zugang, wie man hier mit Blick auf die von WikiLeaks und Edward Snowden veröffentlichten Dokumente hinzufügen könnte (Assange 2015; Harrison 2015; Poitras 2014).

Digitale Transformationen und Disruptionen haben ambivalente Folgen. Sie schaffen neue Branchen und Geschäftsmodelle und zerstören an anderer Stelle sowohl Arbeitsplätze als auch ganze Industrien. Sie ermöglichen ungeahnte Formen von Überwachung, Ausbeutung sowie Kontrolle und bieten gleichzeitig neue Werkzeuge für politische Mobilisierung und die Unterminierung staatlicher und privatwirtschaftlicher Geheimniskrämerei. Sie eröffnen neue Arenen für unterdrückte Stimmen und liefern gleichzeitig nie dagewesene Mittel für Propaganda und Gleichschaltung. Wie alle technologischen Änderungen vor ihr erscheint auch die digitale Transformation der Archive ambivalent und voller Widersprüche. Durch eine genauere Beschreibung der physischen und protokollarischen Infrastruktur digitaler Archive von kommerziellen Sozialen Medien werde ich im Folgenden jedoch aufzeigen, dass in diesem Bereich staatliche Kontrollmacht und privatwirtschaftliches Profitinteresse bei weitem überwiegen - ein Faktum, das eine Suche nach alternativen technischen Lösungen als eine Notwendigkeit erscheinen lässt. ${ }^{1}$

\section{Oberflächen- und Tiefenarchive kommerzieller Sozialer Medien: Ein Modell}

In seinem Buch Reverse-Engineering Social Media beschreibt Robert Gehl (2014, 41-70) Aufbau und Arbeitsweise kommerzieller Sozialer Medien analog zur Architektur moderner Computer. Ihm zufolge ist

1 Der Abschnitt zu digitalen Archiven scheint sich einer wesentlichen Auslassung schuldig gemacht zu haben. Die Arbeiten von Wolfgang Ernst (beispielsweise 2013) setzen sich in detaillierter Art und Weise mit neuen technischen Dynamiken digitaler Technologien auseinander und entwickeln dabei eine Reihe neuer Begriffe und Termini (ebd., 82-87). Leider fehlt in Ernsts Arbeiten zumeist eine Beschreibung der Kontexte, in denen diese Technologien genutzt werden. Dies macht eine Kritik ihrer politischen Ausrichtungen und Folgen schwierig. Jussi Parikka $(2013,13)$ schreibt hierzu in einem Vorwort zu seiner Übersetzung von Ernsts Arbeiten zum Thema: »It is striking how quickly Ernst moves away from even hinting at any sociohistorical contexts for such [digital] devices, emphasizing the objects in themselves - again a demonstration of his cool object focus, which by way of methodological choice saves itself, too, from discussing messy politics of technology.« 
diese Architektur durch ein Zusammenspiel von unterschiedlichen Ebenen gekennzeichnet, die Datenspeicherung (memory) und -verarbeitung (processor) physisch voneinander trennt. Auf Plattformen wie Facebook, TikTok oder Twitter, so Gehl, gleiche der Nutzer einem Prozessor, der konstant neuen Input bearbeitet, dem jedoch die Kontrolle über das maschinelle Speichergedächtnis entzogen ist. Garde-Hansen $(2011,71)$ beschreibt eine ähnliche Struktur, die ihr zufolge aus drei Komponenten besteht: »The Internet is distributing memories into personal, corporate and institutional archives.«In diesem Beitrag sehe ich Garde-Hansens staatliche und kommerzielle Archive als eng miteinander verbunden an, da staatliche Überwachungsinstanzen, wie etwa die amerikanische NSA oder das britische GCHQ, in ihren Analysebestrebungen weitestgehend auf kommerzielle Archive rekurrieren und diese für sich nutzbar machen.

Auf dieser Grundlage differenziere ich hier zwischen Oberflächenund Tiefenarchiven in kommerziellen Sozialen Medien (Abb. 1). Erstere stehen weitgehend unter Kontrolle der Nutzer*innen, die beispielsweise auf ihren Facebook-Profilen relativ frei posten, liken, teilen, schreiben und auch löschen können. Damit ermöglichen die Oberflächenarchive eine explizite Form der Teilnahme im Sinne Schäfers $(2011,105)$, die es Nutzer*innen erlaubt, diese Technologie bewusst zu nutzen, um Meinungen zu verbreiten und bestimmte Identitäten zur Schau zu stellen. Im Gegensatz hierzu sind die Tiefenarchive kommerzieller Sozialer Medien dem Einfluss der Nutzer*innen weitgehend entzogen. Hier sammeln kommerzielle Anbieter sowohl personenbezogene als auch Metadaten, bearbeiten und sortieren diese und verkaufen fertige Datensets und Profile an Werbebüros und Analysefirmen weiter. Durch eine designbedingte, implizite Form der Teilnahme (Schäfer 2011, 105) liefern Nutzer*innen die Daten, welche die Riesen des digitalen Kapitalismus als Rohstoff für erfolgreiche Kommodifizierung und Kapitalakkumulation benötigen, und geben mächtigen Staaten die Möglichkeit prädiktiver Maßnahmen und Eingriffe. Hogan (2015) zufolge erscheinen die digitalen Datenlager der heutigen Sozialen Medien daher weniger als gut sortierte und sorgfältig kuratierte Archive, sondern eher als »dumpsters«- Mülltonnen, in denen man zunächst alles sammelt und es dann anderen zur Bereinigung und Verwertung übereignet.

Beide hier angeführte Formen von Archiven kommerzieller Sozialer Medien haben ihre jeweils spezifischen technologisch-politischen Dynamiken. Wie bereits oben angeführt, machen Oberflächenarchive sowohl aktive Identitätsarbeit als auch politische Mobilisierung mög- 
Implizite Tiefenarchive

- Sammlung, Analyse und Kommodifizierung von User-Daten

$\underline{\text { Robert Gehl: }}$

- Potential für Ausbeutung, Kontrolle und Management

RAM -

- Staatliche und kommerzielle Akteure

- Konstitutive Effekte: «Predictive retention” (Pötzsch 2018)

- $\rightarrow$ open data und public relevance algorithms

Abb. 1: Dynamiken von Oberflächen- und Tiefenarchiven in kommerziellen Sozialen Medien.

lich (Van Dijck 2007; Rettberg 2014). Gleichzeitig sind sie jedoch auch durch ein Interaktionsdesign gekennzeichnet, das instrumentelle Kosten-Nutzen-Relationen zwischen Freunden und Kontakten privilegiert und einer durchgreifenden Quantifizierung und damit Kommodifizierung von Gefühlen und Identitäten Vorschub leistet. Als solches erscheinen kollektive Initiativen und Organisationsformen immer schon im Rahmen einer hegemonialen neoliberalen Gesellschaftsordnung vorpositioniert (Fenton und Barassi 2011; Thayne 2012; Barassi 2016).

Fenton und Barassi $(2011,191)$ drücken diesen Sachverhalt wie folgt aus: Kommerzielle Soziale Medien, so schreiben die Autorinnen, "prioritize individual agency over political and ideological context and resist problematizing the notion of autonomy therein. Autonomy in neo-liberal contexts may be guided principally by ego-centred needs and practices structured around the self that may implicitly endorse individualized and fragmented responses - a further push away from a collective public citizenry to isolated, atomized selfhood.«

Auch wenn kommerzielle Soziale Medien bei der Verbreitung kapitalismuskritischer Inhalte durchaus nützlich sein können, reproduziert die ihrem durchkommerzialisierten Interaktionsdesign immanente neoliberale Logik gleichzeitig politische Subjektivitäten und individuelle Praktiken, welche die eigentlich kritisierte Ordnung in fundamentaler Weise untermauern und weiter stärken (vgl. Pötzsch 2018, 3312-3315). 
Gleichzeitig generieren alle Aktivitäten auf dem Niveau der kommerziellen Oberflächenarchive enorme Datenmengen über Nutzer*innen, die in von Privatunternehmern kontrollierten Tiefenarchiven gesammelt, analysiert und dann weiterverkauft werden. Ein auf Facebook veröffentlichter kritischer Post zu negativen Implikationen des digitalen Kapitalismus wird dadurch weitgehend unbemerkt und automatisch Teil genau der Wertschöpfungsketten, die derselbe Post offen zu kritisieren und herauszufordern versucht. Die so bearbeiteten Daten bilden dann Grundlage für die Profilierung von sowohl individuellen Nutzer*innen als auch abstrahierter Gruppen (siehe insbesondere Fuchs 2017).

Die von kommerziellen und staatlichen Akteur*innen angesammelten Datenmengen machen also eine algorithmisch gesteuerte detaillierte Profilierung individueller wie auch gruppenbasierter Identitäten sowie Handlungsrahmen möglich und ordnen diese Kapitalinteressen und Sicherheitsbestrebungen unter. Wie Daum $(2017,21)$ es ausdrückt, »ein Kapitalismus entsteht, [...] dem es gelingt, die gesamte Gesellschaft mit ihren Gedanken und Tätigkeiten in den Dienst zu nehmen für die Generierung von digitalem Profit - die Silikolonisierung der Welt«.

In Daums Silikolonisierung der Welt - einer Kolonisierung auf Grundlage von siliziumbasierter Technologie - wird eine fundamentale Änderung der Funktionsweisen heutiger Archive deutlich. Während traditionelle Archivar*innen hauptsächlich daran interessiert waren, bestimmtes Wissen über die Vergangenheit zu bewahren und für zukünftige Generationen zugänglich zu machen, richten sich die Ambitionen der digitalen, auf Big Data basierenden Archive kommerzieller und staatlicher Akteur*innen auf die Zukunft. Das Ziel sind akkurate Vorhersagen von Handlungen und Verhältnissen - eine automatisierte Prädiktion, die nicht nur Berechnung des Wahrscheinlichen beinhaltet, sondern auch die Schaffung von Bedingungsgefügen für dessen aktive Aktualisierung miteinbezieht. In einem früheren Beitrag (Pötzsch 2018, 3317-3318) habe ich diese Dynamik als »predictive retention« beschrieben.

Algorithmische Berechnungen auf Grundlage von in Tiefenarchiven gespeicherten Daten zielen also nicht nur auf die akkurate Beschreibung dessen, was ist, sondern richten sich in wachsendem Ausmaß auch auf eine aktive Erschaffung noch kontingenter Zukunft. Algorithmisch generierte Anreize und Anstöße schaffen so die Grundlage für eine Vielzahl kleiner und anscheinend unbedeutender Handlungen, die das quantitativ Prophezeite in tagtäglicher Routine langsam Wirk- 
lichkeit werden lassen - Technologien der Prädiktion auf Grundlage von in Tiefenarchiven gesammelten Daten werden hier konstitutiv für das, was sie eigentlich nur vorzeichnen. Im angesprochenen Artikel (ebd., 3317) habe ich diese Verhältnisse wie folgt ausgedrückt:

What becomes apparent [...] is that the primary function of the archive as a repository governing access to the past has indeed changed. Accompanying this past-bound archive is a new one that is directed at contingent futures - an implicit iArchive with the ambition to algorithmically presage and, indeed, incite probable or merely possible actions and performances that ultimately shape the world in its image.

Damit droht sich Daums Silikolonisierung der heutigen Welt auch auf alle denkbaren zukünftigen Welten auszudehnen.

\section{$5 \quad$ Kritische Medienkompetenz für digitale Zeiten}

Dieser Beitrag zeigt, dass uns neue digitale Technologien wie beispielsweise kommerzielle Soziale Medien vor neue, große Herausforderungen stellen. Wie oben illustriert, haben ihre weitgehend automatisierten algorithmischen Profilierungs- und Rückkopplungsmechanismen einen konstitutiven Effekt. Sie beschreiben nicht nur faktische Identitäten und Absichten, sondern wirken auch implizit handlungsleitend. Damit bedingen sie die Realisierung kontingenter Persönlichkeits- und Handlungspotenziale, die sie eigentlich nur zu reflektieren behaupten. Dies geschieht unter ökonomischen sowie politischen Vorzeichen und dient damit sowohl privaten Profit- als auch staatlichen Kontrollinteressen. Die Macht kommerzieller und staatlicher Tiefenarchive ist produktiv und wird im Foucault'schen Sinne durch die Erschaffung und Reproduktion impliziter Bedingungsgefüge für tagtägliche Handlungen schrittweise und unmerklich realisiert. Solche Tendenzen erfordern politische und gesellschaftliche Antworten. Abschließend möchte ich daher kurz auf bildungspolitische Bestrebungen eingehen, die versuchen, die digitale Transformation in eine Richtung zu lenken, die sowohl Individuen als auch Gesellschaften dienlich sind.

Im Untertitel einer seiner Monographien schreibt Simanowski (2018) von einem Verschwinden der Computer aus Bildung und Gesellschaft. Wovor er hier warnt, ist jedoch nicht die Gefahr, technisch hinter globale Standards zurückzufallen oder den Anschluss an neueste Entwicklungen zu verpassen. Vielmehr beklagt er die Folgen einer zuneh- 
menden »Transparenz des Computers«, dessen Allgegenwärtigkeit ihn unsichtbar macht und im »Gewebe des Alltags « verschwinden lässt (21-22). Simanowski zufolge leistet dieses allgegenwärtige Verschwinden digitaler Technologien einer impliziten Akzeptanz ihrer medienspezifischen Logiken Vorschub und macht politisch und ökonomisch motivierte Kritik an ihrer Einführung und Verbreitung zunehmend schwierig.

Wie unter anderem Buckingham (2007) vor ihm, fordert Simanowski (2018) als Antwort mehr Fokus auf Technologie in der schulischen Grundausbildung. Hierbei gehe es allerdings nicht vorwiegend darum, Lehre und Lernen durch Technologie zu ändern und möglicherweise zu verbessern, sondern den Lernenden Wissen über Technologie zu vermitteln, welches sie ermächtigt, dieser selbstbewusst und kritisch entgegenzutreten. Nur so kann Bildung ihrem Ideal einer Erziehung zu (selbst-)kritischen, reflektierten und reifen Staatsbürger*innen unter den Bedingungen eines digitalen Kapitalismus gerecht werden.

Was heutige Gesellschaften brauchen, ist kritische digitale Medienkompetenz, die praktische Nutzer*innenfertigkeiten mit Erkenntnissen über die sozio-politisch-ökonomischen Rahmenbedingungen und Implikationen digitaler Technologie zusammenführt (Pangrazio 2016; Gray, Gerlitz und Bounegru 2018; Pötzsch 2019). Solche Medienkompetenz sieht ein dialektisches Verhältnis zwischen technisch bedingten Herrschaftsstrukturen und -systemen auf der einen und neuen Möglichkeiten für Mobilisierung, Zusammenarbeit und Autonomie auf der anderen Seite und fördert aktiv bewusste Praktiken, die eine Transformation der Medien für progressive politische Projekte nutzbar machen.

Technologie wird hierbei zu mehr als einem scheinbar neutralen Werkzeug für verbesserte Resultate in einem durchquantifizierten Schulbetrieb. Es tritt klar hervor, dass Politik scheinbar selbstlaufenden technischen Entwicklungen aktiv gegenübertreten kann und muss. Technologie ist ein Werkzeug, dessen Nutzung es (auch in der Schule) praktisch zu erlernen gilt. Gleichzeitig darf Bildung jedoch hier nicht haltmachen. Im Gegenteil muss sie darauf abzielen, vor allem jungen Menschen die Machtmittel an die Hand zu geben, die diese brauchen, um technische Lösungen kritisch einschätzen, approbieren und gegebenenfalls auch abweisen zu können. Denn: Politik, nicht Ökonomie oder Technologie, sollte die Rahmen menschlichen Zusammenlebens in demokratischen Gesellschaftsformen bestimmen. Schulische Vermittlung kritischer digitaler Medienkompetenz kann einer solchen Demokrati- 
sierung von Technologieentwicklung und -nutzung einen notwendigen Vorschub leisten.

\section{Literatur}

Abbate, Janet. 1999. Inventing the Internet. Cambridge: MIT Press.

Andrejevic, Mark. 2007. iSpy: Surveillance and Power in the Interactive Era. Lawrence: University Press of Kansas.

Aneesh, Aneesh. 2009. Global Labor: Algocratic Modes of Organization. Sociological Theory 27 (4): 347-370.

Assange, Julian. 2015. Introduction: WikiLeaks and Empire. In: The Wikileaks Files: The World According to US Empire, herausgegeben von Julian Assange, 1-19. London: Verso.

Barassi, Veronica. 2016. Datafied Citizens? Social Media Activism, Digital Traces and the Question about Political Profiling. Communication and the Public 1 (4): 494-499.

Buckingham, David. 2007. Beyond Technology: Children's Learning in the Age of Digital Culture. Cambridge: Polity Press.

Carter, RGS. 2006. Of Things Said and Unsaid: Power, Archival Silences, and Power in Silence. Archivaria 61: 215-233.

China Labor Watch. 2018. Amazon Profits from Secretly Oppressing its Suppliers' Workers: An Investigative Report on Hengyang Foxconn. http://www.chinalaborwatch.org/report/132. Zugegriffen: 25. Februar 2021.

Chun, Wendy HK. 2006. Control and Freedom: Power and Paranoia in the Age of Fibre Optics. Cambridge: MIT Press.

Cook, Terry. 2013. Evidence, Memory, Identity, and Community: Four Shifting Archival Paradigms. Archival Science 13 (2): 95-120.

Dafoe, Allen. 2015. On Technological Determinism: A Typology, Scope, Conditions, and a Mechanism. Science, Technology \& Human Values 40 (6): 1047-1076.

Daum, Timo. 2017. Das Kapital sind wir: Zur Kritik der digitalen Ökonomie. Hamburg: Edition Nautilus.

Daum, Timo. 2019. Die künstliche Intelligenz des Kapitals. Hamburg: Edition Nautilus.

Dencik, Lina, Joanna Redden, Arne Hintz und Harry Warne. 2019. The sGolden View : Data-Driven Governance in the Scoring Society. Internet Policy Review 8 (2). DOI: 10.14763/2019.2.1413.

Derrida, Jacques. 1995. Archive Fever: A Freudian Impression. Chicago: University of Chicago Press.

Ernst, Wolfgang. 2013. Digital Memory and the Archive. Minneapolis: University of Minnesota Press.

Eubanks, Virginia. 2018. Automating Inequality: How High-Tech Tools Profile, Polics, and Punish the Poor. New York: St. Martin's Press.

Fenton, Natalie, und Veronica Barassi. 2011. Alternative Media and Social Networ- 
king Sites: The Politics of Individuation and Political Participation. The Communication Review 14: 179-196.

Fuchs, Christian. 2017. Social Media: A Critical Introduction. London: Routledge.

Galloway, Alexander. 2004 Protocol: How Control Exists After Decentralization. Cambridge: MIT Press.

Garde-Hansen, Joanne. 2011. Media and Memory. Edinburgh: Edinburgh UP.

Gehl, Robert W. 2014. Reverse Engineering Social Media: Software, Culture, and Political Economy in New Media Capitalism. Philadelphia: Temple University Press.

Gehl, Robert W. 2020. Weaving the Dark Web: Legitimacy on Freenet, Tor, and I2P. Cambridge: MIT Press.

Gehl, Robert W., und Julie Synder-Yuly. 2016. The Need for Social Media Alternatives. Democratic Communiqué 27: 78-82.

Global E-Waste Monitor. 2017. http://ewastemonitor.info/. Zugegriffen: 25. Februar 2021.

Golden, Noah A. 2017. Critical Digital Literacies across Scales and beneath the Screen. Educational Media International 54 (4): 373-387.

Gray, Jonathan, Carolin Gerlitz und Liliana Bounegru. 2018. Data Infrastructure Literacy. Big Data \& Society: 1-13. DOI: 10.1177/2053951718786316.

Haebich, Andrea. 2016. Fever in the Archive. Thesis Eleven 135 (1): 82-98.

Harcourt, Bernard E. 2015. Exposed: Desire and Disobedience in the Digital Age. Cambridge: Harvard University Press.

Harrison, Sarah. 2015. Indexing the Empire. In: The Wikileaks Files: The World According to US Empire, herausgegeben von Julian Assange, 145-158. London: Verso Books.

Hayles, N. Katherine. 2012. How We Think: Digital Media and Contemporary Technogenesis. Chicago: The University of Chicago Press.

Hogan, Mél. 2015. The Archive as Dumpster. Pivot 4 (1): 6-38.

Hopp, Laura, Lynn-Kristin Thorenz und Matthias Zacher. 2017. Unternehmen zwischen Tradition und Wandel: Die digitale Transformation in Deutschland. IDC White Paper. https://news.microsoft.com/uploads/2017/04/IDC_White_Paper-DX__in_Deutschland_2017.pdf. Zugegriffen: 25. Februar 2021.

Joyce, Patrick. 1999. The Politics of the Liberal Archive. History of the Human Sciences 12 (2): 35-49.

Kaufmann, Mareile, Simon Egbert und Matthias Leese. 2019. Predictive Policing and the Politics of Patterns. British Journal of Criminology 59 (3): 674-692.

Kilkki, Kalevi, Martti Mäntylä, Kimmo Karhu, Heikki Hämmäinen und Heiki Ailisto. 2018. A Disruption Framework. Technological Forecasting \& Social Change 129: 275-284.

Kitchin, Rob. 2017. Thinking Critically about and Researching Algorithms. Information, Communication \& Society 20 (1): 14-29.

Lynch, Michael. 1999. Archives Information: Privileged Spaces, Popular Archives and Paper Trails. History of the Human Sciences 12 (2): 65-87.

Mau, Steffen. 2017. Das metrische Wir: Über die Quantifizierung des Sozialen. Frankfurt am Main: Suhrkamp. 
Manoff, Marlene. 2004. Theories of the Archive Across the Disciplines. Portal: Libraries and the Academy 4 (1): 9-25.

Maxwell, Richard, und Toby Miller. 2012. Greening the Media. Oxford: Oxford University Press.

Medina, Eden. 2006. Designing Freedom, Regulating a Nation: Socialist Cybernetics in Allende's Chile. Journal of Latin American Studies 38 (3): 571-606.

Mejias, Ulises A., und Nick Couldry. 2019. Datafication. Internet Policy Review 8 (4). DOI: $10.14763 / 2019.4 .1428$.

Morozov, Evgeny. 2013. To Save Everything, Click Here: Technology, Solutionism, and the Urge to Fix Problems that Don't Exist. London: Allen Lane.

Notley, Tanya. 2019. The Environmental Costs of the Global Digital Economy in Asia and the Urgent Need for Better Policy. Media International Australia 173 (1): 125-141.

O'Neil, Cathy. 2016. Weapons of Math Destruction: How Big Data Increases Inequality and Threatens Democracy. London: Allen Lane.

Orlikowski, Wanda J. 2007. Sociomaterial Practices: Exploring Technology at Work. Organization Studies 28 (9): 1435-1448.

Osborne, Thomas. 1999. The Ordinariness of the Archive. History of the Human Sciences 12 (2): 51-64.

Pangrazio, Luciana. 2016. Reconceptualising Critical Digital Literacy. Discourse: Studies in the Cultural Politics of Education 37 (2): 163-174.

Parikka, Jussi. 2013. Archival Media Theory: An Introduction to Wolfgang Ernst's Media Archaeology. In: Digital Memory and the Archive, herausgegeben von Jussi Parikka, 1-22. Minneapolis: University of Minnesota Press.

Pasquale, Frank. 2016. The Black Box Society: The Secret Algorithms that Control Money and Information. Cambridge: Harvard University Press.

Poitras, Laura. 2014. Citzenfour. Berlin: Praxis Film.

Pötzsch, Holger. 2018. Archives and Identity in the Context of Social Media and Algorithmic Analytics: Towards an Understanding of iArchive and Predictive Retention. New Media \& Society 20 (9): 3304-3322.

Pötzsch, Holger. 2019. Critical Digital Literacy: Technology in Education Beyond Issues of User Competence and Labour-Market Qualifications. TripleC: Communication, Capitalism \& Critique 17 (2): 221-240.

PWC. 2018. Digitisation: A Quantitative and Qualitative Market Research Elicitation. International School of Management. https://www.pwc.de/de/digitale-transformation/pwc-studie-digitalisierung-in-deutschland.pdf. Zugegriffen: 25. Februar 2021.

Qiu, Jack L. 2016. Goodbye iSlave: A Manifesto for Digital Abolition. Urbana: University of Illinois Press.

Redden, Joanna, Lina Dencik und Harry Warne. 2020. Datafied Child Welfare Services: Unpacking Politics, Economics and Power. Policy Studies. DOI: 10.1080/01442872.2020.1724928.

Richards, Thomas. 1993 The Imperial Archive: Knowledge and Fantasy of Empire. London: Verso Books.

Said, Edward W. 1978. Orientalism. London: Routledge. 
Schäfer, Mirko Tobias. 2011. Bastard Culture! How User Participation Transforms Cultural Production. Amsterdam: Amsterdam University Press.

Schmidt, Jakob, und Jannis Funk. 2020. Projekt Cybersyn: Chiles kybernetischer Traum von Gerechtigkeit. Podcast. DLF/WDR. https://www1.wdr.de/radio/ wdr3/programm/sendungen/wdr3-kulturfeature/projekt-cybersyn-chiles-kyber netischer-traum-von-gerechtigkeit-teil-2-100.html. Zugegriffen: 25. Februar 2021.

Schumpeter, Joseph. 1993. Kapitalismus, Sozialismus und Demokratie. Stuttgart: UTB.

Simanowski, Roberto. 2018. Stumme Medien: Vom Verschwinden der Computer in Bildung und Gesellschaft. Berlin: Matthes \& Seitz.

Skog, Daniel A., Henrik Wimelius, und Johan Sandberg. 2018. Digital Disruption. Business \& Information Systems Engineering 60: 431-437.

Thayne, Martyn. 2012. Friends Like Mine: The Production of Socialised Subjectivity in the Attention Economy. Culture Machine 13: 1-23.

Treré, Emiliano. 2016. The Dark Side of Digital Politics: Understanding the Algorithmic Manufacturing of Consent and the Hindering of Online Dissidence. IDS Bulletin: Transforming Development Knowledge 47 (1): 127-138.

Van Dijck, José. 2007. Mediated Memories in the Digital Age. Stanford: Stanford University Press.

Walker Rettberg, Jill. 2014. Seeing Ourselves through Technology. Basingstoke: Palgrave Macmillan.

Williamson, Ben. 2017. Big Data in Education: The Digital Future of Learning, Policy, and Practice. London: Sage.

Williamson, Ben, und Anna Hogan. 2020. Ed-Tech: Commercialization and Privatization in/of Education in the Context of Covid-19. Education International Research. https://issuu.com/educationinternational/docs/2020_eiresearch_gr_ commercialisation_privatisation? $\mathrm{fr}=\mathrm{sZDJkYjE1ODA2MTQ}$.

Winner, Langdon. 1980. Do Artifacts Have Politics? Daedalus 109 (1): 121-136.

Zuboff, Shoshana. 2019. The Age of Surveillance Capitalism. London: Profile.

\section{Open Access}

Dieser Beitrag erscheint unter der Creative-Commons-Lizenz CC BY-ND 3.0 DE: https://creativecommons.org/licenses/by-nd/3.0/de/. 


\title{
Wikipedia und die Transformation der Wissensaushandlung
}

\author{
Johannes Gemkow
}

Keywords: Wissen, Medienkompetenz, Wikipedia, Macht

\section{Abstract}

Die Wikipedia gilt als Paradespiel für kollektive Wissensherstellung. Die Generierung und Prozessierung von Wissen basiert dort auf verschiedenen Handlungsmöglichkeiten und -bedingungen. Im Zusammenspiel mit letzteren treten verschiedene Akteur*innen auf, die durch unterschiedliche Strukturen legitimiert, Einfluss auf das von der Wikipedia repräsentierte Wissen nehmen. Zwischen den Akteur*innen und Strukturen, welche die Handlungen gestalten, entsteht ein Kräfteverhältnis. Dieses kann im Anschluss an Foucault als produktive Macht verstanden werden. Der Beitrag zielt auf die Skizzierung selbiger auf der Wikipedia ab und stellt ihr das medienpädagogische Konzept der Medienkompetenz gegenüber.

Johannes Gemkow: Wikipedia und die Transformation der WissensaushandIung. In: Nils S. Borchers, Selma Güney, Uwe Krüger und Kerem Schamberger (Hrsg.): Transformation der Medien - Medien der Transformation. Verhandlungen des Netzwerks Kritische Kommunikationswissenschaft. Frankfurt am Main: Westend 2021. DOI: https://doi.org/10.53291/TLAJ4696.

Dr. Johannes Gemkow I Universität Leipzig I johannes.gemkow@uni-leipzig.de 


\section{Einführung}

Dieser Beitrag zielt auf die Skizzierung der produktiven Macht auf der Wikipedia ab. Dabei wird er nicht auf einer soziologischen Deskription ebenjener Macht verweilen, sondern mit dem Konzept der Medienkompetenz ein pädagogisches Korrektiv diskutieren. Dafür ist die produktive Macht von doppelter Bedeutung: Erstens werden über sie Möglichkeiten der Partizipation ausgehandelt, und zweitens hat das von Wikipedia repräsentierte Wissen einen erheblichen Stellenwert für die Praxis des informellen Lernens. Das klassische Konzept der Medienkompetenz kann diese beiden Aspekte inhaltlich vereinen, müsste sich dafür aber von seinem - im Folgenden noch skizzierten - idealistischen (vgl. Gapski 2001) und subjektspezifischen (vgl. Baacke 1998) Impetus lösen, um hin zu einer gegenständlichen Verflechtung von Akteur*innen, Strukturen und Plattform zu gelangen.

Der Beitrag wird über den in Abschnitt 3 skizzierten Machtbegriff hinausgehend bei der Unterscheidung von Handlungsmöglichkeiten und -bedingungen auf das sozialwissenschaftliche Dispositivverständnis zurückgreifen (vgl. Bührmann und Schneider 2012; Gemkow 2017). Für das Konzept der Medienkompetenz schließt er an die in der Medienpädagogik aktuelle Debatte um eine Neuakzentuierung des Konzeptes an (vgl. Zorn 2011; Schiefner-Rohs 2012; Walden 2017; Bettinger und Aßmann 2017).

Durch seine Beschreibung, wie in der Wikipedia Wissen hervorgebracht wird, leistet der Artikel einen Beitrag zur Transformation der Wissensaushandlung. Diese bezieht sich dabei auf die historisch und soziotechnisch spezifische Konstellation, mit der sich über die Plattform eine Generierungs- und Strukturierungsweise von Wissen etabliert hat.

\section{Die Wikipedia}

Die Online-Enzyklopädie Wikipedia enthält sprachübergreifend mehr als 36 Millionen Artikel, wobei die englische Version mit knapp über 5 Millionen am umfangreichsten ist. Auf der deutschen Wikipedia gibt es zum Vergleich etwa die Hälfte. Demgegenüber stellt die aktuelle Auflage des Brockhaus - sowohl Online als auch Print - rund 300000 Artikel bereit (vgl. Wikipedia 2020a). Im Januar 2020 wurde die deutsche Version täglich ungefähr 36 Millionen Mal aufgerufen. Die englische Wikipedia kam im selben Zeitraum auf etwa 265 Millionen Aufrufe und 
alle Sprachversionen zusammengenommen auf rund 537 Millionen (vgl. Wikipedia 2020d). Damit stellt sie allein mithin das größte Angebot an Wissensrepräsentationen im World Wide Web dar.

Ebenfalls bietet die Wikipedia eine niedrige Zugangsschwelle. Sofern die Nutzer*innen über Computer, Internetverbindung und Browser verfügen, muss keine zusätzliche Software angeschafft geschweige denn bezahlt werden. Wikis sind zudem in der Regel ohne tiefgreifende technische Kenntnisse nutzbar (vgl. Arnold et al. 2018, 228).

Die zugrundeliegende Software ermöglicht, dass alle Themenbereiche unter einem gemeinsamen technischen Konzept stehen, welches bestimmte Handlungen ermöglicht und andere ausschließt. Einzelne Weblogs, E-Learning-Systeme oder Open Educational Resources müssen beispielsweise nicht zwangsläufig demselben technischen Konzept unterliegen. Die Wiki-Software verfügt dahingehend über einen relativ homogenen Pool an Generierungs- und Strukturierungsweisen von Wissen. Als bekannteste Vertreterin bietet die Wikipedia selbst ebenfalls keine thematische Spezifizierung. Ihre Funktionsweise erlaubt das Verarbeiten, also Prozessieren von Wissensrepräsentationen, durch ein kollaborativ arbeitendes Kollektiv (vgl. Cunningham 2002).

Durch die nutzergesteuerte Bearbeitung und Veröffentlichung verwirklicht die Wiki-Software Aspekte wie kontinuierlichen Prozess, Heterarchie, Dezentralisierung oder Interaktion, die häufig mit der Digitalisierung verbunden werden (vgl. Pscheida 2010, 443). Das Konzept der Wikis, und die Wikipedia als deren Hauptvertreterin, ist damit ein Paradebeispiel für den Gegenstand des digitalisierten Wissens. Ähnlich wie das Manuskript während der Literalisierung oder das Buch während der Typographisierung von Wissen wurde mit ihnen eine Technik geschaffen, welche die historisch spezifische Generierung und Strukturierung von Wissen repräsentiert.

Die Wikipedia gilt folglich auch als Paradespiel für kollektive Wissensherstellung. Einerseits kommt ihr eine euphorische Zuschreibung als Verwirklichung des Traumes eines kollektiven menschlichen Gedächtnisses zu, andererseits werden aber auch negative Perspektiven wie der Verlust individueller Gedächtnisleistungen und fehlende Qualitätssicherung mit der Wikipedia verknüpft. 


\section{$3 \quad$ Die produktive Macht (auf) der Wikipedia}

Das Konzept der produktiven Macht zeichnet sich durch unterschiedliche Aspekte aus. Der erste ist, dass sie niemandem gehört: »[Ü]berall, wo es Macht gibt, wird Macht ausgeübt. Niemand ist im Grunde Inhaber der Macht; und dennoch wird sie stets in eine bestimmte Richtung ausgeübt.« (Foucault 2002, 389-390) In diesem Sinne funktioniert sie »über eine netzförmige Organisation« (Foucault 1978, 82). Dieses Verständnis von Macht ist auch auf die Wissensgenerierung und -strukturierung der Wikipedia anwendbar, da auf keine zentrale, autoritäre Institution verwiesen werden kann. Vielmehr lässt sich ein Zusammenspiel verschiedener Akteur*innen und Wahrheitsansprüche beobachten.

Der zweite wichtige Aspekt der produktiven Macht ist in ihrer Wirkung zu sehen. Weit mehr als ein Netz von Kräfteverhältnissen ist »die Macht produktiv; und sie produziert Wirkliches. Sie produziert Gegenstandsbereiche und Wahrheitsrituale: das Individuum und seine Erkenntnis sind Ergebnisse dieser Produktion« (Foucault 1994, 250). Die produktive Macht konstituiert also selbst das Feld, in dem sie agiert, und etabliert verschiedene Handlungspraktiken. In diesem Sinne stützt sie sich auf »dauerhafte Strukturen« und besteht aus einem »Ensemble von Handlungen « (Foucault 2005, 256). Macht ist also nicht unterwerfend, sondern positioniert Handlungen, Akteur*innen und deren jeweiligen Gegenstandsbereich.

Im Falle der Wikipedia bildet dieser Gegenstandbereich die digitalen Wissensrepräsentationen. Diese sind damit das Objekt der Analyse, jedoch nicht das Wissen im Foucault'schen Sinn selbst, welches er als »einen Prozess, der das Subjekt einer Veränderung unterwirft« (Foucault 1996, 52) definiert. Dieses Verständnis ermöglicht es, Wissen entweder als subjektiven Lernprozess zu deuten (auch im Sinne von Widerstand gegenüber der Macht) oder als Subjektivierung - also eine etablierte Vorstellung der Art und Klassifikation von Subjekten. Die digitalen Wissensrepräsentationen hingegen sind nicht mit diesem Wissensverständnis gleichzusetzen, sondern bilden den austauschbaren Objektbereich, der durch die produktive Macht der Wikipedia hervorgebracht wird.

Hier stellt sich die Frage, wie diese produktive Macht zu analysieren ist. Der Ausgangspunkt setzt mit Foucault nicht beim Objekt (hier: digitale Wissensrepräsentationen) an, sondern bei den Umständen, die dieses Objekt konstituieren (hier: Handlungsmöglichkeiten und -bedingungen auf der Wikipedia). Indem Macht unausweichlich mit 
individuellen Handlungen und übergeordneten Handlungsstrukturen verbunden ist, stellt sich hier die Frage, welche Handlungen bei der Generierung und Strukturierung von Wissensrepräsentationen auf der Wikipedia möglich sind und welchen Bedingungen diese unterliegen.

Bei der konkreten Analyse von Macht im Sinne Foucaults wird im Forschungsfeld wiederholt auf dessen Dispositivkonzept rekurriert. Er selbst hat dieses nur vage als »heterogene Gesamtheit, bestehend aus Diskursen, Institutionen, architektonischen Einrichtungen, reglementierenden Entscheidungen, Gesetzen, administrativen Maßnahmen, wissenschaftlichen Aussagen, philosophischen, moralischen und philanthropischen Lehrsätzen, kurz, Gesagtes ebenso wie Ungesagtes« (Foucault 2003, 392) definiert. In diesem Dispositivbegriff kommt das Netzwerk der Macht zum Ausdruck. Ebenso unterstellt Foucault ihm eine »dominant strategische Funktion« (ebd., 393). Deutlich wird dies an seinen Arbeiten zum Gefängnis- oder Sexualdispositiv. In beiden Fällen werden verschiedene Elemente wie Gefängnisstreik oder eine Transformation des Geschlechts als mögliche Handlungen in Abhängigkeit ihrer Bedingungen wie Richtlinien, Gesetzen oder architektonischen Einrichtungen gesetzt. Diese Verbindung bringt Gegenstände, materialisiert beim Gefängnis oder als Raum des Denkbaren gegenüber dem Geschlecht, erst hervor. Dispositive werden somit zum Analyseinstrument der produktiven Macht. Dieser Umstand hat sich bereits im sozialwissenschaftlichen Methodenarsenal niedergeschlagen (vgl. Jäger 2011; Bührmann und Schneider 2012) und findet sich selbst, wenn auch nur vereinzelt, in medienpädagogischen Diskussionen wieder (vgl. Bettinger und Dander 2016; Dander 2017).

Für die Transformation von Wissensaushandlung unter den Bedingungen der Digitalisierung ist anzumerken, dass sich etablierte Theorien und Konzepte zur Digitalisierung häufig auf gesellschaftliche Veränderungen beziehen. Zwar nehmen sie ihren Ausgangspunkt von digitalen Technologien wie Computer, Smartphone, Internet oder World Wide Web, verharren dabei jedoch nicht auf der technischen Perspektive. Inwieweit Technik unidirektional auf die Gesellschaft wirkt, bleibt in der vorliegenden Literatur oftmals implizit, wobei eine solche Tendenz unter anderem bei den Theorien zum Ende der GutenbergGalaxis (Bolz 1993), zum Postmodernen Wissen (Lyotard 2005 [1979]) oder zum Wikipedia-Universum (Pscheida 2010) auszumachen ist. Aus der Perspektive der produktiven Macht gilt es, eine solche Monokausalität zu vermeiden. 
Hierfür bietet sich das Dispositivkonzept an, welches sich über seinen Netzwerkcharakter von räumlich-technischen beziehungsweise technikzentrierten Konzepten unterscheidet. Digitalisiertes Wissen ist nicht ausschließlich über die räumlich-technische Anordnung von Produktion oder Rezeption erklärbar. Insbesondere vermögen Handlungsmöglichkeiten (im Kontext der Terminologie von Dispositivkonzepten auch: nicht-diskursive Praktiken), Handlungsbedingungen (auch: Objektivationen) und Handlungszuschreibungen (auch: diskursive Praktiken) zur Beschreibung der Wissensgenerierung und -strukturierung beitragen. Dabei kann die Anordnung von Websites und deren technische Bedingtheit durchaus von Bedeutung sein, jedoch nicht ausschließlich auf diese zurückgeführt werden.

Im Folgenden wird die produktive Macht der Wikipedia anhand von Handlungsmöglichkeiten und -bedingungen skizziert. Diese Machtanalytik umgeht somit die diskursiven Praktiken, also das »Gesagte«. Mit letzteren lassen sich unter anderem Zusammenhänge zwischen sprachlichem Handeln und gesellschaftlichen und institutionellen Strukturen herausarbeiten. Eine Analyse dieser Praktiken zielt dementsprechend auf kommunikativ hergestellte Sinnstrukturen. Diese Möglichkeit wird im Beitrag ausgespart, da der Fokus auf den medienspezifischen Kontextfaktoren in Form der Handlungsmöglichkeiten und -bedingungen der Wikipedia liegt.

Die folgende Beschreibung der produktiven Macht der Wikipedia beruht auf einer Dispositivanalyse (nach Bührmann und Schneider 2012) des Autors, welche im Frühjahr 2019 im Rahmen einer Dissertationsschrift durchgeführt wurde. ${ }^{1}$

Im Fall der Wikipedia entfaltet sich die produktive Macht in drei verschiedenen Typen der Wissensgenerierung, -prozessierung und -regulierung: 1) kollaborativ-meritokratisch, 2) expertokratisch-professionalisiert und 3) oligarchisch-technokratisch. Diese Typen vereinen dabei unterschiedliche Handlungsmöglichkeiten und -bedingungen. Sie ergänzen sich gegenseitig zu einem typisierenden Bild der Wissensgenerierung und -strukturierung der Wikipedia.

1 Eine überarbeitete Version der Dissertationsschrift erschien im Januar 2021 (Gemkow 2021). Die Dispositivanalyse teilt sich in die Analyse von diskursiven und nicht-diskursiven Praktiken sowie Objektivationen. Die diskursiven Praktiken wurden inhaltsanalytisch erhoben und ausgewertet. Bei den nicht-diskursiven Praktiken und den Objektivationen erfolgte eine Plattformanalyse auf der Wikipedia. 


\subsection{Kollaborativ-meritokratische Wissensformierung}

Der erste Typ, die kollaborativ-meritokratische Wissensformierung, zeichnet sich durch ein Zusammenspiel der beiden namensgebenden Elemente aus. Kollaborative Handlungsmöglichkeiten treten bei den verschiedenen Diskussions- und Regulierungsmechanismen hervor. Dabei wird deutlich, dass das Konzept in unterschiedliche Facetten zerfällt. Ihrer ursprünglichen Form nach bedeutet Kollaboration auf der Wikipedia, dass alle Nutzer*innen parallel und fortlaufend prinzipiell jeden Teil des potenziellen Endergebnisses (beispielsweise ein Artikel, ein Portal oder eine Kandidatur für einen bestimmten Nutzer*innenstatus) mitgestalten können. Tatsächlich handelt es sich dabei aber nur um einen Teilaspekt. In der Wikipedia werden Möglichkeiten zu dieser ursprünglichen Kollaboration durch hierarchische Elemente eingeschränkt. Benutzungsrechte regeln, wer zu bestimmten Arten der Mitgestaltung befugt ist und wer nicht. Hierdurch entsteht jedoch nichts anderes als eine Kollaboration auf höherer Ebene, für die es, je nach Zweck (etwa personelle Kandidatur, Gestaltung der Startseite oder Vandalismusbekämpfung) unterschiedliche Beteiligungsmöglichkeiten und -bedingungen gibt, da in jedem Fall der Grad der hierarchischen Elemente neu bestimmt wird.

Die beiden hierarchischen Elemente, die dabei zum Tragen kommen, sind zum einen die Zeit und zum anderen der geleistete Beitrag zur Wikipedia. Erstere ist über das Registrierungsdatum der jeweiligen Nutzer*innen bestimmt. Der geleistete Beitrag definiert sich hingegen durch Bearbeitungen und Kommentare auf den jeweiligen Seiten. Hierbei wird beispielsweise bei der Stimmberechtigung (vgl. Wikipedia 2020e) unterschieden, ob sich diese auf Artikel beziehen oder auf Diskussionsseiten.

Durch Einschränkung der parallelen und fortlaufenden Kollaboration auf mehreren Ebenen entsteht eine Form der Meritokratie, deren Prinzip zufolge die Leistungen des Individuums über dessen gesellschaftlichen Status innerhalb einer sozialen Gruppe bestimmen (vgl. Young 1961; Hoffer 2002; Hadjar 2008). Dennoch stellt die Kollaboration immer noch die vorherrschende Form der Wissensgenerierung und -prozessierung auf der Wikipedia dar. Sie wird jedoch durch hierarchische Elemente eingeschränkt, die sich nach dem Meritokratieprinzip legitimieren. Die hierarchischen Elemente sind zumindest im Zugang zu bestimmten Positionen obligatorisch, aber bei weitem nicht hinreichend, da Positionen auch durch Wahlen und damit wiederum durch Kollaborationen besetzt werden. 
Ein wichtiges Beispiel für eine kollaborativ-meritokratische Wissensformierung findet sich im Wettbewerb »Artikelmarathon«. Ziel dabei ist es, während eines festgelegten Zeitraums möglichst viele neue Artikel anzulegen. Die Nutzer*innen mit der höchsten Zahl gewinnen den Wettbewerb. Daran zeigt sich der meritokratische Fokus auf Leistung als zentralem Differenzierungskriterium, unabhängig von etwaigen anderen Legitimationsformen, wie Vorwissen oder Status. Der Wettbewerb beruht aber auch auf kollaborativen Elementen wie der Teilnahme anderer, den Artikelwunschlisten als Orientierung oder den (auch) kollaborativ erstellten Relevanzkriterien. Wie sich am Artikelmarathon ablesen lässt, ist Meritokratie auf der Wikipedia nur im Zusammenspiel mit Kollaboration zu verstehen.

Auffallend ist auch, dass meritokratische Elemente dort eher in quantitativer als in qualitativer Form umgesetzt werden. Bei beiden hierarchischen Elementen, Zeitraum und Beiträgen, stehen die bloße Dauer beziehungsweise Anzahl im Mittelpunkt. Da die Wikipedia aber auch inhaltliche Qualitätsbausteine hat (wie Wettbewerbe oder Kandidaturen), wäre ein zusätzliches meritokratisch qualitatives Element denkbar.

\subsection{Expertokratisch-professionalisierte Wissensformierung}

Der zweite produktive Machttypus, die expertokratisch-professionalisierte Wissensformierung, zeichnet sich durch das Zusammenspiel von expertokratischen Elementen mit und in Formen der Professionalisierung aus. In der Wikipedia sind Formen der Vergemeinschaftung zu verzeichnen, die sich thematisch deutlich spezifizieren. Dabei handelt es sich um eine Form der Kollaboration, bei der aus der Gruppe heraus Wissen generiert und prozessiert wird. Da die Wikipedia zum jetzigen Zeitpunkt schon sehr ausdifferenziert ist, werden in den Vergemeinschaftungen spezifische Themen verhandelt: Ein Portal über die Sezessionskriege gehört ebenso dazu wie eines über den Kampfsport Budō. Dadurch entsteht das Bild von vergemeinschafteten Expert*innen. Die Expertokratie wird auch über andere Elemente befördert, wie beispielsweise durch feste Ansprechpartner*innen für bestimmte Themen, den Einsatz von Tutorien als Form der Einweisung in die Wikipedia oder auch die Funktion »Artikel on Demand «, mit der sich Autor*innen selbst als Expert*innen für ein Thema ausweisen können. Spezifische Ansprechpartner*innen oder Tutor*innen fungieren in ihrer Rolle als 
Schnittstelle zwischen einem konkreten Thema oder einer Funktion der Wikipedia und den jeweiligen Nutzer*innen, die fragend an sie herantreten. Dadurch werden sie zu Expert*innen für Themen an sich und die Wikipedia selbst. Weiterhin können Nutzer*innen durch die sogenannten »Babel-Bausteine « ihre Fähigkeiten, thematisches Wissen, Qualifikationen und Leistungen sowie Funktionen für andere sichtbar machen. Mittels dieser potenziellen Selbstreferenz besteht abermals die Möglichkeit, expertokratische Strukturen in die Wikipedia einzubringen.

Diese werden insbesondere durch die inhaltliche Segmentierung der Plattform befördert. Ähnlich einem klassischen Fächerkanon ist die Wikipedia in verschiedene Portale und Themenfelder gegliedert. Eine solche kanonisierte und ausdifferenzierte Strukturierung von Wissen macht Formen der Reglementierung unabdingbar, die in den bereits erwähnten Vergemeinschaftungen stattfindet. Diese verhandeln die Generierung von neuem Wissen, indem sie Artikelwünsche aufbauen und verwalten. Ebenso verhandeln sie die Prozessierung von bestehendem Wissen, indem sie auf qualitative und quantitative Mängel an bestehenden Artikeln hinweisen. Durch die thematische Spezifität werden hier expertokratische Strukturen sichtbar. Daneben verweisen unter anderem diese Vergemeinschaftungen auch auf einen einsetzenden Professionalisierungsprozess auf der Wikipedia.

Unter letzterem wird eine Verberuflichung verstanden, wobei die Profession auf bestimmte erreichte Standards verweist (vgl. Evetts 2003). Auch wenn diese Maßstäbe unterschiedlich ausgelegt werden (beispielsweise Qualifikationsmöglichkeiten, Interessenvertretung oder gesetzlicher Rahmung), zeigen sich auf der Wikipedia klare Professionalisierungsmuster. So ist es etwa durch den sukzessiven Aufstieg innerhalb der hierarchisch-meritokratischen Benutzungshierarchie möglich, eine - zumindest intern anerkannte - »Karriere« zu durchlaufen. Weiterhin verfügt die Wikipedia über Richtlinien und Konventionen, die als Grundlage der Wissensgenerierung und -strukturierung für alle leitend und einsehbar sind. Individuelle Förderung ist durch die verschiedenen Hilfestellungen in Form von Tutor*innen, Mentor*innen und Ansprechpartner*innen ebenfalls gegeben. Für eine etablierte Interessensvertretung spricht die Implementation von Schlichtern und eines Schiedsgerichts im Streitfall. 


\subsection{Oligarchisch-technokratische Wissensformierung}

Der dritte produktive Machttypus auf der Wikipedia ist der oligarchisch-technokratische. Als Oligarchie wird in der Politikwissenschaft eine Herrschaftsform bezeichnet, »in der eine kleine Gruppe von wenigen Personen auf Dauer Macht ausübt« (Herzog 2004, 609). Eine solche tritt auf der Wikipedia in zwei unterschiedlichen Formen auf.

Die erste vereint die beiden bereits beschriebenen Typen, kollaborativ-meritokratisch und expertokratisch-professionalisiert, und verdeutlicht, dass sich hierarchische Elemente durch das Meritokratieprinzip verhärten. Dies geschieht außerdem über spezialisierte Vergemeinschaftungen, in denen sich professionalisierte Formen der Aufgabenteilung und Rollenverteilung entwickeln sowie Gruppen von wenigen Nutzer*innen entstehen, die ein höheres Maß an Benutzungsrechte besitzen. In der Wikipedia trifft das unter anderem auf die Gruppe der Administrator*innen zu, die beispielsweise über erweiterte Funktionen wie das Löschen und Wiederherstellen von Dateien und Versionen, das Sperren von Benutzungskonten und Diskussionsseiten oder die Bearbeitung von Spezialseiten verfügen. Ihr gehören in Deutschland 182 Nutzer*innen (Stand: 20.06.2020; vgl. Wikipedia 2020c) an. Bei knapp über drei Millionen angemeldeten Mitgliedern ergibt das einen Anteil von 0,006 Prozent oder anders formuliert: Auf eine*n Administrator*in kommen rund 17530 registrierte Mitglieder. Diese Zahlen verdeutlichen das ungleiche Verhältnis zwischen Nutzer*innen mit erweiterten Rechten und Nutzer*innen ohne. Da erstere mehr Entscheidungsgewalt haben (wie etwa bei Wahlen, der Implementierung von neuen Funktionen, Sperrungen von Versionen und Konten) und auch Absprachen nicht auszuschließen sind, kann hier von einem oligarchischen Machttypus gesprochen werden.

Die zweite oligarchische Form auf der Wikipedia wird anhand der Einflussnahme der Wikimedia Foundation deutlich. Sie ist eine gemeinnützige Organisation im Sinne des US-amerikanischen Gesetzes und hält alle Rechte an den verschiedenen nationalsprachlichen Versionen sowie deren Namen, Domains und Servern. In dieser Position nehmen sie und ihre Mitarbeiter*innen in unterschiedlicher Weise Einfluss auf die deutschsprachige Wikipedia und das dort repräsentierte Wissen. Die Wikimedia Foundation hat in ihren »unumstößliche(n)« Grundprinzipien (Wikipedia 2020b) Richtlinien für das Selbstverständnis der Wikipedia festgelegt, auf denen aufbauend sich alle Handlungsmöglichkeiten und -bedingungen entwickelt haben. Weiterhin 
bestimmt sie, wofür ein Benutzungskonto notwendig ist, und stützt die hierarchischen Strukturen über verschiedene Richtlinien, die für Benutzungsgruppen mit erweiterten Rechten bindend sind (beispielsweise die Oversight- oder Stewards-Policy).

Auch die Technik obliegt der Wikimedia Foundation und dem Einfluss von Benutzungsgruppen mit erweiterten Rechten. Alle Features der Wikipedia werden entweder von freischaffenden Developern entwickelt und von der Organisation eingebunden oder direkt von internen Mitarbeiter*innen erarbeitet. Neben der Software und der Benutzungsoberfläche ist auch die Hardware in Form von Servern, dem technischen Grundstein für die Kommunikation und Archivierung der gesamten Wikipedia, in der Hand der Wikimedia Foundation.

Ihre Rolle kommt somit einer oligarchischen Arbeitsorganisation gleich. Die Wikimedia Foundation nimmt über ihre Grundprinzipien, Richtlinien und ihre Technikbestimmtheit indirekt Einfluss auf das von der Wikipedia repräsentierte Wissen. Ebenso sind die hierarchischen Benutzerstrukturen Pfeiler eines oligarchisch anmutenden Systems, welches mit der technokratischen Hervorbringung und Prozessierung von Wissen in Form und mit Hilfe von Bots, Features und der Legitimierung von Wissen durch Expertise produktive Macht entfaltet.

\section{$4 \quad$ Zur Rolle der Medienkompetenz}

Durch kommunikative Medientechnologien werden sowohl neue Möglichkeiten als auch Bedingungen für Medienhandeln bereitgestellt. Innerhalb der Wikipedia entsteht somit eine produktive Macht, die nicht nur mediale Wissensrepräsentationen hervorbringt, sondern über die spezifische Art der Hervorbringungen auch die Rolle von Akteur*innen, Institutionen, Richtlinien und Techniken zueinander in Beziehung setzt. Für die Medienpädagogik stellt sich hier die Frage, ob das Konzept der Medienkompetenz diese spezifische Hervorbringungsweise adressieren kann. Dafür ist ein Blick auf sein theoretisches Fundament vonnöten.

Der Linguist Noam Chomsky hat den Kompetenzbegriff ursprünglich mit dem Spracherwerb verbunden. Kompetent zu sein besteht für ihn in nichts anderem als der Fähigkeit, gesprochene Sprache erlernen zu können. Sprache ist für Chomsky ein Zeichensystem, welches hierarchisch und regelgeleitet geordnet ist. Die allen Sprachen zugrundeliegende Regelhaftigkeit wird als Universalgrammatik bezeichnet. Dabei 
liegt die Kompetenz des Menschen darin, allein durch seine Gattungszugehörigkeit die Grammatik einer gegebenen natürlichen Sprache erlernen zu können. Nur so sei es erklärbar, dass Kinder Sätze bilden können, die sie noch nie zuvor gehört haben. Chomskys Kompetenzbegriff ist nicht auf die tatsächliche Verwendung hin ausgerichtet, sondern stellt ein theoretisches Modell für eine unbewusste anthropologische Fähigkeit dar. Kompetenz wird mithin zu einem idealen und subjektzentrierten Konzept.

Habermas (1971) bezieht sich in der Theorie des kommunikativen Handelns auf diesen Kompetenzbegriff, rückt ihn jedoch von einem biologischen zu einem soziologischen Verständnis. Bei ihm sind Kompetenzen nicht mehr nur von Natur aus gegeben, sondern auch sozial strukturiert und entwickeln sich in intersubjektiver Verständigung. Diese analysiert er mit Hilfe der Sprechakttheorie. In Sprechakten könnten Subjekte Geltungsansprüche wie Wahrheit, Richtigkeit oder Wahrhaftigkeit bezüglich objektiver, sozialer oder subjektiver Gegenstände erheben und anzweifeln. Habermas unterstellt der menschlichen Interaktion jedoch eine ideale Sprechsituation (vgl. Habermas und Luhmann 1971, 136). Der Zweifel an den geäußerten Geltungsansprüchen von Sprecher*innen sei zugleich ein Zweifel an deren kommunikativer Kompetenz. Nach Habermas müsste man nun dem Zweifel in Form einer diskursiven Prüfung genauer nachgehen. Der Diskurs selbst sei jedoch ebenfalls ein Sprechakt, der wiederum angezweifelt werden könne. Dafür bedürfe es eines übergeordneten Diskurses, welcher die Geltungsansprüche des ursprünglichen prüft. Aber ein solcher Vorgang mündet in einem infiniten Regress der Prüfung. Dieser ist laut Habermas nicht nötig, da eine ideale Sprechsituation in jeder Kommunikation zwischen Menschen unterstellt wird (vgl. ebd.). Somit bleibt auch bei ihm der idealistisch-subjektzentrierte Impetus von Kompetenz bestehen.

Dieter Baacke sieht darauf aufbauend die Notwendigkeit zur kommunikativen Kompetenz. Gemäß Baacke $(1975,363)$ sei der Mensch ein »Homo educandus «, also ein erziehungsfähiges, aber auch -bedürftiges Lebewesen. Die Ausprägung der kommunikativen Kompetenz bleibt »ein Spielraum des Menschen für die Bildung unendlich vieler Sätze wie für potenziell unbegrenztes Kommunikationsverhalten« (ebd., 101-102). In diesem Sinne tritt sie wiederum als ein idealistischsubjektzentriertes Konzept auf, da sie dem Mensch Kompetenz unterstellt und diese somit zu einer grundlegenden anthropologischen Eigenschaft macht (vgl. Baacke 1994, 240). 
In Baackes Sinn soll Medienkompetenz hier als Teil der kommunikativen Kompetenz verstanden werden. Er definiert sie als »Fähigkeit, in die Welt aktiv aneignender Weise auch alle Arten von Medien für das Kommunikations- und Handlungsrepertoire von Menschen einzusetzen« (Baacke 1996a, 8). Mit seiner Berücksichtigung von Medien reagiert Baacke auf »die Veränderung der Kommunikationsstrukturen durch technisch industrielle Vorkehrungen und Erweiterungen« (Baacke 1996b, 119). Damit akzentuiert Medienkompetenz als Teil der kommunikativen Kompetenz den Aspekt der Medienkommunikation, der gerade "nicht in face-to-face Situationen stattfindet, sondern in parasozialen Interaktionen mit Medienbotschaften und ihren Trägern« (Baacke 1997, 54).

Chomsky hatte mit der generativen Grammatik eine biologische Determinante geschaffen, die grundsätzlich universell und idealistischsubjektzentriert ausgelegt ist. Diese Attribute ziehen sich durch die kommunikative Kompetenz bei Habermas bis zum Konzept der Medienkompetenz bei Baacke und dessen medienpädagogischem Verständnis (vgl. Gapski 2001, Kerres 2011, Bettinger und Aßmann 2017).

Die produktive Macht in der Wikipedia zeigt ein spezifisches Kräfteverhältnis verschiedener Akteur*innen. Dieses ist spezifisch für jede Plattform beziehungsweise jedes mediale Angebot und bestimmt Handlungsmöglichkeiten und -bedingungen. Medienkompetenz muss daher die jeweilige Medienspezifik reflektieren. Es gilt, sich mit den jeweils gegebenen Medienumgebungen spezifisch auseinanderzusetzen, da Handlungsmöglichkeiten erst in diesen auf ihre Struktur hin untersucht werden können. Dies schließt für das Konzept der Medienkompetenz aber auch ein, die produktive Macht von Plattformen wie der Wikipedia empirisch zu untersuchen, um ihnen gegebenenfalls ein adäquates medienpädagogisches Korrektiv gegenüberzustellen.

Wenn die Wikipedia Wissen über kollaborativ-meritokratische Machtstrukturen repräsentiert, dann gilt es, diese entsprechend zu adressieren. Das bedeutet allgemein erst einmal zu erkennen, dass dort eine Verknüpfung zwischen Kollaboration und Meritokratie besteht. Diese zeigt sich in unterschiedlichen Handlungsmöglichkeiten und -bedingungen wie einem Kollaborationszwang, der über Wunschlisten, Portale und Wettbewerbe aufrechterhalten wird. Ebenso gilt es zu erkennen, dass hierarchisch strukturierte Vergemeinschaftungen bestehen, wobei sich die Hierarchie, wie oben ausgeführt, auf meritokratische Aspekte stützt. Medienkompetenz muss sich dann aber auch auf das Medienhandeln stützen. Dafür können ebenfalls Kompetenzen 
konkretisiert werden, wie beispielsweise das Anbieten eigener Qualitäten über Kandidaturenteilnahme, Software-Entwicklung, Teilnahme am Mentorenprogramm, Hilfestellung für Neulinge oder die Erstellung neuer Vergemeinschaftungen bis hin zur Erhöhung des Mitspracherechts bei bestehenden Kontrollinstanzen.

Für die medienpädagogische Forschung bedeutet dies, dass die Modellierung und Operationalisierung von Medienkompetenz auf medienspezifische Aspekte angewiesen ist. Das heißt, dass Medienkompetenzmodelle entwickelt werden müssen, die sich an medienspezifischen sowie auch thematischen Besonderheiten orientieren.

\section{Das Transformieren der Transformation}

Die Debatten um die Folgen der Digitalisierung von Wissen für dessen Generierung und Prozessierung sind ganz unterschiedlich datiert. Während Lyotard beispielsweise bereits 1979 mit Blick auf die Verbreitung des Computers von einer »technologischen Transformation [...] auf das Wissen « (Lyotard 2005 [1979], 21) sprach, sind bis heute andere Marksteine wie das Web 2.0 (Pscheida 2010) oder die Wiki-Technologie (Iske und Marotzki 2010) hinzugekommen. Sofern der Begriff "Transformation« im Zusammenhang mit medial repräsentiertem Wissen einen Umbruch von einer historisch und soziotechnisch spezifischen Konstellation zu einer anderen bedeutet, dann kann mit Blick auf die weitreichenden Diskussionen um die Digitalisierung von Wissen nicht von einer abgeschlossenen Transformation gesprochen werden. Eine solche abgeschlossene Transformation - wie sie mit den Theorien der Informations-, Wissens- oder Netzwerkgesellschaft assoziiert wird ist für die Dynamik, mit der sich Plattformen wie die Wikipedia verändern können, schwer denkbar. Dementsprechend scheint es konsequent, im Fall der Digitalisierung die Perspektive der Mediatisierung aufzugreifen und von einem Transformationsprozess zu sprechen. Das bedeutet, dass es sich bei letzterem gerade nicht um eine »räumlich und zeitlich umgrenzte Entwicklung mit einem klaren Anfangs- und Endpunkt« (Krotz 2007, 11) handelt. Neben der räumlichen und zeitlichen Entgrenzung gibt es auch keine Begrenzung von sozialen und kulturellen Folgen (vgl. ebd., 12). Diese Langzeitentwicklung ist zwar abhängig von kulturellen Kontexten, aber weder monokausal noch linear erklärbar (vgl. Krotz 2017, 27). Mediatisierung wird in dieser Lesart dezidiert von zeitlich und räumlich begrenzten Ansätzen unterschieden, die ver- 
suchen, gesellschaftliche Entwicklung monokausal zu erklären. Dies öffnet den Blick auf die Digitalisierung als transformativen Mediatisierungsschub (vgl. Hepp und Pfadenhauer 2014, 236).

Gegenwärtig treten eine Vielzahl von sich gegenseitig beeinflussenden Transformationsprozessen auf. Zu nennen sind neben der Digitalisierung (Zink 2019) die Flexibilisierung (Streeck 2011), Ökonomisierung (Beyer 2009) oder Subjektivierung (Moldaschl und Voss 2003). Erstere muss demnach als ein umfassender gesellschaftlicher Transformationsprozess verstanden werden. Eine auf Einzelmedien sowie individuelle Nutzer*innen begrenzte Perspektive greift ebenso zu kurz wie eine rein technologische. In diesem Sinne sind auch die in diesem Beitrag skizzierten Ergebnisse zur produktiven Macht der Wikipedia nur eine Momentaufnahme. Diese versucht jedoch, Transformation in einer dynamischen Perspektive mit mehreren Akteur*innen und unterschiedlichen Handlungsbedingungen zu fassen. Für das Konzept der Medienkompetenz bedeutet diese theoretische Auslegung eine Anpassungsleistung - weg von idealistisch-subjektzentrierten Normen hin zu dynamischen, medienspezifischen Kompetenzaspekten.

\section{$6 \quad$ Fazit}

Mit dem Konzept der produktiven Macht geht der Beitrag einen Mittelweg zwischen dem Fokus auf medienspezifischen Handlungsmöglichkeiten einerseits und medienspezifischen Handlungsbedingungen andererseits. Statt, wie beispielsweise für sozialkonstruktivistische kommunikationswissenschaftliche Forschung typisch, allein nach konkreten aneignenden Interaktionszusammenhängen $\mathrm{zu}$ fragen, stellt der Ansatz dieses Beitrages die Bedingungen für Kommunikation in den Vordergrund. Diese ermöglichen nicht nur die Aneignung selbst, sondern strukturieren auch ihren Gegenstand. Die medienspezifischen Handlungsmöglichkeiten und -bedingungen sind die Wissensformierungen. Analog zu anderen Arbeiten der jüngeren Kommunikationswissenschaft, die beispielsweise das Dispositivkonzept (vgl. Lepa et al. 2014), die Akteur-Netzwerk-Theorie (vgl. Gentzel 2013) oder die materialistische Phänomenologie (vgl. Hepp 2018) anwenden, vertritt dieser Beitrag den Ansatz, dass eine Trennung von autark handelndem Subjekt auf der einen und handlungsdeterminierenden Medien(-technologien) auf der anderen Seite dem Wandel der Digitalisierung nicht gerecht wird. Mit dem Zugang über die Wikipe- 
dia entsteht somit eine spezifische Beschreibung der Wissensaushandlung, die sich gerade durch ihre soziotechnische Konstellation als transformativ zu früheren oder alternativen Formen der Wissensaushandlung verstehen lässt.

Für die Medienkompetenz im Speziellen hat diese theoretische Entwicklung selbst große Bedeutung. Schließlich geht es hier um die Frage, welchen Raum medientechnische Entwicklungen einnehmen und wie das Subjekt dabei gedacht werden kann. Die Stellung des idealisierten Subjekts wurde in der Medienpädagogik in den letzten Jahren immer wieder kritisch reflektiert (vgl. Dander 2017; Kammerl 2017). Die tiefgreifende Durchdringung des Alltags mit digitalen Medien - hier beispielsweise die Wissensaneignung - gestattet jedoch nicht mehr, eine Trennung von Mensch und Medium anzunehmen. Handlungsmöglichkeiten und -bedingungen mit digitalen Wissensrepräsentationen sind nicht medien- oder subjektzentriert zu denken. Sie entwickeln sich vielmehr im heterogenen Spiel verschiedener Akteur*innen zueinander und sind dabei stets wandelbar. Das medienkompetente Subjekt muss sich demnach auch immer kritisch zu seinem eigenen mediatisierten Handeln in Beziehung setzen können. Inwieweit es sich dann als autonom, selbstbestimmt und aufgeklärt begreift, wird mithin selbst zum Gegenstand der eigenen Medienkompetenz.

\section{Literatur}

Arnold, Patricia, Lars Kilian, Anne Thillosen, und Gerhard Zimmer. 2018. Handbuch E-Learning: Lehren und Lernen mit digitalen Medien. 5. Auflage. Bielefeld: Bertelsmann.

Baacke, Dieter. 1975. Kommunikation und Kompetenz: Grundlegung einer Didaktik der Kommunikation und ihrer Medien. 2. Auflage. München: Juventa.

Baacke, Dieter. 1996a. Medienkompetenz als Netzwerk: Reichweite und Fokussierung eines Begriffs, der Konjunktur hat. medien praktisch 20 (78): 4-10.

Baacke, Dieter. 1996b. Medienkompetenz: Begrifflichkeit und sozialer Wandel. In: Medienkompetenz als Schlüsselbegriff, herausgegeben von Antje von Rein, 112124. Bad Heilbrunn: Klinkhardt.

Baacke, Dieter. 1997. Medienpädagogik. Grundlagen der Medienpädagogik. Tübingen: Niemeyer.

Baacke, Dieter. 1998. Zum Konzept der Operationalisierung von Medienkompetenz. http://www.produktive-medienarbeit.de/ressourcen/bibliothek/fachartikel/baacke_operationalisierung.shtml. Zugegriffen: 20. Juni 2020.

Bettinger, Patrick, und Sandra Aßmann. 2017. Das diskursive Feld um Mediatisierung und Mediensozialisation: Eine Analyse deutschsprachiger Fachzeitschrif- 
ten. In: Mediatisierung und Mediensozialisation: Prozesse - Räume - Praktiken, herausgegeben von Dagmar Hoffmann, Friedrich Krotz und Wolfgang Reißmann, 79-100. Wiesbaden: Springer VS.

Bettinger, Patrick, und Valentin Dander. 2016. Das Dispositiv als Bindeglied einer interdisziplinären Medienbildungsforschung. Rezension. MedienPädagogik: Zeitschrift für Theorie und Praxis der Medienbildung. DOI: https://doi. org/10.21240/mpaed/XX/2016.09.12.X.Dander 2017.

Beyer, Jürgen. 2009. Varietät verspielt? Zur Nivellierung der nationalen Differenzen des Kapitalismus durch globale Finanzmärkte. In: Wirtschaftssoziologie. Sonderheft der Kölner Zeitschrift für Soziologie und Sozialpsychologie 49, herausgegeben von Jens Beckert und Christoph Deutschmann, 305-325. Wiesbaden.

Bolz, Norbert. 1995. Am Ende der Gutenberg-Galaxis. München: Fink.

Bührmann, Andrea, und Werner Schneider. 2012. Vom Diskurs zum Dispositiv: Eine Einführung in die Dispositivanalyse. Bielefeld: Transcript.

Chomsky, Noam. 1970. Aspekte der Syntax-Theorie. Berlin: Akademie-Verlag.

Cunningham, Ward. 2002. What is a Wiki. http://www.wiki.org/wiki.cgi?WhatIsWiki. Zugegriffen: 16. August 2020.

Dander, Valentin. 2017. Medien - Diskurs - Kritik: Potenziale der Diskursforschung für die Medienpädagogik. In: Spannungsfelder und blinde Flecken: Medienpädagogik zwischen Emanzipationsanspruch und Diskursvermeidung, herausgegeben von Sven Kommer, Thorsten Junge und Christiane Rust, 50-61.

Foucault, Michel. 1978. Dispositive der Macht: Über Sexualität, Wissen und Wahrheit. Berlin: Merve.

Foucault, Michel. 1994. Das Subjekt und die Macht. In: Michel Foucault: Jenseits von Strukturalismus und Hermeneutik, herausgegeben von Hubert L. Dreyfus und Paul Rabinow, 2. Auflage, 243-261. Weinheim: Beltz-Athenäum.

Foucault, Michel. 1996. Der Mensch ist ein Erfahrungstier: Gespräch mit Ducio Trombadori. Frankfurt am Main: Suhrkamp.

Foucault, Michel. 2002. Schriften. In: vier Bänden = Dits et écrits. Band 2, herausgegeben von Daniel Defert und François Ewald, 2. Auflage. Frankfurt am Main: Suhrkamp.

Foucault, Michel. 2003. Das Spiel des Michel Foucault. In: Schriften. In: vier Bänden = Dits et écrits, herausgegeben von Daniel Defert und Michael Bischoff, 391429. Frankfurt am Main: Suhrkamp.

Foucault, Michel. 2005. Schriften. In: vier Bänden = Dits et écrits. Band 4, herausgegeben von Daniel Defert und François Ewald, 2. Auflage. Frankfurt am Main: Suhrkamp.

Gapski, Harald. 2001. Medienkompetenz: Eine Bestandsaufnahme und Vorüberlegungen zu einem systemtheoretischen Rahmenkonzept. Wiesbaden: Westdeutscher Verlag.

Gemkow, Johannes. 2017: Medienkompetenz und die Mediatisierung des Wissens: Zum Potenzial der Dispositivanalyse am Beispiel mediatisierter Wissensbestände. merzWissenschaft 61 (6): 18-29.

Gemkow, Johannes. 2021. Die Mediatisierung des Wissens: Eine Dispositivanalyse zur Rolle der Medienkompetenz. Wiesbaden: Springer VS. 
Gentzel, Peter. 2013. Praxistheorie und Mediatisierung: Grundlagen, Perspektiven und eine Kulturgeschichte der Mobilkommunikation. Wiesbaden: Springer VS.

Habermas, Jürgen, und Niklas Luhmann. 1971. Theorie der Gesellschaft oder Sozialtechnologie. Frankfurt am Main: Suhrkamp.

Hadjar, Andreas. 2008. Meritokratie als Legitimationsprinzip: Die Entwicklung der Akzeptanz sozialer Ungleichheit im Zuge der Bildungsexpansion. Wiesbaden: Springer VS.

Hepp, Andreas. 2018. Von der Mediatisierung zur tiefgreifenden Mediatisierung. Konstruktivistische Grundlagen und Weiterentwicklungen in der Mediatisierungsforschung. In: Kommunikation - Medien - Konstruktion: Braucht die Mediatisierungsforschung den Kommunikativen Konstruktivismus?, herausgegeben von Jo Reichertz und Richard Bettmann, 27-46. Wiesbaden: Springer VS.

Hepp, Andreas, und Michaela Pfadenhauer. 2014. Mediatisierte Partizipation? Kleine Formen der Beteiligung jenseits von Medienlogik. In: Die Mediatisierung sozialer Welten: Synergien empirischer Forschung, herausgegeben von Friedrich Krotz, Cathrin Despotović und Merle-Marie Kruse, 235-262. Wiesbaden: Springer VS.

Herzog, Dietrich. 2004. Oligarchie. In: Lexikon der Politikwissenschaft, herausgegeben von Dieter Nohlen und Rainer-Olaf Schultze, 609. München: Beck.

Hoffer, Thomas. 2002. Meritocracy. In: Education and sociology: An encyclopedia, herausgegeben von David Levinson, Peter Cookson und Alan Sadovnik, 435442. New York: RoutledgeFalmer.

Iske, Stefan, und Winfried Marotzki. 2010. Wikis: Reflexivität, Prozessualität und Partizipation. In: Medienbildung in neuen Kulturräumen: Die deutschsprachige und britische Diskussion, herausgegeben von Ben Bachmair, 141-151. Wiesbaden: VS Verlag.

Kammerl, Rudolf. 2017. Das Potential der Medien für die Bildung des Subjekts: Überlegungen zur Kritik der Subjektorientierung in der medienpädagogischen Theoriebildung. MedienPädagogik: Zeitschrift für Theorie und Praxis der Medienbildung. DOI: https://doi.org/10.21240/mpaed/27/2017.01.14.X.

Kerres, Michale. 2011. Schule und Internet: Pädagogische Aspekte der Entwicklung von Kompetenz für aktives Medienhandeln. RdJB - Recht der Jugend und des Bildungswesens 58 (4): 416-435.

Krotz, Friedrich. 2007. Mediatisierung: Fallstudien zum Wandel von Kommunikation. Wiesbaden: VS Verlag.

Krotz, Friedrich. 2017. Sozialisation in mediatisierten Welten: Mediensozialisation in der Perspektive des Mediatisierungsansatzes. In: Mediatisierung und Mediensozialisation: Prozesse - Räume - Praktiken, herausgegeben von Dagmar Hoffmann, Friedrich Krotz und Wolfgang Reißmann, 21-40. Wiesbaden: Springer VS.

Lepa, Steffen, Friedrich Krotz, und Anne-Kathrin Hoklas. 2014. Vom »Medium« zum »Mediumdispositiv«: Metatheoretische Überlegungen zur Integration von Situations- und Diskursperspektive bei der empirischen Analyse mediatisierter sozialer Welten. In: Die Mediatisierung sozialer Welten: Synergien empirischer Forschung, herausgegeben von Friedrich Krotz, Cathrin Despotović und MerleMarie Kruse, 115-141. Wiesbaden: Springer VS. 
Lyotard, Jean-François. 2005 [1979]. Das postmoderne Wissen: Ein Bericht. Unter Mitarbeit von Peter Engelmann. 5. Auflage. Wien: Passagen-Verlag.

Moldaschl, Manfred, und G. Günter Voss. 2003. Subjektivierung von Arbeit. 2. Auflage. München: Hampp.

Pscheida, Daniela. 2010. Das Wikipedia-Universum: Wie das Internet unsere Wissenskultur verändert. Berlin: De Gruyter.

Schiefner-Rohs, Mandy. 2012. Kritische Informations- und Medienkompetenz: Theoretisch-konzeptionelle Herleitung und empirische Betrachtungen am Beispiel der Lehrerausbildung. Münster: Waxmann.

Streeck, Wolfgang. 2011. Flexible employment, flexible families, and the socialization of reproduction. In: Imploding populations in Japan and Germany: A comparison, herausgegeben von Florian Coulmas und Ralph Lützeler, 63-95. Leiden, Boston.

Walden, Thomas. 2016. Medienkompetenz 2.1. In: Ent-Grenztes Heranwachsen, herausgegeben von Ulrike Becker, Henrike Friedrichs, Friederike von Gross und Sabine Kaiser, 233-251. Wiesbaden: Springer VS.

Wikipedia. 2020a. Größenvergleich. https://de.wikipedia.org/wiki/Wikipedia:Wikipedistik/Wachstumsprognose. Zugegriffen: 20. Juni 2020.

Wikipedia. 2020b. Ignoriere alle Regeln. https://de.wikipedia.org/wiki/Wikipedia:Ignoriere_alle_Regeln. Zugegriffen: 20. Juni 2020.

Wikipedia. 2020c. Liste der Administratoren. https://de.wikipedia.org/wiki/Wikipedia:Liste_der_Administratoren. Zugegriffen: 20. Juni 2020.

Wikipedia. 2020d. Statistics. http://wikistats.wmflabs.org/display.php?t=wp. Zugegriffen: 20. Juni 2020.

Wikipedia. 2020e. Stimmberechtigung. https://de.wikipedia.org/wiki/Wikipedia:Stimmberechtigung. Zugegriffen: 20. Juni 2020.

Young, Michael. 1961. Es lebe die Ungleichheit: Auf dem Wege zur Meritokratie. Düsseldorf: Econ-Verlag.

Zink, Klaus J. 2019. Arbeit und Organisation im digitalen Wandel. Baden-Baden.

Zorn, Isabel. 2011. Medienkompetenz und Medienbildung mit Fokus auf Digitale Medien. In: Medienbildung und Medienkompetenz: Beiträge zu Schlüsselbegriffen der Medienpädagogik, herausgegeben von Heinz Moser, Petra Grell und Horst Niesyto, 175-209. München: kopaed.

\section{Open Access}

Dieser Beitrag erscheint unter der Creative-Commons-Lizenz CC BY-ND 3.0 DE: https://creativecommons.org/licenses/by-nd/3.0/de/. 


\title{
Zehn Jahre nach den Arabischen Umbrüchen: Kritische Reflektionen zu Medien und Transformation in Ägypten und Tunesien
}

\author{
Hanan Badr
}

Keywords: Arabische Umbrüche, Soziale Medien, Demokratisierung, Transformation

\section{Abstract}

Der Beitrag plädiert für ein kontextsensibles Verständnis von Medien und Transformation im Rahmen der Arabischen Umbrüche, die vor zehn Jahren die arabische Region und die Welt erschütterten. Durch die Entwicklung und Anwendung des Begriffs counter-issues, die sozioökonomische und politische Missstände thematisierten und Menschen mobilisierten, geht der Artikel über die Kontroverse der Rolle von Medien oder Politik beim Auslösen der Transformationsprozesse hinaus. Der Beitrag fasst abschließend die theoretischen Implikationen für die Erforschung von Transformation und Medien in nicht-westlichen Kontexten, mit besonderem Blick auf Ägypten und Tunesien, zusammen. Transformationsprozesse können nur in ihren Kontexten verstanden werden. Die Kommunikationswissenschaft wird von einer Diversifizierung der epistemischen Perspektiven profitieren.

Hanan Badr: Zehn Jahre nach den Arabischen Umbrüchen: Kritische Reflektionen zu Medien und Transformation in Ägypten und Tunesien. In: Nils S. Borchers, Selma Güney, Uwe Krüger und Kerem Schamberger (Hrsg.): Transformation der Medien - Medien der Transformation. Verhandlungen des Netzwerks Kritische Kommunikationswissenschaft. Frankfurt am Main: Westend 2021. DOI: https://doi.org/10.53291/MVLJ2171.

Prof. Dr. Hanan Badr I Gulf University for Science and Technology (GUST), Kuwait I badr.h@gust.edu.kw 


\section{Einleitung}

Die Arabischen Umbrüche ${ }^{1}$ in den Jahren 2010 und 2011 haben eine heftige Debatte über die Rolle der Medien in der politischen Transformation ausgelöst. Obwohl der euphorische Moment der Massenmobilisierung vor zehn Jahren vergangen ist, hat diese Diskussion ihre Relevanz nicht verloren. Der zeitliche Abstand verhilft zur notwendigen Distanz, um kritisch über Transformationsprozesse und ihre politischen und medialen Rahmenbedingungen zu reflektieren.

Heute spricht die Washington Post vom »tragischen Erbe« der arabischen Umbrüche: Die erste Welle der Massenproteste in Tunesien, Ägypten, Libyen, dem Jemen und Syrien zog gravierende Konsequenzen wie Destabilisierung, Re-Autokratisierung und zahlreiche Bürgerkriege nach sich; die sozioökonomische und politische Ungleichheit blieb bestehen. Die zweite Protestwelle, die 2018 und 2019 im Sudan, Libanon, Irak und Algerien ausbrach, lancierte erneut die Debatte über Medien und politische Transformation. Beide Ereignisse sind Zeichen für die erdrückende strukturelle Ungleichheit und mangelnde Selbstbestimmung, gegen welche die Menschen trotz Repression und Polarisierung immer noch protestieren.

Die arabischen Umbrüche führten zu einem kurzlebigen Paradigmenwechsel in der Forschung über die arabische Region, der anstelle von Stagnation die Dynamik in den Mittelpunkt rückte (Harders 2018). Der Beginn der politischen Transformationsphase in Nordafrika geschah umbruchartig und nicht durch kontrollierte Reformen. So ersetzte dies für eine kurze Zeit die Forschung zum »enduring authoritarianism« (Bellin 2012), bevor die regionalen Ereignisse den wissenschaftlichen Blick wieder zunehmend auf Re-Autokratisierungsprozesse richteten (Kneuer und Demmelhuber 2016). In beiden Fällen, unabhängig davon, ob der Fokus auf Stagnation oder Dynamik liegt, sollte die Region nicht als Ausnahmefall konstruiert werden, also weder als demokratieresistent noch als revolutionsfreudig. Denn beide Perspektiven verstärken einen »arab exceptionalism « in Bezug auf Medien und Transformation und reproduzieren somit einen postkolonialen westlichen Blick (Harik 2006; Harders 2018). Ohne das Einbetten kommunikativer Phänomene in ihre regionalen Kontexte verstärkt sich das epistemische Dilemma

1 Der Artikel spricht bewusst nicht vom »Arabischen Frühling «, weil dieser Begriff essentialistisch und eine Fremdzuschreibung von der westlichen Perspektive auf die regionalen Verhältnisse darstellt (Beck 2015; Harik 2006). 
der Wissensproduktion durch den externen Blick auf die unberechenbaren Araber*innen (Said 2003).

In der Erforschung der arabischen Umbrüche treffen zwei Literaturstränge und Disziplinen aufeinander, die Interdependenzen zwischen Medien und Transformation erklären. Als thematische Schnittstelle zwischen Politikwissenschaft und Regionalforschung einerseits sowie Medien- und Kommunikationswissenschaft andererseits brach eine intensive Debatte über den Zusammenhang von Medien und Transformationsprozessen in Nordafrika aus. Der epistemische Standpunkt jeder Disziplin gestaltet die Perspektive auf die Medien. Politikwissenschaft und Regionalforschung betonen die Transformationsprozesse im Sinne von Demokratisierung und Regimewechsel, die Kommunikationswissenschaft dagegen untersucht die Auswirkungen der Digitalisierung auf die politischen und gesellschaftlichen Dynamiken.

Der Begriff der Transformation ist in der Kommunikationswissenschaft zentral und bezieht sich auf den strukturellen digitalen Wandel, der diverse komplexe Prozesse in Gang setzt (Strippel 2020). Das allgegenwärtige Internet und soziale Plattformen führten zu dramatischen gesellschaftlichen Veränderungen bezüglich der Art und Weise, wie wir miteinander kommunizieren, die Welt wahrnehmen und handeln. Diskursive und mediale Aushandlungsprozesse von Identität, Deutungskämpfen und Selbstdarstellung formieren sich unter neuen kommunikativen Bedingungen der Interaktion. Die digitalen Öffentlichkeiten bringen Potenziale von Kooperation, aber auch Dissonanz und Polarisierung (Pfetsch 2018).

In der Politikwissenschaft knüpfen die Untersuchungen der arabischen Umbrüche an die Demokratisierungsforschung zu politischen Umwälzungen in Südeuropa, Lateinamerika und Osteuropa an. Dabei wird Transformation als ein Prozess verstanden, bei dem sich die Transition von der Autokratie zur Demokratie in grob drei Phasen vollziehen kann (siehe O'Donnell und Schmitter 2013): 1) Zusammenbruch des alten Regimes, 2) Aushandlung neuer Grundlagen in der Übergangsphase und 3) Konsolidierung der neuen Demokratie. Die Theorie schließt einen Rückfall in autoritäre Konstellationen nicht aus und macht dies abhängig von vielen begünstigenden oder hemmenden Faktoren in den jeweiligen Kontexten (Merkel 2010). Diese Perspektive begünstigt einen euro- und angloamerikanisch-zentrierten Blick, der auf der veralteten These beruht, dass die Ausbreitung der Demokratie auf der Welt zum internationalen Frieden beiträgt, da sich demokratische Staaten nicht bekriegen würden (Maoz und Russett 1993; Kritik dazu Rosato 2003). 
Anlehnend daran, nannten Expert*innen die arabischen Umbrüche noch in der ersten euphorischen Phase die »vierte Welle der Demokratisierung « (Howard und Hussain 2013). Ähnlich wie in den westlichen Demokratien wurden den Sozialen Medien optimistische Potenziale zur Stärkung der Demokratie und Steigerung der politischen Teilhabe zugeschrieben. Auch in Nordafrika herrschte bezüglich der Proteste in den autoritären Regimes anfänglich die vereinfachte Annahme, dass Onlinemedien und soziale Plattformen der politischen Liberalisierung dienten. Aus heutiger Perspektive wissen wir, dass dies nicht der Fall war. Eine erhoffte Befreiung durch die Medien allein kam nicht zustande. Die meisten Länder, deren Regimes zusammenbrachen - mit Ausnahme Tunesiens - gerieten in abschreckende gesellschaftliche Konstellationen von Polarisierung, politischem Chaos und Bürgerkrieg oder wandelten sich zu noch repressiveren Autokratien. Selbst Tunesien hat - trotz des Ausbleibens größerer Konflikte und Blutvergießens - noch einen langen und unsicheren Weg vor sich, um die Ursachen der systemischen Ungleichheiten zu beheben.

Dieser Beitrag blickt kritisch auf die komplexen Wechselbeziehungen zwischen Mediensystemen und Transformationen im ersten Umbruchsmoment 2010/11 kurz vor dem Zusammenbruch der Regimes in Tunesien und Ägypten. Anhand empirischer Daten im Rahmen des DFG-Forschungsprojekts »Media Functions in Transition « an der Freien Universität Berlin reflektiert der Artikel über die doppelte Bedeutung der Transformation, sowohl in politischer als auch in kommunikationswissenschaftlicher Hinsicht. Methodisch basiert das DFG-Projekt auf qualitativen Inhaltsanalysen von Printmedien und Sozialen Medien im Zeitraum von 2008 bis 2011 sowie Interviews mit Journalist*innen und Aktivist*innen, um die Rolle der Medien in der Transformationsphase zu rekonstruieren. Somit überbrückt diese Untersuchung die getrennten Perspektiven und bringt sie in Dialog. Ziel ist es dabei, die Zusammenhänge von Medien und Transformationsprozessen in ihren regionalen Kontexten zu verstehen. Anlehnend an den Begriff der hybriden Mediensysteme (Chadwick 2017) rekonstruiert der Beitrag aus einer vergleichenden Perspektive die Rolle der Medien bei der Auslösung der Transformationsprozesse in Nordafrika. »Hybridität« bezieht sich dabei auf die Notwendigkeit, die Online-offline-Interaktionen innerhalb von Mediensystemen ganzheitlich zu betrachten, ohne sie binär entweder in alte oder neue Medien zu unterteilen. Der Beitrag widerspricht somit der techno-deterministischen »Facebook-Revolution«. 
Der folgende Artikel besteht aus drei Teilen: Der erste Teil diskutiert kritisch die Kontroverse, ob Medien oder Politik die Transformationsprozesse auslösten. Der zweite Teil wendet das Konzept der counter-issues anhand von empirischen Beispielen aus Tunesien und Ägypten an, um ein kontextsensibles Verständnis von Medien und Transformation zu fördern. Dabei handelt es sich um kritische Themen, die sozioökonomische und politische Missstände thematisieren, weshalb die Machthaber sie von der Öffentlichkeit fernhalten wollen (Mathes und Pfetsch 1991; Pfetsch et al. 2016; Badr 2019). Der dritte und letzte Teil fasst abschließend die theoretischen Implikationen für die Erforschung von Transformation im Zusammenhang mit Medien und besonderem Blick auf Ägypten und Tunesien zusammen.

\section{Die Kontroverse: Die Medien zuerst oder die Politik zuerst?}

Die Frage zur Rolle von Medien bei der Auslösung der Transformationsprozesse in Nordafrika hat zwei gegensätzliche Thesen vorangetrieben: Medien zuerst (»media first«; Abdulla 2011; Khamis und Vaughn 2011) versus Politik zuerst (»politics first«; Wolfsfeld et al. 2013).

\subsection{Zuerst die Medien: Medien fördern die Liberalisierung}

Gemäß dem Standpunkt »Medien zuerst« waren es primär die Medien, die den Beginn der Transformationen auslösten. Somit konzentriert er sich auf die politische Öffnung, die durch die intensive mediale Kommunikation in Tunesien und Ägypten forciert wurde. Unmittelbar nach den Ereignissen des Jahres 2011 wies die empirische Forschung aus den arabischen Ländern auf die starke Wirkung der Sozialen Medien und deren initiierende Rolle bei den politischen Transformationsprozessen hin. In öffentlichen und medialen Diskursen wird diese These als »Facebook-Revolution « bezeichnet und auch seitens der Plattformenunternehmen selbst aufgriffen: Facebook, Twitter und Co. fördern weiterhin dieses Narrativ (Richter und Badr 2018).

Drei Argumente sprachen für diese Anfangseuphorie: Das erste lautet, dass das Internet die Öffentlichkeit dynamisiert und erweitert hat. Die These über die »liberation technology« (Diamond 2010, 96) beruht auf der Prämisse, dass die zwischenmenschliche Kommunikation au- 
ßerhalb der regulierten Massenmedien zunehmend zu einem Empowerment der marginalisierten Akteur*innen führt. Somit verschaffen sich diese einen sichtbareren Platz in den Diskurssphären.

Soziale Medien ermöglichten eine dezentralisierte Kommunikation, so dass Teilöffentlichkeiten in alternativen Onlineräumen an den Kommunikationsprozessen teilnehmen konnten. Durch das Internet kamen marginalisierte Akteur*innen, Jugendliche und oppositionelle soziale Bewegungen verstärkt zu Wort und forderten politische und religiöse Autoritäten heraus (Ghonim 2012). Trotz einer starken Internetzensur, vor allem in Tunesien, konnten zivilgesellschaftliche Akteur*innen die neuen Technologien insofern nutzen, dass sie mittels Blogs und Sozialer Medien kritische Tabuthemen aufgriffen, die von etablierten Medien übersehen oder ausgeblendet wurden. Damals schienen die Onlinediskurse die normativen Bedingungen einer idealen Öffentlichkeit zu erfüllen, da sie allen Nutzer*innen zugänglich waren und gleichberechtigte Teilhabe ermöglichten (Lynch 2014; Ayish 2008). Akteur*innen umfassten Interessengruppen, Bürgerinitiativen und soziale Bewegungen, die ansonsten aufgrund politischer Ausgrenzung oder zu schwacher Ressourcen nur begrenzten Zugang zum Mediensystem gehabt hätten. Insofern standen die autoritären Regimes diesem strukturellen Wandel der Kommunikation unvorbereitet gegenüber. Das Internet war nicht im gleichen Maße wie die traditionellen Medien reguliert und überwacht, so dass es den Akteur*innen mehr Freiräume als die Offline-Welt bot.

Das zweite Argument besagt, dass kommunikative digitale Handlungen eine Form der politischen Teilhabe darstellen. Dabei dient die Kommunikation selbst als eine aktive Form der Bürgerbeteiligung, die Individuen von passiven Konsument*innen zu aktiven Produzent*innen macht. Das Internet stellte dadurch die Möglichkeit offen, die Inkongruenz zwischen der politischen Struktur, also den Institutionen, der politischen Kultur und der Summe aller Einstellungen in einer Gesellschaft, auszugleichen. Laut der Liberalisierungsthese hat das Internet den Bürger*innen ermöglicht, die Öffentlichkeit zurückzufordern und damit Pluralismus und Vielfalt in die politische Diskussionskultur einzubringen (Rinke und Röder 2011).

Das dritte Argument, das den Einfluss digitaler Plattformen auf die politische Kommunikation erklärt, ist die intermediale Agenda-SettingFunktion. Vor den Umbrüchen in den Jahren 2010 und 2011 fand ein Agenda-Transfer der counter-issues von den Sozialen Medien auf die Mainstreammedien statt (Badr 2019). Beachtet man die digitale Un- 
gleichheit in der Verteilung von Infrastruktur, Internetzugang und Endgeräten zu dem Zeitpunkt der arabischen Umbrüche vor zehn Jahren, dann scheint die intermediale Themensetzung von Online- in Offlinemedien sogar noch wichtiger. Durch diesen Mechanismus wurden Themen für breitere Teile der Öffentlichkeit sichtbarer und zugänglicher, die diese Diskurse sonst nicht wahrgenommen hätten. Journalist*innen, vor allem in privaten Medien, mussten somit auf Themeninputs reagieren, die von Teilöffentlichkeiten kamen, um ihre gesellschaftliche Relevanz und Glaubwürdigkeit nicht zu verlieren.

Die »Medien-zuerst«-Argumente fördern eine westlich-zentrierte Perspektive, welche die neuen Technologien für eine Transformation in autoritären Kontexten begrüßt (Richter und Badr 2018). Außerdem übersah dieser Forschungsstrang die »alten « Medien in einer hybriden Umgebung, die durch symbiotische Verknüpfungen zwischen digitalen und nicht-digitalen Formaten zur Transformation beitrugen.

Da sich aus den politischen Transformationsprozessen keine neuen demokratischen Strukturen ergaben, endete diese Kontroverse zwischen der Kommunikations- und Regionalwissenschaft recht bald. Die Forschung zu den Rollen neuer Medien im digitalen Zeitalter verlagerte sich schnell auf internationale Kontexte außerhalb der arabischen Region, bei der die politische Kommunikation in den erforschten Kontexten auf Populismus, Protestkommunikation und Polarisierung fokussierte. Ein Großteil der Literatur benutzte die Begrifflichkeit des »Arabischen Frühlings« nur als Namedropping oder Relevanzbegründung der eigenen empirischen Arbeit (Richter und Badr 2018). Das Forschungsinteresse der Kommunikationswissenschaft an Medien und Transformation in der arabischen Region kam, mit Ausnahme einer geringen Zahl an Forschenden, die sich inhaltlich schon immer mit dieser Region befasst hatten, zum Erliegen (zum Beispiel El-Issawi 2021, El-Nawawy und Khamis 2013, Hafez 2014). So endete auch der mögliche multidisziplinäre Dialog zwischen der Kommunikationswissenschaft und der Regionalforschung, die darauf ausgerichtet war, die Transformations- und Aushandlungsprozesse im Zusammenhang mit den arabischen Umbrüchen nachhaltig zu verstehen. Stattdessen rückten Themen auf die europäische Forschungsagenda, welche die eigenen Sicherheitsinteressen im Blick hatten und pragmatische Ziele wie die Eindämmung von Terrorismus und Migration verfolgten (Teti et al. 2020). 


\subsection{Zuerst die Politik: (Digitale) Medien schaffen allein keine Transformation}

Die Gegenthese zur Liberalisierung durch digitale Medien analysiert die Transformationsprozesse mit Blick auf politische Machtverhältnisse: Für die Anhänger*innen dieser These gilt, dass die Politik (und nicht die Medien) an erster Stelle zur Erklärung der Massenmobilisierung steht (Wolfsfeld et al. 2013). Zwei Argumente erläutern ihre Rolle in der Entstehung von Transformationsprozessen. Das erste betrachtet die neuen Medien differenzierter: Sie sind keine absoluten Mittel zur Ermächtigung und folglich besteht kein Befreiungsautomatismus. Zwar führte die Technologie zu neuen kreativen und kommunikativen Synergiekonstellationen, doch das technologische Werkzeug selbst löste keine Revolution aus. Stattdessen mobilisierten reale Missstände die Menschen. Laut der Studie »Arab Social Media« (Salem 2017) sind sowohl die Zahlen der Internetnutzung als auch die Unzufriedenheitsraten heute größer als vor 2011. Doch Zugang zur digitalen Öffentlichkeit und hohe Nutzer*innenzahlen allein führen nicht zu erneuten Protesten (Badr 2015). Zusätzlich weisen empirische Indikatoren darauf hin, dass die bloße Abschaltung des Internets in Ägypten 2011 und im Sudan 2018 der Massenmobilisierung keinen Einhalt gebieten konnte. Dies spricht für einen kontextualisierten Blick auf die Wirkung digitaler Kommunikation auf das politische Geschehen. Eine Perspektive, welche die digitale Ungleichheit berücksichtigt, wäre treffender: Mehr Kommunikation ist nicht unbedingt befreiend, da sie nicht immer Empowerment der Nutzer*innen bewirkt. Es zählt mehr, wie die Menschen die digitalen Möglichkeiten nutzen und was sie damit bewirken können (Trappel 2019; Ragnedda und Muschert 2016).

Das zweite Argument beruht auf der These des autoritären Lernens. Darunter versteht man, dass die autoritären Regimes ebenso anpassungsfähig sind wie die unterdrückten Bürger*innen. Entsprechend haben sie gelernt, wie sie mit den neuen kommunikativen Herausforderungen umgehen müssen, um die digitale Öffentlichkeit mitzugestalten und zu kolonisieren. Im Jahr 2010 zeigte Mubaraks Antwort »Lasst die Jugend Spaß am Internet haben«, als er nach den jungen FacebookNutzer*innen gefragt wurde, wie die autoritären Regimes die Möglichkeiten der digitalen Öffentlichkeit noch unterschätzten. Seitdem haben die arabischen Regierungen gelernt, diese ernster zu nehmen (Badr 2013). 
Autoritäres Lernen umfasst drei Strategien: 1) Die Machthaber entwickelten digitale Zensur- und Überwachungsstrategien. Die berüchtigte Firewall mit dem Spitznamen »Ammar 404« in Ben Alis Tunesien war noch harmlos, wenn man sie mit den heutigen Sperrtechnologien vergleicht (Raoof 2017). Seit 2018 zum Beispiel wurden der ägyptischen Öffentlichkeit durch Sperr- und Filtertechnologien das Lesen von mehr als 700 arabischen und nicht-arabischen Websites verboten. Zusätzlich sind dort seit 2017 neue Gesetze zur Bekämpfung von Terrorismus und Cyberkriminalität Methoden eines »legalen Autoritarismus« (Hamzawy 2017, 392) geworden. Das bedeutet, dass die Regierungen versuchen, den Schein eines Rechtsstaats zu erwecken, indem sie restriktive Gesetze verabschieden und anwenden, um die digitale Öffentlichkeit enger zu kontrollieren. Administrator*innen von populären Accounts der Opposition in Sozialen Medien müssen nun mit Haftstrafen rechnen. 2) Die arabischen Regimes lernten mit Diskursen über Stabilität und nationale Sicherheit, restriktive Maßnahmen vor der Öffentlichkeit zu rechtfertigen (Elswah und Howard 2020). Trotz kritischer Äußerungen des EU-Parlaments exportieren die europäischen Länder immer noch westliche Überwachungstechnologie an Autokratien. Somit fördern sie eine autoritäre Agenda, welche die nationale Sicherheit an erster Stelle setzt, und untergräbt damit zivilgesellschaftliche Initiativen und Partnerschaften in der Region, die sich eine Selbstzensur auferlegen muss. 3) Schließlich bedient sich das autoritäre Lernen der Nachahmung von Strategien sozialer Bewegungen, um Gegenproteste von Loyalist*innen zu mobilisieren. Bereits während der Tahrir-Proteste im Jahr 2011 starteten Mubarak-Anhänger*innen eine Facebook-Seite mit dem Titel »Es tut uns leid, Präsident Mubarak!« und diskreditierten die Demonstrationen als respektloses Verhalten gegenüber dem »Vater der Nation« (Badr 2013). Damals sollten Desinformationskampagnen von »bezahlten elektronischen Komitees« gefälschte Nachrichten und Gerüchte verbreiten, mit dem Ziel, die digitale Öffentlichkeit zu entpolitisieren (ebd.).

Unter diesen eingeschränkten Bedingungen führt der Anstieg der Nutzer*innenzahlen nicht automatisch zu Protesten, wenn die Bürger*innen die Lage als zu hoffnungslos oder zu riskant für die eigene Sicherheit empfinden. 


\section{3 Über die binäre Logik hinaus: Medien und Transformation durch counter-issues verstehen}

Um die Kontroverse zwischen den Polen »Medien zuerst« und »Politik zuerst« aufzulösen sowie Zusammenhänge zwischen Medien und Transformation zu verstehen, plädiert der Artikel für ein soziopolitisch und regional kontextualisiertes Verständnis des Begriffs counter-issues. Wie bereits erklärt, handelt es sich dabei um Themen, die von Gegeneliten wie der Opposition oder Zivilgesellschaft aufgegriffen werden, um die jeweils herrschenden Regimes zu delegitimieren. In den Kontexten der arabischen Umbrüche umfassen die counter-issues politische Themen wie Menschenrechtsverletzungen, Folter und Korruption oder sozioökonomische Themen wie Regimedysfunktion, Ungerechtigkeit oder unverantwortliche Privatisierung. Das zentrale Argument des Beitrags lautet, dass die Transformationsprozesse auf mediale Aufmerksamkeit und Sichtbarkeit von counter-issues zurückzuführen sind und dass weder Medien noch Politik allein die Transformationsprozesse auslösten. Mittels der Kommunikation in hybriden Mediensystemen delegitimierten Akteur*innen öffentlich die Regimes in Ägypten und Tunesien. Trotz der asymmetrischen Machtverhältnisse reagierten diese langsam, so dass die Strategien der Aktivist*innen Erfolg zeigten. Die Medien reformierten die Beziehungen und vermittelten nicht nur Ideen auf lineare Weise. Medientechnologie allein hat keine Relevanz, wenn es keine Akteur*innen des Wandels gibt, deren Diskurse, Handlungen und Zugang zu Medien die auferlegten Beschränkungen überwinden.

\subsection{Interdependenzen zwischen Medien und ihren politischen und gesellschaftlichen Kontexten}

Die Untersuchung der Interdependenzen von Medien und ihren Kontexten in den Bereichen Politik, Kultur und Gesellschaft hilft uns, politische Wandelprozesse besser zu verstehen. Da Medienaufmerksamkeit in einer übersättigten, hybriden Umgebung eine knappe Ressource ist (Tufekci 2013), erhöhen die Aktivist*innen die Sichtbarkeit ihrer Themen durch diverse Protestrepertoires und kommunikative Strategien und verschaffen so ihren counter-issues in einer breiteren Öffentlichkeit Gehör. Soziale Medien komprimieren Zeit und Raum dramatisch, indem die Nutzer*innen vermittelst ihrer wachsenden Cross-media-Nut- 
zung die räumlichen und medialen Grenzen überschreiten (Kaun 2015). Die Sichtbarkeit der counter-issues ging über den Kreis enger Sympathisant*innen hinaus in eine breitere Öffentlichkeit. Gleichzeitig gelang es den Machthabern nicht, diese Sichtbarkeit zu unterdrücken oder ihr entgegenzuwirken. Im Gegenteil hatte die Repression, je nach Thema, eine noch stärkere Mobilisierung zur Folge, wie zum Beispiel bei der Polizeifolter oder sozioökonomischen Arbeiter*innenstreiks.

Die Entwicklung eines Anti-Folter-Aktivismus in Ägypten seit Mitte der 2000er Jahre zeigt, wie sich die Aufdeckung der Polizeibrutalität im bekannten Fall von Khaled Said durch den Einfluss der hybriden Medien intensivierte. Der junge Mann aus Alexandria, der im Juni 2010 von Polizeibeamten zu Tode geprügelt wurde, erschütterte die moralische Grundlage von Mubaraks Herrschaft (Badr 2019). Da sich der tragische Vorfall vor unzähligen Zeugen am helllichten Tag ereignete, sorgte er schon für Aufruhr und Protest in Alexandria, bevor er überhaupt in den Medien bekannt wurde. Ähnlich hat die Erschießung von Demonstrierenden in Tunesien im Dezember 2010 die mediale Sichtbarkeit und die Aufregung über die Ungerechtigkeit in der nicht-politisierten Öffentlichkeit erhöht. Ohne die Thematisierung durch oppositionelle Aktivist*innen wäre es nicht möglich gewesen, die Wut der Massen auf diese Weise zu mobilisieren.

\subsection{Kontextualisierte Zusammenhänge in hybriden Mediensystemen und strukturelle Rahmenbedingungen der politischen Öffentlichkeit}

Die Erforschung der Zusammenhänge von hybriden Medien erklärt die Transformation in Nordafrika, ohne dabei die neuen Medien überzubewerten oder von ihrem Kontext zu isolieren. Das Erforschen der Sichtbarkeit von counter-issues muss digitale und nicht-digitale Medien innerhalb eines hybriden Systems integrieren. Wenn man die Hybridität der Medien übersieht, vernachlässigt man das weitere Umfeld. Die Verortung der Medien in ihre gesellschaftspolitischen und kulturellen Kontexte und die Anerkennung ihres Dynamikpotenzials führt zu kontextualisierten Ergebnissen. So können counter-issues innerhalb gesellschaftlicher Diskurse rekonstruiert werden. Digitale Medien isoliert zu untersuchen führt zu den blinden Flecken, die in der oben ausgeführten »Medien-zuerst«-These erwähnt wurden. 
Zurück zum Fall Khaled Said in Ägypten: Die Analyse der Medieninhalte und Strategien der Aktivist*innen zeigt, dass private Printmedien eine entscheidende Rolle beim Sichtbarmachen von Gerechtigkeitsnarrativen spielten. Obwohl die staatlichen Medien versuchten, das Thema komplett zu ignorieren oder herunterzuspielen, musste das Regime angesichts der Medienaufmerksamkeit und der andauernden Proteste reagieren und die angeklagten Polizeibeamten vor Gericht stellen.

Eine Fokussierung auf die Rolle der Sozialen Medien allein, zum Beispiel die Facebook-Seite »We are all Khaled Said«, würde die hohe Mediensichtbarkeit außerhalb Facebooks, das damals eine noch geringe Nutzer*innenzahl umfasste, nicht erklären. Denn gerade das counterissue »Polizeigewalt« hat eine Vorgeschichte in nicht-digitalen Medien, wurde es doch seit Jahren von zahlreichen zivilgesellschaftlichen Akteur*innen und Netzwerken von Aktivist*innen bearbeitet. Dieser weltbekannte Fall verweist auf das oft übersehene Intermedia-Agenda-Setting: Während sich die Berichterstattung über den Vorfall verzögerte, zirkulierte das grausige Bild des getöteten jungen Mannes zunächst in einem kleinen Kreis von Blogger*innen. Ein ehemaliger oppositioneller Präsidentschaftskandidat veröffentlichte es daraufhin auf seinem Facebook-Profil (Ghonim 2012). Die regelmäßigen »Silent Stands in Black«, Akte des nicht-konfrontativen Widerstands im Sommer 2010, breiteten sich schnell in Kairo aus und zogen zahlreiche Sympathisant*innen an, die sich vorher nicht kannten. In diesen friedlichen Protestaktionen standen junge Demonstrant*innen still vor dem Meer in Alexandria oder am Nil in Kairo, mit dem Rücken der Straße zugewandt, um der Polizeiopfer zu gedenken. Diese Methode sollte eine Konfrontation mit der Polizei meiden und auf Provokationen verzichten (Ghonim 2012).

Die Printmedien konnten das Ereignis also nicht mehr ignorieren: Sobald das Schweigen gebrochen war, erzeugte die mediale Sichtbarkeit des counter-issues eine hohe Aufmerksamkeit, die schließlich sogar eine Thematisierung in den abendlichen Talkshows zur Folge hatte und somit ein noch breiteres Publikum erreichte. So wurde Khaled Said posthum zum Symbol der Tahrir-Revolution, auch wenn er bereits sechs Monate zuvor getötet worden war.

Die strukturellen Rahmenbedingungen der politischen Ökonomie der Medien spielten eine wesentliche Rolle bei der Funktion des Intermedia-Agenda-Setting. Denn der semi-liberalisierte kontrollierte Pluralismus der privaten Massenmedien förderte die Entwicklung eines professionellen Journalismus, der die publikumsrelevanten Themen aufgreifen musste, um seine gesellschaftliche Relevanz sowie seine 
Verkaufszahlen beizubehalten (Badr 2019). Somit trugen sie zur Liberalisierung der Presselandschaft bei und förderten die Medienfreiheit selbst unter semi-autoritären Bedingungen. Dies belegt, wie wichtig die Unterstützung eines unabhängigen professionellen Journalismus ist, und erklärt auch, warum autoritäre Regimes die politische Ökonomie der Medienindustrie - selbst in digitalen Zeiten - zu kontrollieren versuchen.

Weiterhin förderte die damals noch unregulierte digitale Öffentlichkeit das Entstehen kritischer Diskurse. Vor den arabischen Umbrüchen griffen die Mediengesetze zu kurz und waren nicht darauf ausgelegt, oppositionelle Onlinediskurse zu verfolgen. Deshalb strebten Regimes in der Phase der Re-Autokratisierung eine Etablierung neuer restriktiver Medienregulierungsinstanzen und Gesetze an, um digitale Öffentlichkeiten strenger kontrollieren und abweichende Diskurse, zum Beispiel durch Anti-Terror-Gesetze, bestrafen zu können (Badr 2020).

\subsection{Aufstände sind Prozesse, keine plötzlichen »außergewöhnlichen« Momente}

Der Großteil der Literatur über die arabischen Umbrüche deutete Aufstände als einen plötzlichen unvorhersehbaren Moment in der Geschichte (Bayat 2013). Diesen Moment der Massenmobilisierung als eine Überraschung zu beschreiben übersieht jedoch die Vorgeschichte des Aktivismus: Die Akteur*innen hatten langjährige Erfahrung mit Widerstands- und Medienpraktiken unter repressiven Bedingungen. So kamen die arabischen Umbrüche nicht aus dem Nichts, sondern bildeten Höhepunkte eines andauernden Prozesses der Herausforderung von Unrechtsregimen und der Etablierung gerechter Gesellschaften (El-Hamalawy 2019). Der Nährboden war und ist immer noch gegeben: Marginalisierung, sozioökonomische Ungleichheit und prekäre Lebensbedingungen sowie mangelnde Aushandlungsprozesse in der Öffentlichkeit.

Vergleicht man zwei nordafrikanische Staaten - Ägypten und Tunesien -, die 2011 einen temporären Regimekollaps erlebt hatten, so erkennt man sowohl übergreifende Gemeinsamkeiten als auch regionale Unterschiede. Beide Länder standen jahrzehntelang unter der Herrschaft von Autokraten, ohne die klare Perspektive eines möglichen Machtwechsels. Die neoliberale Medienpolitik im Namen der Modernisierung verursachte in diesen Herrschaftsregimes tiefe Legitimitätskrisen, die durch die sozioökonomischen, politischen und menschen- 
rechtlichen Missstände noch verschärft wurden. Zudem sorgte die strukturelle Marginalisierung von Jugendlichen, die immerhin die demographische Mehrheit in den arabischen Gesellschaften ausmachen, für die Aushöhlung ihrer Herrschaftsbasis (Ali und El-Sharnouby 2014; Ismail 2012).

Trotz der scheinbaren Stagnation heute sieht die Perspektive »Revolution als Prozess (Hamed 2014) die Möglichkeit für eine systembedingt notwendige Transformation und eine erneute Dynamik, da die gesellschaftlichen Konstellationen bis dato nicht nachhaltig stabil und vor allem nicht gerecht sind. Transformation als Prozess bedeutet, dass aufgrund des massiven Destabilisierungspotenzials, welches die sozioökonomische strukturelle Ungleichheit birgt (Weipert-Fenner 2021), neue disruptive Momente aufkommen werden, sobald sich die Gelegenheit dazu ergibt. Eine kontextsensitive Analyse von subversiven und subtilen Mikropraktiken von Medienaktivismus aus Nordafrika liefert empirische Hinweise für diesen langen prozesshaften Charakter der politischen Transformation und dekonstruiert eine schwarz-weiße Sicht der Mainstream-Demokratisierungsforschung. Denn Akteur*innen handeln selbst unter restriktiven Bedingungen in kleineren politischen Gegenöffentlichkeiten, die durch gegenseitiges Vertrauen und Geschlossenheit geprägt sind und somit unter dem Radar der Regimes agieren (Abidin 2021).

Wenn oppositionelle Akteur*innen mit harten repressiven Konsequenzen rechnen, wenden sie subversive Medientaktiken an. So machten sie zum Beispiel von anonymen E-Mail-Verteilern und geheimen Facebook-Gruppen Gebrauch oder operierten aus dem Exil. Vor 2011 nutzten die Aktivist*innen jedoch auch den Duldungsspielraum des Regimes aus. In Ägypten hat die Privatisierung der Medien- und Kulturszene seit Mitte der 1990er Jahre die politischen und medialen Rahmenbedingungen in gewisser Hinsicht gelockert. Literatur und Film öffneten Räume medialer Sichtbarkeit für counter-issues wie Polizeigewalt, Korruption und Ungleichheit für ein breiteres Publikum jenseits direkter politischer Kontrolle. Ersteres wurde zum Beispiel in Alaa alAswanis Roman Der Jakubijān-Bau und Youssef Chahines Film Chaos medial sichtbar. Durch diese kulturellen Diskurse sickerten counterissues in die Öffentlichkeit ein. Die fiktionalen Erzählungen basierten dabei oft auf wahren Geschichten, die zuvor von Aktivist*innen und Blogger*innen enthüllt worden waren.

Ein weiteres Beispiel für Mikroprozesse der Transformation ist das verdeckte Zusammenspiel zwischen Journalismus und der Aktivist*in- 
nenszene. Interviewte Journalist*innen im Rahmen dieses Forschungsprojekts berichten von Überlebens- und Berichterstattungstaktiken in der Nachrichtenredaktion, die es ihnen ermöglichten, über Proteste und counter-issues zu schreiben, indem sie befreundete Aktivist*innen dazu aufforderten, ein bestimmtes Statement in den Sozialen Medien zu veröffentlichen, so dass sie dieses legitim wiedergeben oder zitieren konnten. Im deutlich restriktiveren Tunesien vor 2011 neigten Journalist*innen oppositioneller Zeitungen dazu, die kritische Berichterstattung in kleinerer Schrift in der Nachrichtenrubrik zu verstecken: »Die Leser*innen wussten jedoch genau, wo sie suchen mussten!«, erklärte der ehemalige Chefredakteur einer linken Zeitung. Empirische Hinweise zeigen, wie Mikropraktiken selbst unter stagnierenden Verhältnissen möglich sind. Die Transformation als »Revolution im Prozess « zu sehen bildet deshalb einen geeigneteren Analyserahmen als die binäre Konstruktion von »Autokratien versus Demokratien«.

\subsection{Mehr innerarabische Vergleiche zur regionalen Differenzierung}

Die Länder Nordafrikas unterscheiden sich trotz gewisser sprachlicher, historischer und kultureller Ähnlichkeiten in ihren lokalen Dynamiken teils erheblich. Insgesamt ist die Erforschung von Medien und Kommunikation in der arabischen Region noch wenig vorangeschritten, was durch eine Diversifizierung der Wissensproduktion langfristig behoben werden sollte, um mehr Regionen, die nicht dem Westen zugehören, in den Fokus zu rücken und den dort ansässigen Akteur*innen Gehör zu verschaffen (Chakravartty et al. 2018; Badr et al. 2020; Richter und Kozman 2021). Im Kontext der Transformation bedeutet das, dass wir mehr regional vergleichende Forschung brauchen. Auf den ersten Blick sind Parallelen auf der Makroebene in den Ländern der arabischen Umbrüche nicht zu übersehen: Inkongruenz der politischen Struktur und Kultur, technikaffine Jugend, sozioökonomische Ungleichheit sowie die Zentralisierung der Macht in den Hauptstädten prägen Ägypten und Tunesien gleichermaßen. Doch kontextspezifische Differenzen gestalteten die Verlaufsdynamik der Umbrüche auf andere Art und Weise. Einige wesentliche Unterschiede zwischen beiden nordafrikanischen Ländern ist die Stärke und Vernetzung der Zivilgesellschaft, zum Beispiel von Gewerkschaften, das Bildungsniveau und die Inklusion von Frauen in der Politik. Diese Faktoren begünstigten eine friedlichere - 
wenn auch turbulente - Transformationsphase in Tunesien. Auch prägte dort das stark ausgeprägte postkoloniale Erbe die Medienlandschaft, die in zwei Sprachen (Arabisch für die Massen und Französisch für die Eliten) gespalten war. Die Pakte zwischen den politischen Parteien sowie die Verbindungen zu regionalen und internationalen Akteur*innen definierten die Machtdynamik und die politische Transformation im postrevolutionären Tunesien.

Selbst der Verlauf der Umbruchsdynamik sowohl in Ägypten als auch in Tunesien vor 2011 weist große Unterschiede auf. Der Vergleich beider Staaten zeigt interessante Muster: Zunächst waren die strukturellen sozioökonomischen Ursachen der Arbeiter*innenstreiks von 2008 ähnlich. In beiden Ländern beklagte man prekäre Arbeitsverhältnisse: So protestierten die Arbeiter*innen in Ägypten gegen die Privatisierung, während sie in Tunesien größere Beschäftigungsmöglichkeiten und die Entwicklung der ressourcenreichen Provinzen forderten. In beiden Ländern beeinflusste zudem die geographische Lage die Mediensichtbarkeit und die Reaktionen der Regimes auf diese Proteste. Gegenüber Streiks im tunesischen Gafsa, einer abgelegenen südlichen Provinz, reagierte das Regime mit brutaler Repression und Abschottung. Anders war es hingegen in Ägypten: Dort versuchte die Regierung in der bevölkerungsreichen Nildelta-Stadt Mahalla, einem Zentrum der Textilindustrie, das geographisch viel näher an der Hauptstadt liegt, Verhandlungen aufzunehmen. Die unterschiedlichen Reaktionen der Regimes haben auch medienrelevante Ursachen: Die streng zensierte Medienlandschaft Tunesiens thematisierte die Proteste kaum, weshalb diese nur in oppositionellen Medien mit begrenzter Reichweite Verbreitung fanden. Die ägyptische Regierung war andererseits gezwungen zu reagieren, da die Verbindung zwischen den Arbeiter*innen und der städtischen Jugend zu einer kurzlebigen klassenübergreifenden Solidarität führte. Insofern führte das Zusammenspiel von alten und neuen Medien sowie klassischen und innovativen Protesttechniken zu unterschiedlichen Reaktionen der Regimes, die durch die Medienaufmerksamkeit auf die counter-issues noch verstärkt wurden.

\section{Fazit und Ausblick}

Die Erforschung des Zusammenhangs von Transformation und Medien ist im Fach der Kommunikationswissenschaft relevanter denn je. Aus der arabischen Region kann noch vieles gelernt werden. Dazu gehört 
erstens, dass es das Konzept der counter-issues ermöglicht, kontextsensible Medienanalysen zu Wandelprozessen durchzuführen und auf eine technikzentrierte Interpretation zu verzichten, die sich zu sehr auf digitale Technologien beschränkt und dabei die soziokulturellen und politischen Hintergründe vernachlässigt. Die Berücksichtigung der Interaktionen verschiedener Medienformate vor dem Hintergrund von Dynamik und Hybridität überwindet die Trennung zwischen Onlineund Offlinemedien. Somit entwickeln sich Themen in hybriden Medienumgebungen, indem sie von Akteur*innen trotz autoritärer Strukturen lanciert werden.

Selbst in eingeschränkten Kontexten spielen die Medien eine Rolle bei der öffentlichen Thematisierung von Missständen. Im Zuge eines jeden erfolgreichen Protests neigt die akademische Debatte dazu, schnell zur These des Liberalisierungseffektes der Medien zu greifen, anstatt eine kontextualisierte und regional differenzierte Debatte anzuregen. Es geht darum, dass Medien und Transformation als Prozesse zu betrachten sind. Dabei ist es hilfreich, nicht nur die Akteur*innen zu betrachten, sondern auch die Reaktionen der Machthaber einzuschließen, um die dynamischen Wechselwirkungen und Lernprozesse der beteiligten Parteien zu erfassen. Vor diesem Hintergrund sieht sich die arabische Region unverändert zahlreichen Herausforderungen gegenüber, denn die gegenwärtigen Ungerechtigkeiten sind langfristig nicht tragbar. So besteht weiterhin das Potenzial für erneute Protestwellen und Transformationsprozesse, solange die strukturellen Ursachen der Unzufriedenheit nicht behoben werden. Punktuelle Proteste - trotz hoher politischer Kosten der Repression - belegen diese Instabilität der sozioökonomischen Konstellationen.

Weiterhin fordert dieser Beitrag dazu auf, die regional vergleichende Medien- und Kommunikationswissenschaftsforschung voranzutreiben, anstatt lediglich einzelne Fallstudien zu analysieren. Bislang ist das Potenzial der innerarabischen kommunikationswissenschaftlichen Forschung, anders als etwa in der Politikwissenschaft, noch nicht ausgeschöpft. Zwar besteht in der westlichen akademischen Welt ein größeres Interesse daran, den globalen Norden zu erforschen. Doch um die globale Dimension der Zusammenhänge zwischen Digitalisierung und Öffentlichkeiten zu verstehen, brauchen wir mehr Forschung direkt aus und über nicht-westliche Kontexte. Die regionale Differenzierung deckt Muster auf, die unseren epistemischen Horizont erweitern.

Schließlich sollten wir aus der Forschungswelle zu Medien und den arabischen Umbrüchen lernen, die Transformation als Prozess und 
nicht als Momentaufnahme zu sehen. Selbst unter eingeschränkten autoritären Systembedingungen entstehen subversive Taktiken des Widerstands, die über die kurzlebigen disruptiven Umbruchsmomente hinaus forschungsrelevant sind. Trotz der gegenwärtigen Re-Autokratisierung und Verzweiflung in der Region wissen wir, dass es solche Momente des Aufbruchs gab und wieder geben wird. Wir können Ereignisse wie die des Jahres 2011 nur verstehen, wenn wir auch die Erforschung von Kommunikation in autoritären Kontexten als relevant betrachten (Töpfl 2020). Zwar schränkt die restriktive politische Ökonomie der Medien eine transparente Öffentlichkeit ein, aber die kreative Energie der handelnden Akteur*innen und ihre Widerstandsbemühungen, subversiv kulturelle und soziale Bereiche zu beeinflussen, bleiben ebenso beständig und bemerkenswert. Eine solche kontextualisierende Perspektive überwindet eine binäre Sichtweise auf die Rolle der Medien in Wandelprozessen und verhilft uns zu einem differenzierten Verständnis von Medien in Zeiten der digitalen Transformation.

\section{Literatur}

Abdulla, Rasha A. 2011. The Revolution Will Be Tweeted. The Cairo Review of Global Affairs. https://www.thecairoreview.com/essays/the-revolution-will-betweeted/. Zugegriffen: 20. Februar 2021.

Abidin, Crystal. 2021. From »Networked Publics« to »Refracted Publics«: A Companion Framework for Researching »Below the Radar« Studies. Social Media + Society. DOI: 10.1177/2056305120984458.

Ali, Amro, und Dina El-Sharnouby. 2014. Distorting digital citizenship: Khaled Said, Facebook, and Egypt's streets. In: Wired Citizenship: Youth Learning and Activism in the Middle East, herausgegeben von Linda Herrera, 89-101. New York: Routledge.

Aswani, Alaa A. 2007. Der Jakubijān-Bau. Übersetzt von Hartmut Fähndrich. Basel: Lenos-Verlag.

Ayish, Muhammad I. 2008. The New Arab Public Sphere. Medien und politische Kommunikation - Naher Osten und islamische Welt. Band 15, herausgegeben von Kai Hafez, und Carola Richter. Berlin: Frank \& Timme.

Badr, Hanan. 2013. Battleground Facebook: Contestation Mechanisms in the Social Media in the Framing of the Egypt's Revolution 2011. In: Social Media Go to War: Rage, Rebellion and Revolution in the Age of Twitter, herausgegeben von Ralph D. Berenger, 399-422. Spokane: Marquette Books.

Badr, Hanan. 2015. Limitations of the Social Media Euphoria in Communication Studies. Égypte/Monde arabe 12. DOI: 10.4000/ema.3451.

Badr, Hanan. 2019. Before the »Arab Spring«: How challengers pushed counter-is- 
sues in Egypt's hybrid media system. Media, War and Conflict. DOI: $10.1177 / 1750635219894611$.

Badr, Hanan. 2020. From Disruptive Power to Trapped Endurance: Egypt's Journalistic Agency after the Tahrir Revolution. In: Critical Incidents in Journalism: Pivotal Moments Reshaping Journalism Around the World, herausgegeben von Edson C. Tandoc Jr., Joy Jenkins, Ryan J. Thomas und Oscar Westlund. Milton Park: Routledge.

Badr, Hanan, Markus Behmer, Susanne Fengler, Anke Fiedler, Anne Grüne, Kai Hafez, Oliver Hahn, Kefa Hamidi, Thomas Hanitzsch, Christine Horz, Beate Illg, Anna Litvinenko, Martin Löffelholz, Melanie Radue, Carola Richter, Barbara Thomaß, und Florian Töpfl. 2020. Kosmopolitische Kommunikationswissenschaft: Plädoyer für eine »tiefe Internationalisierung « des Fachs in Deutschland - Ein wissenschaftspolitisches Positionspapier. Publizistik 65: 295-303. DOI: 10.1007/s11616-020-00576-6.

Bayat, Asef. 2013. The Arab Spring and its Surprises. Development and Change 44 (3): 587-601. DOI: 10.1111/dech.12030.

Beck, Martin. 2015. The End of Regional Middle Eastern Exceptionalism? The Arab League and the Gulf Cooperation Council after the Arab Uprisings. Democracy and Security 11 (2): 190-207. DOI: 10.1080/17419166.2015.1037390.

Bellin, Eva. 2012. Reconsidering the Robustness of Authoritarianism in the Middle East: Lessons from the Arab Spring. Comparative Politics 44 (2): 127-149. DOI: $10.5129 / 001041512798838021$.

Chadwick, Andrew. 2017. The Hybrid Media System: Politics and Power. 2. Auflage. New York: Oxford University Press.

Chakravartty, Paula, Rachel Kuo, Victoria Grubbs, und Charlton McIlwain. 2018. \#CommunicationSoWhite. Journal of Communication 68 (2): 254-266. DOI: 10.1093/joc/jqy003.

Chaos. Ägypten und Frankreich 2007. Regie: Youssef Chahines und Khaled Youssef. DVD 3B Productions und MISR International Films.

Diamond, Larry. 2010. Liberation Technology. Journal of Democracy 21 (3): 69-83.

El-Hamalawy, Hossam. 2019. Revolution is a process, and it's far from over. The New Arab vom 27. Februar, https://english.alaraby.co.uk/english/comment/2019/2/27/revolution-is-a-process-and-its-far-from-over. Zugegriffen: 20. Februar 2021.

El-Issawi, Fatima. 2021. Alternative Public Spaces in Hybrid Media Environments: Dissent in High Unvertainty. Journalism \& Mass Communication Quarterly. DOI: 10.1177/1077699021998381.

El-Nawawy, Mohammed, und Sahar Khamis. 2013. Egyptian Revolution 2.0: Political Blogging, Civic Engagement, and Citizen Journalism. New York: Palgrave Macmillan.

Elswah, Mona, und Philip N. Howard. 2020. The Challenges of Monitoring Social Media in the Arab World: The Case of the 2019 Tunisian Elections. Oxford Internet Institute, Oxford University: Project on Computational Propaganda. https:// comprop.oii.ox.ac.uk/wp-content/uploads/sites/93/2020/03/Tunisia-memoEnglish.pdf. Zugegriffen: 20. Februar 2021. 
Ghonim, Wael. 2012. Revolution 2.0. Cairo: Shorouk.

Hafez, Kai. 2014. Radikale Polarisierung im Arabischen Frühling: Aufstieg und Niedergang der Medienfreiheit in Ägypten. Sicherheit und Frieden 32 (4): 254259.

Hamed, Adham. 2014. Revolution as a Process: The Case of the Egyptian Uprising. Wien: Wiener Verlag für Sozialforschung.

Hamzawy, Amr. 2017. Egypt after the 2013 military coup: Law-making in service of the new authoritarianism. Philosophy \& Social Criticism 43 (4/5): 392-405. DOI: $10.1177 / 0191453717695367$.

Harders, Cilja. 2018. Understanding Egypt's Postrevolutionary dynamics »from below«. In: Ways of Knowing Muslim Cultures and Societies: Studies in Honour of Gudrun Krämer, herausgegeben von Bettina Gräf, Birgit Krawietz und Schirin Amir-Moazimi, 411-424. Leiden: Brill Academic Publishers.

Harik, Iliya. 2006. Democracy, »Arab Exceptionalism«, and Social Science. The Middle East Journal 60 (4): 664-684. DOI: 10.3751/60.4.12.

Howard, Philip N., und Muzammil M. Hussain. 2013. Democracy's Fourth Wave? Digital Media and the Arab Spring. New York: Oxford University Press.

Ismail, Salwa. 2012. The Egyptian revolution against the police. Social Research 79 (2): 435-462.

Kaun, Anne. 2015. Regimes of time: Media practices of the dispossessed. Time \& Society 24 (2): 221-243. DOI: 10.1177/0961463X15577276.

Khamis, Sahar, und Katherine Vaughn. 2011. We Are All Khaled Said: The Potentials and Limitations of Cyberactivism in Triggering Public Mobilization and Promoting Political Change. Journal of Arab \& Muslim Media Research 4 (2/3): 145-163. DOI: 10.1386/jammr.4.2-3.145_1.

Kneuer, Marianne, und Thomas Demmelhuber. 2016. Gravity centres of authoritarian rule: a conceptual approach. Democratization 23 (5): 775-796. DOI: 10.1080/13510347.2015.1018898.

Lynch, Marc. 2014. The Arab Uprising Explained: New Contentious Politics in the Middle East. New York: Columbia University Press.

Maoz, Zeez, und Bruce Russett. 1993. Normative and Structural Causes of Democratic Peace, 1946-1986. American Political Science Review 87 (3): 624-638. DOI: $10.2307 / 2938740$.

Mathes, Rainer, und Barbara Pfetsch. 1991. The Role of the Alternative Press in the Agenda-Building Process: Spill-over Effects and Media Opinion Leadership. European Journal of Communication 6 (1): 33-62. DOI: 10.1177/026732319100 6001003.

Merkel, Wolfgang. 2010. Systemtransformation: Eine Einführung in die Theorie und Empirie der Transformationsforschung. Wiesbaden: Springer VS.

O’Donnell, Guillermo, und Philippe C. Schmitter. 2013. Tentative Conclusions about Uncertain Democracies. Baltimore: The Johns Hopkins University Press.

Pfetsch, Barbara. 2018. Dissonant and Disconnected Public Spheres as Challenge for Political Communication Research. Javnost - The Public 25 (1/2): 59-65. DOI: 10.1080/13183222.2018.1423942.

Pfetsch, Barbara, Daniel Maier, Peter Miltner, und Annie Waldherr. 2016. Chal- 
lenger Networks of Food Policy on the Internet: A Comparative Study of Structures and Coalitions in Germany, the UK, the US, and Switzerland. International Journal of E-Politics 7 (1): 16-36. DOI: 10.4018/IJEP.2016010102.

Ragnedda, Massimo, und Glenn W. Muschert. 2016. Theorizing Digital Divides and Inequalities. In: Social Inequalities, Media, and Communication: Theory and Roots, herausgegeben von Jan Servaes und Toks Oyedemi, 23-35. Lanham: Lexington Books.

Raoof, Ramy. 2017. State surveillance and protest: »They try to make people think twice before taking to the streets«. Egyptian Initiative for Personal Rights. https://eipr.org/en/blog/ramy-raoof/2017/10/state-surveillance-and-protest\%E2\%80\%9Cthey-try-make-people-think-twice-taking. Zugegriffen: 20. Februar 2021.

Richter, Carola, und Hanan Badr. 2018. Communication Studies in Transformation: Self-Reflections on an Evolving Discipline in Times of Change. In: Academia in Transformation: Scholars Facing the Arab Uprisings, herausgegeben von Florian Kohstall, Carola Richter, Sarhan Dhouib und Fatima Kastner, 143-160. Baden-Baden: Nomos.

Richter, Carola, und Claudia Kozman. 2021. Arab Media Systems. Cambridge: Open Book Publishers.

Rinke, Eike M., und Maria Röder. 2011. Media Ecologies, Communication Culture, and Temporal-spatial Unfolding: Three Components in a Communication Model of the Egyptian Regime Change. International Journal of Communication 5: 1273-1285.

Rosato, Sebastian. 2003. The Flawed Logic of Democratic Peace Theory. American Political Science Review 97 (4): 585-602.

Said, Edward. 2003 [1978]. Orientalism. London: Penguin Books.

Salem, Fadi. 2017. The 7th Arab Social Media Report: Social Media and the Internet of Things - Towards Data-Driven Policymaking in the Arab World: Potential, Limits and Concerns. https://www.arabsocialmediareport.com/News/description. aspx?NewsID=24\&PriMenuID=15\&mnu=Pri. Zugegriffen: 11. März 2021.

Strippel, Christian. 2020. Strukturwandel der Öffentlichkeit aus der Perspektive einer Theorie der Spätmoderne. In: Digitaler Strukturwandel der Öffentlichkeit: Historische Verortung, Modelle und Konsequenzen, herausgegeben von Mark Eisenegger, Marlis Prinzing, Patrik Ettinger und Roger Blum, 213-238. Wiesbaden: Springer VS.

Teti, Andrea, Pamela Abbott, Valeria Talbot, und Paolo Maggiolini. 2020. Democratisation against Democracy: How EU Foreign Policy Fails the Middle East. Cham: Palgrave Macmillan.

Töpfl, Florian. 2020. Comparing Authoritarian Publics: The Benefits and Risks of Three Types of Publics for Autocrats. Communication Theory 30 (2): 105-125. DOI: $10.1093 / \mathrm{ct} / \mathrm{qtz} 015$.

Trappel, Josef. 2019. Inequality, (new) media and communications. In: Digital media inequalities: Policies against divides, distrust and discrimination, herausgegeben von Josef Trappel, 9-30. Göteborg: Nordicom.

Tufekci, Zeynep. 2013. »Not This One«: Social Movements, the Attention Economy, 
and Microcelebrity Networked Activism. American Behavioral Scientist 57 (7): 848-870. DOI: 10.1177/0002764213479369.

Weipert-Fenner, Irene. 2021. Nichts ist vorbei! Frankfurter Rundschau vom 11. Januar, https://www.fr.de/meinung/nichts-ist-vorbei-90164970.html. Zugegriffen: 20. Februar 2021.

Wolfsfeld, Gadi, Elad Segev, und Tamir Sheafer. 2013. Social Media and the Arab Spring: Politics Comes First. International Journal of Press/Politics 18 (2): 115137. DOI: $10.1177 / 1940161212471716$.

\section{Open Access}

Dieser Beitrag erscheint unter der Creative-Commons-Lizenz CC BY-ND 3.0 DE: https://creativecommons.org/licenses/by-nd/3.0/de/. 


\section{Transformation und Transparenz: Warum im Journalismus das »Quellen-W « wichtiger wird}

\section{Sebastian Köhler}

Keywords: Journalismus, Quellenangabe, Transparenz, Vertrauenskrise, Transformation, W-Fragen, Quellen-W, Völkerverständigung, friedliche Koexistenz

\section{Abstract}

Der Beitrag diskutiert in verschiedener Hinsicht die Wichtigkeit möglichst frühzeitiger Quellenangaben in journalistischen Beiträgen. Hierbei geht es um zentrale Aspekte von Transparenz im Journalismus, auch im Kontext der Befunde zu Misstrauen gegenüber etablierten Medien. Repräsentative Befragungen, öffentliche Diskussionen um Medienqualität und auch Erfahrungen aus eigener journalistischer Arbeit weisen darauf hin, dass Quellentransparenz als (zunehmend) wichtiger Faktor für Vertrauen gegenüber journalistischen Angeboten diskutiert werden sollte. Auch im Hinblick auf zwischenstaatliche Spannungen, Krisen und Konflikte erscheint das Konzept essenziell. Der Beitrag zeigt anhand der Berichterstattung zu den Fällen Babtschenko, Skripal und Nawalny, dass durch mangelhafte Quellentransparenz Spannungen in der Tendenz geschürt werden und sorgfältigen Quellenangaben ein Transformationspotenzial in Richtung friedlicher Koexistenz innewohnt.

Für Hinweise zu einer früheren Fassung dieses Beitrages danke ich Michael Haller, Uwe Krüger und Kerem Schamberger.

Sebastian Köhler: Transformation und Transparenz: Warum im Journalismus das »Quellen-W" wichtiger wird. In: Nils S. Borchers, Selma Güney, Uwe Krüger und Kerem Schamberger (Hrsg.): Transformation der Medien - Medien der Transformation. Verhandlungen des Netzwerks Kritische Kommunikationswissenschaft. Frankfurt am Main: Westend 2021. DOI: https://doi.org/10.53291/ERWL7086. 


\section{Einleitung: In Richtung gelingender gesellschaftlicher Kommunikation}

Most information circulating is doing so precisely because those responsible for it want people to know about it [...] If governments and business are to be held to account, as more than

ever they need to be, then democracy requires a functioning, independent news media. A move towards greater transparency in sourcing might be a step in that direction.

(Phillips 2010, 1, 8)

Das Thema dieses Beitrages lautet: Transformation und Transparenz. Denn Journalist*innen sollten sich angesichts einer anhaltenden Vertrauenskrise (zum Strukturwandel öffentlichen Vertrauens vgl. Haller 2017) gegenüber ihrem Berufsfeld und angesichts wachsender sozialer Spannungen in Gesellschaften wie der in Deutschland nicht zuletzt um mehr Transparenz ihrer Arbeit bemühen (siehe Köhler 2018; Köhler 2019, 76-78). Auch laut der Mainzer Langzeitstudie Medienvertrauen von 2019 war der Anteil derjenigen Personen in Deutschland, die etablierten Medien gegenüber skeptisch sind (die Studie nennt sie sogar »Medienzyniker«; Schultz et al. 2020, 322), zumindest »nicht marginal«. Etwa jede Vierte vertraue etablierten Medien nicht (mehr) bei wichtigen Themen (ebd., 329): „Geht es um politisch besonders umstrittene Fragen, die in aufgeheizter Atmosphäre diskutiert werden, sind die Vertrauenswerte noch geringer.« Dabei handelt es sich um etwa doppelt bis dreimal so viele Menschen wie jene, die 2017 bei der Bundestagswahl die AfD gewählt hatten (12,6 Prozent), was offenbar auf ein tiefergreifendes gesellschaftliches Problem verweist: Misstrauen gegenüber den Medien ist kein Phänomen, das nur den rechten Rand betrifft.

Dabei zählt gerade Quellentransparenz seit Jahrzehnten zum »Kernbestand « vieler journalistischer Qualitätskataloge (Schultz 2019), was auch Silvio Waisbord mit Blick auf digitalen und tradierten Journalismus unterstreicht: Redaktionelles Selbstverständnis bezieht sich weiterhin auch auf Transparenz nicht nur im Sinne von Quellentransparenz als journalistische Norm: »A blend of modernist values (truth, transparency, rationality, factivity, freedom) still anchors the collec- 
tive imaginary of newsrooms.« (Waisbord 2019, 356) Entsprechende Aspekte und Ebenen insbesondere öffentlicher Selbsttransparenz im Journalismus (vgl. Reimer 2017) diskutiere ich in Abschnitt 3.

Schließlich können, ja, sollen journalistische Medien hinsichtlich sozialer Transformationsprozesse und des Aufhebens globaler Krisentendenzen und Pathologien (vgl. Rosa 2013, 89-91; Krüger und Meyen 2018) wesentliche Rollen spielen. Hans-Peter Krüger hat Entsprechendes im Aufgreifen von Vorschlägen Bertolt Brechts und Juri Lotmans als Beiträge zur kulturellen Aufgabe öffentlicher Medien in modernen (oder spätmodernen) Demokratien bestimmt (Krüger 1992, 220-222). Diese gleichsam transformative kulturelle Aufgabe (die auch Politik und Wirtschaft verändern dürfte) kann als »Prinzip Perspektivenwechsel« begriffen werden: Indem man Sichtweisen aufzeigt und sie als solche explizit kenntlich und damit kritisierbar macht, ermöglicht und erleichtert man tendenziell Wechsel. Diese sollten möglichst symmetrisch, auf Augenhöhe erfolgen. Denn im Zuge der Digitalisierung gilt entsprechendes »technisches Kapital« (Rudolph 2019, 104-105) als wichtige Zugangsmöglichkeit zu Information und Kommunikation sowie als entscheidende Ressource in einer Wissensgesellschaft. »Technisches Kapital meint hier im Fortschreiben der Kapitalbegriffe von Marx und Bourdieu, dass sowohl der infrastrukturelle Zugang zum Internet als auch dessen praktisch-technischer Gebrauch durch die sozialen Positionen der Akteur*innen bestimmt werden. Wenn es ungleich oder ungerecht verteilt ist oder wird, dann sorgt die »digital divide« für weiter wachsende soziale Spannungen und Spaltungen.

Was bedeutet das mit Blick auf Quellentransparenz? Ein (normativer) Bereich prinzipiell Perspektiven wechselnder, möglichst symmetrischer Kommunikation mag (gleichsam als Mesoebene) zwischen »Mikro« (individuellem journalistischem Handeln) und »Makro« (Öffentlichkeiten) vermitteln. Diese Verbindung kann auch auf neue Weise als redaktionelles Vermitteln bestimmt werden, sofern Redaktionen nicht als »Sender «, sondern als offen Beitragende begriffen werden (vgl. Köhler 2018). Als Organisationen journalistischen Handelns lassen sich diese hier auf neue Weise als Bindeglied zwischen Individuen (Mikroebene) und dem sozialen Bereich Journalismus (Makroebene) modellieren.

Nutzer*innen ihrerseits sollten daher die Angebote besser einordnen und Rückmeldung geben können. Angela Phillips (2010, 2) schreibt: "Citizens are more easily able to trace information to its source.« Journalist*innen wiederum dürfte diese Art von Vermittlung darin bestär- 
ken, möglichst professionell, selbstkritisch und vielfältig zu arbeiten, hier insbesondere reflektiert und innovativ (auch »gegen den Strom«) Quellen auszuwählen sowie diese dann - kritikoffen - am besten von vornherein in journalistische Beiträge einzubeziehen. Damit würde im Idealfall die kommunikative Kompetenz tendenziell aller Beteiligten gewissermaßen als Vermittlungsleistung wachsen. »Kritikoffen « soll hier unterstreichen, dass Nutzer*innen die Quellen nicht nur kennen, sondern sowohl sie als auch deren Auswahl durch die Redaktion einfacher kritisieren können.

In dieser Richtung mögen die sich historisch entwickelnden oder wandelnden Alltags- und Expert*innenkulturen als gleichrangig gelten-Minderheiten können recht haben und bisherige Hierarchien (zum Beispiel die zwischen Sender*innen und Empfänger*innen) in Frage gestellt werden. Solche Offenheit dürfte einen Wertewandel befördern, der zu neuen Mehrheiten, jenseits tradierter Markt- oder Machtdominanzen, zu führen vermag. Es geht um eine Symmetrisierung von Perspektiven in gesellschaftlicher Kommunikation. Dafür scheint wechselseitiges Vertrauen ein wichtiger Aspekt, sowohl der Journalist*innen in ihre Publika als auch der Nutzer*innen in die journalistischen Angebote. Wenn wir daher auch Kommunikation als das stets erneute Durchlaufen der Differenzen zwischen Kommunikablem und Nichtkommunikablem begreifen, dann wird klar: Die gesamtgesellschaftlich möglichst gleichberechtigte Produktion und Reproduktion dieser Differenzen führt tendenziell zur Entdeckung neuer Themen und Lösungsmöglichkeiten, die bisher keine (oder kaum eine) Rolle spielten. So kann es, was die Transformationsproblematik in Richtung nachhaltiger sozial-ökologischer Demokratisierung angeht, zu grundlegenden Umorientierungen der gesellschaftlichen Kommunikation kommen (vgl. Krüger 1992, 228).

Das heißt für den Journalismus unter anderem: Das Nutzervertrauen hängt nicht zuletzt ab von journalistischer Transparenz, sowohl bezogen auf die Arbeitsprozesse (Themenwahl, Recherche, Produktion, Distribution und redaktionelle Selbstkritik) als auch auf die manifesten Beiträge selbst. Studien deuten darauf hin (vgl. exemplarisch Prochazka 2020, 188), dass »Transparenz « (hier als eines von 19 Qualitätsitems abgefragt) in dreierlei Hinsicht als problematisch gelten kann: Bei der Größe der Diskrepanz zwischen der Wichtigkeit des Qualitätskriteriums und der wahrgenommenen Einlösung beziehungsweise Umsetzung durch die Medien liegt »Transparenz« im Vorderfeld (Rang 
6 von 19). Zudem sind hier laut Studie die Erwartungen der Nutzer*innen extrem gering (Rang 2).

Bisher war es eher die fünfte (und damit meist letzte) der sogenannten W-Fragen, die eine Nachricht als Meldung oder Bericht prägen sollen: Welche Quellen werden ausgewählt und welchen Quellen wird (inwiefern) vertraut? Gerade diese Fragen scheinen mit Blick auf die massive Zunahme journalistischer Angebote einerseits und die deutlichen sozialen und nicht zuletzt medienbezogenen Segregationstendenzen andererseits an Dringlichkeit zu gewinnen, insbesondere für das normative Ziel gelingender gesellschaftlicher Kommunikation im Sinne von Jürgen Habermas oder Michael Haller (Köhler 2015, 13-14). Dieses lässt sich auch beschreiben als eine möglichst rückkopplungsreiche Gesellschaft wie bei Dietmar Dath und Barbara Kirchner (vgl. ebd.) oder als eine Gesellschaft responsiver, resonanter Wechselverhältnisse »Zwischen Selbst und Welt« (Rosa 2013, 147).

\section{Einige Beispiele aus der Krisenberichterstattung}

Fehlende Quellentransparenz scheint ein grundsätzliches Problem im gegenwärtigen Journalismus zu sein, was angesichts von kontrovers bewerteten Krisenlagen seit etwa 2010 vielleicht deutlicher wird als zuvor. Zwei kurze Beispiele zunächst mit Blick auf die höchst umstrittene Situation in Bolivien 2019 im Zusammenhang mit der Absetzung von Evo Morales, die wie auch der folgende Fall Babtschenko für mediale Umgänge mit der transformationstheoretisch und -praktisch grundlegenden Frage »Krieg oder Frieden? - oder konkret: »Internationale Eskalation oder Entspannungsbemühungen?«- stehen. ${ }^{1}$

a. »Das Militär will die Ordnung wiederherstellen«, meldete etwa die Süddeutsche Zeitung online am 12.11.2019 (Gurk 2019). Man rieb

1 In Kapitel 1, Artikel 1 der UN-Charta heißt es seit 1945: „Die Vereinten Nationen setzen sich folgende Ziele: 1. den Weltfrieden und die internationale Sicherheit zu wahren und zu diesem Zweck wirksame Kollektivmaßnahmen zu treffen, um Bedrohungen des Friedens zu verhüten und zu beseitigen, Angriffshandlungen und andere Friedensbrüche zu unterdrücken und internationale Streitigkeiten oder Situationen, die zu einem Friedensbruch führen könnten, durch friedliche Mittel nach den Grundsätzen der Gerechtigkeit und des Völkerrechts zu bereinigen oder beizulegen.« https://www.unric.org/de/charta. Zugegriffen: 16. November 2019. 
sich die Augen: Welche Ordnung? Und warum gerade das mit Putschvorwürfen konfrontierte Militär? Wieso wird der Satz als Tatsache ohne Quellenangabe behauptet? Das Mindeste wäre, die Version - sofern es sich nicht um (recherchiert) »Unstrittiges« wie »Heute ist Sonntag《 handelt - als Version (vgl. Haller 2008, 60; siehe auch Schultz 2019 mit Bezug auf journalistische Quellenkritik) kenntlich zu machen, in etwa also: »Militärführung: Wollen Ordnung wiederherstellen«.

b. Im ARD-Teletext hieß es am 13.11.2019 um 21.10 Uhr auf Tafel 112: »Bolivien hat Interimspräsidentin«. So werden nicht zuletzt medial »Tatsachen « geschaffen. Die rechtsgerichtete Senatorin Jeanine Áñez hatte sich selbst zur Übergangsregentin ernannt, ohne jede nachvollziehbare demokratisch-parlamentarische Legitimation. Auch hier wäre eine zumindest implizite Quellenangabe hilfreich zum Verständnis, im Sinne von »Senatorin ernennt sich zur Interimspräsidentin « - allemal nachrichtlich treffender als die zitierte Überschrift.

Phänomenologisch-explorativ möchte ich zum umfassenden Aufschließen dieses Problemfeldes ausgehen vom Fall zahlreicher Meldungen über die vermeintliche Ermordung des russischen Journalisten Arkadi Babtschenko im Jahr 2018. Eine Überschrift wie »Ukrainische Behörden: Babtschenko getötet « kann in diesem Kontext als empirisch wahre Aussage gelten. Leider hatten sich an jenem 29. Mai nur sehr wenige Medien so geäußert. Stattdessen texteten die Vertreter*innen direkt im Sinne von »Babtschenko getötet« oder »Babtschenko ermordet«. Dass man sich auf Behörden in Kiew als Quelle bezog, tauchte, wenn überhaupt, erst im Laufe des Beitrages auf. Der Fall entpuppte sich wenig später als ein Manöver des ukrainischen Geheimdienstes SBU.

Mein Beitrag soll auch an dieser Stelle ein Plädoyer für (mehr) Transparenz im Journalismus sein, nicht zuletzt mit Blick auf die Quellenlage. Und deshalb ein pragmatischer Vorschlag vorab: Nennen wir doch die (wichtigste oder eben einzige) Quelle so früh wie (sinnvoll und angemessen) möglich. Das sollte es den Nutzer*innen von vornherein und gleichberechtigt ermöglichen, den Beitrag einordnen zu können. Im Fall Babtschenko ruderten viele Medien am 30. Mai 2018 nach Bekanntwerden des Fakes zurück. Sie übten allerdings auch dabei kaum Selbstkritik. Stattdessen wälzten sie die Schuld für dieses spezielle journalistische Versagen nun wahlweise auf Leute aus der Ukraine oder aus Russland ab. 
Abb. 1: Meldung in der 17-Uhr-

Tagesschau am 29.05.2018 im

$A R D$.

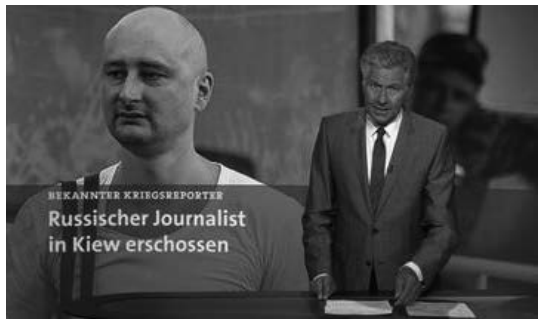

UPDATE $30.05 .2018,15: 26 \mathrm{Uhr}$

\section{Der Mord an Arkadi Babtschenko verdeutlicht die russisch-ukrainische Feindschaft}

Der Journalist Arkadi Babtschenko wird vor seiner Wohnung in der ukrainischen Hauptstadt Kiew erschossen. Der Vorfall sorgt für weitere Spannung zwischen Kiew und Moskau. von OLIVER BILGER

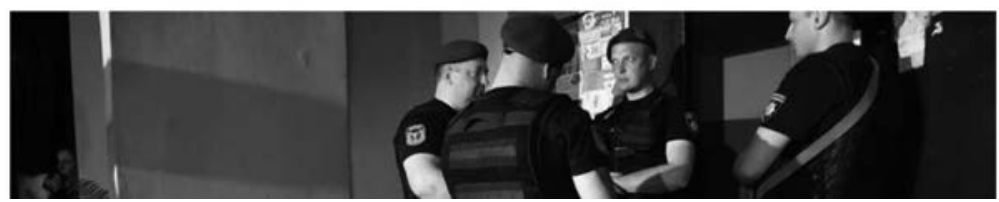

Abb. 2: Schlagzeilen ohne Quellenverweis im Tagesspiegel (Bilger 2018).

Daher nun als phänomenologischer Aufschluss einige medienkritische Aspekte zum Fall Babtschenko, exemplarisch anhand eines längeren Beitrages auf Spiegel Online (vks/dpa 2018). Dieser stammt nach eigenen Angaben der Redaktion vom 1. Juni 2018 um 18.37 Uhr, erschien also etwa zwei Tage, nachdem die ersten Beiträge zum Thema veröffentlicht worden waren. Die Quelle »Ukrainische Behörden« wurde in vielen etablierten deutschen Medien nicht oder kaum angegeben, wie zum Beispiel in der 17-Uhr-Tagesschau am 29. Mai (Abb. 1). Weder in der Dach- noch in der Schlagzeile benennt man die Quelle. Dabei wäre durchaus Platz gewesen - »bekannter Kriegsreporter « und »russischer Journalist« wirken hier synonym. Ähnlich sah das am 30. Mai im Tagesspiegel aus (Abb. 2).

Silvio Waisbord erklärt zu Phänomenen wie diesem mit Blick auf Entwicklungen im tradierten und im digitalen Journalismus: »Readers consume absolute fictions as if they were (f)actual representations of reality, and engage with news without much concern for the identity or the legitimacy of the source.« (Waisbord 2019, 357) Und dies könne auch so interpretiert und kritisiert werden: »Rogue actors spread false information.« (ebd.) Andere Nutzer*innen mögen sich abwenden oder 
den Beiträgen erst gar nicht Aufmerksamkeit schenken, weil sie sich von solchen intransparenten Einseitigkeiten kaum angesprochen fühlen.

Bemerkenswert hierbei eine offenbar durch den digitalen Journalismus und dessen Dynamisierungen tendenziell beförderte Verschiebung mit Blick auf die Quellenlage: Im Fall Babtschenko haben viele Journalist*innen und Redaktionen wie naive Konsument*innen gewirkt: Sie zeigten bemerkenswert wenig Sorge hinsichtlich Identität oder Legitimität der Quelle. Die Herkunft wurde anscheinend nicht nur kaum geprüft, sondern darüber hinaus auch nur selten (und dann eher durch Nischenmedien) von vornherein angegeben.

Einen Erklärungsversuch für das Erheben einer offenbar interessierten Version, einer Fälschung, in den Rang einer Tatsache deutet der Spiegel-Online-Beitrag gegen Ende an: „Viele Journalisten [hier müsste man sagen: prowestliche Journalist*innen; SK] trauerten am Tag des angeblichen Mordes « - und waren offenbar kaum zur professionellen Nachrichtenproduktion geschweige denn zur Analyse fähig. Es ging vermeintlich ganz klar um »den Mord an dem erklärten Kremlkritiker«. Als Kronzeugen zitiert Spiegel Online einen erklärten Freund Babtschenkos, den Investigativreporter Pawel Kanygin von der Moskauer Nowaja Gaseta: »Das ist ein Terroranschlag auf die Gemeinschaft von Journalisten in Russland und in der Ukraine.« Der Kollege sei dann verständlicherweise erleichtert gewesen, als die Fälschung bekannt wurde: »Er lebt, das ist das Wichtigste! Und abends kriegt er eins hinter die Löffel, weil mir die letzten Haare ausgegangen sind.«

Doch auch dieser Beitrag kommt zumindest zu dem (offenbar kritisch gemeinten) Schluss: »Die Glaubwürdigkeit der Medien leidet unter solcher Irreführung «, und »Journalisten müssen noch intensiver und noch viel genauer hingucken«, zitiert der Spiegel-Online-Beitrag wiederum Frank Überall, den Vorsitzenden des Deutschen Journalisten-Verbands (DJV). Das ist nicht falsch, aber oft würde es - angesichts (leider) geringer und weiter schwindender Ressourcen für journalistische Arbeit - schon helfen, professionelle Standards der Nachrichten(Re-)Produktion zumindest zu halten, oder eben dialektisch aufzuheben. Hier würde das bedeuten, die Quelle ganz sachlich zumindest klar und von vornherein anzugeben, falls die Ressourcen nicht für weitergehende Recherchen reichen, und sich nicht von Emotionen hin- und wegreißen zu lassen.

Zu guter Letzt kommt Pawel Gussew, Chefredakteur der russischen Zeitung Moskowski Komsomolez, zu Wort (ebd.): »Das ist nicht nur eine Provokation gegen Russland. Das ist auch eine Provokation Babtschen- 
kos gegen die ganze Journalistenzunft.« Beides ist nicht von der Hand zu weisen. Und in beide Richtungen, bezüglich Länder wie Russland, aber auch hinsichtlich des Journalismus, mag mit Blick auf zu verbessernde Quellentransparenz aus Fällen wie diesem gelernt werden. ${ }^{2}$ Es dürfte (auch hier) Transformationsbedarf bestehen: Für den Journalismus, für die gesellschaftliche Kommunikation und für neue Entspannungspolitiken in einer multipolaren Welt.

\section{$3 \quad$ Systematisches zu Transparenz und Quellen-W}

Nun seien hier einige wichtige Aspekte zur Entwicklung der Rolle des Quellen-W in Rhetorik und Journalismus diskutiert. Denn auch in deren Verlauf gab es Transformationen, die zu Wieder-Entdeckungen im Sinne dialektischen Aufhebens einladen.

»Transparenz « zählt seit langem zu den Kernforderungen an journalistische Qualität (Reimer 2017, 101). Sie soll einerseits und traditionell die Gegenstände journalistischer Beiträge durchschaubar(-er) machen, aber als gewissermaßen reflexive Qualität auch Bedingungen und Prozesse journalistischen Arbeitens selbst erkennbar und damit (besser) kritisierbar werden lassen.

Hier ist vor allem der zweite Aspekt interessant. Zunächst sei diese journalistisch-reflexive Transparenz die Gesamtheit jener journalistischen Kommunikationen, die nicht zuletzt an Rezipienten gerichtet sind und über die journalistische Aussagenproduktion sowie ihre Rahmenbedingungen informieren sollen (Reimer 2017, 102-103). Beim Schaffen journalistischer Selbsttransparenz lassen sich drei Dimensionen unterscheiden (ebd., 103-104):

1. In der ersten Dimension kann zwischen einer Objekt- und einer Metaebene unterschieden werden, auf denen Journalist*innen Transparenz herstellen: a) das Produkt, also der einzelne journa-

2 Es ist kein Einzelfall: Ich habe an anderer Stelle (Köhler 2019, 73-98) ähnliche Medienphänomene mit Blick auf den »Fall Skripal« ausführlich diskutiert. Im Jahr 2020 wiederum stand schon früh für viele Medien hierzulande fest und wurde als Tatsache vermeldet: »Nawalny vergiftet«, und zwar unter Schlagzeilen wie »Konflikt mit Russland«. Quellen wie »Bundesregierung« oder »Bundeswehrlabor « wurden nicht oder kaum angegeben; beispielsweise ZDF: »Nawalny vergiftet«, https://www.zdf.de/nachrichten/video/politik-nawalny-vergiftungnervenkampfstoff-100.html. Zugegriffen: 31. Oktober 2020. 
listische Beitrag, und b) der Prozess, also redaktionelle Routinen und Entscheidungen.

a. Produkt- beziehungsweise Beitragstransparenz soll dem Publikum ermöglichen, auf den Beitrag zu reagieren, weil Verschiedenes überprüft werden kann, was der intersubjektiven Nachvollziehbarkeit in der Wissenschaft ähnelt. Und genau hier ist Quellentransparenz das wohl wichtigste Beispiel: Journalistisch Tätige sollten sowohl die Quelle(-n) explizit (oder zumindest implizit) nennen als auch bei deren Einordnung helfen, indem nicht zuletzt die dahinterstehenden Interessen deutlich gemacht werden.

b. Prozess- beziehungsweise redaktionelle Transparenz hingegen soll auf Entscheidungskontingenzen der redaktionellen Ebene sowie auf entsprechende Rahmenbedingungen hinweisen. Beispiele wären hier die Begründung von Themenauswahl und -umsetzung, die Erläuterung redaktioneller Richtlinien oder auch die Offenlegung von persönlichen Interessen und Interessenkonflikten. »Actor transparency« (ebd., 104) soll den Mediennutzer*innen helfen, Journalist*innen als Personen (besser) einzuordnen, zum Beispiel hinsichtlich deren politischer oder sonstiger soziokultureller Orientierung. Laut Reimer lassen sich diese beiden Arten von Selbsttransparenz zwar unterscheiden, aber kaum trennen: Enthält ein Beitrag einen Fehler, wird er häufig nicht nur verbessert (Beitragstransparenz), sondern es wird auch erläutert, wie und warum es im journalistischen Prozess zu diesem Fehler kommen konnte (redaktionelle Transparenz).

2. In einer zweiten Dimension zerfällt die Transparenz Reimer zufolge nach Kommunikationsform in monologische (Übertragung der Redaktionskonferenz, Angabe von URLs) und dialogische Transparenz (Chat mit Nutzer*innen).

3. In einer dritten Dimension kann differenziert werden, ob das Transparenz-Instrument auf das Internet angewiesen ist oder nicht.

Eine weitere Ebene der Transparenz wäre eine Unterscheidung nach Grad des Nutzens für die Publika als Kommunikationstransparenz: Was ist aus Sicht der Publika notwendig (»must have«), was ist eine sinnvolle Ergänzung (»nice to have«) und was stört sogar eher bei der Nutzung? ${ }^{3}$ Gerade dafür wäre mehr Austausch auf Augenhöhe mit Me-

3 Sicher erhöhen zusätzliche Transparenz-Informationen in der Tendenz die 
diennutzer*innen sinnvoll - zum Beispiel zu Fragen des Einblendens (Insertierens) von Quellen in nachrichtlichen Videobeiträgen. Denn es gibt Hinweise, dass etablierte Redaktionen (wie ARD-Aktuell) den Bedarf zumindest von Teilen ihrer Publika nach Quellentransparenz eher unterschätzen (ebd., 106). Dabei lassen sich neben dem Material, das dort selbst produziert wurde, mindestens sechs Quellenarten unterscheiden: 1) kommerzielle Quellen (PR-Material von Konzernen), 2) andere organisationsnahe Quellen (PR-Material von Greenpeace oder Sportclubs), 3) (quasi-)staatliche Quellen (Material von Regierungen oder Behörden), 4) user-generated content (Nutzerinhalte vor allem via Smartphones), 5) journalismusähnliche Quellen (journalistisch orientierte Blogger wie Rezo oder Rayk Anders) und 6) tradiert-journalistische Quellen (andere Redaktionen, die auch nach professionellen Maßstäben arbeiten, zum Beispiel Agenturen wie AP, Reuters und AFP oder Sender wie CBS, BBC und ZDF).

Nun zu einigen Aspekten der Quellenfrage: In Journalismus und Journalistik soll »Quelle« das Material bezeichnen, das einem journalistischen Beitrag zugrunde liegt (Schultz 2019). Daher gehe es zugleich um dessen Herkunft: Eine Quelle sei diejenige Person, Institution oder Kommunikation, von der eine bestimmte Information herrühre. Viele Arten von Quellen haben sich über die Jahrhunderte mindestens ebenso professionalisiert wie der Journalismus - Medienprofis der Auftragskommunikation in Wirtschaft, Politik, NGOs und Vereinen wissen, wie sie redaktionelle Aufmerksamkeit induzieren. Das sollte für den Journalismus gerade hinsichtlich der Quellentransparenz als Herausforderung verstanden werden: Denn vieles an gesellschaftlich wirksamen Informationen ist ja gerade deshalb in der Welt, weil es an deren Zirkulieren ein (oft machtvoll organisiertes) Interesse gibt, wie etwa Angela Phillips (2010) unterstreicht.

Im digitalen Journalismus kann praktisch jeder zur Quelle werden. Auch Silvio Waisbord (2019, 352-354) zufolge wird nicht mehr (nur) zur Nachricht, was ausschließlich Journalismus-Profis als (einstige) Gatekeeper in ihren Redaktionen entscheiden. Neben »ordinary citizens« fallen hier vor allem (nicht so ganz) neue professionelle Ak-

Komplexität journalistischer Medienangebote - das kann laut Reimer auf Kosten der Verständlichkeit gehen und die Aufmerksamkeit des Publikums von der eigentlichen Nachricht ablenken (Reimer 2017, 109). Betriebswirtschaftlichökonomistisch Orientierte mögen monieren, es handle sich bei besserer Quellen-Transparenz um »Verschwendung von Zeit, Aufwand, Personal und anderen Ressourcen« (ebd.). 
teur*innen als Quellen auf: »Public relations and marketing firms have perfected the science of news virality and native advertising. Government agencies flood the Internet with content that resembles traditional news.« (ebd.) Die Verhältnisse dürften eher komplizierter werden: "News authorship is also more complicated as networks of authors permanently produce layers of content by adding, discussing, excising, deleting, and reframing content.« (ebd.) Die Interessen der Quellen sind ein wichtiger Aspekt für die journalistische Arbeit: »Multiple actors have many motivations to participate in news-making [...] Political propagandists spread news to deceive voters. Legislation mandates government agencies to disseminate news and information.« (ebd.) Gerade weil Organisationen offenbar auch PR betreiben, die nicht mehr selektive Tatsachen verbreitet, sondern anscheinend zielgerichtet Falsches vermittelt, sollte es also im Journalismus wichtiger werden, die Quellen dafür einerseits zu prüfen und andererseits im jeweiligen Beitrag frühestmöglich deutlich zu machen. Denn ein »vorgelagerter Faktor« für das Vertrauen der Publika in journalistische Beiträge dürfte das Vertrauen von Journalist*innen in Quellen sein (Krüger 2020). An Bedeutung scheinen dabei »distanzierte Quellen« zu gewinnen, also Akteur*innen, welche die Journalist*innen nicht persönlich getroffen haben, sondern deren Angebote sie oft über Internetplattformen von Intermediären (Soziale Medien wie Twitter) erreichen - nicht zuletzt in der Krisen- oder Konfliktberichterstattung (vgl. Wintterlin 2019).

\section{Normativ-pragmatische Aspekte als Ausblick - Ansätze für Transformationen über den Journalismus hinaus}

Quellentransparenz (selbstverständlich unter Berücksichtigung etwaigen Quellenschutzes bei investigativen Beiträgen) als ein wichtiger Aspekt von Selbsttransparenz kann als notwendiges Kriterium für journalistische Beiträge gelten. Natürlich lassen sich auch andere Perspektiven relativ »fair« ganz ohne Quellenangabe darstellen. Pragmatistisch mag man an der Stelle darauf hinweisen, die Mediennutzer*innen nicht durch zu viele oder zu frühe Quellenangaben zu überfordern. Damit aber vergäbe man durch Über-Vereinfachung Potenziale für besser gelingende gemeinschaftliche und gesellschaftliche Kommunikation, die hier durch leichtere Perspektivenwechsel und möglichst symmetrische Kom- 
munikation vermittelt wird. ${ }^{4}$ Nicht nur Angela Phillips (2010, 8; 2011, 58; vgl. Reimer 2017, 108) argumentiert daher, dass es - sofern sich mehr und bessere Quellentransparenz als professionsweite Norm durchsetze - für Journalist*innen schwerer werde, besonders einseitig (und gleichsam unbemerkt) Quellen zu verwenden und so tendenziell Fakten sogar zu verdrehen. Andere nennen damit Verwandtes auch das Phänomen »opportuner Zeugen « (Schultz 2019), also das einerseits gezielte und dann andererseits oft auch intransparente Zitieren solcher Quellen, die der (politischen) Tendenz eines Beitrags, eines journalistisch tätigen Individuums oder einer Redaktion am meisten entsprechen.

In Deutschland ist die Rechtslage, was die Sorgfalt im Umgang mit der Herkunft von Ausgangsdaten angeht, durch die Landespressegesetze bestimmt, die sich alle recht ähnlich zu dieser Frage verhalten. Hier sei stellvertretend auf das Berliner Landespressegesetz verwiesen. ${ }^{5}$ In Paragraph 3 heißt es dort zur öffentlichen Aufgabe der Presse und damit der journalistischen Medien überhaupt in Absatz 2: »Die Presse hat alle Nachrichten vor ihrer Verbreitung mit der nach den Umständen gebotenen Sorgfalt auf Inhalt, Wahrheit und Herkunft zu prüfen.« Diese Prüfung sollte wie seit Jahrzehnten gefordert sicher weiterhin geleistet werden, aber der Fall Babtschenko macht auch deutlich: Es bleibt ein systematisches Restrisiko, dass sich die Ausgangsinformationen (»Babtschenko getötet«) schlicht als nicht wahr erweisen - egal, ob nun bewusst gefälscht (manche nennen das dann »Fake News«) oder eher zufällig falsch. Deswegen gehört zur professionellen Sorgfalt beim prüfenden Umgang mit Ausgangsdaten, dass auch und gerade für die Nutzer*innen die Herkunft des Materials möglichst sofort erkennbar und nachvollziehbar werden sollte. Solches Herangehen dürfte die

4 Die Organisation The Media Standards Trust hat in London das Meta-Tag »hNews« für Mikroformate entwickelt, das interessierten Nutzer*innen zeigen soll, wo die Information zuerst auftauchte, was ihre weitere Publikationsgeschichte war und welche Rahmenbedingungen auf den entsprechenden Plattformen galten. Ähnliche Tags wurden auch von der New York Times und anderswo entwickelt (Garton Ash 2016, 188). Diese Daten sollten auch nicht als störend erscheinen: »It is visible only for those who want to access it.« (Phillips 2010, 7)

5 Berliner Pressegesetz vom 15. Juni 1965: http://gesetze.berlin.de/jportal/ portal/t/173q/page/bsbeprod.psml;jsessionid=FEC85A598D974D2282499A6 A0CA8D862.jp29?pid=Dokumentanzeige\&showdoccase $=1 \&$ js_peid $=$ Trefferliste \&documentnumber $=1 \&$ numberofresults $=28 \&$ fromdoctodoc $=$ yes $\&$ doc . $\mathrm{id}=\mathrm{jlr}$-PresseGBErahmen\&doc.part $=$ X\&doc.price $=0.0 \&$ doc. $h \mathrm{l}=1 \#$ jlr-PresseG BEpP3. Zugegriffen: 19. August 2020. 
sorgfältige Prüfung der Herkunft durch die Redaktion nicht ersetzen, sondern sollte sie - mit Blick auf eine zumindest potenziell mündige Nutzer*innenschaft - von vornherein ergänzen. Wenn die Nutzenden gewissermaßen »a priori« wissen, dass das Ausgangsmaterial zum Beispiel von ukrainischen Behörden stammt, dann können sie diese Tatsache aktiv zur eigenständigen Einordnung der Behauptung verwenden. Umgangssprachlich gesagt: Dann kann ich als Nutzer die Behauptung eher »glauben« oder ihr, besser gesagt, vertrauen - oder eben meine Zweifel daran haben.

Bernard Pörksen (2018) fragt zukunftsweisend: Wohin entwickeln sich Redaktionen? Oder anders formuliert: Kann »Redaktion « auf neue Weise sogar zu einem gesellschaftlichen Prinzip werden? Er schlägt eine »Utopie der redaktionellen Gesellschaft« vor. Ihm gehe es darum, publizistische Verantwortung neu zu denken und »die Verantwortungszone« auszuweiten. Damit soll eine redaktionelle Gesellschaft das längst medienmächtig gewordene Publikum ähnlich einbeziehen wie den etablierten Journalismus oder auch die Plattformbetreiber. Allerdings erscheint dieser Ansatz zu stark auf Moral und Ethik konzentriert: Pörksen fragt nicht in ausreichendem Maß nach (handfesten) Interessen, Konflikten und Krisen in Gesellschaften wie der gegenwärtigen hierzulande, die er als »liberale Demokratien « bestimmt, womit er zum Beispiel Turbo-Kapitalismus und verschärfte Konkurrenz ignoriert.

Wenn auch das »Handwerkszeug « laut Pörksen bereits vorhanden ist, bleibt eine Aufgabe: Mit Blick auf ihre Publika müssten sich Journalist*innen von ihren bisherigen elitären Höhen in Bewegung setzen »sie müssten sich von der Rolle des Predigers, des Pädagogen und des autoritär auftretenden Wahrheitsverkünders verabschieden« (ebd.). Pörksen versucht, sein Ideal eines transparent und dialogisch orientierten Journalismus anhand von zwei Imperativen zu formulieren: Erstens gebe man seinem Publikum »jede nur denkbare Möglichkeit, die Qualität der von dir vermittelten Informationen einzuschätzen!«. Auch in dieser Hinsicht scheint frühestmögliche Transparenz mit Blick auf die Quellenlage eine enorm wichtige »denkbare Möglichkeit«. Und zweitens begreife man die eigene Kommunikation nie als Endpunkt, sondern immer als »Anfang und Anstoß von Dialog und Diskurs«. Auch hier kommt die Quellenfrage zuvörderst ins Spiel - Nutzer*innen können bei bestmöglicher Transparenz weitere Quellen suchen und kritisch einbeziehen und nicht zuletzt den primär Beitragenden als selbst auch Beitragende durch Feedback produktive Anstöße geben (vgl. Köhler 2018). 
Mit Blick auf Transformationsfragen für den Journalismus sind also auch daher Schritte in Richtung des (Wieder-)Gewinnens von Vertrauen in professionelle Medienangebote möglich: Wenn Nutzer*innen möglichst frühzeitig erfahren, wessen Perspektive ihnen hier warum präsentiert wird, dann sollten Chancen für symmetrische(-re) Kommunikation tendenziell steigen (vgl. Phillips 2010, 2-4). Derart könnte sich die Umsetzung der zur Erfüllung von kulturell-transformativen Aufgaben öffentlicher Medien und für weitere Demokratisierungen wichtigen Perspektivenwechsel (vgl. Krüger 1992, 220-229) wenigstens nicht noch weiter erschweren.

Nicht nur Redaktionen und Journalist*innen, sondern auch Publika und Gesellschaft sollten journalistische Selbsttransparenz nutzen. Quellentransparenz als Aspekt der Beitragstransparenz kann auf der Objektebene Nutzer*innen-Aktivität sowie -Vertrauen steigern und Redaktionen, die regelmäßig öffentlich über ihre Arbeit berichten, stoßen sich an und werden angestoßen auf der Metaebene zu mehr Reflexion gerade mit Blick auf ihre öffentliche Aufgabe und Verantwortung (vgl. Reimer 2017, 107-108). Oder in Phillips (2010, 8) Worten: Entwicklungen in Richtung von mehr Transparenz gerade hinsichtlich der Quellen journalistischer Arbeit mögen zu weiteren Demokratisierungen beitragen.

So sollte nicht zuletzt mehr und bessere Quellentransparenz - als ein Vermittlungsglied zwischen Journalist*innen und Nutzer*innen einerseits und gesellschaftlichen Öffentlichkeiten andererseits - Perspektivenwechsel und symmmetrische(-re) Kommunikation eher befördern und progressive Transformationen (in diesem Beitrag skizziert an Beispielen im Kontext friedlichen Zusammenlebens) für möglichst alle Menschen zumindest tendenziell erleichtern - global gesehen und auch für künftige Generationen.

\section{Literatur}

Bilger, Oliver. 2018. Der Mord an Arkadi Babtschenko verdeutlicht die russischukrainische Feindschaft. Tagesspiegel vom 30. Mai, https://www.tagesspiegel. de/politik/toter-kremlkritiker-der-mord-an-arkadi-babtschenko-verdeutlichtdie-russisch-ukrainische-feindschaft/22623110.html. Zugegriffen: 13. November 2020.

Garton Ash, Timothy. 2016. Free Speech. Ten Principles for a Connected World. Redefreiheit. Prinzipien für eine vernetzte Welt. New Haven, London: Yale University Press.

Gurk, Christoph. 2019. Bolivien: »Bürgerkrieg jetzt!« Süddeutsche Zeitung vom 19. 
November, https://www.sueddeutsche.de/politik/bolivien-morales-1.4678557. Zugegriffen: 13. November 2020.

Haller, Michael. 2008. Recherchieren. 7. Auflage. Konstanz. UVK.

Haller, Michael. 2017. Vorwort. In: Öffentliches Vertrauen in der Mediengesellschaft, herausgegeben von Michael Haller, 9-12. Köln: Herbert von Halem.

Köhler, Sebastian. 2015. Aufgehobener Journalismus. Zu einigen Aktualisierungen von Internetnutzungspotenzialen für gelingende gesellschaftliche Kommunikation. In: Gesellschaft. Medien. Rezeption. Wie unsere Wirklichkeit kommunikativ gestaltet wird, herausgegeben von Frank Überall und Klaus-Dieter Schulz, 1332. Münster: Lit.

Köhler, Sebastian. 2018. Mehr beitragen, weniger senden. Zur Rolle von Feedback und Artikulation im Journalismus. Journalistik. Zeitschrift für Journalismusforschung, 1 (2): 51-60. http://journalistik.online/ausgabe-02-2018/mehr-beitragen-weniger-senden/. Zugegriffen: 23. August 2018.

Köhler, Sebastian. 2019. Sieh an - (was für) eine Geschichte! In: Richtung nachhaltiger Narrativität: Zum journalistisch-audiovisuellen Storytelling in Zeiten von »Fake News«. In: Storytelling in Journalismus, Organisations- und Marketingkommunikation, herausgegeben von Silvia Ettl-Huber, 73-98. Wiesbaden: Springer VS.

Krüger, Hans-Peter. 1992. Zur kulturellen Aufgabe öffentlicher Medien in einer modernen Demokratie. In: Demission der Helden. Kritiken von innen 1983-1992, herausgegeben von Hans-Peter Krüger, 220-229. Berlin: Aufbau-Verlag.

Krüger, Uwe, und Michael Meyen. 2018. Auf dem Weg in die Postwachstumsgesellschaft. Plädoyer für eine transformative Kommunikationswissenschaft. Publizistik, 63 (3): 341-357.

Krüger, Uwe. 2020. Buchbesprechung zu Wintterlin, Florian: Quelle: Internet. Journalistisches Vertrauen bei der Recherche in sozialen Medien. Publizistik 65 (2), 291-293. DOI: https://doi.org/10.1007/s11616-020-00570-y.

Meyen, Michael. 2018. Fake Debate: Wem »Fake News« wirklich helfen. In: Medienrealität 2018, herausgegeben von Michael Meyen. https://medienblog.hypotheses.org/1009. Zugegriffen 11. April 2018.

Nordquist, Richard. 2019. The 5 Ws (and an H) of Journalism. https://www. thoughtco.com/journalists-questions-5-ws-and-h-1691205. Zugegriffen: 7. August 2019.

Phillips, Angela. 2010. Transparency and the new Ethics of Journalism. Journalism Practice, 4 (3), 373-382. DOI: 10.1080/17512781003642972.

Phillips, Angela. 2011. Journalists as unwilling »sources«. Transparency and the new ethics of journalism. In: Journalists, Sources, and Credibility. New Perspectives, herausgegeben von Bob Franklin und Matt Carlson, 49-60. New York, London: Routledge.

Pörksen, Bernhard. 2018. Alle müssen Journalisten sein. Die Zeit Nr. 8 vom 15. Februar, http://www.zeit.de/2018/08/umgang-medien-fake-news-propagandajournalismus/komplettansicht. Zugegriffen: 13. November 2020.

Prochazka, Fabian. 2020. Vertrauen in Journalismus unter Online-Bedingungen. Zum Einfluss von Personenmerkmalen, Qualitätswahrnehmungen und Nachrich- 
tennutzung. https://link.springer.com/book/10.1007\%2F978-3-658-30227-6. Wiesbaden: Springer VS.

Reimer, Julius. 2017. Vertrauen durch Transparenz? Potentiale und Probleme journalistischer Selbstoffenbarung. In: Öffentliches Vertrauen in der Mediengesellschaft, herausgegben von Michael Haller, 101-119. Köln: Herbert von Halem.

Rezo. 2020. Was ist guter Journalismus? Die Zeit vom 5. Mai, https://www.zeit.de/ kultur/2020-05/henri-nannen-preis-journalismus-youtube-medien/seite-2. Zugegriffen: 18. Oktober 2020.

Rosa, Hartmut. 2013. Beschleunigung und Entfremdung. Entwurf einer Kritischen Theorie spätmoderner Zeitlichkeit. Berlin: Suhrkamp.

Rudolph, Steffen. 2019. Digitale Medien, Partizipation und Ungleichheit. Eine Studie zum sozialen Gebrauch des Internets. Wiesbaden: Springer VS.

Schultz, Tanjev. 2019. Quelle. In: Journalistikon. Das Wörterbuch der Journalistik. http://journalistikon.de/quelle/. Zugegriffen: 16. November 2019.

Schultz, Tanjev, Marc Ziegerle, Ilka Jakobs, Nikolaus Jackob, Oliver Quiring, und Christian Schemer. 2020. Medienzynismus weiterhin verbreitet, aber mehr Menschen widersprechen. Mainzer Langzeitstudie Medienvertrauen 2019. Media Perspektiven 6: 322-330. https://www.ard-werbung.de/fileadmin/user_upload/media-perspektiven/pdf/2020/0620_Schultz_Ziegele_Jakobs_Jackob_ Quiring_Schemer.pdf. Zugegriffen: 13. November 2020.

vks/dpa. 2018. Arkadij Babtschenko: Die vielen Rätsel um das angebliche Mordfoto. Spiegel Online vom 1. Juni, https://www.spiegel.de/politik/ausland/arkadi-babtschenko-ukraine-wie-das-bild-seiner-leiche-zustandekam-a-1210575.html. Zugegriffen: 13. November 2020.

Waisbord, Silvio. 2019. The 5Ws and $1 \mathrm{H}$ of Digital Journalism. Digital Journalism 7 (3): 351-358. DOI: https://doi.org/10.1080/21670811.2018.1545592.

Weischenberg, Siegfried. 2005. Nachricht. In: Handbuch Journalismus und Medien, herausgegeben von Siegfried Weischenberg, Hans J. Kleinsteuber und Bernhard Pörksen, 306-308. Konstanz: UVK.

Wintterlin, Florian. 2020. Quelle: Internet. Journalistisches Vertrauen bei der Recherche in sozialen Medien. Baden-Baden: Nomos.

Wolff, Volker, und Carla Palm. 2006a. Bericht. In: Lexikon Kommunikations- und Medienwissenschaft, herausgegeben von Günter Bentele, Hans-Bernd Brosius und Otfried Jarren, 21-22. Wiesbaden: VS Verlag für Sozialwissenschaften.

Wolff, Volker, und Carla Palm. 2006b. Meldung. In: Lexikon Kommunikations- und Medienwissenschaft, herausgegeben von Günter Bentele, Hans-Bernd Brosius und Otfried Jarren, 190. Wiesbaden: VS Verlag für Sozialwissenschaften.

\section{Open Access}

Dieser Beitrag erscheint unter der Creative-Commons-Lizenz CC BY-ND 3.0 DE: https://creativecommons.org/licenses/by-nd/3.0/de/. 


\title{
Transformationen im Online-Medienmarkt: Was wird aus den journalistischen Kompetenzen?
}

\author{
Michael Haller
}

Keywords: Informationsjournalismus, Journalistische Unabhängigkeit, Medienwandel, Kompetenzen, Kommerzialisierung, Funktionalismus, Normativität, Öffentlich-Rechtlich, Plattformen

\section{Abstract}

Ein Blick auf die Aus- und Weiterbildungsangebote zeigt den enormen Anpassungszwang, dem der Journalismus unter den Produktionsbedingungen im Internet ausgesetzt ist. Der hohe Wettbewerbsdruck und die unzureichende Gegenfinanzierung führen zum Verschleiß der tradierten Kompetenzen. Dieser Beitrag rekonstruiert die mit der Demokratietheorie begründeten Kompetenzgehalte, weiter die mit der universitären Journalist*innenausbildung verbundene Fehlentwicklung des Kompetenzbegriffs und diskutiert die beiden Perspektiven, die sich für die Entfaltung eines substanziellen Kompetenzverständnisses in der Welt der Onlinemedien bieten: Aussichten auf eine Kommunikationsgesellschaft, die über die Vorgänge in der Welt zuverlässig informiert werden und die damit verbundenen Beurteilungen und Positionen im öffentlichen Diskurs klären will.

Michael Haller: Transformationen im Online-Medienmarkt: Was wird aus den journalistischen Kompetenzen? In: Nils S. Borchers, Selma Güney, Uwe Krüger und Kerem Schamberger (Hrsg.): Transformation der Medien Medien der Transformation. Verhandlungen des Netzwerks Kritische Kommunikationswissenschaft. Frankfurt am Main: Westend 2021. DOI: https:// doi.org/10.53291/GCAL8505.

Prof. em. Dr. Michael Haller I Europäisches Institut für Journalismus- und Kommunikationswissenschaft (EIJK)। haller@uni-leipzig.de 
Wie und warum der Journalismus - man denkt an den aktuellen Informationsjournalismus - in einer Strukturkrise steckt, wird seit Jahren vielstimmig diskutiert. Die häufigste Erklärung lautet: Es ist das Internet. Wortführende Onlinejournalist*innen ${ }^{1}$ wie auch zahlreiche Kommunikations- und Medienwissenschaftler*innen (beispielsweise Neuberger 2002; Neuberger et al. 2009; Quandt 2005) haben unermüdlich auf die mit der Digitalisierung verbundenen Transformationsprozesse und auf die für die Onlinewelt neue »medienökonomische Wertschöpfungsdiskussion « (Kolo et al. 2012, 15-16) verwiesen. Die Modernisierer monierten, der Journalismus sei seinem überkommenen Rollenselbstverständnis als Gatekeeper und Welterklärer verhaftet geblieben und habe den Mediennutzungswandel des Publikums nicht ernst genommen oder nicht verstanden. Nun müsse er quasi nachsitzen und seine Hausaufgaben machen (Oswald 2013, 66-79), also den Transformationsprozess verstehen lernen, ihn akzeptieren und mitgestalten: »Wir sind mitten in einem Generationenwechsel - vom Schreiber hin zum Manager.« (Bönisch 2019, 60) ${ }^{2}$

Diese Sichtweise der Modernisierer hat sich zum Common Sense der Branche verfestigt. Man trifft sie heute in praktisch allen Einrichtungen der Aus- und Weiterbildung mit ihren einschlägigen Nachhol- und Umlernkursen etwa für Content-Marketing, Social-Media-Management oder digitales Storytelling für Produktmagazine, PR- und Werbekunden - stets mit dem Label »Journalismus « ${ }^{3}$ versehen. Eine Erhebung unter österreichischen Ausbildungsstätten bestätigt, dass in der Journalist*innenausbildung am weitaus häufigsten fachlich enge Kursthemen zu »Technik / Tools für Bildbearbeitung / Audio-, Videoschnitt« genutzt werden (Schätz und Kirchhoff 2020). Auch in Deutschland

1 Stellvertretend Plöchinger (2013) sowie sieben Jahre später Elmer et al. (2020).

2 Julia Bönisch, damals Mitglied der Chefredaktion der Süddeutschen Zeitung, schrieb in ihrem Beitrag, dass auch die Trennung zwischen Verlag und Redaktion nicht mehr zeitgemäß sei. Dem widersprach die SZ-Chefredaktion vehement (o.A. 2019).

3 Vgl. aktuelle Seminarangebote auf den Webseiten einschlägiger Weiterbildungseinrichtungen, Hier drei Beispiele: https://www.akademie-fuer-publizistik.de/ seminare/alle-seminare/online-seminar-in-drei-schritten-zu-mehr-reichweite; https://www.procontent.de/seminar/digitales-storytelling-interaktive-geschichten-fuer-online-und-mobile/; https://www.merkur.de/lokales/muenchen/stadt-muenchen/deutsche-journalisten-akademie-13794026.html. 
wird der Kompetenzumbau vorangetrieben, vorneweg die SpringerJournalistenschule, die im Herbst 2020 in die FreeTech-Academy der Axel Springer SE integriert wurde; deren »Ziel ist es, die eigene Technologie-Kompetenz langfristig auszubauen « ${ }^{4}$

Mit diesen Stichworten möchte ich die mit dem interaktiven Web 2.0 verbundenen Techniken keineswegs in Frage stellen. Dass Journalist*innen auch in handwerklicher Hinsicht die vielfältigen Interaktionsmöglichkeiten der Onlinekommunikation beherrschen sollten, steht außer Frage. Zu diskutieren wäre indessen das von den Aus- und Fortbildungsprogrammen vermittelte Berufsverständnis. Denn ihnen gemeinsam ist die Auffassung, dass die journalistischen Kompetenzen an die Marktbedingungen der Onlinemedien - etwa: Reichweite statt Relevanz im Kontext der noch immer vorherrschenden »Gratiskultur $\aleph^{5}$ - angepasst und »transformiert « werden sollen (offenbar wird »Kompetenz« als abhängige Variable der »digitalen Transformation« definiert). ${ }^{6}$ Den Medienmacher*innen geht es nicht darum, öffentlich Kritik und Kontrolle zu üben und politische Vorgänge unter den Gegebenheiten des Internets aufzuklären; das Lernziel gilt der Rückgewinnung von Marktanteilen vermittels der die Onlinewelt beherrschenden »Aufmerksamkeitsökonomie« (Ruß-Mohl 2017, 47-48). Und so lautet die von Medienmacher*innen alljährlich auf der re:publica, der Innovation Week von Media Lab Bayern und der Hamburger nextMedia-Konferenz gestellte Frage: Kann der Informationsjournalismus seine Strukturkrise überwinden, indem er sich in der Onlinewelt den „Gesetzen der modernen Erregungsindustrie« (Pörksen 2018) fügt, die derzeit den Medienwandel dirigieren? ${ }^{7}$

Diese Frage unterstellt, dass eine neue, der Digitalisierung der Medien geschuldete Transformationsstrategie entwickelt werden müsse (Schätz und Kirchhoff, 2020). Meine erste These lautet dem gegenüber:

4 https://www.axelspringer.com/de/presseinformationen/axel-springer-gruendet-freetech-academy-und-investiert-in-den-ausbau-der-technologie-kompetenz?

5 https://de.wikipedia.org/wiki/Gratiskultur.

6 Im Zusammenhang der Digitalisierung und der Onlinemedien wird der Begriff »Transformation« inflationär gebraucht. Ich folge hier der etwas grobschlächtigen Wikipedia-Definition: »Die digitale Transformation bezeichnet einen fortlaufenden, in digitalen Technologien begründeten Veränderungsprozess, der in wirtschaftlicher Hinsicht speziell Unternehmen betrifft.« https://de.wikipedia. org/wiki/Digitale_Transformation.

7 Näheres hierzu unter: https://www.nextmedia-hamburg.de/jeff-jarvis-skizziert-beim-scoopcamp-2020-die-zukunft-der-medienbranche/. 
Das Projekt, Journalist*innen in Kommunikationsmanager*innen der digitalen Newsmedien zu verwandeln, stützt sich auf ein Kompetenzverständnis, das keineswegs neu ist, sondern im Fortgang der vergangenen 30 Jahre an den Hochschulen fundamentiert wurde und die Journalist*innenausbildung mehr und mehr beeinflusst hat. Wie erklärt sich das?

\section{2 Über die Funktionalisierung journalistischer Aufgaben}

Anders als in der DDR, wo aus ideologischen Gründen die Journalist*innenausbildung schon in den 1950er Jahren akademisiert und auf die Funktion des Transmissionsriemens der Staatspartei ausgerichtet wurde, blieb Journalismus in der westlichen Bürgergesellschaft ein von der individuellen Eignung abhängiger Anlernberuf ohne Zugangssperre und von daher ein Forum für Begabte und Berufene wie auch ein Spielfeld für Um- und Seiteneinsteiger. Erst im Fortgang der 1960er Jahre änderte sich dies.

Anlass gaben der wachsende Einfluss der reichweitestarken Rundfunksender auf das Meinungsklima, der aggressive Kampagnenjournalismus der Boulevardmedien, die politischen Wirkungen des aufkommenden Investigativjournalismus (sinnbildlich die sogenannte Spiegel-Affäre 1962) und schließlich die vom Bundesverfassungsgericht 1961 (Rundfunkurteil) und 1966 (Spiegel-Urteil) dem Journalismus zugewiesene »öffentliche Aufgabe« (BVerfGE 20, 162-230): Diese »Politisierung von Gesellschaft und Journalismus« (Donsbach 1999, 497) löste unter Medienkontrolleuren (Presserat), Medienmachern, Zeitungsverlegern und Kommunikationswissenschaftlern eine »Professionalisierungsdebatte« aus (Koszyk 1974; Langenbucher 1974; Hömberg 1978). Sie führte zu dem Entschluss, die geforderten Kompetenzen des Journalist*innenberufs konzeptionell zu fassen und sie für die damals vielfältigen Ausbildungswege als Zielstellung zu formulieren. Die vom Deutschen Journalisten-Verband (DJV) in seinen Publikationen umrissenen Sach- und Vermittlungskompetenzen waren damals vom elitenkritischen Zeitgeist beseelt (Zeuner 1973, 13-16; Donsbach 1982, 163-172). Sie wiesen dem Journalismus neben der Informationsfunktion die Aufgabe zu, aus unabhängiger Sicht gegenüber Staat, Parteien und Wirtschaft eine öffentliche Aufklärungsfunktion wahrzunehmen (Schmolke 1970, 54) - ein Rollenverständnis, das die »innere Presse- 
freiheit $«^{8}$ als Bedingung verstand. Rund drei Viertel der Journalist*innen - verschiedenen Befragungen zufolge - reklamierten damals diese Rolle für sich (Donsbach 1982, 173; Fabris 1971, 360-368).

Als dann im Fortgang der 1970er Jahre mehrere Universitäten Journalismus-Studiengänge einrichteten, veränderte sich das Kompetenzverständnis und damit auch das Ausbildungsziel der Journalistik. ${ }^{9}$ Der Hauptgrund: In jener Zeit gewann dort die vor allem von Niklas Luhmann ausgearbeitete Systemtheorie an Einfluss. Kommunikationsund Medienwissenschaftler*innen nutzten sie zur Begründung ihrer Kritik an den normativen, als »links« etikettierten Medien- und Diskurstheorien..$^{10}$ Das Reden über wertneutrale System- und Umweltfunktionen kam in Mode und prägte das Journalismusverständnis als »Funktionsbewusstsein « in den Kommunikations- und Medienwissenschaften (Weischenberg 1990, 33).

Für dieses akademische Funktionsverständnis steht pars pro toto der Leitsatz des Systemtheoretikers und Journalistik-Studiengangleiters Manfred Rühl: Die Journalist*innen hätten keine Aufklärungsund keine Diskursfunktion; die Primärfunktion des »Systems Journalismus « bestehe vielmehr in der »Herstellung und Bereitstellung von Themen zur öffentlichen Kommunikation « (Rühl 1980, 319). Andere der Systemtheorie zugeneigte Journalistik-Wissenschaftler*innen erkannten aber, dass diese ausgedachte Definition auch die weite Welt des Fiktionalen und des Entertainments einschließt, praktisch also unbrauchbar ist. In der Folge theoretisierten sie über andere, den Kompetenzbegriff determinierende Funktionen des Journalismus, nämlich »aktuelle« Themen oder im Sinne Luhmanns einfach nur »Informationen « bereitzustellen (mit dem neuen Problem der Abgrenzung etwa gegenüber dem synthetischen Output der Datenbanken wie auch der Informationsbeschaffung von Geheimagent*innen und Steuerfahnder*innen). ${ }^{11}$ Um eine mit dem Luhmann'schen Systemdenken kompatible Kompetenz-Definition kümmerte sich vor allem Siegfried

8 Ende der 1960er Jahre ging es um die Frage, wie sich die Unabhängigkeit der Zeitungsredaktion gegenüber ihrem Medieneigentümer sichern ließe (Skriver 1970).

9 Vgl. die synoptische Darstellung »Ausbildung in den Tageszeitungen« (Ausbildungsrichtlinien und Tarifvertrag) in DJV (1990, 71-83).

10 Es war ein Machtkampf um Einfluss und Deutungshoheit, gut beschrieben insbesondere bei Holzer (1973, 11-29).

$11 \mathrm{Zu}$ den Gründen für die Realitätsferne jenes akademischen Journalismusverständnisses siehe Haller (2000, 110-120; 2012) sowie Donsbach (2012, 31-33). 
Weischenberg, der für das Journalistikstudium folgende drei Kompetenzdimensionen elaborierte: Fachkompetenz (Wissen und Handwerk), Vermittlungskompetenz (Artikulationsfähigkeit, Präsentation und Darstellungsformen) sowie Sachkompetenz (Ressort- und Spezialwissen). Der gesellschaftspolitische Zusammenhang wurde ausgeklammert, die »soziale Orientierung « als »Funktionsbewusstsein« der Vermittlungskompetenz unterstellt (Weischenberg 1990, 24). Den Älteren unter uns dürfte die gesamtdeutsche Enquête der Münsteraner Forschergruppe Weischenberg, Altmeppen und Löffelholz (1994) noch in Erinnerung sein: Was kompetente Journalist*innen in West wie Ost auszeichne, wurde mit Hilfe einer Delphi-Expertenbefragung ermittelt und nach Maßgabe der Weischenberg'schen Matrix kanonisiert: Fachkompetenz, Vermittlungskompetenz, Sachkompetenz sowie soziale Orientierung. Dieses Set fand in viele Journalistik-Curricula westdeutscher Universitäten Eingang, nicht aber in die Leipziger Fakultät, die das normative Leitbild der demokratietheoretisch begründeten »öffentlichen Aufgabe« zur Maxime erhob. ${ }^{12}$ Im Vergleich zu den anderen dualen Diplomstudiengängen (Dortmund, Eichstätt) fand jener in deutschen Chefredaktionen die relativ größte Wertschätzung (Harnischmacher 2010, 221).

\section{Die Ausdifferenzierung der Kompetenz-Matrix}

Zweifellos half die Münsteraner Kompetenz-Matrix, die akademische Journalist*innenausbildung systematisch zu begründen und auf ein Fundament zu stellen, das die Industrialisierung der Aussagenproduktion rechtfertigt. Sie offenbarte allerdings eine dreifache Problematik: Erstens fällt die starke Betonung der instrumentellen Ebene (das »Fachlich-Sachliche«) auf, zweitens die Unterbewertung der Determinanten der Marktwirtschaft (Medienökonomie) sowie drittens die mangelnde Beschreibung demokratietheoretisch fundierter Funktionen (Normativität). Im Rückblick gewinnt man den Eindruck, dass die von Medienpraktiker*innen in den frühen 1970er Jahren progressiv entwickelten Kompetenz-Inhalte (Sachaufklärung, Meinungsvielfalt, Kritik und Kontrolle) von den systemtheoretisch denkenden Journalistik-Dozent*innen nicht gewollt, vielleicht auch nicht verstanden wurden. Jedenfalls

12 Das »Leipziger Modell« wurde vom Verfasser im Laufe der 1990er Jahre an Jahreskonferenzen des DJV und des BDZV wiederholt vorgestellt und diskutiert. 
haben sie die Münsteraner Matrix im Fortgang der akademischen Debatte - im Bemühen um Anpassung an den Medienwandel - immer weiter ausdifferenziert. So erweiterte Klaus Meier die vier KompetenzDimensionen um die Felder »Technik- und Gestaltungskompetenz « sowie »Organisations- und Konzeptionskompetenz (Abb. 1). Immerhin umschrieb er dieses Kompetenzbündel deutlich pragmatischer, auch näher an den normativ zu begründenden Handlungsmaximen:

Journalismus recherchiert, selektiert und präsentiert Themen, die neu, faktisch und relevant sind. Er stellt Öffentlichkeit her, indem er die Gesellschaft beobachtet, diese Beobachtung über periodische Medien einem Massenpublikum zur Verfügung stellt und dadurch eine gemeinsame Wirklichkeit konstruiert. Diese konstruierte Wirklichkeit bietet Orientierung in einer komplexen Welt. (Meier 2007, 13; unverändert in der 4. Auflage 2018, 14).

Gleichwohl hielt der Systemtheorie-Jargon die akademische Journalistik besetzt (in Meiers Beschreibung recherchieren, selektieren und präsentieren nicht die Akteur*innen, also die Journalist*innen, sondern das abstrakte System »Journalismus«).

Es ist hier nicht der Platz, die aus jener Kompetenzdebatte abgeleiteten Curricula mit ihren Ausbildungszielen und ihrer Praxistauglichkeit zu diskutieren..$^{13}$ Es soll der Hinweis genügen, dass die Idee des gesellschaftlichen Auftrags, aus unabhängiger Perspektive durch Kritik und Kontrolle die Voraussetzung für eine politisch aufgeklärte Öffentlichkeit zu schaffen, nicht zurückgeholt wurde; vielmehr verflüchtigte sich dieses Leitbild zugunsten operativer Fertigkeiten, die den industriellen Routinen der sich beschleunigenden Medienproduktion dienen (stellvertretend Oswald 2013, 63-80) und immer neue, auf den Medienkonsumentenmarkt zugeschnittene Spezifitäten generieren (beispielhaft Becker und Kaiser 2014 nach Maßgabe von www.medienwiki.org) .

Ich leite daraus meine zweite These ab, dass schon seit Beginn der 1990er Jahre in der Aus- und Weiterbildung des Journalismus die auf Marktgängigkeit ausgerichteten instrumentellen Fertigkeiten in den Fokus rückten und den Journalismus unter der Etikette »Transformation « auf Dienstleistungsfunktionen im Kontext kommerzialisierter Medienproduktionen verkürzten - rund zehn Jahre bevor sich mit dem

13 Beschreibungen finden sich im DJV-Memorandum von 2003 sowie im Buchteil III »Klassisches Handwerk und Medientraining « des Sammelbandes herausgegeben von Dernbach und Loosen (2012, 183-271). 


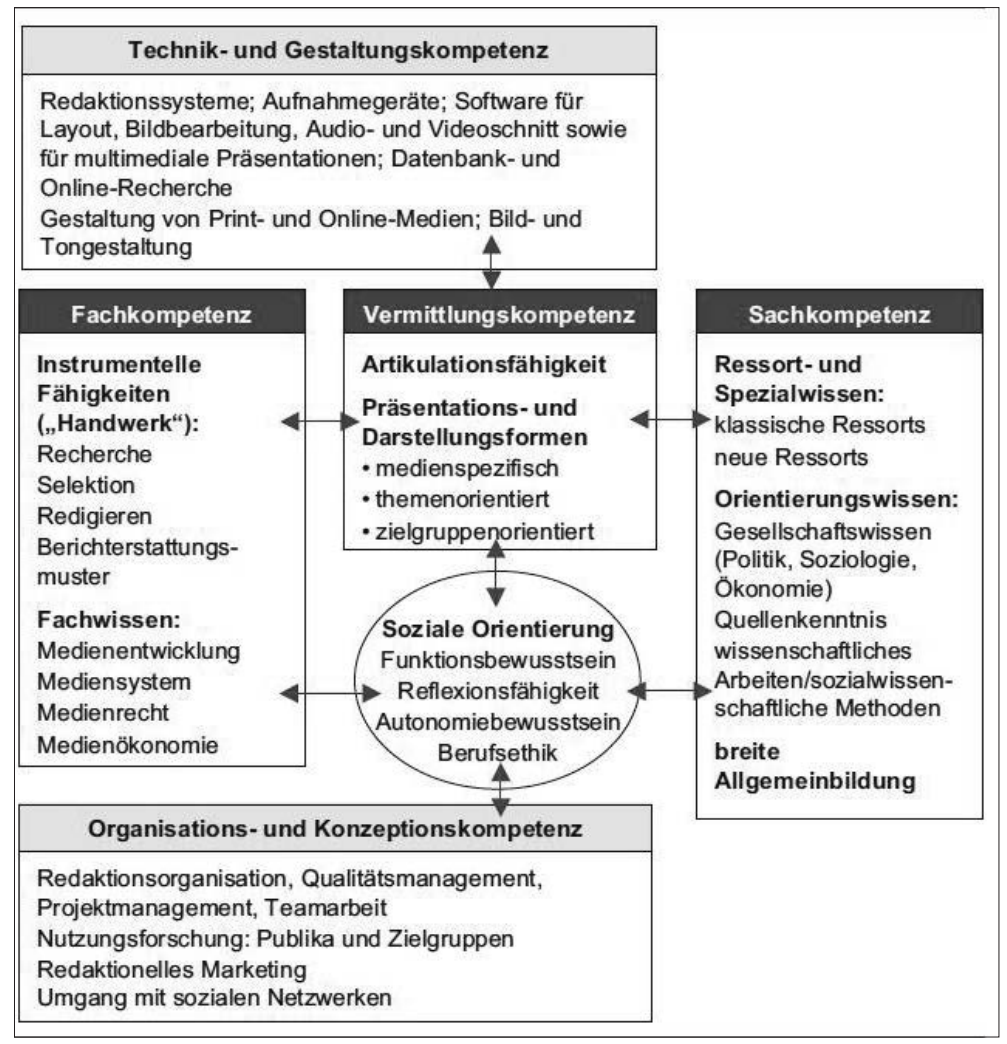

Abb. 1: Dimensionen journalistischer Kompetenz nach Weischenberg (1990) und Meier (2007).

Web 2.0 die Aufmerksamkeitsökonomie (»Gratis-Kultur«) durchzusetzen begann. Ist dieser Trend unumkehrbar?

\section{$4 \quad$ Die Umwelt als neue Dimension}

In der Zeit, als sich das Web 2.0 etablierte, führte die European Journalism Training Association (EJTA) in 16 europäischen Ländern eine Umfrage unter 402 Chef- und Ausbildungsredakteur*innen durch. ${ }^{14}$ Aus den Antworten konzipierte man im Jahr 2006 die sogenannte Tartu-

14 Der Dachverband EJTA umfasst 60 Hochschulen und Ausbildungsakademien mit Journalistik-Lehrgängen. 
Deklaration. ${ }^{15}$ Sie umfasst nicht sechs, sondern 50 in zehn Dimensionen gegliederte Kompetenzen, die für das journalistische Handeln, vor allem für redaktionelle Tätigkeiten maßgeblich sein sollen (»be able to ...«). Diese Kompetenz-Items veranschaulichen, wie vielgestaltig nun die Anforderungen gesehen wurden, die aus Sicht der Medienmacher*innen das journalistische Handeln auszeichnen. Auffällig dabei ist die unterschiedliche Gewichtung einzelner Kompetenzen zwischen Redaktionsleiter*innen und Ausbilder*innen, indem letztere deutlich stärker den gesellschaftlichen Bezug und die soziale Verantwortung für die Folgen journalistischen Handelns betonen (vgl. Baer et al. 2008). Umgekehrt legten die Redaktionschef*innen deutlich mehr Gewicht auf Fertigkeiten, die Managementwissen und technisches Know-how fokussieren und insofern der Medienökonomie in der Onlinewelt dienen.

Vor der Frage, ob mit der Interaktivität der Onlinekommunikation nicht auch eine Rückkehr zu den Kompetenzen angezeigt sei, die den personalisierten Interaktionen Rechnung tragen, mithin weniger systemstrukturell und mehr auf die Akteur*innen zentriert auszurichten seien, hat die Medienexpertin Alexandra Stark (2010) das EJTA-Kompetenzfeld vermittels der Dimensionen »Wissen/Können/Wollen« strukturiert. Bemerkenswert ist hier die Dimension »Wollen«, zu der Stark die Merkmale »Haltung/Einstellung/Bereitschaft« zählt. Es überrascht nicht, dass bei dieser Strukturierung das Kompetenzfeld »Können« (Schwerpunkt »handwerkliche Fertigkeiten«) erneut deutlich dominiert (Abb. 2). Gleichwohl steht dieser Ansatz für den Versuch, die journalistischen Kompetenzen aus der Technikfixierung zu lösen und in den Kontext des gesellschaftlichen Wandels zu stellen: Zur Menge der determinierenden Treiber der Transformation zählt sie neben dem technologischen und dem wirtschaftlichen Wandel auch die sich rasant ändernde Mediennutzung, die ihrerseits den Gesellschaftswandel prägt und insofern zur soziokulturellen Umwelt des Journalismus gehört. Auf diese Umwelt, so Starks Design, sollten sich inskünftig die dem individuellen »Wollen« zugeschriebenen Kompetenzen der TartuDeklaration beziehen, so vor allem die mit Innovation, Verantwortung und Diskursivität konnotierten Fertigkeiten (ebd., 65-67). Darin lässt sich der idealistische Wunsch erblicken, im Zeitalter des Web 2.0 die journalistischen Kompetenzen um soziale, interkulturelle und umweltbezogene Fertigkeiten zu erweitern (ebd., 62-63) - „Wunschdenken«

15 https://www.ejta.eu/tartu-declaration. 
(ebd., 66) deshalb, weil aus der berufsspezifischen Kompetenz ein universelles Vermögen werden soll, dessen Hauptqualität in der ununterbrochenen Anpassung an sich stetig verändernde Umwelten besteht: tranformatorisches Mitdenken und Handeln als Superkompetenz.

\section{5 Über alternative Kommunikationsräume und -ansprüche}

Dieser Rückblick auf vergangene Kompetenzdebatten sollte deutlich machen, dass mit der Professionalisierung des Berufs zunächst die politische Rolle des Journalismus im Mittelpunkt stand; es folgte die Debatte um die kompetenzbehindernden ökonomischen Rahmenbedingungen journalistischen Handelns, ehe die abstrakt-systemisch gedachte Funktionalität des Journalismus das Kompetenzverständnis prägte. Seit dem Web 2.0 und der Dominanz der Onlinemedien diffundiert der Begriff in immer mehr Merkmale und verliert sein auf den Journalist*innenberuf bezogenes Profil. Diese Diffusion ist reaktiv und insofern ein von den marktwirtschaftlichen Treibern des Medienwandels erzeugter Effekt: Die reichweitestärksten Newsmedien des Web 2.0 (im Pandemie-Jahr 2020 waren es die Online-Ausgaben von Bild, Spiegel und Focus) haben unter der einleitend erwähnten Etikette »digitale Transformation « den Journalismus instrumentalisiert und seine Kompetenzmerkmale auf die Vermarktungsinteressen zugeschnitten. Zudem sind auch die digitalen Kommunikationsräume, die der gesellschaftlichen Verständigung dienen, inzwischen weitgehend kommerzialisiert. Selbst der von derartigen Interessen freigehaltene öffentlichrechtliche Rundfunk beugte sich dem von den privaten Anbietern erzeugten Quotendruck durch Programmanpassungen (»Konvergenzhypothese«; Schatz 1994, 67-77; Merten 1994).

An dieser Stelle erwarte ich den Hinweis, dass viele mit »alternativ« apostrophierte Onlinemedien - beispielhaft in Deutschland das Regionalmedium Kontextwochenzeitung, in der Schweiz Republik und in den Niederlanden DeCorrespondent - als Ausbruch aus dieser Sackgasse zu deuten seien. Es stimmt, dass ihnen der Versuch gemeinsam ist, die tradierten, normativ begründeten Funktionszuschreibungen in die digitale Medienumwelt zu transferieren, also beispielsweise die informierende Sachaufklärung über relevante Vorgänge unter die Maximen Transparenz, Meinungsvielfalt und Diskursivität zu stellen. Doch bedürfen auch sie der Bezuschussung durch Mäzen*innen, Gönner *innen und 


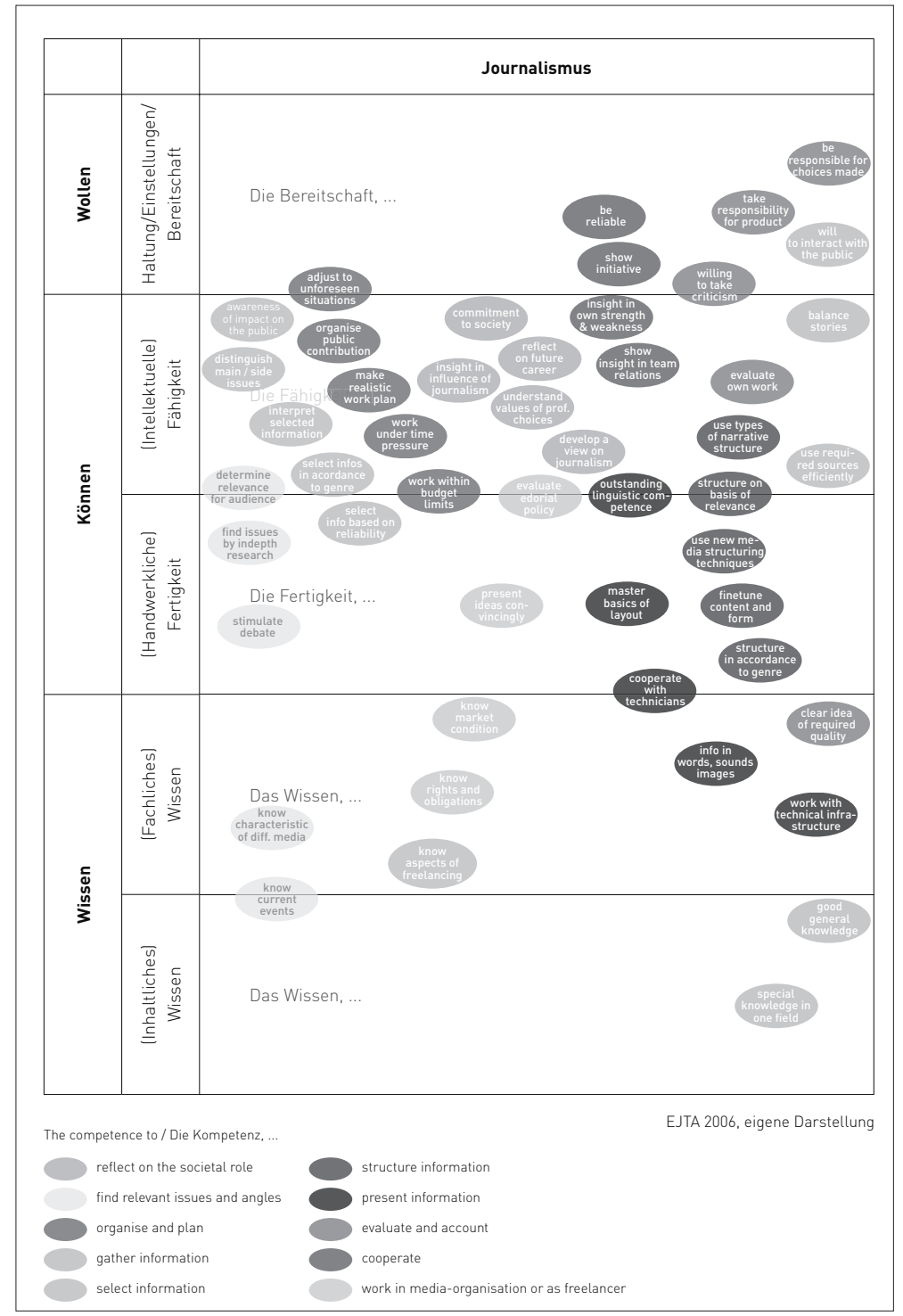

Abb. 2: Die Tartu-Deklaration und die Kompetenz-Matrix nach Stark (2010, 21).

Förderer*innen - und kämpfen, wenn die Spendenmittel knapp werden, mit dem Problem der Refinanzierung ihrer journalistischen Leistungen. 
Auch die Betreiber*innen privatwirtschaftlicher Medienunternehmen - ob Mainstream, in der Nische oder alternativ - sind auf die Refinanzierung der Kosten durch Werbe- und Vertriebserlöse angewiesen. Soweit diese über den Verkauf von Werbezeiten und -flächen erreicht werden soll, zielen sie auf hohe Reichweiten in ihren Zielgruppen und auf Diversifizierung ihrer Dienstleistungen ab (etwa Redakteur*innen als Event-Veranstalter und Touristik-Reiseführer*innen). Nach rund zwei Jahrzehnten des Experimentierens im Online- und Hybridmarkt sehen viele Medienunternehmen, dass ihre Erlösmodelle nicht kostendeckend funktionieren und der Onlinejournalismus trotz seiner Marktanpassung quersubventioniert werden muss. ${ }^{16}$ Die wenigen Ausnahmen - vorneweg die New York Times - dienen nicht als Vorbilder, denn sie nutzen ihre Sonderstellung (die NYT, die Washington Post und The Guardian erreichen mit ihren herausragenden Informationsangeboten den englischsprachigen Raum weltweit als Absatzmarkt) und bestätigen darin ihren Ausnahmecharakter. Auch der Hinweis, dass im deutschsprachigen Raum inzwischen viele Nischenprodukte existieren, die teils als Verein über Abo-Mitgliedschaften, teils dank öffentlicher Zuwendungen oder Fördermittel und Spenden existieren, hilft nicht weiter. Denn diese Medien sind supplementäre Angebote im Dienst der Meinungsvielfalt; sie setzen die kostspielige Informationsleistung der tagesaktuellen Newsmedien voraus. Zudem wirtschaften viele von ihnen mit dem keineswegs beispielgebenden Modell der Selbstausbeutung. Ihre Reichweiten sind gering. Nur wenige dieser Medien - beispielhaft das von der Verlagsgruppe Heise Medien finanzierte Onlinemagazin Telepolis - können jenseits ihrer Community etwas Substanzielles zum gesellschaftlichen Diskurs beitragen.

Der meist betriebswirtschaftlich begründete Personalabbau in vielen Medienredaktionen hat im Laufe der vergangenen zehn Jahre eine bunte Szene an Journalist*innenbüros entstehen lassen (»Media Entrepreneurship «), ${ }^{17}$ die ihre Dienste auf dem Medienmarkt anbieten. Zu ihrem Kompetenzprofil zählt von daher die unspezifische Fertigkeit, Kundenwünsche optimal und effizient zu bedienen. Der

16 Die etablierten Newsmedien - insbesondere von der Süddeutschen Zeitung und der Frankfurter Allgemeinen - meldeten im Herbst 2020 infolge des durch die Corona-Krise ausgelösten Informationsbedarfs einen markant gestiegenen Anteil an Online-Abonnements. Ob dieser zur Refinanzierung genügt und ob er von Dauer sein wird, bleibe dahingestellt.

17 https://www.fachjournalist.de/media-entrepreneuship-wenn-journalisten-unternehmer-werden/. 
Entrepreneur-Trend führte aber auch zur interessanten Überlegung, die Kompetenzen so auszurichten, dass die Journalist*innen kein Medienprodukt, sondern nur Inhalte, also Themen (»Geschichten«) und Berichte bereitstellen. Diese Produkte könnten analog zu Spotify auf einer »anbieterübergreifenden und abonnementbasierten Journalismusplattform « bereitgestellt werden (Wellbrock 2020). Auf diesem Wege, so die Idee, ließe sich der publizistische Wettbewerb und damit die Medien- und Meinungsvielfalt gegen die Web-Monopolisten sichern (ebd.). Der Einwand liegt auf der Hand: Mit diesem Konzept würde der Wettkampf der Solounternehmer*innen um Aufmerksamkeit unterhalb der Medienmarken auf der Mikroebene der Informationsangebote weiter verschärft, mit der Folge eines noch stärkeren Zuschnitts der journalistischen Kompetenzen auf reichweitegenerierende Techniken.

Diese Diskussion führt mich zu der Folgerung, dass der privatwirtschaftlich organisierte Onlinejournalismus ein Gefangener der Vermarktungszwecke und insofern seiner öffentlichen Aufgabe entfremdet bleibt. Und diese Entfremdung wird durch die beschriebene, auf Marktanpassung gerichtete Ausdifferenzierung von Kompetenz weiter verstärkt. So hat es den Anschein, als sei unter den geltenden Bedingungen für den Onlinejournalismus kein Fluchtweg offen: Weder Mitgliedschafts- noch Stiftungs- oder Spendenmodelle generieren die nachhaltig zu sichernden Kapazitäten, um eine gut informierte und diskursiv orchestrierte Medienöffentlichkeit in Gang zu halten. ${ }^{18}$

\section{Zur Rückgewinnung substanzieller Kompetenz: Zwei Perspektiven}

Trotz dieser wenig ermutigenden Bestandsaufnahme bieten die Kommunikations- und Interaktionsräume der Onlinewelt aus meiner Sicht zwei transformatorisch zu deutende Perspektiven, die der Kompetenzdebatte eine neue Richtung geben.

18 Mitunter wird die genossenschaftlich organisierte, sich linksalternativ verstehende tageszeitung (taz) als gelungene Ausnahme genannt. Doch die verkaufte Auflage (Print und E-Paper) erreicht laut IVW knapp 41000 Exemplare. Die minimalen Werbe- und die Vertriebserlöse müssen von den Genossenschaftern bezuschusst werden. Gleichwohl gestatten die Einnahmen keine tarifgemäße Entlohnung der taz-Mitarbeiter*innen. Jedenfalls konnte das taz-Modell unter den Newsmedien nicht als Vorbild dienen. 
Die erste hat das durch die Onlinemedien belebte Projekt »Zivilgesellschaft« im Blick. ${ }^{19}$ Dieses geht davon aus, dass die »Gesellschaftsbürger*innen « quasi unterhalb des Institutionengefüges die Kommunikationsräume durch ihr Bedürfnis, Gestaltungs- und Handlungsziele auszuhandeln, diskursiv beleben (vgl. Habermas 1998, 418-419). Allerdings sind die online interagierenden Individuen, Gruppen und Initiativen selbst nicht in der Lage, die dem Journalismus zugewiesene Informationsfunktion zu erbringen. Indessen können sie sich die Kompetenzen aneignen, die ich zuvor mit dem Leitbild der diskursiven, um Orientierung besorgten Onlinekommunikation umrissen habe. Unter dem Paradigma »Die sich selbst verständigende Zivilgesellschaft « müsste diese Diskurskompetenz aus meiner Sicht als Kulturtechnik vergesellschaftet und in die Bildungsprogramme eingebaut werden vergleichbar der Alphabetisierung der Gesellschaft im Fortgang des 19. Jahrhunderts. Verschiedene Initiativen und Graswurzelprojekte befassen sich derzeit mit diesem Ansatz - auch mein Institut verfolgt unter dem Label »fit for news« ein kleines Pilotprojekt mit dieser Zielstellung. ${ }^{20}$

Die genuin journalistische Kompetenz sollte unter dieser Perspektive auf den Informationsauftrag fokussiert werden: Ihr Kern hätte die mit der öffentlichen Aufgabe verbundene Tätigkeit zum Inhalt, über die relevanten Vorgänge sachrichtig, umfassend und ausgewogen zu informieren und über deren Hintergründe und Handlungszusammenhänge aufzuklären, sprich: Kritik und Kontrolle zu üben. Dies ist weniger trivial, als es erscheinen mag. Studien und Inhaltsanalysen zeigen immer wieder, dass die reichweitestarken Newsmedien der Sichtweise der politischen und wirtschaftlichen Eliten folgen, dass sie komplexe Vorgänge oft einseitig oder parteiergreifend beschreiben, behördliches Versagen wie auch Missstände eher zufällig thematisieren und oftmals statt der nachrichtlichen Aufklärung bevorzugt Meinungs- und Spekulations-

19 Der Begriff ist unscharf und wird in den Sozialwissenschaften auch als Synonym für »Bürger*innengesellschaft« gebraucht (vgl. Zimmer 2012). Ich folge hier Habermas, der »Zivilgesellschaft« als zugangsoffene, freiwillige Kommunikationsgemeinschaft begreift, die auch Formen des gewaltlosen Protestes und zivilen Ungehorsams einschließt. Habermas beschreibt diesen Kommunikationsraum als nicht vermachtete und insofern autochthone Öffentlichkeit. Diesem Raum steht die vermachtete Öffentlichkeit gegenüber, in der die professionellen Mainstreammedien, die politischen Institutionen, Interessengruppen und Lobbyist”innen dominieren (Habermas 1998, 415-467).

20 Näheres unter: https://fitfornews.de/. 
journalismus betreiben. Verkürzt gesagt: Die Kernkompetenz - die unvoreingenommene, auf Offenlegung gerichtete Recherche - findet man nicht regelhaft, sondern ausnahmsweise. Für die deliberativ begründete Diskursöffentlichkeit, die in der zivilgesellschaftlichen Lebenswelt stattfindet, ist diese Informationsaufgabe allerdings die Grundvoraussetzung. Ohne sie gibt es keinen verständigungsorientierten Diskurs, vielmehr Populismus und Propaganda.

Zu dieser journalistischen Kernkompetenz hinzu tritt die Aufgabe, bedeutsame Konflikte und Probleme zu erkennen, zu analysieren und allgemeinverständlich darzustellen - ich nenne sie hier verkürzt »Thematisierungsfunktion«. Denn im Unterschied zu den 1960er Jahren, als die »öffentliche Aufgabe « erkannt und in den Landespressegesetzen verbindlich beschrieben wurde, sind die heutigen Verhältnisse für viele Menschen unübersichtlich und die Wirkungszusammenhänge zwischen Politik, Wirtschaft und Soziokultur undurchschaubar. Mit anderen Worten: Komplexe Vorgänge und Prozesse in Politik und Wirtschaft zu untersuchen und deren Akteur*innen und Interessen durchsichtig zu machen ist Teil dieser Kompetenz; sie gewinnt seit dem Web 2.0 und der desorientierenden Informationsüberflutung weiter an Bedeutung. Vielleicht gelingt es den solcherart kompetenten Journalist*innen, "sich als Mandatar eines aufgeklärten Publikums [zu] verstehen, dessen Lernbereitschaft und Kritikfähigkeit sie zugleich voraussetzen, beanspruchen und bestärken « (Habermas 1998, 457). Dies steht unter der Prämisse, dass auf Seiten des Publikums - gleichsam als Komplementär - die genannte Medienkompetenz erworben werde.

Wie aber sähe die mediale Infrastruktur aus, die diesen gesellschaftlichen Diskurs in Gang halten könnte? Hier setzt meine zweite Perspektive an. Sie greift eine Debatte auf, die vor mehr als 70 Jahren in der Gründungsphase der Bundesrepublik Deutschland schon einmal in Fahrt kam, als es um die Bedingungen eines Journalismus ging, der aus ökonomisch und ideologisch unabhängiger Position informieren kann. Es war die Idee des public service, mithin eines meritorischen Dienstes, vergleichbar dem Gesundheits- und Bildungssystem, die eigentlich nicht marktfähig sind (»öffentliche Güter«; Kiefer 2001, 132-133) und deshalb nicht kommerzialisiert, sondern als gemeinnützige oder öffentlich-rechtliche Einrichtungen zu organisieren wären. Jedenfalls sollte der Informationsjournalismus von keinem Finanzier, keiner Machtgruppe, keiner politischen Partei und keiner gewinnorientierten Eigentümerin abhängig sein. Dies schien realisierbar, sofern diese Medien - ähnlich wie die BBC in Großbritannien - allein über Gebühren 
finanziert und von gesellschaftlich relevanten Gruppen kontrolliert würden (über Organisation und Einflussnahme der Regierung vermittels des BBC Trust vgl. Hahn 2010, 136; inzwischen wurde der BBC Trust durch Ofcom ersetzt).

In Deutschland ist diese Idee so alt wie der vom britischen Journalisten Hugh Carleton Greene im Oktober 1946 gegründete Nordwestdeutsche Rundfunk (NWDR), das Urmodell der ARD: »Unerbittlich in der Abwehr von äußerem Einfluss, aber auch unerbittlich für Toleranz«, nannte Greene (1970) sein Credo. Auf der Suche nach einer Organisationsform, die dieses Prinzip Unabhängigkeit sichern sollte, fand er das Konzept der öffentlich-rechtlichen Einrichtung: Finanzielle Unabhängigkeit gegenüber Verbänden und Werbewirtschaft, also keine Werbung, keine Steuergelder, sondern einzig Zuschauerbeiträge. Zudem politische Unabhängigkeit gegenüber dem Staat und den Parteien, also kein Weisungsrecht der Länderregierungen, vielmehr ein pluralistisch besetzter Rundfunkrat (damals Hauptausschuss), der relevante gesellschaftliche Interessen repräsentiert und der den Intendanten (damals Generaldirektor) wählt.

Greenes Überzeugung, dass in einer Demokratie die Meinungsbildung der Bürger*innen ohne staatliche Einflussnahme allein auf die Informations- und Kommentarleistung unabhängiger Journalist*innen abgestützt sein sollte, fanden sogar die US-amerikanischen Besatzer richtig. In ihrer Anordnung vom 21. November 1947 hieß es: »Es ist die grundlegende Politik der US-Militärregierung, dass [...] die Mittel der öffentlichen Meinungsbildung wie Presse und Rundfunk [...] von jeder Regierungseinwirkung freigehalten werden.«

Es blieben Erinnerungen an die Zukunft des kompetenten Informationsjournalismus, denn bereits im Frühjahr 1948 hatten die deutschen Politiker Greenes Konzept demoliert: Statt unabhängiger Leute aus dem Bildungswesen setzten sich die Kultusminister der vier Länder gleich selbst in den Hauptausschuss und zogen ihre Leute nach. Seither wurde der Einfluss der Politik auf die Rundfunkanstalten nicht ab-, sondern ausgebaut - in den Anstalten der ARD ebenso wie 15 Jahre später im ZDF. Eindrücklich zeigt dies die Causa Brender: Der ZDF-Chefredakteur galt den Unionspolitiker*innen als zu kritisch und politisch zu links, weshalb der von ihnen dominierte Verwaltungsrat Ende 2009 Brenders Vertragsverlängerung ablehnte. Ihre Macht schrumpfte ein wenig, als das Bundesverfassungsgericht 2014 die Zusammensetzung des Verwaltungsrats als rechtswidrig einstufte. Seither werden nur mehr rund ein Drittel der Mitglieder direkt oder indirekt von politischen Parteien und 
Ämtern delegiert. Doch dies genügt. ${ }^{21}$ So sind bis heute die leitenden Journalist*innen der ARD und des ZDF den politisch besetzten Aufsichtsgremien gegenüber rechenschaftspflichtig. Viele Vorfälle belegen, dass keine der beiden Anstalten de facto die Staatsferne aufweist, die ihnen 1947 per Proklamation zugedacht worden war.

Jener Grundsatz der Staats- und Wirtschaftsferne könnte heute wiederbelebt werden, zumal es nicht mehr um die Hoheit über wenige Sendefrequenzen geht, sondern offene Kommunikationsräume im Internet zur Verfügung stehen. Sofern die Zivilgesellschaft ihr Diskursinteresse artikulieren kann, müssten ihre Akteur*innen darauf bestehen, den Informationsjournalismus an die öffentliche Aufgabe zu binden und im Internet als offene Plattform des public service zu organisieren. Dabei müsste die Staatsferne organisationsrechtlich, die ökonomische Eigenständigkeit über Beiträge abgesichert, die medienrechtliche Qualitätskontrolle institutionalisiert und von medienkompetenter Seite supervisioniert werden.

Vorgänge im Ausland zeigen, dass diese Idee verstanden und vom Publikum gewünscht wird. Zum Beispiel die dreisprachige Schweizerische Radio- und Fernsehgesellschaft (SRF): Sie definiert sich als »service public«, ist als Verein organisiert, erhält von der Bundesregierung die Konzession und wird vom Bundesamt für Kommunikation nur in formaler Hinsicht (Einhaltung der Rechtsbestimmungen) kontrolliert. Für die programminhaltliche »Beurteilung (nicht Kontrolle) ist ein Publikumsrat zuständig, dessen 26 Mitglieder verschiedene Bevölkerungsgruppen repräsentieren - ein sich zivilgesellschaftlich legitimierendes Gremium. ${ }^{22}$ Außerdem prüfen in den Sprachregionen OmbudsmannEinrichtungen alle Publikumsbeschwerden; Beschwerdeführer*innen

21 Eine Zusammenstellung markanter Einflussnahmen der Politik auf die journalistische Aussagenproduktion der öffentlich-rechtlichen Anstalten brachte die Süddeutsche Zeitung am 25.10.2012, https://www.sueddeutsche.de/medien/ politik-und-medien-wenn-der-minister-zweimal-klingelt-1.1505696.

22 Aus seiner Selbstdarstellung: »Als wichtiges Glied der Qualitätskontrolle gibt er den Programmverantwortlichen und Programmschaffenden von SRF kritische und konstruktive Anregungen aus der Sicht der Konsumentinnen und Konsumenten von SRF-Programmen. Der Publikumsrat ist unabhängig und nicht weisungsbefugt. Er beobachtet ausgewählte Programme, Sendungen und Online-Angebote von SRF und 3sat nach eigener Wahl. Die Programmbeobachtung wird in ständigen Arbeitsgruppen geleistet. Die Ergebnisse der Arbeitsgruppen werden im Plenum mit den Sendeverantwortlichen diskutiert und anschliessend über die verschiedenen Online- und Offlinekanäle der SRG.D öffentlich gemacht.«https://www.srgd.ch/de/uber-uns/publikumsrat/ueber-uns/. 
können ihren Fall an die »Unabhängige Beschwerdeinstanz« weiterziehen. Während in Deutschland mit seiner zehnfach größeren Bevölkerung in allen Gremien und Beiräten der ARD und des ZDF insgesamt rund 1000 Vertreter*innen von Gruppen, Einrichtungen und Parteien tätig sind, engagieren sich in den Mitglieds- und Regionalgesellschaften der SRG rund 23000 Personen (Siepmann 2012). Im März 2018 hat die große Mehrheit der Schweizer Stimmbürger*innen eine Initiative zur Abschaffung der Rundfunkgebühren rundheraus abgelehnt. Den Bezeugungen zufolge war dies, zivilgesellschaftlich betrachtet, die vielleicht deutlichste Bestätigung weniger der Unterhaltungsleistung als der journalistischen Informations- und Orientierungsfunktion zumal im Zeitalter von YouTube und Instagram.

Abschließend ziehe ich aus den skizzierten Perspektiven einige konkrete Folgerungen. Ich formuliere sie auf der Handlungsebene als Bedingungen für eine Erneuerung der Kompetenzen, die Informationsjournalist*innen in der Ära des partizipatorischen, über Vernetzungen strukturierten, dabei von intermediären Konzernen bemächtigten Internets benötigen:

- Die zivilgesellschaftliche Lebenswelt: Diskursräume zurückholen, öffentlich-rechtlich absichern und dekommerzialisieren.

- Die organisierte Mediengesellschaft: Die Kulturtechnik »Medienund Informationskompetenz « als Basisbildungsprogramm einführen, vergleichbar seinerzeit mit der Alphabetisierung.

- Das Institutionengefüge des politischen Systems: Verrechtlichter Schutz der Kommunikationsräume vor staatlicher beziehungsweise parteipolitischer Einflussnahme (Neutralitätsschutz) sowie kartellrechtliche Abwehr der Monopolisierungstendenzen.

- Die Informationsstruktur als meritorischen public service des »Informationsjournalismus« organisieren und über ein macht- und interessenunabhängiges Modell (etwa Stiftungen, Beiträge) finanzieren.

- Die Handhabung journalistischer Kompetenz durch die angewandte Kommunikations- und Medienwissenschaft periodisch evaluieren und deren Befunde den für die Qualitätskontrolle geschaffenen Gremien auf der Ebene der Zivilgesellschaft an die Hand geben. 


\section{Literatur}

Becker, Sabine, und Markus Kaiser (Hrsg.). 2014. Berufe in den Medien. München: Verlag Dr. Gabriele Hooffacker.

Bönisch, Julia. 2019. Wir brauchen gute Manager an der Spitze von Redaktionen. Journalist 5: 60-64.

Dernbach, Beatrice; Wiebke Loosen (Hrsg.) 2012. Didaktik der Journalistik. Konzepte, Methoden und Beispiele aus der Journalistenausbildung. Wiesbaden: Springer VS.

Deutscher Journalisten-Verband. 2003. Memorandum: Journalistische Aus- und Weiterbildung in der Krise. Beschlossen auf dem DJV-Verbandstag 2003 in Wiesbaden. Bonn: DJV.

Donsbach, Wolfgang.1982. Legitimationsprobleme des Journalismus. Gesellschaftliche Rolle der Massenmedien und berufliche Einstellung von Journalisten. Freiburg im Breisgau: Verlag Karl Alber.

Donsbach, Wolfgang. 1999. Journalismus und journalistisches Berufsverständnis. In: Mediengeschichte der Bundesrepublik Deutschland, herausgegeben von Jürgen Wilke, 489-517. Köln: Böhlau.

Donsbach, Wolfgang. 2012. Hausaufgaben noch immer nicht gemacht: Versäumnisse und Konzepte der Journalistenausbildung. In: Didaktik der Journalistik. Konzepte, Methoden und Beispiele aus der Journalistenausbildung, herausgegeben von Beatrice Dernbach und Wiebke Loosen, 31-44. Wiesbaden: Springer VS.

Elmer, Christina, Stefan Ottlitz, und Matthias Streitz. 2020. Wie wir den Spiegel entwickeln. Journalist 3: 56-60.

Fabris, Hans Heinz. 1971. Das Selbstbild des Kommunikators bei Tageszeitungen. Publizistik 16 (4): 357-368.

Greene, Hugh Carleton. 1970. Entscheidung und Verantwortung - Perspektiven des Rundfunks. Hamburg: Hans-Bredow-Institut.

Habermas, Jürgen. 1998. Faktizität und Geltung. Beiträge zur Diskurstheorie des Rechts und des demokratischen Rechtsstaates. Frankfurt am Main: Suhrkamp.

Hahn, Caroline. 2010. Die Aufsicht des öffentlich-rechtlichen Rundfunks. Bestandsaufnahme und Zukunftsperspektiven. Frankfurt am Main: Peter Lang.

Haller, Michael. 2000. Die zwei Kulturen. Journalismustheorie und journalistische Praxis. In: Theorien des Journalismus. Ein diskursives Handbuch, herausgegeben von Martin Löffelholz, 101-122. Wiesbaden: Westdeutscher Verlag.

Haller, Michael. 2012. Didaktischer Etikettenschwindel? Die Theorie-Praxis-Verzahnung in der Journalistenausbildung. In: Didaktik der Journalistik. Konzepte, Methoden und Beispiele aus der Journalistenausbildung, herausgegeben von Beatrice Dernbach und Wiebke Loosen, 45-58. Wiesbaden: Springer VS.

Harnischmacher, Michael. 2010. Journalistenausbildung im Umbruch. Zwischen Medienwandel und Hochschulreform: Deutschland und USA im Vergleich. Konstanz: UVK.

Holzer, Horst. 1973. Kommunikationssoziologie. Reinbek bei Hamburg: Rowohlt. Hömberg, Walter (Hrsg.). 1978. Journalistenausbildung. Modelle, Erfahrungen, Analysen. München: Ölschläger. 
Kiefer, Marie Luise. 2001. Medienökonomik. Einführung in eine ökonomische Theorie der Medien. München: Oldenbourg.

Kolo, Castulus, Thomas Döbler, und Lars Rademacher. 2012. Wertschöpfung und Medien. Versuch einer Einordnung von Perspektiven, Konzepten und Begrifflichkeit. In: Wertschöpfung durch Medien im Wandel, herausgegeben von Castulus Kolo, Thomas Döbler und Lars Rademacher, 9-18. Baden-Baden: Nomos.

Koszyk, Kurt. 1974. Professionalisierung durch Wissenschaft. Journalistenausbildung zwischen Berufung und Beruf. Aus Politik und Zeitgeschichte 24: 27-37.

Langenbucher, Wolfgang. 1974. Zukünftige Erfordernisse für die Ausbildung der Journalisten. In: Massenmedien in der Prognose. Konzepte und Modelle für die Zukunft, herausgegeben von Uwe Magnus, 150-156. Berlin: Spiess.

Meier, Klaus. 2007. Journalistik. Konstanz: UVK.

Merten, Klaus. 1994. Konvergenz der deutschen Fernsehprogramme: eine Langzeituntersuchung 1980-1993. Münster, Hamburg: Lit.

Neuberger, Christoph, Christian Nuernbergk, und Melanie Rischke (Hrsg.). 2009. Journalismus im Internet. Profession - Partizipation - Technisierung. Wiesbaden: Springer VS.

Neuberger, Christoph. 2002. Online-Journalismus: Akteure, redaktionelle Strukturen und Berufskontext. Medien \& Kommunikationswissenschaft 50 (1): 102114.

o. A. 2019. Trennung von Redaktion und Verlag infrage gestellt: SZ-Digitalchefin Julia Bönisch hat Ärger im eigenen Haus. Meedia.de vom 14. Mai, https://meedia.de/2019/05/14/aerger-um-gastbeitrag-sz-digitalchefin-julia-boenischmusste-sich-vor-kollegen-rechtfertigen/. Zugegriffen: 3. Dezember 2020.

Oswald, Bernd. 2013. Vom Produkt zum Prozess. In: Journalismus in der digitalen Moderne. Einsichten - Ansichten - Aussichten, herausgegeben von Leif Kramp, Leonard Novy, Dennis Ballwieder und Karsten Wenzlaff, 63-79. Wiesbaden: Springer VS.

Plöchinger, Stefan. 2013. »Mauern passen nicht zum Netz«. Interview mit dem Süddeutsche.de-Chef. T3n.de vom 27. Januar, https://t3n.de/magazin/suddeutschede-chef-stefan-plochinger-interview-mauern-231149/. Zugegriffen: 3. Dezember 2020.

Pörksen, Bernhard. 2018. Die große Gereiztheit. Wege aus der kollektiven Erregung. München: Hanser.

Quandt, Thorsten. 2005. Journalisten im Netz. Eine Untersuchung journalistischen Handelns in Online-Redaktionen. Wiesbaden: Springer VS.

Rühl, Manfred. 1980. Journalismus und Gesellschaft. Bestandsaufnahme und Theorieentwurf. Mainz: Hase \& Koehler.

Ruß-Mohl, Stephan. 2017. Die informierte Gesellschaft und ihre Feinde. Warum die Digitalisierung die Demokratie gefährdet. Köln: Herbert von Halem.

Schatz, Heribert. 1994. Rundfunkentwicklung im »dualen System«: die Konvergenzhypothese. In: Politische Kommunikation in Hörfunk und Fernsehen. Elektronische Medien in der Bundesrepublik Deutschland, herausgegeben von Otfried Jarren, 67-80. Opladen: Westdeutscher Verlag.

Schätz, Konstantin, und Susanne Kirchhoff. 2020. Neue Wege im Journalismus, 
Weichenstellung in der Ausbildung. Journalistik 3 (2): 98-110. https://journalistik.online/ausgabe-2-2020/neue-wege-im-journalismus-weichenstellung-inder-ausbildung/.

Schmolke, Michael. 1970. Die deutschen Journalisten der Nachkriegszeit in der Selbstdarstellung ihrer Standespresse. In: Publizistik zwischen Intuition und Gewißheit: Drei Vorträge, herausgegeben vom Institut für Publizistik Münster, 4161. Assen: van Gorkum.

Siepmann, Ralf. 2012. Konvergenz auf eidgenössische Art. Die SRG SSR treibt den Transfer ins digitale Zeitalter voran. epd medien Nr. 28 vom 13. Juli.

Skriver, Ansgar. 1970. Schreiben und schreiben lassen. Innere Pressefreiheit - Redaktionsstatute. Karlsruhe: Müller.

Stark, Alexandra. 2010. Journalism Reloaded - Was Journalistinnen und Journalisten für die Zukunft lernen müssen. Masterarbeit. Leipzig School of Media und Medienausbildungszentrum Luzern. https://www.leipzigschoolofmedia.de/ hubfs/6494216/Masterarbeiten/Masterarbeit_Stark-Alexandra_2010.pdf. Zugegriffen: 3. Dezember 2020.

Weischenberg, Siegfried. 1990. Journalismus und Kompetenz. Qualifizierung und Rekrutierung für Medienberufe. Opladen: Westdeutscher Verlag.

Weischenberg, Siegfried, Klaus-Dieter Altmeppen, und Martin Löffelholz (Hrsg.). 1994. Die Zukunft des Journalismus, Technologische, ökonomische und redaktionelle Trends. Opladen: Westdeutscher Verlag.

Wellbrock, Christian-Mathias. 2020. »Spotify für Journalismus«, »Verlagsplattform«, »Digitales Pressegrosso« - Drei Szenarien für eine anbieterübergreifende Journalismusplattform. Journalistik 3 (2): 131-149. https://journalistik.online/ausgabe-2-2020/spotify-fuer-journalismus-verlagsplattform-digitalespressegrosso/. Zugegriffen: 3. Dezember 2020.

Zeuner, Bodo. 1973. Zur Standesideologie der Journalisten. In: Solidarität gegen Abhängigkeit. Auf dem Weg zur Mediengewerkschaft, herausgegeben von Ulrich Paetzold und Hendrik Schmidt, 13-36. Darmstadt: Luchterhand.

Zimmer, Annette. 2012. Die verschiedenen Dimensionen der Zivilgesellschaft. In: Dossier Deutsche Verhältnisse. Eine Sozialkunde, herausgegeben von der Bundeszentrale für politische Bildung. https://www.bpb.de/politik/grundfragen/ deutsche-verhaeltnisse-eine-sozialkunde/138713/dimensionen. Zugegriffen: 3. Dezember 2020.

\section{Open Access}

Dieser Beitrag erscheint unter der Creative-Commons-Lizenz CC BY-ND 3.0 DE: https://creativecommons.org/licenses/by-nd/3.0/de/. 


\title{
Motherhood in Transition - Who Cares? Eine qualitative Analyse medialer Anerkennungsstrukturen von Mutterschaft und Care-Arbeit
}

\author{
Natalie Berner
}

Keywords: Mutterschaft, Care-Arbeit, Diskursanalyse, Spätmoderne Valorisierungsstrukturen, Multimodalität, Leitmedien, TV-Werbung, Instagram

\section{Abstract}

Strukturelle Veränderung im Sinne einer Care-Revolution muss Bestandteil jedes transformativen Nachdenkens sein. Dieser Beitrag fragt, welche Anerkennungsstrukturen von Mutterschaft und Care-Arbeit medial wirksam sind. Hierfür wurden exemplarische Analyseeinheiten aufverschiedenen medialen Diskursebenen qualitativ untersucht (Leitmedien, TV-Werbung und Instagram im Zeitraum von 2016 bis 2018). Die punktuelle Analyse des Mediendiskurses offenbart 1) eine Lücke in Bezug auf die sprechenden Personen, 2) eine nach wie vor normativ aufgeladene Mutterfigur, die medial eingesetzt wird und als Sehnsuchtsobjekt dient, 3) die Ästhetisierung, Kommodifizierung und Vereinheitlichung von Mutterschaft und 4) die Erschöpfung und Frustration, die symptomatisch für Care-Geber*innen zu sein scheint.

Natalie Berner: Motherhood in Transition - Who Cares? Eine qualitative Analyse medialer Anerkennungsstrukturen von Mutterschaft und Care-Arbeit. In: Nils S. Borchers, Selma Güney, Uwe Krüger und Kerem Schamberger (Hrsg.): Transformation der Medien - Medien der Transformation. Verhandlungen des Netzwerks Kritische Kommunikationswissenschaft. Frankfurt am Main: Westend 2021. DOI: https://doi.org/10.53291/VUAT3055.

Natalie Berner | Ludwig-Maximilians-Universität München I natalie. berner@ifkw.Imu.de 


\section{Einführung}

Die »Große Transformation «, die der Wissenschaftliche Beirat der Bundesregierung 2011 veranschlagt hatte, setzt sich für eine klima- und sozial gerechte, ökologisch wirtschaftende Weltgesellschaft ein. Allerdings werden die Transformationsidee und der Begriff $»$ Nachhaltigkeit« überproportional häufig mit dem Themenkomplex um Klima und Umwelt assoziiert. Der Care-Bereich hingegen, also die Fürsorge, Hinwendung und Pflege des Lebendigen, steht weniger stark im Fokus, obwohl hier ebenfalls ganz unmittelbar die Existenzgrundlagen des menschlichen Seins betroffen sind. Während der Raubbau an der Natur mit medientauglichen Bildern transportiert werden kann, die gerodete Wälder, verschmutzte Ozeane und schmelzende Pole zeigen, vollzieht sich der Raubbau am Menschen unbemerkt und in komplexer Chiffrierung. Übersetzt in sozialwissenschaftliches Vokabular steht er hier für strukturelle Bedingungen, die soziale Ungleichheit, (Selbst-)Ausbeutung und die Unsichtbarmachung großer Teile geleisteter Care-Arbeit fördern.

Im Gegensatz dazu (oder als Reaktion) fordern Barbara Thiessen und Paula-Irene Villa schon lange die strukturelle Anerkennung der Angewiesenheit des Menschen (auf Menschen) als Conditio humana (Thiessen und Villa 2010). Dabei plädieren sie unter anderem dafür, das Recht, Sorge zu geben und versorgt zu werden, im Sozialgesetzbuch als Grundrecht zu verankern. Das Konzept der »Care-Revolution« (Winker 2015) legt in diesem Sinne Maßstäbe für eine solidarische Gesellschaft an und ist zu verstehen als »[...] eine politische Transformationsstrategie, die anknüpfend an die Erkenntnisse feministischer Politik die grundlegende Bedeutung der Sorgearbeit ins Zentrum stellt und darauf abzielt, das gesellschaftliche Zusammenleben ausgehend von menschlichen Bedürfnissen zu gestalten. Damit wird Care-Arbeit, die in den meisten politischen Strategien ebenso wie in den ökonomischen Theorien keine Rolle spielt, als Bezugspunkt der Gesellschaftsveränderung gewählt.« (ebd., 144)

Der Beitrag blickt vor diesem Hintergrund diskursanalytisch auf massenmedial vermittelte Deutungs- und Anerkennungsstrukturen, die unter den Bedingungen der Medienlogik (Karidi 2017) produziert werden. Anerkennungsstrukturen sind hier analog zu Reckwitz (2019) als »Valorisierungsstrukturen « zu verstehen, die sich in hochgradig dynamischen, gesellschaftlichen Prozessen herausbilden und »Elementen der Welt« (ebd., 27) Wert zuschreiben beziehungsweise absprechen. 
Dieser konfliktbeladene »Prozess des >doing value« (ebd.) manifestiert sich auch in medialen Anerkennungsstrukturen. Welchen Lebensformen, Alltagsvorstellungen oder Praktiken wird Wert zugesprochen beziehungsweise aberkannt? Welcher "Stil des Lebens (ebd., 55) ist medial sichtbar oder gerade unsichtbar und somit wertlos? Gesellschaftliche Anerkennungsstrukturen können sich auf Freizeitgestaltung, persönliche Beziehungen, die Geschlechterordnung, das Familienleben, die politische Orientierung und prinzipiell auf alle Formen des Seins beziehen (ebd.).

Gegenstand dieser Betrachtung ist das Thema Mutterschaft und die damit verbundene öffentliche Bewertung von Care-Arbeit. Die Ergebnisse basieren auf einer qualitativen Diskursanalyse, die kategoriengeleitet aufgesetzt und ausgewertet wurde (Löblich 2016; Meyen 2019). Das Untersuchungsmaterial setzt sich aus 282 Analyseeinheiten zusammen, die drei unterschiedlichen medialen Diskursebenen zugehören: 55 entstammen Leitmedien, 27 der TV-Werbung und 200 der digitalen Plattform Instagram. Diese Heterogenität ermöglicht die Herausarbeitung kanalübergreifender und somit symptomatischer Regelmäßigkeiten. Theoretische Grundlagen sind dabei zum einen die diskursanalytischen Prämissen nach Foucault (1981) kombiniert mit der gesellschaftsdiagnostischen Analyse der Spätmoderne nach Reckwitz (2017; 2019) und der wissenschaftlichen Care-Debatte beziehungsweise der Idee einer Care-Revolution (Winker 2015). Die Ergebnisse beschränken sich im Rahmen dieses Beitrags auf punktuelle Skizzierungen und sind als Auskopplung eines größer angelegten Dissertationsprojekts zu sehen.

\section{Problemaufriss: Mutterschaft und Care in der Spätmoderne}

\subsection{Spätmoderne Valorisierungsstrukturen und ihre Kehrseiten}

Nach Reckwitz (2019) leidet die Spätmoderne an einem systematischen Ungleichgewicht. Sie ist geprägt durch die Gleichzeitigkeit von sozialem Auf- und Abstieg sowie kultureller Auf- und Abwertung (ebd., 16). Das heißt: Den Gewinner*innen des spätmodernen Bewertungssystems stehen Verlierer*innen gegenüber und die Aufwertung 
einer bestimmten Lebensweise kommt nicht ohne die Entwertung einer anderen aus. Reckwitz bezeichnet dies als Doppelstruktur der Spätmoderne, als zwei Seiten einer Medaille, die nicht voneinander zu trennen sind. Zwar handelt es sich laut ihm bei der Entwertung um nichtintendierte Handlungsfolgen, die weder bewusst herbeigeführt noch explizit gewünscht werden - aber dennoch in aller Konsequenz existieren. So sind etwa Singularitätsprozesse, die das Individuum mit allerlei Freiheiten und vermeintlichem Entfaltungsspielräumen ausstatten, implizit auch eine Abwertung all dessen, was »standardisiert und massenhaft im Hintergrund verschwindet« (Reckwitz 2019, 17). Viele gesellschaftliche Spannungen lassen sich über die Doppelstruktur von Valorisierung erklären: einseitige oder fehlende Anerkennung und Negierung der Kehrseiten von bessergestellten sozialen Positionen.

Die Kehrseiten spätmoderner Valorisierungsstrukturen zeigen sich nach Reckwitz vielerorts: ihm zufolge wertet der global vernetzte kognitiv-kulturelle Kapitalismus komplexe Güter mit hoher Innovationsdynamik und Kreativität zum Vorteil der Hochqualifizierten auf (ebd., 16), während gleichzeitig einfache Dienstleistungen, Routinejobs und repetitive Arbeiten von Niedrigqualifizierten mit geringem Prestige und sozialer Sicherheit ihren Wert verlieren (ebd.). Die Kehrseite der Akademisierung und des Profilierungswettbewerbs von Schulen, Universitäten und Absolventen um Exzellenz und Alleinstellung zeige sich außerdem in der Abwertung von niedrigen und mittleren Bildungsabschlüssen (ebd., 18). In der digitalen Welt wiederum erhielten eine geringe Zahl von Individuen Aufmerksamkeit und Wertschätzung im Übermaß (ebd.). Diesen Gewinner*innen stellt Reckwitz all jene gegenüber, »die unsichtbar bleiben, die schlecht vernetzt oder isoliert sind, denen es an Anerkennung mangelt - oder die gar ins Zentrum negativer Aufmerksamkeit wie Verachtung oder Hass geraten « (ebd.). Gleichzeitig sei das Individuum selbst erschöpft vom eigenen »Lebensmodell der erfolgreichen Selbstverwirklichung «, das die Gestaltung von »Alltag, Biographie, Freizeit und Familie zu einer ambitionierten Herausforderung « (ebd.) mache und ein hohes Enttäuschungs- und Frustrationspotenzial berge. $\mathrm{Ob}$ das Leben als gelungen empfunden wird, ist nach Reckwitz von fragilen Maßstäben abhängig: dem subjektiven Erleben und der eigenen psychischen Befriedigung (ebd., 21) - Finde ich das gut? Macht mir das Spaß? Dieses Modell werde allerdings nur von einer neuen Mittelklasse, dem »Leitmilieu der Spätmoderne« (ebd., 17), getragen. Die Kehrseite findet sich ihm zufolge 
in der »subtilen kulturellen Abwertung oder sozialen Deklassierung, welche die traditionelle Mittelklasse und prekäre Klasse erfahren« (ebd., 18).

\subsection{Mediale Valorisierungsstrukturen und ihre Bedeutsamkeit}

Dieses Reckwitz'sche »Bewertungssystem der Spätmoderne « findet in Form von besagten Valorisierungsstrukturen ${ }^{1}$ seine Entsprechung im medialen Diskurs. ${ }^{2}$ Die Medienöffentlichkeit schafft Realität, indem sie bewertet. Sie positioniert und hierarchisiert das Subjekt und schafft Vergleichsräume (Arendt und Brosius 2019). Valorisierungsstrukturen werden über Mediendiskurse institutionalisiert und entfalten ihre Wirkung als Orientierungssysteme, die den Mitgliedern einer Gesellschaft bekannt sind. Sie prägen den Wissensvorrat, formen Mythen sowie das kulturelle Gedächtnis und stecken Handlungsspielräume ab (Berger und Luckmann 2016). Valorisierungsstrukturen bieten der Kommunikationswissenschaft eine vielversprechende Analysekategorie, da sie eine elegante Brücke zwischen soziologischer Gesellschafts- und Gegenwartsdiagnose sowie kritischer Medieninhaltsforschung bilden. Sie sind zudem durch die jeweilige Kanallogik geformt und somit in ihren Bedeutungspotenzialen eingeschränkt. Wie im medialen Diskurs Wert zugesprochen beziehungsweise verweigert werden kann, ist den medialen Produktionsbedingungen und den Regeln der Medienlogik unterworfen. Hier stellt sich die Frage, welche Folgen es für das Subjekt hat, wenn sich gesamtgesellschaftlich wirksame Anerkennungsstrukturen in dem Korsett medialer Produktionslogiken formieren. Umso dringlicher wird sie, je weiter fortgeschritten die »reflexive Modernisierung « (Beck et al. 2014) ist, je weniger traditionsgeleitet und vorgeschrieben die Handlungsspielräume des Einzelnen sind und je mehr mediale Valorisierungsstrukturen diese Lücken in den subjektiven Orientierungssystemen füllen können.

1 Kontroverse um Anerkennung oder Umverteilung vgl. Fraser und Honneth (2003).

2 Diskursbegriff nach Foucault (1981). 


\subsection{Care-Arbeit und Mutterschaft als spätmoderner »Aggressionspunkt«}

Mutterschaft und Mutterschaftspraxen stehen nun in besonderem Maße im Zentrum der spätmodernen (Neu-)Formierung entlang der Kategorien »Gender « und »Care (Thiessen 2019, 1146). Die Klammer um das »Neu« ist an dieser Stelle wichtig, weil die Geschichte zeigt, dass die Auslegung von Mutterschaft schon immer von Wandel durchzogen war. Brüche und Neuinterpretationen von Mutterschaft, Elternschaft und Familie begleiten diese Konzepte schon seit ihrer Prägung (Thurer 1995; Thiessen 2019; 2020; Schütze 1986; Vinken 2011). Daher lohnt ein diskursanalytischer Blick, der bestehende Herrschaftsverhältnisse als Grundlage dominanter Deutungen in den Fokus nimmt und sich ihrer Kontingenz bewusst ist. Nachdem sich in Deutschland im Zuge der Industrialisierung und der Herausbildung der bürgerlichen Kleinfamilie eine stark geschlechtshierarchische Arbeitsteilung etabliert hatte, nahmen die Ansprüche und die normative Aufgeladenheit von gelungener Mutterschaft im Zeitverlauf stetig zu (Schütze 1986; Thiessen und Villa 2010). Die voranschreitende Ökonomisierung sowie der steigende Stellenwert des Kindes innerhalb der Familie und die neuentdeckte Lebensphase »Kindheit« führten zu einer fortsetzenden Professionalisierung der Mutterrolle (Thiessen 2020). Gleichzeitig wird das traditionelle Ernährermodell abgelöst von einer Ordnung, welche die Erwerbstätigkeit aller erwachsenen Menschen vorsieht. Das »Adult-Worker-Modell« als erklärtes Ziel familienpolitischer Maßnahmen (Winker 2015) steht für eine normative Verschiebung in eine Richtung, in der alle Menschen zu »geschlechtslosen Marktteilnehmern« (Soiland 2019, 102) reformiert werden, »die dem Markt unabhängig von ihren reproduktiven Fürsorgeaufgaben zur Verfügung stehen sollen« (ebd.).

Zugleich erfahren Care-Tätigkeiten, die meist unbezahlt und informell von Frauen geleistet wurden und werden, als Form von Arbeit wenig gesellschaftliche Anerkennung. Entsprechend gering fällt auch die Entlohnung für staatliche oder privatwirtschaftliche personennahe Tätigkeiten in Betreuung und Pflege aus (Winker 2015, 23). Während der Bedarf an Care-Arbeit steigt (unter anderem durch den demographischen Wandel und eine wachsende Zahl an Alleinstehenden), nehmen die Möglichkeiten für Sorge und Pflege ab - beispielsweise aufgrund von weniger Mehrgenerationenhaushalten, der Flexibilisierung der Arbeitswelt, steigender Mobilität und fehlenden Geschwistern (Eh- 
lert 2016). Care-Praktiken folgen zusätzlich einer Eigenlogik, die sie für Rationalisierungsmechanismen sperrig machen. Sie sind zeitintensiv und lassen sich nicht standardisieren oder verkürzen, ohne an Qualität zu verlieren (Winker 2015). Menschlicher Zeiteinsatz und oftmals physische Präsenz machen Care-Tätigkeiten makroökonomisch teuer. Der Ressourceneinsatz kann nicht unbedingt durch Innovation effektiver oder günstiger gestaltet werden. So gerät Care zu einem »Aggressionspunkt« (Rosa 2018) des spätmodernen Menschen, da diese Tätigkeiten nicht widerstandsfrei »verfügbar « sind beziehungsweise sich nicht in die Maxime einer entgrenzten Lebensweise integrieren lassen. Gelöst wird der hohe Ressourcenaufwand durch billige Arbeitskräfte aus dem Ausland, die oft in prekären Verhältnissen angestellt sind und eigene Familien zurücklassen (»care-chain«; Lutz und Palenga-Mollenbeck 2012). Außerdem lagert man Care-Tätigkeiten oftmals aus (Kinderbetreuung, haushaltsnahe Dienstleistungen, Pflegedienste, digitale Dienste), was zu intersektionalen Schieflagen führt, da sich die Möglichkeiten von Familien und Care-Empfänger*innen entlang von Ressourcen, Milieus oder Regionen unterscheiden (Thiessen 2020; Winker 2015). Eine lohn- und statuswirksame Aufwertung von Care-Arbeit ist daher unerlässlich, um prekäre Auswege aus der Care-Krise zu beheben (Soiland 2019). Vor diesem Hintergrund stellt sich die Frage, wie Valorisierungsstrukturen um Mutterschaft und Care-Arbeit im Mediendiskurs beschaffen sind, welche Machtverhältnisse sich dabei zeigen und wie die mediale Produktionslogik Deutungsstrukturen formt. Eine »Care-Revolution«, die sich an menschlichen Bedürfnissen und insbesondere an der Sorge füreinander orientiert, kann als zentrale »Transformationsstrategie (Winker 2015) nur über entsprechende mediale Valorisierungsstrukturen getragen und vorangebracht werden.

\section{Forschungsleitende Fragen kompakt}

Welche Valorisierungsstrukturen zeigen sich im Untersuchungsmaterial in Bezug auf Mutterschaft und Care-Arbeit?

- Was sagt das über geltende Herrschaftsverhältnisse aus? Wo sind Lücken und Leerstellen?

- Welchen Einfluss hat die Kanallogik? 


\section{Untersuchungsanlage}

Für die qualitative Analyse des Mediendiskurses wurden im Rahmen der Grobanalyse 282 Diskursfragmente berücksichtigt (Tab. 1). Diese entstammen unterschiedlichen Medienkanälen (Leitmedien, TV-Werbung und Instagram als digitale Plattform), um den Diskurs möglichst breit einzufangen. Alle Fragmente wurden im Zeitraum zwischen 2016 und 2018 veröffentlicht. Die Auswahl der Printartikel erfolgte über eine Schlagwortsuche (Mutter, Mutterschaft, Eltern, Elternschaft, Familie, Geburt) und anschließende Gewichtung nach den Kriterien Zentralität und Relevanz. Die Instagram-Posts wurden über die Anzahl der Follower*innen und die Selbstbeschreibung, in der Mutterschaft vorkommen musste, selektiert. Die Auswahl der Werbespots erfolgte über TVMonitoring von Oktober 2018 bis Januar 2019. Hierfür wurden diese gezielt in den reichweitenstärksten Fernsehkanälen gesichtet und die Erhebung durch eine Recherche in Werbedatenbanken ergänzt. Das Selektionskriterium bei den Werbespots bestand ebenfalls darin, dass eine beliebige Deutung von Mutterschaft auffindbar sein musste.

\section{1 Überblick über die Materialbasis}

Tab. 1: Die Materialbasis im Überblick.

\begin{tabular}{|l|l|l|}
\hline Leitmedien & 55 Artikel & $\begin{array}{l}\text { Süddeutsche Zeitung (SZ), Frankfurter Allgemeine Zeitung } \\
\text { (FAZ), Die Tageszeitung (taz), Die Welt, Die Zeit, Der Spiegel }\end{array}$ \\
\hline TV-Werbung & 27 Werbespots & $\begin{array}{l}\text { Nahrungsmittel, Pharmazie, Handel, Reinigungsmittel, } \\
\text { Babyprodukte }\end{array}$ \\
\hline Instagram & 200 Posts & $\begin{array}{l}\text { Sprecher*innen, die sich aufgrund der Selbstbeschreibung } \\
\text { in die Kategorien »Celebrity Moms«, »Working Moms « oder } \\
\text { »Momfluencer « einteilen lassen }\end{array}$ \\
\hline
\end{tabular}

Für die Auswertung wurde ein Kategoriensystem verwendet (Tab. 2). Die Auswertung erfolgte nach Jäger und Jäger (2007) in zwei Stufen: In der Grobanalyse wurden grundsätzliche Regelmäßigkeiten festgestellt und typische Fälle bestimmt. Diese gingen in die Feinanalyse ein und wurden daraufhin in Text- und Bildebene auf die latenten und manifesten Bedeutungsstrukturen untersucht. 


\subsection{Kategoriensystem}

Tab. 2: Das Kategoriensystem, Grundlage für die empirische Untersuchung.

\begin{tabular}{|l|l|}
\hline Kanallogik & \\
\hline Diskursposition & $\begin{array}{l}\text { Leitmedien, TV-Werbung, digitale Plattform } \\
\text { Sprecher*innenhintergrund } \\
\text { Problembezüge/Gegenstandskonzeptualisierung } \\
\text { Anerkennungsstrukturen (Valorisierung) }\end{array}$ \\
\hline Strategien & $\begin{array}{l}\text { Sprachliche Mittel, ideologisches Framing } \\
\text { Kollektivsymbolik, Bildkomposition }\end{array}$ \\
\hline
\end{tabular}

Die Kanallogik berücksichtigt dabei die unterschiedlichen Kontexte, in denen das Diskursfragment entsteht. So folgt ein Printartikel in der SZ einer anderen Logik als ein Instagram-Post oder eine TV-Werbung. Dies hängt mit den Produktionsbedingungen, den Möglichkeiten der Vermittlung (Text, Bild, audiovisuell) sowie den Nutzungskontexten der Medieninhalte zusammen. In der Kategorie Diskursposition werden einerseits die strukturellen Vorbedingungen der Sprecher*innen erhoben sowie die inhaltliche Konzeptualisierung und Bewertung des Gegenstands »Mutter«. Welche visuellen und sprachlichen Mittel dabei zur Anwendung kommen, erfasst die Kategorie Strategien. Die theoretische Fundierung des hier verkürzt dargestellten Kategoriensystems geht zurück auf die Formationsregeln von Foucault (1981) sowie die anwendungsorientierte Adaption von Jäger und Jäger für die Sprachund Sozialforschung (2007). 


\section{Ergebnisse}

\subsection{Sprecher*innenschaft und Leerstellen}

In den hier untersuchten Diskursfragmenten zeichnet sich die Sprecher*innenschaft durch Homogenität hinsichtlich der Ressourcenausstattung und sozialen Position aus. So kann für die untersuchten Analyseeinheiten im erhobenen Zeitraum festgehalten werden: Deutungshoheit hat die neue Mittelklasse gemäß Reckwitz' Definition. So richten sich die Problembezüge, vor denen Mutterschaft medial diskutiert wird, an der Lebenswelt dieser homogenen Gruppe aus. Folglich sind die Interessenlagen und Relevanzsysteme anderer Teile der Bevölkerung medial weniger bis gar nicht sichtbar. Es werden Leerstellen im Mediendiskurs in Bezug auf Diskurszugang bestimmter Sprecher*innenpositionen augenscheinlich. Welche Problembezüge beim Thema Mutterschaft und Care-Arbeit bei der alten Mittelkasse oder der prekären Klasse vorherrschen, findet wenig bis gar keine Beachtung. Den Verlierer*innen des Strukturwandels, die durch eine kulturelle Defensive oder strukturell unsichere Lebensbedingungen geprägt sind, steht als »Kehrseite « keine mediale Entsprechung im vorliegenden Untersuchungsmaterial gegenüber. Das Perfide daran ist aber, dass es oft gerade der unsichtbare Ressourceneinsatz dieser Personen ist, auf dem der spätmoderne Lebenswandel auf der »Gewinner*innenseite« aufbaut. Der Modus der Gleichzeitigkeit und der Synchronität divergierender Rollenansprüche gelingt langfristig nur durch »Ressourcenzukauf«. Haushaltshilfen, Erzieher*innen und Großeltern, die Care-Tätigkeiten übernehmen und dadurch \#WorkingMom ermöglichen, erhalten dafür keine äquivalente Valorisierung. Diese konzentriert sich auf das Subjekt, das im Sinne des spätmodernen Bewertungssystems reüssiert. Hier zeichnen sich Asymmetrien im medialen Bewertungssystem ab, welches ein enges Verständnis von Erfolg und Leistung zur Vergleichskategorie macht, dabei die Frage nach Vorbedingungen und Ressourcen vernachlässigt und so soziale Ungleichheit fördert. 


\subsection{Anerkennungsstrukturen zu Mutterschaft und Care-Arbeit}

Vergleicht man die Konzeptualisierung von Mutterschaft über die Kanäle hinweg, zeigt sich deutlich die Wirksamkeit sich widersprechender Anerkennungsstrukturen. Zum einen erfolgt Anerkennung nach den Kriterien der spätmodernen Steigerungslogik. Das heißt, Mutterschaft wird dann positiv valorisiert, wenn ein Streben nach Selbstverwirklichung, Statuserhalt und sozialem Erfolg parallel zur Sorgearbeit hinzutritt. Gleichzeitig wird Mutterschaft vor allem visuell nach archetypischen Mustern, also mit starken genderspezifischen Markern von Weiblichkeit sowie einer symbiotischen Darstellung von Mutter und Kind (vgl. Abb. 1), inszeniert und instrumentalisiert.
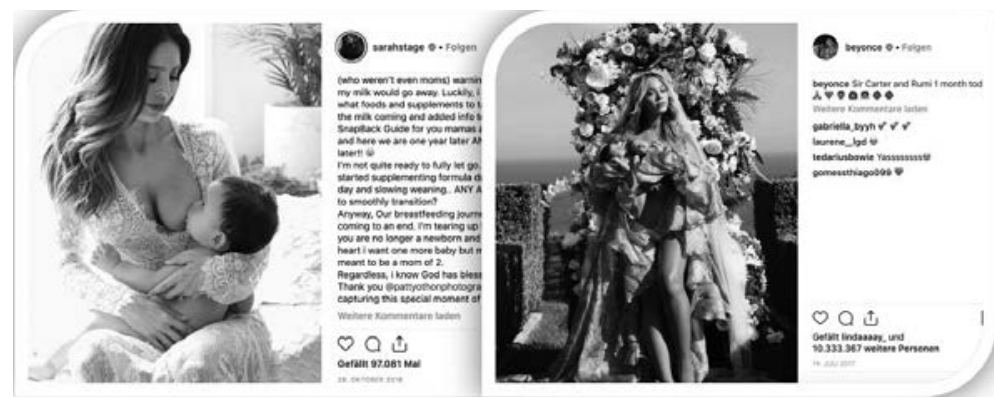

Abb. 1: Beispiele Instagram: Sarah Stage (28.10.2018), Knowles

(14.07.2017).

Das Konzept »Mutterschaft « gerät auf visueller Ebene zur Personifizierung von Fürsorge-Tätigkeiten (Nahrung, Pflege, Aufmerksamkeit, liebevolle Zuwendung) und ist damit stark mit Care-Arbeit verwoben. Nur durch Präsenz, Verfügbarkeit sowie die Bezogenheit auf das Kind scheint die Bedeutung von Mutterschaft visuell transportierbar zu sein. Das steht gerade im diametralen Widerspruch zur Ressourcenverhandlung, die vor allem in den Leitmedien geführt wird und in denen die Bemühung zu beobachten ist, Definitionsmachtverhältnisse (Beck 2017) hinsichtlich Mutterschaft und Mutterschaftspraxen neu zu justieren. Denn in den Analyseeinheiten aus den Leitmedien wird genau diese visuell dominant transportierte Bindung von Ressourcen aufgebrochen und zum Gegenstand der diskursiven Umsortierung. Die Ressource »Mutter« als sich sorgende, sich kümmernde steht zur 
Disposition - und wird gleichermaßen verteidigt wie angegriffen. Dies geschieht sowohl mit Blick auf biopolitische Fragen: Wer darf und soll biologisch oder sozial Mutter sein (etwa in Bezug auf Leihmutterschaft, Reproduktionsmedizin, Rechte von gleichgeschlechtlichen Paaren, Ressourcenausstattung), aber vor allem auch in Bezug auf Verteilungsfragen: Welcher Ressourceneinsatz und welche Emotionen sind in Mutterschaftspraxen legitim? Wie müssen diese in Partner- oder Elternschaft verteilt sein?

Darüber hinaus werden legitime staatliche Maßnahmen diskutiert, die den Ressourceneinsatz einerseits unter Paaren und andererseits zwischen unbezahlter Care-Arbeit und Lohnarbeit ausgleichen sollen. Mutterschaft ist in den Leitmedien folglich auf drei unterschiedlich intimen Ebenen von Diskurskämpfen betroffen: 1) Wer darf beziehungsweise soll Mutter sein? 2) Welcher zeitliche und emotionale Ressourceneinsatz ist für Mutterschaftspraxen gesellschaftlich erwünscht? 3) Durch welche ökonomischen und politischen Steuerungsmaßnahmen lässt sich der Ressourceneinsatz in Fürsorgearbeit mit der Verfügbarkeit für den Arbeitsmarkt zusammenbringen? Eine Doppelstruktur in der diskursiven Herstellung von Mutterschaft (Bewertung des Ressourceneinsatzes nach spätmoderner Marktlogik versus archetypische Care-Ikone) zeigt sich auch innerhalb der einzelnen Diskursfragmente. Hervorzuheben ist dabei der Umstand, dass Care-Arbeit genderspezifisch unterschiedlich valorisiert wird. Beispielsweise bewertet die Materialbasis Väter positiv, die Fürsorge vor beruflichen Aufstieg stellen, während dies bei Frauen nicht der Fall ist (Clauß 2016). Die Wahrnehmung von Sorgetätigkeiten durch eine Frau wird in den Analyseeinheiten nur in Kombination mit anderen Errungenschaften positiv valorisiert. Care-Arbeit ist in der Bewertungshierarchie der Spätmoderne anderen Bezugssystemen nachgeordnet: Das Sich-Sorgen um Kinder oder andere Care-Empfänger ist weniger wert als der Ressourceneinsatz Zeit auf anderen Märkten.

Als Folge der unterschiedlichen Valorisierung von Care- und Lohnarbeit stellt sich in der medialen Inszenierung von Mutterschaft ein Modus der Gleichzeitigkeit und Synchronität ein. Diesem steht ein Erschöpfungsdiskurs gegenüber, welcher die Kehrseite subjektiver Selbstoptimierungsversuche zeigt und als Ventil einer erschöpften neuen Mittelklasse dient, die an den eigenen Maßstäben leidet, ohne diese strukturell in Frage zu stellen oder ins Verhältnis zu setzen.

Gleichzeitigkeit und Erschöpfung sind diskursdynamisch als Reaktion zu bewerten, die den dominanten, aufgeblähten und einseitigen 
spätmodernen Anerkennungskriterien gegenüberstehen. So hat Petra Schmidt (2014) die moderne Mutter bereits als »Pionierin der Spätmoderne«, als »Avantgarde der Subjektivierung von Arbeit« beschrieben, welche »selbstkontrolliert, selbstrationalisiert, selbstökonomisiert « all das mit subjektiven und externalisierten Ressourcen aufzufangen versucht, was an steigenden gesellschaftlichen Erwartungen an das Individuum herangetragen wird.
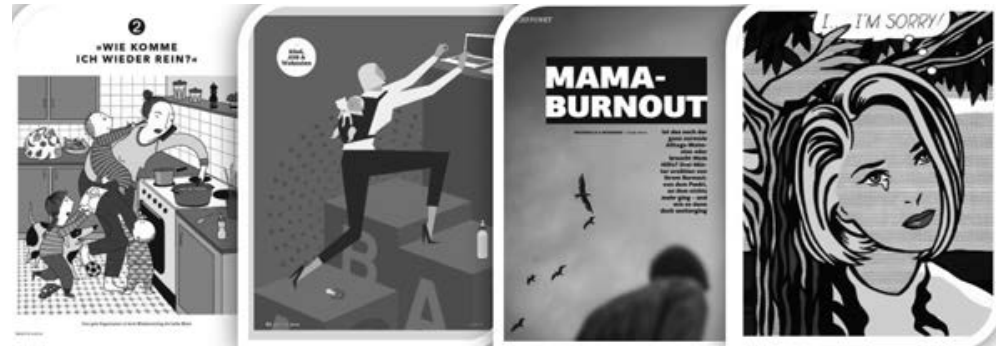

Abb. 2: Beispiele aus Brigitte (2018), Brigitte Mom (Sims 2018, Minner 2018) und Der Spiegel (Voigt 2016).

\subsection{Einfluss der Kanallogik auf den medialen Diskursebenen}

Auf verschiedenen medialen Diskursebenen kommt es dabei zu unterschiedlichen Formen der Ausprägung dieser Doppelstruktur. Es wird im Folgenden beispielhaft auf die Kanallogik von Instagram und TV-Werbung eingegangen.

Die Werbung positioniert die Mutter gemäß Kanallogik strategisch vorteilhaft für das beworbene Produkt. Dabei wird ihr in erster Linie die Funktion zugesprochen, sich um alle Belange des zwischenmenschlichen Um- und Versorgens zu kümmern. Sie ist primär auf das Wohlergehen der anderen (Kind und Partner) bedacht und kümmert sich, wenn überhaupt, zuletzt um sich selbst. Während Kind und Partner Fürsorge empfangen, wird die Mutter stets als Gebende, Wissende, Sorgende, Nährende konzeptualisiert. Dies geht einher mit einem stark vereindeutigten Frauenbild, das ebenfalls keinerlei Irritationen zulässt und die Mutter nur dann explizit positiv valorisiert, wenn sie ein attraktives Erscheinungsbild aufweist, einen kreativen und humorvollen Umgang mit den Unwägbarkeiten des Alltags und der Erziehung findet 
sowie »gute« Entscheidungen für die Versorgung der Familie und des Kindes trifft. Überlappende Rollenansprüche, Ressourcenknappheit und Erschöpfung werden nur dann dargestellt, wenn das beworbene Produkt eine Lösung für die divergierenden Ansprüche bietet, wie etwa Nahrungsergänzungsmittel und Mittel zur psychischen oder physischen Leistungssteigerung. Es zeigen sich im Bereich der TV-Werbung so Diskursfragmente im Sinne der spätmodernen Steigerungslogik bei gleichzeitiger Verfestigung traditioneller Rollenbilder. Einerseits wird eine archetypische Form von Mutterschaft hergestellt, die sich ausschließlich mit Care-Tätigkeiten beschäftigt und so Sehnsüchte nach Versorgung und Geborgenheit befriedigt. Andererseits wird auf den Erschöpfungsdiskurs Bezug genommen, um eine kommerzielle Lösung anzubieten. Durch die Reaktivierung der Leistungsfähigkeit kann das Subjekt den spätmodernen Ansprüchen wieder gerecht werden, so das Versprechen.

Auf Instagram zeigt sich die Doppelstruktur auf andere Weise. Zunächst ist die Logik von Instagram geprägt durch Ästhetisierung und Kommodifizierung - also das Zur-Ware-Machen - von Mutterschaft (Schmidt 2015). Digitale Plattformen wie Instagram begrenzen durch ihre Eigenlogik den Vorstellungsraum des Möglichen und tragen zu einer Vereinheitlichung der Deutungsstrukturen bei. So werden alle Modi von Mutterschaft in das Korsett der Ästhetisierung und des visuell Darstellbaren eingefügt, während das Unästhetische oder visuell nicht Vermittelbare von vorneherein ausgeschlossen sind. Diskursfragmente auf Instagram sind immer zugleich kreative Akte, denen eine bestimmte Wirkungsabsicht vorausgeht. So zeigen sich Leerstellen bei der Darstellung von Normalität und Durchschnittlichkeit, aber auch in Bezug auf die »abgewandte "Mutter (genervt, aggressiv, abweisend, wütend). Insbesondere die »Momfluencer« monetarisieren erfolgreich die Inszenierung der eigenen sozialen Rolle und fokussieren sich hier gänzlich auf eine care-basierte Darstellung von Mutterschaft. Bemerkenswert ist der hohe Einfluss des Kindes auf die Bildkomposition. Ist das Kind abgebildet, scheint nur eine zugewandte, irritationsfreie Form von Mutterschaft darstellbar zu sein. Widersprüche und Inkonsistenzen zeigen sich allein auf der textlichen Ebene, deren Aussagen oft konträr zur Bildlogik stehen.

Die implizite Bedeutungsstruktur der attraktiven Mutter und Frau bleibt hochgradig aktiv. Werden Themen wie Depression, Ermüdung und mentale Überfrachtung angesprochen, ist das Kind nicht auf dem Bild zu sehen. Stattdessen bleibt die Mutter auf sich selbst zurückge- 
worfen. Auch auf Instagram wird Mutterschaft im Modus der Gleichzeitigkeit hergestellt: Die Mutter zeigt sich in der Sphäre der Erwerbstätigkeit, während nur der Text auf die Mutterschaft Bezug nimmt (und umgekehrt). So wird polychrones Zeitmanagement und Entgrenzung auf Instagram zum normalisierten Modus von Mutterschaft, ohne dass die Ressourcen sichtbar werden, die es hierfür benötigt. Divergierende Zeitrhythmen von Arbeits- und Familienwelt lassen sich scheinbar widerspruchsfrei integrieren (Schmidt 2014).

\subsection{Fazit und transformativer Ausblick}

Der Mediendiskurs spielt eine entscheidende Rolle, wenn es um die nachhaltige Transformation gesellschaftlicher Strukturen im Sinne caregerechter Lebens- und Arbeitsbedingungen geht. Die punktuelle Analyse des Mediendiskurses offenbart 1) eine Lücke in Bezug auf die sprechenden Personen, 2) eine nach wie vor wirksame, normativ aufgeladene Mutterfigur, die medial eingesetzt wird und als Sehnsuchtsobjekt dient (Mutter als Versorgende, Liebende), 3) die Ästhetisierung und Kommodifizierung und Vereinheitlichung von Mutterschaft und 4) die Erschöpfung und Frustration, die symptomatisch für Care-Geber*innen zu sein scheint. Ein kritischer Blick auf strukturelle Zusammenhänge bleibt überwiegend aus. Es werden ungelöste Konflikte hinsichtlich der Anforderungen und Eigenschaften von Fürsorgearbeit sowie der Verschränkung von Mutterschaft mit Marktimperativen deutlich. Die Medienlogik fördert die Individualisierung von Konflikten (Erschöpfungsdiskurs) auf der einen und die Kommodifizierung und Ästhetisierung von Mutterschaft auf der anderen Seite. Diskurspositionen, die für Machbarkeit und »Autonomie-Fetischismus« (Thiessen und Villa 2010) stehen, untergraben die gesellschaftliche Aufwertung von fürsorgebasierten Beziehungen, die sich jenseits von Marktimperativen bewegen. Doch nur durch eine solche Aufwertung können sich intersektional gerechte Strukturen ausbilden.

Die Problemlagen der Großen Transformation müssen im Zusammenhang wahrgenommen und bearbeitet werden. Ebenso verhält es sich mit Care-Arbeit und Mutterschaft. Um diesen spätmodernen Aggressionspunkt aufzulösen, bedarf es neuer gesellschaftlicher Zielgrößen wie »Zeitwohlstand « (Habermann et al. 2015). Es gilt, Strukturen zu formen, welche die Möglichkeit, Sorge zu geben und zu empfangen, in den Mittelpunkt stellen - unabhängig von Alter, Gender, Ethnie oder 
sozialem Status. Denn das Menschliche nimmt hier - in der Angewiesenheit - seinen Anfang und sein Ende. Die Möglichkeit, in Verbundenheit zu leben und zu sterben - auch daran muss sich die Große Transformation messen lassen dürfen.

\section{Literatur}

Arendt, Florian, und Hans-Bernd Brosius. 2019. Soziale Vergleiche und Medienwandel. MedienJournal. DOI: https://doi.org/10.24989/medienjournal. v43i2.1732. Zugegriffen: 17. Juli 2020.

Beck, Ulrich. 2017. Die Metamorphose der Welt. Berlin: Suhrkamp.

Beck, Ulrich, Anthony Giddens, und Scott Lash (Hrsg.). 2014. Reflexive Modernisierung: eine Kontroverse. 6. Auflage. Frankfurt am Main: Suhrkamp.

Berger, Peter L., und Thomas Luckmann. 2016. Die gesellschaftliche Konstruktion der Wirklichkeit: eine Theorie der Wissenssoziologie. 26. Auflage. Frankfurt am Main: Fischer Taschenbuch.

Clauß, Anna. 2016. Sie ist wieder da. Der Spiegel Nr. 11, 44-49.

Ehlert, Nancy. 2016. Familienpolitik als Carepolitik für Ältere. https://www.bpb. $\mathrm{de} /$ politik/innenpolitik/familienpolitik/218864/carepolitik-fuer-aeltere? $\mathrm{p}=$ all . Zugegriffen: 17. Juli 2020.

Fraser, Nancy, und Axel Honneth. 2003. Umverteilung oder Anerkennung? Eine politisch-philosophische Kontroverse. Frankfurt am Main: Suhrkamp.

Foucault, Michel. 1981. Archäologie des Wissens. Frankfurt am Main: Suhrkamp.

Habermann, Friederike, Hartmut Rosa, Frigga Haug, Niko Paech, Lena Kirschenmann, und Felix Wittmann. 2015. Zeitwohlstand: Wie wir anders arbeiten, nachhaltig wirtschaften und besser leben. 2. Auflage. München: Oekom.

Jäger, Margret, und Siegfried Jäger. 2007. Deutungskämpfe: Theorie und Praxis kritischer Diskursanalyse. Wiesbaden: VS Verlag für Sozialwissenschaften.

Karidi, Maria. 2017. Medienlogik im Wandel: die deutsche Berichterstattung 1984 und 2014 im Vergleich. Wiesbaden: Springer VS.

Knowles, Beyoncé. 2017. Posts [@beyonce] vom 14. Juli. Instagram-Profil. https:// www.instagram.com/beyonce/?hl=de. Zugegriffen: 15. Mai 2020.

Löblich, Maria. 2016. Theoriegeleitete Forschung in der Kommunikationswissenschaft. In: Handbuch nicht standardisierte Methoden in der Kommunikationswissenschaft, herausgegeben von Stefanie Averbeck-Lietz und Michael Meyen, 6779. Wiesbaden: Springer VS.

Lutz, Helma, und Ewa Palenga-Mollenbeck. 2012. Care Workers, Care Drain, and Care Chains: Reflections on Care, Migration, and Citizenship. Social Politics: International Studies in Gender, State \& Society. DOI: https://doi.org/10.1093/sp/ jxr026.

Meyen, Michael, Maria Löblich, Senta Pfaff-Rüdiger, und Claudia Riesmeyer. 2019. Qualitative Forschung in der Kommunikationswissenschaft. Eine praxisorientierte Einführung. Wiesbaden: Springer VS. 
Minner, Claudia. 2018. Mama-Burnout. Brigitte Mom Nr. 1, 116-122.

Reckwitz, Andreas. 2019. Das Ende der Illusionen: Politik, Ökonomie und Kultur in der Spätmoderne. Berlin: Suhrkamp.

Rosa, Hartmut. 2018. Mehr Welt! Umrisse einer Kritik der Verfügbarkeit. Wien, Salzburg: Residenz.

Sims, Gill. 2018. Raus aus dem Chaos. Brigitte Mom Nr. 3, 82-86.

Schmidt, Petra. 2014. Total Quality Mama: Mutterschaft aus der Perspektive Arbeit. München: Utz.

Schütze, Yvonne. 1986. Die gute Mutter: zur Geschichte des normativen Musters »Mutterliebe«. Theorie und Praxis der Frauenforschung, Band 3. Bielefeld: B. Kleine.

Soiland, Tove. 2019. Ökonomisierung - Privatisierung: die verdeckte Unterseite neoliberaler Restrukturierungen und ihre Implikationen für die Geschlechterforschung. In: Handbuch Interdisziplinäre Geschlechterforschung, herausgegeben von Beate Kortendiek, Birgit Riegraf und Katja Sabisch, 95-104. Wiesbaden: Springer VS. DOI: https://doi.org/10.1007/978-3-658-12496-0_13.

Stage, Sarah. 2018. Posts [@sarahstage] vom 28. Oktober. Instagram-Profil. https://www.instagram.com/sarahstage/?hl=de. Zugegriffen: 15. Mai 2020.

Thiessen, Barbara. 2019. Mutterschaft: Zwischen (Re-)Naturalisierung und Diskursivierung von Gender und Care. In: Handbuch Interdisziplinäre Geschlechterforschung, herausgegeben von Beate Kortendiek, Birgit Riegraf und Katja Sabisch, 1141-1149. DOI: https://doi.org/10.1007/978-3-658-12496-0_64.

Thiessen, Barbara. 2020. Doing Family while Doing Care: Wie Familie gemacht wird. Gendergraphien XI: Geschlecht und Familie. Vortrag vom 7. Februar. LMU München.

Thiessen, Barbara, und Paula-Irene Villa. 2010. Entweder - oder? Mutterschaft zwischen Fundamentalismen und vielschichtigen Praxen. querelles-net. DOI: https://doi.org/10.14766/875.

Thurer, Shari. 1995. Mythos Mutterschaft: Wie der Zeitgeist das Bild der guten Mutter immer wieder neu erfindet. München: Droemer Knaur.

Vinken, Barbara. 2011. Die deutsche Mutter: Der lange Schatten eines Mythos. Frankfurt am Main: S. Fischer.

Voigt, Claudia. 2016. Gut, besser, mittelmäßig. Der Spiegel Nr. 6, 130-132.

»Wie komme ich wieder rein?«. 2018. Brigitte Nr. 4, 92.

Winker, Gabriele. 2015. Care Revolution: Schritte in eine solidarische Gesellschaft. $X$-Texte. Bielefeld: Transcript.

\section{Open Access}

Dieser Beitrag erscheint unter der Creative-Commons-Lizenz CC BY-ND 3.0 DE: https://creativecommons.org/licenses/by-nd/3.0/de/. 


\section{Kommunikation für eine sozial-ökologische Transformation}





\section{Sozial-ökologische \\ Transformationsforschung: Desiderata der Kommunikations- und Medienwissenschaft}

\section{Sigrid Kannengießer}

Keywords: Transformationsforschung, sozial-ökologische Transformation, Nachhaltigkeit, digitale Medien

\section{Abstract}

Auf der Basis zentraler Argumente der interdisziplinären Transformationsforschung im Allgemeinen und der sozial-ökologischen Transformationsforschung im Besonderen sowie des Bereichs der Kommunikations- und Medienwissenschaften, der sich mit Fragen des Wandels beschäftigt, diskutiert dieser Beitrag, wie konkrete Medienpraktiken zur »Großen Transformation «, die auf eine nachhaltige Gesellschaft abzielt, beitragen (können) und wie diese wiederum kommunikations- und medienwissenschaftlich reflektiert werden sollten. Daraus leiten sich Forschungsdesiderata für die Kommunikations- und Medienwissenschaft ab.

Sigrid Kannengießer: Sozial-ökologische Transformationsforschung: Desiderata der Kommunikation- und Medienwissenschaft. In: Nils S. Borchers, Selma Güney, Uwe Krüger und Kerem Schamberger (Hrsg.): Transformation der Medien - Medien der Transformation. Verhandlungen des Netzwerks Kritische Kommunikationswissenschaft. Frankfurt am Main: Westend 2021. DOI: https://doi.org/10.53291/QNC05200.

Prof. Dr. Sigrid Kannengießer I Universität Bremen I sigrid.kannengiesser@ uni-bremen.de 


\section{Einführung}

Dieser Beitrag wurde während der Covid-19-Pandemie geschrieben einer Zeit der globalen Erschütterung etablierter Abläufe. Maskentragen, Abstandhalten und restriktive Begrenzungen der Anzahl der Personen, die sich treffen dürfen, schränken das soziale Leben ein, viele wirtschaftliche Bereiche sind existentiell bedroht, andere, wie der Onlinehandel, wachsen enorm, während die Politik sich (noch mehr als zuvor) an nationalen Fragen und Problemen bei gleichzeitig steigender Notwendigkeit des weltweiten Handelns orientiert.

Während die einen in dieser Krise eine Chance für gesellschaftliche Veränderungen sehen, fürchten andere, dass sie das soziale Gefüge im negativen Sinne stabilisiert: Bestehende Ungleichheiten und Ungerechtigkeiten verschärfen sich innerhalb und zwischen Gesellschaften. Während also die Pandemie wütet, existieren weitere Krisen fort, stehen in interdependenten Verhältnissen und verschärfen sich sogar gegenseitig. So schien die Covid-19-Krise zunächst die sozial-ökologische Krise zu verlangsamen: Kohlenstoffdioxidemissionen und Luftverschmutzung reduzierten sich unter anderem durch die geringere Mobilität im Flug- und individuellen Kraftfahrzeugverkehr. Doch zeigt sich, dass in manchen Bereichen zwar Emissionen eingespart, in anderen dagegen vermehrt produziert werden: Anbieter wie Netflix profitieren von der Pandemie, nicht nur weil die Nachfrage nach ihren Produkten zugenommen hat, sondern auch weil es "zu einer der wenigen Ausspielwege von Hollywood geworden [ist], während die Kinos überall geschlossen sind « (Schuler 2020). Durch die gestiegene Onlinekommunikation in Zeiten der Pandemie, sei es aufgrund der zunehmenden Nachfrage bei Streamingdiensten, der Verlagerung vieler Arbeitsorte ins Home-Office und der damit verbundenen Notwendigkeit zu Videokonferenzen statt Präsenzveranstaltungen und nicht zuletzt des erhöhten Bedarfs nach digitalen Medientechnologien als technischer Voraussetzung, verschärft sich die sozial-ökologische Krise während der Covid-19-Pandemie. Denn nicht nur die materiellen Herstellungsprozesse digitaler Medientechnologien bedürfen Energie, die primär aus fossilen Ressourcen gewonnen wird (Gabrys 2015, 3; Yu et al. 2010). Sie wird auch für die Onlinekommunikation benötigt, hauptsächlich für die riesigen Serverfarmen mitsamt ihren komplexen Kühlanlagen (Cook und Jardmin 2019; Sühlmann-Faul 2019). Bereits vor Covid-19 wurden neun Prozent der global genutzten Energie für das Betreiben digitaler 
Technologien inklusive der benötigten Infrastrukturen verwendet (Morley et al. 2018, 129).

Die »Vielfachkrise« (Demirović et al. 2011) scheint also um eine weitere Krise ergänzt, welche die Weltgesellschaft vor noch größere Probleme stellt. Der Ruf nach einer »Großen Transformation« (WBGU 2011; Schneidewind 2018) ist aktueller, dringlicher und komplexer denn je - gilt es doch vor dem Hintergrund der Pandemie und der sich verschärfenden Ungleichheiten eine komplexe sozio-ökologische Transformation zu forcieren, welche die Krisen mitsamt ihrer Interdependenzen adressiert.

Krüger und Meyen $(2018,343)$ greifen die Forderung nach der Großen Transformation für die Kommunikations- und Medienwissenschaft auf und fordern eine Öffnung des »eingeschränkten Horizonts« des Faches, das in ihren Augen »vor allem für sich selbst arbeitet (ebd.). Sie schlagen der Disziplin das Ziel einer »Demokratischen Postwachstumsgesellschaft« vor, um »Forschung und Lehre« Sinn zu geben und »schnell den Übergang in eine Postwachstumsgesellschaft zu schaffen und die Demokratie gleichzeitig nicht nur zu erhalten, sondern substanziell zu stärken und auf die Weltgesellschaft auszudehnen« (ebd., 347-348).

Während die Autoren im Anschluss diverse Anforderungen an das Fach skizzieren (ebd., 351-353), um schließlich bei Verteilungsfragen zu landen (ebd., 353-355), folgt dieser Beitrag ihrem Aufruf, sich auch in der Kommunikations- und Medienwissenschaft mit der Großen Transformation zu beschäftigen. Dabei wird diese Forderung auf der Basis der interdisziplinären Transformationsforschung im Allgemeinen und der sozial-ökologischen Transformationsforschung im Besonderen sowie des Bereichs der Kommunikations- und Medienwissenschaften, der sich mit Fragen von Transformation und gesellschaftlichem Wandel beschäftigt, diskutiert. Im Mittelpunkt stehen dabei diejenigen Aspekte der Großen Transformation, die im Sinne einer »nachhaltigen Entwicklung« (WCED 1987) die Interdependenzen sozialer, ökologischer und ökonomischer Gerechtigkeit berücksichtigen.

Des Weiteren wird an Beispielen gezeigt, wie konkrete Medienpraktiken zur Großen Transformation beitragen können und wie diese wiederum kommunikations- und medienwissenschaftlich reflektiert werden sollten. So lassen sich schließlich in diesem Zusammenhang konkrete Desiderata für die Kommunikations- und Medienwissenschaft ableiten. 


\section{Interdisziplinäre Transformationsforschung und kommunikations- und medienwissenschaftliche Theorien des Wandels}

Um kommunikations- und medienwissenschaftliche Desiderata zu entwickeln, welche die Frage nach der Großen Transformation adressieren, wird im Folgenden zunächst die Transformationsforschung im Allgemeinen und insbesondere die sozio-ökologische Transformationsforschung im Besonderen definiert. Zusätzlich soll gezeigt werden, wie sich die Kommunikations- und Medienwissenschaft bislang mit gesellschaftlichem Wandel beschäftigt hat.

\subsection{Interdisziplinäre Transformationsforschung}

Transformation ist im wissenschaftlichen Diskurs kein neuer Begriff, ${ }^{1}$ wird aber dennoch als »neues Konzept sozialen Wandels« (Reißig 2009) gehandelt. Mit Hinblick auf die beteiligten Disziplinen, zentralen gesellschaftlichen Bereiche, Themen und Phänomene sowie verwendeten Theorien und Methoden gestaltet sich das Forschungsfeld dabei durchaus komplex. ${ }^{2}$ Transformationsforschung beschäftigt sich nicht mit jeglichem gesellschaftlichen Wandel, sondern mit Prozessen, die »systematischen und substantiellen Charakter tragen, durch identifizierbare Akteure eher revolutionär und steuerungsorientiert begonnen werden sowie deutliche imitative Merkmale aufweisen« (ebd., 12). Der Begriff denotiert also nicht gesellschaftlichen Wandel per se, sondern solche Prozesse, die mit Absicht herbeigeführt werden und deren gesellschaftliche Veränderungen sich über die Zeit hinweg beständig vollziehen. Schien die Relevanz und Brisanz gesellschaftlicher TransformationsprozesseinEuropa nach 1989 abzunehmen, so gewinnen diese-und damit auch die Forschung - vor dem Hintergrund der aktuellen komplexen Krisensituation erneut an politischer und gesellschaftlicher Dringlichkeit.

Aufgrund der ökologischen Krise und des Klimawandels beschäftigt sich die interdisziplinäre Transformationsforschung jüngst vor allem

1 Zur Begriffsgeschichte vgl. Kollmorgen, Merkel und Wagener (2015a, 12-14).

2 Für einen Ein- beziehungsweise Überblick in die Transformationsforschung vgl. Kollmorgen, Merkel und Wagener (2015b). 
mit dem Konzept der Nachhaltigkeit: Ihr Ziel ist es, »Transformation(en) hin zu einer nachhaltigen Gesellschaft zu beschreiben, erklären, bewerten und unterstützen.« (Wittmayer und Hölscher 2017, 11). Im Sinne des Brundtland-Berichts wird eine Entwicklung als nachhaltig charakterisiert, wenn die Bedürfnisse der gegenwärtigen Generationen befriedigt werden, ohne dabei die Bedürfnisse zukünftiger Generationen zu beeinträchtigen (WCED 1987). Die Nachhaltigkeitsforschung hat verschiedene Modelle entwickelt, um den zugrundeliegenden Begriff zu differenzieren, darunter das Drei-Säulen-Modell (Hauff und Claus 2012, 59) und jüngst das Doughnut-Modell (Raworth 2017). Gemein ist ihnen die Betonung, dass Nachhaltigkeit nicht nur eine ökologische, sondern auch eine soziale und ökonomische Dimension umfasst. Als Ziele für nachhaltige Entwicklungen werden genannt: die Sicherung der menschlichen Existenz, die Bewahrung der globalen ökologischen Ressourcen, der Erhalt des gesellschaftlichen Produktivpotenzials und die Gewährleistung der Handlungsmöglichkeiten heutiger und zukünftiger Generationen (Pufé 2014, 18). Die 17 Ziele für nachhaltige Entwicklung, welche die Staatengemeinschaft der Vereinten Nationen 2015 verabschiedete (Vereinte Nationen 2015), konkretisieren diese Ambitionen.

Transformationsforschung, die Nachhaltigkeit in den Fokus setzt, nutzt daher oftmals den Zusatz »sozial-ökologisch«, um zu betonen, dass beide Dimensionen gleichermaßen nötig sind (Brand und Brad 2019). Das Diktum »Transformation ist heute ein Schlüsselbegriff des Nachhaltigkeitsdiskurses« (Luks, Bohunovsky und Höltl 2018, 257) gilt also auch umgekehrt. Während die Transformationsforschung auch die sozial-ökologischen Auswirkungen der Digitalisierung aufgreift (beispielsweise Höfner und Frick 2019; Lange und Santarius 2018), werden sozial-ökologische Prozesse, welche das Ziel der Nachhaltigkeit verfolgen, im Fach der Kommunikations- und Medienwissenschaften kaum thematisiert (Kannengießer 2020a). Doch kommt dem Fach eine zentrale Verantwortung in Hinblick auf Nachhaltigkeit zu (ebd.). Bislang setzt sich die Kommunikations- und Medienwissenschaft durchaus explizit mit Transformationen im Sinne eines gesellschaftlichen Wandels auseinander, jedoch noch zu wenig mit Fragen ihrer sozial-ökologischen Dimension. 


\subsection{Kommunikations- und medienwissenschaftliche Theorien des Wandels}

Vor allem der Wandel von Medien sowie das Zusammenspiel von gesellschaftlichem und medialem Wandel standen bislang im Fokus kommunikations- und medienwissenschaftlicher Forschung, die sich mit Transformation auseinandersetzt.

Kinnebrock, Schwarzenegger und Birkner $(2015,12)$ konstatieren, dass Medienwandel sin den letzten Jahren eines der bestimmenden Schlagwörter im kommunikations- und medienwissenschaftlichen Fachdiskurs geworden « sei. Forschende des Fachs befassten sich mit Wandel in nahezu allen Bereichen des sozialen Lebens, in denen Praktiken und Phänomene der medienvermittelten Kommunikation eine Rolle spielen können (ebd., 11-13.). Auch wenn die Autor*innen als Herausgeber*innen des Sammelbands Theorien des Medienwandels mit diesem Titel den Fokus auf Medien setzen, so betonen sie doch, dass »die Verbindung zwischen Wandel von gesellschaftlich-kulturellen Phänomenen einerseits und sich wandelnden Praktiken der medialen Kommunikation sowie den dafür verfügbaren Kommunikationstechnologien andererseits « (ebd., 12) oftmals in den Blick genommen werden.

So wird der Wandel bezüglich der Medieninhalte (vgl. Donsbach und Büttner 2005) genauso untersucht wie medientechnologische Veränderungen durch Innovationen (vgl. Latzer 2013; Kannengießer 2020c), der Wandel der medialen Öffentlichkeit (vgl. Jarren 1998; Imhof 2011; van Dijk und Poell 2015), des Journalismus (vgl. Lünenborg und Berghofer 2010), des Medienrechts (vgl. Dommann 2014), der Medienindustrie (vgl. Winseck und Jin 2011) sowie das Zusammenspiel des medialen und gesellschaftlichen Wandels (vgl. Münch und Schmidt 2005; Krotz 2007; Hepp, Breiter und Hasebrink 2017). Auch sind die theoretischen Zugänge, die Medienwandel erklären wollen, durchaus komplex und haben eine lange Tradition, wie Wilke (2015) in einer Systematisierung unterschiedlichster Theorieansätze zeigt.

Doch auch wenn verschiedene Ansätze das Zusammenspiel von medialem und gesellschaftlichem Wandel in den Blick nehmen, so offenbart sich tatsächlich, wie Krüger und Meyen (2018) feststellen, eine Forschungslücke in Hinblick auf die Frage nach der Großen Transformation. Dieser Beitrag diskutiert nun im Folgenden, wie sich die Kommunikations- und Medienwissenschaft mit der Großen Transformation beschäftigen kann, indem sie den Fokus auf Medienpraktiken setzt, die zu sozial-ökologischen Transformationsprozessen beitragen wollen. 


\section{Forschungsdesiderata: Medienpraktiken für die Große Transformation}

In ihrem Plädoyer für eine transformative Kommunikationswissenschaft fordern Krüger und Meyen (2018) das Fach auf, sich auf den „Weg in die Postwachstumsgesellschaft « zu machen. Der dahinterliegende ökonomische Ansatz sieht eine »Wirtschaft ohne Wachstum « (vgl. Paech 2005) vor, in der sich die Rolle der Individuen verändert, die nicht mehr "passive « Konsumierende sind und Güter als solche regelmäßig konsumieren und ersetzen, sondern durch einen entsprechenden Umgang mit diesen zu deren Langlebigkeit und schließlich auch zu einer nachhaltigen Gesellschaft beitragen (Paech 2012, 6061). So gilt das Reparieren in diesem Kontext als zentrale Praktik einer nachhaltigen sozialen Ordnung (Nagel und Paech 2018).

Auch in der Kommunikations- und Medienwissenschaft wurde das Reparieren von Medientechnologien als Medienpraktik für eine nachhaltige Gesellschaft diskutiert (vgl. Kannengießer 2017; 2020b). ${ }^{3}$ In empirischen Studien zeigte sich, dass Menschen ihre Medienapparate reparieren, um die Nutzungsdauer der Geräte zu verlängern und damit nicht nur die Produktion von Müll zu vermeiden, sondern auch Ressourcen zu schonen (ebd.). Damit versuchen sie durch die Praktik des Reparierens über eine sozial-ökologische Transformation hin zu einer nachhaltigeren Gesellschaft zu wirken (ebd.).

Dieses Ziel verfolgen auch Akteur*innen, die Medientechnologien unter fairen Bedingungen mit nachhaltigen Ressourcen produzieren oder nutzen. Das wohl prominenteste Beispiel auf dem Markt ist das Fairphone, ein Smartphone des gleichnamigen niederländischen Unternehmens, das unter ebensolchen Bedingungen und Ressourcennutzung hergestellt werden soll. Auch die Produktion und Aneignung dieses Produkts wurde aus kommunikations- und medienwissenschaftlicher Perspektive untersucht (vgl. Kannengießer

3 Eine Praktik ist ein sozial geteiltes, routinisiertes und durch ein implizites sowie interpretatives Wissen gekennzeichnetes, »sozial sverstehbares< Bündel von Aktivitäten « (Reckwitz 2003, 289); Medienpraktiken sind entsprechend auf diese Weise charakterisierbare Handlungen, die sich auf Medien beziehen (für einen Überblick des Forschungsfeldes Gentzel 2015, 15-17; Pentzold 2015). Dabei wird zwischen solchen differenziert, in denen Medien als Vermittler in Kommunikationsprozessen fungieren, und solchen, in denen sie (als Inhalte, Organisationen oder Technologien) selbst im Fokus der Praktiken stehen (Kannengießer und Kubitschko 2017). 
2020b; 2020c). Obwohl im Fairphone nur wenige nachhaltig abgebaute Rohstoffe zu finden sind (Dießenbacher und Reller 2016) und das Unternehmen durch verschiedene Strategien den Neukauf eines Smartphones bewirbt und damit letztendlich doch wieder die Nachfrage ankurbelt und den Ressourcenverbrauch in Kauf nimmt (Kannengießer 2020c), kann die Produktion und Nutzung dieser Medientechnologie als Versuch gesehen werden, zu sozial-ökologischen Transformationsprozessen beizutragen, die auf Nachhaltigkeit zielen (Kannengießer 2020b; 2020c; zu nachhaltigen Medientechnologien auch van der Velden 2018).

Sowohl das Reparieren als auch die Produktion und Nutzung fairer Medientechnologien sind also Beispiele dafür, wie Medienpraktiken zu einer Großen Transformation beitragen können - auch wenn diesen Praktiken Ambivalenzen inhärent sind. So regt das Fairphone-Unternehmen durch Werbestrategien und Kaufanreize doch eher Konsum an, anstatt Nichtkonsum als nachhaltigste Praktik zu proklamieren. Außerdem problematisch ist der Umstand, dass sich solche Praktiken nur in einer gesellschaftlichen Nische vollziehen (Kannengießer 2020b; 2020c). Die handelnden Akteur*innen versuchen mit diesen bewusst, gesellschaftlichen Wandel im Sinne eines engen Begriffsverständnisses von Transformation auszulösen, der nicht nur substantiell, sondern auch beständig wirkt.

Bezweckt man aus kommunikations- und medienwissenschaftlicher Perspektive die gesellschaftlichen Transformationsprozesse, die auf Nachhaltigkeit zielen, zu verstehen und kritisch zu reflektieren, ist es geboten, diese und weitere Medienpraktiken in den Blick zu nehmen. Im Folgenden werden daher anhand einiger Beispiele Forschungsdesiderata entwickelt, anhand deren das Zusammenspiel zwischen den Medien und der Großen Transformation analysiert werden kann. Dabei werden erstere als Technologien, Inhalte und Organisationen begriffen sowie ihre Aneignung berücksichtigt.

In Hinblick auf Medientechnologien gilt es beispielsweise, weitere Initiativen zu analysieren, die Medienapparate unter fairen Bedingungen herstellen (wollen) wie etwa in Deutschland die Computermaus von Nager IT (Kannengießer 2016) oder das Smartphone Shift, das ähnlich dem Fairphone als modulares Gerät reparierbar sein und unter fairen Bedingungen produziert werden soll. Aus einer kommunikations- und medienwissenschaftlichen Perspektive ist es erforderlich, solche Initiativen weitergehend zu untersuchen, um ihr transformatives Potenzial aufzuzeigen und durch die Sichtbarmachung von Grenzen 
und Ambivalenzen dieser Projekte (wie oben am Beispiel des Fairphones skizziert) zu ihrer kritischen Weiterentwicklung beizutragen.

Auch wie Medientechnologien nach dem Ende ihrer Nutzungsdauer zu entsorgen sind, ohne dass sie auf den großen Müllhalden der Welt die Gesundheit von Menschen und Tieren gefährden oder deren Lebensgrundlage zerstören (zu den sozio-ökologische Auswirkungen elektronischen Mülls vgl. Kaitatzi-Whitlock 2015; Gabrys 2011), sollte untersucht werden. Die Verlängerung der Nutzungsdauer durch das bereits thematisierte Reparieren von Medientechnologien stellt dabei zumindest einen Versuch dar, ihre Entsorgung zu verhindern oder zumindest zu verschieben.

Neben der Praktik der Instandsetzung ist es in der Kommunikations- und Medienwissenschaft relevant, weitere Analysen der Medienaneignung vorzunehmen, mit denen Menschen zu einer nachhaltigen Gesellschaft beitragen wollen. Erkenntnisbringend sind etwa Praktiken der Nichtnutzung, die zwar schon im Fokus der Forschung stehen (vgl. Roitsch 2020; Kaun und Schwarzenegger 2014; Portwood-Stacer 2013), aber noch nicht im Zusammenhang mit der Großen Transformation gedacht werden.

Dass die zunehmende Aneignung von Onlinemedien zu einem erhöhten Energiebedarf und -verbrauch führt, wurde eingangs bereits thematisiert. Dieser steigt nicht nur durch die Nutzung der digitalen Endgeräte, sondern auch durch den Betrieb riesiger Serverfarmen, die durch jeden Klick in Onlinemedien aktiviert werden, sowie deren komplexe Kühlanlagen (Gabrys 2015). Problematisch ist hierbei vor allem, dass der Strom derzeit maßgeblich aus fossilen Quellen stammt (ebd.). In diesem Zusammenhang gilt unter anderem festzustellen, inwiefern sich dieser Energieverbrauch und die produzierte Abwärme nachhaltiger nutzen lassen (vgl. Velkova 2016).

Schließlich sollte man auch auf der Inhaltsebene den Zusammenhang von Medien und der Großen Transformation näher in den Blick nehmen. So existieren kaum Studien zu der Frage, wie durch Medieninhalte zu einer nachhaltigen Gesellschaft beigetragen werden kann. ${ }^{4}$ Gerade vor dem Hintergrund der UN-Ziele für nachhaltige Entwicklung, die unterschiedliche gesellschaftliche Transformationsprozesse fordern, ist es von Aktualität und Dringlichkeit (da sie bis 2030 umgesetzt sein sollen), die

4 Für Ausnahmen vgl. Kannengießer (2020c) über die Onlineplattform utopia.de, die für nachhaltigen Konsum wirbt, oder Young und McComas (2016) zu Medien und ihrem Beitrag für eine nachhaltige Entwicklung in Sambia. 
Rolle von Medienorganisationen und ihren Inhalten für die Forderung nach Nachhaltigkeit und der Großen Transformation zu untersuchen.

Mit diesen Beispielen seien einige Forschungsdesiderata der Kommunikations- und Medienwissenschaft aufgezeigt, die im Zusammenhang von Medien und der Großen Transformation bestehen.

\section{Kommunikations- und medienwissenschaftliche Transformationsforschung}

Die aktuelle Transformationsforschung setzt einen Schwerpunkt auf gesellschaftliche Wandlungsprozesse, die auf Nachhaltigkeit zielen. Im Sinne der Großen Transformation (WBGU 2011) werden solche Prozesse analysiert, kritisch reflektiert und in transdisziplinären Ansätzen auch begleitet, die einen gesellschaftlichen Wandel mit dem Ziel der Nachhaltigkeit verfolgen. Obwohl sich, wie an einigen Beispielen illustriert, die Kommunikations- und Medienwissenschaft mit gesellschaftlichem Wandel (vor allem im Zusammenspiel mit medialem Wandel) beschäftigt, gibt es kaum Arbeiten, die sich mit einem oben ausgeführten engeren Fokus gesellschaftlicher Transformationsprozesse, die auf Nachhaltigkeit zielen, auseinandersetzen.

Auf der Grundlage dieser Erkenntnis schließe ich mich der Forderung von Krüger und Meyen (2018) an, dass sich auch die Kommunikationsund Medienwissenschaft mit der Großen Transformation beschäftigen sollte. Eine Möglichkeit, dieser nachzukommen, besteht darin, sich mit konkreten Medienpraktiken auseinanderzusetzen, mit denen Akteur*innen versuchen, auf eine nachhaltige Gesellschaft hinzuwirken. In diesem Beitrag wurden einige Studien vorgestellt, die untersuchen, wie mit Medien (als Inhalte und Technologien) zu einer nachhaltigen Gesellschaft beigetragen werden kann, sowie anhand weiterer Beispiele Forschungsdesiderata für die Kommunikations- und Medienwissenschaft aufgezeigt. Will man die Große Transformation auch aus kommunikations- und medienwissenschaftlicher Perspektive kritisch analysieren und begleiten, so sind diese Lücken zu schließen und gesellschaftliche Herausforderungen und Phänomene weiterhin kritisch zu beobachten, um zusätzliche Desiderata zu identifizieren. Neben diesen Betrachtungen ist es auch eine Aufgabe der Kommunikations- und Medienwissenschaft, in transformativen Projekten Gesellschaft mitzugestalten, etwa durch die Unterstützung nachhaltiger Medienpraktiken oder die Entwicklung nachhaltiger Medientechnologien. Solche 
transformativen Projekte lassen sich dabei vor allem durch transdisziplinäre Ansätze, also in Kooperation mit Akteur*innen der Medienpraxis (Nichtregierungsorganisationen und Unternehmen), umsetzen.

Kommunikations- und Medienwissenschaftler*innen werden damit selbst zu Gestalter*innen der Großen Transformation, die sie gleichzeitig (selbst)kritisch analysieren.

\section{Literatur}

Brand, Ulrich, und Alina Brad. 2019. Sozial-ökologische Transformation. In: Wörterbuch Land- und Rohstoffkonflikte, herausgegeben von Jan Brunner, Anna Dobelmann, Sarah Kirst und Louisa Prause, 279-285. Bielefeld: Transcript.

Cook, Gary, und Elizabeth Jardim. 2019. Clicking Clean Virginia. The Dirty Energy Powering Data Center Alley. Greenpeace Reports. https://www.greenpeace. org/usa/wp-content/uploads/2019/02/Greenpeace-Click-Clean-Virginia-2019. pdf. Zugegriffen: 20. Februar 2019.

Demirovi, Alex, Julia Dück, Florian Becker, und Pauline Bader. 2011. VielfachKrise. Im finanzmarktdominierten Kapitalismus. Hamburg: VSA.

Dießenbacher, Joshua, und Armin Reller. 2016. Das »Fairphone«: Ein Impuls in Richtung nachhaltige Elektronik? In: Kritische Rohstoffe in der Großen Transformation: Metalle, Stoffstrompolitik und Postwachstum, herausgegeben von Andreas Exner, Martin Held und Klaus Kümmerer, 269-292. Wiesbaden: Springer.

Dommann, Monika. 2014. Autoren und Apparate: Die Geschichte des Copyrights im Medienwandel. Frankfurt am Main: S. Fischer.

Donsbach, Wolfang, und Katrin Büttner. 2005. Boulevardisierungstrend in deutschen Fernsehnachrichten. Publizistik 50: 21-38.

Gabrys, Jennifer. 2015. Powering the Digital: From Energy Ecologies to Electronic Environmentalism. In: Media and the Ecological Crisis, herausgegeben von Richard Maxwell, Jon Raundalen und Nina Lager Vestberg, 3-18. Milton Park: Routledge.

Gabrys, Jennifer. 2011. Digital Rubbish: A Natural History of Electronics. Ann Arbor: University of Michigan Press.

Gentzel, Peter. 2015. Praxistheorie und Mediatisierung: Grundlagen, Perspektiven und eine Kulturgeschichte der Mobilkommunikation. Wiesbaden: Springer VS.

Hauff, Michael von, und Katja Claus. 2012. Fair Trade: Ein Konzept nachhaltigen Handels. Stuttgart: UTB.

Hepp, Andreas, Andreas Breiter, und Uwe Hasebrink (Hrsg.). 2017. Commuicative Figurations: Transforming communications in times of deep mediatization. London: Palgrave Macmillan

Höfner, Anja, und Vivian Frick (Hrsg.). 2019. Was Bits und Bäume verbindet: Digitalisierung nachhaltig gestalten. München: Oekom. 
Imhof, Kurt. 2011. Die Krise der Öffentlichkeit: Kommunikation und Medien als Faktoren des sozialen Wandels. Frankfurt am Main: Campus.

Jarren, Otfried. 1998. Medien, Mediensystem und politische Öffentlichkeit im Wandel. In: Politikvermittlung und Demokratie in der Mediengesellschaft: Beiträge zur politischen Kommunikationskultur, herausgegeben von Ulrich Sarcinelli, 74-94. Bonn: Bundeszentrale für politische Bildung.

Kaitatzi-Whitlock, Sophia. 2015. E-waste, Human-waste, Inflation. In: Media and the Ecological Crisis, herausgegeben von Richard Maxwell, Jon Raundalen und Nina Lager Vestberg, 69-84. Milton Park: Routledge.

Kannengießer, Sigrid. 2020a. Nachhaltigkeit und das »gute Leben«: Zur Verantwortung der Kommunikations- und Medienwissenschaft in digitalen Gesellschaften. Publizistik 65 (1): 7-20.

Kannengießer, Sigrid. 2020b. Acting on Media for Sustainability. In: The Turn to Practice in Media Research: Implications for the Study of Citizen- and Social Movement Media, herausgegeben von Hilde Stephansen und Emiliano Treré, 176188. London: Routledge.

Kannengießer, Sigrid. 2020c. Fair Media Technologies: Innovative Media Devices for Social Change. Media Innovations 6 (1): 38-49.

Kannengießer, Sigrid. 2017. »I am not a Consumer Person«: Political Participation in Repair Cafés. In: (Mis)Understanding Political Participation: Digital Practices, New Forms of Participation and the Renewal of Democracy, herausgegeben von Jeffrey Wimmer, Cornelia Wallner, Rainer Winter und Karoline Oelsner, 78-94. London: Routledge.

Kannengießer, Sigrid. 2016. Conceptualizing Consumption-Critical Media Practices as Political Participation. In: Politics, Civil Society and Participation, herausgegeben von Leif Kramp et al., 193-207. Tartu: Tartu University Press.

Kannengießer, Sigrid, und Sebastian Kubitschko. 2017. Editorial. Acting on Media: Influencing, Shaping and (Re)configuring the Fabric of Everyday Life. Media and Communication 5 (3): 1-4.

Kaun, Anne, und Christian Schwarzenegger. (2014). »No Media, Less Life?« Online Disconnection in Mediatized Worlds. First Monday 19 (11). DOI:10.5210/fm. v19i11.5497.

Kollmorgen, Raj, Wolfgang Merkel, und Hans-Jürgen Wagener. 2015a. Transformation und Transformationsforschung: Zur Einführung. In: Handbuch Transformationsforschung, herausgegeben von Raj Kollmorgen, Wolfgang Merkel und HansJürgen Wagener, 11-30. Wiesbaden: Springer VS.

Kollmorgen, Raj, Wolfgang Merkel, und Hans-Jürgen Wagener (Hrsg.). 2015b. Handbuch Transformationsforschung. Wiesbaden: Springer VS.

Kinnebrock, Susanne, Christian Schwarzenegger, und Thomas Birkner. 2015. Theorien des Medienwandels: Konkturen eines emergierenden Forschunsgfeldes? In: Theorien des Medienwandels, herausgegeben von Kinnebrock, Susanne, Christian Schwarzenegger und Thomas Birkner, 11-28. Köln: Herbert von Halem.

Krotz, Friedrich. 2007. Mediatisierung: Fallstudien zum Wandel von Kommunikation. Wiesbaden: Springer VS.

Krüger, Uwe, und Michael Meyen. 2018. Auf dem Weg in die Postwachstumsgesell- 
schaft: Plödoyer für eine transformative Kommunikationswissenschaft. Publizistik 63 (3): 341-357.

Lange, Steffen, und Tilmann Santarius 2018. Smarte grüne Welt? Digitalisierung zwischen Überwachung, Konsum und Nachhaltigkeit. München: Oekom.

Latzer, Michael. 2013. Medienwandel durch Innovation, Ko-Evolution und Komplexität: Ein Aufriss. Medien \& Kommunikationswissenschaft 61 (2): 235-252.

Lünenborg, Margreth, und Simon Berghofer. 2010. Politikjournalismus im Wandel: Merkmale, Einstellungen \& Perspektiven deutscher Politikjournalisten angesichts aktueller Entwicklungen im Berufsfeld. Fachjournalist 10 (3): 17-25.

Luks, Fred, Lisa Bohunovsky, und Andrea Höltl. 2018. Transformationsforschung: Wirtschafts- und sozialwissenschaftliche Perspektiven. GAIA - Ecological Perspectives for Science and Society 27 (2): 257-259.

Münch, Richard, und Jan Schmidt. 2005. Medien und sozialer Wandel. In: Mediensoziologie: Grundlagen und Forschungsfelder, herausgegeben von Michael Jäckl, 201-218. Wiesbaden: VS.

Morley, Janine, Kelly Widdick, und Mike Hazas (2018): Digitalisation, Energy and Data Demand: The Impact of Internet Traffic on Overall and Peak Electricity Consumption. Energy Research \& Social Science 38: 128-137.

Nagel, Manuel, und Niko Paech. 2018. Reparatur kontra Obsoleszenz: Chancen für eine Postwachstumsökonomie. In: Konsumkritische Projekte und Praktiken: Interdisziplinäre Perspektiven auf gemeinschaftlichen Konsum, herausgegeben von Sigrid Kannengießer und Ines Weller, 39-56. München: Oekom.

Paech, Niko. 2005. Nachhaltiges Wirtschaften jenseits von Innovationsorientierung und Wachstum: Eine unternehmensbezogene Transformationstheorie. Marburg: Metropolis.

Paech, Niko. 2012. Befreiung vom Überfluss: Auf dem Weg in die Postwachstumsökonomie. München: Oekom.

Pentzold, Christian. 2015. Praxistheoretische Prinzipien, Traditionen und Perspektiven kulturalistischer Kommunikations- und Medienforschung. Medien und Kommunikationswissenschaft 63 (2): 229-245.

Portwood-Stacer, Laura. 2013. Media Refusal and Conspicuous Non-Consumption: The Performative and Political Dimensions of Facebook Abstention. New Media and Society 15 (7): 1041-1057.

Pufé, Iris. 2014. Nachhaltigkeit. 2., überarbeitete und erweiterte Auflage. Konstanz: UVK.

Raworth, Kate. 2017. Doughnut Economics: 7 Ways to Think Like a 21st Century Economist. Vermont: Chelsea Green.

Reckwitz, Andreas. 2003. Grundelemente einer Theorie sozialer Praktiken: Eine sozialtheoretische Perspektive. Zeitschrift für Soziologie 32 (4): 282-301.

Reißig, Rolf. 2009. Gesellschafts-Transformation im 21. Jahrhundert: Ein neues Konzept sozialen Wandels. Wiesbaden: VS.

Roitsch, Cindy. 2020. Kommunikative Grenzziehung: Herausforderungen und Praktiken junger Menschen in einer vielgestaltigen Medienumgebung. Wiesbaden: Springer VS. 
Schneidewind, Uwe. 2018. Die Große Transformation: Eine Einführung in die Kunst gesellschaftlichen Wandels. Frankfurt am Main: S. Fischer.

Schuler, Marcus. 2020. Rekord in der Corona-Krise Netflix boomt. tagesschau.de vom 22. April, https://www.tagesschau.de/wirtschaft/netflix-quartalszahlencoronavirus-103.html. Zugegriffen: 14. April 2021.

Sühlmann-Faul, Felix. 2019. Streaming heizt unserem Planeten ein: Die ökologischen Auswirkungen von Videostreaming. In: Was Bits und Bäume verbindet. Digitalisierung nachhaltig gestalten, herausgegeben von Anja Höfner und Vivian Frick, 32-33. München: Oekom.

van Dijk, José, und Thomas Poell. 2015. Social Media and the Transformation of Public Space. Social Media and Society 1 (2): 1-5.

van der Velden, Maja. 2018. ICT and Sustainability: Looking Beyond the Anthropocene. In: This Changes Everything - ICT and Climate Change: What Can We Do? herausgegeben von David Kreps, Charles Ess, Louise Leenen und Kai Kimppa, 166-180. New York: Springer.

Velkova, Julia. 2016. Data That Warms: Waste Heat, Infrastructural Convergence and the Computation Traffic Commodity. Big Data \& Society 3 (2): 1-10.

Vereinte Nationen. 2015. Resolution der Generalversammlung, verabschiedet am 1. September 2015. Entwurf des Ergebnisdokuments des Gipfeltreffens der Vereinten Nationen zur Verabschiedung der Post-2015-Entwicklungsagenda. https://www.un.org/Depts/german/gv-69/band3/ar69315.pdf. Zugegriffen: 14. April 2021.

Wilke, Jürgen. 2015. Theorien des Medienwandels: Versuch einer typologischen Systematisierung. In: Theorien des Medienwandels, herausgegeben von Susanne Kinnebrock, Christian Schwarzenegger und Thomas Birkner, 29-50. Köln: Herbert von Halem.

Winseck, Dwayne, und Dal Jong Yin. 2011. The Political Economies of Media: The Transformation of the Global Media Industries. London: Bloomsbury Academic.

WBGU. 2011. Welt im Wandel. Gesellschaftsvertrag für eine Große Transformation. Hauptgutachten des Wissenschaftlichen Beirats der Bundesregierung Globale Umweltveränderungen. Bonn. https://www.wbgu.de/fileadmin/user_upload/wbgu/publikationen/hauptgutachten/hg2011/pdf/wbgu_jg2011.pdf.

Wittmayer, Julia, und Katharina Hölscher. 2017. Transformationsforschung: Definitionen, Ansätze, Methoden. Dessau-Roßlau: Umweltbundesamt.

WCED. 1987. Report of the World Commission on Environment and Development: Our Common Future. http://www.un-documents.net/wced-ocf.htm. Zugegriffen: 14. April 2021.

Young, Carrie, und Katherine McComas. 2016. Media's Role in Enhancing Sustainable Development in Zambia. Mass Communication and Society 19 (5): 626-649. Yu, Jinglei, Eric Williams, und Ju Meiting. 2010. Analysis of Material and Energy Consumption of Mobile Phones in China. Energy Policy 38: 4135-4141.

\section{Open Access}

Dieser Beitrag erscheint unter der Creative-Commons-Lizenz CC BY-ND 3.0 DE: https://creativecommons.org/licenses/by-nd/3.0/de/. 


\title{
Public Relations in der transformativen Wissenschaft: Der Beitrag Strategischer Kommunikation zum Gelingen eines transformativen Forschungsparadigmas
}

\author{
Thomas Pleil, Sandra Müller \& Lea Matusiak
}

Keywords: Public Relations, Transformative Forschung, nachhaltige Entwicklung

\section{Abstract}

Public Relations werden üblicherweise auf der Ebene von Organisationen beschrieben. Eine gesellschaftliche Perspektive ist selten, hat aber eine gewisse Tradition. Beispielhaft zu nennen wären der Ansatz der verständigungsorientierten Öffentlichkeitsarbeit von Roland Burkart (1992), aber auch einzelne Handlungsfelder wie zum Beispiel öffentlich getragene Gesundheitskampagnen. In diesen Bereichen zielt PR nicht auf die Vertretung von Einzelinteressen $a b$, sondern auf gesellschaftliche Lösungen. Dieser Beitrag diskutiert, welche Rolle PR-Forschung und -Praxis in gesellschaftlichen Veränderungsprozessen spielen können. Konkret geht es um Bezugspunkte zwischen PR und einer transformativen Wissenschaft sowie damit verbunden um einen möglichen Beitrag der PR hin zu einer nachhaltigen Entwicklung.

Thomas Pleil, Sandra Müller \& Lea Matusiak: Public Relations in der transformativen Wissenschaft: Der Beitrag Strategischer Kommunikation zum Gelingen eines transformativen Forschungsparadigmas. In: Nils S. Borchers, Selma Güney, Uwe Krüger und Kerem Schamberger (Hrsg.): Transformation der Medien - Medien der Transformation. Verhandlungen des Netzwerks Kritische Kommunikationswissenschaft. Frankfurt am Main: Westend 2021. DOI: https://doi.org/10.53291/JFPN1141.

Prof. Dr. Thomas Pleil | Hochschule Darmstadt | thomas.pleil@h-da.de Sandra Müller I Hochschule Darmstadt I sandra.mueller@h-da.de Lea Matusiak I Pickware I lea.matusiak@gmx.net 


\section{Einführung}

Ähnlich wie in der deutschsprachigen Kommunikationswissenschaft (beispielsweise Vorderer 2015; Strippel et al. 2018; Krüger und Meyen 2018; Kannengießer 2020; Neverla 2020) die Frage nach Identität, Verortung und künftiger Entwicklung diskutiert wird, stellen sich auch für das Teilgebiet Public Relations grundsätzliche Fragen: In Anlehnung an Strippel et al. (2018) ist zu klären, welchen Beitrag das Fach zu drängenden gesellschaftlichen Problemen leistet. Die Selbstverständnisfrage wird gelegentlich auch in der engeren PR-Community gestellt. 2010 hatten zum Beispiel Howard Nothhaft und Stefan Wehmeier (2013) auf der Tagung der Fachgruppe PR und Organisationskommunikation (PROK) der Deutschen Gesellschaft für Publizistikund Kommunikationswissenschaft (DGPuK) festgestellt, dass PR-Forschung gesellschaftlich kaum relevant sei und öffentlich wenig wahrgenommen werde. Kurz: Sie diagnostizierten »Morbus Kommunikationswissenschaft«. Diesen Begriff setzen wir für eine Disziplin, die zwar in Forschung, Lehre und Ressourcen einen langanhaltenden Aufschwung erlebt, aber in der öffentlichen Wahrnehmung nur eine geringe Rolle spielt (vgl. Hömberg 1990, Langenbucher 1990, Strippel et al. 2018, Krüger und Meyen 2018). Wie die Kommunikationswissenschaft, so die PR.

Lange schon haben in der deutschsprachigen Kommunikationswissenschaft Selbstverständnisdebatten Tradition. Neverla (2020, 333) betrachtet sie gar als Teil der DNA des Faches und begründet dies mit der engen Verbindung sozialen Wandels und medialer, öffentlicher und interpersonaler Kommunikation. Seit dem 100-jährigen Jubiläum der deutschen Kommunikationswissenschaft ist die Debatte um Identität und Selbstverständnis wieder lebendiger geworden. Die Rezepte schwanken zwischen Homöopathie und Medizin. Debatin (2017, 20 21) fordert zunächst, dass Kommunikationswissenschaftler*innen »zu gesellschaftlichen Themen Stellung nehmen«, empfiehlt mit Blick auf internationale Konflikte und Klimakrise die Zuwendung zu Konfliktund Friedensforschung - mit dem Ziel, »Ansätze des Peace Journalism nicht nur zu reflektieren, sondern auch in Forschung und Ausbildung einzubinden«. Kurz: Der Journalismus wird's - richtig angepackt schon richten. Kannengießer (2020) schlägt dagegen vor, die Themen Nachhaltigkeit und Kommunikationswissenschaft zusammenzubringen: Ihr geht es um die sozial-ökologischen Effekte von Medientechnologien und um ein Forschungsfeld »Ökologie der Mediengesellschaft«, 
welches »Nachhaltigkeit« und »das gute Leben« in den Mittelpunkt rückt (ebd., 15). Ob solche Vorschläge Einfluss auf das Fachverständnis haben, gilt es zu untersuchen. Zu fragen wäre auch, ob diese genügen in einer Zeit, in der enorme gesellschaftliche Herausforderungen bestehen, wie etwa Digitalisierung, Klimakrise oder Angriffe auf die liberale Demokratie, und in deren Windschatten zahllose Veränderungen zu diskutieren sind - von der Datafizierung über Veränderungen von Öffentlichkeit und Medien bis zu inhaltlichen Fragen öffentlicher Kommunikation. Man denke nur an Framing, Verschwörungsmythen oder die Glaubwürdigkeit politischer Kommunikation.

Notwendig erscheinen deshalb weitergehende Überlegungen, wie durch Krüger und Meyen $(2018,347)$ formuliert: »Wir stehen auf dem Standpunkt, dass Kommunikationswissenschaft zum Gelingen gesellschaftlicher Kommunikation beitragen, also normativ sein sollte.« Ihr Ansatz geht deutlich weiter als das Verständnis vieler Kolleg*innen: Sie fordern eine transformative Kommunikationswissenschaft.

Das Konzept der transformativen Wissenschaft ist bereits seit einiger Zeit in der Diskussion und beschreibt eine Wissenschaft, die durch aktive Partizipation ihrerseits zur Akteurin in Veränderungsprozessen wird (Schneidewind 2015, 88). Darüber hinaus entsteht ein transdisziplinäres Feld. Hier fließt Wissen aus einzelnen Disziplinen ein, aber auch Ergebnisse aus der Zusammenarbeit von Disziplinen, so dass insgesamt in Verbindung mit der Partizipation von Akteur*innen gesellschaftliche Orientierung resultiert (ebd., 89). Kommunikationswissenschaft als Transformationsforschung problematisiert laut Krüger und Meyen $(2018,351)$ die »mit öffentlicher Kommunikation verbundenen Aspekte der Transformation«. Dabei adressieren sie auch die Rolle von Akteur*innen des Journalismus sowie Strategischer Kommunikation und formulieren zwei wichtige Fragen: Welche Akteur*innen, Strukturen und Prozesse öffentlicher Kommunikation behindern Transformation und welche unterstützen sie (ebd.)? Im Zentrum ihrer Betrachtung stehen jedoch (Massen-)Medien und Plattformen; am Rande erwähnen sie außerdem das Feld »Communication for Social Change « - also Entwicklungskommunikation (ebd., 352).

Die Forderung nach einer transformativen Kommunikationswissenschaft erstreckt sich automatisch auch auf alle Bereiche just dieser Disziplin, die sich durchaus als Integrationswissenschaft verstehen sollte (vgl. Debatin 2017, 19). Eine sehr einfache Frage wäre deshalb: Welchen Beitrag können die Mitglieder der 19 Fachgruppen der DGPuK für eine transformative Kommunikationswissenschaft durch ihre Expertise 
und ihren spezifischen Blick auf besondere Aspekte des Feldes leisten? Natürlich ist die Vereinigung nicht mit der Disziplin gleichzusetzen, doch organisiert sie zumindest in Deutschland einen guten Teil des fachlichen Austauschs. Lässt man sich auf diese Behelfsargumentation ein, fragt sich zum Beispiel konkret, welchen Beitrag die Gesundheitskommunikation oder die Medienpädagogik zu einer transformativen Wissenschaft leisten könnten. Ähnlich verhält es sich mit der PROK.

Dieser Beitrag soll einen ersten Aufschlag machen und die Frage nach der PROK in einem transformativen Forschungsumfeld diskutieren. Betrachtet man zunächst die Selbstverständnisdebatte innerhalb der Fachgruppe, so hat die Mahnung von Nothhaft und Wehmeier (2013) zwar große Aufmerksamkeit, aber in der Folge wenig konkreten Widerhall gefunden. Die beiden kritisieren eine »Abkehr von gesellschaftlichen Fragestellungen und gleichzeitige Hinwendung zu Fragestellungen der organisationalen Effizienz- und Effektivitätssteigerung « (ebd., 316). Damit verbunden - so der Vorwurf - sei die Akzeptanz durch die Praxis zum »Erfolgssurrogat« (ebd.) geworden. Wollen PRForscher*innen also vor allem den Kommunikationschef*innen und deren Vorgesetzten gefallen?

Doch welche Lösung sehen Nothhaft und Wehmeier? Statt sich auf das - in den Sozialwissenschaften ohnehin oft unmögliche - Entdecken expliziter Gesetzmäßigkeiten zu fokussieren, skizzieren sie einen weiteren Entwurf von Wissenschaft als »konkrete, fallbezogene, kontextsensitive und wertebewusste Forschung (ebd., 319), die gesellschaftlich mitmischt und auf Basis wissenschaftlicher Erkenntnis Beratung leistet. Diese könne man, so wird argumentiert, auch durch qualitative Feldforschung unterstützen, wodurch sich das kommunikative Aushandeln von Regeln, Macht und Widerspruch besser verstehen (ebd., 324) sowie kommunikative Interventionen und deren Auswirkungen besser analysieren lassen (ebd., 323). Ihre vorgeschlagene Wissenschaft stellt sich in den Dienst der Gesellschaft (ebd., 326) und befindet sich damit äußerst nahe am transformativen Gedanken.

Um konkrete Ansätze zu diskutieren, schlagen wir vor, nicht nur allgemein über transformative Forschung zu diskutieren, sondern stattdessen einzelne Projekte zu betrachten. Diese Perspektive geht auch einher mit der Erkenntnis, »dass Akzeptanz und Legitimation immer stärker dezentral und projektspezifisch gewonnen werden müssen«, so Zerfaß $(2016,5)$ mit Blick auf Bauvorhaben, die oft »einen massiven Eingriff in die Lebenswelt der Bürger« darstellen (Sandhu 2017, 238). Transformative Projekte sind in diesem Sinne vergleichbar, 
auch hier spielen entsprechend Akzeptanz und Legitimation entscheidende Rollen.

Zunächst wirft dieser Beitrag jedoch einen genaueren Blick auf transformative Forschung. Dann werden in zwei Schritten Bezüge zu PR diskutiert. Im ersten folgen wir dem Ansatz der Grounded-TheoryMethodologie und stellen Ergebnisse aus Interviews mit Expert*innen für PR-Forschung und transformative Forschung vor. Im zweiten Schritt ordnen wir die Rolle von PR praktisch im Fallbeispiel eines transformativen Projektes ein, um daraus schließlich allgemeine Thesen bezüglich der Rollenverhältnisse dieses Zusammenspiels abzuleiten.

\section{Transformative Forschung}

Ausgehend von den Megatrends, vor allem der Globalisierung von Wirtschaft und Gesellschaft, und im Zuge der Veröffentlichung des Hauptgutachtens des Wissenschaftlichen Beirates der Bundesregierung zu Umweltfragen (WBGU 2011) erlebte die transformative Wissenschaft einen Entwicklungsschub. Auch »Transformationsforschung « genannt, setzt sich diese für eine gesellschaftliche Veränderung zur nachhaltigen Entwicklung ein (ebd., 25) und verbindet dies mit einem neuen Wissenschaftsverständnis.

Ein Ausgangspunkt für ihre Entwicklung ist die Erkenntnis, dass in einer zunehmend komplexeren Welt die Notwendigkeit zur Zusammenarbeit verschiedener Wissenschaftsdisziplinen besteht (BMBF 2016, $16-18)$. Schneidewind und Wissel $(2015,4)$ sehen für die Wissenschaft eine Herausforderung, technologische Möglichkeiten, gesellschaftliche, wirtschaftliche und ökologische Aspekte gemeinsam zu denken. Unter anderem fordert Schneidewind (2009, 31-32) deshalb eine Verzahnung von Geistes- und Naturwissenschaften. Ziel dabei ist, unter Beteiligung verschiedener Akteur*innen - auch außerhalb der Wissenschaft - nachhaltige gesellschaftliche Entwicklungen auf den Weg zu bringen. Der WBGU $(2011,1)$ spricht in diesem Zusammenhang von der »Großen Transformation«. Forschung und Bildung sieht er bei der Gestaltung dieses Prozesses in zentralen Rollen (ebd., 341, 375).

Die Große Transformation muss sich nach dem Verständnis des WBGU (ebd.) auf eine Art und Weise vollziehen, an der Zivilgesellschaft, Unternehmen, Wissenschaft und Politik gleichermaßen beteiligt sind. Als gesellschaftsintegrierter Perspektivwechsel ist dieser neue transformative Wissenschaftsansatz keine inhaltliche Neuausrichtung 
(Schneidewind und Singer-Brodowski 2014, 121-122), sondern »vielmehr mit einem umfassenden institutionellen Wandel verbunden« (ebd., 122). Die (Zivil)-Gesellschaft tritt dabei als Akteurin des Wissens auf (ebd., 123). In einer transformativen Wissenschaft kommt es auf das Zusammenwirken dreier Arten von Wandel (ebd., 124) an: 1) den Forschungswandel, der aus transformativer Forschung resultiert, 2) den Lehrwandel, der auf transformativem Lernen basiert, und 3) den institutionellen Wandel, der sich aus der Transition des Wissenschaftssystems ergibt. Dieses Konzept »zielt auf die Wissenschaft als Ganzes, auf die Idee von Wissenschaft, aber auch auf ihre Funktion als zentrales gesellschaftliches Subsystem moderner Gesellschaften« (Schneidewind 2016).

\section{$3 \quad$ PR und transformative Forschung}

Wenn Wissenschaft und Gesellschaft neu gedacht werden sollen, gilt dies auch für die Rolle einzelner Disziplinen. In diesem Artikel geht es speziell um Public Relations. Die Motivation dabei: Akteur*innen dieses Transformationsprozesses benötigen Kommunikationsarbeit, um ihn gezielt voranzubringen. Spannend erscheint uns vor diesem Hintergrund auch die Frage nach einem Wandel in PR-Forschung und -Lehre, welche die Disziplin stärker in den Dienst der Gesellschaft stellen.

Grundsätzlich verfügt PR über wirkungsvolle Mechanismen, um auf die öffentliche Diskussion sowie auf Einstellungs- und Meinungsbildung in der Gesellschaft - oder besser: bei Stakeholdern*innen - Einfluss auszuüben. In der wissenschaftlichen Diskussion über Vertrauen und Öffentlichkeit steht meist jedoch die Meso-Ebene - also die Perspektive von Organisationen - im Mittelpunkt (beispielsweise bei Sandhu 2014; Theis-Berglmair 2015; Kunczik 2010). Die darüber liegende Ebene, welche die gesellschaftliche Perspektive als Ausgangspunkt nimmt, kommt in der PR-Forschung hingegen nur selten vor. Am stärksten findet sich das Konzept einer Gesellschaftsorientierung der PR wohl im Ansatz der verständigungsorientierten Öffentlichkeitsarbeit von Roland Burkart (1992) wieder: Hier geht es vor allem um den kommunikativ initiierten Interessenausgleich und gesellschaftlich akzeptierte Lösungen, etwa bei der Standortentscheidung für Sondermülldeponien. Dabei baut Burkarts Ansatz auf der Theorie des kommunikativen Handelns von Habermas auf und übernimmt die dort beschriebenen Voraussetzungen für Verständigung: Verständlichkeit, Wahrheit, Wahrhaftigkeit und 
Richtigkeit (Burkart 2012, 19). Öffentlichkeitsarbeit, die dies berücksichtigt, könne Einverständnis für Entscheidungen herstellen, die Verständigung dient also im Habermas'schen Sinne der Handlungskoordinierung (ebd., 22).

Betrachtet man auf der anderen Seite die Literatur zu transformativer Forschung, so wird, wie bereits erwähnt, häufig das Zusammenspiel der unterschiedlichen Akteur*innengruppen Zivilgesellschaft, Wirtschaft, Wissenschaft und Politik betont. Pfrien et al. (2017) erwarten von den Wirtschaftswissenschaften, dass sie diese an der Transformation beteiligen und ausgehend davon Forschung und Lehre umgestaltet werden, um dies dann praktisch zu ermöglichen. Wie die Partizipation - die wir vor allem als kommunikative Aufgabe betrachten - zu verwirklichen ist, wird jedoch nicht aufgeschlüsselt.

Der WBGU (2019) weist der Strategischen Kommunikation klar eine Schlüsselrolle zu, wenn er von der Bedeutung einer weltumspannenden Kommunikation und Vernetzung für das Gelingen der Großen Transformation spricht. Von Weizsäcker und Wijkman (2019, 342-343) fordern im aktuellsten Bericht des Club of Rome Multi-Stakeholder-Kollaborationen, die aus ihrer Sicht am besten für Zusammenarbeit und Innovation geeignet sind. Bewusst sieht man dabei vor, Akteur*innen mit gegenläufigen Interessen zusammenzubringen. Dass öffentliche Kommunikation hierbei eine wichtige Rolle spielt, ist für die Autoren selbstverständlich und wird nur beiläufig erwähnt - wie dann eine gesellschaftliche Verständigung jedoch zustande kommen kann, bleibt auch hier eine ungelöste Frage. Offen bleibt zugleich, welche Kommunikationsunterstützung seitens der transformativen Forschung konkret erforderlich ist und wie die Unterschiedlichkeit der beteiligten Disziplinen wiederum die PR beeinflussen könnte.

Für die praktische Kommunikation nennt der WBGU (2011) einige Aufgaben zum Ziel eines aufklärenden und konstruktiven Gesellschaftsdiskurses. Dafür sollen die Zielgruppen an Alltagsschnittstellen erreicht und eine Akzeptanz für die Notwendigkeit und die Pfade der Großen Transformation etabliert werden (ebd.).

Als Zwischenfazit lässt sich also festhalten, dass einige Akteur*innen innerhalb der transformativen Forschung zwar der Strategischen Kommunikation eine Rolle in diesem Feld einräumen, zugleich aber dem »Wie?« bisher kaum Beachtung schenkten. 


\subsection{PR und das Zusammenwirken der Akteur*innen}

Um Bezugspunkte zwischen transformativer Forschung und PR-Forschung zu erschließen, wurde ein qualitativer Ansatz gewählt. Grundlage bildet die explorative Haltung der Grounded-Theory-Methodologie (GTM; vgl. Strauss und Corbin 2010), deren Techniken und Analyseverfahren die Entwicklung von bereichsbezogenen Theorien ermöglicht (ebd., 18). Die GTM wird als zirkulärer Prozess verstanden, in dem Datenerhebung und -analyse nicht getrennt ablaufen, sondern ineinander verschränkt sind (Glaser et al. 2010, 23; Strauss und Corbin 2010, 119).

Im Rahmen einer studentischen Forschungsarbeit wurden zwei Mal zwei qualitative Interviews mit Wissenschaftler*innen geführt, die als Expert*innen für transformative Forschung sowie für PR-Forschung gelten. Die Auswertung der ersten beiden erfolgte mit Hilfe eines systematischen Kodierungsprozesses und enthielt mehrere Reflexionszyklen, die es erlaubten, die gewonnenen Erkenntnisse zu überprüfen und in Relation zu setzen sowie die darauffolgenden Schritte anzupassen. Das gleiche Vorgehen wurde unter Berücksichtigung der daraus gewonnenen Erkenntnisse beim dritten und vierten Interview umgesetzt. Ziel war dabei, aus der Synthese der Aussagen ein initiales, simples Modell zu entwickeln, das die Rolle der PR in der transformativen Forschung verortet und damit einige der oben angesprochenen Lücken schließt.

Die Auswertung der Interviews zeigt zunächst Hürden für die Integration von PR-Wissen in der transformativen Forschung auf. Grundsätzlich gehen die Expert*innen von wechselseitigen Wissenslücken aus: Einerseits seien Vertreter*innen der PR-Wissenschaft und -Praxis größtenteils kaum mit transformativer Wissenschaft vertraut, andererseits wüssten Vertreter*innen der transformativen Wissenschaft wenig über PR-Forschung und -Praxis, zugleich diese Felder aber aufgrund deren üblichen Orientierung an Wirtschaftsinteressen nicht viel Vertrauen genießen. Dieses müsse erst im Einzelfall, also von Projekt zu Projekt, erarbeitet werden. In diesen sehen die Expert*innen zunächst die Rolle der PR für transformative Wissenschaft, um deren gesellschaftliche Akzeptanz und das Vertrauen in ihre Arbeit zu erhöhen. Parallel erkennen sie auch eine Rolle der PR innerhalb der transformativen Wissenschaft - gemeint sind damit Beiträge zur Lösung konkreter Aufgaben und zum Gelingen transformativer Projekte.

Demnach schreiben die Expert*innen der PR im Kontext der Großen Transformation (wir betrachten diese als Summe aller transformativen 
Projekte) die Rolle eines Katalysators zu. Bildhaft gesprochen basiert der Erfolg der Einzelvorhaben ihnen zufolge auf dem Ineinandergreifen unterschiedlicher Zahnräder: (Transformative) Wissenschaft auf der theoretischen, Politik, Wirtschaft und Zivilgesellschaft auf der praktischen Seite. Noch ist dieses Uhrwerk jedoch in vielen Fällen - wenn es um transformative Veränderungen geht - nicht sehr beweglich. Unabhängig von der PR der einzelnen Akteur*innengruppen kommt der PR-Praxis und -Forschung eine separate Rolle in der transformativen Forschung zu: Sie soll das Zusammenspiel der Gruppen zur Entwicklung neuer Problemlösungen kommunikativ unterstützen und sichtbar machen, während der Journalismus die Prozesse unabhängig und kritisch begleitet.

Doch wie genau lässt sich diese Rolle der PR in der transformativen Forschung nun ausbuchstabieren? Die Expert*innen nannten unter anderem Aspekte wie Aufmerksamkeitssteuerung oder Grundlagen der Verständigung. Diese wurden insbesondere vor dem Hintergrund aktueller Veränderungen der gesellschaftlichen Rahmenbedingungen diskutiert, zu denen auch zunehmender Populismus und Manipulationsrisiken in der öffentlichen Kommunikation zählen. PR in der transformativen Forschung hat somit die Aufgabe, auf Basis des Wissens angewandter PR-Forschung und aktueller Entwicklungen von Öffentlichkeiten Information, Dialog und Zusammenarbeit der Akteur*innengruppen zu ermöglichen. Oft jedoch, so wurde angemerkt, steht die strategische interne und externe Kommunikation in transformativen Projekten aufgrund fehlender Visionen und nicht klar formulierter Zielsetzungen auf wackeligem Boden. Mangelnde Kommunikationskompetenz vieler Akteur*innen innerhalb der Wissenschaft und ein zu geringes Maß an Reflexion der Rolle der Öffentlichkeit für transformative Projekte wurden als weitere Probleme benannt, zu deren Lösung auch praktische PR-Kompetenz einen Beitrag leisten kann.

Das Ziel der Strategischen Kommunikation sollte zunächst darin bestehen, Relevanz und Zielsetzung der transformativen Wissenschaft in den Mittelpunkt zu stellen. Sie soll erklärbar und öffentlich sichtbar werden sowie Vertrauen und Aufmerksamkeit geschenkt bekommen und sogar schlussendlich ihrerseits den Mainstream bilden. Die Utopie: Ein transformatives Grundlagenverständnis, das allen gesellschaftlichen Akteur*innen und Zielgruppen offensteht. Dabei kommt die wichtige Komponente der Akzeptanz als Voraussetzung für Vertrauen hinzu, deren eigene Voraussetzung wiederum Bekanntheit ist. 
Aus diesem Umstand heraus ergibt sich auch für die PR-Forschung und -Lehre die Aufgabe, sich zu positionieren. Anregungen aus den Expert*inneninterviews hierzu sind:

- Wissenschaftskommunikation sollte in Forschung und Lehre jeder Wissenschaftsdisziplin als Modul eingeführt werden.

- Kommunikationsstudiengänge sollten Mittler*innen für den Austausch zwischen den Akteur*innen (vor allem zwischen der Wissenschaft und den Stakeholder*innen) ausbilden.

- Die Grundlagen der transformativen Forschung sollten in Forschung und Lehre jeder Wissenschaftsdisziplin eingeführt werden.

- Die Themen wissenschaftlicher Arbeiten aus dem PR-Umfeld sollten sich vermehrt mit transformativer Wissenschaft auseinandersetzen. Darunter fallen auch die Lehrpläne und die Auswahl der Partner*innen von entsprechenden Hochschulprojekten.

- Forschende und Lehrende sollten Möglichkeiten haben, Kompetenz zu transformativer Wissenschaft aufzubauen. Besonders wichtig hierfür sind Tagungen ebenso wie Stellen.

- Im Sinne praktischer Kommunikation gilt es Bekanntheit und Vertrauen für transformative Forschung aufzubauen und Stakeholder*innen von deren Sinnhaftigkeit und Notwendigkeit zu überzeugen.

- Benötigt werden Impulse, die von konkreten Vorbildern innerhalb der Disziplin, aber auch von klaren Ausrichtungen von Hochschulen und Forschungseinrichtungen ausgehen können.

Relativ offen bleiben jedoch Fragen bezüglich Auftrag und Finanzierung. Die Expert*innen sehen zum Beispiel im Rahmen der europäischen Pläne für eine nachhaltige Entwicklung und die dort vorgesehenen Investitionen (Europäische Kommission 2019) Möglichkeiten; ebenso schlagen sie vor, solvente Privatakteur*innen zu gewinnen (Höpner und Demircan 2012).

Natürlich handelt es sich bei den vorgestellten Aspekten um erste Ergebnisse eines überschaubaren Untersuchungsschrittes, der nur einen Anfang zur Diskussion über die Rolle und Aufgabe von PR in der transformativen Forschung bilden kann. Festzuhalten ist jedoch in erster Linie, dass die Expert*innen von einer positiven Wirkung der Integration von PR auf die Qualität von Transformationsprozessen ausgehen. Aspekte wie die Verständlichkeit der Kommunikation für Stakeholder*innen, Verständigung zwischen Stakeholder*innen sowie Einfluss auf 
Machtpolitik und Wirtschaftsinteressen werden hier besonders betont. Hierbei stellen die öffentliche Meinung beziehungsweise die Öffentlichkeit selbst wichtige Felder dar, innerhalb derer sich PR bewegt.

Im nächsten Schritt wechseln wir die Perspektive und geben anhand eines Fallbeispiels aus der transformativen Forschung einen Einblick, welche Rolle PR dort spielt.

\section{4 s:ne - ein Projekt der transformativen Forschung}

Projekte transformativer Forschung entstehen typischerweise in einem Co-Design-Prozess (Moser 2016), an dem Wissenschaftler*innen unterschiedlicher Disziplinen sowie verschiedene Praxisakteur*innen beteiligt sind. Dabei stellt sich die Frage, inwiefern Projekte der transformativen Forschung durch Methoden der PR wie auch Beziehungs- und Netzwerkbildung unterstützt werden können - und natürlich, inwieweit die PR-Praxis und -Forschung dazu beitragen.

Am Beispiel des von 2018 bis Ende 2022 laufenden transformativen BMBF-Projekts »Systeminnovation für Nachhaltige Entwicklung « (s:ne), das die Hochschule Darmstadt im Rahmen des Programms »Innovative Hochschule« mit Forschungs- und Praxispartner*innen durchführt, beschreiben wir, wie man dort in der bisherigen Projektlaufzeit vorgegangen ist, um Wissen und Kompetenzen aus PR-Forschung und -Praxis in ein transformatives Projekt zu integrieren. Für die Kommunikationsfunktion wurde zunächst ein erstes Modell für s:ne entwickelt, das die Handlungsfelder projektintern und nach außen in den einzelnen Arbeitsphasen beschreibt.

Die Hochschule Darmstadt (h_da) verfolgt mit s:ne das Ziel, Prozesse der nachhaltigen Entwicklung in der Region zu etablieren, unter anderem ausgerichtet an den Sustainable Development Goals (SDGs) der UN. Diese Prozesse sind angewiesen auf technische, soziale und organisationale Innovationen - jeweils unterstützt durch veränderte institutionelle Rahmenbedingungen. Dafür baut das Projekt ein lernendes System auf, in dem sich Akteur*innen aus Wirtschaft, Wissenschaft, Politik und Zivilgesellschaft gemeinsam auf die Suche nach Lösungen begeben, um ganze Systeme wie beispielsweise ein Stadtquartier oder eine Lieferkette in Richtung nachhaltiger Entwicklung zu gestalten.

s:ne beruht auf dem Grundgedanken, dass Veränderungen dieser Art nicht in etablierten Kontexten, wie etwa einer bestimmten Forschungsdisziplin oder einem Verwaltungsressort, entstehen. Vielmehr 
geht es darum, Akteur*innen mit unterschiedlichen Erfahrungen, Perspektiven und Interessen zusammenzubringen und mit ihnen auf der Basis eines geteilten Problemverständnisses neue Forschungsfragen zu formulieren (Abb. 1).

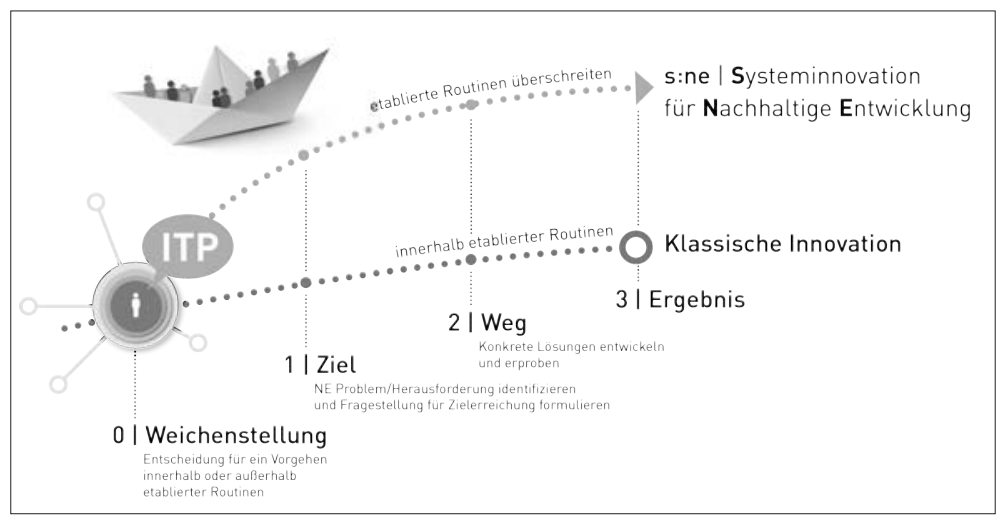

Abb. 1: Systeminnovation für Nachhaltige Entwicklung (Quelle: $\left.h \_d a\right)$.

Sieben große Partner beteiligen sich am Projekt: das Darmstädter Institut Wohnen und Umwelt (IWU), das Institut für sozial-ökologische Forschung (ISOE), das Öko-Institut, die Schader-Stiftung, die Software AG, die Unternehmensberatung e-hoch-3 und RTI Sports. Die Teilprojekte sind breit gefächert und kommen aus den Bereichen Mobilität, Konsum, Stadtentwicklung, Energie und Lieferketten.

Im Kontext des Projekts, an dem im engeren Feld 50 Forschende aus acht Fachbereichen und Vertreter*innen aus der Praxis arbeiten, wurde eine Innovations- und Transformationsplattform (ITP) als strukturbildendes Herzstück geschaffen, die aus dem Kernteam des Transformationsprojektes besteht. Dieses spielt die Rolle des Kompetenzträgers für das lernende System, also die fortwährende Weiterentwicklung der transformativen Forschung. Die ITP organisiert einen regelmäßigen Austausch unter den Forschenden und pflegt eine digitale Plattform im Sinne des Wissensmanagements. So ermöglicht sie den Forschenden, mit wirtschaftlichen, gesellschaftlichen und politischen Akteur*innen sowie Forschungseinrichtungen in der Region neue Formen der Zusammenarbeit zu entwickeln. 


\section{1 PR in s:ne}

Die ITP organisiert Innovation, Wissensmanagement und Kommunikation sowohl nach innen als auch nach außen. Ausgehend von Konzepten des integrierten Managements (vgl. Bruhn et al. 2014, 10) zeigte sich schnell, dass gerade die transdisziplinäre Arbeitsweise und die dadurch stark unterschiedlichen Wissens- und Methodenhintergründe sowie die verschiedenen (Fach)Kulturen besondere Herausforderungen darstellen.

Für alle drei Aufgaben - Innovations-, Kommunikations- und Wissensmanagement - wurden prototypische Modelle innerhalb von s:ne entwickelt und erprobt. Abb. 2 zeigt den Aspekt der PR, wobei es sich hierbei um ein lebendiges Modell handelt, das es weiterzuentwickeln gilt. Die Anschlussfähigkeit für andere transformative Projekte kann unter anderem durch die Zuordnung oder Darstellung der drei Stufen im forschungsbasierten Transfer (Lang et al. 2012) gewährleistet werden. ${ }^{1}$

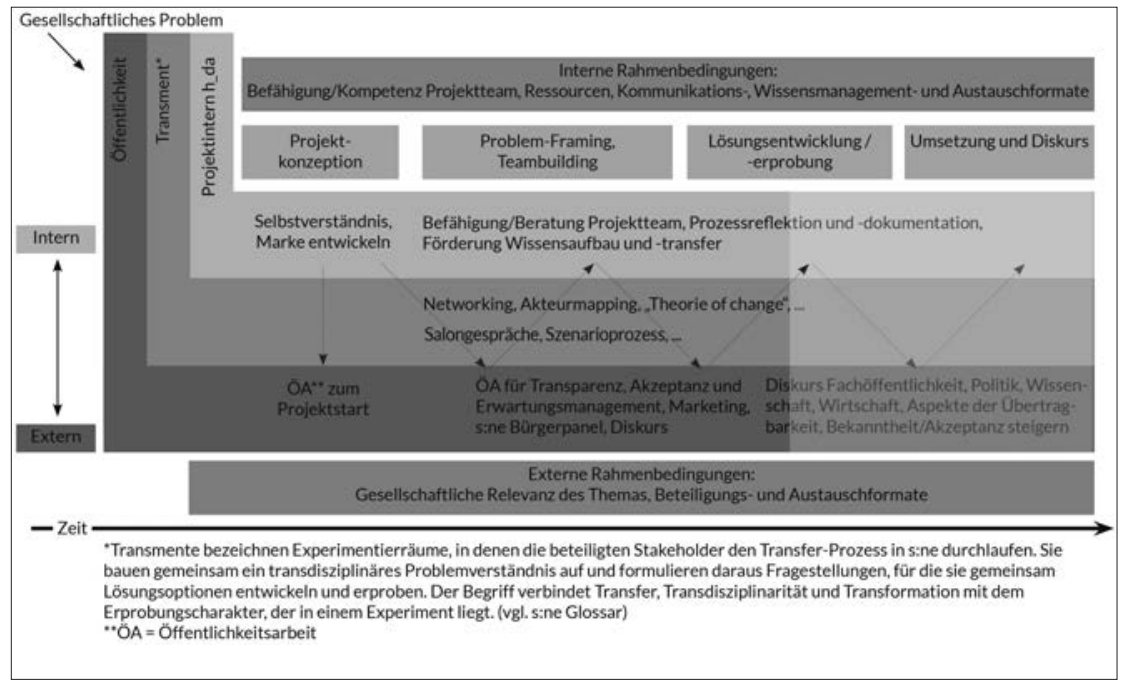

Abb. 2: Die Rolle von PR in s:ne (eigene Darstellung).

1 Transdisciplinary research process: Phase A (Problem framing, Team building), Phase B (Co-creation of solution-oriented transferable knowledge), Phase C ((Re)Integration and application of created knowledge) (Lang et al. 2012). 
Eine Herausforderung bestand zunächst in der Definition, was externe und interne Kommunikation in s:ne bedeutet beziehungsweise welche Stakeholder*innen als intern und welche als extern zu betrachten sind. Verbunden ist dies mit der Analyse von Erwartungen und Bedürfnissen an die Kommunikation. Hier sind eindeutige Differenzierungen nicht ohne weiteres möglich, da zum Beispiel in Co-Creation-Prozessen Externe durchaus zum internen Kreis gezählt werden können.

Die Heterogenität der Beteiligten vermag zu unterschiedlichen Verständnisweisen sowie Innen- und Außendarstellungen des Projektes führen. Wichtig war deshalb die Erkenntnis, dass ähnlich wie in Change-Projekten (vgl. Kotter 2011) eine gemeinsame Vision und Marke entwickelt werden sollten. Zu Beginn startete daher ein Markenentwicklungsprozess, unterstützt durch eine externe Agentur. Die Herausforderung bestand darin, den zahlreichen, sehr unterschiedlichen Zielgruppen gerecht zu werden. Die Marke muss die vielfältigen Ziele des Projektes vermitteln, ein gemeinsames Selbstverständnis für die Arbeit schaffen, aber auch die Hochschule mit dem strategischen Thema nachhaltige Entwicklung positionieren. In Abb. 3 sind die Markenbotschaften für die Zielgruppe Wirtschaft beispielhaft aufgeführt.

Eine weitere Herausforderung stellen die unterschiedlichen Kulturen der beteiligten Forschenden und Projektpartner*innen sowie daraus resultierende Perspektiven und Arbeitsweisen dar. Dies erfordert Community Building und das Schaffen einer Projektkultur, die beispielsweise in formellen und informellen Aspekten der Zusammenarbeit Ausdruck findet. Dazu gehören etwa intern regelmäßige Updates am Scrum-Board, Formate, die Einblicke in disziplinäres Wissen geben, interne Community-Regeln oder extern dezidierte Formate zur Stakeholder*innen-Beteiligung. Auch eine gemeinsame Sprache zu finden ist kein unwesentlicher Bestandteil der interdisziplinären Zusammenarbeit (Jaeger et al. 1998). Zentrale Begrifflichkeiten wurden zu diesem Zweck eigens in einem s:ne-Glossar festgehalten.

In der Strategischen Kommunikation nach außen ist zu berücksichtigen, dass die unterschiedlichen Partner*innen normalerweise eigene Kommunikationsstrategien verfolgen - dies schafft Koordinationsaufwand, bietet aber gleichzeitig die Chance für Netzwerkeffekte. Die Öffentlichkeitsarbeit in der ersten Projektphase konzentrierte sich auf den allgemeinen Rahmen und war nicht inhaltlicher Natur. Der Fokus lag auf der Projektdarstellung über Hochschulkanäle, wie beispielsweise den Webseiten, und auf klassischer Pressearbeit in der Region. 


\section{h da \\ Wir sind :ne Ein Inkubator für Nachhaltige Entwicklung.}

Wir glauben daran, dass wir die Lebensgrundlagen auf der Erde dauerhaft sichern können, wenn soziale, technische und organisationale Innovationen und veränderte Rahmenbedingungen zusammenwirken.

\section{Dafür fragen wir uns gemeinsam mit unseren Partnern:}

? Wie können wir Marktchancen nutzen und zugleich neue Wege in Richtung Nachhaltige Entwicklung beschreiten?

Welche Akteure verfügen über die Bereitschaft und die notwendigen Mittel, die Prozesse mitzugestalten?

Wie schaffen wir Gelegenheiten für konstruktive Begegnungen, die das kreative Potenzial der Beteiligten freisetzen, um daraus neue Lösungen zu entwickeln und zu erproben?

Wo ist es notwendig, Rahmenbedingen zu verändern, um Anreize zu stärken und Hemmnisse abzubauen?

Wir arbeiten insbesondere mit:

(8) Unternehmen aus der Region Rhein-Main-Neckar Politik und Verwaltung

wissenschaftlichen und zivilgesellschaftlichen Partnern

\section{Dabei sind wir:}

2 Motivator / Katalysator / Pfadfinder
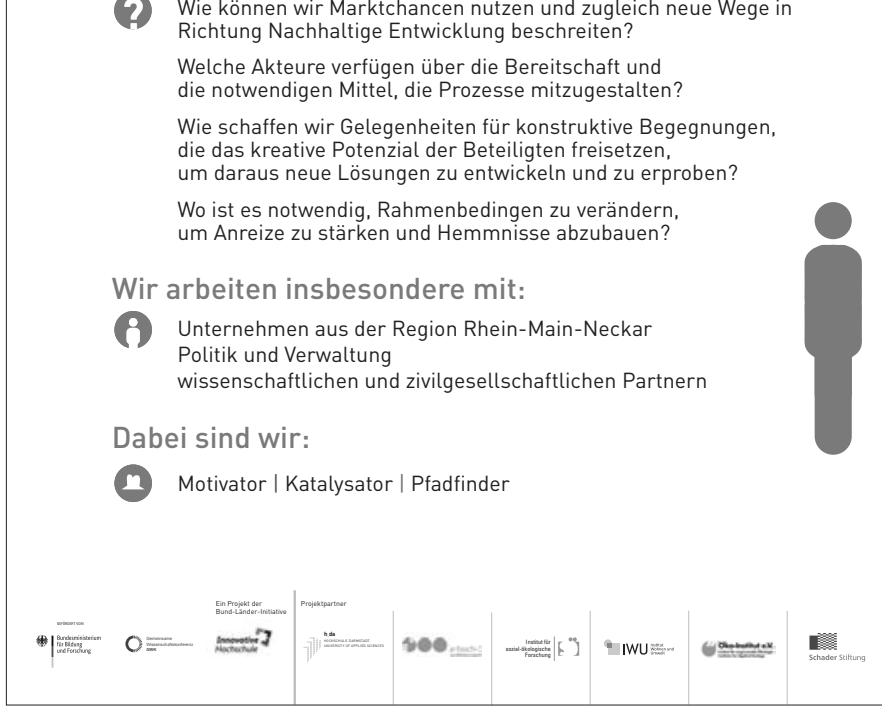

Abb. 3: Markenbotschaften des s:ne-Projektes für die Zielgruppe Wirtschaft

(Quelle: $h_{-} d a$ ).

Auch in der Phase des Problem-Framings und Teambuildings (Abb. 2) stand die externe PR zunächst im Hintergrund. Der Fokus lag hier auf der Netzwerkkommunikation, die überwiegend auf persönlicher Ebene stattfand. Diese Interaktion wurde unterstützt durch transfor- 
mative Methoden der Stakeholder*innen-Beteiligung wie beispielsweise Salongespräche. ${ }^{2}$ Wichtig für die Kommunikation zwischen den Beteiligten war es, Regeln der Zusammenarbeit zu finden, um zielgerichtet auf Akteur*innen zuzugehen, also mit den passenden Botschaften und in einem geschützten Rahmen. Dies erfordert gute Kenntnis von Hemmnissen und wirksamen Anreizen, die das aktuelle Verhalten der Beteiligten bestimmen. Herausarbeiten lassen sich diese beispielsweise durch den verhaltenswissenschaftlichen Forschungsansatz der Transdisziplinären Delta-Analyse,$^{3}$ welche diesbezügliche Analysen ermöglicht.

Erst nachdem sich die Arbeitsgruppen gebildet hatten, begannen erste öffentliche Kommunikationsmaßnahmen zu Inhalten der transformativen Forschung. Der Fokus lag zunächst auf einem Bürgerpanel. ${ }^{4}$ Dieses hat zum Ziel, Innovationsideen aus s:ne-Handlungsfeldern aufzugreifen und es Bürger*innen zu ermöglichen, regelmäßig ihre Meinungen und Präferenzen zu diesen Innovationen im Rahmen von Befragungen zu äußern. Hierdurch sollen sie an der Gestaltung nachhaltiger Entwicklung mitwirken können. Die Erkenntnisse fließen wiederum in die Weiterentwicklung und Umsetzung der Innovationen ein. Begleitet wird das Panel regelmäßig durch Pressearbeit, unterstützt durch die Hochschulkommunikation. Zudem werden eigene Social-Media-Kanäle genutzt sowie die persönliche Ansprache von Bürger*innen bei regionalen Veranstaltungen gesucht.

Die Offenheit des Vorgehens im Projekt und die Heterogenität der Teilprojekte führen dazu, dass man neben der Kommunikation des Gesamtvorhabens eigens für diese individuelle Kommunikationsstrategien entwickelt. Beispielsweise stellt das Teilprojekt zur nachhaltigeren Gestaltung von Lieferketten in der Lederindustrie durch die Beteiligung internationaler Fachakteur*innen ganz andere Anforderungen als die nachhaltige Weiterentwicklung eines Stadtquartiers. Es variieren also immer wieder Ziele und Zielgruppen, die im Projektverlauf neu identifiziert und verstanden werden müssen. Unterstützend wirken hierbei zum Beispiel Online- und Medienmonitoring, Zielgruppenanalysen

2 Die Idee der Salongespräche entstand in Anlehnung an die philosophischen, naturwissenschaftlichen und literarischen Salons des 18. und 19. Jahrhunderts. Dort trafen sich Denker, Politiker, Wissenschaftler mit Dichtern und anderen Künstlern in einem vertrauten Rahmen, um sich gemeinsam über Themen auszutauschen, die von aktuellem Interesse waren.

3 https://www.sofia-darmstadt.de/wir-ueber-uns/delta-analyse.

4 https://buergerpanel.h-da.de/. 
und Persona (Beschreibungen typischer Vertreter*innen einer Stakeholder*innen-Gruppe).

Insgesamt hat sich gezeigt, dass der Beratungsbedarf der Teilprojekte zu interner Kommunikation, Öffentlichkeitsarbeit und Stakeholder*innen-Beteiligung deutlich höher ausfällt als ursprünglich angenommen und in der Ressourcenplanung vorgesehen war. Die (Methoden-) Kompetenzen in den einzelnen Teams bezüglich der voran genannten Themenfelder waren teilweise nur bedingt vorhanden oder mussten im Projektverlauf weiter auf- und ausgebaut werden. Auch die bereits erwähnte Offenheit des Vorgehens im Projekt erfordert einmal mehr das Verständnis einer integrierten Kommunikation. Deutlich wurde darüber hinaus: Zwar kann PR das Gesamtprojekt im Rahmen der üblichen Wissenschaftskommunikation begleiten, jedoch sind für die einzelnen, ergebnisoffenen Teilprojekte eigene Strategien notwendig, die sich allerdings nicht längerfristig planen lassen. Der Einsatz von PR-Management-Tools (Zerfaß und Volk 2019) erweist sich für die internen Arbeitsprozesse als hilfreich.

Aufgrund des Projektselbstverständnisses sowie aus Kapazitätsgründen wurde sehr früh deutlich, dass Personen in den Teilprojekten zu PR befähigt werden müssen. Dies enthält die direkte Beratung zu konkreten Kommunikationsthemen, ein »Sparring « beim Erstellen von zielgruppengerechten Texten für unterschiedlichste Medienkanäle sowie eine Qualitätssicherung durch das Vier-Augen-Prinzip. Workshops sind in Planung: In diesen gilt es, aufgaben- und themenspezifisch Wissen zu vermitteln, wie beispielsweise Pressearbeit funktioniert oder wie gute Social-Media-Kommunikation gelingen kann.

Damit verbunden ist die Anforderung an die Wissenschaftler*innen, im transformativen Prozess unterschiedliche Rollen einzunehmen, die teilweise eine Schnittmenge mit PR-Kompetenzen aufweisen: Change Agents, Wissensvermittler*innen, (öffentlich) reflektierende Wissenschaftler*innen, selbstreflektierende Wissenschaftler*innen und Prozessbegleiter*innen (Wittmayer und Schäpke 2014).

Einige s:ne-Teilprojekte befinden sich bereits in der Phase der Lösungsentwicklung und -erprobung (Abb. 2). Öffentlichkeitsarbeit zielt hier besonders darauf ab, Transparenz, Akzeptanz und ein entsprechendes Erwartungsmanagement zu betreiben. Natürlich erfolgt die Kommunikation hierbei medienvermittelt, aber auch in Form von Veranstaltungen. In einem eigenen Format wird mit wechselnden Schwerpunkten der Frage nachgegangen, wie Forschung und Transfer Veränderungsprozesse in Richtung nachhaltiger Entwicklung unterstützen können. 
Die Methoden, die im Experimentierfeld zur Anwendung kommen, enthalten teilweise Bausteine, die in der Kommunikationsarbeit stärkeren Anklang finden sollten - wie beispielsweise in der Szenario-Technik nach Geschka et al. (1997), in der gemeinsam mit Akteur*innen aus der Praxis eine Vision in einzelnen Teilprojekten entwickelt wird. Fruchtbringend ist beispielsweise auch die systematische Integration der Theory of Change (Claus und Belcher 2020) in die Strategische Kommunikation, auf deren Basis Narrative entwickelt werden können. Immer wieder ergeben sich Bezüge zu Methoden der PR, beispielsweise wenn es um die Analyse von Stakeholder*innen-Erwartungen an die Kommunikation geht oder um die Formulierung von Botschaften. Nicht nur die gemeinsame Sprache ist demnach wesentlich in transformativen Projekten, sondern auch die Freiheit zum Einsatz und der Weiterentwicklung der unterschiedlichen Methoden passend zum spezifischen Projektcharakter (Jaeger et al. 1998).

\section{$5 \quad$ Fazit und Ausblick}

Aus den in diesem Beitrag vorgestellten Ergebnissen von Expert*inneninterviews sowie dem Fallbeispiel lassen sich erste Learnings und Thesen zur Rolle von PR in transformativer Forschung ableiten. Dabei wurde zunächst deutlich, dass Akteur*innen PR an vielen Stellen zunächst praktisch verstehen.

Learnings für die praktische Kommunikation ergeben sich aus der Heterogenität der Beteiligten, die mit unterschiedlichen Motivationen, Kulturen, Kommunikations- und Verhaltensweisen sowie Zielen verbunden ist. Anforderungen an die Kommunikation sind demnach:

- Ein hohes Maß an Netzwerk-Kommunikation (persönlich und medienvermittelt) und Regeln für Kommunikation und Zusammenarbeit.

- Gute Kenntnis von Hemmnissen und wirksamen Anreizen als Grundlage für die Einleitung und Betreuung von Innovationsprozessen in Richtung nachhaltiger Entwicklung, aber auch für die Strategische Kommunikation.

- Erarbeiten einer Projektkultur und Community Building, um das Aufprallen unterschiedlicher Fach- und Arbeitskulturen produktiv zu nutzen.

- Grundlage für die interne und die Strategische Kommunikation nach außen sowie für das transformative Handeln bildet das Herausarbei- 
ten von Vision und Marke. Auf diese Weise können unterschiedliche Verständnisweisen erschlossen, Gemeinsamkeiten herausgearbeitet und möglichst widerspruchsfreie Innen- und Außendarstellungen des Projektes erreicht werden.

- Durch die Offenheit des Vorgehens haben Projekte der transformativen Forschung zunächst unspezifische Stakeholder*innen, die im Projektverlauf immer wieder neu identifiziert und verstanden werden müssen; zudem ist es notwendig, während des Projekts Kommunikationsstrategien zu entwickeln und laufend anzupassen.

Für die weitere Diskussion und Forschung stellen wir die folgenden vier Thesen auf:

1. Forschende benötigen eine Form von PR-Literacy. Damit meinen wir eine Grundkompetenz zu interner Kommunikation in heterogenen Teams sowie basale Kenntnisse in Strategischer Kommunikation, um in der Öffentlichkeit klar, verständlich und im Sinne des Projektes zielorientiert kommunizieren zu können.

2. Kommunikations- und Wissensmanagement sind Basisfunktionen in transformativen Projekten.

3. Kommunikations- und Wissensmanagement tragen Mitverantwortung für ein gemeinsames Projektverständnis sowie eine gemeinsame Projektkultur.

4. Kommunikations- und Wissensmanagement stellen kontinuierliche Aufgaben, die am besten in einem Kernteam in transformativen Projekten wahrgenommen werden.

Insgesamt sehen wir in der transformativen Forschung vielfältige Einsatzmöglichkeiten für die unterschiedlichen Teildisziplinen der Kommunikationswissenschaft, insbesondere der PR-Forschung und nicht lediglich der praktischen Anwendung Strategischer Kommunikation. Welche bisherigen Erkenntnisse und Modelle der Disziplin sowie Praxismethoden und strategischen Ansätze für Transdisziplinäre Forschung fruchtbar sind, bleibt bislang ungeklärt. Dabei ist zu berücksichtigen, dass andere Disziplinen teilweise für ähnliche Aufgaben eigene Methoden entwickelt haben. Beispielhaft zeigt sich dies bei solchen, die Verständnis für Stakeholder*innen oder deren Beteiligung an Innovationsprozessen erlauben sollen. Nicht nur im Kontext transdisziplinärer Projekte kann die PR-Forschung viel aus anderen Disziplinen lernen und diese umgekehrt befruchten - im Kontext von s:ne haben 
sich bisher insbesondere Berührungspunkte zu Psychologie, Politikwissenschaft und Innovationsforschung gezeigt. Auch die Fragen, wie einzelne transformative Projekte mit Hilfe von Strategischer Kommunikation eine gesellschaftliche Dynamik auslösen können und wie sich die Disziplin der PR in einem solchen Umfeld selbst verändert, lässt viel Raum für weitergehende Arbeiten. Ein möglicher erster Schritt bestünde in einer Diskussion des bisher im deutschen Sprachraum wenig wahrgenommenen Felds der Public Interest Communication (Fessmann 2017; Ciszek 2018) bezogen auf transformative Forschung. Dieses in den USA entwickelte Konzept bezieht sich auf öffentliche und wissenschaftsbasierte Kampagnen, die einen konstruktiven Ansatz verfolgen und gesellschaftlichen Wandel unterstützen sollen, etwa im Zusammenhang mit der LGBT-Bewegung (Ciszek 2018).

Gezeigt hat sich aus unserer Sicht, dass PR in transformativen Forschungsprojekten tatsächlich ihre Rolle finden kann und von Anfang an ihren Platz haben sollte. PR-Praxis und -Forschung sind aus unserer Sicht dabei integrativ zu betrachten. Die meisten Akteur*innen unseres Fallbeispiels halten die PR-Funktion und das PR-Wissen inzwischen für unverzichtbar. Die übergreifende Disziplin hat vor allem die Aufgabe, ihr Wissen zur Relevanz von Öffentlichkeit und deren Mechanismen im Rahmen transformativer Wissenschaft einzubringen und die Stakeholder*innen-Integration in einzelnen Projekten zu unterstützen. Über diese hinaus ist die Unterstützung bei der Übertragung von Wissen und das öffentliche Sichtbarmachen von Ergebnissen bedeutsam. Die PR-Disziplin kann auf diesem Weg eine stärkere gesellschaftliche Perspektive einnehmen und die Mitwirkung an gesellschaftlicher Zukunftssicherung neben die traditionelle Aufgabe der organisationalen Effizienzsteigerung (Nothhaft und Wehmeier 2013, 316; Fessmann $2017,21)$ stellen. Anknüpfungspunkte ergeben sich dabei für die praktische PR, aber auch für die PR-Lehre und -Forschung, die sich im transformativen Umfeld automatisch in den Austausch mit benachbarten Disziplinen begeben. Letztlich gehen wir davon aus, dass eine Beteiligung der PR-Disziplin in transformativen Kontexten ihre bisherigen Perspektiven erweitert und auf lange Sicht ganz im transformativen Sinne auch diese selbst verändern kann. 


\section{Literatur}

BMBF. 2016. Bundesbericht Forschung und Innovation 2016: Forschungs- und innovationspolitische Ziele und Maßnahmen. https://www.bundesbericht-forschung-innovation.de/files/Publikation-bmbf_bufi_2016_hauptband_barrierefrei.pdf. Zugegriffen: 12. März 2021.

BMBF. 2018. Bundesbericht Forschung und Innovation 2018: Forschungs- und innovationspolitische Ziele und Maßnahmen. Bundesministerium für Bildung und Forschung. https://www.bmbf.de/upload_filestore/pub/Bufi_2018_ Hauptband.pdf. Zugegriffen: 12. März 2021.

Bruhn, Manfred, Siglinde Martin, und Stefanie Schnebelen. 2014. Integrierte Kommunikation in der Praxis. Wiesbaden: Springer VS.

Burkart, Roland. 2012. Verständigungsorientierte Öffentlichkeitsarbeit. In: Kommunikation und Verständigung: Theorie - Empirie - Praxis, herausgegeben von Walter Hömberg, Daniela Hahn und Timon B. Schaffer, 17-37. Wiesbaden: VS Verlag für Sozialwissenschaften.

Burkart, Roland. 1992. Public Relations als Konfliktmanagement: Ein Konzept für verständigungsorientierte Öffentlichkeitsarbeit. Untersucht am Beispiel der Planung von Sonderabfalldeponien in Niederösterreich. Wien: new academic press.

Ciszek, Erica. 2018. Constructive Advocacy: Positivity and Solutions-Based Information in Activist Communication. The Journal of Public Interest Communications 2 (2): 202-220.

Claus, Rachel, und Brian Belcher. o. J. Theory of Change. TD-Net Toolbox for CoProducing Knowledge. https://naturalsciences.ch/co-producing-knowledge-explained/methods/td-net_toolbox/theory_of_change. Zugegriffen: 12. März 2021.

Danielzyk, Rainer, und Ina Peters. 2016. Warum transformative Wissenschaft? Nachrichten der ARL 2. https://shop.arl-net.de/media/direct/pdf/nachrichten/2016-2/NR2_2016_Schneidewind_S13_online.pdf. Zugegriffen: 12. März 2021.

Debatin, Bernhard. 2017. Der schmale Grat zwischen Anpassung und Integration: Kritische Anmerkungen aus Anlass des 100-jährigen Jubiläums der deutschen Kommunikationswissenschaft. Publizistik 62 (1): 7-23.

Europäische Kommission. 2019. Nachhaltige Finanzierung. https://ec.europa.eu/ info/business-economy-euro/banking-and-finance/green-finance_de. Zugegriffen: 12. März 2021.

Fessmann, Jasper. 2017. Conceptual Foundations of Public Interest Communications. The Journal of Public Interest Communications 1 (1): 16-30.

Geschka, H., und R. Hammer. 1997. Die Szenario-Technik in der strategischen Unternehmensplanung. In: Strategische Unternehmungsplanung / Strategische Unternehmungsführung, herausgegeben von Dietger Hahn und Bernard Taylor. Heidelberg: Physica.

Glaser, Barney G., Anselm L. Strauss, und Bruno Hildenbrand. 2010. Grounded Theory: Strategien qualitativer Forschung. 3., unveränderte Auflage. Bern: Verlag Hans Huber. 
Hömberg, Walter. 1990. Editorial. Aviso. Informationsdienst der Deutschen Gesellschaft für Publizistik und Kommunikationswissenschaft 1 (1). https://www. dgpuk.de/sites/default/files/Aviso_01_11-1990.pdf. Zugegriffen: 12. März 2021.

Höpner, Axel, und Demircan, Ozan. 2012. Studie der Munich Re: Die Kosten des Klimawandels. Handelsblatt vom 24. August, https://www.handelsblatt.com/ finanzen/banken-versicherungen/studie-der-munich-re-die-kosten-des-klimawandels/7043678.html. Zugegriffen: 12. März 2021.

Jaeger, Jochen, und Martin Scheringer. 1998. Transdisziplinarität: Problemorientierung ohne Methodenzwang. GAIA - Ecological Perspectives for Science and Society 7 (1): 10-25.

Kannengießer, Sigrid. 2020. Nachhaltigkeit und das »gute Leben«. Zur Verantwortung der Kommunikations- und Medienwissenschaft in digitalen Gesellschaften. Publizistik 65 (1): 7-20.

Kotter, John P. 2011. Leading Change: Wie Sie Ihr Unternehmen in acht Schritten erfolgreich verändern. München: Vahlen.

Krüger, Uwe, und Michael Meyen. 2018. Auf dem Weg in die Postwachstumsgesellschaft. Plädoyer für eine transformative Kommunikationswissenschaft. Publizistik 63 (3): 341-357. Zugegriffen: 8. Januar 2021.

Kunczik, Michael. 2010. Public Relations: Konzepte und Theorien. 5., überarbeitete und erweiterte Auflage. Köln: Böhlau.

Lang, Daniel J., Arnim Wiek, Matthias Bergmann, Michael Stauffacher, Pim Martens, Peter Moll, Mark Swilling, und Thomas J. Christopher. 2012. Transdisciplinary Research in Sustainability Science: Practice, Principles, And Challenges. Sustainability Science 7 (1): 25-43.

Langenbucher, Wolfgang R. 1990. Das Fach in der Krise? Aviso. Informationsdienst der Deutschen Gesellschaft für Publizistik und Kommunikationswissenschaft 1 (1): 1-3. https://www.dgpuk.de/sites/default/files/Aviso_01_11-1990.pdf. Zugegriffen: 12. März 2021.

Moser, Susanne C. 2016. Can Science on Transformation Transform Science? Lessons from Co-Design. Current Opinion in Environmental Sustainability 20: 106115.

Neverla, Irene. 2020. Nachhaltigkeit: Zur Theoretisierung einer politischen Kategorie. Publizistik 65 (3): 333-339.

Nothhaft, Howard, und Stefan Wehmeier. 2013. Make Public-Relations-Research matter: Alternative Wege der PR-Forschung. In: Organisationskommunikation und Public Relations: Forschungsparadigmen und neue Perspektiven, herausgegeben von Ansgar Zerfaß, Lars Rademacher und Stefan Wehmeier, 311-330. Wiesbaden: Springer VS.

Pfriem, Reinhard, Uwe Schneidewind, Jonathan Barth, Silja Graupe, und Thomas Korbun (Hrsg.). 2017. Transformative Wirtschaftswissenschaft im Kontext nachhaltiger Entwicklung. Marburg: Metropolis.

Sandhu, Swaran 2017. Krebber, Felix: Akzeptanz durch inputorientierte Organisationskommunikation. Infrastrukturprojekte und der Wandel der Unternehmenskommunikation. Rezension. Publizistik 62 (2): 237-238. 
Schneidewind, Uwe. 2009. Nachhaltige Wissenschaft: Plädoyer für einen Klimawandel im deutschen Wissenschafts- und Hochschulsystem. Marburg: Metropolis.

Schneidewind, Uwe. 2015. Transformative Wissenschaft - Motor für gute Wissenschaft und lebendige Demokratie. GAIA - Ecological Perspectives for Science and Society 24 (2): 88-91.

Schneidewind, Uwe. 2016. Was ist und warum provoziert eine »transformative Wissenschaft«? Merton - Onlinemagazin des Stifterverbandes vom 25. Februar, https://merton-magazin.de/was-ist-und-warum-provoziert-eine\%E2\%80\%9Etransformative-wissenschaft $\% \mathrm{E} 2 \% 80 \% 9 \mathrm{C}$. Zugegriffen: 12 . März 2021.

Schneidewind, Uwe, und Mandy Singer-Brodowski. 2014. Transformative Wissenschaft: Klimawandel im deutschen Wissenschafts- und Hochschulsystem. 2., überarbeitete und erweiterte Auflage. Marburg: Metropolis.

Schneidewind, Uwe, und Carsten v. Wissel. 2015. Transformative Wissenschaft: Warum Wissenschaft neue Formen der Demokratisierung braucht. Forum Wissenschaft 32 (4): 4-8. https://epub.wupperinst.org/frontdoor/index/index/ docId/6123.

Strauss, Anselm L., und Juliet M. Corbin. 2010. Grounded Theory: Grundlagen qualitativer Sozialforschung. Weinheim: Beltz.

Strippel, Christian, Annekatrin Bock, Christian Katzenbach, Merja Mahrt, Lisa Merten, Christian Nuernbergk, Christian Pentzold, Cornelius Puschmann, und Annie Waldherr. 2018. Die Zukunft der Kommunikationswissenschaft ist schon da, sie ist nur ungleich verteilt: Eine Kollektivreplik auf Beiträge im »Forum«. Publizistik 63 (1): 11-27.

Theis-Berglmair, Anna Maria. 2015. Public Relations aus organisationssoziologischer Perspektive. In: Handbuch der Public Relations: Wissenschaftliche Grundlagen und berufliches Handeln. Mit Lexikon, herausgegeben von Romy Fröhlich, Peter Szyszka und Günter Bentele, 47-61. Wiesbaden: Springer VS.

Vorderer, Peter. 2015. Der mediatisierte Lebenswandel. Publizistik 60 (3): 259276.

WBGU. 2011. Welt im Wandel. Gesellschaftsvertrag für eine Große Transformation. Hauptgutachten des Wissenschaftlichen Beirats der Bundesregierung Globale Umweltveränderungen. Bonn. https://www.wbgu.de/fileadmin/user_upload/wbgu/publikationen/hauptgutachten/hg2011/pdf/wbgu_jg2011.pdf. Zugegriffen: 12. März 2021.

WBGU. 2019. Unsere gemeinsame digitale Zukunft. Hauptgutachten des Wissenschaftlichen Beirats der Bundesregierung Globale Umweltveränderungen. Berlin. https://www.wbgu.de/fileadmin/user_upload/wbgu/publikationen/ hauptgutachten/hg2019/pdf/wbgu_hg2019.pdf. Zugegriffen: 12. März 2021.

Weizsäcker, Ernst Ulrich, und Anders Wijkman. 2019. Wir sind dran: Was wir ändern müssen, wenn wir bleiben wollen. München: Pantheon.

Wittmayer, Julia M., und Niko Schäpke. 2014. Action, Research and Rarticipation: Roles of Researchers in Sustainability Transitions. Sustainability Science 9 (4): 483-496.

Zerfaß, Ansgar. 2016. Geleitwort. In: Akzeptanz durch inputorientierte Organisati- 
onskommunikation: Infrastrukturprojekte und der Wandel der Unternehmenskommunikation, 5-6. Wiesbaden: Springer VS.

Zerfaß, Ansgar, und Sophia Charlotte Volk. 2019. Toolbox Kommunikationsmanagement. Denkwerkzeuge und Methoden für die Steuerung der Unternehmenskommunikation Wiesbaden: Springer VS.

\section{Open Access}

Dieser Beitrag erscheint unter der Creative-Commons-Lizenz CC BY-ND 3.0 DE: https://creativecommons.org/licenses/by-nd/3.0/de/. 


\title{
Strategische Devianz: Potenziale und Risiken ungehorsamer Ästhetik in der Kommunikation sozialer Bewegungen
}

\author{
Melanie Malczok
}

Keywords: Strategische Kommunikation, Devianz, Legitimität, Hambacher Forst, Bildanalyse

\section{Abstract}

In der Frage danach, wohin sich eine Gesellschaft bewegen soll, kommen nicht alle Stimmen gleichermaßen zu Wort. Um dem zu begegnen, nutzen insbesondere ressourcenschwache Akteure im Kampf um öffentliche Sichtbarkeit kreative und kontroverse Mittel. Dabei gehen sie jedoch das Risiko ein, dass ihre Handlungen als normverletzend, also deviant wahrgenommen werden. Dies kann die öffentlich zugeschriebene Legitimität der jeweiligen Positionen bedrohen, die jedoch notwendig ist, um Deutungshoheit für bestimmte Themen zu erlangen und gesellschaftlichen Wandel zu erreichen. Der Beitrag differenziert Devianz in funktionale und dysfunktionale Formen der Normenabweichung. Erstere stellt eine progressive Herausforderung des Gegebenen dar, während letztere eher als systemzersetzend wahrgenommen wird. Das Beispiel der visuellen Kommunikation um die Rodungsarbeiten im Hambacher Forst verdeutlicht, welche Inszenierungsstrategien der Devianz zwar aufmerksamkeitsförderlich, jedoch potenziell legitimitätsbedrohend für Akteure sind und welche Formen die Zuschreibung von Legitimität tatsächlich befördern können.

Melanie Malczok: Strategische Devianz: Potenziale und Risiken ungehorsamer Ästhetik in der Kommunikation sozialer Bewegungen. In: Nils S. Borchers, Selma Güney, Uwe Krüger und Kerem Schamberger (Hrsg.): Transformation der Medien - Medien der Transformation. Verhandlungen des Netzwerks Kritische Kommunikationswissenschaft. Frankfurt am Main: Westend 2021. DOI: https://doi.org/10.53291/ZBAM1601.

Melanie Malczok I Hochschule Osnabrück I m.malczok@hs-osnabrueck.de 


\section{Einführung}

Die Frage danach, wohin sich die Gesellschaft in Zukunft bewegen sollte, ist gesellschaftlich stark umkämpft. Kräfte, die auf Beharrung bestehender Institutionen pochen, stehen drängenden Forderungen nach Wandel gegenüber. Ort dieser Aushandlung ist die Öffentlichkeit. Sie hat die Funktion, der Gesellschaft einen Ort der Selbstthematisierung und Reflexion zur Verfügung zu stellen (Görke 2008; Wimmer 2007) und wird wesentlich von Journalismus hergestellt. Gleichzeitig spielen auch andere Akteure eine Rolle - im hier betrachteten Fall Organisationen, die als strategische beziehungsweise persuasive Kommunikatorinnen in Erscheinung treten und ihre Positionen diversen Öffentlichkeiten vermitteln wollen. Sie gestalten durch eigene Strategische Kommunikation (beispielsweise in den Sozialen Medien), aber auch in direktem Bezug auf den Journalismus Öffentlichkeit mit und versuchen so, eigene Deutungen zu etablieren (grundlegend Merten und Westerbarkey 1994; Saxer 2008). Zu beachten ist ferner, dass Deutungen nicht schlicht durchgesetzt werden können, sondern immer auch auf von anderen Akteuren eingebrachte Gegenentwürfe stoßen. Diese verschiedenen Deutungsangebote konkurrieren in der Folge um Aufmerksamkeit, und es liegt an der mobilisierbaren Durchsetzungsmacht, welches sich etabliert und höhere Reichweiten erzielt.

Als gutes Beispiel für diese Prozesse lässt sich das Ringen um eine sozialökologische Transformation der Gesellschaft verstehen, welches mit einem »Kampf um Aufmerksamkeit (Crary 2002; Franck 1998) und dominante Deutungshoheiten im öffentlichen Diskurs einhergeht. Neben inhaltlichen Kriterien (wie etwa Nachrichtenfaktoren) entscheiden auf einer vorgelagerten Ebene auch ökonomische Bedingungen und Strukturen darüber, welche Themen überhaupt in den Blick der Öffentlichkeit gelangen können (Herman und Chomsky 2002; Schade 2018). Diese Kriterien gelten als Ursachen für die auf den ersten Blick zu beobachtende Dominanz der Positionen ressourcenstarker Akteure in der Öffentlichkeit. Dagegen zeige ich im Folgenden, dass diese ökonomischen Mechanismen mitunter gezielt unterwandert werden - wie am Beispiel kleinerer sozialer Bewegungen zu erkennen ist.

Sozialen Bewegungen lässt sich gesellschaftlich die Rolle von Impulsgeberinnen zuschreiben: "Within the mediating sector of politics, social movements specifically serve to give the initial impulses 
for change« (Neidhardt und Rucht 1991). Sie machen auf Missstände aufmerksam und wirken auf Veränderungen hin. Diese Akteure sind jedoch häufig weniger ressourcenstark und verfügen daher über weniger Möglichkeiten, Zugang zu relevanten Öffentlichkeiten zu finden (Schade 2018; Oy 1997). Folglich sind sie darauf angewiesen, sich auf unkonventionelle Weise Gehör zu verschaffen, und wählen subversivere und häufig subkulturell konnotierte Strategien zur Generierung von Aufmerksamkeit (Juris 2012; Ertl 2015; Veneti 2017). Diesbezüglich spreche ich im Folgenden von devianten Kommunikationsstrategien. Damit sind Strategien gemeint, die abweichendes Verhalten in Kauf nehmen oder aktiv suchen, um Aufmerksamkeit zu generieren. Fraglich ist in diesem Zusammenhang, ob Devianz neben der Aufmerksamkeit auch die Zustimmung für die vertretenen Botschaften und Deutungsangebote erhöht. Das heißt, deviante Kommunikationsstrategien bergen immer auch die Gefahr, die wahrgenommene Legitimität der Forderungen zu bedrohen, da die Form der Kommunikation als normverletzend und so als potenziell gemeinwohlschädlich abqualifiziert wird. Soziale Bewegungen müssen hier wesentliche Abwägungen treffen.

Die Forschung zur Devianz betrachtet bisher vorrangig Makro- und Mikrophänomene (Peuckert 2016; Lamnek 2013). Die Beschreibung einer Mesoperspektive, die deviantes Verhalten von organisationalen Akteuren in den Blick nimmt, ist bisher eher randständig. Zwar beschreibt etwa Luhmann (1999) nonkonformes Verhalten von Organisationsmitgliedern mit dem Konzept der »brauchbaren Illegalität«, geht damit jedoch auf organisationsinterne Normen ein. Nach außen beziehungsweise auf die Gesellschaft orientiertes Verhalten lässt sich dagegen ideal mit einer neo-institutionalistischen Perspektive auf Organisationen verbinden, welche gesellschaftliche Erwartungen an Organisationen in den Mittelpunkt rückt (Meyer und Rowan 1977; Sandhu 2012; Kette und Barnutz 2019). Auf diese Perspektive möchte ich im Folgenden zurückgreifen, um Verhaltenserwartungen an handelnde Personen auf gesellschaftliche Erwartungen an Organisationen zu übertragen.

In meinem Beitrag gehe ich folgendermaßen vor. Zuerst stelle ich das Verständnis von Organisation, Öffentlichkeit und Legitimität heraus, um dieses für die Kommunikation sozialer Bewegungen zu konkretisieren. Darauf aufbauend nehme ich auf das Konzept der Gegenöffentlichkeit (Ahlemeyer 1995; Scholl 2009; Wimmer 2007) Bezug, bevor ich im nächsten Schritt das Konstrukt der Devianz erläutere. Hier mache 
ich insbesondere von dem an sozialen Zuschreibungen orientierten »Labeling-Ansatz« (Lamnek 2013) Gebrauch. Nach der Begriffsklärung beziehe ich die Devianz auf die Strategische Kommunikation und Eindruckssteuerung (Ebert und Piwinger 2007) von Organisationen und sozialen Bewegungen und stelle hier Potenziale sowie Risiken heraus. Konkret illustriere ich schließlich am Fall der umstrittenen Rodungsarbeiten am Hambacher Forst, wie Devianz als analytische Kategorie bei der Untersuchung Strategischer Kommunikation behilflich sein kann. Mittels einer rekonstruktiven Bildanalyse (Przyborski und Slunecko 2012) der Kommunikation der Initiative Ende Gelände wird verdeutlicht, dass die Inszenierung funktionaler Devianz großes Potenzial für Legitimitätsgewinne bietet.

\section{Organisation, Öffentlichkeit und Legitimität}

Aus neo-institutionalistischer Perspektive kommt Organisationen der Status eines organisationalen Akteurs zu. Das bedeutet, dass Organisationen nicht nur handlungsfähig, sondern auch aktiv und interessengetrieben sind (Meyer und Rowan 1977). Sie sehen sich in einer komplexen Gesellschaft mit diversen und teils disparaten Erwartungen aus der Umwelt konfrontiert, mit denen sie umgehen müssen (ebd.; Sewell 1992). Diese Erwartungen werden als sozial etablierte Muster und Schemata - als Institutionen - gefasst (Sandhu 2012; Sewell 1992). Idealerweise sind die an die Organisation gestellten Erwartungen dieser dienlich und ihren Handlungen wird von den für sie relevanten Öffentlichkeiten Legitimität zugeschrieben (Werder et al. 2018).

\subsection{Strategische Kommunikation}

Jegliche Handlung einer Organisation trägt zur Eindrucksbildung in spezifischen Öffentlichkeiten bei. Sind sie jedoch bestrebt, das Bild, welches ihre Umwelt von ihnen hat, und die damit verbundenen Erwartungen gezielt und organisationsdienlich zu gestalten, nutzen Organisationen Strategische Kommunikation (ebd.). Hierbei zeigt sich ein durchaus kreativer und strategischer Umgang mit den Anforderungen der Umwelt: Zwar wäre eine Anpassung der Organisationen an die Erwartungen denkbar (Isomorphie), eine solche gestaltet sich allerdings aufgrund deren disparater Natur schwierig bis unmöglich. Gängiger ist 
daher das zeremonielle Darstellen von Adäquanz durch organisationale Strukturen oder Rituale als »Legitimitätsfassade« (Sandhu 2012), um sich ein Stück weit von den für sie dysfunktionalen Erwartungen zu entkoppeln. Hierzu betreibt die Organisation auf der "Schauseite« (Kühl 2011) gezielte Eindrucks- und Erwartungssteuerung oder »Impression Management « (Ebert und Piwinger 2007).

Nach Femers (2015) ist eine persuasive Eindruckssteuerung dann besonders erfolgreich, wenn die Organisation »Inszenierungen zeigt, die sich neben dem eigenen Wunschbild auch an gesellschaftlich relevanten Werten orientieren «. Das bedeutet, dass sie sich neben ihren funktionalen Kerndimensionen (wie zum Beispiel ökonomische Leistungsfähigkeit) auch darum bemüht, sich als gesellschaftlich wertvoll und als guter »Corporate Citizen« (Valor 2005; Kim und Lee 2018) darzustellen. Die Organisation betont somit Rechtschaffenheit und einen positiven gesellschaftlichen Beitrag.

Die zentralen Erwartungen, an denen sich eine Organisation ausrichtet, sind nicht statisch und je nach Zweck, den sie verfolgt, verschieden. So ist bei der Zuschreibung von Legitimität vorrangig die Einschätzung spezifischer Öffentlichkeiten, die der sogenannten Stakeholder*innen (Freeman 1984; Karmasin und Weder 2014), von Belang. Diesen wird organisationsseitig das Potenzial zugeschrieben, Handlungen positiv oder negativ zu beeinflussen. Als wichtige Stakeholder*innen sind vorab schon politische Entscheidungsträger*innen zu nennen, da sie für gesellschaftlich relevante Themen Regelungen anstoßen und den regulativen Rahmen für die Handlungen organisationaler Akteure bereitstellen (Melenhorst 2015). Wichtig ist an dieser Stelle zu verstehen, dass die zur Schau gestellten Werte je nach aktuellem Kontext, Organisationszweck und Stakeholder*innen-Kreis variieren, wie im Beispiel noch genauer zu sehen sein wird.

\section{2 »Klassische« Organisationen und Öffentlichkeit}

Medien kommt durch ihre Thematisierungsfunktion und die Herstellung von Öffentlichkeit (an der sich auch Politik orientiert) entsprechend eine besondere Bedeutung zu (Vliegenhart et al. 2016; Walgrave und van Aelst 2006), denn sie stellen ein "Netzwerk der gegenseitigen Beobachtung (Sandhu 2012, 106) zur Verfügung. Für Organisationen sind hier besonders Agenda- und Frame-Building-Effekte relevant (Buchmeier 2020; Colistra 2018; Hänggli 2012). Orga- 
nisationen achten folglich darauf, Themen, die deswegen für sie von Bedeutung sind, weil sie mit spezifischen Lösungen oder Positionen auf diese reagieren und sie zur strategischen Positionierung nutzen können, in den medialen Diskurs zu erheben und spezifisch zu framen. Das Gleiche gilt für die Kehrseite: Im sogenannten »Agenda Cutting « werden potenziell organisationsbedrohende Themen eben nicht thematisiert (Buchmeier 2020).

Wie bereits erwähnt, richten Organisationen ihre kommunikativen Bemühungen besonders an ihren spezifischen Öffentlichkeiten aus. Mittelbar ist jedoch auch eine eher disperse, allgemeinere und bürgerlicher geprägte Öffentlichkeit bedeutsam - der sogenannte »Mainstream « - (Scholl 2009, 84), da hier allgemeinere Erwartungen ausgehandelt werden und sich somit potenziell neue Themen und Ansprüche formieren können, auf welche die Organisation gegebenenfalls reagieren muss (Lauzen 1997). Sie adressiert daher nicht nur ihre unmittelbaren Stakeholder*innen, sondern ist auch an einer dienlichen Konstruktion der medialen Wirklichkeit (Merten 2009) durch aktive Beobachtung und Gestaltung von Themen in einer übergeordneten Öffentlichkeit - dem Mainstream - interessiert.

\section{Mainstream und Gegenöffentlichkeit}

Der Mainstream lässt sich grob als Ort der Bildung und Reflexion konsensueller Positionen beschreiben, in welchem gesellschaftlich zentrale Sinnmuster, Werte und Ideologien ausgehandelt, bestärkt und eine hegemoniale öffentliche Meinung etabliert wird. Dieser Prozess verstärkt sich durch eine medienübergreifende Konsonanzbildung zusätzlich (Krüger 2016). In der Bewegungsforschung wird die bürgerliche Öffentlichkeit als "gehobene, herrschende Mainstreamkultur« (Scholl 2009; Jacke 2004) thematisiert, an der sich eine »Gegenöffentlichkeit« reibt, um mit anderen Selektionen und Frames als im Mainstream eine kontrastierende Position einnehmen zu können.

Journalistischen Medien kommt neben der Konstruktion gesellschaftlicher Wirklichkeit eine diskursordnende Sonderrolle zu, in der den strategischen Selbstbeschreibungen der Organisationen kontrastierende Fremdbeschreibungen gegenübergestellt werden (Hoffjann 2011). Idealisierend wird eine grundlegend kritische Haltung des Journalismus gegenüber den strategischen Bestrebungen von machtvollen Akteuren unterstellt (Herman und Chomsky 2002). In der Praxis zeigt sich jedoch eine durchaus kooperative Zusammenarbeit organisationaler Pressestellen mit dem Journalismus (Altmeppen, Röttger und 
Bentele 2004; Macnamara 2014; Baerns 1991). ${ }^{1}$ Je ressourcenstärker die Akteure, je intensiver die organisationalen Kontakte in den Journalismus und je professioneller die Aufbereitung strategischer Kommunikationsmaterialien, desto größer ist empirisch die Übernahmewahrscheinlichkeit der vorbereiteten Inhalte und Botschaften sowie eine durch journalistische Medien legitimierte Positionierung in einer größeren Öffentlichkeit (ebd.). ${ }^{2}$ Für diese professionalisierte Kommunikation bedarf es Ressourcen, die in eine persuasive Inszenierung fließen und den Zugang zu Journalismus ermöglichen (Herman und Chomsky 2002). Mit Gamson und Wolfsfeld lässt sich ergänzen: »Organization, resources, and media sophistication are all markers journalists use to identify who the serious players are." (Gamson und Wolfsfeld 1993, 121; zitiert nach Schade 2018, 251) Und dies sind Merkmale, über die nicht alle Akteure gleichermaßen verfügen.

\subsection{Soziale Bewegungen als besondere Organisationen}

In der Konzeption als Organisationen stellen soziale Bewegungen eine Sonderform dar. Sie sind loser gekoppelt und hinsichtlich ihrer Eintrittsvoraussetzungen in der Regel deutlich geringer formalisiert als dies bei klassischen Organisationen wie Unternehmen oder Vereinen der Fall ist (Ahlemeyer 1995; Stickler 2005). Jedoch kommen soziale Bewegungen für ihre kollektiven Aktionen nicht ohne eine gewisse Stabilität und Grundstruktur aus, welche vorrangig durch eine »relativ stabile [Kern] Gruppe getragen werden« (Rucht 1984, 610).

Die Struktur einer Bewegung ist dabei abhängig von ihrer Zielsetzung. Rucht (ebd.; 1994) unterscheidet zwischen inward- und outward-orientierten Ausprägungen. Erstere wollen vorrangig das Verhalten ihrer Mitglieder ändern, während letztere auf »die Gesellschaft«

1 Aktuelle Studien zum Verhältnis zwischen Journalismus und PR gibt es nach Kenntnis der Autorin vorrangig von Praktiker*innen und Berufsverbänden. Hier sei beispielsweise auf Hadwiger (2019) verwiesen. Auskunft über wissenschaftliche Gütekriterien lassen sich aus diesen Publikationen häufig nicht entnehmen. Die Ergebnisse Hadwigers in einer Praktiker*innenbefragung in Journalismus und PR verweisen jedoch auf ein kooperatives Zusammenwachsen der beiden Disziplinen auf operativer Ebene.

2 Hier sei angemerkt, dass die Übernahmewahrscheinlichkeit in Krisenberichterstattung deutlich sinkt und stattdessen die journalistische Recherchetätigkeit zu diesen fraglichen Themen ansteigt (vgl. Brodbeck 2018, 287). 
oder zumindest so viele Menschen wie möglich abzielen. Daher werden sie auch als »machtorientierte Bewegungen« (Rucht 1984, 610) beschrieben. Sie tendieren zu stärker formalisierten Organisationen, da hier ein gewisser Grad an Planbarkeit und Routinisierung von Abläufen als notwendig unterstellt wird.

Wer zu einer Bewegung gehört und wer nicht, ist aushandlungsbedürftig, da formale Beitrittsroutinen wie bei anderen Organisationsformen entfallen. Strukturell beschreibt Rucht (ebd.) die Organisation sozialer Bewegungen deshalb mit Hilfe dreier konzentrischer Kreise. Im Zentrum steht für ihn die Kerngruppe, beziehungsweise die »Eliten«, die über mehr oder minder bindende Entscheidungskompetenzen verfügen. Darum gruppieren sich die »Basisaktivisten «, während sich am Rande Anhänger*innen und Unterstützer*innen sammeln (ebd., 612).

Die Funktion sozialer Bewegungen liegt in der Interessenartikulation und der Mobilisierung, welche sich auch als ihre Elementaroperation verstehen lässt (Ahlemeyer 1995; Rucht 1984; 1994). Luhmann (1994) verweist auf Protest als zentrale Funktion und Kommunikationsform. Hierbei versuchen soziale Bewegungen »Themen für politisch relevant zu erklären « (Jarren und Donges 2011, 130) und darauf bezogene transformative Handlungen hervorzurufen. Scholl $(2009,85)$ beschreibt die Funktion auch als das Aufzeigen von Alternativen »zur aktuellen politischen, ökonomischen, rechtlichen usw. Verfasstheit der Gesellschaft allgemein sowie zu den politischen, ökonomischen, rechtlichen usw. Organisationen und partikularen Handlungen speziell«. Soziale Bewegungen lassen sich also auch als Gegenentwurfsakteure beschreiben.

Im Folgenden werde ich mich auf die kommunikativen Handlungen und Strukturen von machtorientierten Bewegungen konzentrieren. Diese sind zur Erreichung ihrer Ziele auf öffentliche Aufmerksamkeit angewiesen - und entsprechend auch auf Strategische Kommunikation.

\subsection{Soziale Bewegungen und Öffentlichkeit}

Scholl (2009) verortet die Kommunikation sozialer Bewegungen vorranging im Spektrum sogenannter Alternativmedien. Diese lassen sich mit Bezug zu Rucht (1994) und Oy (1997) als Ort eigener Themensetzungen konzipieren, die im sogenannten Mainstream nicht oder nur am Rand auftauchen. Da Akteure hier zunächst weitestgehend Deutungshoheit über die von ihnen publizierten Botschaften haben, sind sie vorrangig als Ort der internen Selbstvergewisserung zu denken, die 
eine »innere Mobilisierung « der Bewegungsmitglieder gegen vielfältige Positionen des Mainstreams ermöglicht. Auch teilöffentliche Foren und Chaträume in Sozialen Medien lassen sich zu diesen eher internen Räumen zählen (Harlow 2012; Kidd und McIntosh 2016).

Um jedoch auch in der bürgerlichen Öffentlichkeit Aufmerksamkeit zu erlangen, sind soziale Bewegungen auf die Thematisierung ihrer Deutungsangebote im Mainstream angewiesen: a) um bei Bürger*innen Aufmerksamkeit für ihre Anliegen zu erzeugen, b) um ihre Anliegen als legitime Forderungen positionieren zu können, c) um für diese Anliegen weitere potenzielle Unterstützer*innen zu gewinnen und d) um vermittelt durch eine breitere Medienöffentlichkeit »auf politische Entscheidungsträger einzuwirken« (Rucht 1994, 348).

Schade $(2018,254)$ benennt Publizität für soziale Bewegungen als oberste Priorität:

Wenn [soziale Bewegungen] ihre Anliegen öffentlich machen, »können sich die Eliten nur bei Strafe des Legitimitätsverlustes einer Auseinandersetzung mit ihnen verweigern." (Schmitt-Beck 1998, 21). Denn dadurch wird der von einer Bewegung angemeldete Entscheidungsbedarf als legitim anerkannt und mit hoher Wahrscheinlichkeit in Entscheidungsprozesse eingespeist (auf die politische Agenda gesetzt). (Schade 2018, 254)

Diese Argumentation erscheint ad hoc plausibel. Allerdings lässt sie den Modus der Auseinandersetzung beziehungsweise der Entscheidung außer Acht und setzt Publizität mit Legitimität gleich. So ist zu bedenken, dass die öffentliche Aufmerksamkeit zwar zu einer Auseinandersetzung mit einer Bewegung zwingt. Eine inhaltliche Auseinandersetzung mit den Positionen, die diese Bewegung für gesellschaftlich relevant erklären möchte, ergibt sich daraus jedoch nicht zwingend. Je nach Kontextualisierung und gewähltem Framing in der Berichterstattung können auch andere Aspekte ins Zentrum der öffentlichen Debatte gerückt werden (Ertl 2015; Hänggli 2012). Dementsprechend ist eine Reaktion auf mehreren Ebenen möglich, die eine Auseinandersetzung mit den inhaltlichen Forderungen der Bewegung sogar explizit vermeidet. $\mathrm{Zu}$ diesen zählt einerseits die Akteursebene: Eine Strategie zum Umgehen der inhaltlichen Auseinandersetzung ist die Personalisierung. Statt über die bewegungsseitig angebrachte Kritik und Veränderungspotenziale zu sprechen, werden die handelnden Akteur*innen (ab-)qualifiziert und ihr Anliegen dadurch delegitimiert. Unrühmliches Beispiel ist hier die Klimaaktivistin Greta Thunberg, die sich persönlichen Angriffen in Bezug auf ihr Geschlecht, ihr Alter oder das Asperger- 
Syndrom ausgesetzt sieht (Möllers 2019). Auf der Formebene konzentriert sich die Auseinandersetzung hingegen auf die äußere Form der Mitteilung oder des Protestes, indem deren Angemessenheit als fraglich gekennzeichnet wird. Beispielhaft sind hier die Interventionen des Zentrums für politische Schönheit zu nennen (Gerk und Bernhard 2019) oder Protestaktionen verschiedener Umwelt- und Klimaaktivist*innen (Ehl und Hänlein 2019).

Ertl $(2015,147)$ stellt heraus, »dass Proteste im Laufe der Jahre zunehmend als Ärgernis geframed werden [und] vielmehr als die Forderungen des und die Gründe für den Protest Taktik, Spektakel und dramatische Aktionen medial veröffentlicht [werden] «. Hierzu verweist sie auf die empirischen Arbeiten von Harlow und Johnson (2011), Boyle, McLeod und Armstrong (2012) sowie Di Cicco (2010). Ertl (2015, 146-147) führt des Weiteren aus: »Extremeく und sradikale Protestkollektive, die am Status quo rütteln, rufen eher eine negative, marginalisierende Medienreflexion bzw. Berichterstattung hervor.« Teune und Sommer (2017, 30-32) differenzieren in einer Analyse der deutschen Medienberichterstattung zu Protesten, dass insbesondere »konservative Medien in ihrer Berichterstattung weniger die inhaltliche Kritik in den Fokus rücken, sondern die Form des Protests. Protestierende selbst kommen zudem seltener selbst zu Wort. Kommt es bei Protesten »zu Konfrontationen mit der Polizei« (ebd., 26), sinkt in allen Medien die Auseinandersetzung mit den Hintergründen und die Beschreibung der normverletzenden, also devianten Handlungen und der Reaktionen darauf dominiert. Spektakel und potenzielle Normverletzungen, die von sozialen Bewegungen ausgehen, liefern also Stoff für Berichterstattung und damit für Publizität - jedoch auch Potenzial für den Wechsel der Thematisierungsebene. Das Protesthandeln wird so zwar publik, erfährt aber eine Rahmung, die von Irritation bis hin zu Kriminalität reicht. Es bedient dominante Nachrichtenfaktoren wie Konflikt und Gewalt (Bonfadelli und Friemel 2001; Schulz 1979), die in journalistischer Selektion und (notwendiger) Verkürzung in den Vordergrund rücken, die inhaltlichen Positionen jedoch überlagern.

Dazu kommt, dass, wie eingangs dieses Abschnitts skizziert, soziale Bewegungen nicht zu klassischen Formaten der Strategischen Kommunikation neigen (Oy 1997). Dies kann bedingt sein durch ihre Struktur und ihren Ressourcenmangel, aber auch durch die subkulturelle Prägung, die klassische Formate der Medienarbeit quasi unmöglich machen (Veneti 2017; Philipps 2012). Gemeint sind damit Deutungen, kulturelle Praktiken, aber auch eine eigene Protestästhetik (Veneti 
2017), die spezifische subkulturelle Codes und Identifikationsmodelle hervorbringen (Oy 1997, 79; Lamnek 2013). Die in diesen Kontexten ausgebildeten Anerkennungssysteme können beinhalten, dass Handlungen und Ziele goutiert werden, die außerhalb dieses Raumes keine Anerkennung finden (Lamnek 2013, 185-187). Gerade vor dem Hintergrund der sogenannten bürgerlichen Öffentlichkeit haben beispielsweise das Ausüben von Gewalt oder das unerlaubte Eindringen in privates Gelände das Potenzial, normverletzende wenn nicht gar kriminelle Zuschreibungen hervorzurufen. In klassischen Medienformaten wird es deshalb schwierig, die eigenen inhaltlichen Positionen unterzubringen.

Indes lässt sich argumentieren, dass soziale Bewegungen für tatsächlichen gesellschaftlichen Wandel auf Anerkennung und Zuschreibung von Legitimität aus dem bürgerlichen Mainstream, den sie mitunter ablehnen und in dem sie als deviant geframed werden, angewiesen sind. Mithin stecken kleinere soziale Bewegungen in einem ressourcen- und kulturbedingten Dilemma: Um gesellschaftliche Transformation und im Wortsinn »Bewegung « zu erreichen, sind sie auf Aufmerksamkeit für ihre Positionen angewiesen, die über die eigene Bezugsgruppe hinausgeht. Die These im Folgenden wird deshalb sein: Da sie in einem auch an sozialen und ökonomischen Ressourcen orientierten Mediensystem einen schweren Stand haben, setzen kleinere soziale Bewegungen zwar auf spektakuläre und "photografierbare (Luhmann 1991, 152) Aktionen, um Aufmerksamkeit zu erlangen. Diese bergen jedoch immer das Risiko, als Normverstöße in den Fokus zu rücken und damit vom eigentlichen inhaltlichen Anliegen abzulenken. Das leitet über zum Konzept der Devianz.

\section{Devianz und die Inszenierung von Protest}

Dass soziales Verhalten an Normen gebunden ist, »ist eine einfache, ja triviale Alltagserfahrung « (Popitz 1961, 185). Normen dienen dazu, soziales Verhalten in einem gewissen Maße zu konditionieren und erwartbar zu machen. Devianz stellt die Abweichung von diesen Erwartungen dar. Krumpal und Berger $(2020,1)$ fassen darunter »Verhaltensweisen oder Einstellungen [...], welche von allgemein anerkannten, normativen Erwartungen einer Gesellschaft abweichen und entsprechend einer informellen oder formellen Sanktionsdrohung unterliegen«. Je nach Kontext und Grad der Normverletzung kann das Sanktionspotenzial 
von sozialer Ächtung bis hin zu gerichtlicher Ahndung reichen. Zweck der Kennzeichnung, Ächtung und Sanktionierung von Devianz ist die Durchsetzung einer Normierung in bestimmten sozialen Kontexten:

Gemeinsam ist allen Arten abweichenden Verhaltens, dass es sich um Abweichungen von gesamtgesellschaftlich dominanten Normen handelt, die jeden Menschen als Mitglied der Gesellschaft betreffen und der Stabilisierung des gesellschaftlichen Status quo - nicht nur in Form gesetzlicher Regelungen, sondern auch in Form bestimmter Leitbilder von "geordneten « Verhältnissen in den zentralen gesellschaftlichen Bereichen Arbeit, Konsum und Familie - dienen. (Peuckert 2016, 129).

In dieser Ausarbeitung soll es um den spezifischen Prozess der Rahmung eines Verhaltens als deviant und unangemessen gehen. Im Folgenden werde ich daher insbesondere auf den »Labelling-Ansatz« der Devianz eingehen.

Dieser geht davon aus, dass eine Abweichung von einer Norm als "Zuschreibungsprozess des Attributes der Devianz zu bestimmten Verhaltensweisen im Rahmen von Interaktionen « (Lamnek 2013, 223) zu verstehen ist. Ob ein Verhalten also überhaupt als deviant wahrgenommen wird, ist nicht von vorneherein auszumachen. Becker (2014, 31) stellt heraus, »dass gesellschaftliche Gruppen abweichendes Verhalten dadurch schaffen, dass sie Regeln aufstellen, deren Verletzung abweichendes Verhalten konstituiert, und dass sie diese Regeln auf bestimmte Menschen anwenden, die sie als Außenseiter etikettieren«. Die Frage, ob etwas von einer Norm abweicht oder nicht, wird somit als aushandlungsbedürftig sowie kontext- und personenabhängig angesehen (Lamnek 2013, 223). Und so haben »einige Abweichler [...] Mitleid zu erwarten, andere verbreiten Angst oder werden verachtet« (Peuckert 2016, 129).

Abweichendes Verhalten ist demnach nicht objektiv zu identifizieren und keine Qualität, die einer Handlung inhärent wäre, sondern wird vielmehr durch gleichzeitige Normsetzung definiert. Mithin ist die Markierung einer Abweichung ein alltäglicher, unausweichlicher Vorgang. Gleichwohl ist auf selektive Normanwendungen hinzuweisen: Gleiche Verhaltensweisen werden mitunter situations- und personenspezifisch unterschiedlich definiert (Lamnek 1977, 77-78; 2013). Je nach Adressat*in kann ein Verhalten als konform oder deviant gelten:

Da allgemeine Normen immer auf bestimmte Situationen bezogen werden müssen und somit interpretationsbedürftig sind, entscheidet das soziale 
Publikum darüber, ob einer bestimmten Handlung oder Person das Etikett abweichend zugeschrieben wird oder nicht. (Peuckert 2016, 141)

Bezogen auf das hier behandelte Thema heißt das, dass (kleinere) soziale Bewegungen und ihr Handeln von diversen medialen Publika unterschiedlich bewertet werden können. In Bezug auf das skizzierte Mediendilemma sozialer Bewegungen ist dabei zu beachten, dass »klassischen « Medien eine wesentlich höhere Reichweite im sogenannten Mainstream und damit Deutungsmacht in der Zuschreibung von Devianz zukommt (Hänggli 2012).

\section{Funktionale und dysfunktionale Devianz}

Wie zuvor erläutert, dient das Sanktionspotenzial hinter der Normierung von Verhalten dem Erhalt sozialer Ordnung. Zentral ist jedoch auch, dass sich diese Ordnung immer wieder aufs Neue bewähren muss, also fortlaufend auch in Frage gestellt wird. Durch diese Aushandlungs- oder Vergewisserungsprozesse, durch die geltende Regeln und Normen auf ihre Legitimität hin überprüft werden, kann sich eine Gesellschaft erneuern (Lamnek 2013, 45). Die Abweichung von der Norm erscheint so als »funktionale Devianz« (Peuckert 2016, 132). Nimmt die Abweichung allerdings überhand, kann sie eine Gesellschaft auch durch Gewalt und Kriminalität zutiefst schädigen. Diese Fälle von dysfunktionaler Devianz haben eher soziale Desintegration der Akteur*innen und deren Anliegen zur Folge.

Protest richtet sich immer gegen herrschende Normen und hat die Einführung einer neuen Norm zum Ziel (Scholl 2009). Dies birgt zunächst großes Irritationspotenzial für die herrschende Mehrheit. Entsprechend hoch ist der Nachrichtenwert, wenn Konflikt und Rebellion, Neu- und Andersartigkeit zusammenkommen. Abweichungen von einer bestehenden Norm weisen immer auch auf Grenzüberschreitendes bis hin zum Skandalösen hin und bedienen so journalistische Selektionskriterien. Gleichzeitig schlägt eine gesamtgesellschaftliche Ablehnung devianten Verhaltens zu Buche und ein stärker ausgeprägtes Konformitätsstreben der »Mitte«, die sich mit dem Mainstream und seinen Positionen identifiziert. In bestimmten Situationen kann es jedoch auch zu einer breiten Solidarisierung mit dem »Underdog « kommen (Menzel 1997, 119). Nämlich insbesondere dann, wenn die Devianz als funktional und innovativ für die Mehrheitsgesellschaft erkannt wird. Diese Zuschreibung birgt großes Potenzial für die Strategische Kommunikation sozialer Bewegung und die Inszenierung von Protest, wie ich am folgenden Fallbeispiel deutlich machen möchte. 


\section{Fallbeispiel Hambacher Forst}

Der Hambacher Forst ist ein etwa 500 Hektar großes Waldgebiet zwischen Köln und Aachen. Ebenso ist er Schauplatz diverser Interaktionen zwischen aktivistischen Protestformen und staatlichen Eingriffen. In diesem Abschnitt werden nun die dabei entstandenen Konflikte der Jahre 2017 bis 2019 als Fallbeispiel für die Strategische Kommunikation sozialer Bewegungen herangezogen. Im beschriebenen Fall gelang es diesen nämlich äußerst gut, hohe gesamtgesellschaftliche Anschlussfähigkeit herzustellen.

Bereits seit den 1970er Jahren rodet der Energiekonzern RWE den Hambacher Forst zur Braunkohlegewinnung. Dagegen hatte sich vor Ort schon gegen Ende des Jahrzehnts eine aktive Widerstandsbewegung gebildet. Diese intensivierte sich in den 2010er Jahren und errichtete an mehreren Stellen im Wald Barrikaden und Protestcamps, die immer wieder gewaltvoll unter großem medialem Interesse geräumt, aber stets wiederaufgebaut wurden (Dalkowski 2018).

2018 beschloss RWE weitere großflächige Rodungsarbeiten im Hambacher Forst. Eine Klage des BUND gegen diese Rodung wurde abgewiesen. Dies hatte eine erneute Räumung der Protestcamps zur Folge, die jedoch zu erheblichen Auseinandersetzungen zwischen Polizei und Umweltaktivist*innen führte. Nicht zuletzt deshalb richtete sich das öffentliche Interesse auf die Geschehnisse im Hambacher Forst, der bereits zuvor zum Symbol der Anti-Kohle-Bewegung geworden war. Zentral in diesem Protest waren die Initiativen »Hambi bleibt« und »Ende Gelände«. Ihnen gelang es, einer devianten linken Protesterzählung einen zunehmend gesellschaftlich anschlussfähigeren David-gegen-Goliath-Topos entgegenzustellen. Eine Großdemonstration mit rund 50000 Teilnehmer*innen am Hambacher Forst stand exemplarisch für die hohe Anschlussfähigkeit ihrer Botschaften. Den Initiativen gelang es, Devianz und die damit verbundene Aufmerksamkeit strategisch zu kapern, ein funktionales Narrativ zu etablieren und somit Reichweite und Zuspruch zu generieren. Zum Vergleich werden nun ein Pressebild der dpa und ein PR-Bild der Initiative »Ende Gelände« in einer rekonstruktiven Bildanalyse (Przyborski und Slunecko 2012) gegenübergestellt, um den Unterschied zwischen der Selbst- und der Fremddarstellung hinsichtlich der gezeigten Devianz zu verdeutlichen. 


\subsection{Rekonstruktive Bildanalyse}

Neben sprachlichen Botschaften aller Art erfahren visuelle Botschaften insbesondere durch die Dominanz Sozialer Medien wie Facebook, YouTube und Instagram zunehmend Beachtung in der Strategischen Kommunikation (Goransson und Fagerholm 2018). Doch auch analytisch ist ein »visual turn« (Burri 2008) in den Sozialwissenschaften zu konstatieren. Bilder lassen sich als Artefakte visueller Kulturen interpretieren und verweisen auf gestaltete Konstruktionen von Realität und Bedeutung (Phillips 2012, 2; Przyborsky und Slunecko 2012). Vor diesem Hintergrund ziehe ich im Folgenden ein Bild einer Pressepublikation heran und stelle es einem Bild, das von »Ende Gelände « publiziert wurde, gegenüber. ${ }^{3}$ Beide stellen freilich nur einen Ausschnitt des Geschehens dar. Die Analyse soll aber vorrangig verdeutlichen, wie unterschiedlich und geradezu strategisch Devianz aufgegriffen werden kann. Im Folgenden wird eine rekonstruktive Bildanalyse nach Przyborsky und Slunecko (2012; grundlegend Bohnsack 2009; Panofsky 1975) durchgeführt. In dieser wird zunächst auf den generellen Bildaufbau und dann auf die Ikonologie eingegangen.

\subsection{Bildanalyse 1}

Das erste Bild (Abb. 1) zeigt eine Aufnahme aus dem besetzten Hambacher Forst. Im Zuge eines tödlichen Sturzes eines Journalisten war die Räumung im Forst vorübergehend ausgesetzt worden. Durch die gewählte Perspektive des Bildes empfinden sich die Betrachtenden als Teil des Geschehens. Die Bildtemperatur ist eher kühl und die Farben sind dunkel und getrübt; das Bild wirkt nass.

Die dominanteste Linie stellt eine Barrikade aus zusammengetragenem (Sperr-)Holz und Reisig dar, die das Bild in einer absteigenden Linie nahezu in der Mitte teilt. Sie wirkt behelfsmäßig, aber gerade durch die beiden Baumstämme massiv. Für ihre Konstruktion wurde vor allem natürliches, urwüchsiges Material verwendet. Es ist keine technisch hochwertige, militärische Barrikade, sondern ein chaotischer Haufen.

3 Die Analyse wurde mit der Unterstützung von Studierenden der Hochschule Osnabrück im Seminar »Übung Kommunikationskonzept« in mehreren Iterationen durchgeführt. An dieser Stelle möchte ich mich für die angeregte Diskussion bedanken. 
Gleichzeitig weckt sie auch Assoziationen mit einem Abriss oder einem behelfsmäßig errichteten Scheiterhaufen. Mit der Barrikade verwoben ist ein Protestschild mit der Aufschrift »Ende Gelände. Der $\mathrm{CO}_{2}$-Countdown läuft.« Das Schild wirkt ausrangiert und auf den Müll geworfen. Der Kampf um den Wald scheint verloren.

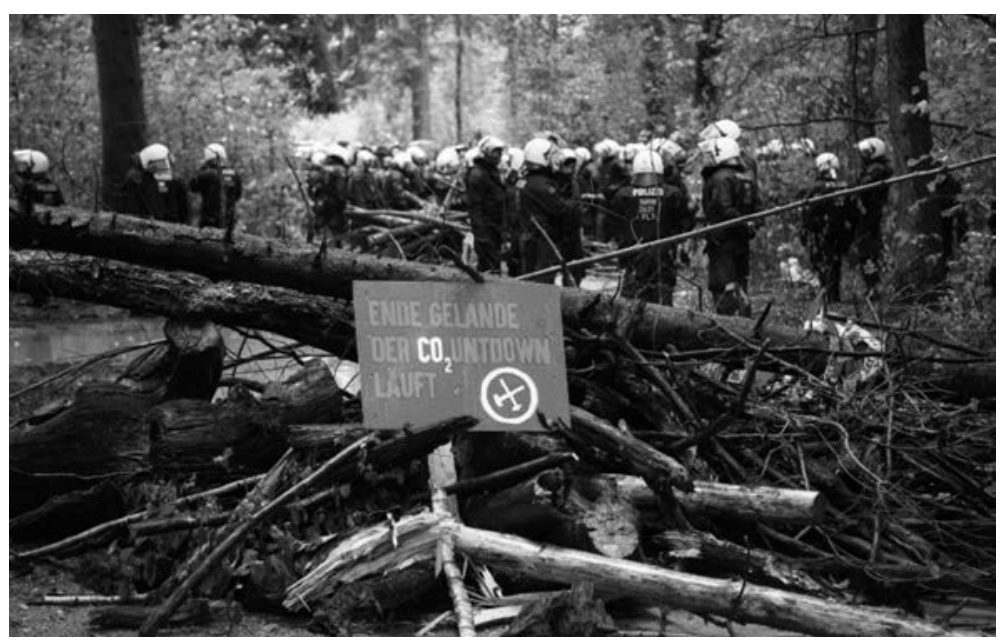

Abb. 1: dpa-Bild zur Dokumentation der Proteste im Hambacher Forst der Organisation »Ende Gelände« (Gateau, 24.09.2018).

Die Barrikade teilt das Bild und den abgebildeten Raum in ein Davor und ein Dahinter. Im Hintergrund, mit verminderter Schärfe, sind Polizist*innen in Einsatzkleidung zu sehen, welche mit der scheinbaren Natürlichkeit kontrastieren. Durch ihre Einsatzkleidung und Helme wirken sie nicht wie Personen, sondern wie die anonyme Exekutive, die deutlich besser ausgestattet erscheint als die auf dem Bild nicht sichtbaren Erbauer*innen der Barrikade.

Visuell wird eine klare Trennlinie zur Polizei als Repräsentation des Rechtsstaats und Vertretung von Recht und Ordnung gezogen. Die Barrikade mit Schild weckt Assoziationen an Elemente »klassischer « Protestästhetik wie brennende Straßenbarrikaden, die eine kritische Auseinandersetzung mit staatlicher Gewalt manifestieren. Damit ist bildsprachlich ein Moment der Devianz markiert, wobei die Polizei als Ordnungshüterin bereits vor Ort ist und die Lage beruhigt hat. Das Protestgeschehen bleibt unsichtbar und ist nur latent durch die zurückgelassene Barrikade im Bild enthalten. 


\subsection{Bildanalyse 2}

Das zweite Bild (Abb. 2) zeigt den Protest am Rande des Braunkohleabbaugebietes. Neben diversen Publikationen der Organisation »Ende Gelände « findet sich das Bild auf der Fotoplattform flickr in einem Album mit der Bezeichnung »Ende Gelände November 2017 - as it happened «. Bereits durch diese Bezeichnung wird ein Gegengewicht zu presseöffentlichen Darstellungen angedeutet (vgl. Abschnitt 2.3).

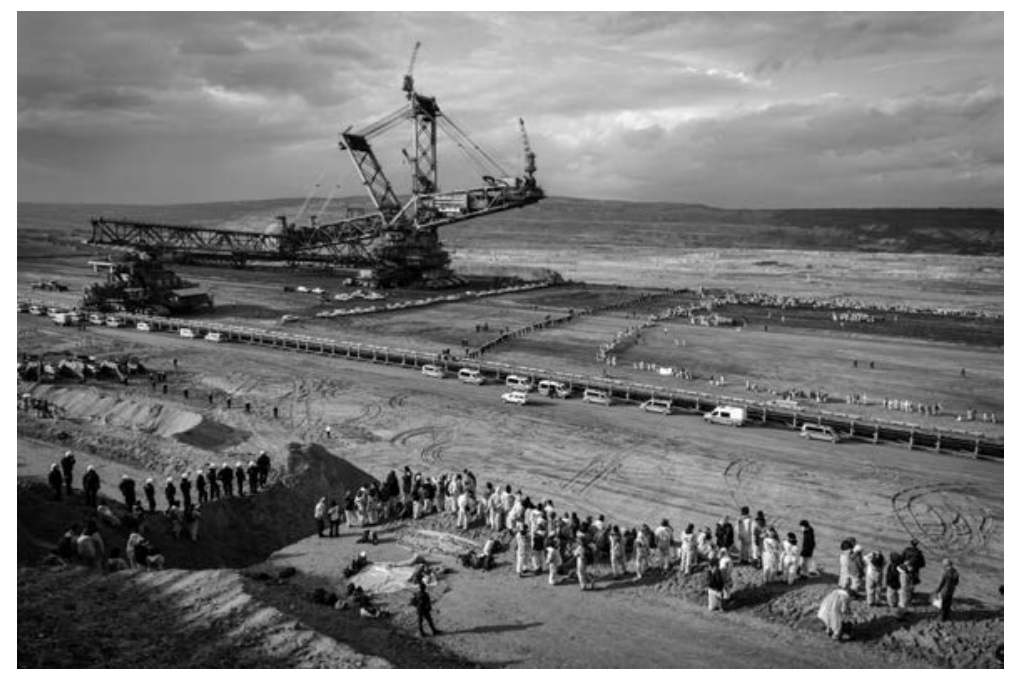

Abb. 2: PR-Bild der Organisation »Ende Gelände« (Bock, 05.11.2017).

Das Bild teilt sich in vier Bereiche. Im Vordergrund reihen sich Protestierende und Polizist*innen am Rande des Tagebaus auf, wo sich eine befestigte Absperrung in Form eines Zauns befindet. Zentral im Bild ist ein Bagger inmitten einer Kohlegrube zu sehen. Auch hiervor finden sich Protestierende und Polizei. Das vierte Element bildet der verblassende und verblauende Horizont. Farblich ist das Bild vor allem in Wüstentönen gehalten, die Assoziationen zu Trockenheit und Ödnis wecken. Aus dem Forst ist eine Kohlegrube geworden.

Die Polizist*innen im Vordergrund sind in ihrer Einsatzkleidung auch in diesem Bild nicht als Personen voneinander zu unterscheiden. Allerdings ist die Kluft der Protestierenden ebenfalls uniform, hier handelt es sich um Überzüge, wie sie für Malerarbeiten verwendet werden. In Verbindung mit dem öden und »toten« Hintergrund wirken sie jedoch 
wie Schutzanzüge, die bei Katastrophenfällen zum Einsatz kommen. Die Menschen müssen sich in und vor dieser lebensfeindlichen Umgebung schützen. Das Bild suggeriert dadurch einen Blick in eine dystopische Zukunft, die von profitgenerierender Maschinerie und nicht von und für Menschen gestaltet wird.

Im Zentrum des Bildes steht der Kohlebagger, der als Werkzeug der Organisation RWE die alte Industriemoderne repräsentiert. Dem gegenüber stehen die Menschen, die eine Abkehr von dieser Zeit und ihren Zielstellungen anstreben. Die Anordnung der Protestierenden und der Polizei erinnert an Schlachtreihen. Erstere sind in der Überzahl, jedoch ist ihre Formation weniger akkurat und organisiert als die der Polizei. Diese steht im Bild auf Seiten des Kohlebaggers und RWE - die Exekutive - erscheint als Verteidigerin der bestehenden Ordnung, die sich mit breiter Brust vor die Vergangenheit stellt und diese vor dem (unbewaffneten und weniger organisierten) Protest beschützt.

Die Zuschreibung von Devianz und Legitimität erfährt in diesem Bild gleichwohl eine Umkehr. Durch die verwendete Farbigkeit und Ödnis werden Endzeitszenarien wie im Film Mad Max aufgerufen, die einen Blick in eine potenzielle Zukunft gewähren. Das potenziell deviante Verhalten der Protestierenden und das zur Schau gestellte Machtverhältnis zur Polizei lässt sich im Bild als Aufstand für das Natürliche lesen, der eine herannahende Dystopie abwenden will. Der vermeintliche Angriff auf den Rechtsstaat und das unbefugte Betreten des Meilers werden nun durch die übergeordnete gute Sache der Daseinsvorsorge legitimiert, an der auch die Allgemeinheit Interesse hat. Entsprechend erfolgt die Abbildung der Normverletzung nunmehr als eine funktionale Devianz. Umgekehrt wird das bisher erwartungskonforme Verhalten von RWE (der Abbau von Braunkohle) als normverletzend inszeniert. Das Bild zielt darauf, das Festhalten am Status quo als potenziell gemeinwohlschädlich zu framen und zu delegitimieren.

\section{Strategisches Reframing}

Im zweiten Bild zeigt sich eine Abkehr von klassisch rebellischer und devianter Protestästhetik (Veneti 2017) hin zu einem stärkeren visuellen Verweis auf übergeordnete Topoi (hier beispielsweise David und Goliath). Der Bewegung gelingt in diesem Bild eine »Rahmenveränderung bzw. Neuinterpretation der Situation, die sog. Frame Transformation. [...] Ereignisse, die bereits in einem Rahmen interpretiert wurden, erhalten plötzlich eine andere, neue Bedeutung im Kontext eines neuen Rahmens, so dass sich die Wahrnehmung und Erfahrung der Situation än- 


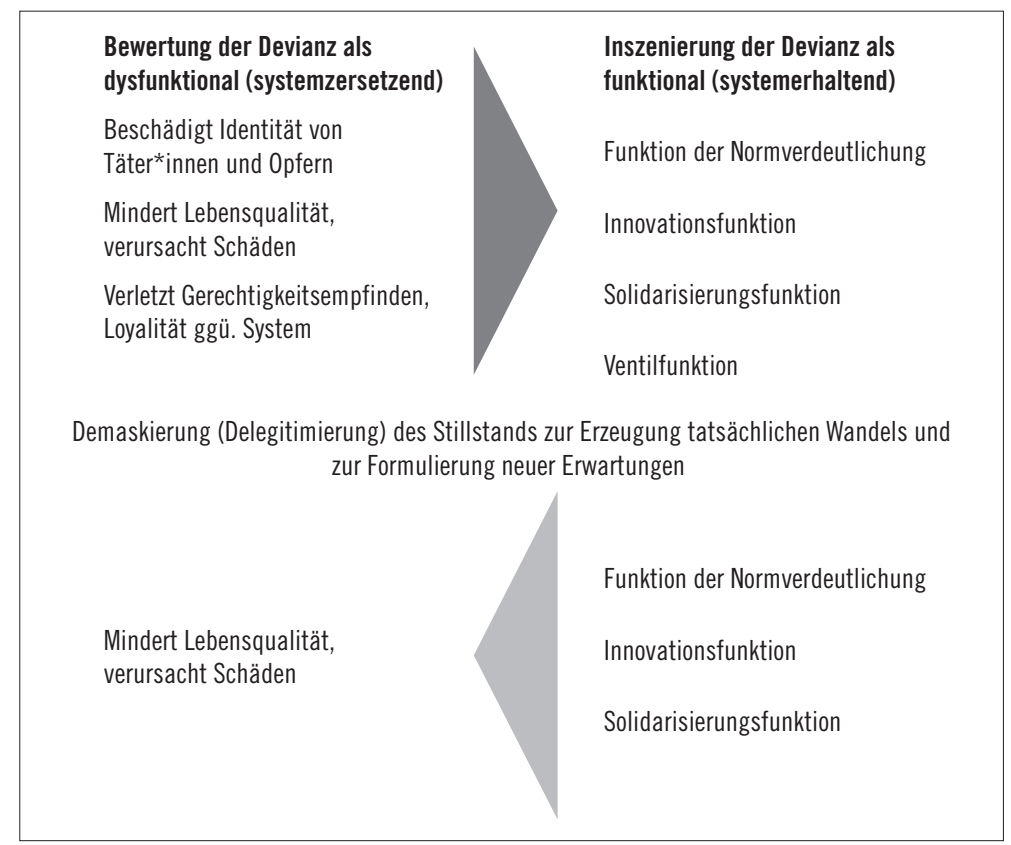

Abb. 3: Prozess des Reframings der Devianz-Zuschreibung (eigene Darstellung nach Peuckert 2016).

dert« (Schade 2018, 277; grundlegend hierzu Snow et al. 1986, 473-474). Schade verweist weiter darauf, dass insbesondere durch den Wandel des Frames bisher tolerierte Problemstellungen nun als nicht mehr hinnehmbar gesehen werden. Als besonders zielführend sieht sie hier die Umkehr der Schuldzuschreibung an, welche im zweiten Bild besonders im Mittelpunkt steht.

Anhand dieser Bilder zeigt sich, wie die Bewertung der Proteste im Hambacher Forst von ihrer ursprünglich systemzersetzenden Interpretation hin zu einer funktionalen und systemstärkenden Devianz umgedeutet und aufmerksamkeitsstark eingesetzt wurde (siehe Abschnitt 3). Im zweiten Bild ist eine klare Verschiebung in der Zuschreibung der dysfunktionalen Devianz erkennbar: Das Handeln der Organisation RWE, obwohl eigentlich formalrechtlich legitimiert, erfuhr Delegitimation in der öffentlichen Wahrnehmung, was zur Formulierung neuer Erwartungen führte (siehe Abschnitt 2). Nun ist nicht mehr die soziale Protestbewegung Träger der dysfunktionalen Devianz, sondern RWE, die durch das Festhalten an delegitimierten Normen systembe- 
drohende Muster reproduzieren. Der Prozess ist in Abb. 3 nochmals grafisch dargestellt.

\section{$5 \quad$ Zusammenfassung und Fazit}

In diesem Beitrag stand die Frage im Mittelpunkt, inwieweit der strategische Einsatz devianter Kommunikationsformen förderlich oder hinderlich für das Erreichen der Ziele einer Bewegung sein kann. Nach dem Darlegen der theoretischen Bausteine habe ich meine Überlegungen am Bespiel der visuellen Darstellung der Proteste im Hambacher Forst verdeutlicht.

Aufgrund von häufig geringerer Ressourcenausstattung haben es soziale Bewegungen nicht leicht, ihre Anliegen einer breiten Öffentlichkeit zugänglich zu machen. Sie sind daher auf aufmerksamkeitsstarke Ereignisse und sowohl die »Photografierbarkeit« (Luhmann 1991, 152) als auch zunehmend auf die Filmbarkeit ihrer kommunikativen Handlungen angewiesen. Ertl (2015, 78-80) beschreibt dies auch als die "Spektakularisierbarkeit« der Protestaktionen sozialer Bewegungen. Diese bedienen insbesondere die Nachrichtenfaktoren Konflikt, Schaden, Gewalt bis hin zur Kriminalität und auch das Aufbegehren gegen Eliten (Bonfadelli 2000; Schulz 1976). Sie sind damit hochgradig aufmerksamkeitsstark, jedoch auch hochgradig deviant.

Für tatsächlichen gesellschaftlichen Wandel sind soziale Bewegungen auf Aufmerksamkeit und eine gewisse Zuschreibung von Legitimität seitens einer bürgerlichen Öffentlichkeit angewiesen, deren Maßstäbe und Deutungen sie jedoch zumindest in bestimmten Bereichen ablehnen. Die Medienberichterstattung über spektakuläre Protestaktionen setzt nun nicht immer vorrangig deren inhaltliche Positionen in den Fokus, sondern maßgeblich ihre deviante Form. Diese Handlungen haben das Potenzial, als normverletzend bis hin zu kriminell dargestellt und entsprechend von der Gesamtgesellschaft als ablehnungswürdig und illegitim klassifiziert zu werden. Die Chance der Strategischen Kommunikation sozialer Bewegungen liegt nun in einem Reframing ihres Handelns und in der Inszenierung funktionaler Devianz. Hierdurch wird ihr innovatives Moment betont und herausgestellt, dass ihr Handeln einen Mehrwert für die Gesamtgesellschaft bietet. Dies begünstigt eine Solidarisierung mit dem »Underdog « und dessen Anliegen. Gelingt auch hier ein Wandel des Framings hin zu einer neuen geteilten Problembeschreibung, können so gesamtgesell- 
schaftliche Energien für wirkliche »Bewegung«freigesetzt und Erwartungen gemeinsam neu ausgehandelt werden.

\section{Literatur}

Ahlemeyer, Heinrich W. 1995. Soziale Bewegungen als Kommunikationssystem. Wiesbaden: VS Verlag für Sozialwissenschaften.

Altmeppen, Klaus-Dieter, Ulrike Röttger, und Günter Bentele. 2004. Public Relations und Journalismus: Eine lang andauernde und interessante »Beziehungskiste«. In: Schwierige Verhältnisse, herausgegeben von Klaus-Dieter Altmeppen, Ulrike Röttger und Günter Bentele, 7-15. Wiesbaden: VS Verlag für Sozialwissenschaften.

Baerns, Barbara. 1991. Öffentlichkeitsarbeit oder Journalismus: Zum Einfluß im Mediensystem. Köln: Wissenschaft und Politik.

Becker, Howard S. 2014. Außenseiter. Wiesbaden: Springer VS.

Bock, Christian. 2017. Ende_Gelände_2017_CHB_23. https://www.flickr.com/ photos/133937251@N05/26439720559/in/album-72157688093187921/.Zugegriffen: 25. März 2021

Bohnsack, Ralf. 2009. Qualitative Bild- und Videointerpretation: Die dokumentarische Methode. Opladen: Budrich.

Bonfadelli, Heinz, und Thomas N. Friemel. 2001. Medienwirkungsforschung. 2., überarbeitete Auflage. Konstanz: UVK.

Boyle, Michael P., Douglas M. McLeod, und Cory L. Armstrong. 2012. Adherence to the Protest Paradigm. The International Journal of Press/Politics 17 (2): 127144. DOI: https://doi.org/10.1177/1940161211433837.

Buchmeier, Yosuke. 2020. Towards a Conceptualization and Operationalization of Agenda-Cutting: A Research Agenda for a Neglected Media Phenomenon. Journalism Studies 21 (14): 2007-2024. DOI: https://doi.org/10.1080/1461670X. 2020.1809493.

Burri, Regula Valérie. 2008. Bilder als soziale Praxis: Grundlegungen einer Soziologie des Visuellen. Zeitschrift für Soziologie 37 (4): 342-358.

Colistra, Rita F. 2018. Power Pressures and Pocketbook Concerns: Perceptions of Organizational Influences on News Content in the Television Industry. International Journal of Communication 12: 1790-1810.

Crary, Jonathan. 2002. Aufmerksamkeit: Wahrnehmung und moderne Kultur. Frankfurt am Main: Suhrkamp.

Dalkowski, Sebastian. 2018. Der dauerbesetzte Wald. Rheinische Post vom 14. September, https://rp-online.de/nrw/panorama/hambacher-forst-chronologieder-ereignisse_aid-32968789. Zugegriffen: 25. März 2021.

Di Cicco, Damon T. 2010. The Public Nuisance Paradigm: Changes in Mass Media Coverage of Political Protest since the 1960s. Journalism \& Mass Communication Quarterly87(1):135-153.DOI: https://doi.org/10.1177/107769901008700108.

Ebert, Helmut, und Manfred Piwinger. 2007. Impression Management: Die Notwendigkeit der Selbstdarstellung. In: Handbuch Unternehmenskommunikation, 
herausgegeben von Manfred Piwinger und Ansgar Zerfaß, 205-225. Wiesbaden: Gabler.

Ehl, David, und Lisa Hänlein. 2019. Extinction Rebellion: Wie weit darf Protest gehen? Deutsche Welle vom 6. Oktober, https://p.dw.com/p/3PPnD. Zugegriffen: 25. März 2021.

Ertl, Sarah. 2015. Protest als Ereignis: Zur medialen Inszenierung von Bürgerpartizipation. Bielefeld: Transcript. DOI: http://dx.doi.org/10.14361/9783839430675.

Femers, Susanne. 2015. Public Relations aus sozialpsychologischer Sicht. In: Handbuch der Public Relations, herausgegeben von Romy Fröhlich, Peter Szyszka und Günter Bentele, 63-84. Wiesbaden: Springer VS.

Franck, Georg. 1998. Ökonomie der Aufmerksamkeit: Ein Entwurf. München: Hanser.

Freeman, R. Edward. 1984. Strategic Management: A Stakeholder Approach. Boston: Pitman Publishing.

Gamson, William A., und Gadi Wolfsfeld. 1993. Movements and Media as Interacting Systems. In: The Annals of the American Academy of Political and Social Science, herausgegeben von Richard D. Lambert und Alan W. Heston, 114-125. Newbury Park: Sage.

Gateau, Christophe. 2018. Räumung des Hambacher Forsts geht weiter - Aktivisten blockieren Kohlebahn. Spiegel Online vom 24. September, https://www.spiegel. $\mathrm{de} /$ panorama/hambacher-forst-raeumung-geht-weiter-aktivisten-blockierenkohlebahn-a-0604a3a1-a9ef-46cc-a2b8-0e1fcba5a5d9\#bild-5307098b-e9f44f74-83ac-647d33d82168. Zugegriffen: 25. März 2021.

Gerk, Andrea, und Henry Bernhard. 2019. Ist die Künstlergruppe ZPS eine kriminelle Vereinigung? Deutschlandfunk Kultur vom 3. April, https://www.deutschlandfunkkultur.de/zentrum-fuer-politische-schoenheit-ist-die-kuenstlergruppe.1013.de.html?dram:article_id=445408. Zugegriffen: 25. März 2021.

Goransson, Karina, und Anna-Sara Fagerholm. 2018. Towards visual strategic communications. JCOM 22 (1): 46-66. DOI: https://doi.org/10.1108/JCOM-122016-0098.

Görke, Alexander. 2008. Perspektiven einer Systemtheorie öffentlicher Kommunikation. In: Theorien der Kommunikations- und Medienwissenschaft, herausgegeben von Carsten Winter, Andreas Hepp und Friedrich Krotz, 173-191. Wiesbaden: VS Verlag für Sozialwissenschaften.

Hänggli, Regula. 2012. Key Factors in Frame Building. American Behavioral Scientist 56 (3): 300-317. DOI: https://doi.org/10.1177/0002764211426327.

Harlow, Summer. 2012. Social Media and Social Movements: Facebook and an Online Guatemalan Justice Movement That Moved Offline. New Media \& Society 14 (2): 225-243. DOI: https://doi.org/10.1177/1461444811410408.

Harlow, Summer, und Thomas J. Johnson. 2011. Overthrowing the Protest Paradigm? How The New York Times, Global Voices and Twitter Covered the Egyptian Revolution. International Journal of Communication 5: 1359-1374. https:// ijoc.org/index.php/ijoc/article/view/1239/611. Zugegriffen: 25. März 2021.

Herman, Edward S., und Noam Chomsky. 2002. Manufacturing Consent: The Political Economy of the Mass Media. New York: Pantheon. 
Hoffjann, Olaf. 2011. Vertrauen in Public Relations. Publizistik 56 (1): 65-84. DOI: https://doi.org/10.1007/s11616-010-0103-4.

Jacke, Christoph. 2004. Medien(sub)kultur: Geschichten - Diskurse - Entwürfe. Bielefeld: Transcript.

Jarren, Otfried, und Patrick Donges. 2011. Politische Kommunikation in der Mediengesellschaft. Wiesbaden: VS Verlag für Sozialwissenschaften.

Juris, Jeffrey S. 2012. Reflections on \#Occupy Everywhere: Social Media, Public Space, and Emerging Logics of Aggregation. American Ethnologist 39 (2): 259279. DOI: https://doi.org/10.1111/j.1548-1425.2012.01362.x.

Karmasin, Matthias, und Franzisca Weder. 2014. Stakeholder-Management als kommunikatives Beziehungsmanagement: Netzwerktheoretische Grundlagen der Unternehmenskommunikation. In: Handbuch Unternehmenskommunikation, herausgegeben von Ansgar Zerfaß und Manfred Piwinger, 81-103. Wiesbaden: Springer VS.

Kette, Sven, und Sebastian Barnutz. 2019. Was ist Compliance Management? Ein organisationstheoretischer Bestimmungs- und Einordnungsvorschlag. In: Compliance managen, herausgegeben von Sven Kette und Sebastian Barnutz, 7-22. Wiesbaden: Springer VS.

Kidd, Dustin, und Keith McIntosh. 2016. Social Media and Social Movements. Sociology Compass 10 (9): 785-794. DOI: https://doi.org/10.1111/soc4.12399.

Kim, Hyosun, und Tae Ho Lee. 2018. Strategic CSR Communication: A Moderating Role of Transparency in Trust Building. International Journal of Strategic Communication 12 (2): 107-124. DOI: https://doi.org/10.1080/1553118X.2018. 1425692.

Krüger, Uwe. 2016. Mainstream: Warum wir den Medien nicht mehr trauen. 2., durchgesehene und aktualisierte Auflage. München: C.H. Beck.

Krumpal, Ivar, und Roger Berger. 2020. Einleitung. In: Devianz und Subkulturen, herausgegeben von Ivar Krumpal und Roger Berger, 1-9. Wiesbaden: Springer VS.

Kühl, Stefan. 2011. Organisationen. Wiesbaden: VS Verlag für Sozialwissenschaften.

Lamnek, Siegfried. 1977. Kriminalitätstheorien, kritisch: Anomie u. Labeling im Vergleich. Kritische Information 60. München: Fink.

Lamnek, Siegfried. 2013. Theorien abweichenden Verhaltens I - »Klassische Ansätze«: Eine Einführung für Soziologen, Psychologen, Juristen, Journalisten und Sozialarbeiter. 9., durchgesehene Auflage. Paderborn: Fink.

Lauzen, Martha M. 1997. Understanding the Relation Between Public Relations and Issues Management. Journal of Public Relations Research 9 (1): 65-82. DOI: https://doi.org/10.1207/s1532754xjprr0901_03.

Luhmann, Niklas. 1991. Soziologie des Risikos. Berlin: de Gruyter.

Luhmann, Niklas. 1994. Systemtheorie und Protestbewegungen. Ein Interview. Forschungsjournal Neue Soziale Bewegungen 7 (2): 53-69.

Luhmann, Niklas. 1999. Funktionen und Folgen formaler Organisation. 5. Auflage. Berlin: Duncker \& Humblot.

Macnamara, Jim. 2014. A review of public communication by the mine owner and government departments and agencies during the 2014 Hazelwood Coal Mine 
Fire. University of Technology Sydney. http://hazelwoodinquiry.vic.gov.au/wpcontent/uploads/2014/08/Report-of-Prof-MacNamara.pdf. Zugegriffen: 25. März 2021.

Melenhorst, Lotte. 2015. The Media's Role in Lawmaking. The International Journal of Press/Politics 20 (3): 297-316. DOI: https://doi.org/10.1177/19401612155 81924.

Menzel, Birgit. 1997. Devianz im Wandel: Definitionstheoretisch orientierte Devianzsoziologie und die Gewaltthematik. Soziale Probleme 8 (2): 189-198.

Merten, Klaus (Hrsg.). 2009. Konstruktion von Kommunikation in der Mediengesellschaft. Wiesbaden: VS Verlag für Sozialwissenschaften.

Merten, Klaus, und Joachim Westerbarkey. 1994. Public Opinion und Public Relations. In: Die Wirklichkeit der Medien, herausgegeben von Klaus Merten, Siegfried J. Schmidt und Siegfried Weischenberg, 188-211. Wiesbaden: VS Verlag für Sozialwissenschaften.

Meyer, John W., und Brian Rowan. 1977. Institutionalized Organizations: Formal Structure as Myth and Ceremony. American Journal of Sociology 83 (2): 340 363.

Möllers, Tobias. 2019. »Sie ist krank«: Merz kritisiert Gretas Auftritt vor der UN. Frankfurter Rundschau vom 28. September, https://www.fr.de/politik/friedrich-merz-kritisiert-gretas-auftritt-sie-sind-krank-13042471.html. Zugegriffen: 25. März 2021.

Neidhardt, Friedhelm, und Dieter Rucht. 1991. The Analysis of Social Movements: The State of the Art and Some Perspectives for Further Research. In: Research on Social Movements: The State of the Art in Western Europe and the USA, herausgegeben von Dieter Rucht, 421-464. Frankfurt am Main: Campus.

Oy, Gottfried. 1997. Gegenöffentlichkeit: Wandlungsprozesse linker Medienpolitik in der BRD. Forschungsjournal Neue Soziale Bewegungen 10 (3): 77-81.

Panofsky, Erwin. 1975. Ikonologie und Ikonographie. Eine Einführung in die Kunst der Renaissance. In: Sinn und Deutung in der bildenden Kunst, herausgegeben von Erwin Panofsky, 36-67. Köln: Dumont.

Peuckert, Rüdiger. 2016. Abweichendes Verhalten und soziale Kontrolle. In: Einführung in Hauptbegriffe der Soziologie, herausgegeben von Hermann Korte und Bernhard Schäfers, 127-151. Wiesbaden: Springer VS.

Philipps, Axel. 2012. Visual protest material as empirical data. Visual Communication 11 (1): 3-21. DOI: https://doi.org/10.1177/1470357211424675.

Popitz, Heinrich. 1961. Soziale Normen. European Journal of Sociology 2 (2): 185198. DOI: https://doi.org/10.1017/S0003975600000394.

Przyborski, Aglaja, und Thomas Slunecko. 2012. Linie und Erkennen: Die Linie als Instrument sozialwissenschaftlicher Bildinterpretation. Journal für Psychologie 20 (3): 1-37.

Rucht, Dieter. 1984. Zur Organisation der neuen sozialen Bewegungen. In: Politische Willensbildung und Interessenvermittlung: Verhandlungen der Fachtagung der DVPW vom 11.-13. Oktober 1983 in Mannheim, herausgegeben von Jürgen W. Falter, Christian Fenner und Michael T. Greven, 609-620. Wiesbaden: VS Verlag für Sozialwissenschaften. 
Rucht, Dieter. 1994. Modernisierung und neue soziale Bewegungen: Deutschland, Frankreich und USA im Vergleich. Frankfurt am Main: Campus.

Sandhu, Swaran. 2012. Public Relations und Legitimität: Der Beitrag des organisationalen Neo-Institutionalismus für die PR-Forschung. Wiesbaden: Springer VS.

Saxer, Ulrich. 2008. Gestaltung von Realität durch Public Relations. Communicatio Socialis 41 (4): 360-71. DOI: https://doi.org/10.5771/0010-3497-2008-4-360.

Schade, Henriette. 2018. Soziale Bewegungen in der Mediengesellschaft. Wiesbaden: Springer VS.

Schmitt-Beck, Rüdiger. 1998. Kommunikation (Neuer) Sozialer Bewegungen. In: Politische Kommunikation in der demokratischen Gesellschaft, herausgegeben von Otfried Jarren, Ulrich Sarcinelli und Ulrich Saxer, 473-481. Wiesbaden: VS Verlag für Sozialwissenschaften.

Scholl, Armin. 2009. Vom Dissens zur Dissidenz. Die Bedeutung alternativer Gegenöffentlichkeit für die Gesellschaft. In: Konstruktion von Kommunikation in der Mediengesellschaft, herausgegeben von Klaus Merten, 83-95. Wiesbaden: VS Verlag für Sozialwissenschaften.

Schulz, Winfried. 1979. Die Konstruktion von Realität in den Nachrichtenmedien: Analyse der aktuellen Berichterstattung. Freiburg: Alber.

Sewell, William H. 1992. A Theory of Structure: Duality, Agency, and Transformation. American Journal of Sociology 98 (1): 1-29.

Snow, David A., E. Burke Rochford, Steven K. Worden, und Robert D. Benford. 1986. Frame Alignment Processes, Micromobilization, and Movement Participation. American Sociological Review 51 (4): 464-481. DOI: https://doi. org/10.2307/2095581.

Stickler, Armin. 2005. NGOs und Soziale Bewegungen: Der Beitrag der Bewegungsforschung. In: Soziale Bewegungen und Global Governance: Eine Kritische Bestandsaufnahme, herausgegeben von Armin Stickler, 91-162. Bielefeld: Transcript.

Teune, Simon, und Moritz Sommer. 2017. Zwischen Emphase und Aversion: Großdemonstrationen in der Medienberichterstattung. https://protestinstitut.eu/ wp-content/uploads/2017/07/ipb-Forschungsbericht-Gro\%C3\%9Fdemonstrationen-in-der-Medienberichterstattung.pdf. Zugegriffen: 25. März 2021.

Valor, Carmen. 2005. Corporate Social Responsibility and Corporate Citizenship: Towards Corporate Accountability. Business \& Society Review 110 (2): 191-212. DOI: https://doi.org/10.1111/j.0045-3609.2005.00011.x.

Veneti, Anastasia. 2017. Aesthetics of Protest: An Examination of the Photojournalistic Approach to Protest Imagery. Visual Communication 16 (3): 279-298. DOI: https://doi.org/10.1177/1470357217701591.

Vliegenhart, Rens, Stefaan Walgra, Frank R. Baumgartner, Shaun Bevan, Christian Breuning, Sylvain Brourad, Laura Chaqués Bonafont. 2016. Do the media set the parliamentary agenda? A comparative study in seven countries. European Journal of Political Research 55 (2): 283-301. DOI: https://doi.org/10.1111/14756765.12134.

Walgrave, Stefaan, und Peter van Aelst. 2006. The Contingency of the Mass Media's Political Agenda Setting Power: Toward a Preliminary Theory. Journal of Com- 
munication 56 (1): 88-109. DOI: https://doi.org/10.1111/j.1460-2466.2006. 00005.x.

Werder, Kelly Page, Howard Nothhaft, Dejan Verčič, und Ansgar Zerfaß. 2018. Strategic Communication as an Emerging Interdisciplinary Paradigm. International Journal of Strategic Communication 12 (4): 333-351. DOI: https://doi. org/10.1080/1553118X.2018.1494181.

Wimmer, Jeffrey. 2007. (Gegen-)Öffentlichkeit in der Mediengesellschaft. Wiesbaden: VS Verlag für Sozialwissenschaften.

\section{Open Access}

Dieser Beitrag erscheint unter der Creative-Commons-Lizenz CC BY-ND 3.0 DE: https://creativecommons.org/licenses/by-nd/3.0/de/. 


\title{
Der Index der Eliten? Politische und mediale Perspektiven auf die nachhaltige Entwicklung in Deutschland
}

\author{
Moritz Clauß
}

Keywords: Indexing, Nachhaltigkeit, Drei-Säulen-Konzept, Grounded Theory

\section{Abstract}

Schreibt die Presse nur das, was die politischen Eliten sagen? Die IndexingHypothese von W. Lance Bennett legt einen solchen Schluss nahe. Diese Arbeit untersucht am Beispiel der Nachhaltigkeitsdebatte in Deutschland eine abgeschwächte Variante der Hypothese, die davon ausgeht, dass die politischen und medialen Darstellungen größtenteils deckungsgleich sind. Zunächst fasst der Beitrag grundlegende Erkenntnisse zum Verhältnis von Politik und Medien sowie zur Entstehung des Nachhaltigkeitskonzepts und der nachhaltigen Entwicklung in Deutschland zusammen. Unter Zuhilfenahme der Grounded Theory untersucht er danach, wie der Themenkomplex »Nachhaltigkeit« in der 229. Sitzung des 18. Deutschen Bundestages vom 31. März 2017 und in den Online-Auftritten deutscher Qualitätszeitungen dargestellt wird. Der Vergleich zeigt, dass die Medienberichterstattung sich oft stark mit der politischen Darstellung überschneidet, teilweise aber deutlich über sie hinausgeht oder hinter ihr zurückbleibt.

Ich danke Ulrich Roos für den Anstoß zu dieser Forschungsarbeit und den jahrelangen offenen und kritischen Austausch.

Moritz Clauß: Der Index der Eliten? Politische und mediale Perspektiven auf die nachhaltige Entwicklung in Deutschland. In: Nils S. Borchers, Selma Güney, Uwe Krüger und Kerem Schamberger (Hrsg.): Transformation der Medien - Medien der Transformation. Verhandlungen des Netzwerks Kritische Kommunikationswissenschaft. Frankfurt am Main: Westend 2021. DOI: https://doi.org/10.53291/YVMY2211.

Moritz Clauß | Journalist I info@moritzclauss.de 


\section{Einführung}

Glauben Sie, was in der Zeitung steht? Laut einer repräsentativen Umfrage von Infratest Dimap (2020) im Auftrag des WDR würden die meisten Menschen in Deutschland auf diese Frage mit »Ja« antworten. Allerdings denken auch 35 Prozent, dass Staat und Regierung den Medien vorgeben, worüber sie berichten sollen. Doch für den Verdacht, dass der deutsche Staat die Presse aktiv kontrolliert, gibt es keine Belege. Was nicht bedeutet, dass die Berichterstattung frei von äußeren Zwängen ist: W. Lance Bennett $(1990,106)$ etwa geht in seiner Indexing-Hypothese davon aus, dass die klassischen Medien meist die unter den politischen Eliten vorherrschenden Standpunkte wiedergeben ganz ohne direkte Beeinflussung. Ob die Presse tatsächlich vor allem den Eliten-Diskurs »indexiert«, also dessen Meinungsspanne anzeigt, untersuche ich im Folgenden am Beispiel der Nachhaltigkeitsdebatte in Deutschland.

\section{Das Verhältnis von Politik und Medien}

Beginnen wir mit einer Kluft, nämlich der zwischen dem journalistischen Anspruch und der Wirklichkeit. Die meisten Journalist*innen beabsichtigen, »die Realität so abzubilden, wie sie ist « (Weischenberg et al. 2006, 102). Pressegesetze und Berufskodizes schreiben eine objektive und wahrheitsgemäße Berichterstattung vor (Neuberger und Kapern 2013, 147-151). Dabei sind Nachrichten immer narrativ und hängen unausweichlich mit sozialen Werten zusammen (Parisi 1997, 673). Die Wissenschaftlerin Cornelia Mothes (2014, 270-271) kommt in einer Studie zu dem Ergebnis, dass Journalist*innen tendenziell Tatsachen den Faktenstatus absprechen, die ihrer eigenen Meinung zuwiderlaufen. Andere Forscher*innen beobachten, dass die Medienberichterstattung regelmäßig Informationen verkürzt darstellt. Sie verweisen zum Beispiel auf eine einseitige Auswahl von Meinungen und auf die bevorzugte Darstellung von Sensationen und negativen Ereignissen (Pfetsch und Marcinkowski 2009, 12). 


\subsection{Einflüsse der politischen Eliten auf die Medien}

Bereits in den 1980er Jahren stellten Edward Herman und Noam Chomsky (1988) ihr Propagandamodell vor. Sie erläutern am Beispiel der USA, welchen äußeren Einflüssen Journalist*innen und Medien ausgesetzt sind. Dabei geht es nicht um eine kontrollierte Meinungsmanipulation, sondern um dezentrale, häufig unbewusste Vorgänge (Krüger 2019, 56). Die beiden Forscher beobachten fünf Filter in der Berichterstattung der US-Medien, darunter die Profitorientierung der Verleger*innen, Werbung als Haupteinkommensquelle und die Abhängigkeit von Informationen, die Regierungen, Unternehmen und Expert*innen zur Verfügung stellen (Herman und Chomsky 1988, 2). Allerdings kritisieren Lang und Lang (2004, 94-97) unter anderem, dass die Beispiele, mit denen Herman und Chomsky ihre Annahmen überprüfen, fast alle aus der US-Außenpolitik stammen. Die Quellenlage ist in diesen Fällen für Journalist*innen häufig schlecht. Aus Sicht seiner Kritiker*innen bleibt deshalb fragwürdig, ob das Modell verallgemeinert werden kann.

Ähnliche Vorhersagen wie das Propagandamodell macht die Indexing-Hypothese von W. Lance Bennett. Sie geht anhand des Beispiels der USA davon aus, dass Medien in der politischen und gesellschaftlichen Debatte vor allem die in der Regierung und in den Parlamenten vorherrschenden Standpunkte wiedergeben (Bennett 1990, 106). Das Meinungsspektrum, das die Medien kommunizieren, ist aus dieser Perspektive ein »Index für die Meinung der politischen Eliten« (Brüggemann und Weßler 2009, 639). Laut Krüger $(2019,54)$ kann eine solche (unbewusst verfolgte) Indexing-Norm unproblematisch sein, solange die politischen Eliten alle relevanten Informationen und Argumente diskutieren - wobei sich natürlich die Frage stellt, woran dies gemessen werden soll.

Laut Bennett (2009) gibt es drei Gründe für Indexing:

• Journalist*innen entwickeln durch tägliche Routinen ein gemeinsames Verständnis davon, wie Quellen und Sichtweisen zu bewerten sind (Bennett 2009, 89). Sie filtern Perspektiven heraus, die als nicht relevant gelten.

- Politiker*innen und ihre Mitarbeiter*innen verstärken diesen Filter, weil sie Informationen an Journalist*innen weitergeben können, die in ihrem Sinne berichten (Bennett 2009, 90). Es besteht ein »Konformitätsdruck«, der auf eine »Anpassung [der Journalist*innen] an 
den Diskursrahmen der politischen Machthaber zielt« (Krüger 2016, 26).

Es entsteht ein Konsens der Eliten, der die Grenzen des öffentlich Denkbaren festlegt. In diesem abgesteckten Rahmen greifen Journalist*innen die Ansichten von Expert*innen und Politiker*innen auf, verbreiten sie und interviewen wiederum letztere dazu. Rezipiert werden diese Beiträge oft von anderen Meinungsführer*innen. Das heißt: Die bestehenden Machtwahrnehmungen und deren Darstellung zementieren sich gegenseitig (Bennett 2009, 90).

Bennett versteht Indexing nicht als allgemeingültiges Gesetz, sondern als Norm, die Tendenzen im Verhalten von Journalist*innen beschreibt (Bennett 1990, 106). Bennett und Livingston $(2003,360)$ distanzieren sich deshalb teilweise von der ursprünglichen Hypothese. Sie bezeichnen Journalist*innen als »semi-independent players« (ebd.), die je nach Fall abhängig oder unabhängig von der Politik handeln. Michael Brüggemann und Hartmut Weßler (2009, 640-642) wiederum halten die von Bennett beobachteten Abhängigkeiten in der Kriegsberichterstattung für gut begründbar, lehnen es jedoch ab, die Medien pauschal als »passive Instrumente« (ebd.) abzustempeln. Bei der Indexing-Hypothese bestehen also ebenfalls Zweifel, ob sie in der Innenpolitik und in friedlichen Szenarien gültig ist.

Im Falle Deutschlands gibt es einige Studien, die analysieren, ob die Medien bei ihrer Berichterstattung von den politischen Eliten abhängig sind. Jürgen Gerhards et al. (1998, 90-95) etwa untersuchen die Berichterstattung der Süddeutschen Zeitung (SZ) und der Frankfurter Allgemeinen Zeitung (FAZ) zum Thema Abtreibung. Sie stellen fest, dass sich die mediale Darstellung stark an der politischen Agenda orientiert. Silke Adam (2008) zeigt mit ihrer Analyse deutscher und französischer Medien von 2000 bis 2002, dass es in Deutschland im Hinblick auf die EU-Erweiterung nationalen politischen Sprecher*innen gelungen ist, »eine innenpolitische Debatte zu vermeiden« (Adam 2008, 137). Sie fügt aber hinzu, dass die mediale Darstellung teilweise über die Darstellung der politischen Eliten hinausgeht (ebd., 137-143).

Torsten Maurer et al. (2008) kommen in ihrer Medienanalyse zu den Kriegen im Kosovo, in Afghanistan und im Irak zu dem Ergebnis, dass Indexing in der deutschen Kriegsberichterstattung eine Leitlinie darstellt. Die Forscher merken aber an, dass ihre Befunde auch davon unabhängig erklärt werden können: Denn die Berichterstattung zu den Kriegen spiegelt nicht nur die Mehrheitsmeinung in den politischen 
Eliten, sondern auch die Mehrheitsmeinung in der deutschen Bevölkerung wider (ebd., 161-165).

Auch Uwe Krüger (2019, 253-258) gelangt in seiner Inhaltsanalyse der Medienberichterstattung über die Münchner Sicherheitskonferenz zu differenzierten Ergebnissen. Demnach orientieren sich die Zeitungen SZ, Welt und FAZ von 2007 bis 2010 deutlich an den politischen und wirtschaftlichen Eliten, bei der tageszeitung (taz) und der Frankfurter Rundschau (FR) ist das hingegen nicht der Fall. In Krügers Analyse der Beiträge von vier einflussreichen Journalisten, die zum Untersuchungszeitpunkt über potenzielle Kontakte in die außen- und sicherheitspolitischen Strukturen der Bundesregierung, der USA oder der NATO eingebunden waren, zeigt sich zudem eine Korrelation zwischen der Berichterstattung dieser Autoren und den Argumentationen US- und NATO-naher Netzwerke. Allerdings stellt auch Krüger fest, dass sich aus der inhaltlichen Nähe politischer und journalistischer Darstellungen kein Kausalzusammenhang ableiten lässt. Möglich wäre etwa, dass die geistige Nähe zwischen Journalist*innen und politischen und wirtschaftlichen Eliten keine Folge, sondern eine Ursache der Berührungspunkte zwischen diesen Gruppen ist.

\subsection{Einflüsse der Medien auf die politischen Eliten}

Wenn wir aber nicht von einfachen Kausalketten ausgehen können, dann bestimmt das Verhältnis zwischen Politiker*innen und Journalist*innen womöglich keine einseitige Abhängigkeit. Wissenschaftler*innen gehen davon aus, dass es sich bei letzteren trotz der aufgezeigten Kritik um Akteur*innen handelt, die aktiv Informationen für die Berichterstattung auswählen, Ereignisse kommentieren und interpretieren (Brüggemann und Weßler 2009, 635; Kabalak et al. 2008, 56; Krüger 2016, 27; Voltmer 2008, 93-94).

Bereits vor einem halben Jahrhundert wurde zudem vermutet, dass die Orientierung der Medien an bestimmten Interessen der Leser*innen langfristig Konsequenzen für Politiker*innen und Parteien haben kann (Gerber 1968, 100). So lässt sich aus dem Akteur-Status der Medien ableiten, dass das Mediensystem den Politiker*innen »seine eigenen Regeln der Aufmerksamkeitserzeugung aufzwingt« (Steiner und Jarren 2009, 251). Wenn diese in der Öffentlichkeit gehört werden wollen, müssen sie die Medien mit Inhalten versorgen, die interessant genug sind, um sie zu veröffentlichen. Politiker*innen handeln 
deshalb unter besonderer Berücksichtigung der Medien. Sie achten etwa darauf, ihre Themen und Vorschläge mediengerecht aufzubereiten und haben dafür eigene PR-Abteilungen. Dazu kommt noch, dass die »Nicht-Informiertheit« bei Politiker*innen eine exkludierende Wirkung entfaltet. Schließlich nutzen sie die mediale Darstellung als »Rückkopplungsinstrument« (Kabalak et al. 2008, 55-59), um herauszufinden, wie bestimmte Themen und Vorschläge bei den Wähler*innen ankommen.

\section{$3 \quad$ Nachhaltigkeit und die nachhaltige Entwicklung}

Eines der vielen Themengebiete, über das Medien in Deutschland seit Jahren ausführlich berichten, ist Nachhaltigkeit. Egal ob Plastiktüten, Elektroautos oder Corona-Pandemie: Aktuell scheint es kaum noch ein Thema zu geben, das nicht mit der nachhaltigen Entwicklung zusammenhängt. Nur: Was ist das überhaupt, Nachhaltigkeit?

\subsection{Historischer Hintergrund des Nachhaltigkeitsbegriffs}

Viele Forscher*innen sehen den Ursprung des Nachhaltigkeitsbegriffs in der Forstwirtschaft (Soentgen 2016, 117; Giulio 2004, 17; Zürcher 1965, 99). Seine vermutlich erste Verwendung geht auf Hans Carl von Carlowitz zurück (Zürcher 1965, 99), der im Jahr 1713 eine »continuierliche, beständige und nachhaltende [Wald-]Nutzung [sic] « fordert (Carlowitz 1713, 105; zitiert nach Zürcher 1965, 99). Damit meint er, dass dort mindestens so viel Holz nachwachsen soll, wie entfernt wird (Carlowitz 2000, 106-111; zitiert nach Soentgen 2016, 118). Deutsche Historiker*innen und Forstwissenschaftler*innen sind der Auffassung, dass von Carlowitz das Nachhaltigkeitskonzept erfunden hat (Soentgen 2016, 118).

Die Idee, die hinter der nachhaltenden Nutzung steckt, lässt sich allerdings auf das bereits 3000 vor Christus bei den Römer*innen geltende Nießbrauchkonzept zurückführen: usus fructus. Bürger*innen Roms durften bestimmte Dinge - etwa Wälder oder Äcker - nutzen, obwohl sie ihnen nicht gehörten, solange die Substanz der Dinge erhalten blieb (ebd., 118-120). Das Problem dabei: Worin die Substanz, also das Wesentliche einer Sache, besteht, ist Ansichtssache (Rickert 1929, 38). So kann eine Forstwirtin eine ganz andere Vorstellung von 
der Substanz eines Waldes haben als ein Waldökologe (Soentgen 2016, 121-123). Bei vielen Nachhaltigkeitsdefinitionen treffen deshalb unterschiedliche Perspektiven aufeinander - auch bei der wohl wichtigsten, nämlich derjenigen der Vereinten Nationen (UN).

\subsection{Der Nachhaltigkeitsbegriff der Vereinten Nationen}

Die UN sehen einen Zusammenhang zwischen globalen Umweltproblemen und globaler Ungerechtigkeit (Brand und Jochum 2000, 174). Ihre Antwort auf diese Krisen ist das Konzept der nachhaltigen Entwicklung, dem sie sich erstmals im Brundtland-Bericht (1987) und in der Agenda 21 (1992) widmeten. Im Brundtland-Bericht heißt es dazu:

Sustainable development is development that meets the needs of the present without compromising the ability of future generations to meet their own needs. It contains within it two key concepts: the concept of »needs«, in particular the essential needs of the world's poor, to which overriding priority should be given; and the idea of limitations imposed by the state of technology and social organization on the environment's ability to meet present and future needs. (WCED 1987, 41)

Die schützenswerte Substanz bleibt hier weitestgehend unbestimmt. Auffällig ist außerdem, dass der Umwelt kein Eigenwert zugeschrieben wird. Im Vordergrund steht die Funktion der Natur, die menschlichen Bedürfnisse zu befriedigen.

In den Dokumenten der UN-Konferenz 1992 in Rio de Janeiro werden die Begriffe »Nachhaltigkeit« und »nachhaltige Entwicklung « zwar nicht definiert, die UN beziehen sich dort aber auf den Brundtland-Bericht (Giulio 2004, 145). Hiervon ausgehend fasst Antonietta Di Giulio (ebd.) Kernaspekte des UN-Nachhaltigkeitsbegriffs zusammen: Die nachhaltige Entwicklung der Menschheit findet aus UN-Sicht regional, national und global statt. Ihr Ziel ist die Bedürfnisbefriedigung aller Menschen auch zukünftiger Generationen - weltweit. Jedem und jeder soll ein »gutes Leben« ermöglicht werden. Zu diesem Zweck müssen alle Menschen und Staaten partnerschaftlich zusammenarbeiten und die Interessen der anderen respektieren. Am Schluss soll ein weltweiter Konsens entstehen. Nachhaltigkeit wiederum meint im UN-Verständnis den Zustand, der mit der nachhaltigen Entwicklung angestrebt wird. Es handelt sich also um eine in der Zukunft liegende »bessere Welt«, in der keine Widersprüche zwischen dem Sozialen, der Wirtschaft und der Umwelt bestehen (ebd.). 
Ein relevantes aktuelleres Dokument für das UN-Nachhaltigkeitsverständnis ist die »Agenda 2030 für nachhaltige Entwicklung«. Dort benennen die Vereinten Nationen 17 Sustainable Development Goals (SDGs), etwa das weltweite Ende von Armut und Hunger, nachhaltiges Wirtschaftswachstum sowie den Schutz und die nachhaltige Nutzung von Ökosystemen (UN-Generalversammlung 2015, 14). Ein Blick auf die SDGs zeigt: Nachhaltigkeit ist schwer zu erreichen. Die große Zahl der Ziele lässt außerdem offen, welche Bereiche Priorität haben (Samanta 2016). Diese Unklarheiten sind keine Ausnahme, sondern in der Nachhaltigkeitsdebatte die Regel. Denn unterschiedliche Akteur*innen verwenden den Begriff nicht nur oft, sondern oft auch unterschiedlich (Brand und Jochum 2000, 175; Giulio 2004, 11; Brand und Görg 2002, 16). Di Giulio (ebd.) beobachtet eine womöglich inflationäre Verwendung: Sie sieht die Gefahr, dass Nachhaltigkeit zu einem »leeren Modewort zu werden droht«. Immerhin: In der Debatte besteht in zwei Punkten weitestgehend Einigkeit. Erstens gilt die intra- und intergenerationale Gerechtigkeit als ein Kernelement von Nachhaltigkeit. Zweitens wird allgemein anerkannt, dass diese Gerechtigkeit gerade verletzt wird (Bilharz 2008, 328). Keine Einigkeit gibt es hingegen im Hinblick auf die Frage, wer genau die Probleme lösen soll und auf welchem Weg (Bilharz 2005, 5).

\subsection{Die nachhaltige Entwicklung in Deutschland}

In Deutschland verbreitete sich die Rede von der nachhaltigen Entwicklung mit der Agenda 21. Nachhaltigkeit galt lange verstärkt als Mittel zum Zweck, von dem sich Politiker*innen eine verbesserte Wettbewerbsfähigkeit der Wirtschaft erhofften - Stichwort: »nachhaltige[s] Wachstum« (Seefried 2015, 392-395). 2001 berief die rot-grüne Bundesregierung den Rat für Nachhaltige Entwicklung (RNE) ein, der bei der Weiterentwicklung der deutschen Nachhaltigkeitsstrategie helfen und die Regierung beraten soll (RNE 2018). Der Rat definiert die nachhaltige Entwicklung auf seiner Website; Kern sind dort ebenfalls die Generationengerechtigkeit und die gleichberechtigte Trias aus Umwelt, Sozialem und Wirtschaft (RNE 2020). Auf dieses Drei-Säulen-Konzept hatte sich 1993 auch eine Enquête-Kommission des Deutschen Bundestages geeinigt (Brand und Jochum 2000, 75) - die Nähe zur UN-Definition ist offensichtlich.

Unter Bundeskanzlerin Angela Merkel hat das Nachhaltigkeitskonzept in der Bundespolitik deutlich an Gewicht gewonnen (Welfens 
2011, 21-22). Die Bundesregierung hat eine 256 Seiten starke Nachhaltigkeitsstrategie ausgearbeitet, in der sie Nachhaltigkeit als lokales, nationales und globales »Leitprinzip« bezeichnet (Bundesregierung 2017, 17) und sich der Nachhaltigkeitsdefinition des Brundtland-Berichts anschließt (ebd., 24). Im Rahmen einer nachhaltigen Entwicklung fördert sie seit längerem die Elektromobilität (Bundesregierung 2020) und den Ausbau erneuerbarer Energien (Mautz et al. 2008, 42). Im Hinblick auf die Energiewende ist häufig sogar von einer Vorreiterrolle Deutschlands die Rede (Mautz et al. 2008, 12; Welfens 2011, 23).

Das wissenschaftliche Fundament der deutschen Nachhaltigkeitspolitik ist die Theorie der Ökologischen Modernisierung: Neue Technologien sollen den Schutz der Umwelt sicherstellen und zu wirtschaftlichem Erfolg beitragen (Seefried 2015, 395). Da der Anteil deutscher Umwelt- und Klimaschutztechnologien auf dem Weltmarkt hoch ist, gilt die Energiewende als Chance für Deutschland und die deutsche Wirtschaft (Schafhausen 2013, 15). Allerdings betonen manche Ökonom*innen, dass die Anhänger*innen des grünen Wachstums mit unrealistischen Umwelttechnologie-Sprüngen rechnen (Paqué 2012, 1718). Andere halten fest, dass weniger umweltschädliche Technologien nicht automatisch zum Umweltschutz beitragen. Das Problem ist der Rebound-Effekt: Effizienzsteigerungen beim Energie- oder Ressourcenverbrauch werden häufig durch eine steigende Nachfrage aufgefressen (Santarius 2012, 5-6).

\section{Methodik und Forschungsfrage}

In der folgenden Analyse zeige ich, welche Gemeinsamkeiten und Differenzen sich in den Darstellungen des Themenkomplexes Nachhaltigkeit durch die politischen Eliten und durch die Online-Angebote von Qualitätszeitungen beobachten lassen. Im Gegensatz zur ursprünglichen Indexing-Hypothese beschäftige ich mich nicht mit kausalen Mechanismen, weil die hier vorgestellten Studien belegen, dass eine einseitige Auslegung des Verhältnisses von Politik und Medien in Deutschland nicht haltbar ist. Meine schwächere Variante der Hypothese lautet, dass die politischen und medialen Darstellungen größtenteils deckungsgleich sind. Diese Aussage bleibt relevant, weil ich wie Dahrendorf $(1968,17)$ und Krüger $(2019,53)$ davon ausgehe, dass die Medienberichterstattung in einer Demokratie grundsätzlich über die Debatte im politischen Zentrum hinausgehen sollte. Aufgabe des Jour- 
nalismus ist es auch, Optionen aufzuzeigen, die von den politischen Entscheider*innen ignoriert oder übersehen werden (ebd.). Da die Nachhaltigkeitsdebatte alle Menschen betrifft, ist eine breite, ausgewogene und offene Berichterstattung in diesem Fall besonders wichtig.

Als Methodologie greife ich auf eine Variante der Grounded Theory zurück, die auf Vorarbeiten von Jörg Strübing (2008) sowie von Ulrich Franke und Ulrich Roos (2010) basiert. Die Grounded Theory verfolgt einen rekonstruktiven Ansatz und setzt eine möglichst große Offenheit der Forscher*innen gegenüber dem Untersuchungsgegenstand voraus (Franke und Roos 2010, 285). Qualitative Analyseschritte finden abwechselnd statt und beeinflussen sich gegenseitig. Forscher*innen kodieren das Datenmaterial, entwickeln Vermutungen, interpretieren und suchen nach relevanten Zusammenhängen. Spontane Beobachtungen und Thesen sollen in Form von Memos erhalten bleiben. Im Lauf der Analyse zeigt sich dann, ob eine These zu halten ist oder verworfen werden muss (Strübing 2008, 14).

Zu den politischen Eliten zählen in der Regel »alle unmittelbar an der Staatsleitung beteiligten Personen und Gruppen, unabhängig davon, ob sie sich bei einzelnen Entscheidungen durchsetzen oder nicht « (Herzog und Weßels 2005, 732). Ich fasse den Begriff etwas weiter und beziehe ihn auf alle Politiker*innen, die im Analysezeitraum ein Mandat im Deutschen Bundestag innehatten. Das schließt die Opposition mit ein. Im Falle der politischen Eliten untersuche ich die Nachhaltigkeitsdebatte in der 229. Sitzung des 18. Deutschen Bundestages, die am 31. März 2017 stattfand (Deutscher Bundestag 2017). Darin beziehen alle zum damaligen Zeitpunkt im Parlament vertretenen Parteien Stellung zur deutschen Nachhaltigkeitsstrategie. Ich gehe davon aus, dass die jeweiligen Sprecher*innen im Rahmen der Debatte sämtliche Punkte ansprechen, die aus Sicht ihrer politischen Zugehörigkeit wichtig sind.

$\mathrm{Zu}$ den wichtigsten deutschen Qualitätszeitungen werden meist die Frankfurter Allgemeine Zeitung (FAZ), Die Welt, die Süddeutsche Zeitung (SZ), die Frankfurter Rundschau (FR) und die tageszeitung (taz) gezählt (Lüter 2008, 117; Jandura und Kösters 2017, 30-31; Krüger 2019, 232). Ich schließe mich dieser Auswahl an. ${ }^{1}$ Die Zeitungen lassen sich in

1 Offenlegung: Im Jahr 2016 habe ich zwei Monate in der Onlineredaktion der taz gearbeitet. Ich sehe hierin keinen Interessenkonflikt, weil die Arbeitsbeziehung zum Analysezeitpunkt mehr als ein Jahr zurücklag und ich in der Analyse keine Texte von mir persönlich bekannten Autor*innen untersucht habe. Die Auswahlkriterien für die taz-Texte unterschieden sich nicht von denen für die anderen Zeitungen. 
einem Links-Rechts-Schema anordnen: Artikel in der taz und der FR vertreten vergleichsweise häufig linke, Artikel in der $F A Z$ und der Welt oft konservative bis rechte Positionen. Die $S Z$ tendiert eher zu linken Positionen, positioniert sich aber insgesamt ausgewogener als der Rest des Feldes (Lüter 2008). In der Analyse werden Texte der Online-Angebote dieser Zeitungen zum Thema Nachhaltigkeit analysiert, die maximal sechs Monate vor oder nach der Bundestagsdebatte erschienen sind. Hinzu kommen zwei weitere Auswahlkriterien: der Inhalt und seine Gewichtung. Über die Suchfunktionen der Zeitungswebsites habe ich nach Artikeln zum Stichwort »Nachhaltigkeitsstrategie« gesucht; bei einer geringen Zahl von Treffern folgten außerdem Suchen nach »Nachhaltigkeit« und »nachhaltig«. Ins Datenmaterial aufgenommen wurden die Beiträge, die sich am ausführlichsten dem Thema Nachhaltigkeit widmeten. Insgesamt habe ich 20 Zeitungsartikel (Tab. 1) analysiert, also vier Artikel pro Zeitung. Diese Zahl sollte groß genug sein, um einen aussagekräftigen Überblick über die mediale Darstellung zu erhalten.

Jeweils vier Artikel sind meiner Ansicht nach aber zu wenig, um die Berichterstattung der einzelnen Zeitungen wertend zu vergleichen. Die Kategorisierung greift auf die verschiedenen Positionen zurück, die in den Artikeln wiedergegeben werden. Da mitunter in einem Zeitungsbeitrag mehrere gegenläufige Aussagen enthalten sind, kann ein Artikel auch verschiedene, sich widersprechende Analysekategorien stützen. Bei der Einordnung wird außerdem nicht zwischen Textgattungen wie Bericht, Meldung oder Kommentar unterschieden. Wichtig ist für die vorliegende Analyse nicht, ob der oder die Journalist*in eine bestimmte Meinung oder Position vertritt, sondern welche Meinungen und Positionen in den Artikeln dargestellt werden. Wenn ich im Folgenden von »medialen Darstellungen « schreibe, folgt daraus also nicht automatisch, dass alle untersuchten Artikel oder Zeitungen die entsprechende Darstellung stützen.

Tab. 1: Liste der analysierten Medienartikel.

\begin{tabular}{|l|l|l|l|}
\hline Titel & Autor*in & Medium & Datum \\
\hline $\begin{array}{l}\text { Nachhaltige Investments werden für Anleger } \\
\text { immer wichtiger }\end{array}$ & $\begin{array}{l}\text { Christoph } \\
\text { Scherbaum }\end{array}$ & FAZ.net & 01.06 .2017 \\
\hline IHK entdeckt die Nachhaltigkeit & FAZ.net & FAZ.net & 15.02 .2017 \\
\hline
\end{tabular}




\begin{tabular}{|c|c|c|c|}
\hline Titel & Autor*in & Medium & Datum \\
\hline Alles nachhaltig oder was? & Thomas Klemm & FAZ.net & 11.08 .2017 \\
\hline Ist Nachhaltigkeit nur ein Schlagwort? & Elena Witzeck & FAZ.net & 17.09.2017 \\
\hline $\begin{array}{l}\text { Mehr leben. Nachhaltiges Konsumieren, geht } \\
\text { das überhaupt? }\end{array}$ & Christine Ax & FR.de & 12.05 .2017 \\
\hline $\begin{array}{l}\text { Nachhaltigkeit ist auch beim Autobau ein } \\
\text { wichtiges Thema }\end{array}$ & Fabian Hoberg & FR.de & 30.12 .2016 \\
\hline Zwischen heiter und wolkig & Daniela Vates & FR.de & 11.01.2017 \\
\hline Wem gehört der letzte Tropfen? & Joachim Wille & FR.de & 13.06.2017 \\
\hline Prekäre Erkenntnis & $\begin{array}{l}\text { Michael } \\
\text { Bauchmüller }\end{array}$ & SZ.de & 24.01.2017 \\
\hline Verzichten können andere & $\begin{array}{l}\text { Michael } \\
\text { Bauchmüller und } \\
\text { Kristiana Ludwig }\end{array}$ & SZ.de & 16.03 .2017 \\
\hline Die Leiden des aufgeklärten Konsumenten & $\begin{array}{l}\text { Michael } \\
\text { Kläsgen }\end{array}$ & SZ.de & 01.01 .2017 \\
\hline Mehr als grünes Geschwätz & Jan Willmroth & SZ.de & 25.06 .2017 \\
\hline Party ohne Ende & Edith Kresta & taz.de & 19.03.2017 \\
\hline Erfolg durch schwache Kriterien & $\begin{array}{l}\text { Malte } \\
\text { Kreutzfeldt }\end{array}$ & taz.de & 11.01.2017 \\
\hline Mehlwurm statt Mehrwert & Bernhard Pötter & taz.de & 30.05 .2017 \\
\hline Interdisziplinärer Thinktank & $\begin{array}{l}\text { Manfred } \\
\text { Ronzheimer }\end{array}$ & taz.de & 12.05 .2017 \\
\hline »Nachhaltig « ist unser »halal» & Matthias Heine & Welt.de & 05.06.2017 \\
\hline Was bringen Ökolabels im Tourismus? & Steven Hille & Welt.de & 09.06.2017 \\
\hline $\begin{array}{l}\text { „Das Immer-mehr führt auf Dauer zum } \\
\text { Kollaps « }\end{array}$ & Frank Lorentz & Welt.de & 07.06.2017 \\
\hline $\begin{array}{l}\text { So geht Deutschland Klima-China auf den } \\
\text { Leim }\end{array}$ & Daniel Wetzel & Welt.de & 02.06.2017 \\
\hline
\end{tabular}




\section{Ergebnisse der Analyse}

In der Analyse habe ich sechs Kategorien gebildet, die sich jeweils aus mehreren Subkategorien zusammensetzen. In den folgenden Abschnitten gehe ich einzeln auf diese ein.

\subsection{Dominanz des Nachhaltigkeitsverständnisses der UN}

Die Analyse zeigt, dass die politischen Eliten Nachhaltigkeit fast ausschließlich im Sinne des UN-Verständnisses darstellen. Die drei Nachhaltigkeitssäulen Wirtschaft, Soziales und Umwelt werden von allen politischen Akteur*innen als Bestandteile einer nachhaltigen Entwicklung angesehen. Die Parteien heben teilweise zwar unterschiedliche Aspekte hervor - etwa betonen Linke, Grüne und SPD im Gegensatz zur Union, dass der Faktor Gerechtigkeit besonders wichtig ist -, verlassen dabei aber nicht den durch die UN gesteckten Rahmen: Kein*e Politiker*in geht eindeutig über die 17 SDGs hinaus oder wendet sich gegen sie. Die analysierten Medien verbreiten größtenteils ebenfalls das Nachhaltigkeitsverständnis der UN - häufig jedoch, ohne es direkt zu benennen.

In der Bundestagsdebatte betonen mehrere Redner*innen, dass es eine besonders positive und konstruktive politische Zusammenarbeit in der nachhaltigen Entwicklung gibt. Sowohl die Bundesregierung als auch die im Parlament vertretenen Parteien stufen die nachhaltige Entwicklung außerdem im Sinne des UN-Begriffs als alternativlos ein:

Die Verankerung des Prinzips der nachhaltigen Entwicklung als Leitprinzip in allen Politikbereichen ist gerade in weltpolitisch schwierigen Zeiten kein Luxus, sondern pure Notwendigkeit. (Altmaier; zitiert nach Deutscher Bundestag 2017, 4)

Dieser Alternativlosigkeit-Frame wird auch in vielen Medienberichten dargestellt. Im Gegensatz zu den Politiker*innen geben die Medien aber auch der entgegengesetzten Annahme Raum: Sie stellen Nachhaltigkeit teilweise als eine (politische) Option unter anderen, stellenweise sogar als schädlich dar und verweisen auf eine mangelhafte wissenschaftliche Überprüfbarkeit der vorgebrachten Thesen. So schreibt die Welt zur Nachhaltigkeitsdefinition des Brundtland-Berichts: »In ihr deutet sich schon die quasireligiöse Verschwurbelung des Begriffs Nachhaltigkeit an [...]« (Heine 2017). Den Frame der besonders positiven politischen Kooperation greifen die Medien außerdem nicht auf. 
Tab. 2: Zusammenfassung der Analysekategorie »Dominanz des Nachhaltigkeitsverständnisses der UN «.

\begin{tabular}{|l|l|l|}
$\begin{array}{l}\text { Gemeinsame } \\
\text { Darstellungen }\end{array}$ & $\begin{array}{l}\text { Breiter Nachhaltigkeitsbegriff auf Grundlage des UN-Nachhaltigkeitsver- } \\
\text { ständnisses; ungeklärtes normatives Verhältnis der drei Nachhaltigkeits- } \\
\text { säulen; Darstellung der nachhaltigen Entwicklung als alternativlos. }\end{array}$ \\
\hline $\begin{array}{l}\text { Exklusive } \\
\text { Darstellungen }\end{array}$ & $\begin{array}{l}\text { Medien: Darstellung der nachhal- } \\
\text { tigen Entwicklung als nicht alter- } \\
\text { nativlos; Thematisierung weiterer } \\
\text { Nachhaltigkeitsvorstellungen. }\end{array}$ & $\begin{array}{l}\text { Politik: Betonung einer besonders } \\
\text { guten politischen Zusammenarbeit; } \\
\text { Betrachtung der nachhaltigen } \\
\text { Entwicklung als Phänomen, das } \\
\text { national und global vorangetrieben } \\
\text { werden muss. }\end{array}$ \\
\hline Einordnung & Kein Indexing. & \\
\hline
\end{tabular}

Mehrere Politiker*innen betonen, dass die nachhaltige Entwicklung national und global vorangetrieben werden muss. Es entsteht der Eindruck, dass sie versuchen, sich, ihre Partei oder ihr Land besonders positiv erscheinen zu lassen, indem sie große Handlungsbereitschaft und Verantwortungsbewusstsein kommunizieren. Die Medien gehen nicht auf diesen möglichen Versuch der Selbstprofilierung ein - sie unterstützen ihn nicht, üben aber auch keine Kritik daran.

Die Auswertung der Bundestagsdebatte zeigt zudem, dass das normative Verhältnis der drei Nachhaltigkeitssäulen bisher ungeklärt ist. Die drei Bereiche der nachhaltigen Entwicklung werden zwar von allen politischen Akteur*innen grundsätzlich anerkannt, es wird aber noch darüber gestritten, wie genau diese auszubalancieren sind - die Bundesregierung und die Vertreter*innen der Union sprechen von »Zielkonflikte[n] « (Deutscher Bundestag 2017, 5, 6, 7, 10). Die Union warnt vor einer Dominanz der ökologischen Säule und vertritt das Primat des Wachstums. Linke und Grüne rücken den Klimaschutz als Ausgangspunkt einer effektiven Armutsbekämpfung in den Vordergrund. Diese Zielkonflikte spielen auch in der Medienberichterstattung eine Rolle. Die analysierten Zeitungen stellen die Konflikte - etwa zwischen Ökonomie und Ökologie - allerdings umfassender dar als die Politiker*innen.

Die Medien thematisieren zudem weitere Nachhaltigkeitsvorstellungen, mit denen sie über die politische Darstellung hinausgehen. So wird der UN-Nachhaltigkeitsbegriff zwar so gut wie gar nicht direkt kritisiert, wohl aber werden alternative Konzepte aufgezeigt; etwa be- 
sonders weiche Definitionen, denen zufolge es bereits nachhaltig ist, keine geächteten Firmen zu unterstützen. Mehrfach hinterfragen die Zeitungsartikel außerdem direkt oder indirekt, ob einheitliche, allgemein anerkannte Nachhaltigkeitskataloge möglich sind:

Das Siegel des Tourism Sustainability Council (TSC) sollte Nachhaltigkeitskriterien für alle touristischen Angebote der Welt enthalten und nachhaltiges Reisen vereinfachen. Das Vorhaben scheiterte. Denn ein Campingplatz in Österreich zum Beispiel hat ganz andere Grundvoraussetzungen als eine Eco-Lodge im Dschungel von Borneo. (Hille 2017)

Reines Indexing lässt sich in dieser Analysekategorie somit nicht beobachten. Auffällig ist allerdings, dass das Nachhaltigkeitsverständnis der UN in der Berichterstattung weit verbreitet ist, aber kaum direkt reflektiert oder kritisiert wird.

\subsection{Nachhaltigkeit als Mittel zur Interessenverfolgung}

Die Bundesregierung und die Union zeigen in der Debatte, dass sie die nachhaltige Entwicklung für ein umweltverträgliches Wirtschaftswachstum nutzen möchten. Der Umweltschutz wird dabei teilweise dem wirtschaftlichen Erfolg untergeordnet. Auch die Medienberichterstattung stellt eine enge Verknüpfung zwischen diesen beiden Zielen dar. Während die politischen Eliten eher die gesamte Volkswirtschaft oder den Staat im Blick haben, konzentrieren sich die analysierten Artikel auf den wirtschaftlichen Nutzen für Unternehmen und Investor*innen. Die SZ zitiert etwa Wolfgang Fink, den Deutschland-Chef von Goldman Sachs, mit den Worten:

Der ganze Komplex ESG [Environmental, Social and Corporate Governance; $\mathrm{MC}$ ] wird als Instrument des Risikomanagements unterschätzt. [...] Wir können inzwischen herauslesen, welche Faktoren am stärksten mit dem langfristigen Erfolg einer Firma korrelieren. (zitiert nach Willmroth 2017)

Während die Politiker*innen an diesem Punkt der Verknüpfung von nachhaltiger Entwicklung und wirtschaftlichem Erfolg stehen bleiben, gehen die Medien deutlich darüber hinaus. Sie zeigen ausführlich, dass Unternehmen das Stichwort »Nachhaltigkeit« häufig zur Imagepflege nutzen oder gar missbrauchen. Zentral ist der Vorwurf des Greenwashings. 
Tab. 3: Zusammenfassung der Analysekategorie »Nachhaltigkeit als Mittel zur Interessenverfolgung".

\begin{tabular}{|c|c|c|}
\hline Gemeinsame & \multicolumn{2}{|c|}{ Nachhaltigkeit soll zum wirtschaftlichen Erfolg beitragen. } \\
\hline $\begin{array}{l}\text { Exklusive } \\
\text { Darstellungen }\end{array}$ & $\begin{array}{l}\text { Medien: Nachhaltigkeit als Label } \\
\text { zur Imageförderung; übertrieben } \\
\text { positive Selbstdarstellung von Un- } \\
\text { ternehmen und ihren Leistungen. }\end{array}$ & $\begin{array}{l}\text { Politik: Umstrittener Vorreiterstatus } \\
\text { Deutschlands. }\end{array}$ \\
\hline Einordnung & Kein Indexing. & \\
\hline
\end{tabular}

Der im Forschungsstand angesprochene Vorreiterstatus Deutschlands in der nachhaltigen Entwicklung ist in der Parlamentsdebatte umstritten: Die Bundesregierung und beide Regierungsparteien framen Deutschland als international führende Kraft und stellen das deutsche Handeln als besonders positiv, verantwortungsvoll und hilfreich dar, während die Opposition wiederum aufzeigt, dass Politik und Wirtschaft hierzulande teilweise alles andere als nachhaltig handeln. Die analysierten Medien greifen die Debatte um den Vorreiterstatus nicht direkt auf, widersprechen jedoch stellenweise indirekt dem VorreiterFrame, indem sie Kritikpunkte an der Bundespolitik benennen. Auch diese Kategorie widerspricht der Indexing-Hypothese.

\subsection{Gemeinsame Verantwortung für die nachhaltige Entwicklung}

In der politischen Debatte gilt die Annahme, dass eine nachhaltige Entwicklung in der gemeinsamen Verantwortung von Politik, Wirtschaft, Wissenschaft und Gesellschaft liegt. Die Medienberichterstattung kommuniziert dieselbe gesamtgesellschaftliche Verantwortung. In der Bundestagsdebatte legen die Politiker*innen häufig, aber meist nicht konkret dar, welche Aufgaben die (Bundes-)Politik in der nachhaltigen Entwicklung erfüllen sollte; etwa die Mitfinanzierung dieser Entwicklung und ihre Förderung in mehreren Bereichen (beispielsweise Umwelt-, Wirtschafts- und Außenpolitik).

Mehrfach betonen Redner*innen, dass Bürger*innen im Zuge der nachhaltigen Entwicklung gebildet und informiert werden müssen. Die Oppositionsparteien fordern die Regierung zudem dazu auf, mehr 
Druck auf Behörden, aber auch auf Unternehmen und Konzerne im Dienst der nachhaltigen Entwicklung auszuüben. In der Medienberichterstattung werden ebenfalls die Faktoren Bildung, Information sowie gesetzlicher Druck benannt; sie sollen die nachhaltige Entwicklung vorantreiben. Auch die Förderung durch Investitionen ist Thema dieses Diskurses. Ähnlich wie Oppositionsvertreter*innen schreiben mehrere Journalist*innen dem Staat ein bisher geringes Interesse an nachhaltigem Handeln zu. So schreibt die $S Z$ über eine Reform des Vergaberechts, das Vorgaben für öffentliche Aufträge macht:

[E]ine Gesamtstrategie für nachhaltigen Staatskonsum entstand dabei nicht. Den Behörden wurde lediglich erlaubt, ihre Aufträge auch an soziale oder umweltbezogene Standards zu koppeln. Ein freiwilliger Schritt, auf den jede Kommune, die unter Spardruck steht, auch verzichten kann. (Bauchmüller und Ludwig 2017)

Tab. 4: Zusammenfassung der Analysekategorie »Gemeinsame Verantwortung für die nachhaltige Entwicklung«.

\begin{tabular}{|l|l|l|}
$\begin{array}{l}\text { Gemeinsame } \\
\text { Darstellungen }\end{array}$ & $\begin{array}{l}\text { Politik, Wirtschaft, Wissenschaft und Gesellschaft sollen die nachhaltige } \\
\text { Entwicklung gemeinsam vorantreiben; Politik als verbindendes Glied in der } \\
\text { nachhaltigen Entwicklung. }\end{array}$ \\
\hline $\begin{array}{l}\text { Exklusive } \\
\text { Darstellungen }\end{array}$ & Medien: Keine. & Politik: Keine. \\
\hline Einordnung & Indexing.
\end{tabular}

Insgesamt bleibt die Beschreibung konkreter Aufgabenfelder der Politik in beiden Fällen diffus. Klare Forderungen finden sich sowohl in der politischen Debatte als auch in den analysierten Zeitungen kaum. Sowohl die politische als auch die mediale Darstellung rahmen die Politik als verbindendes Glied, das nachhaltiges Handeln aller Akteur*innen fördern oder ermöglichen kann. In diesem Fall verlaufen beide, gemäß der Indexing-Hypothese, größtenteils deckungsgleich.

\subsection{Positive Bewertung der nachhaltigen Entwicklung}

In der politischen Debatte stellen die Bundesregierung und die Regierungsparteien den Verlauf der nachhaltigen Entwicklung in Deutsch- 
land äußerst positiv dar, etwa wenn SPD-Redner Carsten Träger sagt, die Regierung habe »wirklich hervorragende Arbeit geleistet« (zitiert nach Deutscher Bundestag 2017, 8). Kritik an der Regierungspolitik blenden sie zwar nicht aus, rücken sie jedoch in den Hintergrund oder stellen sie als haltlos - oder politisch motiviert - dar:

Wir haben - das ist der wesentliche Ansatz, dem die Politik im Augenblick folgt - auch die Mittel zur Klimaschutzfinanzierung über das BMZ - mittlerweile 2 Milliarden Euro - verdoppelt. [...] Frau Göring-Eckardt, ich glaube nicht, dass Sie, wenn Sie diese Dinge bewusst übersehen, Ihrer Fraktion und Ihrer Partei einen Gefallen tun. (Marschall; zitiert nach Deutscher Bundestag 2017, 13)

Tab. 5: Zusammenfassung der Analysekategorie »Positive Bewertung der nachhaltigen Entwicklung«.

\begin{tabular}{|l|l|l|}
$\begin{array}{l}\text { Gemeinsame } \\
\text { Darstellungen }\end{array}$ & $\begin{array}{l}\text { Verlauf der nachhaltigen Entwicklung ist grundsätzlich positiv; Vereinbar- } \\
\text { keit ökologischer, sozialer und ökonomischer Interessen ist möglich. }\end{array}$ \\
\hline $\begin{array}{l}\text { Exklusive } \\
\text { Darstellungen }\end{array}$ & $\begin{array}{l}\text { Medien: Nachhaltigkeitsgedanke } \\
\text { kann aufgrund seiner weiten Ver- } \\
\text { breitung die nachhaltige Entwick- } \\
\text { lung in Deutschland vorantreiben; } \\
\text { freier Markt trägt seinen Teil zur } \\
\text { nachhaltigen Entwicklung bei. }\end{array}$ & Politik: Keine. \\
\hline Einordnung & Kein Indexing. \\
\hline
\end{tabular}

Die analysierten Medienbeiträge beziehen sich oft direkt auf Aussagen von Politiker*innen und greifen deshalb auch die positive Darstellung der nachhaltigen Entwicklung von Regierung und Regierungsparteien auf. Während einige Parlamentarier*innen betonen, dass die Entwicklung durch Information und Weiterbildung der Bürger*innen vorangetrieben werden kann, sehen die Medien hier bereits erste Erfolge: Mehrfach findet sich in der medialen Darstellung die Perspektive, dass der in Deutschland bereits weit verbreitete Nachhaltigkeitsgedanke die nachhaltige Entwicklung vorantreiben kann. Die Berichterstattung thematisiert eine Macht der Konsument*innen über die Konzerne. Sowohl in der politischen als auch in der medialen Darstellung wird zudem mehrfach die Vereinbarkeit der drei Nachhaltigkeitsbereiche als möglich eingestuft. 
Häufig stellen die analysierten Medien die Position dar, dass der freie Markt seinen Teil zur nachhaltigen Entwicklung beiträgt. Zentral ist hierbei die Annahme, dass die Umsetzung ökologischer und sozialer Interessen den wirtschaftlichen Interessen dienen kann - und umgekehrt:

Tourismus, so die Welttourismusorganisation (UNWTO), sei ein Instrument zur Abschaffung der Armut, zum Schutz der Umwelt, zur Verbesserung der Lebensqualität und zur wirtschaftlichen Stärkung von Frauen und Jugendlichen. (Kresta 2017)

In diesem Fall handelt es sich um eine Sichtweise, die von der Autorin Edith Kresta zwar festgehalten, im Laufe des Artikels aber abgelehnt wird. Ähnliche mediale Darstellungen führen bis zur These, dass nachhaltigere Unternehmen oft auch erfolgreichere Unternehmen sind. Die politischen Eliten thematisieren die positive Bedeutung des freien Marktes für die nachhaltige Entwicklung hingegen kaum. Das gilt auch für die Annahmen, dass der Nachhaltigkeitsgedanke in Deutschland bereits etabliert ist und dass seine Verbreitung sich bereits positiv auf die nachhaltige Entwicklung auswirkt. Trotz der vielen Überschneidungen der politischen und medialen Darstellungen widerspricht diese Kategorie somit der Indexing-Hypothese.

\subsection{Kritische Bewertung der nachhaltigen Entwicklung}

Den positiven Bewertungen des Verlaufs der nachhaltigen Entwicklung stehen die negativen gegenüber. Sowohl in der oppositionellen als auch in der medialen Darstellung findet sich die Ansicht, dass der freie Markt bisher kaum oder gar nicht zu einer nachhaltigen Entwicklung der Wirtschaft beigetragen hat. So werfen etwa die Linken der Regierung vor, in Sachen Nachhaltigkeit fälschlicherweise auf freiwilliges Handeln zu setzen. Die Medienberichterstattung kommuniziert diese Perspektive ebenfalls - und zwar deutlich ausführlicher als die Opposition. In den Zeitungsartikeln findet sich wiederholt der Standpunkt, dass Anleger*innen und Unternehmen kein großes Interesse an nachhaltigen Investitionen haben. Somit berichten die Medien nicht nur ausführlicher über die Möglichkeiten des freien Marktes, sondern geben auch der Kritik an diesem Konzept deutlich mehr Raum als die politischen Eliten. Die Einflussmöglichkeiten der Einzelnen werden hierbei nicht generell bestritten. Laut der Berichterstattung nutzen die meisten Menschen diese Möglichkeiten aber noch nicht oder kaum: 
Es gebe zwar »einen Trend zum Individualtourismus«, berichtete Friederike Grupp, die Nachhaltigkeitsbeauftrage des Touristik-Unternehmens Thomas Cook. Doch die meisten Menschen wollten eben »an den Strand«. Der Badetourismus, ob am Mittelmeer oder zunehmend auch in fernen Ländern, bleibe der Schwerpunkt. (Wille 2017)

Die $S Z$ thematisiert außerdem, dass es für Individuen sehr schwierig sein kann, nachhaltig zu handeln. Das Beispiel ist in diesem Fall der nachhaltige Konsum:

Nie war Einkaufen so kompliziert, es gibt zu viele Fragen, die sich kaum beantworten lassen. Der moderne Konsument rennt im Hamsterrad seiner eigenen Ansprüche. (Kläsgen 2017)

Wer nachhaltig konsumieren will, benötigt dafür viele miteinander zusammenhängende Informationen und muss diese auch auswerten können. Die Medienberichterstattung zeigt an vielen Stellen auf, dass bisher unklar ist, welchen Einfluss Individuen tatsächlich durch ihren Konsum auf die nachhaltige Entwicklung haben. In der Bundestagsdebatte spielt diese Frage wiederum kaum eine Rolle. Mehrere der untersuchten Zeitungsartikel beschäftigen sich außerdem direkt oder indirekt mit der Frage, ob sich Nachhaltigkeit und Konsum nicht grundsätzlich widersprechen.

Die Berichterstattung geht auch darauf ein, dass weniger Konsum nicht automatisch weniger Zufriedenheit oder Lebensqualität bedeuten muss. In der politischen Debatte nimmt das Thema Verzicht eine weitaus kleinere Rolle ein. Seine Notwendigkeit wird zwar stellenweise angedeutet, er selbst aber nur in einem einzigen Fall konkret gefordert: Linken-Politikerin Katja Kipping will weniger Verkehr auf den Straßen (Deutscher Bundestag 2017, 5).

Die analysierten Medien greifen zudem immer wieder die Annahme auf, dass die nachhaltige Entwicklung nur erfolgreich sein kann, wenn Perspektivwechsel stattfinden. Neben dem Verzicht auf Konsumgüter thematisiert die Medienberichterstattung auch eine mögliche Reduzierung der Arbeitszeit oder das Essen von Insekten als Alternative zum Fleischkonsum. In der politischen Debatte finden sich solche Perspektivwechsel meist nur als abstrakte Schlagworte ohne Erklärung - etwa »Paradigmenwechsel« (Strässer; zitiert nach Deutscher Bundestag 2017, 14) oder »Transformationsauftrag « (Träger; zitiert nach Deutscher Bundestag 2017, 8). 
Tab. 6: Zusammenfassung der Analysekategorie »Kritische Bewertung der nachhaltigen Entwicklung«.

\begin{tabular}{|l|l|l|}
\hline $\begin{array}{l}\text { Gemeinsame } \\
\text { Darstellungen }\end{array}$ & $\begin{array}{l}\text { Freier Markt hat bisher kaum zu einer nachhaltigen Entwicklung der Wirt- } \\
\text { schaft beigetragen; Nachhaltigkeitspolitik der Bundesregierung ist noch } \\
\text { nicht erfolgreich. }\end{array}$ \\
\hline $\begin{array}{l}\text { Exklusive } \\
\text { Darstellungen }\end{array}$ & $\begin{array}{l}\text { Medien: Nachhaltiges Handeln der } \\
\text { Individuen ist hierzulande nicht } \\
\text { etabliert; Verzicht als Alternative } \\
\text { zum nachhaltigen Konsum; } \\
\text { Notwendigkeit von Perspektiv- } \\
\text { wechseln, damit die nachhaltige } \\
\text { Entwicklung erfolgreich sein kann. }\end{array}$ \\
\hline Einordnung & Kein Indexing. \\
\hline
\end{tabular}

Artikel der FR, der $S Z$ und der taz bewerten die Nachhaltigkeitspolitik der Regierung als nicht besonders erfolgreich. Unter anderem wird kritisiert, dass man keine großen Veränderungen anstrebe. Die von der Regierung kommunizierten Erfolge werden in der Mediendarstellung mitunter auf angepasste Nachhaltigkeitskriterien zurückgeführt und relativiert. Diese Kritik spielt auch in der Parlamentsdebatte eine Rolle: Grüne und Linke kritisieren die Regierung intensiv. Sie werfen ihr vor, zu langsam, teilweise sogar kontraproduktiv zu handeln. Doch trotz dieser Überschneidungen in der oppositionellen und in der medialen Darstellung widerspricht diese Kategorie der Indexing-Hypothese - die Medien gehen an entscheidenden Punkten deutlich über die politische Darstellung hinaus.

\subsection{Nachhaltigkeitsbegriff als tendenziell leerer Signifikant}

Insgesamt entsteht der Eindruck, dass der Nachhaltigkeitsbegriff innerhalb der politischen Eliten anerkannt ist. In der Medienberichterstattung ist das weniger eindeutig. Der dort thematisierte Gebrauch zu Imagezwecken deutet darauf hin, dass der Begriff von einigen Unternehmen ausgehöhlt wird. Auch deutsche Politiker*innen neigen der Berichterstattung zufolge dazu, Dinge als nachhaltig zu bezeichnen, die aus der Sicht anderer Akteur*innen nicht oder kaum nachhaltig sind.

Es gibt also eine große Bandbreite an Nachhaltigkeitsbehauptungen, die qualitativ erhebliche Unterschiede aufweisen können. Die Vielzahl 
an möglichen Definitionen wird in den analysierten Artikeln mehrfach kritisiert. Sie gilt als Hindernis für diejenigen, die eine nachhaltige Entwicklung tatsächlich vorantreiben wollen. Aufgrund der intransparenten und vagen Nutzung des Begriffs können Konsument*innen demnach oft nicht wissen, woran sie sich orientieren sollen und welchen Versprechen sie glauben können:

Es fängt damit an, dass er [der aufgeklärte Konsument; $\mathrm{MC}$ ] nicht mehr weiß, welchen Informationen er noch vertrauen kann. Ist da, wo Bio draufsteht, auch wirklich Bio drin? Kann es stimmen, dass die Lebensmittel aus Italien geliefert wurden? Und wie sollen Bio und China bitte schön zusammengehen? Informieren kann man sich heute über die Herkunft der Produkte rund um die Uhr. Das Smartphone liegt immer in erreichbarer Nähe. Aber sind die Informationen nicht interessengeleitet und manipuliert? (Kläsgen 2017)

\section{Tab. 7: Zusammenfassung der Analysekategorie » Nachhaltigkeits-} begriff als tendenziell leerer Signifikant«.

\begin{tabular}{l|l|l|}
\hline $\begin{array}{l}\text { Gemeinsame } \\
\text { Darstellungen }\end{array}$ & Keine. \\
\hline $\begin{array}{l}\text { Exklusive } \\
\text { Darstellungen }\end{array}$ & $\begin{array}{l}\text { Medien: Vieles, was als nachhaltig } \\
\text { bezeichnet wird, ist nicht wirklich } \\
\text { nachhaltig; Nachhaltigkeitsbegriff } \\
\text { sorgt derzeit für Verwirrung und } \\
\text { Vertrauensverlust unter Kundin- } \\
\text { nen und Anleger*innen; Nachhal- } \\
\text { tigkeitsbegriff ist möglicherweise } \\
\text { sinnlos. }\end{array}$ & \multicolumn{1}{|c|}{ Politik: Keine. } \\
\hline Einordnung & Kein Indexing. \\
\hline
\end{tabular}

In der Berichterstattung wird der Begriff Nachhaltigkeit teilweise als tendenziell leerer Signifikant präsentiert, wenn auch nicht vollends in diesen Status erhoben. Ein großer Teil der medialen Darstellung deckt sich mit Giulios $(2004,11)$ Feststellung, dass der Nachhaltigkeitsbegriff zu einem »leeren Modewort« (ebd.) werden könnte. An dieser Stelle treten die Unterschiede zwischen der medialen und der politischen Darstellung klar hervor: Diese von den Medien thematisierte Problematik kommt in der Bundestagsdebatte so gut wie nicht vor. Es handelt sich um ein weiteres Beispiel dafür, dass die Medienberichterstattung an entscheidenden Stellen deutlich über die politische Darstellung hinausgeht. 


\section{Fazit}

Im Rahmen der untersuchten Nachhaltigkeitsdebatte gibt es große Überschneidungen zwischen den politischen und medialen Darstellungen. Sie zeigen, dass es durchaus eine gemeinsame Basis an Perspektiven gibt, die Politiker*innen und Qualitätsmedien nach außen kommunizieren. Der UN-Nachhaltigkeitsbegriff etwa ist weitgehend anerkannt, genauso wie die gemeinsame Verantwortung von Politik, Wirtschaft, Wissenschaft und Gesellschaft für die nachhaltige Entwicklung. Mehrere Darstellungen widersprechen aber der abgeschwächten Variante der Indexing-Hypothese, die davon ausgeht, dass die politischen und medialen Darstellungen größtenteils deckungsgleich sind. So beschäftigen sich die analysierten Medien mit dem Thema Greenwashing, das in der Bundestagsdebatte keine Rolle spielt, und gehen deutlich über die politische Darstellung hinaus, wenn sie über den Verzicht als Alternative zum nachhaltigen Konsum berichten und den Nachhaltigkeitsbegriff als inhaltsleer einordnen. Die Frage, ob Deutschland ein internationaler Vorreiter in der nachhaltigen Entwicklung ist, taucht wiederum nur in der Bundestagsdebatte, nicht aber in der untersuchten Berichterstattung auf.

Die Abweichungen der beiden Darstellungen voneinander sind im untersuchten Fall an entscheidenden Stellen zu groß, um von Indexing zu sprechen. Stattdessen untermauern die Ergebnisse Krügers (2016, 27) These, dass Politiker*innen und Journalist*innen teilweise abhängig, teilweise unabhängig voneinander agieren. Der qualitative Analyseansatz hat sich an dieser Stelle als hilfreich erwiesen. Er ermöglicht, komplexe Sinnzusammenhänge zu erkennen, die in einer quantitativen Analyse untergehen können. Allerdings hat sich auch gezeigt, dass die vielen Uneindeutigkeiten in der Nachhaltigkeitsdebatte die Komplexität der qualitativen Analyse drastisch erhöhen. Um Indexing noch genauer zu untersuchen, wäre es ratsam, qualitative und quantitative Ansätze stärker miteinander zu verknüpfen. Eine interessante Fragestellung bestünde darin, ob die Analyse aktueller Darstellungen die hier vorgestellten Ergebnisse stützt beziehungsweise wie sich die politischen und medialen Darstellungen seit Anfang 2017 verändert haben - sei es durch das Aufkommen von Fridays for Future, die Corona-Pandemie oder die Einzüge der AfD und der FDP in den Bundestag.

Für den Qualitätsjournalismus in Deutschland zeigt die Analyse, dass die untersuchten Medien im Falle der Nachhaltigkeitsdebatte größtenteils ihrer Aufgabe nachkommen, kritisch und offen zu berichten. Aller- 
dings wäre es Aufgabe der Presse, über die Vorreiterdebatte zu schreiben und sie einzuordnen. Hier zeigt sich, dass Indexing stellenweise wünschenswert sein könnte: Die Berichterstattung über die Debatte ist Voraussetzung für eine tiefergehende Auseinandersetzung mit relevanten Fragen: Ist Deutschland in der nachhaltigen Entwicklung tatsächlich internationaler Vorreiter? Und welche Rolle spielt dieser Umstand?

Bemerkenswert ist, dass die Medien sich intensiv dem Komplex »Verzicht versus nachhaltiger Konsum « widmen. Denn die Annahme, dass wir in der nachhaltigen Entwicklung notwendigerweise auf Dinge verzichten müssen, widerspricht dem Drei-Säulen-Konzept und befürwortet das, was die jungen Klimaaktivist*innen auf ihren Freitagsdemos fordern. Aus dieser Perspektive ist die gleichwertige Behandlung von Umwelt, Sozialem und Wirtschaft nicht mehr zeitgemäß.

\section{Literatur}

Adam, Silke. 2008. Massenmedien als Herausforderer oder Agenturen nationaler Eliten? Eine Analyse der deutschen und französischen EU-Erweiterungsdebatte. In: Massenmedien als politische Akteure. Konzepte und Analysen, herausgegeben von Barbara Pfetsch und Silke Adam, 116-143. Wiesbaden: VS Verlag für Sozialwissenschaften.

Bauchmüller, Michael, und Kristiana Ludwig. 2017. Verzichten können andere. Süddeutsche Zeitung vom 16. März, https://www.sueddeutsche.de/wirtschaft/ umweltpolitik-verzichten-koennen-andere-1.3422358. Zugegriffen: 28. Juni 2018.

Bennett, W. Lance. 1990. Toward a Theory of Press-State Relations in the United States. Journal of Communication 40 (2): 103-125.

Bennett, W. Lance. 2009. Power and the News Media: The Press and Democratic Accountability. In: Politik in der Mediendemokratie, herausgegeben von Frank Marcinkowski und Barbara Pfetsch, 84-102. Wiesbaden: VS Verlag für Sozialwissenschaften.

Bennett, W. Lance, und Steven Livingston. 2003. Editors' Introduction: A Semi-Independent Press: Government Control and Journalistic Autonomy in the Political Construction of News. Political Communication 20 (4): 359-362.

Bilharz, Michael. 2005. Nachhaltiger Konsum: Die Suche nach dem nächsten Schritt. Consumer Science 5. http://www.keypointer.de/fileadmin/media/Bilharz_2005_Nachhaltiger-Konsum-die-Suche-nach-dem-nächsten-Schritt_Bericht.pdf. Zugegriffen: 22. November 2020.

Bilharz, Michael. 2008. „Key Points« nachhaltigen Konsums. Ein strukturpolitisch fundierter Strategieansatz für die Nachhaltigkeitskommunikation im Kontext aktivierender Verbraucherpolitik. Marburg: Metropolis.

Brand, Karl-Werner, und Georg Jochum. 2000. Der deutsche Diskurs zu nachhalti- 
ger Entwicklung. Abschlussbericht eines DFG-Projekts zum Thema »Sustainable Development/Nachhaltige Entwicklung - Zur Sozialen Konstruktion Globaler Handlungskonzepte im Umweltdiskurs.«MPS-Texte 1.

Brand, Ulrich, und Christoph Görg. 2002. »Nachhaltige Globalisierung«? Sustainable Development als Kitt des neoliberalen Scherbenhaufens. In: Mythen globalen Umweltmanagements, herausgegeben von Christoph Görg und Ulrich Brand, 12-47. Münster: Westfälisches Dampfboot.

Brüggemann, Michael, und Hartmut Weßler. 2009. Medien im Krieg. Das Verhältnis von Medien und Politik im Zeitalter transnationaler Konfliktkommunikation. In: Politik in der Mediendemokratie, herausgegeben von Frank Marcinkowski und Barbara Pfetsch, 635-657. Wiesbaden: VS Verlag für Sozialwissenschaften.

Bundesregierung. 2017. Deutsche Nachhaltigkeitsstrategie. Neuauflage 2016. https://www.bundesregierung.de/Content/Infomaterial/BPA/Bestellservice/ Deutsche_Nachhaltigkeitsstrategie_Neuauflage_2016.pdf. Zugegriffen: 22. November 2020.

Bundesregierung. 2020. Neue Kraftstoffe und Antriebe. https://www.bundesregierung.de/breg-de/themen/neue-kraftstoffe-und-antriebe-994216. Zugegriffen: 22. November 2020.

Dahrendorf, Ralf. 1968. Festansprache: Professor Ralf Dahrendorf. „Demokratie glaubwürdig machen«. In: Theodor-Heuss-Preis 1968. Demokratie glaubwürdig machen, herausgegeben von Waldemar Besson, Adolf Butenandt, Ralf Dahrendorf, Hildegard Hamm-Brücher und Karin Storch, 13-21. https://theodorheuss-stiftung.de/wp-content/uploads/Jahresband-1968.pdf. Zugegriffen: 22. November 2020.

Deutscher Bundestag. 2017. Stenografischer Bericht. 229. Sitzung. Protokoll 18/229. http://dip21.bundestag.de/dip21/btp/18/18229.pdf. Zugegriffen: 1. August 2018.

Eckl, Christian. 2011. Wie unabhängig von politischen Eliten sind die Printmedien? https://refubium.fu-berlin.de/handle/fub188/6071. Zugegriffen: 22. November 2020 .

Franke, Ulrich, und Ulrich Roos. 2010. Rekonstruktionslogische Forschungsansätze. In: Handbuch der Internationalen Politik, herausgegeben von Carlo Masala, Frank Sauer und Andreas Wilhelm, 285-303. Wiesbaden: VS Verlag.

Gerber, Claus-Peter. 1968. Soziale Strukturen und Interaktionsmuster. In: Die Massenmedien und die Organisation politischer Interessen, herausgegeben von ClausPeter Gerber und Manfred Stosberg, 61-105. Bielefeld: Bertelsmann Universitätsverlag.

Gerhards, Jürgen, Friedhelm Neidhardt, und Dieter Rucht. 1998. Zwischen Palaver und Diskurs. Strukturen öffentlicher Meinungsbildung am Beispiel der deutschen Diskussion zur Abtreibung. Opladen: Westdeutscher Verlag.

Giulio, Antonietta Di. 2004. Die Idee der Nachhaltigkeit im Verständnis der Vereinten Nationen. Anspruch, Bedeutung und Schwierigkeiten. Münster: Lit.

Heine, Matthias. 2017. »Nachhaltig« ist unser »Halal«. Die Welt vom 5. Juni, https:// www.welt.de/debatte/kommentare/article165225725/Nachhaltig-ist-unserhalal.html. Zugegriffen: 22. November 2020. 
Herman, Edward, und Noam Chomsky. 1988. Manufacturing Consent. The Political Economy of the Mass Media. New York: Pantheon.

Herzog, Dietrich, und Bernhard Weßels. 2005. Lexikon der Politikwissenschaft: Theorien, Methoden, Begriffe. In: Lexikon der Politikwissenschaft: Theorien, Methoden, Begriffe. Band 2: N-Z, herausgegeben von Dieter Nohlen und RainerOlaf Schultze, 732-736. München: C. H. Beck.

Hille, Steven. 2017. Was bringen Ökolabels im Tourismus? Die Welt vom 9. Juni, https://www.welt.de/reise/article165296995/Was-bringen-Oekolabels-imTourismus.html. Zugegriffen: 28. Juni 2018.

Infratest Dimap. 2020. Glaubwürdigkeit der Medien 2020. https://www.infratestdimap.de/umfragen-analysen/bundesweit/umfragen/aktuell/glaubwuerdigkeit-der-medien-2020/. Zugegriffen: 22. November 2020.

Jandura, Olaf, und Raphael Kösters. 2017. Neue Medienumgebungen, andere Auswahlkriterien? Überlegungen zur Auswahl von Medienangeboten bei Inhaltsanalysen. Publizistik 62 (1): 25-41.

Kabalak, Alihan, Birger Priddat, und Markus Rohmberg. 2008. Medien als Schnittstelle zwischen politischen und ökonomischen Strukturen - Politische Kommunikation in der Perspektive der Institutionenökonomie. In: Massenmedien als politische Akteure. Konzepte und Analysen, herausgegeben von Barbara Pfetsch und Silke Adam, 52-72. Wiesbaden: VS Verlag für Sozialwissenschaften.

Kläsgen, Michael. 2017. Die Leiden des aufgeklärten Konsumenten. Süddeutsche Zeitung vom 1. Januar, https://www.sueddeutsche.de/wirtschaft/nachhaltigeinkaufen-die-leiden-des-aufgeklaerten-konsumenten-1.3315584. Zugegriffen: 28. Juni 2018.

Kresta, Edith. 2017. Party ohne Ende. taz vom 19. März, https://www.taz.de/Archiv-Suche/!5390075. Zugegriffen: 28. Juni 2018.

Krüger, Uwe. 2019. Meinungsmacht. Der Einfluss von Eliten auf Leitmedien und Alpha-Journalisten - Eine kritische Netzwerkanalyse. 2., überarbeitete und erweiterte Auflage. Köln: Herbert von Halem.

Krüger, Uwe. 2016. Medien im Mainstream - Problem oder Notwendigkeit? Aus Politik und Zeitgeschichte 66 (30-32): 22-27.

Lang, Kurt, und Gladys Engel Lang. 2004. Noam Chomsky and the Manufacture of Consent for American Foreign Policy. Political Communication 21 (1): 93-101.

Lüter, Albrecht. 2008. Die Kommentarlage. Profilbildung und Polyphonie in medienöffentlichen Diskursen. Wiesbaden: VS Verlag für Sozialwissenschaften.

Maurer, Torsten, Jens Vogelgesang, Moritz Weiß, und Hans-Jürgen Weiß. 2008. Aktive oder passive Berichterstatter? Die Rolle der Massenmedien während des Kosovo-, Afghanistan- und Irakkriegs. In: Massenmedien als politische Akteure. Konzepte und Analysen, herausgegeben von Barbara Pfetsch und Silke Adam, 144-170. Wiesbaden: VS Verlag für Sozialwissenschaften.

Mautz, Rüdiger, Andreas Byzio, und Wolf Rosenbaum. 2008. Auf dem Weg zur Energiewende. Die Entwicklung der Stromproduktion aus erneuerbaren Energien in Deutschland. Göttingen: Universitätsverlag Göttingen.

Mothes, Cornelia. 2014. Objektivität als professionelles Abgrenzungskriterium im 
Journalismus. Eine dissonanztheoretische Studie zum Informationsverhalten von Journalisten und Nicht-Journalisten. Baden-Baden: Nomos.

Neuberger, Christoph, und Peter Kapern. 2013. Grundlagen des Journalismus. Wiesbaden: Springer VS.

Paqué, Karl-Heinz. 2012. Wert des Wachstums: Kompass für eine Kontroverse. Aus Politik und Zeitgeschichte 27-28: 15-19.

Parisi, Peter. 1997. Toward a »Philosophy of Framing«: News Narratives for Public Journalism. Journalism \& Mass Communication Quarterly 74 (4): 673-686.

Pfetsch, Barbara, und Frank Marcinkowski. 2009. Problemlagen der »Mediendemokratie«. Theorien und Befunde zur Medialisierung von Politik. In: Politik in der Mediendemokratie, herausgegeben von Frank Marcinkowski und Barbara Pfetsch, 11-33. Wiesbaden: VS Verlag für Sozialwissenschaften.

Rickert, Heinrich. 1929. Zur Lehre von der Definition. 3., verbesserte Auflage. Tübingen: J. C.B. Mohr.

RNE - Rat für Nachhaltige Entwicklung. 2018. Auftrag an den Rat für nachhaltige Entwicklung. https://www.nachhaltigkeitsrat.de/der-rat/auftrag-des-rates/. Zugegriffen: 25. Juli 2018.

RNE - Rat für Nachhaltige Entwicklung. 2020. Nachhaltige Entwicklung. https:// www.nachhaltigkeitsrat.de/nachhaltige-entwicklung/. Zugegriffen: 22. November 2020.

Samanta, Sayan. 2016. Priority Setting - or Rather Not? Positive Concerns for SDGs. http://www.die-gdi.de/uploads/media/German_Development_Institute_Samanta_12.09.2016.pdf. Zugegriffen: 22. November 2020.

Santarius, Tilman. 2012. Der Rebound-Effekt. Über die unerwünschten Folgen der erwünschten Energieeffizienz. Wuppertal: Wuppertal Institut für Klima, Umwelt, Energie $\mathrm{GmbH}$.

Schafhausen, Franzjosef. 2013. Die Energiewende - Aufbruch in Die Zukunft. Vierteljahreshefte zur Wirtschaftsforschung 82 (3): 11-28.

Seefried, Elke. 2015. Rethinking Progress. On the Origin of the Modern Sustainability Discourse, 1970-2000. Journal of Modern European History 13 (3): 377399.

Soentgen, Jens. 2016. Nachhaltigkeit als Nießbrauch. Das römische Rechtsinstitut des usus fructus und seine systematische Bedeutung für das Konzept der nachhaltigen Nutzung. GAIA - Ecological Perspectives for Science and Society 25 (2): 117-125.

Steiner, Adrian, und Otfried Jarren. 2009. Intermediäre Organisationen unter Medieneinfluss? Zum Wandel der politischen Kommunikation von Parteien, Verbänden und Bewegungen. In: Politik in der Mediendemokratie, herausgegeben von Frank Marcinkowski und Barbara Pfetsch, 251-269. Wiesbaden: VS Verlag für Sozialwissenschaften.

Strübing, Jörg. 2008. Grounded Theory. Zur sozialtheoretischen und epistemologischen Fundierung des Verfahrens der empirisch begründeten Theoriebildung. Wiesbaden: VS Verlag.

UN-Generalversammlung. 2015. Transforming Our World: The 2030 Agenda for 
Sustainable Development. http://www.un.org/ga/search/view_doc.asp?symbol=A/RES/70/1\&Lang=E. Zugegriffen: 22. November 2020.

Voltmer, Katrin. 2008. »Vierte Gewalt« im Schatten der Vergangenheit - Die Transformation der Massenmedien in Neuen Demokratien. In: Massenmedien als politische Akteure. Konzepte und Analysen, herausgegeben von Barbara Pfetsch und Silke Adam, 92-115. Wiesbaden: VS Verlag für Sozialwissenschaften.

WCED. 1987. Report of the World Commission on Environment and Development: Our Common Future. http://www.un-documents.net/our-common-future.pdf. Zugegriffen: 22. November 2020.

Weischenberg, Siegfried, Armin Scholl, und Maja Malik. 2006. Die Souffleure der Mediengesellschaft: Report über die Journalisten in Deutschland. Konstanz: UVK.

Welfens, Paul J.J. 2011. Überwindung der Banken- und Finanzkrise: Optionen der Wachstums- bzw. Wirtschaftspolitik. In: Zukunftsfähige Wirtschaftspolitik für Deutschland und Europa, herausgegeben von Paul J.J. Welfens, 1-74. Heidelberg: Springer.

Wille, Joachim. 2017. Wem gehört der letzte Tropfen? Frankfurter Rundschau vom 13. Juni, https://www.fr.de/wirtschaft/gehoert-letzte-tropfen-11081921.html. Zugegriffen: 28. Juni 2018.

Willmroth, Jan. 2017. Mehr als grünes Geschwätz. Süddeutsche Zeitung vom 25. Juni, https://www.sueddeutsche.de/wirtschaft/geldanlage-mehr-als-gruenes-geschwaetz-1.3559816. Zugegriffen: 28. Juni 2018.

Zürcher, Ulrich. 1965. Die Idee der Nachhaltigkeit unter spezieller Berücksichtigung der Gesichtspunkte der Forsteinrichtung. ETH Zürich. https://www.research-collection.ethz.ch/handle/20.500.11850/132556. Zugegriffen: 22. November 2020.

\section{Open Access}

Dieser Beitrag erscheint unter der Creative-Commons-Lizenz CC BY-ND 3.0 DE: https://creativecommons.org/licenses/by-nd/3.0/de/. 


\title{
Wo steht der deutschsprachige Nachhaltigkeitsjournalismus? Ein Überblick
}

\author{
Torsten Schäfer \& Stella Lorenz
}

Keywords: Nachhaltigkeitsjournalismus, Umweltjournalismus, Klimajournalismus, Impact Journalism, Magazinjournalismus, Erzählformen

\section{Abstract}

Die mediale Berichterstattung rund um den Themenkomplex »Nachhaltigkeit« hat sich sowohl im klassischen Zeitungsjournalismus als auch auf dem Zeitschriftenmarkt, den dieser Beitrag als Trendindikator exemplarisch in den Blick nimmt, fortentwickelt. Auch große Verlage setzen nun auf Heftneugründungen im »grünen « Printsegment. Gemeinsam mit bereits vorhandenen Titeln etablieren diese zum Teil alternative journalistische Erzählformen für Nachhaltigkeitsthemen. Dabei verschwimmt nicht selten die Grenze zwischen Literatur und Journalismus, wie anhand zweier Beispiele gezeigt wird. Zudem fasst der Beitrag Metastrukturen in Aus- und Weiterbildung sowie die Genese neuer grüner Onlinemedien und medialer Fachportale zusammen und macht Vorschläge für künftige Forschungsansätze zur Analyse des Netzwerks und seiner Einzelakteur*innen.

Torsten Schäfer \& Stella Lorenz: Wo steht der deutschsprachige Nachhaltigkeitsjournalismus? Ein Überblick. In: Nils S. Borchers, Selma Güney, Uwe Krüger und Kerem Schamberger (Hrsg.): Transformation der Medien - Medien der Transformation. Verhandlungen des Netzwerks Kritische Kommunikationswissenschaft. Frankfurt am Main: Westend 2021. DOI: https://doi.org/10.53291/JNRT8200.

Prof. Dr. Torsten Schäfer I Hochschule Darmstadt I torsten.schaefer@h-da.de

Stella Lorenz I Universität Freiburg und Hochschule Darmstadt I stella-marie @t-online.de 


\section{Einführung}

Die deutschen Medien sind ergrünt. Sie berichten häufiger als früher über den Themenbereich »Nachhaltigkeit«, wie unter anderem Studien der Leuphana Universität Lüneburg gezeigt haben (Fischer und Hauke 2016). Dass der Begriff heute etwa doppelt so häufig in der Berichterstattung auftaucht wie noch vor 20 Jahren, wurde von Daniel Fischer und Franziska Hauke in einer Studie zur »Verwendung von ^Nachhaltigkeit in deutschen Zeitungen « (Fischer und Hauke 2016) untersucht. Dieser Befund deckt sich mit dem (rein subjektiven) Eindruck, dass in den großen Medien seit etwa 2018 häufiger Themen wie Artenvielfalt und speziell Insekten Erwähnung finden. Auch die Berichterstattung zum Klimawandel hat - nach dem Extremsommer 2018 und den seit 2019 anhaltenden Fridays-for-Future-Protesten - deutlich zugenommen.

Ganz unabhängig davon besetzen neuere und neue Printmagazine wie enorm, transform, Futurzwei oder oya die grüne Nische, die auch durch den Erfolg der Landhefte mit ihrer idealisierten Sicht auf Naturund Umweltthemen breiter geworden ist. Schon deutlich länger gibt es Zeitschriften wie das Ökologisches Wirtschaften, die Politische Ökologie oder die Umweltbriefe, die sich als Fachmagazine in den 1980er Jahren etabliert haben und nach wie vor halten. Auch online sind $\mathrm{zu}$ verschiedenen Aspekten von Nachhaltigkeit in den vergangenen zehn Jahren zahlreiche neue Portale entstanden wie Klimareporter, Utopia, Karmakonsum, WiWoGreen oder Biorama sowie die klimajournalistische Nachwuchsplattform Klimareporter. in aus Österreich. ${ }^{1}$ Einige Portale wie Perspective Daily entstammen dem sogenannten »Konstruktiven Journalismus«, der bewusst Ideen, Lösungen und Erfolge transportiert - besonders gern aus dem alternativen und grünen Milieu und eben öfter mit Bezug zu Klima, Energie und Nachhaltigkeit.

Im Folgenden wird gezeigt, welchen Veränderungen der deutsche Nachhaltigkeitsjournalismus ${ }^{2}$ unterliegt - zunächst unter der Per-

1 Einen Überblick über jene Portale gibt es beispielsweise auf der Website futurphil.de (Oestreicher 2020).

2 Der in der Wissenschaft noch nicht allzu lange verwendete Begriff des Nachhaltigkeitsjournalismus wurde vorrangig von Gerd Michelsen und Daniel Fischer im Rahmen entsprechender Forschungen an der Leuphana Universität Lüneburg geprägt. Er fasst »journalistische Aktivitäten zusammen, die einen Beitrag zur Debatte des Konzepts einer nachhaltigen Entwicklung leisten beziehungsweise sich darauf beziehen« (Michelsen und Fischer 2016, 10). Synonym, 
spektive der relevanten Zeitschriftengründungen sowie darauffolgend mit der Analyse weiterer Strukturmerkmale, etwa Aus- und Weiterbildungsmöglichkeiten, Medienpreise oder Studiengänge.

\section{Aus der Praxis: Das Zeitschriftenregal als Transformationsindikator}

Seit dem ersten Erscheinen der Landlust 2005, das magazinjournalistisch gesehen als Initialzündung für einen neuen Naturdiskurs (wenn auch mit eskapistischen Tendenzen) ${ }^{3}$ gesehen werden kann, hat sich der Printmagazinmarkt in diesem Bereich stark entwickelt. Über 50 neue Publikumsmagazine ${ }^{4}$ sind an den Markt gegangen, die sich in einem ähnlichen Themengebiet bewegen (siehe Tab. 1). Ein ganz eigenes Segment haben die zahlreichen, in den letzten zehn Jahren neugeschaffenen Publikationen begründet: Unter dem von Schäfer, Kasper und Austen (2015) vorgeschlagenen Komplex »Sinn + Muße« lassen sich rund 30 Magazine mit breitgefächerten Schwerpunkten verorten: angefangen bei der Achtsamkeitspublikation Flow (und zahlreichen Nachahmern) über vegane Ernährungs- und Kochzeitschriften bis hin zu Testballons wie der autonom gegründeten und unabhängig von Werbeanzeigen finanzierten Zeitschrift transform, deren Macher*innen als Journalist*innenkollektiv arbeiten.

aber auch ergänzend dazu werden oft auch die Begriffe »Umwelt-« oder »Klimajournalismus«, »Grüner Journalismus« und »Transformationsjournalismus« verwendet (vgl. Krüger in diesem Band). Auch Impact-Journalismus (vgl. Borner, Oxenfarth und Ronzheimer 2019) weist ähnliche Charakteristika wie der Nachhaltigkeitsjournalismus auf.

3 Die Landlust und viele der anschließend veröffentlichten Landhefte zeichnen sich vor allem durch eine sehr idyllische Naturdarstellung aus. Problematische Themen wie Klimawandel oder Umweltverschmutzungen spielen keine Rolle. Die Beschreibung des Familienmagazins LandKind bringt es auf den Punkt: »Die Rückbesinnung auf die einfachen, alltäglichen Dinge des Lebens und ein Leben im Einklang mit der Natur stehen dabei immer im Vordergrund. LandKind stillt die heutige Sehnsucht nach einer heilen Welt [...].« (Panini Verlags GmbH 2019; Hervorhebungen TS \& SL).

4 Unter dem Begriff der Publikumsmagazine werden solche Hefte verstanden, deren Zielgruppe (im Gegensatz zu den oftmals sehr spezifisch ausgerichteten Fachmagazinen) eine gesamtgesellschaftliche ist und die neben der Wissensvermittlung auch der Unterhaltung und Beratung dienen (Menhard und Treede 2004, 21-22). 
Die Übersicht, die im Rahmen der laufenden Dissertation der Mitautorin dieses Beitrages entstanden ist, will einen Überblick über die Publikationen des von Schäfer, Kasper und Austen (2016) geschaffenen Segments geben, umfasst aber darüber hinaus auch die davor bereits etablierten Magazine, die sich in ihrer Grundausrichtung mit ökosozialem Wandel, der Sehnsucht nach einem alternativen Leben, Verbundenheit (also mit Achtsamkeit im weitesten Sinne) und Nachhaltigkeit beschäftigen und mindestens einen dieser Werte auch vermitteln. ${ }^{5}$

Tab. 1: Aktuell erhältliche Publikumszeitschriften mit Nachhaltigkeits- und Achtsamkeitsbezug seit 1976 (eigene Darstellung).

\begin{tabular}{|l|l|l|}
\hline Magazinname & Launch & Claim \\
\hline info3 & 1976 & Bewusst leben. Gesellschaft gestalten. \\
\hline natur & 1980 & $\begin{array}{l}\text { Das Magazin für Umwelt, Natur und ein besseres } \\
\text { Leben. }\end{array}$ \\
\hline Kraut und Rüben & 1984 & Biologisch gärtnern, natürlich leben. \\
\hline Ökotest & 1985 & - \\
\hline natur\&heilen & 1986 & Die Monatszeitschrift für gesundes Leben. \\
\hline Greenpeace Magazin & 1993 & - \\
\hline BIO & 1994 & Das Magazin von Körper, Geist und Seele. \\
\hline NaturApotheke & 1994 & $\begin{array}{l}\text { Das Magazin für Gesundheit und bewusstes } \\
\text { Leben. }\end{array}$ \\
\hline bewusster leben & 2003 & Sei gut zu dir! \\
\hline Landlust & 2005 & Schönes Landleben. \\
\hline natürlich & 2006 & Gut für mich. \\
\hline Liebes Land & 2008 & Das Beste vom Land. \\
\hline Futurzwei (zeozwei) & 2008 & Magazin für Zukunft und Politik. \\
\hline Kochen ohne Knochen & Das vegane Magazin. \\
\hline
\end{tabular}

5 Reine »Glücksmagazine«, bei denen Meditation, psychologische Themen und Spiritualität (wie etwa bei happinez oder Happy Way) im Vordergrund stehen, wurden aus diesem Grund nicht mit in die Betrachtung aufgenommen, ebenso wie etwa Yoga-Hefte oder Wander-Magazine als Special-Interest-Magazine mit Bezug auf ein spezielles Hobby. 


\begin{tabular}{|c|c|c|}
\hline Magazinname & Launch & Claim \\
\hline Landleben & 2009 & Lebensstil mit Liebe zur Natur. \\
\hline Landldee & 2009 & Land erleben und genießen. \\
\hline köstlich vegetarisch & 2010 & Die neue Lust am Kochen. \\
\hline Mein schönes Land & 2010 & Gutes bewahren, Schönes entdecken. \\
\hline Land und Berge & 2010 & Die schönste Art, die Natur zu erleben. \\
\hline Servus in Stadt \& Land & 2010 & Einfach. Gut. Leben. \\
\hline Meine gute Landküche & 2010 & Ländlicher Genuss und regionale Vielfalt. \\
\hline enorm & 2010 & Die Zukunft fängt bei Dir an. \\
\hline oya & 2010 & anders denken. anders leben. \\
\hline LandGenuss & 2011 & Die besten Gerichte der Saison! \\
\hline Landldee - Wohnen und Deko & 2011 & Natürliche Wohnideen für zuhause. \\
\hline Landldee - Landapotheke & 2012 & Heilen und pflegen nach alter Tradition. \\
\hline LandKind & 2012 & Landglück für die ganze Familie. \\
\hline Landzauber & 2012 & Die Vielfalt des Landlebens. \\
\hline Flow & 2013 & $\begin{array}{l}\text { Eine Zeitschrift ohne Eile, über kleines Glück und } \\
\text { das einfach Leben. }\end{array}$ \\
\hline evolve & 2013 & Magazin für Bewusstsein und Kultur. \\
\hline veganmagazin & 2014 & - \\
\hline vegan world & 2014 & - \\
\hline Slow Food (Relaunch) & 2014 & Genießen mit Verstand. \\
\hline Mein schöner Landgarten & 2014 & Gärtnern im Einklang mit der Natur. \\
\hline Mein schönes Landhaus & 2014 & Ländlich wohnen. Natürlich leben. \\
\hline emotion slow & 2014 & Runterkommen. Genießen. Einfach leben. \\
\hline Welt Vegan Magazin & 2015 & - \\
\hline Land \& Leute Edition & 2015 & Die schönen Seiten unseres Landes. \\
\hline Vegan für mich & 2015 & Glücklich, fit und Spaß dabei. \\
\hline Walden & 2015 & Abenteuer vor der Haustür. \\
\hline
\end{tabular}




\begin{tabular}{|c|c|c|}
\hline Magazinname & Launch & Claim \\
\hline ma vie & 2015 & Die Kunst, sich Zeit zu nehmen. \\
\hline greenLIFESTYLE & 2015 & Das Magazin für einen nachhaltigen Lebensstil. \\
\hline Biouty & 2015 & Das einzigartig natürliche Beauty-Magazin. \\
\hline Werde & 2015 & Wir leben das Leben. \\
\hline transform & 2015 & Magazin für das Gute Leben. \\
\hline maas & 2016 & Impulse für ein erfülltes Leben. \\
\hline Food \& Farm & 2016 & Wissen, was man isst. \\
\hline Slowly Veggie & 2016 & Vegetarisch \& vegan genießen. \\
\hline ma vie-Gesund leben & 2016 & Die beste Medizin für mich! \\
\hline Anderswo & 2016 & Europa nachhaltig entdecken. \\
\hline greenup & 2016 & Nachhaltiger leben! \\
\hline $\begin{array}{l}\text { Mein schönes Land - Grüne } \\
\text { Apotheke }\end{array}$ & 2017 & Gesundheit aus der Natur. \\
\hline hygge & 2017 & Vom Glück, das Leben mit anderen zu teilen. \\
\hline Landldee - Altes Wissen & 2018 & Omas Tipps \& Kniffe wieder neu entdeckt. \\
\hline carpe diem & 2019 & Zeit für ein gutes Leben. \\
\hline Wohllebens Welt & 2019 & Ein neuer Blick auf die Natur. \\
\hline Brigitte Be Green & 2019 & Das Magazin für ein nachhaltiges Leben. \\
\hline Vegan Food \& Living & 2019 & Das vegane Lifestyle-Magazin. \\
\hline $33 \%$ & 2020 & Das Waldmagazin. \\
\hline Landldee - natürlich leben & 2020 & Einfach nachhaltige Tipps für jeden Tag \\
\hline
\end{tabular}

Neu ist auch, dass die Mainstream-Printmedien Nachhaltigkeit als Trendthema verstärkt aufgreifen. So erschienen 2019 mit Brigitte Be Green und Wohllebens Welt (beide aus dem Verlagshaus Gruner + Jahr) gleich zwei neue Magazine für unterschiedliche Zielgruppen im breiteren Publikum (Altrogge 2019; Matzig 2019). Das Interesse daran ist offenbar groß: Der Verlag meldete bei beiden Erstausgaben Verkaufszahlen von rund 45000 (Wohllebens Welt) beziehungsweise 50000 Exemplaren (Brigitte Be Green) (Tusch 2019; Borgböhmer 2019). 
Dass sich Printmagazine für die Vermittlung von komplexeren Fragestellungen aus dem Nachhaltigkeitskontext, sei es Energiewende, Artensterben oder Mobilität, besonders gut eignen, hängt einerseits mit der Beschaffenheit des Mediums Zeitschrift an sich zusammen: Denn sie stehen per se mit ihren langen Beiträgen für Tiefe und Detailfülle in der Darstellung, sind das Medium des Hintergrunds und kombinieren dies zudem noch mit einer ausgeprägten Visualität, was das Verständnis komplexer Stoffe erleichtert. Sie müssen ob der analogen Form, die nicht selten auch besonders ästhetisch, haptisch und optisch ansprechend daherkommt, mit Zeit und Muße konsumiert werden; entsprechend gut stehen die Chancen, dass durch die intensive Rezeption Inhalte nachhaltig im Gedächtnis bleiben. Andererseits bieten Zeitschriften auch journalistischen Spielraum: Sie sind durch ihre thematische Ausrichtung sowie den gratwandernden Charakter zwischen unterhaltendem und wissensvermittelndem Medium freier in der Themenpräsentation, in Erzählformen und vor allem auch in der Gestaltung als beispielsweise Tageszeitungen. Zeitschriften sollen »ihre Leser emotional erreichen, sie begeistern «, hebt der Wissenschaftsjournalist Martin Meister im Interview mit Torsten Schäfer $(2012,57)$ hervor. Die Basis, um transformativen Inhalten die notwendigen »Strukturen, Erfahrungs- und Resonanzräume« (Borner et al. 2019, 19) einzurichten, welche die Voraussetzung für nachhaltiges Handeln ist, scheint bei Magazinen schon von Grund auf gegeben.

Vor allem im Bereich des Nachaltigkeitsjournalismus ist eine zwar grundsätzlich sachlich-kritische, aber dennoch engagierte journalistische Haltung oder vielleicht sogar Meinung zum Themenkomplex präsenter als in anderen Bereichen und weicht von der Neutralität ab, die etwa im Nachrichtenjournalismus den journalistischen Berufsethos auszumachen scheint. ${ }^{6}$ Vielmehr ist Neutralität gegenüber den Themen Umweltschutz und Nachhaltigkeit kontraproduktiv für ein Magazin, das sich vorrangig mit diesen Themen beschäftigt: Nicht wenige der Magazingründer*innen - insbesondere die der unabhängigen, »nischigen« Hefte wie oya, transform oder Futurzwei - haben ihre Publikationen aus einer Überzeugung heraus gegründet und machen diese auch

6 Diesen Zwiespalt haben beispielsweise auch Humburg, Fischer, Marwege und Michelsen in ihrer Delphi-Studie (2013) untersucht. Die befragten Journalist*innen sahen darin einerseits die Notwendigkeit, ihr eigenes Engagement sichtbarer zu machen, um auch die Leser*innen zu aktivieren, waren sich aber des »Rollenkonflikts« (ebd., 23) bewusst. 
in ihren journalistischen Ausdrucksformen deutlich, ohne dabei pathetisch, mahnend oder lediglich unterhaltend zu wirken.

Das Problem des Klimawandels, dessen Lösung ein achtsameres Handeln der Gesellschaft voraussetzt, muss so kommuniziert werden, dass es auch für fachfremde Leser*innen verständlich ist. Die wissenschaftliche Komplexität von Klima-, Umwelt- und Nachhaltigkeitsthemen so zu vermitteln, dass möglichst viele Rezipierende sich für sie interessieren, im besten Fall selbst aktiv werden und so mitunter die für eine Nachhaltigkeitswende unabdingbaren politisch-strukturelle Reformen mit anstoßen, erfordert neue Journalismusformen. ${ }^{7}$ In diesem Zusammenhang taucht im Kontext der aktuellen Debatte zu Nachhaltigkeit und Journalismus in einer Sondierungsstudie des Umweltbundesamtes (Borner et al. 2019) der passende Begriff dazu auf, der zuvor im deutschsprachigen Raum kaum präsent war: ${ }^{8}$ »Impact-Journalismus « - ein Journalismus, der Leser*innen nicht nur zu einer Meinung, sondern auch zu einem Handlungswillen verhilft. Bezeichnend für ihn sind qualitativ hochwertige journalistische Arbeit, saubere Recherche und gleichzeitig eine Nähe zu den Rezipierenden, die letztere einbindet und sie den Journalismus mitgestalten lässt (ebd., 26-28). Aber auch literarische Formen kommen im Magazinjournalismus verstärkt zum Tragen - nicht zuletzt in Form von Nature Writing, das seinen Ursprung im englischsprachigen Raum hat und insbesondere in der hiesigen Literaturszene stark an Bedeutung gewinnt (vgl. Schäfer 2018). ${ }^{9}$

Ansätze des daraus resultierenden transformativen Charakters werden in vielen der neueren Magazine nicht nur inhaltlich, sondern auch

7 Damit ist selbstredend nicht nur die persönliche Verhaltensveränderung im Alltag gemeint, sondern auch die Anregung zu politischem Engagement. Dass grundlegende, wortwörtlich nachhaltige, gesamtgesellschaftliche Veränderungen geschehen und sich festgefahrene wirtschaftliche Strukturen auflösen, ist im Wesentlichen Aufgabe der Politik. Dafür ein Bewusstsein herzustellen muss ebenso Ziel des Nachhaltigkeitsjournalismus sein.

8 Das französische Start-up Sparknews etablierte den Begriff 2013 im Zusammenhang mit handlungsaktivierenden Geschichten, als es erstmals einen »Impact Journalism Day« veranstaltete (vgl. Krüger in diesem Band).

9 Henry David Thoreaus Selbsterfahrungsroman Walden (1854) gilt als Schlüsselwerk, das den Impuls gab, real Erlebtes in der Natur - also subjektive Erfahrungen - literarisch zu verarbeiten. Dabei werden auch naturwissenschaftliche Fakten eingeflochten. In vielerlei Hinsicht sind Ansätze von Nature Writing daher auch im Journalismus, oft in der Form der Reportage, zu finden und eignen sich gut, um ökologische Themen auf literarische Weise aufzuarbeiten. 
in der Erzählform sichtbar. Zwei Fallbeispiele sollen dies im Folgenden verdeutlichen.

\subsection{Poetische Sprache und visuelle Gestaltung bei Wohllebens Welt}

Im 2019 innerhalb der GEO-Markengruppe neu erschienenen Naturmagazin Wohllebens Welt wird im Beitrag »Weder Wasser noch Land « von Rainer Harf anschaulich gezeigt, wie literarische Charakteristika in bereits etablierte journalistische Formen (in diesem Fall ist es ein Feature mit szenischem Einstieg) eingeflochten werden können.

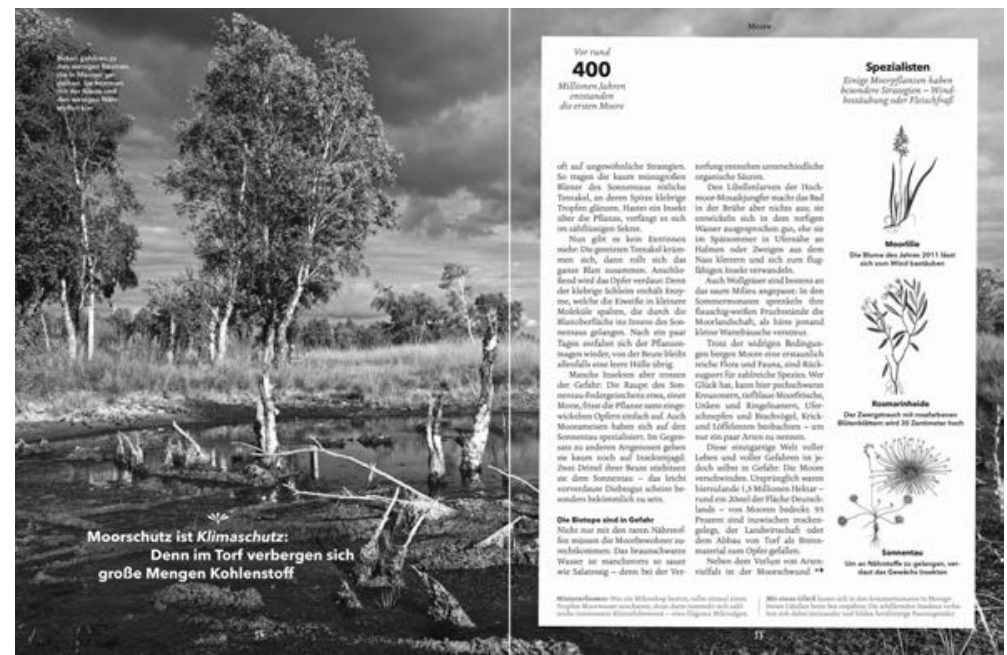

Abb. 1: Zahlreiche Formen der Wissensvermittlung finden sich auf dieser Doppelseite des Beitrags von Rainer Harf in Wohllebens Welt (Harf 2019, 54-55).

Der Artikel, in dem es um Moorlandschaften, deren Funktion im Ökosystem und deren Erhalt geht, spricht die Leser*innen zunächst visuell mit seitenfüllenden, fast schon romantischen Bildern an. Auch neben dem Fließtext ist viel auf den Seiten zu entdecken: Naturwissenschaftliche Pflanzenzeichnungen, Trivia-Beiträge zum Thema unten auf der Seite sowie hervorgehobene Zitate und Zahlen. Im Text selbst ist vor allem der erzählerische, literarisch anmutende Einstieg bemerkenswert: 
Bei jedem Schritt ertönt ein Gurgeln und Schmatzen. Nebelschwaden wabern über den morastigen Grund. Wie erstarrte Figuren ragen die Silhouetten knorriger Birken aus dem Riedgras. Hin und wieder unterbrechen seltsame Laute die gespenstische Stille: »Bu bu bu bu« - der Ruf einer Sumpfohreule. (Harf 2019, 51)

Die Poesie der Naturklänge dient hier als Vehikel für die Phantasie der Leser*innen und erleichtert es ihnen, sich auf die Thematik einzulassen. Gleichwohl ist der Beitrag reich an Fakten:

Da die abgestorbenen Pflanzen nur unvollständig verwesen und sich zu mächtigen Lagen aufschichten, entweicht der in ihnen gebundene Kohlenstoff nicht als Kohlendioxid in die Luft - so wie bei allen anderen verwesenden Pflanzen. Obwohl sie weltweit nur drei Prozent der Landfläche ausmachen, speichern Moore so viel Kohlenstoff wie alle Wälder der Erde zusammen. (Harf 2019, 56)

Die Komplexität des Verwesungsvorgangs nicht unerwähnt zu lassen ist Teil der Strategie zur Wissensvermittlung. Mit Hilfe der konsequent angewandten Erzählform versucht der Autor, die Informationsaufnahme der Leser*innen möglichst effektiv zu gestalten. Er schließt die Klammer mit einem literarischen Ausstieg: »Und dann kann man sie wieder genießen: die magische Aura dieser tückischen Lebensräume.« (Harf 2019, 56)

\subsection{Das Märchen als journalistischer Schreibmodus bei transform}

Ebenfalls erzählerisch, allerdings ohne visuelle Unterstützung und durchweg literarisch aufgezogen ist der Beitrag »\#HansImGlück« von Hans Rusinek (2018) in der werbeunabhängig und ausschließlich mit Crowdfunding produzierten Zeitschrift transform. Der Autor schildert darin konsequent im Märchenerzählstil die Geschichte von Hans im Glück in der modernen, kapitalistischen Welt und vermittelt den Leser*innen anhand dessen die Folgen der Konsumsucht sowie die Möglichkeit eines besitzlosen und dennoch freudvollen Lebens. Dabei greift er gleichermaßen auf den typischen Sprachduktus eines Märchens wie auf Begriffe und Phänomene des 21. Jahrhunderts zurück:

»Wohl wahr, lieber Hans, mein ist eine Bahncard 100. Auf ihrer Gunst fahre ich in allen Zügen, wann es mir beliebt. Ingleichen trenne ich mich vom 
sperrigen Besitz, mein Luxus ist die Reise.«— »Ei, was gäb ich darum, solch eine Bahncard mein eigen zu nennen!«, sagte Hans, den planetaren Grenzen seines Konsums bewusst. (Rusinek 2018, 62)

Im gleichen ungewöhnlichen Kontext werden außerdem Handlungsoptionen in Bezug auf Mobilität und Umweltauswirkung vermittelt:

»Hört, Hans«, sprach der [Sitz-]Nachbar und zeigte ihm ein Instagram-Abbild seines Rennrads, »euch zu Liebe will ich tauschen und euch das Rad für die Karte lassen. Bedenkt doch: Hier [beim Bahnfahren im ICE; TS \& SL] wird die Energie aus ungezählten Kohlekraftwerken durch die Trasse gejagt. Dekarbonisierung sieht anders aus. Das Rad schont die Umwelt und ihr reist mit eigener Kraft.« (Rusinek 2018, 63)

Die fiktionale Erzählung greift real existente Umstände auf und präsentiert sie in einer bekannten Form - die Kombination von Märchen und ökosozialer Betrachtung allerdings ist ungewöhnlich. Sie löst Neugier auf den Ausgang der Geschichte aus und regt zur Reflexion an: Wie hat der Autor die populären Eckpfeiler der Grimm'schen Erzählung auf die heutige Zeit übertragen? Was bedeutet das für mich und mein Handeln? Der Text transportiert Fakten, Unterhaltung und Handlungsoptionen gleichermaßen und stellt damit ein gelungenes Beispiel für den Ausbruch aus gewohnten journalistischen Formaten dar.

\subsection{Wie weiter? Literarisches Erzählen als Chance für Printmagazine}

Nicht nur die grüne Printmagazinlandschaft entwickelt sich stark weiter, auch der darin enthaltene Journalismus ist im Umbruch: Haltungsverdeutlichung, erzählerische Experimente und partizipative Ansätze mit Leser*innen kommen vermehrt vor und zeigen, dass und wie sich Nachhaltigkeit in ihrer ganzen Dimension in Publikumszeitschriften positioniert.

Die beiden Fallbeispiele verdeutlichen, wie verschieden die Durchschlagskraft und die Schnelligkeit dieses Wandels ablaufen kann: Während Wohllebens Welt als Publikation eines tradierten Verlagshauses noch recht behutsam auf literarische Erzählformen (in diesem Fall Nature Writing) zurückgreift, kann das unabhängige Magazin transform in Bezug auf fiktionales Erzählen aus den Vollen schöpfen (ohne den journalistischen Anspruch zu vernachlässigen). In jedem Fall zeigt 
sich, dass Magazine offen sind für Literarischen Journalismus, wie ihn Eberwein (2013, 144, 181, 188-189) beschreibt, und diesen praktisch nutzen: Kreativität, Subjektivität und die Tendenz, bestehende journalistische Konventionen aufzubrechen, sind prägende Merkmale.

Letztlich sind dies nur zwei Exempel für einen in Transformation begriffenen Nachhaltigkeitsjournalismus, der sich neben experimentelleren, literarischen Erzählformen zudem durch eine veränderte, haltungsstärkere Rolle der Schreibenden auszeichnet. Insbesondere angesichts des tendenziell steigenden Interesses der Mainstream-Medien an diesen Inhalten darf die weitere Umsetzung mit Spannung verfolgt werden. Mit Blick auf den sukzessiven gesellschaftlichen Wandel verändern sich möglicherweise die Vorzeichen für kleinere Magazine, die den Aufbruch als Chance nutzen könnten. Dass für Journalist*innen, die sich in diesem Bereich betätigen, die Voraussetzungen stimmen, ist dabei essenziell. Letztere haben sich in Teilen positiv entwickelt, wie im Folgenden anhand von neu entstandenen Metastrukturen für den praktischen Nachhaltigkeitsjournalismus gezeigt wird. Dabei geht es um Fachportale, Medienpreise, Aus- und Weiterbildungsmöglichkeiten, Berufsverbände und Hochschulangebote.

\section{Eine neue Infrastruktur aus Projekten, Plattformen, Stiftungen und Studiengängen ${ }^{10}$}

In den vergangenen zehn Jahren ist eine Infrastruktur entstanden, die das grüne Mediengeschehen bewertet, fördert und untersucht. Getragen werden die Forschungsprojekte, Rechercheplattformen, Studiengänge und Seminare von Hochschulen und Akademien, oft finanziert mit privaten Geldern und Stiftungsvermögen. Ebenfalls zugenommen hat die Zahl grüner Journalist*innenpreise. Derer 13 zählt das Portal journalistenpreise.de mittlerweile, darunter auch ein eigener Umweltjournalismus-Preis für Österreich.

Eines der jüngsten Elemente dieser Infrastruktur ist das Netzwerk Weitblick (NWW), ein Verein, der sich seit März 2015 für Nachhaltigkeit im Journalismus einsetzt. Derzeit sind mehr als 60 Journalist*innen und andere Medienschaffende sowie Wissenschaftler*innen dabei, von ARD und Deutschlandfunk bis FAZ und Tagesspiegel. Sie wollen Re-

10 Dieser Abschnitt ist eine überarbeitete Version eines Beitrags auf der Website klimafakten.de (Schäfer 2019b). 
cherchehilfen, Seminare sowie Stipendien anbieten und als Ansprechpartner*innen für Kolleg*innen dienen. Das Vorstandsteam hat ein zweijähriges Qualifizierungsprojekt samt Publikationsreihe entwickelt, um insbesondere jungen Journalist*innen zugehöriges Handwerk und Wissen in verschiedenen Feldern des Nachhaltigkeitsjournalismus vermitteln zu können. An vielen Akademien und Hochschulen ist das NWW mit seiner Weiterbildungsreihe präsent und damit zum bislang wichtigsten Anbieter von nachhaltigkeitsjournalistischen Seminaren geworden. Andere Initiativen, wie etwa die Initiative Nachhaltigkeitsjournalismus in Österreich, sind kleiner und weniger sichtbar.

Übrigens haben sich im NWW erstmals überhaupt deutschsprachige Journalist*innen im Feld von Umwelt und Nachhaltigkeit zusammengetan. In anderen Ländern war dies schon viel früher der Fall, beispielsweise in den USA mit der einflussreichen Society of Environmental Journalists (SEJ), aber etwa auch in Frankreich, Brasilien, Schweden, Indonesien, Kenia und Tansania.

\subsection{Gemeinsam publizieren: Synergien online nutzen}

Während beim NWW vor allem das Vernetzen und Fördern im Mittelpunkt steht, haben sich andere Journalist*innen explizit zum gemeinsamen Publizieren zusammengeschlossen: Eines der bekanntesten Beispiele ist das genossenschaftlich organisierte Onlineportal krautreporter.de, das sich durch Leserbeiträge finanziert und seine Artikel nur für Mitglieder zugänglich macht. Ohne eine generelle Bezahlschranke publizieren hingegen riffreporter.de, eine Gemeinschaft freier Journalist*innen, die in kleinen Gruppen themenspezifisch arbeiten und jeweils ihr Sachgebiet in einer »Koralle « online bündeln, um dort ihre Texte in Teilen zum Kauf anzubieten. Unter anderem gibt es thematische Kanäle für die Berichterstattung über spezielle Bereiche wie Vögel und Flüsse ebenso wie allgemeinere, etwa über das Klima.

Sowohl die Klima-Koralle der Riffreporter als auch klimareporter.de sind interessante, neue Stränge innerhalb des neuen medialen Netzwerkes der Nachhaltigkeit. Denn dort - ganz so wie bei oya und auch der Politischen Ökologie zur Nachhaltigkeit insgesamt - sind neue Einblicke und das ganze Tableau der Themen aus Klimapolitik, -forschung und Energiewende zu bekommen. Eine bewährte Recherchequelle auf Papier ist zudem die Zeitschrift Umwelt aktuell und die dazugehörige Website eu-koordination.de des Deutschen Naturschutzrings (DNR). Beide 
Medien informieren lückenlos vor allem über die EU-Perspektive von Klima- und Umweltthemen. Diese Sichtweise ist so kompakt sonst kaum zu finden und gerät bei Recherchen häufig in Vergessenheit. Ein weiterer Kanal speziell für den europäischen Blick ist das mehrsprachige Portal Euractiv mit eigenen Rubriken für Energiepolitik und Klimawandel.

Eng verknüpft mit dem erwähnten Netzwerk Weitblick ist die Plattform grüner-journalismus.de (die Torsten Schäfer, Mitautor dieses Beitrags, leitet). Das Projekt versucht seit Anfang 2014 von der Hochschule Darmstadt aus, die Berichterstattung zu Umwelt- und Nachhaltigkeitsthemen zu fördern - mit Themendossiers, Linklisten, einem Blog oder auch Interviews mit Umweltjournalist*innen und Forscher*innen. Das Geld zum Aufbau kam von der privaten Stiftung Forum für Verantwortung des früheren Metro-Vorstandes Klaus Wiegandt. Mittlerweile muss sich die Plattform selbst tragen. Entwickelt hat die Idee der Kommunikationswissenschaftler Peter Seeger, der schon seit Jahren dem Nachwuchs Nachhaltigkeit vermittelt. Noch immer, sagt er, gebe es große Defizite, etwa bei Themenauswahl und Blickwinkel, insbesondere in den großen Massenmedien: „Thematisiere ich eine vermeintliche >Wachstumsschwäche der Wirtschaft unhinterfragt - oder gelingt es, das Konzept von Wirtschaftswachstum kritisch zu betrachten und mit der Ressourcenund Verteilungsfrage zu verknüpfen? (Seeger, zitiert in Schäfer 2019b)

\subsection{Aus- und Weiterbildungsmöglichkeiten für Nachhaltigkeitsjournalist*innen}

Auch die Aus- und Weiterbildungslandschaft hat sich weiterentwickelt: Das Deutsche Journalistenkolleg bietet mittlerweile eine ganze Reihe zum Umweltjournalismus an. Dazu kommen Medienseminare zu Themen wie Klima, Energiewende oder Verkehr, die Stiftungen, Umweltverbände oder Beratungsagenturen anbieten. Ein Beispiel dafür ist die Sommeruniversität zu Storytelling und Klimawandel des Climate Culture Communications Lab in Brandenburg. Aber auch die RobertBosch-Stiftung bot im Rahmen ihrer Förderlinien wie etwa der Masterclass für Wissenschaftsjournalist*innen schon ganze Themenjahre zu Klima und Energie an. Fachverbände wie die Wissenschaftspressekonferenz machen ebenso klimajournalistische Weiterbildungsangebote für Medien wie Institutionen aus der Wissenschaft selbst, sei es das Potsdam-Institut für Klimafolgenforschung, der Deutsche Wetterdienst oder der Think Tank Ecologic. 
Entsprechende Fachseminare bieten nun die Hochschulen in Ansbach und Nürnberg an. Etabliert sind solche Veranstaltungen und Module schon in Darmstadt, an der FH Rhein-Sieg in St. Augustin sowie der Universität Dortmund, die seit 2013 den Medien-Doktor Umwelt betreibt. In diesem Projekt begutachten Fachjournalist*innen (zeitweise darunter auch Torsten Schäfer, Mitautor dieses Artikels) anhand von 14 Qualitätskriterien die Umweltberichterstattung deutscher Medien. Die Gelder stammen auch hier von der privaten Wilo-Foundation, hinter welcher der Dortmunder Pumpensystemhersteller Opländer steht.

Stiftungsgelder sind zunächst ein Segen, der aber meist nicht ewig währt. Sie schieben an, sichern vielleicht auch ab, garantieren aber meist keine dauerhafte Unterstützung. Eine langfristig tragfähige Mischfinanzierung scheint beispielsweise die gemeinnützige Rechercheplattform correctiv.org gefunden zu haben - angeschoben mit Geldern der Essener Brost-Stiftung, akquiriert sie inzwischen Mittel sowohl von anderen Stiftungen als auch privaten Unterstützer*innen, zu denen große Internetkonzerne wie etwa Google oder Facebook zählen.

Dauerhafter können Hochschulen und Universitäten arbeiten - aber eben vor allem in der Forschung und Ausbildung. Gerade die kommunikationswissenschaftliche Erforschung des Klimajournalismus hat sich in den vergangenen zehn Jahren stark entwickelt; zu nennen sind hier etwa die Universitäten in Hamburg, Ilmenau, Lüneburg, Dortmund und Zürich, aber auch Hochschulen in Nürnberg und Darmstadt.

Auch Universitäten ohne journalistische Bezüge haben sich in die Debatte eingebracht: Die Forschungsstelle für Umweltpolitik der FU Berlin hat unter der Leitung von Roland Zieschank zusammen mit dem umtriebigen Berliner Wissenschaftsjournalisten Manfred Ronzheimer Medienseminare zur Großen Transformation ins Leben gerufen, zu denen Aktivist*innen, Forscher*innen, Journalist*innen und Stiftungspersonal in den Jahren 2016 und 2017 erschienen und die Vernetzung des losen, grünmedialen Netzwerks weiter voranbrachten.

Überhaupt Berlin: Hier finden die meisten Seminare und Konferenzen zum Themenkreis statt, im Juli 2019 etwa ein Workshop zu Klimawandel und Sprache, den das Netzwerk Degrowth-Journalismus und die taz-Panther-Stiftung organisierten. Damit zeigten sie, welche Qualität und Tiefe die Vernetzung mittlerweile erreicht hat. Denn es ging, wie so oft in den vergangenen Jahren, nicht mehr um die grundlegende Frage, wie Medien über Klima oder Energie berichten und wie sie dies besser machen könnten. Sondern die eingeladenen Journalist*innen, darunter GEO-Reporterin Johanna Romberg und Johannes Heimrath 
von oya, diskutierten stundenlang um sperrige Begriffe und mögliche alternative Wortschöpfungen für die Klimakommunikation. Hintergrund waren neue Sprachregelugen, die etwa der britische Guardian für seine Klimaberichterstattung jüngst etabliert hatte (Carrington 2019).

Die Metadebatte zum Klimajournalismus differenziert sich also aus. Was fehlt, ist noch ein eigener Studiengang in diesem Bereich, wie es ihn an der Universität von Boulder (Colorado) in den USA gibt, aber auch im schwedischen Jonköping. Den einzigen eigenständigen Ausbildungsgang bot, oft in Wochenendkursen, bisher die Leuphana Universität Lüneburg mit dem 2012 gestarteten, berufsbegleitenden Zertifikat »Nachhaltigkeit und Journalismus « an (der Autor war daran beteiligt). Inzwischen liegt das Programm auf Eis, es fanden sich zuletzt zu wenige interessierte Berufstätige, die bereit waren, rund 4500 Euro an Gebühren zu bezahlen. Einige frühere Absolvent*innen haben zwischenzeitlich das Netzwerk Weitblick mitgegründet, insofern haben die Lüneburger Aktivitäten strukturelle Spuren hinterlassen - aber auch wissenschaftliche, denn in Lüneburg entstand unter Daniel Fischer und Gerd Michelsen ein eigener Forschungsbereich, der sich Nachhaltigkeit und Medien widmet.

\section{Zwischenfazit: Hoffnungsvolle Entwicklungen, wenige Ressourcen}

Was hat das vielfältige Netzwerk rund um den grünen Journalismus bisher erreichen können? Nützlich sind sicherlich die zahlreichen Recherchehilfen und Themendossiers auf manchen Websites. In welchem Umfang diese tatsächlich genutzt werden und welche Auswirkung sie auf den praktischen Journalismus haben, müsste näher untersucht werden. Ein Indikator für Erfolg ist die beobachtbare Vertiefung und Differenzierung von Debatten. So geht es auf Podien bisweilen speziell um Sprache im Klimajournalismus - und nicht mehr nur um Klimajournalismus im Allgemeinen. Hoffnungsvoll stimmen gerade auch die Aktivitäten von jungen Kolleg*innen wie im Fall des Netzwerk Degrowth-Journalismus. Ebenso positiv ist die Beobachtung, dass sich augenscheinlich immer mehr Bachelor- und Masterkandidat*innen für nachhaltigkeitsjournalistische Themen und Fragen der medialen Nachhaltigkeit entscheiden, was aber ebenfalls übergreifend analysiert werden müsste.

Vielleicht ist es noch zu früh, um ein Fazit zu ziehen. Der eingangs zitierte Daniel Fischer, der die Lüneburger Projekte mit aufgebaut 
hat, weist darauf hin, dass der Journalismus erst vergleichsweise spät begonnen habe, sich intensiver mit Nachhaltigkeit und deren Einzelthemen zu befassen - »viel später als etwa der Bildungssektor oder die Wissenschaft« (Fischer, zitiert in Schäfer 2019b).

Verändert hat der Medien-Doktor Umwelt bereits die Sicht auf die deutsche Umweltberichterstattung. Denn nach einer Analyse der ersten 50 Beiträge, jeweils anhand von 13 Kriterien begutachtet, wird klar, wo es klemmt und was Medien gut machen: Recht selten werden Umweltprobleme aufgebauscht oder verharmlost und es fanden sich auch nur in sechs Artikeln klare Faktenfehler wie etwa falsche Zahlen. Häufiger versäumen es Journalist*innen, verschiedene Standpunkte zu recherchieren; Tendenzen zur Einseitigkeit sind erkennbar. Oft mangelt es an kundiger Einordnung: Selbst wenn beispielsweise der $\mathrm{CO}_{2}$-Ausstoß eines Landes korrekt angegeben wird, erklärt die Zahl für sich genommen noch wenig - sie müsste in Bezug gesetzt werden zu Vorjahren, anderen Staaten oder Zielmarken (vgl. Rögener 2015).

Das größte Problem ist laut Medien-Doktor Umwelt aber fehlender Kontext: 42 von 50 Zeitungsartikeln, Radioanalysen und Onlinestücken berichteten relativ eng gefasst und ereignisfixiert über Umweltprobleme und setzten sie nicht weiter in Bezug zu wirtschaftlichen, sozialen oder politischen Hintergründen. Dahinter dürften Mängel beim Sachwissen zum Klimawandel stehen, aber etwa auch zur EU-Dimension der Umwelt- und Klimapolitik (vgl. ebd.). Ein Grund für die fatale "Dekontextualisierung«, wie Forscher*innen es nennen, ist aber auch das Mehrfachparadoxon, in dem Journalist*innen heute oft arbeiten: Sie sollen mit weniger Personal in kürzerer Zeit komplexer werdende und noch in der Zahl zunehmende Themen zu einer insgesamt besseren Qualität mit Hilfe immer neuer Technologien fortwährend attraktiver produzieren. Im Ergebnis fehlt vor allem eine Ressource: Zeit - für Recherche und Faktencheck, für Weiterbildung und Wissenserwerb. Dies gilt vor allem für kleinere und regionale Medien.

Dasselbe lässt sich für den Nachhaltigkeitsjournalismus konstatieren, zu dessen Verbesserung es unterm Strich neue Ideen der Finanzierung braucht, gerade im Hinblick auf kleine und regionale Medien, die über die Einzelthemen aus dem Nachhaltigkeitskontext berichten sollen. In Skandinavien gibt es erfolgreiche Systeme der öffentlichen Medien- und Presseförderung durch unabhängige Räte, die staatliche Gelder meist an kleinere Regionalmedien geben - um explizit die publizistische Vielfalt in der Provinz zu sichern (Schäfer 2019a). Solche Modelle könnten auch für Deutschland diskutiert werden im Hinblick auf eine Ausweitung und 
Verbesserung etwa des Klimajournalismus, der im Zuge der Klimafolgen (Waldsterben, Wassermangel, Landwirtschaft und Trockenheit) zunehmend lokaler werden wird und dem vor dem Hintergrund der fortschreitenden Klimanot eine immer größere Verantwortung zukommt.

\section{Literatur}

Altrogge, Georg. 2019. „Waldbaden« mit Wohlleben als Magazin: Warum es höchste Zeit ist, dass wir alle mal einen Baum umarmen. Meedia.de vom 18. April, https://meedia.de/2019/04/18/waldbaden-mit-wohlleben-als-magazinwarum-es-hoechste-zeit-ist-dass-wir-alle-mal-einen-baum-umarmen/. Zugegriffen: 25. August 2020.

Borgböhmer, Thomas. 2019. Mehr als 55.000 Exemplare: G+J meldet Verkaufszahlen für Premierenausgabe von »Brigitte be Green«. Meedia.de vom 10. Dezember, https://meedia.de/2019/12/10/mehr-als-55-000-exemplare-gj-meldet-verkaufszahlen-fuer-premierenausgabe-von-brigitte-be-green/. Zugegriffen: 25. August 2020.

Borner, Joachim, Anke Ochsenfarth und Manfred Ronzheimer. 2019. Impact-Journalismus und zielgenaues Storytelling für gesellschaftlichen Wandel. Sondierungsstudie des Umweltbundesamtes. Berlin: Kolleg für Management und Gestaltung nachhaltiger Entwicklung GmbH, Umweltbundesamt. http://kmgne.de/wpcontent/uploads/2019/12/Sondierungsstudie-des-Umweltbundesamtes-2019. pdf. Zugegriffen: 25. August 2020.

Carrington, Daniel. 2019. Why the Guardian changes the language it uses about the environment. The Guardian vom 17. Mai, https://www.theguardian.com/ environment/2019/may/17/why-the-guardian-is-changing-the-language-ituses-about-the-environment/. Zugegriffen: 25. August 2020.

Eberwein, Tobias. 2013. Literarischer Journalismus. Theorie - Traditionen - Gegenwart. Köln: Herbert von Halem.

Fischer, Daniel. 2020. Nachhaltigkeitskommunikation. In: Nachhaltigkeit - interdisziplinär. Konzepte, Diskurse, Praktiken. Ein Kompendium, herausgegeben von Evi Zemanek und Ursula Kluwick, 42-55. Köln: UTB Böhlau.

Fischer, Daniel, und Franziska Hauke. 2016. Die Verwendung von »Nachhaltigkeit« in deutschen Zeitungen: Ergebnisse einer empirischen Medienanalyse. In: Nachhaltigkeit und Journalismus. Erkenntnisse und Impulse aus Wissenschaft und Praxis, herausgegeben von Gerd Michelsen und Daniel Fischer, 55-70. Bad Homburg: Verlag für Akademische Schriften.

Fischer, Daniel, und Thomas Stollenwerk. 2016. Das gute N-Wort. Grüner Journalismus vom 28. Dezember, https://gruener-journalismus.de/studie-begriffnachhaltigkeit/. Zugegriffen: 27. August 2020.

Harf, Rainer. 2019. Weder Wasser noch Land. Wohllebens Welt Nr. 2, 46-56.

Matzig, Gerhard. 2019. Weltretten ist Frauensache. Süddeutsche Zeitung vom 14. 
Oktober 2019, https://www.sueddeutsche.de/medien/frauenzeitschrift-brigitte-be-green-nachhaltigkeit-1.4638443/. Zugegriffen: 25. August 2020.

Menhard, Edigna, und Tilo Treede. 2004. Die Zeitschrift. Von der Idee bis zur Vermarktung. Konstanz: UVK.

Michelsen, Gerd, und Daniel Fischer (Hrsg.). 2016. Nachhaltigkeit und Journalismus. Erkenntnisse und Impulse aus Wissenschaft und Praxis. Bad Homburg: Verlag für Akademische Schriften.

Oestreicher, Fabian (Hrsg.). 2020. Nachhaltigkeitsmedien. https://futurphil.de/ medien/nachhaltigkeitsmedien/. Zugegriffen: 30. September 2020.

Panini Verlags GmbH (Hrsg.). 2019. Mediadaten LandKind 2020, https://blaufeuer.com/wp-content/uploads/LandKind_Mediadaten_2020.pdf. Zugegriffen: 30. September 2020.

Rögener, Wiebke. 2015. Umweltjournalismus. Einbettung in den Kontext fehlt. European Journalism Observatory vom 15. Oktober 2015, https://de.ejo-online. eu/qualitaet-ethik/umweltjournalismus-einbettung-den-kontext-fehlt/. Zugegriffen: 25. August 2020.

Rusinek, Hans. 2018. \#HansImGlück. transform Nr. 5, 62-63.

Schäfer, Torsten. 2019a. Zeitungssterben. Lösungsansätze aus Skandinavien. Fachjournalist.de vom 29. August, https://www.fachjournalist.de/zeitungssterbenloesungsansaetze-aus-skandinavien/. Zugegriffen: 30. September 2020.

Schäfer, Torsten. 2019b. Wo steht der deutschsprachige Umwelt- und Klimajournalismus? Ein Überblick. klimafakten.de vom 16. September, https://www.klimafakten.de/meldung/wo-steht-der-deutschsprachige-umwelt-und-klimajournalismus-ein-ueberblick/. Zugegriffen: 27. August 2020.

Schäfer, Torsten, und Martin Meister. 2012. Es gibt eine gewisse Borniertheit. In: Umwelt Europa. Grüne Gesellschaft und europäische Krise - neue Fragen an den Journalismus, herausgegeben von Carla Schulte-Reckert und Torsten Schäfer, 52-59. Berlin: Friedrich-Ebert-Stiftung Journalistenakademie.

Schäfer, Torsten, Lena Kasper, und Felix Austen. 2015. Der Kiosk als sozialer Spiegel: Wertewandel und Zeitschriftenmarkt. Fachjournalist.de vom 23. Januar, https://www.fachjournalist.de/der-kiosk-als-sozialer-spiegel-wertewandelund-zeitschriftenmarkt/. Zugegriffen: 25. August 2020.

Schäfer, Torsten. 2018. Erfolgsfaktor Natur - Das Genre Nature Writing. Fachjournalist.de vom 13. Dezember, https://www.fachjournalist.de/erfolgsfaktor-natur-das-genre-nature-writing/. Zugegriffen: 30. September 2020.

Tusch, Robert. 2019. Gruner + Jahr: Naturmagazin »Wohllebens Welt« übertrifft zum Start die Erwartungen. Meedia.de vom 1. Juli, https://meedia. de/2019/07/01/gruner-jahr-naturmagazin-wohllebens-welt-uebertrifft-zumstart-die-erwartungen/. Zugegriffen: 25. August 2020.

\section{Open Access}

Dieser Beitrag erscheint unter der Creative-Commons-Lizenz CC BY-ND 3.0 DE: https://creativecommons.org/licenses/by-nd/3.0/de/. 


\title{
Geburtshelfer für öko-soziale Innovationen: Konstruktiver Journalismus als Entwicklungskommunikation für westlich-kapitalistische Gesellschaften in der Krise
}

\author{
Uwe Krüger
}

Keywords: Konstruktiver Journalismus, Transformativer Journalismus, Development Journalism, journalistisches Rollenverständnis, Lösungsorientierter Journalismus, Große Transformation, Nachhaltigkeit, Kapitalismus, Berichterstattungsmuster

\section{Abstract}

In westlichen Gesellschaften ist seit Beginn der 2010er Jahre eine kleine Strömung im Journalismus sichtbar geworden, die sich der Berichterstattung über positive Entwicklungen und gelingende Problemlösungen verschrieben hat: Sie nennt sich »Lösungsorientierter « oder "Konstruktiver Journalismus«. Dieser Beitrag diskutiert die theoretische Fundierung des Konstruktiven Journalismus und wie er in Richtung eines "Transformativen Journalismus« weiterentwickelt oder präzisiert werden kann, indem man ihn mit der Idee einer »Großen Transformation « zur Nachhaltigkeit und den Sustainable Development Goals der Vereinten Nationen verknüpft. Abschließend wird das Konzept mit dem des »Development Journalism« verglichen, das seit den 1960er Jahren im Globalen Süden Anwendung findet. Als brauchbares Erbe erscheint dessen Strang, der kritisch und unabhängig über langfristige Entwicklungsprozesse und Innovationen berichtet; zurückgewiesen wird dessen Ausprägung in autoritären Staaten, die Journalist*innen zu PR-Agent*innen der Regierung degradiert. 
Ich danke den Kollegen Holger Pötzsch und Armin Scholl sowie den Studierenden Thilko Gläßgen, Alexandra Hilpert, Maria Ludowika Leidinger, David Muschenich, Kai Remen, Leonie Rottmann, Elisabeth Winkler und Teresa Wolny für ihre konstruktive Kritik des Manuskripts.

Uwe Krüger: Geburtshelfer für öko-soziale Innovationen: Konstruktiver Journalismus als Entwicklungskommunikation für westlich-kapitalistische Gesellschaften in der Krise. In: Nils S. Borchers, Selma Güney, Uwe Krüger und Kerem Schamberger (Hrsg.): Transformation der Medien - Medien der Transformation. Verhandlungen des Netzwerks Kritische Kommunikationswissenschaft. Frankfurt am Main: Westend 2021. DOI: https://doi. org/10.53291/SDTM5470.

Dr. Uwe Krüger I Universität Leipzig | uwe.krueger@uni-leipzig.de

\section{Journalismus: Eine Institution zur Reproduktion des Kapitalismus?}

Eure größte Aufgabe in den kommenden Jahrzehnten besteht darin, innovativ zu sein, aber nicht in Bezug auf Maschinen, sondern in Hinblick auf euch selbst.

(Ismael, in Daniel Quinn: Ismaels Geheimnis, Goldmann 1999, 228)

Kapitalistische Gesellschaften, so sieht es die Kritische Theorie marxistischer Prägung, sind trotz einer krisenanfälligen Wirtschaft und hoher Ungleichheit stabil, weil ihre Mitglieder sie in alltäglichen Tätigkeiten unbewusst und passiv reproduzieren und weil bestimmte Institutionen aktiv für eine Reproduktion sorgen. Zu letzteren gehören staatliche Bürokratie, Polizei und Gerichte, welche die bestehenden Macht- und Herrschaftsstrukturen in letzter Konsequenz mit Zwangsmitteln schützen, sowie das Bildungssystem und die Medien, die auf softere Weise dafür sorgen, dass die Subjektivität der (meisten) Individuen von den herrschenden Normen, Ideen, Werten, Doktrinen und Theorien geprägt wird (vgl. Wright 2017, 378, 388). Nicht nur in der europäischmarxistischen Tradition kritischen Denkens erscheinen die großen Medienhäuser und der darin organisierte redaktionelle Journalismus als Hüter kapitalistischer Wachstums- und Ungleichheitsideologie; auch die nordamerikanischen Spielarten der Critical Political Economy (vgl. Sevignani 2016, 6) sehen sie so. Beispielhaft seien zwei Sätze von Herman und Chomsky $(2002,1)$ über die Massenmedien zitiert: 
It is their function to amuse, entertain, and inform, and to inculcate individuals with the values, beliefs, and codes of behavior that will integrate them into the institutional structures of the larger society. In a world of concentrated wealth and major conflicts of class interest, to fulfil this role requires systematic propaganda.

Europäische Marxist*innen argumentieren, dass Medien die kapitalistische Wirtschaftsweise stützen, indem sie verschiedene Funktionen für das Kapital erfüllen. Knoche $(2002,106)$ nennt derer vier:

- eine Kapitalverwertungsfunktion für die Medienwirtschaft (etwa: Medieneigentümer*innen erzielen mit ihren Produkten Gewinne),

- eine Absatz-, Werbe- und PR-Funktion der Medien für die übrige Wirtschaft (etwa: Werbetreibende Unternehmen machen ihre Produkte oder Marken der Öffentlichkeit bekannt),

- Funktionen der Legitimations- und Herrschaftssicherung sowie der Förderung eines allgemeinen Konsumklimas (etwa: Ideologie wird durch Medieninhalte an die Rezipient*innen vermittelt),

- Funktionen der Regeneration und Qualifizierung des Arbeitsvermögens als Basis für die Kapitalverwertung (etwa: Arbeiter*innen entspannen sich nach einem harten Tag bei Unterhaltungssendungen).

Allerdings: Der in den Medienhäusern betriebene redaktionelle Journalismus als (formal unabhängige) Institution zur Berichterstattung über das aktuelle Geschehen beziehungsweise zur Selbstbeobachtung der Gesellschaft kommt in dieser Sichtweise als Stütze des Kapitalismus ${ }^{1}$ kaum vor. Allenfalls dem Wirtschaftsjournalismus wird eine explizite Funktion für die Kapitalakkumulation zugeschrieben, wenn er Informationen über Märkte und Unternehmen verbreitet und damit Investor*innen und Aktionär*innen bei der Entscheidungsfindung hilft, also eine Rolle in der »Zirkulationssphäre« des Kapitals spielt (vgl. Sevignani

1 Kapitalismus wird hier mit Wright $(2017,78)$ verstanden als »eine bestimmte Art, die Wirtschaftstätigkeit einer Gesellschaft zu organisieren. Er kann anhand zweier Hauptaspekte charakterisiert werden: des Wesens seiner Klassenverhältnisse und seiner zentralen Mechanismen wirtschaftlicher Koordinierung.« (Hervorhebung im Original) Zentrale Merkmale sind Privateigentum an Produktionsmitteln und »Mechanismen des dezentralisierten, freiwilligen Tausches zwischen privat verhandelnden Vertragsparteien « (freier Markt), »wodurch die Preise und Mengen der produzierten Güter und Dienstleistungen bestimmt werden«. Hieraus »geht der charakteristische Wettbewerbstrieb kapitalistischer Betriebe hervor, ihr Streben nach Profit und Kapitalakkumulation« (ebd., 78-79). 
2016, 9). Die nordamerikanischen Kolleg*innen sehen dagegen eine generelle Rolle des Journalismus (zumindest wie er von großen, etablierten Medienhäusern produziert wird) bei der Reproduktion kapitalistischer Macht- und Ungleichheitsstrukturen. Das zentrale Argument hierbei lautet, dass die Journalist*innen großer Medien hauptsächlich den Elitendiskurs abbilden, also die vorhandenen Konflikte zwischen den politischen und wirtschaftlichen Entscheider*innen spiegeln, gleichzeitig aber einen jeweils gegebenen Elitenkonsens (etwa zur geopolitischen Grundorientierung oder makroökonomischen Ordnung) teilen und Dissens von »außen « beziehungsweise »unten « marginalisieren oder delegitimieren. Diese Denkfigur findet sich in verschiedenen Konzepten und Ansätzen, allen voran im Propagandamodell von Herman und Chomsky (2002), aber auch in der Indexing-Hypothese von Bennett, in der Schutzhund-Perspektive von Donohue, Tichenor und Olien oder im Protest-Paradigma von McLeod und Hertog (vgl. Krüger 2019, 46-71).

Die Begründung, warum formal unabhängige Journalist*innen sich mehr oder weniger auf die Abbildung des Elitendiskurses beschränken, fällt jeweils etwas unterschiedlich aus: Einmal ist es die Dominanz offizieller Quellen, bedingt durch ein Bestreben in den Newsrooms, effizient Storys zu produzieren und Druck oder Kritik zu vermeiden; einmal sind es Tiefenstrukturen ökonomischer und politischer Macht beziehungsweise die Verflechtungen der Medienhäuser und ihres Personals mit Institutionen von Staat und Wirtschaft (vgl. ebd., 71-72); aber auch familiärer Hintergrund, Bildungsbiographie und Milieuzugehörigkeit vieler Journalist*innen mögen eine gewisse Eliten-Nähe begünstigen (Krüger 2016, 71-84). Doch selbst in einer wenig gesellschaftskritischen Theorietradition wie der Nachrichtenwertforschung erscheint ein solches Medienverhalten plausibel, denn Nachrichtenfaktoren wie Elite-Personen, Elite-Institutionen, Konflikt, Reichweite und Folgenschwere stellen wichtige Kriterien für journalistische Selektions- und Gewichtungsentscheidungen dar (vgl. Galtung und Ruge 1965; Beiler 2013, 127). Daher dürften Journalist*innen schon qua Gewohnheit und beruflicher Sozialisation den Konflikten im Eliten-Milieu, die potenziell große unmittelbare Auswirkungen auf die Bevölkerung haben, einen hohen Nachrichtenwert zuschreiben. Für die Elitenorientierung großer Medien sind also möglicherweise nicht nur die fünf »Filter« des Propagandamodells ausschlaggebend (Besitzverhältnisse und Medieneigentümer, Werbekunden, hauptsächliche Quellen, Flakfeuer und Ideologie), sondern auch vier »Filter« aus der Nachrichtenwerttheorie, also vier Nachrichtenfaktoren, die sich im Fall von Konflikten im Eliten- 
Milieu stets addieren und so dafür sorgen, dass der Elitendiskurs in der Berichterstattung dominiert und ein jeweiliger Elitenkonsens zu einem Thema quasi automatisch übernommen wird (oder zumindest die Prämissen des Elitendiskurses kaum hinterfragt werden).

Diese Überlegungen führen zu der Annahme, dass (große) Medien beziehungsweise der in ihnen organisierte professionelle Journalismus nicht zwangsläufig und ausschließlich Institutionen zur aktiven Reproduktion einer kapitalistischen Wirtschaftsform darstellen, sondern diese möglicherweise auch passiv und unbewusst reproduzieren. Zumindest gibt es ein mit dem Berufshandeln professioneller Journalist*innen verbundenes Set an redaktionellen Selektionsroutinen und journalistischem Rollenselbstverständnis, das bewusster, begründeter Veränderung zugänglich ist und sich auch gegen die Reproduktion des Kapitalismus wenden kann. Tatsächlich gibt es bereits im journalistischen Feld Akteur*innen, die abweichende Rollenbilder und Routinen ausgeprägt haben, und tatsächlich gibt es nicht den einen Journalismus, sondern verschiedene Journalismen im Sinne von »Berichterstattungsmustern«, die (oft in denselben Zeitungen, Fernsehprogrammen und News-Portalen) nebeneinander herlaufen: Meier (2018, 194-200) nennt neben dem dominanten Nachrichtenparadigma des »Objective Reporting «, das durch seinen Fokus auf die Themen und Positionen etablierter Organisationen am ehesten den Status quo legitimiert und stabilisiert, unter anderem die Muster des »Investigativen«, des »Anwaltschaftlichen « und des »Konstruktiven Journalismus«.

Ziel dieses Beitrags ist es, den Raum für Journalist*innen und Berichterstattungsmuster, die sich gegen die Reproduktion des Kapitalismus wenden oder über ihn hinausgehen und eine (wie auch immer geartete) nachkapitalistische Gesellschaft ${ }^{2}$ befördern wollen, auszuweiten und durch theoretische Begründung abzusichern. Dies erscheint dringlich aufgrund der aktuellen ökologischen und sozialen Vielfachkrise, welche die Stabilität der Gesellschaften und letzten Endes sogar den Fortbestand der menschlichen Art bedroht (Bendell

2 Dabei wird anerkannt, dass kein reales Wirtschaftssystem komplett kapitalistisch (oder sozialistisch oder etatistisch) organisiert ist, sondern stets eine Mischform darstellt. Die Rede vom Kapitalismus meint hier, dass innerhalb des Wirtschaftssystems die kapitalistische Form dominiert; und eine Transformation zu einem nachkapitalistischen Wirtschaftssystem wird nicht als »binärer Übergang von einem System zum anderen begriffen [...], sondern vielmehr als Verschiebung innerhalb der Anordnung der Machtverhältnisse, die eine Mischform ausmachen« (Wright 2017, 488). 
2020; Krüger und Pfeiffer 2020). Diese Krise ist zumindest mitverursacht von systemisch begründeten Wachstums-, Beschleunigungsund Externalisierungszwängen im Kapitalismus (vgl. Dörre et al. 2017; Dörre in diesem Band), weshalb eine »demokratische Postwachstumsgesellschaft « (Krüger und Meyen 2018, 348) erstrebenswert ist.

Der Beitrag folgt der Überlegung, dass die Institutionen zur aktiven gesellschaftlichen Reproduktion »nicht [...] immer wirksam sind « und zudem »Grenzen und Widersprüche« aufweisen, die für gesellschaftliche Emanzipation und Transformation genutzt werden können (Wright 2017, 378). Verschiedene Berichterstattungsmuster und Rollenverständnisse werden hier im Sinne von Widersprüchen und Vielfältigkeit innerhalb des regelgeleiteten Systems »Journalismus « angesehen. ${ }^{3}$ Der Beitrag folgt auch dem von Krüger und Meyen (2018) skizzierten Forschungsprogramm einer »transformativen Kommunikationswissenschaft«. Teil dieses Programms ist es, das Konzept des Konstruktiven Journalismus »so zu formulieren, dass es Nachhaltigkeits- und Gerechtigkeitszielen dient und eine Komponente transnationaler Solidarität enthält, anstatt zu kommerzialisierter Wellness-Berichterstattung für das heimische Wohlstandspublikum zu pervertieren« (ebd., 353). Im Folgenden wird daher der Konstruktive Journalismus mit der Idee einer "Großen Transformation « zur Nachhaltigkeit und dem aus dem Globalen Süden stammenden Konzept des Entwicklungsjournalismus (»Development Journalism«) zusammengebracht, um daraus Folgerungen für das Rollenverständnis und die Selektionsroutinen eines »Transformativen Journalismus« im Globalen Norden zu ziehen.

\section{Der Trend des Konstruktiven Journalismus}

Unter dem Oberbegriff »Konstruktiver Journalismus« werden ungefähr seit den letzten zehn Jahren im überwiegend europäischen und amerikanischen Raum journalistische Ansätze diskutiert, die sich dem vorherrschenden »negativity bias« in den Medien entgegenstellen und unter Einbezug

3 Journalismus wird hier im Sinne des Neo-Institutionalismus als Institution angesehen, da er als dauerhaft angelegtes Regelsystem sowohl soziales Handeln begrenzt und ermöglicht als auch auf seine Umwelt im normierenden, regulierenden, konstitutiven und repräsentativen Sinne einwirkt (vgl. Donges 2006, 568-569). Journalismus ist dann »eine Erwartungsstruktur, die durch soziale Praktiken über große Spannen von Raum [...] und Zeit [...] hinweg reproduziert wird« (Buschow 2012, 36). 
von Erkenntnissen der positiven Psychologie eine vermehrt konstruktive, lösungsorientierte Berichterstattung von Journalist*innen einfordern.

So umreißt Schmidt $(2017,15)$ den Trend, der hier von Interesse ist und der sich in den vergangenen Jahren etwa in der Gründung des Solutions Journalism Network in New York (2013), des Constructive Institute an der Universität Aarhus (2017) und des Constructive Journalism Network (2017) äußerte. Seit 2013 veranstaltet das Pariser Medien-Startup Sparknews jährlich einen weltweiten »Impact Journalism Day«, an dem Zeitungen aus aller Welt untereinander lösungsorientierte Artikel austauschen und gesammelt drucken. Spezialisierte Zeitungen, Zeitschriften und Onlineportale wurden gegründet, beispielsweise Positive News (1994) in Großbritannien, Yes! (1996) in den USA sowie enorm (2010), oya (2010), Perspective Daily (2015), Kater Demos (2015), transform (2015) und andere in Deutschland. Rundfunkanstalten führten lösungsorientierte Rubriken und Sendereihen ein, wie NDR Info »Perspektiven« (2016), das ZDF die Doku-Reihe »Plan B« (2017) und tagesschau.de den »Lösungsfinder« (2019). Außerdem bringen Zeitungen vermehrt Artikelserien und Sonderausgaben mit Good News (Beispiele in Kramp und Weichert 2020; Meier 2018; Krüger und Gassner 2014). Breit rezipiert wurden in der Medienbranche einige Bücher zum Thema von Vordenker*innen und Protagonist*innen der Szene (Haagerup 2015; Gyldenstedt 2015; Urner 2019).

Der Trend ist weiterhin ablesbar an der Veranstaltung spezialisierter Konferenzen (»Global Constructive Journalism Conference« seit 2017 an der Universität Aarhus, »Constructive Journalism Day« seit 2018 von Hamburg Media School und NDR), der Auslobung eines Preises (»Global Constructive Journalism Award«) und der Aufnahme des Themas in die Curricula von Journalist*innenschulen und Hochschulen. Konstruktiver Journalismus wird zudem von Stiftungen gefördert: in Deutschland von der Noah Foundation und der Schöpflin-Stiftung, die seit 2017 »Schöpflin-Stipendien für lösungsorientierten Journalismus« vergeben, von der in Wien ansässigen UNGSII Foundation (United Nations Global Sustainability Index Institute), die seit 2017 den »Global Constructive Journalism Award « finanziert, und von Dutzenden USStiftungen, die das Solutions Journalism Network unterstützen (darunter Knight Foundation, Bill \& Melinda Gates Foundation und Rockefeller Foundation). ${ }^{4}$

4 Die Geldgeber des SJN finden sich unter: https://www.solutionsjournalism. 
Aber mit Hilfe welcher theoretischen Konzepte kann Konstruktiver Journalismus nun genauer gefasst werden? Meier (2018, S. 7-8) sieht ihn als ein »alternatives Berichterstattungsmuster«, das den klassischen »objektiven Journalismus« (der einen Fokus auf offizielle Standpunkte und von mächtigen Institutionen inszenierten Ereignisse legt) ergänzt und dabei in der Tradition des »Civic« oder »Public Journalism« steht, welcher auf lokaler Ebene Lösungen recherchieren beziehungsweise durch die Organisation entsprechender Foren und demokratischer Prozesse selbst anstoßen will. Konstruktiver Journalismus zeichnet sich laut Meier (ebd.) dadurch aus, dass er einerseits nicht ereignisfixiert ist, sondern langfristige Prozesse in den Blick nimmt, und andererseits nicht nur soziale Probleme beschreibt, sondern auch Debatten über mögliche Lösungen anschieben will. Diese Gegenüberstellung von Problem(-orientierter Berichterstattung) und Lösung(-sorientierter Berichterstattung), die auch in Statements von Praktiker*innen des Feldes häufig anzutreffen ist (vgl. Kramp und Weichert 2020), verweist auf die Möglichkeit, die Idee des Konstruktiven Journalismus an das kommunikationswissenschaftliche Konzept des »Framing « anzuschließen (vgl. Krüger 2016, 107). Ein Frame - also ein kognitiver Rahmen beziehungsweise ein Deutungsmuster, mit dem Menschen einen bestimmten Ausschnitt aus der Realität fokussieren und damit Komplexität reduzieren - besteht nach der klassischen Definition von Entman (1993) aus vier Elementen: 1) Thema oder Problem, 2) Ursachenzuschreibung, 3) Bewertung und 4) Lösung oder Handlungsempfehlung. Entsprechend schreibt McIntyre (2019, 30): "In solutions journalism, the frame is such that the solution part of the story is highlighted, whereas traditional news stories often make the problem part of the story more salient."

Zugleich macht McIntyre gemeinsam mit Gyldenstedt die Verbindung zu einem anderen theoretischen Konstrukt stark: der Positiven Psychologie. Dabei handelt es sich um eine Strömung innerhalb der Psychologie und Psychotherapie, welche die Ressourcen von Patient*innen anstelle von deren Defiziten in den Mittelpunkt stellt, etwa um Depressionen zu

org/who-we-are/funders. Die Unterstützung durch die philanthropischen Arme von Superreichen und Konzernen wirft freilich die Frage auf, ob Konstruktive Journalist*innen dann die Ideologie des »Philanthrokapitalismus« übernehmen und mit Themenwahl und Framing den Status quo jenes globalen Kapitalismus unterstützen, aus dem die Geldgeber ihren Reichtum bezogen haben (vgl. Scott et al. 2017, 168) - obwohl sie angesichts der multiplen Krisen unserer Zeit eigentlich die Systemfrage stellen müssten. 
heilen, die aufgrund von »erlernter Hilflosigkeit« auftreten. Während klassische problemzentrierte Berichterstattung den Rezipient*innen ein Gefühl von Hilflosigkeit vermittele und zu Apathie und Zynismus führe, wende Konstruktiver Journalismus Techniken der Positiven Psychologie an, »in an effort to create productive and engaging coverage, while holding true to journalism's core functions « (McIntyre und Gyldenstedt 2017, 23; vgl. Beiler und Krüger 2018, 176-178). Mit der Entscheidung für dieses Konzept aus der Individualpsychologie betonen McIntyre und Gyldenstedt die Mikro-Ebene des Individuums als Bezugspunkt des Konstruktiven Journalismus und begründen die Notwendigkeit des Berichterstattungsmusters vorrangig mit dem persönlichen Wohlbefinden der Nutzer*innen, welches es zu erhalten oder herzustellen gelte.

Allerdings: Historisch gesehen hatten die Vorläufer der heutigen Strömung mit Positiver Psychologie nichts im Sinn. Dem Publizisten und Zukunftswerkstätten-Erfinder Robert Jungk, der Ende der 1940er Jahre mit dem »Good News Bulletin« den Aufschlag machte (vgl. Krüger 2016, 101-103), und dem Nachrichtenwert- und Friedensforscher Johan Galtung, der lösungsorientierten »Friedensjournalismus« statt gewaltorientierten »Kriegsjournalismus« forderte, ging es eher um gesellschaftlichen Fortschritt auf der Makro-Ebene: Mit einer bewussten Änderung eingeschliffener redaktioneller Selektions- und Gewichtungsroutinen (Stichwort: Nachrichtenwerttheorie) sollte Journalismus gewaltfreie Lösungsansätze, öko-soziale Innovationen und emanzipatorische Bewegungen aus der Zivilgesellschaft öffentlich sichtbar machen und fördern.

Nun kann die derzeitige (kleine) Strömung des Konstruktiven Journalismus in der Medienbranche zunächst als Antwort auf die Krise der Medienbranche selbst gesehen werden. Diese Krise betrifft die Aspekte Finanzierung, Reichweite, Glaubwürdigkeit und Status in der Gesellschaft und hängt mit dem aktuellen Strukturwandel der Öffentlichkeit im Zuge von Digitalisierung und Globalisierung zusammen (vgl. Krüger 2018; Jarren 2015). Wenn etablierte Medienhäuser sich in Konstruktivem Journalismus versuchen, werden sie wohl nicht nur einen Nutzen auf der individuellen Mikro-Ebene oder gesamtgesellschaftlichen Fortschritt auf der Makro-Ebene anstreben, sondern auch und vor allem einen Nutzen auf der Meso-Ebene - also für ihre eigene Organisation (vgl. Krüger 2016, 98-101). Demgegenüber ist die Sehnsucht vieler Journalist*innen und Rezipient*innen nach mehr lösungsorientierter Berichterstattung ${ }^{5}$ wohl auch Reaktion auf eine gesamtgesellschaftli-

5 Eine solche Sehnsucht zeigt sich in Statements Konstruktiver Journalist*innen 
che Krisenhaftigkeit, die mit einer grundstürzenden »Metamorphose der Welt« (Beck 2017) in Richtung Kosmopolitismus, mit globalen Bedrohungen wie dem Klimawandel und unbewältigten »weltinnenpolitischen « Gerechtigkeits- und Ungleichheitsproblemen zu tun hat (die beispielsweise einen hohen Migrationsdruck nach sich ziehen). Sie ist sicher auch Reaktion auf eine wahrgenommene systemische Starre beziehungsweise Alternativ- und Utopielosigkeit innerhalb westlich-kapitalistischer Wachstumsgesellschaften, die ihre Versprechen auf ständig steigenden Wohlstand nicht mehr erfüllen können und deren mentale Infrastrukturen und grundlegende Fortschrittsnarrative erodieren (vgl. Welzer 2013).

So sieht sich zumindest ein Teil der Akteur*innen im Feld des Konstruktiven Journalismus als »Geburtshelferin ökosozialer Innovationen« (Ute Scheub), als »Change Agent für die Große Transformation« (Manfred Ronzheimer) oder als "Sterbebegleiter für ein abgewirtschaftetes System und Geburtshelfer für eine neue Kultur « (Geseko von Lüpke; alle zitiert nach Krüger und Gassner 2014, 25; Krüger 2016, 100-101). Diesen Teil des Feldes bezeichne ich als systemkritische »Jungk-Fraktion«, die neben einer systemimmanenten, kapitalismusfreundlichen »Ashoka-Fraktion« existiert (benannt nach der Organisation Ashoka zur Förderung des Sozialen Unternehmertums, in der einige Akteur*innen im Feld vernetzt sind, vgl. Krüger 2016, 105-106).

Während letztere sich politisch neutral gibt und epistemologisch die Position vertritt, dass der Journalismus erst mit einem konstruktiven Ansatz sein Versprechen auf Objektivität einlösen kann (»Mainstream media has a bias for bad news « ${ }^{6}$ ), bekennt sich die »Jungk-Fraktion « zu Subjektivität und Normativität und möchte einen grundlegenden, mehr oder weniger zielgerichteten Wandel in Richtung Postwachstumsökonomie mit publizistischen Mitteln unterstützen. In jenem Teil des Feldes könnte man nicht (nur) von Konstruktivem, sondern sogar von "Transformativem Journalismus« sprechen. Es fragt sich nur: Welche Art Transformation wird genau angestrebt? Im Sinne welcher Werte und politischen Wunschvorstellungen soll sich die Gesellschaft grundlegend verändern und zu welchen Mitteln dürfen und sollen Journa-

(etwa in Krüger und Gasser 2014; Kramp und Weichert 2020) und in repräsentativen Bevölkerungsumfragen (Loosen, Reimer und Hölig 2020; weitere Umfragen zitiert in Beiler und Krüger 2018, 169-170).

6 Slogan des Solutions Journalism Network bei dessen Start 2012: https://web. archive.org/web/20130209025903/http://solutionsjournalism.org/. 
list*innen dafür greifen? Ist die Konstruktive beziehungsweise Transformative Journalistin dann noch Beobachterin und Berichterstatterin oder eher Aktivistin, PR-Frau und Politikerin? In welcher Beziehung steht sie dann zu (anderen) Aktivist*innen und relevanten Akteur*innen wie Eliten aus Politik und Wirtschaft? Verletzt ein Engagement für eine gezielte Transformation wichtige Kriterien journalistischer Qualität, wie Unabhängigkeit, Unparteilichkeit, Kritik, Objektivität, Ausgewogenheit und Neutralität? Diese Fragen sollen im Folgenden zumindest ansatzweise beantwortet werden.

\section{Die "Große Transformation « zur Nachhaltigkeit}

Polanyi (1957) war der erste, der von dem Begriff einer »Großen Transformation« Gebrauch machte. Sie bezeichnet bei ihm den Übergang von der feudalen Agrargesellschaft zur kapitalistischen Industrie- und Marktgesellschaft, der sich vor allem im 19. Jahrhundert ereignete und neben der Struktur des Wirtschaftens auch soziale und kulturelle Normen und Werte fundamental veränderte. Seitdem hat der Kapitalismus für einen historisch beispiellosen Anstieg der Produktivität und des Wohlstands gesorgt, allerdings auch für gravierende ökologische Probleme, materielle Ungleichheiten und daraus folgende Defizite in sozialer und politischer Gerechtigkeit (vgl. Krüger und Meyen 2018, 348-350; Wright 2017, 53). Der Wissenschaftliche Beirat der Bundesregierung Globale Umweltveränderungen (WBGU) fordert daher in seinem Hauptgutachten »Welt im Wandel - Gesellschaftsvertrag für eine Große Transformation« eine neuerliche Umwälzung von Werten, Normen und Institutionen: „Es geht um einen neuen Weltgesellschaftsvertrag für eine klimaverträgliche und nachhaltige Weltwirtschaftsordnung «, schreibt etwa der WBGU (2011, 1-2, Hervorhebung im Original). Er verlangt weiterhin »die Schaffung eines nachhaltigen Ordnungsrahmens, der dafür sorgt, dass Wohlstand, Demokratie und Sicherheit mit Blick auf die natürlichen Grenzen des Erdsystems gestaltet « (ebd., 1) werden. Auch andere Forscher*innengruppen weltweit vertreten diese Idee, so das Sustainability Transitions Research Network (STRN) und das Great Transition Network (GTN) mit dem Tellus Institute in Cambridge, Massachusetts (vgl. Göpel 2016).

Das gesellschaftliche Kernprinzip, das die Richtung der erwünschten neuen Transformation angibt, ist »Nachhaltigkeit (englisch: sustainability). Damit gemeint ist, dass »die Bedürfnisse der gegenwärtigen 
Generationen befriedigt werden, ohne dass die Bedürfnisse zukünftiger Generationen beeinträchtigt werden« (Kannengießer 2020, 12). Der Begriff besitzt »normativ-politischen Charakter« (Neverla 2020, 335) und "hat sich etabliert als Gegenentwurf zum ressourcenverschlingenden Leben der Spätmoderne, als kritische Gegenposition zur herrschenden sozialen Logik « (ebd., 336). Allgemein akzeptiert ist die Vorstellung, dass Nachhaltigkeit eine ökologische, eine soziale und eine wirtschaftliche Dimension hat, umstritten ist hingegen, ob diese gleichwertig nebeneinander stehen (in einem »Drei-Säulen-Modell«) oder hierarchisch ineinander eingebettet sind (in einem »Vorrang-Modell«) - die Wirtschaft in der Gesellschaft und die Gesellschaft wiederum in der Umwelt, so dass ökologische Nachhaltigkeit Vorrang vor sozialer und soziale Nachhaltigkeit Vorrang vor wirtschaftlicher hat (vgl. Göpel 2016, 87-88).

Nachhaltigkeit ist ein globales Leitbild geworden, spätestens mit der Verabschiedung der »Agenda 2030 für nachhaltige Entwicklung « durch die Vereinten Nationen im Jahr 2015: Sie definiert 17 Sustainable Development Goals (SDGs) mit 169 konkreten Unterzielen (Abb. 1; vgl. Clauß in diesem Band). Auch die Bundesregierung bekennt sich in ihrer »Deutschen Nachhaltigkeitsstrategie« zu Generationengerechtigkeit, dem Schutz der natürlichen Lebensgrundlagen und sozialer Verantwortung auch gegenüber ärmeren Ländern als Maßstäbe des Regierungshandelns und spricht von einer »notwendigen wirtschaftlichen und gesellschaftlichen Transformation « (Bundesregierung 2018, 11), ohne freilich die Dysfunktionalitäten und Machtstrukturen des modernen globalen Kapitalismus zu problematisieren und einen »radikalen, inkrementellen Wandel « des Wirtschaftssystems zu fordern, wie es ehemalige Angehörige und Mitarbeiter*innen ihres Beirats WBGU tun (Schneidewind 2018, 65-106; Göpel 2016). Wichtig ist jedoch der Perspektiv- und Paradigmenwechsel, der mit der Definition und Operationalisierung von »nachhaltiger Entwicklung « durch die Vereinten Nationen einhergeht und alle Länder - auch Deutschland - in die Pflicht nimmt: Entwicklung soll nicht mehr nur eine Aufgabe für "Entwicklungsländer « sein und vor allem wirtschaftliches Wachstum nach westlichem Vorbild im Sinne einer »nachholenden Entwicklung" bezeichnen. Legt man den Maßstab der 17 SDGs an (darunter Herstellung von Geschlechtergerechtigkeit, Beendigung von Armut, Verringerung von Ungleichheit sowie Gewährleistung nachhaltiger Konsum- und Produktionsmuster), so sind auch ökonomisch erfolgreiche Länder im Zentrum des Weltwirtschaftssystems in vielerlei Hinsicht »Entwicklungsländer« (die durchaus auch in bestimmten Punkten von 
den traditionell so betitelten Staaten lernen können, vgl. Schneidewind 2018, 119).

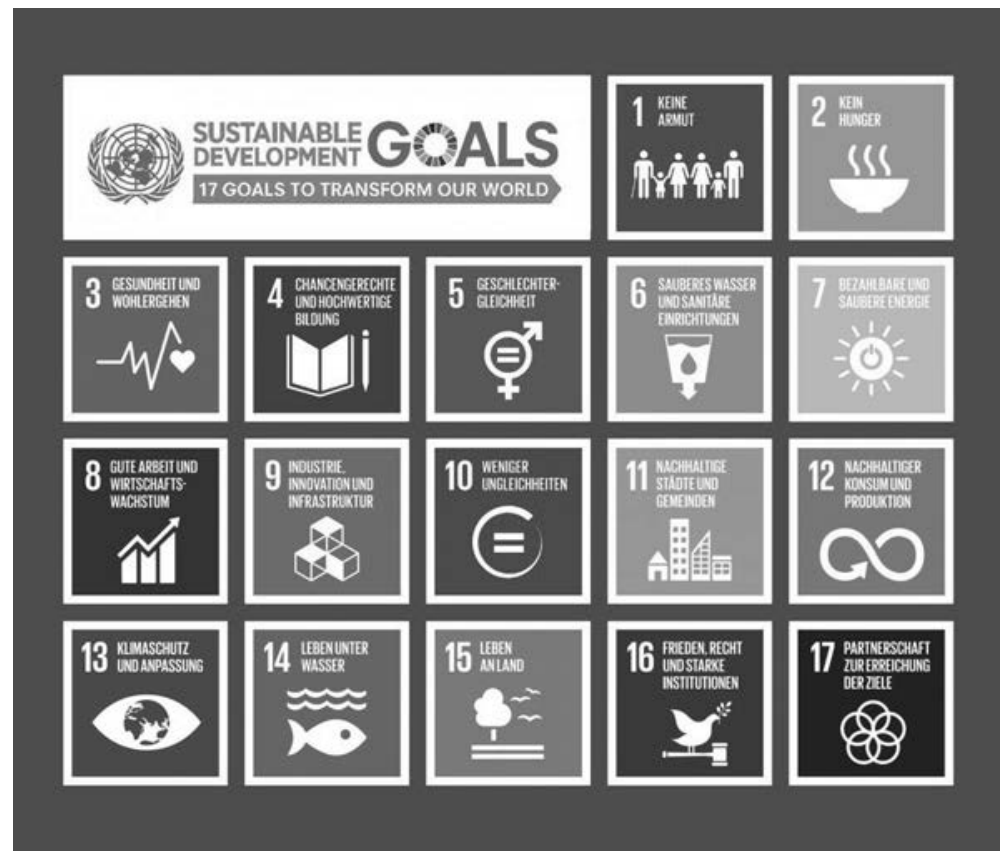

Abb. 1: Die Ziele für nachhaltige Entwicklung der Vereinten Nationen, verabschiedet 2015 (Quelle: UN, CC-BY-SA 3.0, https://www.unesco.de/ bildung/agenda-bildung-2030/bildung-und-die-sdgs).

Das revolutionäre Moment des Begriffs »Nachhaltigkeit« darf also trotz dessen inflationärer Verwendung in Medien, Wirtschaft und Politik nicht übersehen werden. Schneidewind (2018, 23, 25) stellt dieses Moment eindrucksvoll heraus, wenn er die Idee der nachhaltigen Entwicklung als ein »kulturelles Projekt« und ein »umfassendes Zivilisationsprojekt « bezeichnet sowie als eine »moralische Revolution«, die Ähnlichkeiten mit früheren moralischen Revolutionen wie der Einführung der Demokratie, der Abschaffung der Sklaverei und der Einführung des Frauenwahlrechts hat:

Das Konzept der Nachhaltigen Entwicklung liegt [...] genau auf dieser zivilisatorischen Entwicklungslinie: Es ist eine systematische Erweiterung der Idee der Menschenrechte, indem sie allen Menschen auf diesem Planeten so- 
wie auch zukünftigen Generationen die gleichen Entwicklungsmöglichkeiten eröffnen möchte. Es beschreibt ein wachsendes Verständnis des Respekts gegenüber anderen Menschen, global und intergenerationell. (ebd., 26)

Sollte diese moralische Revolution eines Tages vollendet und »die Würde und die Entfaltungsmöglichkeiten von Menschen überall auf dieser Welt heute und in Zukunft Kompass für gesellschaftliches, politisches und ökonomisches Handeln« (ebd., 23) geworden sein, wird die Menschheit sich übrigens - ähnlich wie bei früheren moralischen Revolutionen - fragen, wie die alte Praxis jemals bestehen konnte. Rückblickend bleibt nur Kopfschütteln: »Was haben wir da nur gedacht? Wie konnten wir das all die Jahre tun?« (Appiah 2011, zitiert in Schneidewind 2018, 28)

\section{Transformativer Journalismus und sein Verhältnis zum »Development Journalism»}

Zur Unterstützung der »Großen Transformation« fordert der WBGU (2011) eine »Transformative Wissenschaft« und eine »Transformative Bildung «, die transformationsrelevantes Wissen generieren und vermitteln sowie auch Veränderungen in die gewünschte Richtung anstoßen sollen. Er erkennt auch die Bedeutung von Kommunikationstechnologien und öffentlicher Kommunikation für den angestrebten gesellschaftlichen Such- und Aushandlungsprozess an, der demokratisch und partizipativ anzulegen sei. Genaueres zu öffentlichkeitsbezogenen Fragen - etwa zur Rolle von Strategischer Kommunikation und Journalismus - ist nicht zu finden. An anderer Stelle erwähnt das ehemalige WBGU-Mitglied Schneidewind $(2018,357)$ im Zusammenhang mit dem Konstruktiven Journalismus einen »Transformativen Journalismus«, der »analog zu einer Transformativen Wissenschaft [...] Pionierinnen und Initiativen des Wandels ermutigt, orientiert, informiert und vernetzt«. In ähnlicher Weise verwenden Ronzheimer (2013) sowie Borner et al. (2019) den Begriff, ebenfalls ohne ihn kommunikationswissenschaftlich beziehungsweise journalismustheoretisch zu fundieren.

Zunächst soll hier eine Arbeitsdefinition vorgestellt werden, welche die Analogie zur Transformativen Wissenschaft aufnimmt, aber den Gegenstand weiter spezifiziert:

Transformativer Journalismus ist eine Form der Berichterstattung, die Öffentlichkeit herstellt für Akteur*innen, Prozesse und Strukturen, die eine »Große 
Transformation» zur Nachhaltigkeit begünstigen, um sie durch Sichtbarkeit zu stärken und ihre weitere Verbreitung und Entwicklung zu ermöglichen. Er ist normativ verankert in der Nachhaltigkeitsdebatte und den SDGs; diese Verankerung versteckt er nicht, sondern legt sie offen und reflektiert sie kritisch. Grundlegende Werte für den Transformativen Journalismus sind die Schonung ökologischer Ressourcen und die Einhaltung planetarer Grenzen, soziale Gerechtigkeit, transnationale Solidarität und Demokratie. Seine typischen Themen drehen sich um die »sieben Arenen « der Großen Transformation nach Schneidewind (2018, 14): Wohlstands- und Konsumwende, Energiewende, Ressourcenwende, Mobilitätswende, Ernährungswende, Urbane Wende und Industrielle Wende.

Von Strategischer Kommunikation und Öffentlichkeitsarbeit grenzt sich der Transformative Journalismus dadurch ab, dass er institutionell und mental unabhängig von den Akteur*innen des Wandels agiert und daher auch mit nüchternem Blick deren Fehler, Misserfolge und Missstände sieht und offenlegt. Trotz seiner Wertegebundenheit erfüllt er also zentrale journalistische Qualitätskriterien wie Unabhängigkeit, Kritik und Objektivität. ${ }^{7}$

Transformativer Journalismus im Dienst einer »nachhaltigen Entwicklung« lässt sich als Teilmenge zweier größer gezogener Konstrukte begreifen:

1. von Nachhaltigkeitskommunikation, einem »Verständigungsprozess, in dem es um eine zukunftsgesicherte gesellschaftliche Entwicklung geht, in deren Mittelpunkt das Leitbild einer Nachhaltigen Entwicklung steht« (Michelsen 2007, 27).

2. von Entwicklungskommunikation oder Communication for Social Change, einer »Sammelbezeichnung für die vielfältigen Formen von Kommunikationsstrategien [...], die gesellschaftliche Veränderungspotenziale sondieren oder aktivieren« (Hamidi und Mielke Möglich 2019, 5).

7 Viele Vertreter*innen des Konstruktiven Journalismus lehnen das Qualitätskriterium »Objektivität« als Schimäre oder Berufsideologie ab. Hier wird das Kriterium jedoch befürwortet und eingefordert, verstanden als Abstrahierung von einer rein persönlich-individuellen Subjekt-Perspektive und »schrittweises Erweitern der Perspektive in Richtung eines (nie zu erreichenden) >Blicks von nirgendwo« (Schultz 2020). Mit einer Kopplung des Transformativen Journalismus an bestimmte Werte und normative Wunschvorstellungen erscheint eine so verstandene Objektivität vollauf vereinbar, da sie keine (Wert-)Neutralität voraussetzt. 
Auf der Ebene des Journalismus als spezifischer Kommunikationspraxis beziehungsweise -institution sind wiederum zwei semantisch ähnliche Begriffe in der Diskussion:

1. der Nachhaltigkeitsjournalismus, eine junge Begriffsprägung von Wissenschaftler*innen der Leuphana Universität Lüneburg, welche ein Studienprogramm »Nachhaltigkeit und Journalismus« anbietet; der Begriff "fasst journalistische Aktivitäten zusammen, die einen Beitrag zur Debatte des Konzepts einer nachhaltigen Entwicklung leisten beziehungsweise sich darauf beziehen « (Michelsen und Fischer 2016, 10). ${ }^{8}$

2. der Entwicklungsjournalismus (Development Journalism), ein Begriff aus dem Globalen Süden mit über 50-jähriger Geschichte, der für eine Diskussion über Qualitätskriterien eines Transformativen Journalismus besonders interessant ist.

Wenn wir Transformativen Journalismus als eine Art kommunikative Entwicklungshilfe für entwickelte (westlich-kapitalistische) Gesellschaften in der Krise verstehen, liegt folgende Frage nahe: Kann der Globale Norden - der seine Entwicklungsgeschichte als Königsweg, seine Werte und Institutionen als Muster und Vorbild für eine erfolgreiche Entwicklung des Globalen Südens ansah, heute aber selbst in einer Sackgasse steckt und sich grundlegend wandeln muss - eventuell hier von Asien, Afrika sowie Süd- und Mittelamerika ${ }^{9}$ lernen? Was kann er vom Konzept des Development Journalism übernehmen, was sollte er zurückweisen?

Das Konzept des Development Journalism entstand Ende der 1960er Jahre im Zuge eines Workshops für Wirtschaftsjournalist*innen, den der britische Journalist und Asien-Kenner Alan Chalkley 1968 in Manila (Philippinen) leitete. In seinem »Manual of Development Journalism« wird deutlich, dass es ihm um kritischen, akkuraten Wirtschafts-

8 Die Autoren sehen den Nachhaltigkeitsjournalismus wiederum in semantischer Nähe zu »Umweltjournalismus«, »Klimajournalismus«, »Grünem Journalismus« (vgl. Schäfer und Lorenz in diesem Band) und »Transformationsjournalismus« nach Ronzheimer (2013).

9 Einschränkend muss gesagt werden, dass die Grenze zwischen Globalem Norden und Globalem Süden nicht strikt anhand von Kontinenten verläuft. Beispielsweise zählt Japan, obwohl ein asiatischer Staat, nicht zum Globalen Süden, während arme europäische Länder wie Albanien oder Moldawien nicht unter den Begriff des Globalen Nordens fallen. 
journalismus unter den besonderen Umständen von weit verbreiteter Armut und mangelhaften amtlichen Wirtschaftsstatistiken ging. Entwicklungsjournalist*innen haben, so Chalkley, drei Aufgaben: 1) die Rezipient*innen zu informieren, also ihnen die Fakten zu liefern, 2) die Fakten zu interpretieren und in den richtigen Rahmen zu setzen und 3) den Rezipient*innen die Augen für mögliche Lösungen zu öffnen, um den Teufelskreis der Armut zu durchbrechen (Chalkley 1969, 3). Ein wichtiges Anliegen war ihm, dass über Wirtschaft auf eine Weise berichtet wird, die nicht (nur) für Eliten und Entscheider*innen, sondern auch für einfache Bürger*innen verständlich ist:

Tell the housewife $[\ldots]$ about the things that affect her little home economy and home budget. [...] Tell the »faceless" people, with no titles, no names, perhaps no jobs, no money. Bring them into the circle, give them a role to play. (ebd., 53)

Neben der Lösungsorientierung war also auch Ermächtigung zur Teilhabe die Grundidee; es ging um »furthering the emancipation of such deprived groups as the urban poor, the rural people, women and so on and helping them actively to participate in the political process, that is actively influence their destinies« (Quebral 1975; zitiert nach Xu 2009, 359).

Chalkleys Idee machte in den 1970er und 1980er Jahren vor allem in Asien und Afrika Karriere. Für die Staaten, die gerade ihre politische Unabhängigkeit erlangt hatten, schien es attraktiv, nicht das liberaldemokratische Journalismusmodell ihrer westlichen Kolonisatoren zu übernehmen, sondern ein neues Konzept zu finden, das ihren besonderen lokalen Bedingungen (wie politischer Instabilität, ethnischer Vielfalt und prekärer Wirtschaftslage) und kulturellen Werten (wie Betonung von Harmonie statt Konflikt, Vorrang von Gruppeninteressen vor individueller Autonomie und Respekt vor Autoritäten) entsprach. Ideologisch eng verknüpft mit Bestrebungen einer »De-Westernization« und der Bemühung um eine »New World Information and Communication Order« (NWICO) im Rahmen der UNESCO, entstanden oftmals mit staatlicher Förderung Strukturen der journalistischen Ausbildung, die das Rollenbild des Development Journalism propagierten. Dabei entwickelte sich die Idee durchaus widersprüchlich weiter. Laut Xu $(2009,358)$ enthält sie fünf Schlüsselkomponenten:

1. Berichterstattung über Entwicklungsprojekte und die Differenz zwischen deren proklamierten Zielen und den erreichten Ergeb- 
nissen sowie zwischen den behaupteten und realen Auswirkungen auf die Menschen,

2. Schwerpunkt auf langfristigen Entwicklungsprozessen statt auf aktuellen Ereignissen,

3. Unabhängigkeit von und konstruktive Kritik an der Regierung,

4. Schwerpunkt auf wirtschaftlicher und sozialer Entwicklung bei gleichzeitiger konstruktiver Zusammenarbeit mit der Regierung beim Nation-Building,

5. Ermächtigung von Normalbürger*innen, ihr Leben und ihre Gemeinschaften zu verbessern.

Von Forscher*innen ist das Konzept kritisiert worden, weil es in einigen Ländern von autoritär Regierenden dazu missbraucht wurde, um Konformität von den Medien einzufordern - am Ende diente die Idee also oftmals dem Machterhalt der Elite und nicht der Emanzipation der Deprivierten (Xu 2009; Waisbord 2010; Cenite et al. 2008; Hanusch und Uppal 2015). In seinem kritischen Review der Idee konstatiert Waisbord (2010, 150), dass das Konzept kein einheitliches Set an theoretischen Prinzipien aufweist, weil es die Wünsche und Erwartungen von vielen unterschiedlichen Akteur*innen im Globalen Süden ausdrückt; es werde lediglich zusammengehalten in der kategorischen Ablehnung des liberalen Modells der Presse beziehungsweise eines jeglichen westlichen Kommunikationsparadigmas.

Waisbord spitzt die widersprüchliche Lage in Theorie und Praxis des Development Journalism zu zwei unterschiedlichen Ansätzen zu: Der »communitarian approach « fokussiere auf Nicht-Eliten, eigentumslose und arme Menschen sowie deren Lebensumstände, biete Perspektiven und Lösungen, beobachte kritisch die Regierungspolitik sowie Entwicklungsprogramme und fördere Bürgerbeteiligung und Emanzipation. Im Gegensatz dazu sehe der "statist approach « den Journalismus als Instrument des Nation-Building und als Unterstützer von Regierungsprogrammen, denn Entwicklungsziele hätten Priorität vor Konflikten und Meinungsverschiedenheiten; junge und fragile Staaten könnten sich keine freie und oppositionelle Presse leisten.

An dieser Zuspitzung wird klar, was Transformativer Journalismus im Globalen Norden von diesem Modell aus dem Globalen Süden übernehmen kann - Fokus auf langfristige Prozesse, Wissenstransfer über öko-soziale Innovationen und Beobachtung von Entwicklungsprojekten - und wo es gefährlich wird: Die in langen, opferreichen Kämpfen erstrittene Pressefreiheit und Unabhängigkeit von Machthaber*innen 
sollte ein Transformativer Journalismus keinesfalls aufgeben; zu einem PR- und Verlautbarungsorgan von politischen, wirtschaftlichen oder zivilgesellschaftlichen Protagonist*innen einer Nachhaltigkeitsrevolution darf er sich - bei aller Sympathie und Übereinstimmung in den grundlegenden Werten - nicht degradieren lassen. Da aller Macht die Gefahr von Machtmissbrauch innewohnt, bleibt die Watchdog-Funktion selbst für Transformative Journalist*innen relevant. Denn politische Akteur*innen - seien es die herrschenden Eliten oder aufstrebende Gegen-Eliten - benutzen die Wahrheit im Zweifel instrumentell zur Erreichung ihrer politischen Ziele. Die Aufgabe von Journalist*innen ist es deshalb, einen eigenständigen »öffentlichen Wahrheitsdiskurs« zu führen, der über den »Herrschaftsdiskurs« hinausgeht und diesen permanent kritisch hinterfragt (vgl. Pöttker 2003, 150).

\section{$5 \quad$ Fazit und Ausblick}

Die Presse könne »mit einem Gerüst verglichen werden, das um ein im Bau befindliches Gebäude errichtet wird; es zeigt die Umrisse des Gebäudes an, erleichtert den Verkehr zwischen den einzelnen Bauarbeitern, hilft ihnen, die Arbeit zu verteilen und die durch die organisierte Arbeit erzielten gemeinsamen Resultate zu überblicken« (zitiert nach Autorenkollektiv 1981, 72). Diese Baugerüst-Metapher scheint zur Idee des Konstruktiven Journalismus, der zu gesellschaftlichem Fortschritt beitragen will, gut zu passen - und vielleicht noch besser zu einem Transformativen Journalismus, der eine Nachhaltigkeitsrevolution befördern, also gezielt an der »Konstruktion « einer besseren, gerechteren, nachkapitalistischen Welt mitwirken will. Das Zitat stammt auch von einem ausgewiesenen Antikapitalisten: Wladimir Iljitsch Lenin (aus seiner Schrift »Was tun?«). Es illustriert innerhalb seiner Pressetheorie eine der drei Funktionen der sozialistischen Parteipresse, nämlich die »Organisation« (neben der »Propaganda« und der »Agitation«).

Lenin befürwortete eine strikte Unterordnung der Parteipresse unter die Parteiführung und deren politische Linie. Nach der Oktoberrevolution zerstörte er die demokratische Öffentlichkeit in Russland durch die Unterdrückung Andersdenkender und das Verbot der gesamten nicht-bolschewistischen Presse (vgl. Poerschke 2020). Diese scheinbare geistige Nachbarschaft erklärt womöglich, dass die Idee des Konstruktiven Journalismus vielen Journalist*innen in westlichen De- 
mokratien (und auch in postsozialistischen Gesellschaften Osteuropas, wie ich bei Vorträgen vor russischen, ukrainischen und moldawischen Medienmacher*innen erlebte) Bauchschmerzen bereitet. Im Umkehrschluss liefert sie auch eine Begründung, warum so manche Führer postkolonialer Staaten in Afrika, die zuvor als Journalisten gearbeitet hatten und mit dem Marxismus-Leninismus und der Sowjetunion sympathisierten, von der Idee eines regierungsnahen Development Journalism angetan waren - etwa Kwame Nkrumah in Ghana, Jomo Kenyatta in Kenia und Julius Nyerere in Tansania (vgl. Xu 2009, 359).

Diesen Geist trägt jedoch weder die Idee des Konstruktiven noch des Transformativen Journalismus; er passt auch nicht zur Idee des WBGU einer Großen Transformation zur Nachhaltigkeit: Jener wünschenswerte Umbau von Werten, Praktiken und Institutionen soll nicht nach einem Masterplan von oben oktroyiert werden, sondern ein "gesamtgesellschaftlicher Suchprozess « sein, an dem »alle gesellschaftlichen Akteure [...] zu beteiligen sind « (WBGU 2011, 380), und der auf »Einsicht in die Notwendigkeit (ebd., 341) setzt. Entsprechend bleibt ein Transformativer Journalismus, der hier (analog zu einer Transformativen Bildung und einer Transformativen Wissenschaft) als ein Berichterstattungsmuster unter mehreren konzeptualisiert wurde, ein autonomer Akteur, der zentrale journalistische Qualitätskriterien wie Unabhängigkeit, Kritik und Objektivität erfüllen soll. Er ist alles andere als wertneutral, sondern ausdrücklich wertgebunden - was allerdings kein Alleinstellungsmerkmal dieses Berichterstattungsmusters darstellt. So ist im westlichen Journalismus unumstritten, dass Journalist*innen die Demokratie verteidigen sollen, also an demokratische Werte (zu denen die Presse- und Meinungsfreiheit gehört) gebunden sind. Transformativer Journalismus bekennt sich darüber hinaus zum Schutz der natürlichen Lebensgrundlagen, ohne die Demokratie oder eine funktionierende Gesellschaft allgemein nicht möglich sind, ${ }^{10}$ und zu einer Reihe anderer Prinzipien, die im weiteren Sinn mit sozialer und politischer Gerechtigkeit zu tun haben (vgl. Wright 2017, 53) und unter dem Schirmbegriff »Nachhaltigkeit« von der Staatengemeinschaft weitgehend konsentiert sind.

10 Zu Recht fragt Schäfer $(2018,84)$, ob man sich als Journalist*in im Zeitalter des Anthropozäns zu ökologischer Nachhaltigkeit »auf berufsethischer Ebene überhaupt neutral verhalten kann« und ob Nachhaltigkeit »nicht mittlerweile zu einem universellen Wert geworden ist [...]. Ganz so wie Gleichberechtigung, freie Meinungsäußerung oder Minderheitenschutz, die interessanterweise weniger oft Thema für journalistische Selbstbefindlichkeiten sind.« 
Was in diesem Beitrag aus Platzgründen nicht geleistet werden konnte, ist ein Bezug der Idee des Transformativen Journalismus auf Transformationstheorien und -modelle. Anbieten würde sich der neomarxistische Ansatz von Wright (2017), der mögliche Wege in eine nachkapitalistische Gesellschaft per »Transformation durch Bruch«, »Transformation durch Freiräume« und »Symbiotische Transformation« sieht. Die reale Praxis des Konstruktiven und Transformativen Journalismus in der gegenwärtigen Gesellschaft ist demnach am ehesten mit der »Transformation durch Freiräume« verbunden: So wie der Kapitalismus einst in den Freiräumen der Feudalgesellschaft entstand, könne das gegenwärtige Wirtschaftssystem transformiert werden durch »Institutionen, die die angestrebte alternative Welt bereits im Hier und Jetzt verkörpern« (ebd., 441). Solche Institutionen, Praktiken und Akteur*innen werden von Transformativen Journalist*innen publizistisch begleitet und durch die Herstellung von Öffentlichkeit gefördert.

Denkbar ist ebenso eine theoretische Fundierung des Transformativen Journalismus mit Hilfe der »Multilevel Perspective on Transitions«. MLP ist eine Theorie mittlerer Reichweite, die ihre Wurzeln in den Science and Technology Studies, der Evolutionsökonomik, der Strukturationstheorie und dem Neo-Institutionalismus hat und erklärt, wie sich Innovationen aus Nischen in bestehenden soziotechnischen Regimen durchsetzen (Geels und Schot 2010). Im Modell der MLP wäre der Transformative Journalismus der Beobachter der Nischen, in denen öko-soziale Innovationen entwickelt werden - während der Mainstream-Journalismus, der auf das Abbilden des Elitendiskurses per »Objective Reporting « fokussiert ist, als Beobachter der etablierten Regime vorgestellt werden kann. Genaueres, auch bezüglich der Implikationen für das journalistische Rollenverständnis, die journalistische Ethik und die journalistische Qualität, bleibt einer späteren Ausarbeitung vorbehalten.

\section{Literatur}

Autorenkollektiv (verantwortlich für die Redaktion: Wolfgang Böttger). 1981. Wörterbuch der sozialistischen Journalistik. 2., wesentlich veränderte Auflage, KarlMarx-Universität Leipzig, Sektion Journalistik.

Beck, Ulrich. 2017. Die Metamorphose der Welt. Frankfurt am Main: Suhrkamp.

Beiler, Markus. 2013. Nachrichtensuche im Internet. Inhaltsanalyse zur journalistischen Qualität von Nachrichtensuchmaschinen. Konstanz: UVK.

Beiler, Markus, und Uwe Krüger. 2018. Mehr Mehrwert durch Konstruktiven Journa- 
lismus? Idee des Konzepts und Implikationen zur Steigerung des Public Values von Medien. In: Der öffentliche (Mehr-)Wert von Medien. Public Value aus Publikumssicht, herausgegeben von Nicole Gonser, 167-191. Wiesbaden: Springer VS.

Bendell, Jem. 2020. Deep Adaptation: A Map for Navigating Climate Tragedy. IFLAS Occasional Paper 2. http://lifeworth.com/deepadaptation.pdf. Zugegriffen: 8. Januar 2021.

Bennett, W. Lance. 1990. Toward a Theory of Press-State Relations in the United States. Journal of Communication 40 (2): 103-125.

Borner, Joachim, Anke Oxenfarth, und Manfred Ronzheimer. 2019. Impact-Journalismus und zielgenaues Storytelling für gesellschaftlichen Wandel. Sondierungsstudie des Umweltbundesamtes. Berlin: Kolleg für Management und Gestaltung nachhaltiger Entwicklung. http://kmgne.de/wp-content/ uploads/2019/12/Sondierungsstudie-des-Umweltbundesamtes-2019.pdf. Zugegriffen: 8. Januar 2021.

Bundesregierung. 2018. Deutsche Nachhaltigkeitsstrategie. https://www.bundesregierung.de/resource/blob/975274/1546450/65089964ed4a2ab07 ca8a4919e09e0af/2018-11-07-aktualisierung-dns-2018-data.pdf. Zugegriffen: 8. Januar 2021.

Buschow, Christopher. 2012. Strategische Institutionalisierung durch Medienorganisationen. Der Fall des Leistungsschutzrechtes. Köln: Herbert von Halem.

Cenite, Mark, Chong Shing Yee, Han Teck Juan, Lim Le Quin, und Tan Xian Lin. 2008. Perpetual development journalism? Balance and framing in the 2006 Singapore election coverage. Asian Journal of Communication 18 (3): 280-295.

Chalkley, Alan. 1969. A Manual of Development Journalism (Or how to help one thousand million Asians earn a decent living ... yes, we mean YOU). Cardiff: Thomson Foundation Editorial Study Centre und Press Foundation of Asia.

Donges, Patrick. 2006. Medien als Institutionen und ihre Auswirkungen auf Organisationen. Perspektiven des soziologischen Neo-Institutionalismus für die Kommunikationswissenschaft. Medien \& Kommunikationswissenschaft 54 (4): 563-578.

Dörre, Klaus, Stephan Lessenich, und Hartmut Rosa. 2017. Soziologie - Kapitalismus - Kritik. Eine Debatte. 5. Auflage. Frankfurt am Main: Suhrkamp.

Entman, Robert. 1993. Framing. Toward clarification of a fractured paradigm. Journal of Communication 43 (4): 51-58.

Galtung, Johan, und Mari Holmboe Ruge. 1965. The structure of foreign news. The presentation of the Congo, Cuba and Cyprus crises in four Norwegian newspapers. Journal of Peace Research 2 (1): 64-91.

Geels, Frank W., und Johan Schot. 2010. The Dynamics of Transitions: A SocioTechnical Perspective. In: Transitions to Sustainable Development. New Directions in the Study of Long Term Transformative Change, herausgegeben von John Grin, Jan Rotmans und Johan Schot, 11-104. New York, Abingdon: Routledge.

Göpel, Maja. 2016. The Great Mindshift. How a New Economic Paradigm and Sustainability Transformations go Hand in Hand. Wuppertal Institut und Springer Open. https://www.springer.com/de/book/9783319437651. Zugegriffen: 8. Januar 2021. 
Gyldensted, Cathrine. 2015. From mirrors to movers. Five elements of positive psychology in constructive journalism. Charleston: Group Publishing.

Haagerup, Ulrik. 2015. Constructive News. Warum »bad news« die Medien zerstören und wie Journalisten mit einem völlig neuen Ansatz wieder Menschen berühren. Salzburg: Oberauer.

Hamidi, Kefa, und Antonia Mielke Möglich. 2019. Entwicklungskommunikation Communication for Social Change. Aufbau und Etablierung eines neuen Schwerpunktes in der deutschen Kommunikationswissenschaft. Global Media Journal (German Edition) 9 (1): 1-15. https://www.db-thueringen.de/servlets/ MCRFileNodeServlet/dbt_derivate_00044867/GMJ17_Hamidi_Mielke_final. pdf. Zugegriffen: 8. Januar 2021.

Hanusch, Folker, und Charu Uppal. 2015. Combining detached watchdog journalism with development ideals: An exploration of Fijian journalism culture. The International Communication Gazette 77 (6): 557-576.

Herman, Edward S., und Noam Chomsky. 2002. Manufacturing Consent. The Political Economy of the Mass Media. New York: Pantheon.

Jarren, Otfried. 2015. Journalismus - unverzichtbar?! Publizistik 60 (2): 113-122.

Kannengießer, Sigrid. 2020. Nachhaltigkeit und das "gute Leben«. Zur Verantwortung der Kommunikations- und Medienwissenschaft in digitalen Gesellschaften. Publizistik 65 (1): 7-20.

Knoche, Manfred. 2002. Kommunikationswissenschaftliche Medienökonomie als Kritik der Politischen Ökonomie der Medien. In: Medienökonomie in der Kommunikationswissenschaft: Bedeutung, Grundfragen und Entwicklungsperspektiven. Manfred Knoche zum 60. Geburtstag, herausgegeben von Gabriele Siegert, 101-109. Münster: Lit.

Kramp, Leif, und Stephan Weichert. 2020. Nachrichten mit Perspektive. Lösungsorientierter und konstruktiver Journalismus in Deutschland. Frankfurt am Main: Otto-Brenner-Stiftung. https://www.otto-brenner-stiftung.de/fileadmin/user data/stiftung/02_Wissenschaftsportal/03_Publikationen/AH101_konstr_Journalismus.pdf. Zugegriffen: 8. Januar 2021.

Krüger, Uwe. 2018. Der neue Strukturwandel der Öffentlichkeit und die German Angst. In: Die neue Öffentlichkeit. Wie Bots, Bürger und Big Data den Journalismus verändern, herausgegeben von Gabriele Hoofacker, Wolfgang Kenntemich und Uwe Kulisch, 9-25. Wiesbaden: Springer VS.

Krüger, Uwe. 2019. Meinungsmacht. Der Einfluss von Eliten auf Leitmedien und Alpha-Journalisten - eine kritische Netzwerkanalyse. 2., überarbeitete und erweiterte Auflage. Köln: Herbert von Halem.

Krüger, Uwe. 2016. Mainstream - Warum wir den Medien nicht mehr trauen. 2., durchgesehene und aktualisierte Auflage. München: C. H. Beck.

Krüger, Uwe, und Nicole Gassner. 2014. Abschied von den Bad News. Message o. Jg. (1): 20-25. https://www.message-online.com/wp-content/uploads/SoJ.pdf. Zugegriffen: 8. Januar 2021.

Krüger, Uwe, und Michael Meyen. 2018. Auf dem Weg in die Postwachstumsgesellschaft. Plädoyer für eine transformative Kommunikationswissenschaft. Publizistik 63 (3): 341-357. 
Krüger, Uwe, und Juliane Pfeiffer. 2020. Die Neoklassische Ökonomik und der Romantische Konsumismus: Ideologische Bremsklötze einer »Großen Transformation« zur Nachhaltigkeit. In: Ideologie, Kritik, Öffentlichkeit: Verhandlungen des Netzwerks Kritische Kommunikationswissenschaft, herausgegeben von Uwe Krüger und Sebastian Sevignani, 212-239. Frankfurt am Main: Westend sowie Universität Leipzig. DOI: 10.36730/ideologiekritik.2019.10.

Loosen, Wiebke, Julius Reimer, und Sascha Hölig. 2020. Was Journalisten sollen und wollen: (In-)Kongruenzen zwischen journalistischem Rollenselbstverständnis und Publikumserwartung. Hamburg: Hans-Bredow-Institut. https://www.hansbredow-institut.de/uploads/media/default/cms/media/vhj8v7a_ AP49Was\%20Journalisten\%20wollen\%20und\%20sollen.pdf. Zugegriffen: 8. Januar 2021.

McIntyre, Karen. 2019. Solutions journalism: The Effects of Including Solution Information in News Stories about Social Problems. Journalism Practice 13 (1): $16-34$.

McIntyre, Karen, und Cathrine Gyldensted. 2017. Constructive Journalism: An Introduction and Practical Guide for Applying Positive Psychology Techniques to News Production. The Journal of Media Innovations 4 (2): 20-34.

Meier, Klaus. 2018. Journalistik. 4. Auflage. Konstanz: UTB.

Meier, Klaus. 2018. Wie wirkt Konstruktiver Journalismus? Ein neues Berichterstattungsmuster auf dem Prüfstand. Journalistik 1 (1): 4-25. https://journalistik.online/ausgabe-012018/wie-wirkt-konstruktiver-journalismus/. Zugegriffen: 8. Januar 2021.

Michelsen, Gerd. 2007. Nachhaltigkeitskommunikation: Verständnis - Entwicklungen - Perspektiven. In: Handbuch Nachhaltigkeitskommunikation. Grundlagen und Praxis, herausgegeben von Gerd Michelsen und Jasmin Godemann, 2. Auflage, 25-41. München: Oekom.

Michelsen, Gerd, und Daniel Fischer. 2016. Vom Umwelt- zum Nachhaltigkeitsjournalismus? Die Initiative »Nachhaltigkeit und Journalismus«. In: Nachhaltigkeit und Journalismus. Erkenntnisse und Impulse aus Wissenschaft und Praxis, herausgegeben von Gerd Michelsen und Daniel Fischer, 9-19. Bad Homburg: Verlag für Akademische Schriften.

Neverla, Irene. 2020. Nachhaltigkeit: Zur Theoretisierung einer politischen Kategorie. Publizistik 65 (3): 333-339.

Poerschke, Hans. 2020. Das Prinzip der Parteiliteratur. Partei und Presse bei und unter Lenin 1899-1924. Köln: Herbert von Halem.

Polanyi, Karl. 1957. The Great Transformation: The Political and Economic Origins of Our Time. Boston: Beacon Press.

Pöttker, Horst. 2003. Kommunikationsstörungen? Zur Systematik der sozialen Beziehung zwischen Politikern und Journalisten. In: Machtdarstellung und Darstellungsmacht. Beiträge zur Theorie und Praxis moderner Politikvermittlung, herausgegeben von Ulrich Sarcinelli und Jens Tenscher, 149-167. Baden-Baden: Nomos.

Ronzheimer, Manfred. 2013. Vom Nullthema in den Mainstream. Die Rolle der Medien in der Transformation. Politische Ökologie 133 (31): 118-123. https:// 
jbzzukunftsbuch.files.wordpress.com/2014/12/politische-c3b6kologie-transformationsjournalismus.pdf. Zugegriffen: 8. Januar 2021.

Schäfer, Torsten. 2018. Geschichten als Chance. Erzählformen im Umweltjournalismus. In: Politische Ökologie 152: 83-90. München: Oekom.

Schmidt, Jasmina. 2017. Konstruktiver Journalismus - ein Ansatz zur kosmopolitischen Vermittlung fernen Leids? Global Media Journal (German Edition) 7 (2): 1-26. https://www.db-thueringen.de/servlets/MCRFileNodeServlet/dbt_derivate_00039841/GMJ14_Schmidt_final.pdf. Zugegriffen: 8. Januar 2021.

Schneidewind, Uwe. 2018. Die Große Transformation. Eine Einführung in die Kunst gesellschaftlichen Wandels. Frankfurt am Main: S. Fischer.

Schultz, Tanjev. 2020. Der Reporter-Blick von nirgendwo? Journalismus in der Spannung zwischen Objektivität und Subjektivität. Publizistik. DOI: https:// doi.org/10.1007/s11616-020-00624-1. Zugegriffen: 8. Januar 2021.

Scott, Martin, Mel Bunce, und Kate Wright. 2017. Donor Power and the News: The Influence of Foundation Funding on International Public Service Journalism. The International Journal of Press/Politics 22 (2): 163-184.

Sevignani, Sebastian. 2016. Kritische Politische Ökonomie. In: Handbuch Medienökonomie, herausgegeben von Jan Krone und Tassilo Pellegrini, 1-28. Wiesbaden: Springer VS.

Urner, Maren. 2019. Schluss mit dem täglichen Weltuntergang. Wie wir uns gegen die digitale Vermüllung unserer Gehirne wehren. München: Droemer Knaur.

Waisbord, Silvio. 2010. Rethinking »Development« Journalism. In: The Routledge Companion to News and Journalism, herausgegeben von Stuart Allan, 148-158. London: Routledge.

WBGU. 2011. Welt im Wandel. Gesellschaftsvertrag für eine Große Transformation. Hauptgutachten des Wissenschaftlichen Beirats der Bundesregierung Globale Umweltveränderungen. Bonn. https://www.wbgu.de/fileadmin/user_upload/wbgu/publikationen/hauptgutachten/hg2011/pdf/wbgu_jg2011.pdf. Zugegriffen: 8. Januar 2021.

Welzer, Harald. 2013. Selbst denken. Eine Anleitung zum Widerstand. Frankfurt am Main: S. Fischer.

Wright, Erik Olin. 2017. Reale Utopien. Wege aus dem Kapitalismus. Frankfurt am Main: Suhrkamp.

Xu, Xiaoge. 2009. Development Journalism. In: The Handbook of Journalism Studies, herausgegeben von Karin Wahl-Jorgensen und Thomas Hanitzsch, 357370. New York: Routledge.

\section{Open Access}

Dieser Beitrag erscheint unter der Creative-Commons-Lizenz CC-BY-ND 3.0 DE: https://creativecommons.org/licenses/by-nd/3.0/de/. 


\section{Filmförderung als Transformationsbremse. Die politische Gestaltung der Kinospielfilmproduktion in Deutschland}

\section{Thomas Wiedemann}

Keywords: Medienpolitik, Medienproduktion, Spielfilm, Akteur-StrukturDynamiken, Bedeutungskonstitution

\section{Abstract}

Unter Bezugnahme auf Schimanks Ansatz der Akteur-Struktur-Dynamiken fragt der Beitrag kritisch nach den Mechanismen, die das deutsche Filmschaffen angesichts des filmpolitischen Gestaltungswillens hierzulande prägen. Auf der Grundlage von 95 Expert*inneninterviews mit Vertreter*innen aller für die Entstehung deutscher Kinospielfilme relevanten Betätigungsfelder (Drehbuch, Regie, Produktion, Verleih, Kinoabspiel, Festivals, Förderung, öffentlich-rechtliches Fernsehen) sowie Dokumentenanalysen wird argumentiert, dass die filmische Aussagenentstehung unter dem Dach des Filmförderkomplexes neben dem Bemühen um Kunst, Wirtschaftlichkeit und Publikumswünschen auch eine politische Dimension besitzt und Machtverhältnisse in der Gesellschaft weiter verfestigt. Da spezifische Akteurskonstellationen und soziale Strukturen autonomes Handeln auf Seiten der Kommunikator*innen im Filmproduktionsprozess deutlich begrenzen und damit auch das Spektrum filmischer Wirklichkeitskonstruktionen einengen, können Kinospielfilme in Deutschland keine transformative Kraft entwickeln und das dem Medium theoretisch innewohnende emanzipatorische Potenzial kaum entfalten.

Thomas Wiedemann: Filmförderung als Transformationsbremse. Die politische Gestaltung der Kinospielfilmproduktion in Deutschland. In: Nils S. Borchers, Selma Güney, Uwe Krüger und Kerem Schamberger (Hrsg.): Transformation der Medien - Medien der Transformation. Verhandlungen des Netzwerks Kritische Kommunikationswissenschaft. Frankfurt am Main: Westend 2021. DOI: https://doi.org/10.53291/JHTJ5611.

Dr. Thomas Wiedemann I Ludwig-Maximilians-Universität München I thomas.wiedemann@ifkw.Imu.de 


\section{Erkenntnisinteresse und Relevanz}

Vor dem Hintergrund des Filmförderkomplexes beleuchtet dieser Beitrag kritisch die Mechanismen der Aussagenentstehung im Produktionsprozess von Kinospielfilmen in Deutschland. Gestützt auf den Ansatz der Akteur-Struktur-Dynamiken und mit einer Materialbasis von 95 Expert*inneneninterviews sowie Dokumentanalysen wird gezeigt, dass das heimische Filmschaffen auch eine politische Dimension besitzt und Machtverhältnisse in der Gesellschaft weiter verfestigt. Die nationale Kinospielfilmproduktion tut sich infolgedessen schwer, auf die großen Herausforderungen der Gegenwart (Krise der Demokratie, Klimawandel, Demographie, Migration, Digitalisierung, Arbeit im Spätkapitalismus und viele mehr) progressiv zu reagieren.

Den Ausgangspunkt bildet die Tatsache, dass Kinospielfilme gerade in Zeiten der audiovisuellen Durchdringung des Alltags sowie ihrer medienübergreifenden Präsenz eine Form der öffentlichen Kommunikation darstellen (Prommer 2016; Beck 2018), sich an ein Publikum richten und mit Funktionen verbunden werden oder, allgemeiner formuliert, in einem wechselseitigen Bedingungsverhältnis mit der Gesellschaft stehen (vgl. Heinze et al. 2012). Folgt man einer grundsätzlich konstruktivistischen Perspektive (vgl. Hepp et al. 2017), sind Filme kein Spiegel der Realität. Treffender ist, dass die von ihnen entworfenen Gesellschaftsbilder ein theoretisch unbegrenztes Wirklichkeitsspektrum mit eigenem Geltungsanspruch konstruieren und auf diesem Weg Wissen transportieren sowie Deutungsangebote und Sinnmuster zur Verfügung stellen (vgl. Schroer 2008; Mikos 2015). Denn als fiktionale Unterhaltungsangebote unterliegen sie zwar einem geringeren Faktizitätsanspruch als etwa journalistische Produkte (vgl. Stöber 2013, 170), doch können sie insbesondere aufgrund ihrer imaginativen Kraft, ihres Involvements und affektiven Potenzials eine strukturierende Wirkung entfalten, indem sie für Orientierung sorgen, die Integration fördern, der Herausbildung einer kollektiven Identität dienen und zur Erinnerungskultur beitragen sowie Antworten auf die drängendsten Fragen der Zeit geben (vgl. Mai 2006; Denzin 2010; Sutherland und Feltey 2013). Der Rolle von Kinospielfilmen als wirkmächtiges Referenzsystem für Pluralität und Diversität sowie als Motor gesellschaftlicher Emanzipation steht jedoch der Umstand gegenüber, dass sie von sozialen Faktoren geformt und somit durch die Gesellschaft vorstrukturiert sind (vgl. Silbermann 1980; Winter 2012). 
Bekannt ist, dass Kinospielfilme in einem arbeitsteiligen Komplex mit einer Vielzahl von Akteur*innen mit unterschiedlichen Zielhorizonten (beispielsweise Drehbuchautor*innen und Regisseur*innen an der kreativen Spitze gegenüber den für das Projektmanagement verantwortliche Produktionsunternehmen) entstehen und insofern sowohl eine kulturelle Praxis als auch ein Wirtschaftszweig sind (vgl. von Rimscha 2010; Grothe-Hammer 2015). Von der Forschung weniger berücksichtigt wurde bislang jedoch, dass die Kinospielfilmproduktion in Deutschland auch expliziter Gegenstand politischen Handelns ist. Dafür steht im Besonderen die öffentliche Filmförderarchitektur auf Bundes- und Länderebene, die jährlich fast eine halbe Milliarde Euro in die nationale Filmbranche steckt. ${ }^{1}$ Hinzu kommt, dass die große Mehrheit deutscher Kinospielfilme von öffentlichrechtlichen Rundfunkanstalten - Institutionen, die neben gesellschaftlichen auch politischen Einflüssen unterliegen - koproduziert wird (vgl. von Heinz 2012), was ebenso die Unabhängigkeit der Filmschaffenden, insbesondere der Kommunikator*innen ${ }^{2}$ im deutschen Kinospielfilm, wie auch die Staatsferne des Mediums insgesamt in Frage stellt. Demzufolge steht zur Vermutung, dass im heimischen Filmschaffen gesellschaftliche Hierarchien zum Ausdruck kommen (vgl. Mikos 2015) und hier ferner eine Auseinandersetzung um legitime - mehrheitlich anerkannte - Wirklichkeitskonstruktionen stattfindet (vgl. Dörner und Vogt 2012), so dass in letzter Konsequenz anstelle gesellschaftlicher Transformationsprozesse ohnehin schon dominante Deutungsangebote und Sinnmuster im Diskurs weiter befeuert werden.

1 Angesichts der massiven Beeinträchtigungen der Filmbranche im Zuge der Corona-Krise haben die Filmfördereinrichtungen aktuell darüber hinaus eine Reihe von Hilfsprogrammen gestartet. Die zur Verfügung gestellten Mittel belaufen sich insgesamt voraussichtlich auf rund 100 Millionen Euro (vgl. Filmförderungsanstalt 2020a).

2 Wie in der Kommunikationswissenschaft üblich sind mit Kommunikator*innen hier und im Folgenden die Handlungs- und Rollenträger*innen gemeint, die Aussagen öffentlicher Kommunikation bereitstellen, dabei schöpferisch und gestaltend tätig sind und so als Scharniere eine Schlüsselposition im Kommunikationsprozess einnehmen (vgl. Maletzke 1963, 43). Bezogen auf das Medium Film sind das insbesondere Akteur*innen aus den Bereichen Drehbuch, Regie und Produktion. 
Zur Ermittlung der Mechanismen und Konventionen, die das deutsche Filmschaffen in Anbetracht des politischen Gestaltungswillens prägen, fragt die vorliegende Studie mit Hilfe von Schimank, wie Akteurskonstellationen und soziale Strukturen die Aussagenentstehung deutscher Kinospielfilme in eine bestimmte Richtung lenken. Geleistet wird damit ein sozialwissenschaftlicher Beitrag zur Filmforschung, der in der Kommunikationswissenschaft anschlussfähig mindestens zur Kommunikatorforschung und zur Forschung im Bereich Medienpolitik ist. Welche Konstellationen von Akteur*innen sind im Produktionsprozess also von Bedeutung, wenn die Politik mitspricht? Wer hat die Möglichkeit, als Kommunikator*in an der Wirklichkeitskonstruktion im deutschen Kinospielfilm teilzuhaben und zu welchem Grad? Welche Anforderungen werden an die Kommunikator*innen im Produktionsprozess herangetragen? Welches Selbstverständnis zeichnet sie als Folge davon mehrheitlich aus und was sind ihre Strategien in der Interaktion mit anderen Akteur*innen? Zusammengefasst und kritisch gewendet: Sind Kinospielfilme in Deutschland angesichts dessen überhaupt in der Lage, als Segment der Gegenöffentlichkeit zu wirken, also denen eine Stimme zu geben, die sonst nicht gehört werden, und den hegemonialen Diskurs mit alternativen Wirklichkeitskonstruktionen herauszufordern?

Der folgende Abschnitt skizziert Schimanks Ansatz der Akteur-Struktur-Dynamiken, wendet ihn auf die soziale Konfiguration der deutschen Kinospielfilmproduktion an und informiert über Methode und Forschungsmaterial. Die Ergebnisse im dritten Abschnitt machen dann in vielerlei Hinsicht deutlich, dass das Filmschaffen in Deutschland alles andere als voraussetzungslos ist und "transformative Kinospielfilme« unter den Vorzeichen des Filmförderkomplexes nicht zu erwarten sind.

\section{Theorie, Methode und Forschungsmaterial}

Der Ansatz der Akteur-Struktur-Dynamiken, der die »wechselseitige Konstitution von handelndem Zusammenwirken und sozialen Strukturen « (Schimank 2007, 121-122) in den Mittelpunkt rückt und die Systemtheorie um eine Akteursperspektive erweitert, geht von (individuellen und kollektiven) Akteur*innen aus, die spezifische Interessen besitzen, über bestimmte (Macht-)Ressourcen verfügen und so eine Strategie für die Durchsetzung ihrer Ziele entwickeln (vgl. Schimank 2000). Dass sie mit ihrem Handeln stets auf andere Akteur*innen tref- 
fen, führt zu einer bewussten oder unbewussten Anpassung ihrer eigenen Handlungsstrategie - basierend auf ihren »Akteurfiktionen «, also ihrem Wissen über die Interessen und Ressourcen der anderen Akteur*innen sowie die Funktionslogik der sozialen Systeme, denen sie jeweils angehören (vgl. Schimank 1988). »Soziale Strukturdynamiken« werden somit »intentional vorangetrieben«, doch »entgleiten« sie den Akteur*innen »mal mehr, mal weniger ins Transintentionale (Schimank 2007, 125). Mit anderen Worten: Das Zustandekommen deutscher Kinospielfilme vollzieht sich aus dieser Perspektive in einer Aneinanderreihung von Konstellationen von Akteur*innen, die sich gegenseitig beobachten, beeinflussen und ihr Handeln notgedrungen aufeinander abstimmen. Und selbstverständlich gehören zu diesen Akteur*innen nicht nur die traditionell am Filmproduktionsprozess beteiligten Gewerke (von Drehbuch über Regie und Produktion bis hin zu Verleih und Kinoabspiel), sondern genauso die Filmförderung und das öffentlich-rechtliche Fernsehen mit ihren wirtschafts- und kulturpolitischen Zielsetzungen. Erst in solchen umfassenden Handlungsverkettungen können demzufolge filmische Konstruktionen von Realität erzeugt sowie soziale Strukturen erschaffen, erhalten und um- oder abgebaut werden.

Um das handelnde Zusammenwirken von Akteur*innen zu untersuchen, schlägt Schimank (2007) vor, die Konstellations-, Erwartungsund Deutungsstrukturen zu analysieren, in die es eingebettet ist und die es prägt. Für die Frage nach den Mechanismen und Konventionen der Aussagenentstehung im Produktionsprozess deutscher Kinospielfilme bedeutet das erstens, das »Können« der Kommunikator*innen im Filmschaffen hierzulande (Konstellationsstrukturen), also die eingespielten Gleichgewichte und Muster in ihrem Handeln (Herkunft, Sozialisation, Arbeitsbedingungen, Marktstrukturen, Ressourcen, Routinen, Zwänge), zu ergründen. Zweitens ist ihr »Sollen« zu ermitteln (Erwartungsstrukturen). Hier gilt es, die wesentlichen Ansprüche und Anforderungen herauszuarbeiten, mit denen die Kommunikator*innen im Filmproduktionsprozess konfrontiert werden (rechtliche Vorschriften, Richtlinien, formelle oder informelle Vorgaben der Filmförderung, Vorstellungen der Projektpartner einschließlich Fernsehen, Wünsche und Erwartungshaltungen der projektierten Zielgruppe). Drittens ist schließlich das »Wollen« der Kommunikator*innen zu adressieren (Deutungsstrukturen) und nach ihren evaluativen und kognitiven Orientierungen zu fragen (Selbstverständnis, Stoffauswahl und -umsetzung, Verhaltenskodex, Erfahrungen, Rezeptwissen). 
Gemäß dem hier vertretenen Verständnis von qualitativer theoriegeleiteter Forschung (vgl. Löblich 2016; Meyen et al. 2019) wurde auf Basis der theoretischen Perspektive ein Kategoriensystem mit den soeben skizzierten Konstellations-, Erwartungs- und Deutungsstrukturen als Hauptanalysedimensionen entwickelt. Wichtigstes Forschungsmaterial sind 95 Expert*inneninterviews mit Vertreter*innen aller für die Entstehung deutscher Kinospielfilme als zentral erachteten Betätigungsfelder. Das Sample orientierte sich dabei an der theoretischen Sättigung und umfasste zunächst sieben Drehbuchautor*innen, 35 Filmregisseur*innen (von denen etwa die Hälfte auch Drehbücher schreiben) sowie 19 Filmproduzent*innen, die sich nach Geschlecht, Alter, kulturellem Hintergrund und Ausbildung (Filmhochschulabsolvent*innen gegenüber Quereinsteiger*innen), aber auch mit Blick auf die Ausrichtung ihrer Arbeit (Mainstream gegenüber Arthouse) und ihren bisherigen Erfolg (künstlerisch gegenüber kommerziell) unterscheiden. Interviewt wurden außerdem sechs Vertreter*innen von großen und kleinen Verleihfirmen, sieben Kinobetreiber*innen (sowohl Multiplex als auch Programmkino) und fünf Filmfestival-Verantwortliche, ferner zwölf Angehörige nationaler und regionaler Filmfördereinrichtungen sowie vier Redakteur*innen öffentlich-rechtlicher Fernsehsender im Bereich Kinospielfilm. Um die so erzielten Erkenntnisse besser einschätzen zu können, waren die Expert*inneninterviews von mehreren Dutzend Dokumenten flankiert, darunter Marktdaten und Statistiken, Stellungnahmen von Branchenverbänden, offene Briefe, Thesenpapiere, Protokolle von Diskussionsveranstaltungen und journalistische Artikel.

\section{Ergebnisse}

Die Befunde der Studie können hier nur in Ausschnitten präsentiert werden. ${ }^{3}$ Nichtsdestotrotz veranschaulichen sie, dass der filmpolitische Gestaltungswille deutliche Spuren in den Konstellations-, Erwartungs- und Deutungsstrukturen des deutschen Filmschaffens hinterlässt und das Spektrum möglicher filmischer Wirklichkeitskonstruktionen in vielfacher Hinsicht einschränkt. Dem transformativen Potenzial von heimischen Kinospielfilmen wird so - willentlich oder nicht - ein Riegel vorgeschoben.

3 Für ausführlichere Befunde, wenngleich vorrangig bezogen auf das Gewerk Regie, vgl. Wiedemann (2018; 2019). 


\subsection{Konstellationsstrukturen}

Die Mehrheit der deutschen Kinospielfilmproduktionen sind Autor*innenfilme. Der Prozess der Wirklichkeitskonstruktion nimmt seinen Ausgang also in der Regel bei Drehbuchautor*innen und Regisseur*innen, die nicht selten auch an der Produktionsplanung und der Postproduktion teilhaben. Dazu gesellen sich gleichwohl meist schon während der Buchentwicklung Produzent*innen, die fortan bis zur Fertigstellung eines Films auch bei kreativen Entscheidungen mitsprechen und insofern, wenn auch in geringerem Maße, ebenso als Kommunikator*innen zu betrachten sind. Dennoch ist die Macht dieser letztgenannten Akteur*innen in Deutschland begrenzt. Es gibt kaum ein echtes Studiosystem und an den 157 deutschen Spielfilmen, die 2019 Kinopremiere hatten, waren knapp 200 Produktionsfirmen beteiligt (vgl. Spitzenorganisation der Filmwirtschaft 2020). Zu den Akteurskonstellationen im Produktionsprozess deutscher Kinospielfilme zählen ferner rund 120 Verleihfirmen, die im günstigsten Fall schon in der Entwicklungsphase eine Distributionszusage abgeben, sowie über 1600 Kinos als traditionell wichtigster kommerzieller Auswerter, wenngleich diese an vorderster Stelle von den gegenwärtigen Umbrüchen der Branche (Stichwort: Home Entertainment) betroffen sind. Zu nennen sind schließlich auch bedeutende deutsche Filmfestivals wie allen voran die Internationalen Filmfestspiele Berlin, auch bekannt als Berlinale, das Filmfest München, die Hofer Filmtage oder der Max-Ophüls-Preis in Saarbrücken, die längst eine zentrale Rolle für die Distribution und Zirkulation insbesondere von Arthouse-Filmen spielen, zumal sie für öffentliche Aufmerksamkeit sorgen und bisweilen weitere Einnahmequellen erschließen, zumindest wenn für die Film-Programmierung eine Bezahlung (»screening fees«) erfolgt.

Nichtsdestotrotz: Nur ein Viertel der durchschnittlichen Produktionskosten eines deutschen Kinospielfilms, die etwa drei bis vier Millionen Euro betragen, ist durch Eigenmittel, Rückstellungen und idealerweise Verleihgarantie und Weltvertrieb gedeckt. Rund die Hälfte des Budgets stammt dagegen aus den Töpfen der öffentlichen Filmfördereinrichtungen (darunter Filmförderungsanstalt, Deutscher Filmförderfonds, FilmFernsehFonds Bayern, Film- und Medienstiftung Nordrhein-Westfalen und Medienboard Berlin-Brandenburg), die 2019 ein Gesamtfördervolumen in Höhe 455,92 Millionen Euro auswiesen (vgl. Filmförderungsanstalt 2020b). Natürlich: Ohne diese umfassende Unterstützung kann der deutsche Film in seiner gegenwärtigen Form - gerade mit Blick auf sein hohes Produktionsaufkommen - nicht überleben. Aller- 
dings fungiert die Filmförderung auch als Gatekeeper, denn nur etwa jedes fünfte Filmprojekt erhält Förderung und kann realisiert werden: »Die Förderzusage für deinen Film bedeutet ganz klar das Ende eines anderen Filmprojekts«, kommentierte ein befragter Produzent. Dabei sind Verrenkungen in der Produktionsplanung und »Fördertourismus« (ein geförderter Film erhält meist nicht nur von einer Einrichtung Zuschüsse) auch im besten Fall einzukalkulieren, wie die interviewten Produzent*innen einstimmig erklärten. Für noch verbleibende Lücken im Budget (rund 25 Prozent) wird schließlich schon frühzeitig der Verkauf der TV-Lizenz angestrebt - in der Regel an öffentlich-rechtliche Fernsehsender, die im Gegenzug weitreichende Rechte in Sachen Koproduktion erwerben. Auch hier findet ein strikter Selektionsprozess statt. Den entsprechenden Senderredaktionen (für den Nachwuchs zum Beispiel »Das kleine Fernsehspiel« im ZDF) kommt also ebenfalls eine gewichtige Rolle in den Konstellationsstrukturen hinter der filmischen Wirklichkeitskonstruktion zu.

Ein Blick auf die Herkunft und Sozialisation der Kommunikator*innen zeigt, dass Drehbuchautor*innen, Regisseur*innen und Produzent*innen in Deutschland unabhängig von ihrem Alter fast ausnahmslos der oberen Mittelschicht entstammen und einen Familienhintergrund aufweisen, in der die Entscheidung für eine Tätigkeit in der Filmbranche ideell und finanziell Unterstützung erfährt. »Meine Eltern haben mich nicht unter Druck gesetzt, etwas Handfestes zu lernen«, resümierte stellvertretend ein Regisseur und berichtete von den »Finanzspritzen«, die er bis zu seinem 30. Lebensjahr von zu Hause bekam. Außerdem absolvierten die meisten befragten Kommunikator*innen ein Studium an der Filmhochschule, einer oft staatlichen und stark zugangsbeschränkten Ausbildungsstätte, dies es hierzulande nur an wenigen Standorten gibt, was die Elitisierung unter den Kommunikator*innen weiter verstärkt (vgl. Wiedemann 2019). Dort sammelt der Nachwuchs das nötige Startkapital für den Berufseintritt (insbesondere Social Skills, also Teamfähigkeit, Kompromissbereitschaft und die Wertschätzung von Teamarbeit, sowie Kontakte - zu Kommiliton*innen, noch wichtiger aber zu Förderreferent*innen und TV-Redakteur*innen, die zu Pitch-Terminen regelmäßig geladen werden), wird aber zugleich auch mit den Gesetzmäßigkeiten des Filmemachens hierzulande, vor allem den herrschenden Interaktionsroutinen, vertraut gemacht und so zu konformem Verhalten angeleitet. Ein ArthouseFilmemacher fasste es so zusammen: „Wir werden ausschließlich auf diesen kleinen Markt hin ausgebildet.« 
Die Ressourcen, die für eine Teilhabe an der filmischen Wirklichkeitskonstruktion in Deutschland erforderlich sind, verweisen einmal mehr auf das hohe Gewicht, das der Filmförderung und dem öffentlich-rechtlichen Fernsehen in den Akteurskonstellationen im Produktionsprozess deutscher Kinospielfilme zukommt. Deutlich zutage trat in den Interviews, dass die Kommunikator*innen für einen dauerhaften Verbleib in der Branche neben künstlerischem und technischem Know-how, Organisationstalent und finanzieller Absicherung mindestens ebenso Beziehungen und eine »Visitenkarte« (ein Film mit Publikumserfolg, eine Auszeichnung) vorweisen müssen - die Währung schlechthin, um für den nächsten Film Fördermittel und Sendergelder zugesprochen zu bekommen. Ohne Zweifel ist die Zementierung von Diversitätsgrenzen auch dadurch vorprogrammiert. So treffen sozial Benachteiligte, nicht zu Kompromissen bereite Außenseiter, Einzelgänger*innen und allgemein Frauen (vgl. Loist und Prommer 2019), die allesamt aufgrund ihrer Herkunft und ihres Lebensweges vermutlich eher in der Lage sein dürften, den herrschenden Diskurs in Frage zu stellen und Räume für alternative Wirklichkeitskonstruktionen zu öffnen, auf deutlich gröBere Hindernisse, dauerhaft an der Aussagenentstehung im Produktionsprozess deutscher Kinospielfilme mitzuwirken.

\subsection{Erwartungsstrukturen}

Wenig überraschend treffen in den beschriebenen Akteurskonstellationen ganz unterschiedliche Zielsetzungen aufeinander, die als Erwartungsstrukturen Einfluss auf die Aussagenentstehung deutscher Kinospielfilme nehmen. Beschränkt man sich zunächst auf die traditionell am Filmproduktionsprozess beteiligten Akteur*innen, wird deutlich, dass die narrativen und ästhetischen Visionen der für Drehbuch und Regie Verantwortlichen notgedrungen mit dem Gebot der wirtschaftlichen Rentabilität konfrontiert werden. Dies bezieht sich auf Produzent*innen, die sich zwar als kreative Kompliz*innen verstehen, aber dennoch Risikoabwägungen treffen müssen. Entsprechend werden ihnen von den interviewten Regisseur*innen und Autor*innen oft Mutlosigkeit und Vorbehalte gegenüber provokanten Stoffen attestiert. Ähnliches trifft zu für Verleihfirmen, die unabhängig von ihrer Größe und Ausrichtung auf Gewinnmaximierung und Zielgruppenorientierung aus sind und umso mehr Mitsprache einfordern, je eher sie in ein Projekt eingebunden sind. »Wenn ich mit der Besetzung oder mit dem 
Film-Ende nicht einverstanden bin«, berichtete etwa selbstbewusst der Chef eines Independent-Verleihs, »dann gebe ich meiner kommerziellen Perspektive unmissverständlich Ausdruck.« Diese Praxis wurde von den Kommunikator*innen im deutschen Filmschaffen allerdings kaum in Frage gestellt, da sie Verleihfirmen als Sprachrohr der Kinobetreiber*innen erachten, welche die Wünsche des Publikums aus erster Hand erfahren und Experimente scheuen. »Wir sterben für Filmkunst. Aber am Ende des Tages müssen wir unsere Löhne bezahlen«, erklärte dazu der Betriebsleiter zweier Programmkinos in Frankfurt am Main, und die Betreiberin eines Münchner Kinos im Premiumsegment sagte: „Wir setzen auf Bewährtes. Egal ob es immer von denselben vier, fünf Leuten kommt.«

Natürlich spielt Rentabilität auch bei den Erwartungen der wichtigsten beiden Finanziers deutscher Kinospielfilme eine Rolle. Der Filmförderung und dem Fernsehen geht es aber nicht nur darum. Die Spielfilmredaktionen der öffentlich-rechtlichen Rundfunkanstalten, um hier zu beginnen, verweisen einerseits auf den im Rundfunkstaatsvertrag festgeschriebenen Kulturauftrag, betonen andererseits aber auch ihre Zuschauerorientierung und verknüpfen diese mit dem Anspruch auf Aktualität. »Unser Ziel«, so erklärte die Redakteurin einer Landesrundfunkanstalt der ARD, »ist ein Archiv der Gegenwart. Die von uns koproduzierten Filme sollen repräsentieren, was die deutsche Bevölkerung gerade bewegt: Flüchtlingskrise, Europa, aber auch Umwelt, Comingof-Age, Cybermobbing.« Ist ein Koproduktionsvertrag unterzeichnet, haben die verantwortlichen Redakteur*innen weitreichende Entscheidungsbefugnisse bei der Buchentwicklung und dem Cast, aber auch in Sachen Kamera und Postproduktion, wenngleich sie beteuern, vorrangig beratend tätig zu sein. Dennoch beurteilten die meisten interviewten Drehbuchautor*innen, Regisseur*innen und Produzent*innen ihre Zusammenarbeit mit den Sendern rückblickend als problematisch und monierten die verbreitete Angst, an Tabus zu rütteln oder von den gesellschaftlich relevanten Gruppen, welche die Sender in den Aufsichtsgremien kontrollieren, zur Rechenschaft gezogen zu werden. Ein weiterer Kritikpunkt ist die zunehmende Konvergenz von Kino- und Fernsehfilmen (vgl. Mikos 2011) zugunsten der Fernsehlogik, für die Alt-Filmemacher Edgar Reitz in einem Thesenpapier anlässlich des Kongresses »Zukunft deutscher Film« zu Perspektiven der deutschen Kino- und Filmkultur 2018 in Frankfurt am Main deutliche Worte fand: Da sich »halbstaatliche Superproduzenten« in alle Geschmacksentscheidungen einmischten, erkenne man den »camouflierten Fernseh- 
film [...] sofort an seiner thematischen Überspanntheit und der Instrumentalisierung der Handlungsfiguren« (Reitz 2018).

Das oberste Ziel der Filmförderinstitutionen ist einerseits die wirtschaftliche Stärkung der heimischen Filmindustrie, weshalb Wert gelegt wird auf Standorteffekte und kommerziell erfolgversprechende Produktionen, die dem System seinerseits Einnahmen bescheren, sei es in Form der Rückzahlung von Darlehen oder, im Fall der Filmförderungsanstalt, über die sogenannte Filmabgabe, die Kinos jährlich zu entrichten haben. Andererseits möchte man als Beitrag zu einer lebendigen deutschen Filmkultur künstlerisch herausragende Projekte unterstützen, die dann auf dem (internationalen) Filmfestival-Parcours reüssieren oder Auszeichnungen wie den Deutschen Filmpreis erhalten sollen. Folgt man Monika Grütters, Beauftragte des Bundes für Kultur und Medien, zielt die kulturelle Filmförderung (insbesondere gebündelt bei der Staatsministerin selbst) auf anspruchsvolle Arthouse-Filme und innovative Formate, denn »nur so entsteht Fortschritt, nur so, mit kritischen Positionen, halten wir unsere Demokratie wach « (zitiert nach Kniebe 2019). Abgesehen von der automatischen Förderung für Filmvorhaben, die mindestens ein Viertel ihrer Kosten in Deutschland auszugeben beabsichtigen, seitens des Deutschen Filmförderfonds und der Referenzfilmförderung (bemessen am kommerziellen oder künstlerischen Erfolg des Vorgängerfilms) befindet über die selektive Projektfilmförderung meist eine aus der Branche rekrutierte Expert*innenkommission mit Zweidrittelmehrheit hinter verschlossenen Türen. Entscheidungsgrundlage sind, wie die interviewten Kommissionsmitglieder angaben, das Drehbuch und das »kreative Package«, also die Projektbeteiligten und ihre Reputation (die Kooperation mit einem Sender ist ebenfalls mindestens gerne gesehen), sowie die Produktionsparameter einschließlich des zu erwartenden Standortnutzens.

Auch hier gibt es Kritik auf Seiten der Filmschaffenden - wegen der zu sehr auf Regionaleffekte bedachten Länderförderungen (laut einer Autorenfilmemacherin drohe das »Menetekel: Schreibt das Drehbuch doch um auf Berlin«), vor allem aber aufgrund der Konsensorientierung in den Fördergremien. So würden, folgt man einem Regisseur mit jahrzehntelanger Berufserfahrung, die Vorstellungen in den Gremien immer »konservativer, ängstlicher und kulturspießiger«, so dass nur noch Verantwortung übernommen werde für Feel-Good-Komödien und den »Problemfilm, der gemacht werden muss und zwar möglichst konventionell«. Wenig anders hält das von vielen namhaften Filmschaffenden erarbeitete Abschlusspapier des oben erwähnten Kon- 
gresses zu Perspektiven der deutschen Kino- und Filmkultur fest, dass es dem sogenannten »Gremienfilm« an »Ecken und Kanten« fehle und nur das durchgewinkt werde, was von »etablierten« Filmemacher*innen komme oder an »Bestehendes« anknüpfe. Für »das Extreme, das Ungewöhnliche, das Bodenlose und das ästhetisch Innovative« fließe dagegen kein Geld (Frankfurter Positionen 2018, 3). In der Tat können die wichtigsten deutschen Filmfestivals hier nur auf dem Papier als Gegengewicht erachtet werden. Denn insbesondere Deutschlands A-Filmfestival, die Berlinale, orientiert sich als staatlich bezuschusstes Flaggschiff des nationalen Films in seiner Ausrichtung und Programmpolitik vorrangig an dieser wirtschafts- und kulturpolitischen Agenda (vgl. Wiedemann und Krainhöfer 2018).

\subsection{Deutungsstrukturen}

Die für den Filmproduktionsprozess in Deutschland typischen Akteurskonstellationen ziehen nicht nur eine Reihe von Forderungen und Ansprüchen nach sich, wie die Wirklichkeitskonstruktion deutscher Kinospielfilme beschaffen sein soll. Der hohe Stellenwert der Förderung und des öffentlich-rechtlichen Fernsehens sowie die daraus resultierenden Erwartungen an das Filmschaffen hierzulande schlagen sich, in Verbindung mit generellen Machtstrukturen in der Gesellschaft, auch auf die evaluativen und kognitiven Orientierungen der Kommunikator*innen im deutschen Kinospielfilm nieder. Solche Deutungsstrukturen beziehen sich zunächst auf eine klar erkennbare Berufsideologie. Dazu gehören - diese Begriffe tauchen in den Interviews immer wieder auf die Erfahrung von »Durststrecken« und »Niederlagen« zu Karrierebeginn, gepaart einerseits mit »Dankbarkeit«, andererseits aber auch mit "Stolz«, es schließlich geschafft, also gegenüber Mitstreitenden mehr »Durchsetzungsvermögen « an den Tag gelegt zu haben und dabei immer »stur« der »inneren Stimme gefolgt« zu sein, ohne den »eigenen Kopf « aufgegeben zu haben.

Das Selbstverständnis der Kommunikator*innen gestaltet sich dann recht homogen. Während nur wenige Autorenfilmemacher*innen erklärten, sie wollten die Zuschauer*innen nicht nötigen, »etwas Bestimmtes zu denken«, und verfolgten »keinen pädagogischen oder didaktischen Ansatz«, versteht sich das Gros der Interviewten als Themensetzer*innen und Aufklärer*innen über "gesellschaftlich relevante Sachverhalte« (Regisseur). Das Ansinnen, den »Unterhaltungscharak- 
ter von Filmen« mit einem »ernsthaften Diskurs« zu verbinden (Drehbuchautor), ist dementsprechend die Regel. Von einem Produzenten treffend formuliert: »Es macht mich sehr glücklich, mit diesem brisanten Thema auf dem Höhepunkt der Flüchtlingsdebatte so viele Leute erreicht zu haben.«Doch, wie gleich noch deutlicher wird, nehmen die Kommunikator*innen ihre Themensetzer*innen- und Aufklärer*innenrolle - den »Akteurfiktionen « entsprechend - lediglich in einem eng abgesteckten Rahmen wahr.

Das Wissen um die Ziele und Ressourcen der anderen Akteur*innen macht sich darüber hinaus in einer gehörigen Portion Pragmatismus bemerkbar. Neben dem oftmaligen »Kuhhandel« um Szenen (Drehbuchautor) zwischen den Kommunikator*innen selbst bedeutet das beispielsweise, dass nach dem Verleiher-Feedback, ohne mit der Wimper zu zucken, »kooperativ« (Drehbuchautorin und Regisseurin) neue Buch- oder Schnittfassungen erstellt werden. Ebenso sind von der Stoffentwicklung bis zur Postproduktion Zugeständnisse an die Vorstellungen der beteiligten Fernsehredakteur*innen an der Tagesordnung. »Mein Film«, so erinnerte sich eine Autorenfilmemacherin an ihr Kinodebüt, »wurde durch den WDR-Redakteur sehr stark in Richtung Realismus gedrängt.« Dass die Filmförderung auf die tatsächliche Produktion kaum noch Einfluss nimmt, ändert nicht viel, denn die Erwartungshaltung dieses Akteurs wurde von den Kommunikator*innen schon längst - wieder gemäß Schimanks Vorstellung von »Akteurfiktionen « - antizipiert. Man sei »beim Schreiben und Entwickeln in den Gesetzmäßigkeiten der Branche gefangen «, offenbarte ein Drehbuchautor, der mittlerweile auch als Produzent tätig ist. Man wisse, »was man tun kann, um Geld zu bekommen«, und erfülle so Erwartungen, »ohne dass diese überhaupt bewusst formuliert sein müssen«.

Mehr noch: Dass selbst etablierte Filmemacher*innen und Produzent*innen wiederholt von Konflikten berichteten und ihre Kompromissfähigkeit schließlich als Tugend deklarierten, unterstreicht, wie begrenzt die Autonomie der Kommunikator*innen im deutschen Filmschaffen ist. »Es gibt viele Sachen, die ich gerne erzählen würde. Aber die will keiner hören«, gestand eine Drehbuchautorin und ist damit keine Ausnahme. Stattdessen vollzieht sich die Aussagenentstehung deutscher Kinospielfilme fast ausschließlich unter strenger Einhaltung folgender Kriterien: die Grenze zwischen Arthouse und Mainstream wahren, keine Genre-Experimente wagen, sondern lieber beispielsweise auf Culture-Clash- und Family-Entertainment-Formate oder historische Stoffe (am besten Biographien) setzen, sowie Themenfilme 
»geschmackvoll« und »ernst« umsetzen. Dass dabei die Systemfrage gestellt wird, ist auch angesichts der Herkunft und Sozialisation der meisten Kommunikator*innen alles andere als wahrscheinlich.

\section{$4 \quad$ Fazit}

Gestützt auf den Ansatz der Akteur-Struktur-Dynamiken zeigt die Untersuchung der dominanten Konstellations-, Erwartungs- und Deutungsstrukturen im Produktionsprozess deutscher Kinospielfilme, dass sich das heimische Filmschaffen keineswegs bloß im Spannungsfeld zwischen Kunst, Wirtschaftlichkeit und Publikumswünschen bewegt. Vielmehr weist die Kinospielfilmproduktion in Deutschland, das belegen die Ergebnisse in vielfacher Hinsicht, auch eine politische Dimension auf und zeichnet sich in der Tat durch klare Hierarchien aus, was sich in den filmischen Deutungsangeboten und Sinnmustern niederschlägt und schlussendlich die bestehenden Machtverhältnisse in der Gesellschaft weiter verfestigen dürfte. Denn als Kommunikator*innen nehmen vor allem Drehbuchautor*innen und Regisseur*innen zwar eine Schlüsselposition für die Wirklichkeitskonstruktion von Kinospielfilmen ein, doch übernehmen den Gegenpart im Kampf zwischen Kreativen und Geldgebern keineswegs nur Produktionsunternehmen, Verleihfirmen und Kinoauswerter, sondern mindestens ebenso die Filmförderung und das öffentlich-rechtliche Fernsehen als wichtigster Finanzier oder Koproduktionspartner. Die Folge: Kinospielfilme können in Deutschland erst realisiert werden und ein Publikum finden, wenn die Filmförderung von der Lukrativität oder Relevanz des Vorhabens überzeugt ist und der Stoff zum Profil der öffentlich-rechtlichen Sender passt.

Mehr noch: Neben der Elitisierung der Branche (und etwa auch der Zementierung von Geschlechterungerechtigkeiten) sowie der Herausbildung einer klaren Berufsideologie auf Seiten der Kommunikator*innen versuchen insbesondere die Filmemacher*innen, gemäß ihren »Akteurfiktionen « an Bestehendes anzudocken. Der wesentliche Grund hierfür ist die Konstellation mit weiteren Akteur*innen im Filmproduktionsprozess, die über Risikomanagement, Gewinnmaximierung und Zielgruppenorientierung nachdenken, vor allem jedoch Vorbehalte gegenüber provokanten Stoffen haben, auf Publikumserfolge hoffen und sich mit Auszeichnungen schmücken möchten sowie eine standort- und kulturpolitische Agenda verfolgen. Während "gefördert wird, 
was Deutschland braucht«, so formulierte es Regisseur Dominik Graf bereits 2012 in der Zeit (Graf 2012), gelingt es mit dem Filmförderkomplex offenbar nicht, Diversität und Pluralität zu verwirklichen. In diesem Sinne: Ohne eine strukturelle Reform des Filmfördersystems, wie sie im Übrigen auch von einigen Brancheninitiativen propagiert wird (neben den genannten Frankfurter Positionen beispielsweise auch von ProQuote Film und vom Hauptverband Cinephilie), lassen sich die imaginative Kraft und das emanzipatorische Potenzial von Spielfilmen allenfalls bedingt ausschöpfen. Dass von der nationalen Kinospielfilmproduktion Impulse bezogen auf die großen Herausforderungen der Gesellschaft ausgehen oder gar Transformationsprozesse aktiv vorangetrieben werden, ist demzufolge nicht zu erwarten.

\section{Literatur}

Beck, Klaus. 2018. Das Mediensystem Deutschlands. Strukturen, Märkte, Regulierung. Wiesbaden: Springer VS.

Denzin, Norman K. 2010. Reading Film. Filme und Videos als sozialwissenschaftliches Erfahrungsmaterial. In: Qualitative Forschung. Ein Handbuch, herausgegeben von Uwe Flick, Ernst von Kardoff und Ines Steinke, 416-428. Reinbek bei Hamburg: Rowohlt.

Dörner, Andreas, und Ludgera Vogt. 2012. Unterhaltungskultur als politische Kultur. Politikvermittlung in der Gegenwartsgesellschaft. In: Unterhaltungsrepublik Deutschland. Medien, Politik und Entertainment, herausgegeben von Andreas Dörner und Ludgera Vogt, 11-31. Bonn: Bundeszentrale für politische Bildung.

Filmförderungsanstalt 2020a. Soforthilfeprogramme der Filmförderungen. https://www.ffa.de/corona-soforthilfe-1.html. Zugegriffen: 29. September 2020.

Filmförderungsanstalt. 2020b. Zahlen aus der Filmwirtschaft. https://www.ffa. de/download.php?f=5d26f0e1995b98c331af13c33ff775aa\&target $=0$. Zugegriffen: 23. August 2020.

Frankfurter Positionen. 2018. Zur Zukunft des deutschen Films. www.lichter-filmfest.de/media/180426_zdf_ergebnisspapier_06.pdf. Zugegriffen: 27. August 2020.

Graf, Dominik. 2012. Das Grauen ... das Grauen! Die Zeit vom 26. April, https:// www.zeit.de/2012/18/Deutscher-Filmpreis. Zugegriffen: 28. August 2020.

Grothe-Hammer, Michael. 2015. »Du passt auf, dass der Irre pünktlich fertig wird.« Zum Machtgleichgewicht zwischen Regie und Produktionsleitung in Filmprojekten. Studies in Communication and Media 4 (3): 189-247.

Heinz, Julia von. 2012. Die freundliche Übernahme. Der Einfluss des öffentlich-rechtlichen Fernsehens auf den deutschen Kinofilm von 1950 bis 2010. Baden-Baden: Nomos. 
Heinze, Carsten, Stephan Moebius, und Dieter Reicher (Hrsg.). 2012. Perspektiven der Filmsoziologie. Konstanz: UVK.

Hepp, Andreas, Wiebke Loosen, Uwe Hasebrink, und Jo Reichertz. 2017. Konstruktivismus in der Kommunikationswissenschaft. Über die Notwendigkeit einer (erneuten) Debatte. Medien \& Kommunikationswissenschaft 65 (2): 181-206.

Kniebe, Tobias. 2019. »Das Geld wird sinnvoll genützt.« Interview mit Monika Grütters. Süddeutsche Zeitung vom 31. Juli, 9.

Löblich, Maria. 2016. Theoriegeleitete Forschung in der Kommunikationswissenschaft. In: Handbuch nicht standardisierte Methoden in der Kommunikationswissenschaft, herausgegeben von Stefanie Averbeck-Lietz und Michael Meyen, 6779. Wiesbaden: Springer VS.

Loist, Skadi, und Elizabeth Prommer, 2019. Gendered production culture in the German film industry. Media Industries 6 (1): 95-115.

Mai, Manfred, 2006. Künstlerische Autonomie und soziokulturelle Einbindung. Das Verhältnis von Film und Gesellschaft. In: Das Kino der Gesellschaft - die Gesellschaft des Kinos. Interdisziplinäre Positionen, Analysen und Zugänge, herausgegeben von Manfred Mai und Rainer Winter, 24-47. Köln: Herbert von Halem.

Maletzke, Gerhard. 1963. Psychologie der Massenkommunikation. Theorie und Systematik. Hamburg: Hans-Bredow-Institut.

Meyen, Michael, Maria Löblich, Senta Pfaff-Rüdiger, und Claudia Riesmeyer. 2019. Qualitative Forschung in der Kommunikationswissenschaft. Eine praxisorientierte Einführung. Wiesbaden: Springer VS.

Mikos, Lothar. 2011. Amphibischer Film versus transmediale Erzählung. Zu den komplexen Wechselbeziehungen zwischen Film und Fernsehen. In: Kino in Bewegung. Perspektiven des deutschen Gegenwartsfilms, herausgegeben von Thomas Schick und Tobias Ebbrecht, 137-154. Wiesbaden: VS Verlag für Sozialwissenschaften.

Mikos, Lothar. 2015. Film- und Fernsehanalyse. Konstanz: UVK.

Prommer, Elizabeth. 2016. Film und Kino. Die Faszination der laufenden Bilder. Wiesbaden: Springer VS.

Reitz, Edgar. 2018. Vier Thesen zur Erneuerung der Filmkultur. Unveröffentlichtes Manuskript.

Rimscha, Bjørn von. 2010. Risikomanagement in der Entwicklung und Produktion von Spielfilmen. Wie Produzenten vor Drehbeginn Projektrisiken steuern. Wiesbaden: VS Verlag für Sozialwissenschaften.

Schimank, Uwe. 1988. Gesellschaftliche Teilsysteme als Akteurfiktionen. Kölner Zeitschrift für Soziologie und Sozialpsychologie 40 (4): 619-639.

Schimank, Uwe. 2000. Handeln und Strukturen. Einführung in die akteurtheoretische Soziologie. Weinheim: Juventa.

Schimank, Uwe. 2007. Handeln in Konstellationen. Die reflexive Konstitution von handelndem Zusammenwirken und sozialen Strukturen. In: Journalismustheorie: Next Generation. Soziologische Grundlegung und theoretische Innovation, herausgegeben von Klaus-Dieter Altmeppen, Thomas Hanitzsch und Carsten Schlüter, 121-137. Wiesbaden: VS Verlag für Sozialwissenschaften. 
Schroer, Markus. 2008. Einleitung: Die Soziologie und der Film. In: Gesellschaft im Film, herausgegeben von Markus Schroer, 7-13. Konstanz: UVK.

Silbermann, Alphons. 1980. Zur soziologischen und sozialpsychologischen Analyse des Films. In: Filmanalyse. Grundlagen, Methoden, Didaktik, herausgegeben von Alphons Silbermann, Michael Schaaf und Gerhard Adam, 13-32. München: Oldenbourg.

Spitzenorganisation der Filmwirtschaft. 2020. Filmstatistisches Jahrbuch. BadenBaden: Nomos.

Stöber, Rudolf. 2013. Neue Medien. Geschichte. Von Gutenberg bis Apple und Google. Medieninnovation und Evolution. Bremen: Edition lumière.

Sutherland, Jean-Anne, und Kathryn Feltey (Hrsg.). 2013. Cinematic sociology: Social life in film. Thousand Oaks: Sage.

Wiedemann, Thomas. 2018. Die Logik des Filmemachens. Zwölf Interviews mit deutschen Filmregisseurinnnen und -regisseuren. Köln: Herbert von Halem.

Wiedemann, Thomas. 2019. Filmregisseurinnen und Filmregisseure in Deutschland. Strukturen und Logik eines heteronomen Berufsfeldes. Publizistik 64 (2): 205-223.

Wiedemann, Thomas, und Tanja C. Krainhöfer. 2018. Filmfestival dekonstruiert. Akteurskonstellationen in der Debatte zur Zukunft der Berlinale. Navigationen 18 (2): 177-196.

Winter, Rainer. 2012. Das postmoderne Hollywoodkino und die kulturelle Politik der Gegenwart. Filmanalyse als kritische Gesellschaftsanalyse. In: Perspektiven der Filmsoziologie, herausgegeben von Carsten Heinze, Stephan Moebius und Dieter Reicher, 41-59. Konstanz: UVK.

\section{Open Access}

Dieser Beitrag erscheint unter der Creative-Commons-Lizenz CC BY-ND 3.0 DE: https://creativecommons.org/licenses/by-nd/3.0/de/. 



\section{Visionen für transforma- tive Kommunikations- verhältnisse}





\title{
Wird die Große Transformation geteilt? Zum Einfluss der Geschäftsmodelle von Sharing-Plattformen auf das transformative Potenzial der Sharing Economy
}

\author{
Nils S. Borchers \& Sebastian Jürss
}

Keywords: Sharing Economy, Transformation, Peer-to,Peer; Geschäftsmodell, Plattformkooperativismus

\section{Abstract}

Der Sharing Economy wird von ihren Befürworter*innen transformatives Potenzial zugeschrieben: Sie ermögliche ihren Nutzer*innen finanzielle Unabhängigkeit und mache das Wirtschaften nachhaltiger und demokratischer. Kritiker*innen sprechen ihr dieses Potenzial hingegen ab. Wir gehen in diesem Beitrag davon aus, dass die konkrete Ausgestaltung einer Sharing-Plattform dafür entscheidend ist, ob die Plattform - und dann in Summe: die Sharing Economy - in der Lage ist, einen transformativen Beitrag zu leisten oder nicht. Diese Ausgestaltung wiederum hängt vom jeweils adaptierten Geschäftsmodell ab. Wir befragen daher die sechs von Muñoz und Cohen (2017) vorgeschlagenen Dimensionen der Geschäftsmodelle von Sharing-Plattformen bezüglich ihrer Auswirkungen auf die transformativen Versprechen. Auf diese Weise können wir den Idealtyp einer transformativen Sharing-Plattform bestimmen. Die bekannten Sharing-Plattformen, insbesondere Airbnb und Uber, weichen jedoch deutlich von diesem Idealtyp ab. Ihnen sind daher Alternativen entgegenzusetzen, soll die Sharing Economy in den Dienst einer Großen Transformation gestellt werden.

Nils S. Borchers \& Sebastian Jürss: Wird die Große Transformation geteilt? Zum Einfluss der Geschäftsmodelle von Sharing-Plattformen auf das transformative Potenzial der Sharing Economy. In: Nils S. Borchers, Selma Güney, Uwe Krüger und Kerem Schamberger (Hrsg.): Transformation der Medien - Medien der Transformation. Verhandlungen des Netzwerks Kritische Kommunikationswissenschaft. Frankfurt am Main: Westend 2021. DOI: https://doi.org/10.53291/IPWR8205. 
Dr. Nils S. Borchers I Eberhard Karls Universität Tübingen I nils.borchers@ uni-tuebingen.de

Sebastian Jürss I Universität Bremen I s.juerss@uni-bremen.de

\section{Einführung}

Medientechnische Innovationen haben immer auch transformative Hoffnungen geweckt. Brecht (1982 [1932/33]) etwa beschrieb das transformative Potenzial des Radios als Empfangs- wie auch als Sendegerät, und Enzensberger (1997 [1970]) spekulierte auf einen emanzipativen Mediengebrauch durch die Demokratisierung der Videotechnik. Auch der epochemachende Medienumbruch, den wir in den vergangenen Jahrzehnten durch das Internet erleben, sorgte für weitreichende transformative Hoffnungen. In ihrem Kern heben diese Hoffnungen auf das Schaffen einer gerechteren Gesellschaft durch die Veränderung von Machtbalancen (sensu Elias 2009 [1970]) ab, die über unterschiedlichste Gesellschaftsbereiche hinweg in emanzipatorischen Vorstellungen ihren Ausdruck finden: in der Politik etwa in einer neu belebten partizipativen und deliberativen Demokratie (etwa Buchstein 1997), in der Wirtschaft im »Consumer Empowerment« (etwa Labrecque et al. 2013) oder im Gesundheitsbereich im »Patient Empowerment« (etwa Borchers und Krömer 2015).

Besondere Hoffnungen wurden in diesem Zusammenhang in die Sharing Economy gesetzt, weil sie eine Medieninnovation auf die Organisation wirtschaftlicher Prozesse anwendet: Die Sharing Economy nutzt die Netzwerkstruktur des Internets, um neue Märkte zu schaffen (Chase 2015; Gansky 2010). Die Hoffnungen, die sich aus dieser Anwendung des Internets ergeben, verfestigen sich in drei Versprechen (Jürss und Borchers 2020): 1) ein nachhaltigerer Umgang mit begrenzten Ressourcen; 2) eine Demokratisierung der Wirtschaft; und 3) eine stärkere (finanzielle) Unabhängigkeit des Individuums. Diese Versprechen sind, wie noch zu zeigen sein wird, transformativ. Sie sind zudem anschlussfähig etwa zu den UN-Nachhaltigkeitszielen (United Nations o.J.), zu einer Großen (sozial-ökologischen) Transformation (Göpel 2020), durchaus auch im Rahmen eines ideologischen Programms wie dem Ökosozialismus (Kovel 2007). Nichtsdestotrotz ist die Sharing Economy verstärkt ins Kreuzfeuer der Kritik geraten (etwa Hill 2015; 
Scholz 2017). Denn offensichtlich war sie bislang nicht in der Lage, ihre Versprechen einzulösen.

Trotz der durchweg begründeten Kritik an der real existierenden Sharing Economy geht dieser Beitrag davon aus, dass die transformativen Hoffnungen, die in sie gesetzt wurden, prinzipiell berechtigt sind. Vor diesem Hintergrund fragen wir, wie eine Sharing Economy gestaltet sein müsste, um ihre transformativen Potenziale zu realisieren. Wir setzen dazu an den Sharing-Plattformen an, genauer noch: an ihren Geschäftsmodellen. Denn diese Plattformen stellen die Infrastruktur der Sharing Economy und bestimmen somit darüber, unter welchen Bedingungen ihre Nutzer*innen miteinander interagieren. Unser Ziel ist es, verschiedene Geschäftsmodelle hinsichtlich ihres Einflusses auf das Einlösen der transformativen Versprechen der Sharing Economy einzuschätzen.

\section{Die Sharing Economy als Akteurin einer sozial-ökologischen Transformation?}

\subsection{Zum Konzept der Sharing Economy}

Die Sharing Economy lässt sich - zumindest tentativ - bestimmen als »ein Set von Geschäftsmodellen, Plattformen und Austauschbeziehungen [...], in dem unter der Beteiligung von Privatpersonen (Peerto-Peer) Ressourcen, Dienstleistungen oder das Zugangsrecht zu Dingen (temporär) gegen eine Gebühr oder andere Kompensation [...] über Social-Media-Plattformen des Internets [...] verschenkt, getauscht, geliehen oder verkauft werden« (Hertwig und Papsdorf 2017, 524). Obwohl diese Definition eine gewisse konzeptionelle Klarheit suggeriert, ist die Sharing Economy kein eindeutig bestimmter Handlungsbereich. Keiner der vorgelegten Bestimmungsversuche (etwa Acquier, Daudigeos und Pinkse 2017; Frenken 2017; Hamari, Sjöklint und Ukkonen 2015; Muñoz und Cohen 2017) hat sich bislang etablieren können. Vor diesem Hintergrund ist es der Verdienst der hier angeführten Definition nach Hertwig und Papsdorf, einen Minimalkonsens innerhalb der Forschung bestimmen zu wollen. Dennoch dürften einige ihrer Definitionsentscheidungen strittig sein - etwa die Beschränkung auf Peer-to-Peer-Transaktionen oder die Festschreibung auf temporäre Aktivitäten, die eine dauerhafte Überlassung von 
Tauschobjekten ausschließt. Diese Uneinigkeit über die genaue Bestimmung der Sharing Economy hat unterschiedliche Gründe. Nicht unwesentlich dürfte sein, dass sich der Handlungsbereich zum einen noch immer als recht dynamisch erweist, so dass allzu enge Definitionen zum Teil nicht in der Lage sind, neue Entwicklungen zu erfassen. Zum anderen lassen sich aber auch politische Programme in der Definitionsfindung wiederfinden, die Einfluss darauf nehmen, wie eng oder weit das Konzept gefasst wird (zur Rekonstruktion der Ideologie der Sharing Economy siehe Jürss und Borchers 2020). Das Resultat: Sich voneinander deutlich unterscheidende Plattformen werden im Diskurs gemeinsam als Teile der Sharing Economy verhandelt. Wiederum Hertwig und Papsdorf (2017) differenzieren drei Segmente der Sharing Economy:

- die Tausch- und Schenkwirtschaft, in der güterspezifische Tauschbeziehungen bestehen, die weder Äquivalenz der getauschten Güter noch monetäre Kompensation vorsehen,

- die Nischen- und Nebenerwerbswirtschaft, in der Nutzer*innen vorrangig bislang nicht kommerzialisierte Dienstleistungen anbieten,

- die Plattformökonomie, in der für gewöhnlich Angebote und Dienstleistungen der bestehenden Ökonomie (der sogenannten »old economy«) unter Rekurs auf die Sharing-Rhetorik und mittels Plattformeinsatz auf digitale Märkte überführt und dort in der üblichen kapitalistischen Weise gehandelt werden.

Diese Unterschiedlichkeit der drei als Sharing Economy verhandelten Segmente spiegelt sich auch in der Beurteilung der Rolle wider, die die Sharing Economy in einer notwendigen gesellschaftlichen Transformation spielen kann.

\subsection{Die Versprechen der Sharing Economy und was daraus wurde}

Die Sharing Economy wurde von vielen Akteur*innen mit großer Euphorie begrüßt, nicht nur von Unternehmer*innen, sondern auch von Politiker*innen und Aktivist*innen. Diese Euphorie lässt sich nachvollziehen, nimmt man die Versprechen in den Blick, die der Sharing Economy zugeschrieben werden. Im Diskurs lassen sich drei zentrale Versprechen identifizieren (Jürss und Borchers 2020). 
Erstens soll die Sharing Economy eine effizientere Nutzung von Ressourcen und dadurch ein nachhaltiges Wirtschaften ermöglichen. Durch das Teilen von Bohrmaschinen, Zelten und Lebensmitteln über Sharing-Plattformen steigert sich deren - abstrakt gesprochen - Nutzungsintensität. So müssen weniger neue Bohrmaschinen, Zelte und Lebensmittel produziert werden. Das gelingt zum einen durch kurzfristiges Teilen in den Leerzeiten, während denen die Objekte von ihren Eigentümer*innen selbst nicht genutzt werden. So besagt die für die Sharing Economy ikonische Erzählung von der Bohrmaschine, dass diese im Schnitt nur zwischen 6 und 13 Minuten tatsächlich gebraucht wird und den Rest ihrer Existenz ungenutzt im Regal liegt (Botsman und Rogers 2011, 83). Sharing-Plattformen wie Peerby schaffen nun die Infrastruktur, um ungenutzte Geräte mit vertretbarem Aufwand zu verleihen. Zum anderen lässt sich die Nutzungsintensität steigern, indem man diese nach Bedarf verschenkt oder verkauft: Das nicht mehr benötigte Zelt wird dann über eBay veräußert.

Zweitens soll die Sharing Economy zu einer demokratischeren Form des Wirtschaftens führen. Weil (idealtypisch) Peers, also einander strukturell gleichgestellte Nutzer*innen, miteinander interagieren, werden Hierarchien abgeschafft. Gleichzeitig wird durch die Begegnung als Peers soziales Kapital generiert: Indem man über Couchsurfing bei privaten Gastgeber*innen übernachtet und nicht in einem Hotel, entstehen neue Bekannt- oder gar Freundschaften.

Drittens soll es die Sharing Economy ihren Nutzer*innen ermöglichen, (finanziell) unabhängig zu werden und sich so aus strukturellen Zwängen zu befreien. Sie schafft Sichtbarkeit für Privatpersonen, die als Anbietende auf einem Markt auftreten. Indem diese etwa ein leerstehendes Gästezimmer über Airbnb vermieten oder ihre Zeit samt Fähigkeiten einsetzen, um über TaskRabbit haushaltsnahe Dienstleistungen zu übernehmen, erschließen sich Plattformnutzer*innen als Mikro-Entrepreneure (Daum 2017) neue Einnahmequellen.

Diese Versprechen zeigen bereits an, wie die Sharing Economy transformativ wirken kann. ${ }^{1}$ Um es am Beispiel der UN-Nachhaltigkeitsziele (United Nations o. J.) nachzuzeichnen: Die Sharing Economy

1 Wenn wir in diesem Beitrag von Transformation sprechen, meinen wir eine gesellschaftlich wünschenswerte sozial-ökologische Transformation, wie sie an unterschiedlichen Stellen und mit unterschiedlichem politischem Unterbau imaginiert und propagiert wird, etwa in der Vorstellung einer »Großen Transformation« zur Nachhaltigkeit (Göpel 2020) oder im Konzept des Ökosozialismus (Kovel 2007), vgl. auch Krüger in diesem Band. 
unterstützt, so sie diese Versprechen erfüllt, insbesondere die Ziele der Nachhaltigkeit in Konsum und Produktion, der Verringerung von Ungleichheiten, der nachhaltigen Städte und Gemeinden sowie von menschenwürdiger Arbeit und Wirtschaftswachstum. Daneben bestehen zumindest indirekte Verbindungen zu einer Reihe weiterer UN-Ziele wie Maßnahmen zum Klimaschutz sowie zu Gesundheit und Wohlergehen. So wird die Sharing Economy potenziell zu einer Transformationsagentin.

Allerdings haben Kritiker*innen darauf hingewiesen, dass die Sharing Economy dieses Potenzial nicht nur nicht einlöst, sondern eine gesellschaftliche Transformation gar blockiert, indem sie die kapitalistische Ausbeutungslogik weiter forciert (etwa Hill 2015; Scholz 2017; Slee 2015). Dieser Einwand bezieht sich zumeist auf das Konzept des Plattformkapitalismus (Srnicek 2017) und blickt auf beobachtbare Dysfunktionalitäten wie die Wohnraumverknappung in touristischen Hotspots durch Airbnb-Vermietungen oder die geringen Einkommen und mangelnde soziale Absicherung der Gig-Worker von Uber. In den Augen der Kritiker*innen ist die Sharing Economy dann nicht weniger als »neoliberalism on steroids« (Murillo, Buckland und Val 2017).

Nun liegt es nahe, diese unterschiedlichen Positionen mit der Unterschiedlichkeit der als Sharing Economy verhandelten empirischen Phänomene in Verbindung zu bringen, wie sie Hertwig und Papsdorf (2017) beschreiben. An anderer Stelle haben wir nachgezeichnet, wie das Segment der Tausch- und Schenkwirtschaft in der Debatte dazu herhalten muss, um die Sharing Economy als Ganzes und damit auch das Segment der Plattformökonomie diskursiv zu legitimieren (Jürss und Borchers 2020). Hier stellen wir nun die Frage, wie eine Sharing Economy beschaffen sein müsste, um einen transformativen Beitrag zu leisten.

\section{Sharing-Plattformen und ihre Geschäftsmodelle}

Die einzelnen Sharing-Plattformen stellen die Infrastruktur der Sharing Economy dar. Sie sind es, die Märkte als Grundlage für Transaktionen schaffen. Darüber hinaus geben sie einseitig die Bedingungen vor, unter denen ihre Nutzer*innen als Teilnehmer*innen auf diesen Märkten miteinander interagieren, und bestimmen so deren Agency. Auch mit Blick auf die Sharing Economy gilt also Lessigs (2006) paradigmatische Feststellung »Code is law! 
Die Sharing Economy kann mithin nur so transformativ sein, wie es die konkreten Plattformen zulassen. Deren Ausgestaltung hängt wesentlich von den Plattformbetreiber*innen ab, da diese sie zur optimalen Erreichung ihrer Ziele gestalten. Das verbindende Element zwischen diesen Zielen der Betreiber*innen und der Ausgestaltung der Plattform ist das Geschäftsmodell, auf dessen Grundlage Designentscheidungen getroffen werden (Abb. 1).

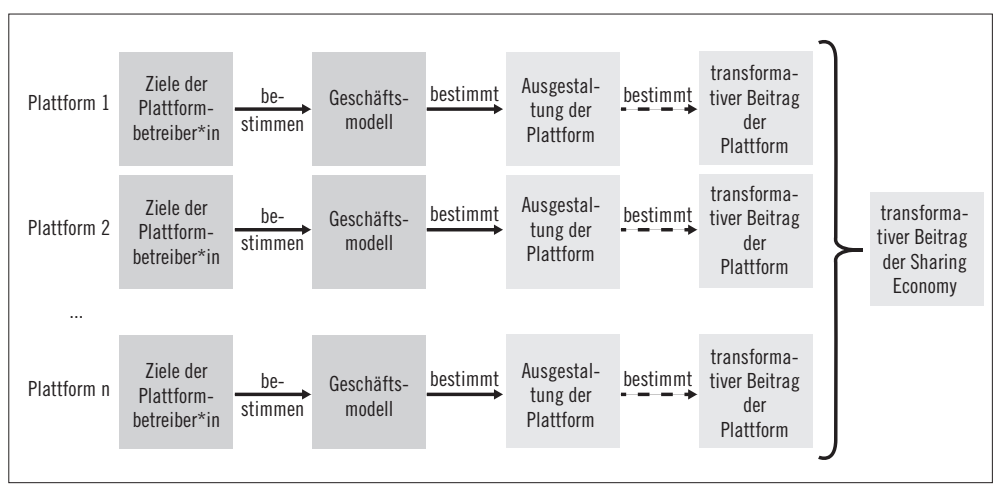

Abb. 1: Abhängigkeit des transformativen Beitrags der Sharing Economy vom Geschäftsmodell einzelner Sharing-Plattformen als Übersetzung der Ziele der Plattformbetreiber"innen.

Ein detailliertes Raster zur Analyse der Geschäftsmodelle von SharingPlattformen haben Muñoz und Cohen (2018) mit ihrem »Sharing business modell compass « vorgelegt. Dieser Kompass unterscheidet sechs Dimensionen: Plattform, Transaktion, Governance-Modell, Geschäftsansatz, Tauschobjekt und Technologie. Innerhalb dieser Dimensionen unterscheidet er jeweils drei Kategorien, in denen die einzelne Dimension ihre Ausprägung finden kann.

Bei der Erstellung des Kompasses gehen Muñoz und Cohen deduktiv vor, unter besonderem Einbezug der Forschungsergebnisse zur Sharing Economy. Ihre Überprüfung des Modells zeigt dann, dass der Kompass in der Lage ist, die Geschäftsmodelle von 36 zu Testzwecken ausgewählten Plattformen zufriedenstellend abzubilden. Damit bietet er eine geeignete Grundlage für die Analyse in diesem Beitrag. 


\section{Die sechs Dimensionen der Geschäftsmodelle}

Im Folgenden werden wir für die sechs von Muñoz und Cohen (2018) vorgeschlagenen Dimensionen der Geschäftsmodelle von SharingPlattformen analysieren, welche Folgen ihre unterschiedlichen Ausprägungen auf den transformativen Beitrag der Sharing Economy zeitigen. Auf diese Weise möchten wir ermitteln, welche Ausprägungen zu wählen sind, damit eine Plattform die Versprechen der Sharing Economy einzulösen vermag. Zum Zweck der Komplexitätsreduktion werden wir für diese Prüfung vom »Optimalfall« ausgehen und eine kritische Masse an Nutzer*innen sowie kooperatives Verhalten voraussetzen.

\subsection{Plattform}

Muñoz und Cohen bestimmen den Typ der Plattform anhand einer strukturellen Verortung der Akteur*innen, die auf der Plattform als Anbietende und Nachfragende interagieren. Dazu unterscheiden sie zwischen institutionalisierten Akteur*innen (im Grunde: Unternehmen) und Privatpersonen. Erstere können in der Position der Anbietenden auftreten, Letztere sowohl in der Position der Anbietenden als auch der Nachfragenden. Daraus ergeben sich für den Plattformtyp drei mögliche Konstellationen: 1) Unternehmen als Anbietende und Nachfragende (in der Diktion von Muñoz und Cohen: business-tobusiness ( b2b); 2) Unternehmen als Anbietende, Privatpersonen als Nachfragende (business-to-crowd / b2c); und 3) Privatpersonen als Anbietende und Nachfragende (peer-to-peer / p2p). Tab. 1 zeigt, wie sich diese Ausprägungen auf die Versprechen der Sharing Economy auswirken.

Nach unserer Einschätzung besitzt der Plattformtyp eine entscheidende Bedeutung dafür, inwiefern die transformativen Versprechen eingelöst werden können. In der Diskussion der weiteren Dimensionen werden wir daher fragen, inwiefern bestimmte Ausprägungen nicht nur die drei eigentlichen Versprechen, sondern eben auch p2p-Transaktionen als entscheidenden Mechanismus einer transformativen Sharing Economy fördern (dazu auch Frenken 2017; Schor 2014).

\section{Peer-to-Peer}

Als Typ $p 2 p$ verhandeln Muñoz und Cohen Plattformen, bei denen nicht-institutionalisierte Akteur*innen sowohl in der Position der An- 
Tab. 1: Auswirkungen der Ausprägungen in der Dimension Plattform auf die Versprechen der Sharing Economy.

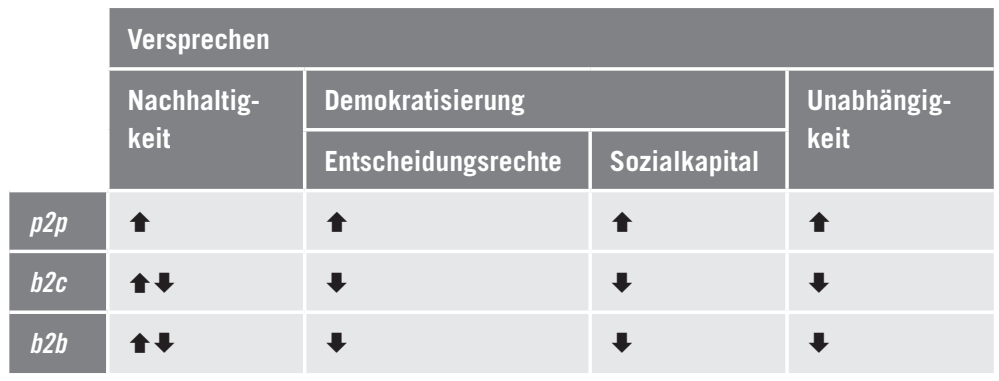

- = positiver Einfluss der Ausprägung auf Versprechen; $=$ kein positiver Einfluss (Festschreibung des Status quo) oder sogar negativer Einfluss; $\varnothing=$ kein Zusammenhang zwischen Ausprägung und Versprechen; = positiver oder negativer Einfluss, abhängig von Ausprägung in anderer Dimension; ( $)$ = positiver Einfluss, der aber hinter den Möglichkeiten zurückbleibt; p2p = Einfluss der Ausprägung auf das Entstehen von p2p-Konstellationen

bietenden als auch der Nachfragenden auftreten. Ein idealtypisches Beispiel für diesen Typ ist die Plattform Tauschgarten, die es Nutzer*innen ermöglicht, Pflanzensamen, Setzlinge und Ähnliches über Tauschtickets, die plattformeigene Währung (siehe Dimension Transaktion), untereinander zu handeln.

Um Muñoz und Cohens Differenzierung zu schärfen, sei an dieser Stelle angemerkt, dass die beiden Autoren im Diskurs üblicherweise p2p mit consumer-to-consumer-Interaktionen gleichsetzen. Diese Gleichsetzung wird deshalb vorgenommen, weil in der wirtschaftswissenschaftlichen Debatte Konsument*innen für gewöhnlich den Gegenpart zum Unternehmen darstellen. Als Konsument*innen werden sodann alle Akteur*innen kategorisiert, die nicht institutionalisiert sind. Allerdings wird hierbei unterschlagen, dass die Rolle des Peers voraussetzungsreicher ist als die der Konsument*in. Erstere erfordert nämlich, dass sich die Interaktionsteilnehmer*innen als strukturell gleichrangig begegnen und prinzipiell auch ihre Position wechseln können - also sowohl als Anbietende als auch als Nachfragende auftreten. Diese Erwartung wird dagegen nicht an Konsument*innen gerichtet. Unter diesem Gesichtspunkt fällt beispielsweise auf, dass die allgemeine Beschreibung etwa von Airbnb als einer p2p-Plattform nur bedingt zutrifft. Analytisch korrekt ist, dass dort Transaktionen zwischen Peers stattfinden, wenn etwa ein nicht genutztes Gästebett in einem Privathaushalt, in 
dem auch die Anbietenden leben, gebucht wird. Anders verhält es sich, wenn Anbietende eigens Wohnungen anmieten, um diese über Airbnb weiterzuvermieten.

In solchen Fällen mag die Anbietende zwar vordergründig als Privatperson (und damit als Konsument*in) auftreten. Analytisch handelt sie aber nicht mehr als Peer, weil sie durch die geschäftsmäßige Anmietung signalisiert, dass sie ausschließlich oder zumindest deutlich häufiger als Anbietende agiert - unabhängig davon, ob sie ihre Tätigkeit (ordnungsgemäß) als Gewerbe angemeldet hat und somit auch formal als institutionalisierte*r Akteur*in auftritt. Durch diese strukturelle Präferenz für die Position der Anbietenden wird nun aber die Reziprozitätserwartung außer Kraft gesetzt. Zu beobachten ist dann nichts anderes als die geschäftsmäßige Vermietung von Übernachtungsmöglichkeiten - eine Leistung, wie sie jedes Hotel erbringt. Entsprechend liegen in diesen Fällen analytisch keine p2p-, sondern b2c-Transaktionen vor, und Airbnb lässt sich daher mit dem Kategorisierungsraster von Muñoz und Cohen nicht eindeutig einem Plattformtyp zuordnen. Um diese Ungenauigkeit zu umgehen, werden wir in entsprechenden Fällen nicht auf Ebene der Plattformen, sondern der einzelnen Transaktionen argumentieren.

Sharing-Plattformen, die der Kategorie $p 2 p$ angehören, ermöglichen es Privatpersonen, mit ihren Angeboten auf dem Markt auffindbar zu werden. Natürlich konnten Hobbygärtner*innen auch zuvor versuchen, Pflanzensamen aus ihrem Garten in kleinen Mengen gegen Samen Gleichgesinnter zu tauschen. Der Aufwand, sich als Anbietende zu identifizieren, liegt ohne entsprechende Plattformen allerdings deutlich höher. Möglichkeiten sind hier etwa das Herumfragen im Bekanntenkreis oder der Aushang an einem Schwarzen Brett - Möglichkeiten, die eine deutliche lokale und temporale, im ersten Fall zudem noch eine deutliche soziale Beschränkung aufweisen. Spezialisierte Zeitschriften, die Kleinanzeigen aufnehmen, sind zwar lediglich temporal beschränkt, dafür kostet das Inserat jedoch in der Regel Geld. Entsprechend muss auch in diesem Fall von hohen Transaktionskosten - also den nötigen Ressourcen, damit eine Transaktion vonstattengehen kann - ausgegangen werden. Diese Kosten können gerade bei Tauschobjekten, denen Transaktionspartner*innen einen verhältnismäßig geringen Wert zuschreiben, stark ins Gewicht fallen, so dass sie davon absehen könnten, ihre Leerlaufkapazitäten (»idle resources«) feilzubieten beziehungsweise sich auf die Suche nach entsprechenden Tauschobjekten zu begeben. Im Vergleich dazu ermöglichen Sharing-Plattformen eine entscheidende Senkung der anfallenden Kosten. Sie heben temporale, 
lokale sowie soziale Beschränkungen auf und machen Angebote ebenso unaufwändig (Transaktionskosten) wie erwartbar (Erfolgswahrscheinlichkeit) auffindbar.

Aus dem vereinfachten Marktzugang folgt hinsichtlich des Versprechens auf Unabhängigkeit, dass p2p-basierte Plattformen ihre Nutzer*innen in die Lage versetzen, neue Einkommensquellen zu erschließen, indem sie ihre Leerlaufkapazitäten zur Nutzung anbieten. Das beeinflusst wiederum das Nachhaltigkeitsversprechen: Nur wenn es sich für Privatpersonen lohnt (sei es finanziell oder ideologisch), ihre Leerlaufkapazitäten als Tauschobjekte anzubieten, können Nachfragende auf diese zugreifen, statt neu produzierte Objekte zu erwerben. So wird die steigende Nachfrage nach Übernachtungsmöglichkeiten durch die Bereitstellung freier Betten in einzelnen Privathaushalten befriedigt, statt neue Hotelkapazitäten zu schaffen. Positive Effekte von $\mathrm{p} 2 \mathrm{p}$-Transaktionen sind aber auch hinsichtlich des Versprechens auf Demokratisierung zu erwarten. Denn die Reziprozitätserwartung, der zufolge Nutzer*innen sowohl in der Angebots- als auch der Nachfrageposition agieren sollten, führt dazu, dass sich Peers prinzipiell als strukturell Gleiche begegnen. Dafür sorgt nicht zuletzt die Tatsache, dass sie durch den Rollenwechsel Empathie für die jeweils andere in ihrer Rolle ausbilden, denn ihnen sind die Bedingungen auch deren Rolle bekannt. Schließlich ist zu erwarten, dass p2p-Transaktionen die Bildung von Sozialkapital fördern, da sie die Möglichkeit der Begegnung ebenbürtiger Partner*innen stiften. Es ist zwar zu vermuten, dass der Pathos, mit dem dieser Aspekt von so mancher Sharing-Plattform eingebracht wird, eine Übertreibung darstellt, weil Begegnungen von Peers in diesem Kontext immer auch zweckfunktional sein können und müssen: Man trifft sich (etwa über Paul Camper), um den Wohnmobilschlüssel zu übergeben, und macht genau das. Nichtsdestotrotz verweist die Peer-Konstellation durch die strukturelle Gleichheit auf die Person hinter der Rolle: Man wird eher mit einem Peer-Anbietenden auch über die Erlebnisse des Tages oder die bevorstehende Reise plaudern als mit der Angestellten der Automobilvermietung, die auf die Rolle der Unternehmensvertreterin festgeschrieben ist. So berichten etwa Nutzer*innen von Plattformen wie Couchsurfing davon, dass durch die dort vermittelten Transaktionen Bekannt- oder gar Freundschaften entstanden sind (Decrop et al. 2018).

Damit handelt es sich bei der Kategorie $p 2 p$ um die einzige Kategorie (über alle Dimensionen hinweg), die sich durchweg positiv auf die Erfüllung der drei Versprechen auswirkt. 


\section{Business-to-Crowd}

Unter den Typ $b 2 c$ fallen nach Muñoz und Cohen Plattformen, die die Position der Anbietenden auf institutionelle Akteur*innen und die der Nachfragenden auf nicht-institutionalisierte Akteur*innen festschreiben. Ein Beispiel ist die aus dem Zusammenschluss von car2go (Daimler) und DriveNow (BMW) entstandene Plattform Share Now, die (ausschließlich) firmeneigene Fahrzeuge zur Kurzmiete anbietet. Im Grunde handelt es sich dabei also um eine gewöhnliche Autovermietung, die ihre Transaktionen lediglich über eine eigens dafür aufgesetzte Plattform verwaltet.

Mit Blick auf das Versprechen der Nachhaltigkeit lässt sich für b2cPlattformen feststellen, dass die zur Verfügung gestellten Tauschobjekte dem Markt in der Regel eigens zum Zweck der kommerziellen Nutzung zugeführt werden, um über ihre Vermietung Profit zu erwirtschaften (siehe auch Dimension Tauschobjekt). Share Now hat beispielsweise die dort buchbaren Fahrzeuge speziell als Neuwagen zugelassen, um Geld an ihnen zu verdienen. Analog mieten kommerzielle Vermieter*innen auf Airbnb Wohnungen eigens zu dem Zweck an, diese ihrerseits weiterzuvermieten, und entziehen sie so dem Mietmarkt. Das impliziert, dass hier eben nicht Leerlaufkapazitäten effizienter genutzt, sondern für die Angebotserstellung neue Produkte hergestellt werden - sei es unmittelbar (Neubau von Automobilen bei Share Now) oder mittelbar (Neubau von Wohnungen, um die dem Markt entzogenen Wohnungen zu ersetzen bei Airbnb). Entsprechend zeigen Daten für Berlin und Hamburg, dass der Ausbau von kommerziellen Carsharing-Angeboten nicht zu einer Verringerung der Autozulassungen geführt hat (Kearney, o. J.). Auch das Versprechen der Unabhängigkeit kann von Plattformen des Typs $b 2 c$ nicht erfüllt werden, weil sie per definitionem einzig institutionelle Akteur*innen in der Position der Anbietenden zulassen. Diese Exklusivität hat außerdem zur Folge, dass sich über entsprechende Plattformen keine Peers begegnen. Zu beobachten sind also Geschäftsbeziehungen zwischen Unternehmen und Kund*innen, die sich strukturell nicht von den hinlänglich bekannten Geschäftsbeziehungen der »old economy« unterscheiden. Folglich kann der b2c-Typ auch das Demokratisierungsversprechen nicht einlösen.

\section{Business-to-Business}

b2b-Plattformen sind Plattformen, auf denen Unternehmen sowohl in der Angebots- als auch der Nachfrageposition auftreten. Als Beispiel nennen Muñoz und Cohen das Logistikunternehmen Cargomatic, das 
freie Ladekapazitäten von Lastkraftwagen vermittelt. ${ }^{2}$ Auf diese Weise werden tatsächlich ungenutzte Ressourcen effizienter eingesetzt, so dass entsprechende b2b-Plattformen den Ressourcenverbrauch verringern können. Dies gilt natürlich nur dann, wenn wie bei Cargomatic bereits bestehende Kapazitäten zum Einsatz kommen, und nicht wie bei Share Now eigens hergestellt werden, um sie über die Plattform anzubieten (siehe Dimension Tauschobjekt). Für die Versprechen Unabhängigkeit und Demokratisierung gilt hingegen das, was wir im vorangegangenen Abschnitt bereits für b2c-Plattformen festgestellt haben: Durch die Festschreibung der Position der Anbietenden auf institutionelle Akteur*innen tragen b2b-Plattfromen nicht zur Erfüllung dieser Versprechen bei.

\subsection{Transaktion}

Transaktionstypen lassen sich nach Muñoz und Cohen (2018, 131) anhand des Ausmaßes unterscheiden, sto which transactions on the platform are left to market forces or if they are suppressed or altered by the intermediary". Im Prinzip verbirgt sich dahinter die Frage, ob - und wenn ja: wie - Transaktionen kompensiert werden. Der Kompass unterscheidet drei Typen von Transaktionen: Markt, Alternativ und Frei. Tab. 2 gibt einen Überblick über ihre jeweiligen Auswirkungen.

\section{Markt}

Der Typ Markt ist dadurch charakterisiert, dass Transaktionen mit Geld kompensiert werden, also mit einer Währung, die auch außerhalb der Plattform genutzt werden kann. Dadurch, dass das Angebot einen Wert erhält, der in einer allgemeingültigen Währung angegeben ist, so argumentieren Muñoz und Cohen, hält »der Markt« Einzug in die Transaktion. Denn die Preisgestaltung der Anbietenden auf der Plattform sollte, der Logik der Preisabhängigkeit von Angebot und Nachfrage folgend,

2 Zwei weitere von Muñoz und Cohen als Beispiel angeführte Plattformen, Cohealo und Munirent, ermöglichen die Organisation des Ressourceneinsatzes zwischen Abteilungen eines einzigen (Groß-)Unternehmens. Hierbei handelt es sich aber um ein organisationsinternes Wissensmanagementsystem, weshalb die beiden Plattformen nicht als Marktplatz kategorisierbar sind, weil ein und derselbe Akteur als Anbieter und als Nachfragender auftritt. 
Tab. 2: Auswirkungen der Ausprägungen in der Dimension Transaktion auf die Versprechen der Sharing Economy (Legende siehe Tab. 1).

\begin{tabular}{|c|c|c|c|c|}
\hline & \multicolumn{4}{|l|}{ Versprechen } \\
\hline & \multirow{2}{*}{$\begin{array}{l}\text { Nachhaltig- } \\
\text { keit }\end{array}$} & \multicolumn{2}{|l|}{ Demokratisierung } & \multirow{2}{*}{$\begin{array}{l}\text { Unabhängig- } \\
\text { keit }\end{array}$} \\
\hline & & Entscheidungsrechte & Sozialkapital & \\
\hline Markt & 사 & $\emptyset$ & $\emptyset$ & -1 \\
\hline Alternativ & 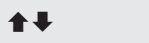 & $\boldsymbol{\wedge}(p 2 p)$ & - $(p 2 p)$ & (ㅅ) \\
\hline Frei & - & $\emptyset$ & - $(p 2 p)$ & $\sqrt{t}$ \\
\hline
\end{tabular}

die Preise von vergleichbaren Angeboten außerhalb der Plattform (also etwa des Zimmers in besagtem Hotel) berücksichtigen.

Die Einnahmen können Anbietende beim Transaktionstyp Markt aufgrund der allgemeinen Gültigkeit der Währung vielfältig einsetzen (Lebensmittel einkaufen, an Sea Watch spenden und Ähnliches). Auf diese Weise eröffnen Plattformen dieses Transaktionstyps neue, potenziell substantielle Einkommensquellen. Mit Blick auf das Unabhängigkeitsversprechen lässt sich also konstatieren, dass die Nutzung allgemeingültiger Währungen seine Einlösung unterstützt. Gleichzeitig schafft sie die Möglichkeit, frei verwendbare Einkommen zu generieren, Anreize für das Upscaling, also eine Steigerung der Transaktionsanzahl. Solche Upscaling-Prozesse sind mit Blick auf das Unabhängigkeitsversprechen positiv zu bewerten. Auch das Versprechen der Nachhaltigkeit profitiert, wenn die Anreize potenzielle Anbieter dazu motivieren, ihre Leerlaufkapazitäten tatsächlich anzubieten. Am Beispiel: Lässt sich mit der Vermietung der eigenen Bohrmaschine Geld verdienen, lohnt sich der damit verbundene Aufwand. So muss die Nachfrage nicht durch neu produzierte Bohrmaschinen befriedigt werden.

Der Transaktionstyp Markt hat aber auch negative Aspekte: Zum einen können die Anreize dazu führen, dass Anbieter statt Leerlaufkapazitäten neue oder bislang anders genutzte Ressourcen über die Plattform anbieten: Wohnungen werden dem Mietmarkt entzogen, um sie über Airbnb in Kurzzeitvermietung rentabler zu vermieten - was unter Umständen die Mietpreise in die Höhe treibt (Unabhängigkeit) und lokale Sozialstrukturen zerstört (Demokratisierung). Auch können ein gesteigertes Angebot an Übernachtungsmöglichkeiten und möglicherweise sinkende Übernachtungspreise zu einem Anstieg an Reisen füh- 
ren (Nachhaltigkeit). Zum anderen ist eine Kommodifizierung bislang kostenloser Produkte und Leistungen denkbar - wenn beispielsweise die nachbarschaftliche Einkaufshilfe nunmehr mit Hilfe von SharingPlattformen in Wert gesetzt wird.

Der Transaktionstyp Markt ermöglicht es Plattformnutzer*innen zudem, einseitig in einer Position der Anbietenden oder der Nachfragenden auf der Plattform zu agieren. Er erzwingt damit keine p2pStruktur, wie es beim folgenden Transaktionstyp Alternativ der Fall ist, weshalb entsprechende Plattformen auch nicht in der Lage sind, qua Design p2p-Effekte zu provozieren (siehe Dimension Plattformtyp).

\section{Alternativ}

Es gibt Plattformen, die eigene Währungen eingeführt haben, wie beispielsweise die sogenannten TimeCoins auf TimeRepublik. Muñoz und Cohen ordnen diese Fälle dem alternativen Transaktionstyp zu. Die plattformeigenen Währungen werden nur dort als Zahlungsmittel akzeptiert und besitzen keinen darüberhinausgehenden Wert, was die Anwendungsmöglichkeiten stark einschränkt. Die Nicht-Übertragbarkeit des auf der Plattform generierten Einkommens in andere Handlungszusammenhänge begrenzt das Upscaling und damit die Möglichkeit für Nutzer*innen, sich neue, substanzielle Einkommensquellen zu erschließen. Um das Versprechen auf Unabhängigkeit zu erfüllen, ist der alternative Transaktionstyp also nur bedingt geeignet. Allerdings sorgt die Nicht-Übertragbarkeit der plattformeigenen Währung auch dafür, dass der über die Plattform erwirtschaftete Mehrwert in der Community verbleibt. Es gibt schlicht keine Abflussmöglichkeiten, so dass Nutzer*innen das Einkommen nur dort einsetzen können. Diese Abflusssperre stärkt die p2p-Struktur, weil es den Rollenwechsel qua Design forciert: Das Erwirtschaften eines Einkommens in der Position der Anbietenden ist für Nutzer*innen nur dann sinnvoll, wenn dieses zu einem anderen Zeitpunkt in der Position der Nachfragenden auch genutzt wird. Mit Blick auf das Versprechen der Nachhaltigkeit ist die Bewertung des alternativen Transaktionstypen nicht eindeutig.

\section{Frei}

Als freie Transaktionen bezeichnen Muñoz und Cohen solche, in denen Anbietende Angebote erstellen, ohne dafür eine Gegenleistung zu verlangen. Dieser Typ findet sich etwa auf den Plattformen Couchsurfing (Übernachtungsmöglichkeit) und foodsharing (Lebensmittel). Entsprechende Plattformen werden daher mitunter als Teil einer Schenk- 
wirtschaft (»gift economy«) verhandelt (Mikołajewska-Zając 2016). Bei diesem Transaktionstyp ist ein Upscaling nicht sinnvoll. Wenn die Anbietenden keine Gegenleistungen verlangen können, lohnt sich der Ausbau der Aktivitäten nicht. Damit bietet dieser Plattformtyp auch keine Möglichkeiten, alternative Einkommensquellen zu erschließen. Aus Perspektive der Nachfragenden ermöglicht die Nutzung hingegen eine Reduktion allgemeiner Ausgaben, da sie die benötigten Produkte kostenfrei erhalten und diese nicht auf einem Markt erwerben müssen (etwa das Abendessen aus der foodsharing-Box). Mit Blick auf das Nachhaltigkeitsversprechen lässt sich zudem festhalten, dass der Transaktionstyp Frei durch Senkung der Transaktionskosten dazu beitragen kann, Leerlaufkapazitäten zu nutzen: Das Essen wird aufwandsniedrig gespendet, statt es wegzuwerfen. Auf diese Weise zahlen Plattformen, die den freien Transaktionstyp nutzen, auf das Versprechen der Nachhaltigkeit ein.

Wie schon der Transaktionstyp Markt bietet auch der freie Transaktionstyp die Option, die Plattform einseitig in einer Rolle zu nutzen. Positionswechsel zwischen Anbietenden zu Nachfragenden werden nicht qua Design forciert. Nichtsdestotrotz ist zumindest bei einigen Plattformen eine konkrete Reziprozitätserwartung zu beobachten: Wer über Couchsurfing bei anderen Nutzer*innen nächtigt, sollte auch selbst Gäste beherbergen (Liu et al. 2016). Plattformen können allerdings auch ohne eine solche Reziprozitätserwartung operieren, da der übergreifende Transaktionstyp Frei ihr Vorhandensein nicht erzwingt. Wie stark diese Reziprozitätserwartung ist, hängt maßgeblich von der durch die Plattformbetreiber*innen formulierte Vision sowie von der gelebten Praxis in der Plattform-Community ab.

\subsection{Governance-Modell}

Muñoz und Cohen unterscheiden die Geschäftsmodelle von Plattformen in der Dimension Governance-Modell danach, wie Entscheidungen getroffen und der Werttausch (»value exchange«) organisiert werden. Die drei Ausprägungen sind: Korporativ, Kollaborativ und Kooperativ. Mit Blick auf die aktuelle Diskussion um Plattformkooperativen drängt es sich jedoch auf, zwei Varianten des kooperativen Typs danach zu differenzieren, ob lediglich die Anbietenden oder alle Nutzer*innen an diesen beteiligt sind. Tab. 3 liefert einen ersten Überblick über die Auswirkungen. 
Tab. 3: Auswirkungen der Ausprägungen in der Dimension Governance-Modell auf die Versprechen der Sharing Economy (Legende siehe Tab. 1).

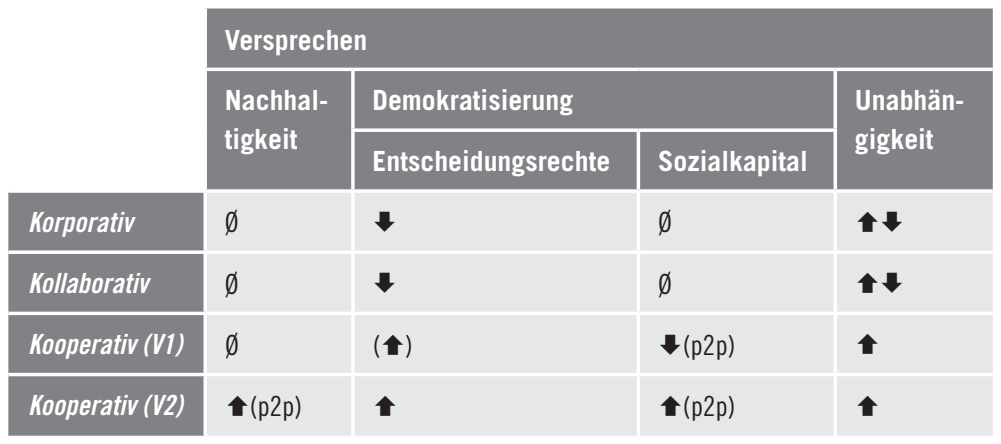

\section{Korporativ}

Zum korporativen Typ gehören laut Muñoz und Cohen (2018, 133) Plattformen, die »traditional corporate governance models« adaptieren. De facto sind damit diejenigen Plattformen gemeint, die wie ein herkömmliches Unternehmen hierarchisch geführt werden. Die Autoren weisen selbst darauf hin, dass die Mehrzahl der Sharing-Plattformen in diese Kategorie fällt - darunter der Großteil der bekannteren Vertreter wie Airbnb, Uber, BlaBlaCar, TaskRabbit oder Share Now. Bei diesem Governance-Modell sind die Nutzer*innen nicht in die Entscheidungsfindung eingebunden. Stattdessen werden diese durch das Management, gegebenenfalls in Abstimmung mit den Eigentümer*innen, getroffen. Entsprechend tragen Plattformen dieses GovernanceModells nicht zur Demokratisierung bei. Mit Blick auf das Versprechen der Unabhängigkeit ist es generell möglich, dass Nutzer*innen neue Einkommensquellen erschließen, wenn die Plattform einen entsprechenden Transaktionsmodus verwendet (siehe Dimension Transaktion). Es liegt allerdings für die Betreiber*innen nahe, einen Geschäftsansatz zu wählen, der auf das Erwirtschaften von Profiten abzielt (profitgetrieben oder hybrid). Daher gelten hier die in diesem Zusammenhang bereits diskutierten Limitationen (siehe Dimension Geschäftsansatz).

\section{Kollaborativ}

Die Informationen, die Muñoz und Cohen zum kollaborativen Governance-Modell bereitstellen, sind recht begrenzt. Sie bemerken lediglich 
im Kontext einer Plattform zum Mieten und Vermieten von Haushaltsgegenständen: »Peerby raised a funding round via crowdfunding with their own user community, which we consider to be reflective of collaborative governance, because the user community became partial coowners in the platform as a result." (Muñoz und Cohen 2018, 133) Anders als im Zitat angedeutet, war die Finanzierungsrunde von Peerby allerdings nicht auf Nutzer*innen der Plattform beschränkt, sondern für alle interessierten Investor*innen offen. Folglich unterscheidet sich die Bewertung des kollaborative Governance-Typs damit nicht vom korporativen: Ähnlich wie man sich (das nötige Investitionskapital und die entsprechende Gesinnung vorausgesetzt) Aktien von Uber zulegen kann, ist es auch möglich, sich über die Crowfunding-Aktion als Shareholder bei Peerby einzukaufen, freilich ohne dass damit eine Stimmberechtigung einherginge. Hinsichtlich der Versprechen besitzt die Bewertung des korporativen Typs demnach Gültigkeit auch für den kollaborativen Typ.

\section{Kooperativ}

Dem kooperativen Typ ordnen Muñoz und Cohen Plattformen zu, die genossenschaftlich organisiert sind. Hier suchen sie also Anschluss an die Debatte zum Plattformkooperativismus (Scholz und Schneider 2017). Genossenschaften zeichnen sich gemeinhin dadurch aus, dass die Mitarbeiter*innen gleichzeitig Eigentümer*innen des Unternehmens sind. Im Kontext der Sharing Economy wird diese Idee dann zumeist auf die Nutzer*innen der Sharing-Plattform bezogen. Hier sind in der Regel zwei Varianten zu unterscheiden, die von Cohen und Muñoz selbst nicht weiter differenziert werden.

In Variante 1 treten nur die Anbietenden als Eigentümer*innen auf. Als Beispiel können kooperative Zusammenschlüsse von Taxifahrer*innen dienen, die gemeinsam eine Plattform betreiben, um Fahrten zu vermitteln (etwa Green Taxi Cooperative). Diese Variante, die auch Muñoz und Cohen maßgeblich vor Augen schwebt, hat vor allem Scholz (2017) in Abgrenzung zu Uber ausgearbeitet. Prüft man ihre Auswirkungen auf die Versprechen der Sharing Economy, stellt man zunächst fest, dass sie - in Verbindung mit einem entsprechenden Transaktionstyp - das Erschließen neuer Einkommensquellen ermöglicht. Verglichen mit den beiden bereits besprochenen Governance-Typen ist ihr Potenzial hierfür sogar größer: Die Tatsache, dass die Anbietenden gleichzeitig die Eigentümer*innen sind, ermöglicht es, die Gebühren für die Abwicklung von Transaktionen zu minimieren. Es gibt schließ- 
lich nur eine Akteur*innengruppe, die an den Transaktionen verdienen möchte - und nicht zwei wie bei der Trennung von Anbietenden und Eigentümer*innen. Im Vergleich zu den beiden anderen GovernanceTypen lässt sich sodann konstatieren, dass Variante 1 der kooperativen Plattformen zum Versprechen der Demokratisierung beiträgt, weil Anbietenden als Eigentümer*innen ein Mitspracherecht bei Entscheidungen eingeräumt wird. Die Entstehung von Sozialkapital wird durch diese Variante allerdings nicht gefördert, weil sie dazu neigt, Plattformnutzer*innen auf nur eine Position - Anbietende oder Nachfragende festzuschreiben. Da erstere gleichzeitig die Eigentümer*innen der Plattform sind, muss man zur Eigentümer*in werden, um die Rolle der Anbietenden einzunehmen. Der Rollenwechsel wird dadurch deutlich erschwert, so dass im Fall von Variante 1 p2p-Interaktionen unterdrückt werden. Entsprechend handelt es sich bei den Eigentümer*innen (und Anbietenden) des Green Taxi Cooperative in der Regel um hauptberufliche Taxifahrer*innen.

Variante 2 des kooperativen Typs löst diese Festschreibung auf, indem sie alle Nutzer*innen der Plattform zu Mitgliedern der Plattform-Kooperativen und damit zu Eigentümer*innen macht. Für diese Variante steht vor allem die Idee des »Open Cooperativism«, die das Konzept der Kooperativen mit dem der »Commons-based Peer Production «, also der gemeinsamen Produktion in einer als Allmende organisierten Gemeinschaft, zusammendenkt (Bauwens und Kostakis 2014; Pazaitis, Kostakis und Bauwens 2017). Auf diese Weise sind zum einen p2p-Interaktionen möglich, zum anderen wird das Versprechen auf Demokratisierung umfassender erfüllt, indem nun alle Nutzer*innen und nicht mehr nur die Anbietenden ein Mitspracherecht erhalten.

\subsection{Geschäftsansatz}

Die Dimension Geschäftsansatz erfasst das Ziel, mit dem eine Plattform betrieben wird. Muñoz und Cohen unterscheiden finanzielle von ideellen Absichten. Daraus ergibt sich eine Kategorisierung in profitgetriebene und missionsgetriebene Geschäftsansätze sowie hybride Mischformen. Tab. 4 bietet einen Überblick über die Auswirkungen der drei Varianten. 
Tab. 4: Auswirkungen der Ausprägungen in der Dimension Geschäftsansatz auf die Versprechen der Sharing Economy (Legende siehe Tab. 1).

\begin{tabular}{|c|c|c|c|c|}
\hline & \multicolumn{4}{|c|}{ Versprechen } \\
\hline & \multirow{2}{*}{$\begin{array}{l}\text { Nachhal- } \\
\text { tigkeit }\end{array}$} & \multicolumn{2}{|l|}{ Demokratisierung } & \multirow{2}{*}{$\begin{array}{l}\text { Unabhän- } \\
\text { gigkeit }\end{array}$} \\
\hline & & Entscheidungsrechte & Sozialkapital & \\
\hline Profitgetrieben & A & $\emptyset$ & $\emptyset$ & 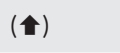 \\
\hline Missionsgetrieben & $\emptyset$ & $\emptyset$ & - & $\uparrow$ \\
\hline Hybrid & 园 & $\emptyset$ & $\emptyset$ & (†) \\
\hline
\end{tabular}

\section{Profitgetrieben}

Plattformen fallen in die Kategorie Profitgetrieben, wenn ihr Ziel in der Erwirtschaftung eines Profits für die Eigentümer*innen besteht. Ein Großteil der bekannten Anbieter gehört zu dieser Kategorie, beispielsweise Uber, Airbnb oder Helpling. Plattformen aus dieser Kategorie können generell dazu beitragen, dass die Sharing Economy ihr Versprechen auf Nachhaltigkeit einlöst, etwa indem das leerstehende Gästezimmer über Airbnb vermietet wird. Allerdings setzt das Ziel, Profit zu erwirtschaften, einen Anreiz dafür, die Plattform so zu gestalten, dass auch neu produzierte Tauschobjekte und nicht allein Leerlaufkapazitäten auf der Plattform getauscht werden - wie im Falle des Ankaufs eines Wohnwagens zur Vermietung über Paul Camper.

Zusätzliche Angebote erhöhen die Chance zusätzlicher Transaktionen und damit eines höheren Profits. Werden Plattformen auf diese Weise gestaltet, können sie sich negativ auf das Versprechen der Nachhaltigkeit auswirken (siehe Dimension Tauschobjekt). Die Einlösung des Unabhängigkeitsversprechens scheint dagegen möglich: Sobald die Transaktionsgebühr eine Einnahmequelle der Plattformbetreiber*innen darstellt, werden sie daran interessiert sein, dass für Transaktionen gezahlt wird (Transaktionstyp Markt). Binden sie deren Höhe an den jeweiligen Preis, werden sie zudem daran interessiert sein, Mechanismen einzuführen, die zur Maximierung der abrufbaren Preise beitragen. Von diesen Anreizen für die Plattformbetreiber*innen profitieren auch die Anbietenden. Allerdings werden Plattformbetreiber*innen ebenfalls daran interessiert sein, die Transaktionsgebühr zu maximieren. Damit führt das Ziel der Profitgenerierung aus Perspektive der Anbietenden dazu, 
dass sie einen nicht unerheblichen, von den Plattformbetreiber*innen maximierten Teil des erwirtschafteten Mehrwerts als Gebühr abführen müssen. Sie können also eine neue Einkommensquelle erschließen, ihr Erlös ist wegen der Gebühr jedoch geringer, als er sein könnte.

\section{Missionsgetrieben}

Muñoz und Cohen stellen profitgetriebenen Plattformen missionsgetriebene gegenüber, die sich auf ein allgemeinnütziges Ziel verpflichten. Unter diese Kategorie fällt beispielsweise foodsharing, über das die Anbietenden Lebensmittel, die sie nicht mehr benötigen, an andere Nutzer*innen abgeben können.

Weil missionsgetriebene Plattformen keinen Profit erwirtschaften müssen, können sie auf eine Transaktionsgebühr verzichten. Somit unterstützen sie in Kombination mit den Transaktionstypen Alternativ und insbesondere Markt das Versprechen auf Unabhängigkeit besser als profitgetriebene Plattformen, die in der Regel einen Teil des Mehrwerts per Gebühr abschöpfen. Die Verpflichtung der missionsgetriebenen Plattformen auf ein gemeinnütziges Ziel zieht auch Nutzer*innen an, die ähnliche Werte vertreten. Dadurch begegnen sich in diesem Kontext Gleichgesinnte, was wiederum die Wahrscheinlichkeit der Entstehung von Sozialkapital erhöht, weil das gemeinsame Anliegen als Grundlage für ein Kennenlernen dienen kann.

\section{Hybrid}

Ansätze, die sowohl profit- als auch missionsgetrieben sind, bezeichnen Muñoz und Cohen als Hybriden. Sie haben hierbei vor allem (USamerikanische) B Corporations wie Kickstarter oder ehemals Etsy im Blick - also For-Profit-Unternehmen, die sich ihr (zusätzliches) Ziel einer positiven Einwirkung auf Gesellschaft und Umwelt durch die Non-Profit-Organisation B Lab haben zertifizieren lassen.

Plattformen mit hybridem Geschäftsansatz können als For-Profit-Unternehmen zum Versprechen der Unabhängigkeit beitragen. Allerdings gelten auch hier die im Zusammenhang mit der Gewinnorientierung diskutierten Einschränkungen durch eine mögliche Transaktionsgebühr. Hinsichtlich des Nachhaltigkeitsversprechens besitzt die zu profitgetriebenen Plattformen geführte Diskussion für hybride Plattformen ebenfalls Gültigkeit, weil sich auch in ihrem Fall Anreize für das Einführen zusätzlicher Ressourcen herausbilden können. Bezüglich des Demokratisierungsversprechens stellt sich die Frage, ob eine Zertifizierung als B Corp bereits ausreicht, um eine Community von Gleichgesinnten 
anzuziehen. Diese Frage kann letztlich nur empirisch beantwortet werden, aber der Blick auf die von Muñoz und Cohen für diesen Geschäftsansatz angeführten Beispiele Kickstarter und Etsy lässt vermuten, dass hier keine nennenswerten positiven Auswirkungen zu erwarten sind.

\subsection{Tauschobjekt}

In der Dimension Tauschobjekt (»shared resources«) berufen sich Muñoz und Cohen (implizit) auf zwei Kriterien, um Plattformtypen zu unterscheiden. Zum einen berücksichtigen sie die Eigentumsverhältnisse: Die Tauschobjekte können entweder nach der Transaktion im Besitz der Anbietenden bleiben (Verleih, Vermietung) oder aber in den Besitz der Nachfragenden übergehen (Verkauf, Schenkung). Muñoz und Cohen gehen also, wie der Großteil der Literatur, von einem weit gefassten Sharing-Begriff aus, der eine ganze Reihe an Aktivitäten enthält: »traditional sharing, bartering, lending, trading, renting, gifting and swapping (Botsman und Rogers 2011, xv). Zum anderen berücksichtigen sie den Zeitraum, in dem sich das Tauschobjekt im Besitz der Anbietenden befindet: Sie können dieses zum Beispiel bereits länger besitzen, eventuell ohne es bislang auf einer Sharing-Plattform angeboten zu haben. In diesem Fall ist davon auszugehen, dass dieses ursprünglich aufgrund seines Nutzwerts angeschafft wurde, wie etwa die Bohrmaschine, die nach Erfüllung ihres Zwecks ungenutzt im Regal liegt. Demgegenüber können Anbietende das Tauschobjekt aber auch genau mit dem Ziel angeschafft haben, es auf einer Sharing-Plattform anzubieten. In diesem Fall ist der Tauschwert des Objekts für die Anschaffung ausschlaggebend. Mit Bezug auf diese beiden Kriterien leiten

Tab. 5: Auswirkungen der Ausprägungen in der Dimension Tauschobjekt auf die Versprechen der Sharing Economy (Legende siehe Tab. 1).

\begin{tabular}{|c|c|c|c|c|}
\hline & \multicolumn{4}{|c|}{ Versprechen } \\
\hline & \multirow{2}{*}{$\begin{array}{l}\text { Nachhal- } \\
\text { tigkeit }\end{array}$} & \multicolumn{2}{|l|}{ Demokratisierung } & \multirow{2}{*}{$\begin{array}{l}\text { Unabhän- } \\
\text { gigkeit }\end{array}$} \\
\hline & & Entscheidungsrechte & Sozialkapital & \\
\hline Unternutzte & 수 & $\emptyset$ & $\emptyset$ & - \\
\hline Optimierte neue & $\sqrt{7}$ & $\emptyset$ & $\emptyset$ & - \\
\hline Besitzwechse/nde & 个 & $\emptyset$ & $\emptyset$ & 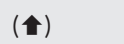 \\
\hline
\end{tabular}


Muñoz und Cohen dann drei Kategorien ab: unternutzte Tauschobjekte (»under-utilized«), optimierte neue Tauschobjekte (»optimize new«) und besitzwechselnde Tauschobjekte (»new home 4 used«). Tab. 5 liefert einen Überblick über deren Auswirkungen.

\section{Unternutzte Tauschobjekte}

Laut Muñoz und Cohen umfasst die Kategorie unternutzte Tauschobjekte solche Objekte, die sich bereits zuvor im Besitz der Anbietenden befanden und die nun zur zeitweiligen Nutzung auf einer SharingPlattform angeboten werden. Beispielhafte Plattformen für diese Kategorie sind Airbnb für Übernachtungsmöglichkeiten, Peerby für Haushaltsgegenstände und BlaBlaCar für Reisemöglichkeiten. Aus analytischer Perspektive sei hier angemerkt, dass die pauschale Zuordnung einer Plattform wie Airbnb zu dieser Kategorie nicht gerechtfertigt ist. Die Zuordnung sollte anstatt auf der Ebene der Plattform auf der Ebene der einzelnen Transaktionen stattfinden: Es macht einen Unterschied, ob das nach dem Auszug des Kindes freigewordene Gästezimmer auf der Plattform angeboten oder ob eine Wohnung eigens zur Untervermietung über Airbnb angemietet wird. Der zweite Fall ist analytisch der Kategorie optimierte neue Tauschobjekte zuzuordnen.

Plattformen der Kategorie unternutzte Tauschobjekte können zu einer nachhaltigeren Nutzung von Ressourcen beitragen. Sie verkörpern damit die ikonische Erzählung der gemeinsam genutzten Bohrmaschine. Bei diesem Plattformtyp zeigt sich besonders gut, wie die Sharing Economy dazu beitragen kann, eine generellere gesellschaftliche Verschiebung der Prioritäten von Besitz zum Zugang zu Objekten (Rifkin 2000; Belk 2007) zu unterstützen: Teilen ist das neue Besitzen.

Auch ermöglichen es Plattformen dieser Kategorie - in Kombination mit einem entsprechenden Transaktionstyp - ihren Nutzer*innen, neue Einkommensquellen zu erschließen. Im Endeffekt besteht das Prinzip bei all solchen Plattformen, auf denen physische Objekte getauscht werden, ${ }^{3}$ daraus, dass Kapital eingesetzt wird, um eine Rendite zu erwirtschaften. Als Kapital dienen bei Plattformen der Kategorie unternutzte Tauschobjekte bislang nicht als produktives Kapital behandelte Objekte

3 Zur Unterscheidung zwischen den physischen Tauschobjekten sowie Zeit und Fähigkeiten als Tauschobjekten siehe Frenken (2017). Allerdings trifft Frenken die nicht näher begründete und zumindest ungewöhnliche Entscheidung, Zeit und Fähigkeiten als Tauschobjekte definitorisch aus der Sharing Economy auszuschließen. 
im Besitz der Anbietenden. Das Auftreten als Anbietende setzt damit allerdings voraus, dass man überhaupt über solches Kapital verfügt. Fehlt dieses dagegen, bleibt auch das Versprechen auf Unabhängigkeit ein leeres. Anders verhält es sich bei Plattformen, bei denen keine physischen Objekte getauscht werden, sondern Zeit samt Fähigkeiten als Tauschobjekt fungieren. Das ist etwa bei Zeitbanken wie TimeRepublik der Fall, aber auch bei Service-Plattformen wie TaskRabbit für haushaltsnahe Dienstleistungen oder Helpling speziell für häusliche Reinigungsarbeiten. Hier wird kein Kapital investiert, sondern Arbeitskraft verkauft. Fungiert die Arbeitskraft als Tauschobjekt, ist die Anbietendenposition, zumindest in der Theorie, deutlich inklusiver angelegt, da wesentlich mehr Menschen in der Lage sein dürften, ihre Arbeitskraft zu verkaufen als Kapital zu investieren.

\section{Optimierte neue Tauschobjekte}

Auf Plattformen, die zur Kategorie optimierte neue Tauschobjekte gehören, werden Objekte zum Tausch gebracht, die Anbietende eigens zum Zweck des Anbietens auf diesen Plattformen angeschafft haben. Darunter fallen beispielsweise die Fahrzeugvermietung Share Now, aber eben auch bestimmte Transaktionen »gemischter « Plattformen wie Airbnb.

Ihr Transaktionsprinzip gleicht denen der Kategorie unternutzte Tauschobjekte. Allerdings wirkt sich die Neuanschaffung darauf aus, wie gut diese Plattformen die Versprechen der Sharing Economy erfüllen können. Im Gegensatz zur ersten Kategorie werden nämlich zusätzliche Ressourcen verbraucht, um die neu anzuschaffenden Objekte zu produzieren: Share Now vermietet Neuwagen statt bereits genutzte Fahrzeuge. Auch wenn diese Wagen intensiver genutzt werden sollten als Privatfahrzeuge, führen Plattformen dieses Typs daher zwangsläufig zu einem zusätzlichen Ressourcenverbrauch. Entsprechend ist ihr Beitrag zu einem nachhaltigen Wirtschaften als deutlich geringer einzuschätzen.

Ähnlich wie Plattformen der Kategorie unternutzte Tauschobjekte ermöglichen es Plattformen der Kategorie optimierte neue Tauschobjekte ihren Nutzer*innen wiederum, neue Einkommensquellen zu erschließen. Im Vergleich zur ersten Kategorie spitzt sich hier allerdings die Frage des Kapitalbesitzes als Zugangsvoraussetzung zur Anbietendenposition zu. So mag es sein, dass man ein Auto besitzt, das man in den ungenutzten Zeiten anderen über eine Plattform wie SnappCar überlässt und durch diesen Kapitaleinsatz eine Rendite erwirtschaftet. Die 
Anschaffung eines Wagens hingegen, der nicht für den Eigenbedarf genutzt werden soll, sondern eine reine Investition darstellt, erfordert das Vorhandensein eines zu Anlagezwecken einsetzbaren Kapitals.

\section{Besitzwechselnde Tauschobjekte}

Während die Tauschobjekte bei Plattformen der ersten beiden Typen im Besitz der Anbietenden verbleiben, gehen sie bei Plattformen des besitzwechselnden Typs in den Besitz der Nachfragenden über. Das ist etwa bei Versteigerungsplattformen wie eBay der Fall, aber auch bei Tauschplattformen wie Tauschgarten. Anbieter wie Kleiderkreisel erlauben sowohl Tausch als auch Verkauf. Ähnlich wie Airbnb bei der kurzfristigen Überlassung operiert jedoch auch eBay mit einem hybriden Ansatz und lässt den Verkauf gebrauchter wie neuer Waren zu. Für den zweiten Fall, den Verkauf oder Tausch eigens für diese Transaktion über die Plattform erworbener Objekte, sieht der Kompass von Muñoz und Cohen allerdings keine eigene Kategorie vor.

Hinsichtlich des Versprechens auf Nachhaltigkeit lässt sich für Plattformen dieses dritten Typs ein positiver Einfluss konstatieren. Indem nicht mehr genutzte Objekte über die Plattform feilgeboten werden und in den Besitz von Nutzer*innen gelangen, die ihnen einen Gebrauchswert beimessen, wird ihre Nutzungsdauer verlängert. Gleichzeitig müssen Nachfragende keine neu produzierten Objekte erwerben. Diese Einschätzung gilt selbstverständlich nur für den von Muñoz und Cohen vorgesehenen Fall der bereits gebrauchten Tauschobjekte. Das Versprechen auf Unabhängigkeit können Plattformen dieses Typs mit einem entsprechenden Transaktionsmodell ebenfalls unterstützen, indem sie nicht gebundenes, da nicht mehr genutztes Warenkapital durch Verkauf oder Tausch in Geldkapital verwandeln. Allerdings sind diesem Vorgang engere Grenzen gesetzt als in den Fällen der ersten beiden Plattformtypen: Ein Tauschobjekt kann nur einmal verkauft oder getauscht werden, während es beliebig oft verliehen oder vermietet werden kann.

\subsection{Technologie}

Mit der Dimension Technologie erfassen Muñoz und Cohen (2018, 130) den Stellenwert, den digitale Technologien für eine Sharing-Plattform besitzen: „We define technology as the reliance on digital technologies for facilitating discovery and exchange on the platform.«Der Kompass 
unterscheidet drei Grade: niedriger/kein Technologieeinsatz (»low/notech«), durch Technologie ermöglicht (»tech-enabled«) und technologiebetrieben (»tech-driven«). Allerdings ist diese Konzeption nur bedingt sinnvoll: Erstens scheint bei Plattformen die Möglichkeit einer Technologielosigkeit (»no-tech«) ausgeschlossen. Zweitens wirkt die von Muñoz und Cohen als Nebenkriterium für Plattformen mit niedrigem/ keinem Technologieeinsatz angeführte gemeinsame Nutzung einer physischen Infrastruktur wenig überzeugend. Denn auch bei Uber, das nach Muñoz und Cohen zu den technologienutzenden Plattformen gehört, wird der Zugang zu einem physischen Gut in Form des Fahrzeugs ermöglicht. Es liegt daher nahe, vorzuschlagen, die Unterscheidung vorranging auf den Einsatz einer technologischen Lösung zur Schaffung eines Marktes zu beziehen; hier zeigt sich eben im Fall von Uber, wie sehr die Transaktionen auf vom Algorithmus durchgeführten Operationen beruhen. Dieser berechnet, welche Nachfragenden mit welchen Anbietenden zu welchem Preis und zu welcher Zeit zusammengebracht werden.

Drittens, und das ist unser Haupteinwand, sind die beiden letzten Kategorien nicht trennscharf. Muñoz und Cohens Erklärung beschränkt sich auf den Hinweis, dass Plattformen der ersten Kategorie von Faceto-face-Interaktionen "profitieren « (ebd., 130). Weil die Autoren aber kein Beispiel für die erste Kategorie benennen und einzig Uber als Beispiel für die zweite Kategorie anführen, es aber auch bei Uber-Transaktionen in Zeiten nicht-autonomen Fahrens zwangsläufig zu Face-toface-Interaktionen kommt, sind diese Interaktionen kein geeignetes Unterscheidungskriterium. So scheint sich die Dreiteilung vielmehr aus dem Wunsch nach Symmetrie denn aus inhaltlichen Gründen zu ergeben. Wir schlagen daher vor, lediglich zwei Ausprägungen zu unterscheiden: Low Tech und High Tech (siehe Tab. 6).

Tab. 6: Auswirkungen der Ausprägungen in der Dimension Technologie auf die Versprechen der Sharing Economy (Legende siehe Tab. 1).

\begin{tabular}{|c|c|c|c|c|}
\hline & \multicolumn{4}{|c|}{ Versprechen } \\
\hline & \multirow{2}{*}{$\begin{array}{l}\text { Nachhal- } \\
\text { tigkeit }\end{array}$} & \multicolumn{2}{|l|}{ Demokratisierung } & \multirow{2}{*}{$\begin{array}{l}\text { Unabhän- } \\
\text { gigkeit }\end{array}$} \\
\hline & & Entscheidungsrechte & Sozialkapital & \\
\hline Low Tech & $(p 2 p)$ & $(p 2 p)$ & $(p 2 p)$ & $\boldsymbol{v}(\mathrm{p} 2 \mathrm{p})$ \\
\hline High Tech & - $(p 2 p)$ & - $(p 2 p)$ & - $(p 2 p)$ & - $(p 2 p)$ \\
\hline
\end{tabular}


Low Tech

Für den Typ Low Tech lässt sich feststellen, dass der weitgehende Verzicht auf eine technologische Lösung bei der Schaffung eines Marktes die Plattformen eines grundlegenden Vorteils beraubt, der der Sharing Economy überhaupt erst ihren Status als potenzielle Transformationsagentin verleiht. Denn es ist die Netzwerkarchitektur des Internets und damit die technologische Basis, die es erleichtert, schwache Verbindungen (sensu Granovetter 1973) zwischen Peers herzustellen, indem sie lokale, temporale und soziale Beschränkungen entscheidend verringert. Entsprechend gilt für Plattformen dieses Typs, dass sie nicht in vergleichbarem Ausmaß zur Entstehung von p2p-Beziehungen beitragen können, womit ihr Beitrag zur Realisierung der drei Versprechen als gering einzuschätzen ist.

\section{High Tech}

Plattformen der Kategorie High Tech nutzen digitale Technologien, um einen Markt zu schaffen, und sind dadurch in der Lage, die Beschränkungen bei der Etablierung schwacher Verbindungen zwischen Marktteilnehmenden zu verringern. Auf diese Weise können sie, einen entsprechenden Plattformtyp vorausgesetzt, zur Entstehung von p2p-Transaktionen beitragen und so indirekt die Realisierung der Versprechen unterstützen.

\section{Eine transformative Sharing Economy ist möglich}

Die Diskussion der Dimensionen des »Sharing business model compass« von Muñoz und Cohen (2018) hat gezeigt, wie sich die Entscheidung der Betreiber*innen für ein bestimmtes Geschäftsmodell auf das Potenzial ihrer Plattform - und damit, in Summe, der Sharing Economy - auswirkt, eine Große Transformation zu unterstützen. Für jede Dimension wurde der jeweils mögliche Beitrag seiner Ausprägungen zur Erreichung dieses Ziels herausgearbeitet.

Die vollständige Beschreibung eines Geschäftsmodells erhält man jedoch erst, wenn man alle sechs Kompassdimensionen in ihrer Kombination betrachtet. Auf Grundlage unserer Analyse lässt sich nun bestimmen, welches Zusammenspiel von Ausprägungen besser oder weniger gut geeignet ist, um eine Transformation zu unterstützen. Tab. 7 stellt die günstigste und ungünstigste Kombination vor. 
Tab. 7: Am ehesten für eine Transformation geeignete und am wenigsten geeignete Kombination von Ausprägungen der Geschäftsmodelldimensionen von Sharing-Plattformen.

\begin{tabular}{|l|l|l|}
\hline & $\begin{array}{l}\text { geeignetste } \\
\text { Ausprägungskombination }\end{array}$ & $\begin{array}{l}\text { ungeeignetste } \\
\text { Ausprägungskombination }\end{array}$ \\
\hline Plattform & $\mathrm{p} 2 \mathrm{p}$ & b2c/b2b \\
\hline Transaktion & $\begin{array}{l}\text { Abhängig von Priorisierung der } \\
\text { Versprechen }\end{array}$ & $\begin{array}{l}\text { Abhängig von Priorisierung der } \\
\text { Versprechen }\end{array}$ \\
\hline Governance & $\begin{array}{l}\text { Kooperativ (Variante 2: } \\
\text { "Open Cooperativism «) }\end{array}$ & Korporativ/Kollaborativ \\
\hline Geschäftsansatz & Missionsgetrieben & Profitgetrieben \\
\hline Tauschobjekt & Unternutzte T0 & Optimierte neue Tauschobjekte \\
\hline Technologie & High Tech & Low Tech \\
\hline
\end{tabular}

Der Blick auf die Flaggschiffe der Sharing Economy - dazu zählen unter anderem Airbnb, BlablaCar, eBay, TaskRabbit und Uber - offenbart nun allerdings, dass ihre Geschäftsmodelle tendenziell nahe an der ungünstigsten Kombination liegen. Tab. 8 illustriert dies exemplarisch an den Plattformen Uber sowie Airbnb und schlüsselt insbesondere den auf Uber dominanten und auf Airbnb im Aufstieg begriffenen (Twickel 2020) Fall der professionellen Anbietenden gesondert auf.

Tab. 8: Transformatives Potenzial der Geschäftsmodelle von Uber und Airbnb.

\begin{tabular}{|c|c|c|c|c|}
\hline & \multicolumn{2}{|c|}{$\begin{array}{l}\text { Uber: } \\
\text { professionelle Fahrer*innen } \\
\text { Airbnb: } \\
\text { professionelle Vermieter*innen }\end{array}$} & \multicolumn{2}{|c|}{$\begin{array}{l}\text { Uber: } \\
\text { gelegentliche Fahrer*innen } \\
\text { Airbnb: } \\
\text { gelegentliche Vermieter*innen }\end{array}$} \\
\hline Plattform & b2c & $\downarrow$ & $\mathrm{p} 2 \mathrm{p}$ & - \\
\hline Transaktion & Markt & $\emptyset$ & Markt & $\emptyset$ \\
\hline Governance & Korporativ & 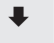 & Korporativ & 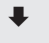 \\
\hline Geschäftsansatz & Profitgetrieben & $\downarrow$ & Profitgetrieben & $\sqrt{7}$ \\
\hline Tauschobjekt & Optimierte neue T0 & 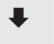 & Unternutzte T0 & - \\
\hline Technologie & High Tech & - & High Tech & - \\
\hline
\end{tabular}


Bei diesen Flaggschiffen handelt es sich durchweg um Plattformen, die nach dem oben eingeführten Raster von Hertwig und Papsdorf (2017) dem Segment der Plattformökonomie zugehören. Auch im Hinblick auf die Geschäftsmodelle gilt also, was sich bereits in der diskursiven Legitimierung der Sharing Economy beobachten ließ (Jürss und Borchers 2020): Das in der real existierenden Sharing Economy dominierende Segment der Plattformökonomie rechtfertigt nicht die in die Sharing Economy gesetzten Hoffnungen. Diese Hoffnungen beruhen vielmehr auf anderen, nicht der Plattformökonomie zuzuordnenden Plattformen wie Tauschgarten oder foodsharing, deren wünschenswerte Auswirkungen durch einen ideologisch motivierten »Brückenschlag« (ebd., 194) auch für die Plattformökonomie in Anspruch genommen werden.

Ungeachtet dieser Beschränkungen der real existierenden Sharing Economy legt unsere Analyse jedoch nahe, dass Sharing-Plattformen, ein entsprechendes Geschäftsmodell vorausgesetzt, durchaus einen Beitrag zu einer sozial-ökologischen Transformation leisten könnten. Eine besondere Aufgabe kommt hier Plattformen zu, die das von uns als am günstigsten identifizierte Geschäftsmodell - sozusagen den Idealtyp einer transformativen Sharing-Plattform - adaptieren. Sie können einen Baustein in der »realen Utopie« (Wright 2017) einer nachkapitalistischen Gesellschaft bilden. Andere Plattformen, die eine Variation dieses Geschäftsmodells adaptieren, sind in diesem Zusammenhang ebenfalls von Hilfe. Entsprechende Abstufungen lassen sich auf Grundlage einer Priorisierung der Versprechen entwickeln. Gewichtet man etwa das Versprechen des nachhaltigen Wirtschaftens höher als das Versprechen, neue, unabhängige Einkommensquellen zu erschließen eine Entscheidung, die etwa aus einer ökosozialistischen Perspektive (Kovel 2007) notwendig erscheint -, sind der freie und der alternative Transaktionstyp dem markt-förmigen vorzuziehen.

Um das transformative Potenzial der Sharing Economy nutzbar zu machen, müssten also gerade solche Plattformen eine größere Rolle im Feld spielen, deren Geschäftsmodell sich am Idealtyp einer transformativen Plattform orientiert. Zwar sind uns keine Anbieter bekannt, die diesen Idealtyp in Reinform verkörpern, es gibt allerdings Plattformen, die sich ihm bereits annähern wie etwa foodsharing, Tauschgarten oder BeWelcome. Es ist also notwendig, Projekte dieser Art gezielt aufzubauen und ihre Nutzung zu popularisieren. Denn es dürfte klar sein, dass sie aus der Perspektive von Investor*innen, die den Imperativen eines kapitalistischen Wirtschaftssystems folgen, deutlich weniger an- 
sprechend erscheinen als Plattformen des von uns als am ungünstigsten identifizierten Typs. Die geringere Attraktivität für Investor*innen zeigt sich besonders offensichtlich an der Adaption eines missions- statt eines profitgetriebenen Geschäftsansatzes, aber auch in anderen Dimensionen des Geschäftsmodells wie dem Verzicht auf Zulassung von b2c-Transaktionen und von neuen Tauschobjekten sowie an der Wahl eines kooperativen statt korporativen Governance-Typs.

Um transformationsunterstützende Sharing-Plattformen auch ohne die Dynamiken eines kapitalistischen Marktes etablieren zu können, ist daher zum einen die Arbeit von Aktivist*innen nötig, die bereit sind, missionsgetriebene Plattformen aufzusetzen und am Leben $\mathrm{zu}$ halten. Zum anderen sind die Nutzer*innen gefragt, sich im Rahmen von Plattformkooperativen einzubringen. Weil die Transformation schließlich nicht einzig von Individuen geschultert werden kann, ist zudem eine politische Unterstützung entsprechender Plattformen notwendig. Diese Unterstützung sollte von finanziellen Hilfen bis hin zu Veränderungen der »Marktregeln« zugunsten transformationsunterstützender Plattformen, die etwa den Nachteil begrenzter UpscalingMöglichkeiten ausgleichen, reichen. Beispielweise ließe sich nachdenken über nichtkommerzielle lokale Sharing-Gemeinschaften für Gegenstände des alltäglichen und nicht alltäglichen Bedarfs (Rasenmäher, Festzelte, Campingausrüstung), die auf einer gemeinsamen, von Städten und Gemeinden finanzierten technischen Plattform aufbauen. Überlegenswert ist es ebenfalls, Marktbedingungen zugunsten genossenschaftlich organisierter Plattformen im Sinne von Felbers Gemeinwohl-Ökonomie (2014) zu verändern, etwa durch Steuervergünstigungen oder die bevorzugte Vergabe von Aufträgen oder Privilegien. Beispielsweise könnten Städte und Gemeinden genossenschaftlich organisierten »Mobilitätsunternehmen« (Kurzzeitleihe von Fahrrädern, E-Rollern, Autos und anderem) bevorzugt günstige Park- und Abstellpunkte zuweisen.

\section{Literatur}

Acquier, Aurélien, Thibault Daudigeos, und Jonatan Pinkse. 2017. Promises and paradoxes of the sharing economy: An organizing framework. Technological Forecasting and Social Change 125: 1-10. DOI: https://doi.org/10.1016/j.techfore.2017.07.006.

Bauwens, Michel, und Vasilis Kostakis. 2014. From the communism of capital to capital for the commons: Towards an open co-operativism. TripleC: Communica- 
tion, Capitalism \& Critique 12 (1): 356-361. http://www.triple-c.at/index.php/ tripleC/article/view/561/678.

Belk, Russell. 2007. Why not share rather than own? The ANNALS of the American Academy of Political and Social Science 611 (1): 126-140. DOI: https://doi. org/10.1177/0002716206298483.

Borchers, Nils S., und Nicola Krömer. 2015. Die Rolle von Arztbewertungsportalen im Prozess der Arztwahl: Patienten-Empowerment durch Laienbewertungen? In: Gesundheitskommunikation im gesellschaftlichen Wandel, herausgegeben von Markus Schäfer, Oliver Quiring, Constanze Rossmann, Matthias R. Hastall und Eva Baumann, 153-164. Baden-Baden: Nomos.

Botsman, Rachel, und Roo Rogers. 2011. What's mine is yours: How collaborative consumption is changing the way we live. London: Collins.

Brecht, Bertolt. 1982 [1932/33]. Der Rundfunk als Kommunikationsapparat. In: Gesammelte Werke in 20 Bänden, Band 18, 127-134. Frankfurt am Main: Suhrkamp.

Buchstein, Hubertus. 1997. Bytes that bite: The internet and deliberative democracy. Constellations 4 (2): 248-263. DOI: https://doi.org/10.1111/14678675.00052 .

Chase, Robin. 2015. Peers Inc: How people and platforms are inventing the collaborative economy and reinventing capitalism.

Daum, Timo. 2017. Das Kapital sind wir: Zur Kritik der digitalen Ökonomie. Hamburg: Nautilus.

Decrop, Alain, Giacomo Del Chiappa, Jérôme Mallargé und Pietro Zidda. 2018. "Couchsurfing has made me a better person and the world a better place": The transformative power of collaborative tourism experiences. Journal of Travel \& Tourism Marketing 35 (1): 57-72. DOI: https://doi.org/10.1080/10548408.201 7.1307159 .

Elias, Norbert. 2009 [1970]. Was ist Soziologie? 11. Auflage. Weinheim: Juventa.

Enzensberger, Hans Magnus. 1997 [1970]. Baukasten zu einer Theorie der Medien: Kritische Diskurse zur Pressefreiheit. München: Fischer.

Felber, Christian (2014). Die Gemeinwohl-Ökonomie: Eine demokratische Alternative wächst. Aktualisierte und erweiterte Neuausgabe. Wien: Deuticke.

Frenken, Koen. 2017. Political economies and environmental futures for the sharing economy. Philosophical Transactions of the Royal Society A: Mathematical, Physical \& Engineering Sciences 375 (2095): 1-15.

Gansky, Lisa. 2010. The mesh: Why the future of business is sharing. New York: Penguin.

Göpel, Maja. 2020. Unsere Welt neu denken: Eine Einladung. Berlin: Ullstein.

Granovetter, Mark S. 1973. The strength of weak ties. American Journal of Sociology 78 (6): 1360-1380.

Hamari, Juho, Mimmi Sjöklint, und Antti Ukkonen. 2015. The sharing economy: Why people participate in collaborative consumption. Journal of the Association for Information Science and Technology. DOI: https://doi.org/10.1002/ asi.23552.

Hertwig, Markus, und Christian Papsdorf. 2017. Varieties of Sharing: Handlungs- 
orientierungen, Strukturen und Arbeitsbedingungen eines neuartigen Feldes. Berliner Journal für Soziologie 27 (3-4): 521-546. DOI: https://doi.org/10.1007/ s11609-018-0359-5.

Hill, Steven. 2015. Raw deal: How the »Uber economy « and runaway capitalism are screwing American workers. New York: St. Martin's.

Jürss, Sebastian, und Nils S. Borchers. 2020. Die Ideologie der Sharing Economy. In: Ideologie, Kritik, Öffentlichkeit: Verhandlungen des Netzwerks Kritische Kommunikationswissenschaft, herausgegeben von Uwe Krüger und Sebastian Sevignani, 188-211. Frankfurt am Main: Westend. DOI: https://doi. org/10.36730/ideologiekritik.2019.9.

Kearney. (о. J.). The demystification of car sharing: An in-depth analysis of customer perspective, underlying economics, and secondary effects. https://www.de.kearney.com/automotive/article?/a/the-demystification-of-car-sharing. Zugegriffen: 1. Mai 2021.

Kovel, Joel. 2007. The enemy of nature: The end of capitalism or the end of the world? 2. Auflage. London: Zed.

Labrecque, Lauren I., Jonas vor dem Esche, Charla Mathwick, Thomas P. Novak, und Charles F. Hofacker. 2013. Consumer power: Evolution in the digital age. Journal of Interactive Marketing 27 (4): 257-269. DOI: https://doi.org/ 10.1016/j.intmar.2013.09.002.

Lessig, Lawrence. 2006. Code: Version 2.0. 2. Auflage. New York: Basic.

Liu, Yaping, Linlin Nie, und Li Li. 2016. Homogeneity, trust, and reciprocity: Three keys to the sustainable hospitality exchange of Couchsurfing. Tourism Analysis 21 (2): 145-157. DOI: https://doi.org/10.3727/108354216X14559233984610.

Mikołajewska-Zaj c, Karolina. 2016. Sharing as labour and as gift: Couchsurfing as an »affective enterprise«. Ephemera 16 (4): 209-222.

Muñoz, Pablo und Boyd Cohen. 2017. Mapping out the sharing economy: A configurational approach to sharing business modeling. Technological Forecasting and Social Change 61 (1): 114-147. DOI: https://doi.org/10.1016/j.techfore.2017.03.035.

Muñoz, Pablo und Boyd Cohen. 2018. A compass for navigating sharing economy business models. California Management Review 61 (1): 114-147. DOI: https:// doi.org/10.1177/0008125618795490.

Murillo, David, Heloise Buckland und Esther Val. 2017. When the sharing economy becomes neoliberalism on steroids: Unravelling the controversies. Technological Forecasting and Social Change 125: 66-76. DOI: https://doi.org/10.1016/j.techfore.2017.05.024.

Pazaitis, Alex, Vasilis Kostakis und Michel Bauwens. 2017. Digital economy and the rise of open cooperativism: The case of the Enspiral Network. Transfer: European Review of Labour and Research 23(2): 177-192. DOI: https://doi. org/10.1177/1024258916683865.

Rifkin, Jeremy. 2000. The age of access: The new culture of hypercapitalism, where all of life is a paid-for experience. New York: Tarcher/Putnam.

Rifkin, Jeremy. 2014. The zero marginal cost society: The internet of things, the collaborative commons, and the eclipse of capitalism. New York: Palgrave Macmillan. 
Scholz, Trebor. 2017. Uberworked and underpaid: How workers are disrupting the digital economy. Cambridge: Polity.

Scholz, Trebor, und Nathan Schneider (Hrsg.). 2017. Ours to hack and to own: The rise of platform cooperativism, a new vision for the future of work and a fairer internet. New York: OR.

Schor, Juliet B. 2014. Debating the sharing economy. http://www.greattransition. org/publication/debating-the-sharing-economy. Zugegriffen: 3. März 2021.

Slee, Tom. 2015. What's yours is mine: Against the sharing economy. New York: OR. Srnicek, Nick. 2017. Platform Capitalism. Cambridge: Polity.

Twickel, Christoph. 2020. Mehr als Luftmatratze mit Frühstück. Die Zeit vom 30. November, https://www.zeit.de/wirtschaft/unternehmen/2020-11/airbnb-corona-wirtschaftskrise-boersengang-erfolg-unternehmen. Zugegriffen: 3. März 2021.

United Nations. o. J. 17 goals to transform our world. https://www.un.org/sustainabledevelopment/. Zugegriffen: 3. März 2021.

Wright, Erik Olin. 2017. Reale Utopien: Wege aus dem Kapitalismus. Frankfurt am Main: Suhrkamp.

\section{Open Access}

Dieser Beitrag erscheint unter der Creative-Commons-Lizenz CC BY-ND 3.0 DE: https://creativecommons.org/licenses/by-nd/3.0/de/. 


\section{Für ein neues duales System: Der öffent- lich-rechtliche Rundfunk als Ausgangs- punkt für datensparsame Plattformen - Plädoyer eines Medienpolitikers}

\section{Heiko Hilker}

Keywords: Duales System, Medien, Daten, Datensparsamkeit, Plattform, Datenschutz, Medienvielfalt

\section{Abstract}

Die Bedeutung von Nutzer*innendaten wächst für die verschiedenen Anbieter digitaler Dienstleistungen. Es zeichnet sich ab, dass insbesondere der Schutz privater Daten zu einem wichtigen Differenzierungsmerkmal von digitalen Angeboten wird. Wenn alle anderen Anbieter Daten erheben, um ihre Angebote zu optimieren und zu individualisieren, wäre ein öffentlich-rechtliches Angebot, das keine Daten erheben darf, nicht konkurrenzfähig. Die entscheidende Frage ist dabei aber nicht, ob grundsätzlich Daten erhoben werden, sondern unter welchen Bedingungen, mit welchen Zielsetzungen und gemä $\beta$ welcher Standards. So müssen die Nutzer*innen nicht nur die Möglichkeit haben, der Speicherung ihres Profils zuzustimmen, sondern auch verlangen können, dass alle ihre Daten wieder gelöscht und das Profil an sie zurückgegeben wird. Datenschutz und-sparsamkeit werden in der Folge für einen Teil der Bürger*innen ein relevantes Entscheidungskriterium dafür sein, ob sie Angebote nutzen wollen. Für die öffentlich-rechtlichen Sender öffnen sich dadurch neue Perspektiven und gesellschaftliche Aufgaben, indem sie den relevanten Standards entsprechend individualisierte Medienangebote erstellen sowie einen Raum besetzen können, in dem Datenschutzstandards gelten.

Heiko Hilker: Für ein neues duales System: Der öffentlich-rechtliche Rundfunk als Ausgangspunkt für datensparsame Plattformen - Plädoyer eines Medienpolitikers. In: Nils S. Borchers, Selma Güney, Uwe Krüger und Kerem Schamberger (Hrsg.): Transformation der Medien - Medien der Transformation. Verhandlungen des Netzwerks Kritische Kommunikationswissenschaft. Frankfurt am Main: Westend 2021. DOI: https://doi.org/10.53291/XUPB2907. 
Heiko Hilker I Dresdner Institut für Medien, Bildung und Beratung | hilker@dimbb.de

\section{Dienende Freiheit des Rundfunks}

Der Rundfunk in Deutschland, so das Bundesverfassungsgericht, hat »keine Freiheit an sich«, sondern eine »dienende Freiheit«. Er soll der freien öffentlichen und individuellen Meinungs- und Willensbildung und damit der Demokratie »dienen« (BVerfG 1991, 315). Die Medienpolitik wiederum soll die dienende Freiheit der Medien und insbesondere des Rundfunks zur Sicherung freier individueller und öffentlicher Meinungs- und Willensbildung stärken und sichern. Dabei muss sie nicht allein den Blick auf die privatrechtlich, öffentlich-rechtlich oder anders organisierten Akteure haben, sondern auch auf die gesamtgesellschaftliche Kommunikation. Die Medienpolitik geschieht heute offensichtlich unter grundlegend anderen Bedingungen als noch vor 30 Jahren, dem Bezugsdatum des zwischenzeitlich mehrfach abgeänderten Rundfunkstaatsvertrags. Das Internet steckte damals noch in den Kinderschuhen, mobile Kommunikation gab es nur über Handys, deren Ausmaße und Gewicht eine Nutzung außerhalb des Autos faktisch unmöglich machten, soziale Netzwerke und Communitys bestanden nur in real vermittelter Form.

Öffentliche Kommunikation ist eine Grundvoraussetzung der Demokratie, Meinungs- und Willensbildung bedürfen des kommunikativen Austauschs. Das Bundesverfassungsgericht hat immer wieder darauf verwiesen, dass es eine zentrale Aufgabe der Medienpolitik sowie der sich daraus ergebenden Gesetzgebung sei, vorherrschende Meinungsmacht zu verhindern

\section{Medienvielfalt}

Doch gibt es auf den jeweiligen (Demokratie-)Ebenen tatsächlich ein Medienangebot, welches »sicherstellt, dass die Vielfalt der bestehenden Meinungen [...] in möglichster Breite und Vollständigkeit Ausdruck « findet, wie es das Bundesverfassungsgericht 2007 gefordert hat (BVerfG 2007, 115)? Ist zudem gewährleistet, »dass die in einer Gesellschaft verfügbaren Informationen, Erfahrungen, Werthaltungen und Verhaltensmuster abgebildet werden« (ebd., 117)? Wird also die Medi- 
enlandschaft ihrer Aufgabe und Funktion in der repräsentativen Demokratie »als ständiges Verbindungs- und Kontrollorgan zwischen dem Volk und seinen gewählten Vertretern in Parlament und Regierung« gerecht, wie sie das Bundesverfassungsgericht im Spiegel-Urteil von 1966 formulierte:

Sie fasst die in der Gesellschaft und in ihren Gruppen unaufhörlich sich neu bildenden Meinungen und Forderungen kritisch zusammen, stellt sie zur Erörterung und trägt sie an die politisch handelnden Staatsorgane heran, die auf diese Weise ihre Entscheidungen auch in Einzelfragen der Tagespolitik ständig am Maßstab der im Volk tatsächlich vertretenen Auffassungen messen können. (BVerfG 1966, 35)

Grundsätzlich ist festzuhalten, dass Vielfalt im medienrechtlichen Sinne nicht nur und auch nicht in erster Linie ein quantitativer Aspekt ist. Die Tatsache, dass es eine Vielzahl an Angeboten gibt, reicht nicht aus, um von Vielfalt zu sprechen. Zwar erweitert eine Vielzahl neuer Anbieter das Angebot und bietet Alternativen. Doch selbst wenn es eine Vielzahl Anbieter mit großer Massenrelevanz gibt, ist Medienvielfalt noch lange nicht garantiert.

Die Sicherung medialer Vielfalt ist eine zentrale Voraussetzung für eine lebendige Demokratie. Denn nur sie versetzt die mündigen Bürger*innen in die Lage, sich umfassend zu informieren, um in der Folge kompetente Entscheidungen treffen zu können. So weist Paul Leo Giani zu Recht auf Folgendes hin:

Deshalb ist dem Postulat der Vielfaltssicherung nur dann Rechnung getragen, wenn die Tiefe und Qualität der Informationen und Hintergründe von Meinungsverschiedenheiten in einer Weise aufgearbeitet werden, die ihrer Komplexität gerecht wird. Je schwieriger, komplexer also eine Frage ist, umso notwendiger ist die inhaltliche Aufbereitung - und zwar - in der Vielfalt der in der Gesellschaft bestehenden Wertungen, Erfahrungen etc. (Giani 2013, 286) 


\section{3 »Duales System« im Rundfunk}

Vor 30 Jahren spielten die Medienpolitiker*innen noch eine aktive Rolle bei der Gestaltung der Medienlandschaft. So schufen sie die gesetzlichen Grundlagen für den privaten Rundfunk. Lange sprach man in Deutschland von einem dualen System aus öffentlich-rechtlichen und privaten Anbietern: Erstere wurden zu großen Teilen über Rundfunkgebühren (heute: Rundfunkbeiträge) finanziert, letztere finanzierten sich im Wesentlichen über Werbung.

Finanziell gesehen agieren die beiden lange als »Säulen « des Rundfunksystems beschriebenen Anbietergruppen auf Augenhöhe. Während die öffentlich-rechtlichen Sender im Jahr 2019 über mehr als neun Milliarden Euro im Jahr verfügen konnten, setzten die privaten Rundfunk- und Medienanbieter in Radio und Fernsehen sowie über Pay-TV, Video-on-Demand, Teleshopping sowie über Mobile und Online etwa 13 Milliarden Euro um. Allerdings stagnieren die Umsätze in den Bereichen Radio und Fernsehen seit einiger Zeit und sind anteilsmäßig auf unter 50 Prozent gesunken (Vaunet 2019). Mittlerweile entfällt ein wesentlicher Anteil der Werbeausgaben auf Plattformen im Internet. Allerdings agieren hier nicht nur Rundfunk- und Medienanbieter. Viele journalistische Quereinsteiger*innen wie etwa Google, Facebook und Apple, aber beispielsweise auch speziell in Deutschland die Ströer SE \& Co. KGaA, die das News-Portal t-online.de betreibt, nutzen die Plattformen sowie Apps und machen den Medienunternehmen auf deren Feld Konkurrenz. Damit brechen ihnen weiter Einnahmen weg.

Doch heißt das, dass der Journalismus nicht mehr finanziert werden kann? Es gab und gibt nur wenige Medien, die ihren Umsatz ausschließlich über die Einnahmen für ihre journalistischen Angebote generieren. Zeitungen und Zeitschriften finanzierten sich nur selten allein über die Verkaufserlöse, sondern auch über Werbung oder die Rubrikenmärkte. Journalistische Angebote dienten paradoxerweise für einen Teil der Anbieter vor allem dazu, Werbeeinnahmen zu generieren.

Medienunternehmen erschließen sich deshalb digital neue Geschäftsfelder. Grundlage dafür ist das Sammeln von Nutzer*innendaten, die dazu dienen, die Kundschaft interessenspezifisch mit Inhalten zu versorgen und Werbeangebote möglichst gezielt auszuspielen. Die gewonnenen Datenprofile werden mitunter auch weiterverkauft. 


\section{Medienvielfalt ist nicht allein über den Markt realisierbar}

Wer den Medienmarkt vor allem unter ökonomischen Gesichtspunkten betrachtet, greift zu kurz. Journalistische Vielfalt kann nur dann garantiert werden, wenn es ein relevantes Medienangebot gibt, das unabhängig von politischen und ökonomischen Interessen ist.

Bereits Karl Marx hatte sich die Frage gestellt, welche Unabhängigkeit oder Freiheit Medien noch haben, wenn die Informationen einen Warencharakter aufweisen, als er in der Rheinischen Zeitung schrieb:

Die erste Freiheit der Presse besteht darin, kein Gewerbe zu sein. [...] Gewerbefreiheit, Freiheit des Eigentums, des Gewissens, der Presse, der Gerichte, sind alle Arten einer und derselben Gattung, der Freiheit ohne Familiennamen. Alleinwie gänzlich irrig ist es nun, über der Einheit den Unterschied zu vergessen und gar eine bestimmte Art zum Maß, zur Norm, zur Sphäre der anderen Arten zu machen? [...] Deine Freiheit ist nicht meine Freiheit, ruft die Presse dem Gewerbe zu. Wie du den Gesetzen deiner Sphäre, so will ich den Gesetzen meiner Sphäre gehorchen. (Marx 1842)

Es ist ein Irrglaube, dass eine umfassende Medienvielfalt auf rein wirtschaftlichem Wege möglich sei. Gewerblich orientierte Medien sind in ihrer Freiheit beschränkt. Werbefreiheit ist also eine erste und wesentliche Voraussetzung für freie Medien. Kurz gesagt bedeutet das: Das Geld folgt dem Auftrag und nicht der Auftrag dem Geld. Dazu stellte das Bundesverfassungsgericht im Jahr 2018 fest:

[D]er publizistische und ökonomische Wettbewerb führt nicht automatisch dazu, dass in den Rundfunkprogrammen die Vielfalt der in einer Gesellschaft verfügbaren Informationen, Erfahrungen, Werthaltungen und Verhaltensmuster abgebildet wird. Auch wegen des erheblichen Konzentrationsdrucks im privatwirtschaftlichen Rundfunk und der damit verbundenen Risiken einer einseitigen Einflussnahme auf die öffentliche Meinungsbildung sind daher Vorkehrungen zum Schutz der publizistischen Vielfalt geboten. (BVerfG 2018, 77)

Die ARD ist prinzipiell ähnlicher Meinung:

Die Journalistinnen und Journalisten in der ARD arbeiten politisch und wirtschaftlich unabhängig - sie müssen sich nicht um die Maximierung von Klickraten und Werbeeinnahmen sorgen, denn ihre Arbeit ist dem öffentlich-rechtlichen Gemeinschaftsprinzip und nicht der Gewinnerzielung verpflichtet. (ARD 2017, 12) 
Doch die Realität sieht anders aus, denn man orientiert sich auch beim öffentlich-rechtlichen Rundfunk gegenwärtig in weiten Teilen des Programmangebots klar an Marktanteilen und Quoten. Der wesentliche Unterschied zwischen den kommerziellen, werbefinanzierten Angeboten der privaten Sender oder Presseverlage und dem beitragsfinanzierten Journalismus besteht gerade darin, dass letzterer keine Marktkriterien zur Grundlage haben muss. Der Erfolgsmaßstab ist nicht der Marktanteil, sondern die gesellschaftliche Reichweite einer Vielzahl qualitativ guter Angebote für alle Bevölkerungsgruppen und ihr Beitrag zur freien Meinungsbildung. Akzeptanz ist auch eine Frage der Breite und Vielfalt des Angebots. Der öffentlich-rechtliche Rundfunk soll, so das Bundesverfassungsgericht in seinem ZDF-Urteil aus dem Jahr 2014, »durch eigene Impulse und Perspektiven zur Angebotsvielfalt beitragen und unabhängig von Einschaltquoten und Werbeaufträgen ein Programm anbieten, das den verfassungsrechtlichen Anforderungen gegenständlicher und meinungsmäßiger Vielfalt entspricht« (BVerfG 2014, 37).

Für das Bundesverfassungsgericht gehört dazu auch, dass sich die Sender mit ihren Angeboten nicht nur an ein möglichst breites Publikum wenden und dementsprechend Standardformate für den Massengeschmack bieten. Der Auftrag ist nicht »auf eine Mindestversorgung oder auf ein Ausfüllen von Lücken und Nischen, die von privaten Anbietern nicht abgedeckt werden «, beschränkt. Die Sender sollen stattdessen »die volle Breite des klassischen Rundfunkauftrags« abdecken, zu dem neben der Information auch die Unterhaltung gehört. Außerdem haben die Sender eine kulturelle Verantwortung und sollen sich mit der Gesamtheit ihrer Angebote an das gesamte Publikum richten: »Dabei muss sein Programmangebot für neue Publikumsinteressen oder neue Inhalte und Formen offenbleiben und darf auch technisch nicht auf einen bestimmten Entwicklungsstand beschränkt werden.« (BVerfG 2014, 37)

Vier Jahre später wurde das Bundesverfassungsgericht dahingehend noch deutlicher. Es stellte fest, dass die Digitalisierung der Medien und insbesondere die Netz- und Plattformökonomie des Internet einschließlich der sozialen Netzwerke Konzentrations- und Monopolisierungstendenzen bei Anbietern, Verbreitern und Vermittlern von Inhalten begünstigen. Wenn deren Angebote zum größten Teil werbefinanziert sind, fördern sie nicht unbedingt den publizistischen Wettbewerb: 
[...] auch im Internet können die für die Werbewirtschaft interessanten größeren Reichweiten nur mit den massenattraktiven Programmen erreicht werden. Hinzu kommt die Gefahr, dass - auch mit Hilfe von Algorithmen - Inhalte gezielt auf Interessen und Neigungen der Nutzerinnen und Nutzer zugeschnitten werden, was wiederum zur Verstärkung gleichgerichteter Meinungen führt. Solche Angebote sind nicht auf Meinungsvielfalt gerichtet, sondern werden durch einseitige Interessen oder die wirtschaftliche Rationalität eines Geschäftsmodells bestimmt, nämlich die Verweildauer der Nutzer auf den Seiten möglichst zu maximieren und dadurch den Werbewert der Plattform für die Kunden zu erhöhen. Insoweit sind auch Ergebnisse in Suchmaschinen vorgefiltert und teils werbefinanziert, teils von "Klickzahlen" abhängig. Zudem treten verstärkt nicht-publizistische Anbieter ohne journalistische Zwischenaufbereitung auf. (BVerfG 2018, 79)

\section{Datenschutz als wesentliches Merkmal eines neuen dualen Systems}

Es zeichnet sich ab, dass insbesondere die Datensicherheit für einen Teil der Nutzer*innen zu einem wichtigen Differenzierungsmerkmal von digitalen Angeboten wird, das deren Auswahl maßgeblich bestimmt:

Datenschutz und Privatsphäre sind nicht nur für den einzelnen Menschen existenziell wichtig. Viel zu wenig wird in der öffentlichen Diskussion gesehen, dass sie auch völlig unverzichtbar für die Demokratie sind. Ohne Privatsphäre und Datenschutz gibt es keine Demokratie. (Boehme-Neßler 2018)

Doch welche Medienanbieter können nicht nur Datenschutzstandards für ihre Angebote garantieren, sondern verfügen auch über eine hinreichende Größe, Reichweite und Relevanz in der Gesellschaft, um diese Standards mit durchzusetzen beziehungsweise ihnen zum Durchbruch zu verhelfen? Die öffentlich-rechtlichen Sender kämen dafür in Frage. Während das alte duale System durch öffentlich-rechtlichen und privaten Rundfunk gekennzeichnet war, könnte sich das neue duale System am Umgang mit personenspezifischen Daten ausdifferenzieren und so zwischen datensparsamen und »datenfressenden« Plattformen unterscheiden.

In den letzten Jahren bieten immer mehr Drittanbieter und Quereinsteiger Rundfunk beziehungsweise rundfunkähnliche und andere mediale Angebote, die zum Teil auch die Meinungs- und Willensbildung 
beeinflussen. Dies geschieht vor allem deshalb, um die Nutzer*innen auf ihre Plattformen zu locken und personenspezifische Daten zu akquirieren. Kommerzialisiert werden diese Daten durch das Schalten personalisierter Werbung, die Unterbreitung von Kaufangeboten oder einen Weiterverkauf der Daten. Es geht vor allem darum, die (endliche) Aufmerksamkeit der jeweiligen Nutzer*innen für sich zu gewinnen und möglichst lange zu binden. Das lässt sich am besten mit personenspezifischen medialen Angeboten bewerkstelligen. Dementsprechend werden auch die neuen Möglichkeiten der sozialen Netzwerke genutzt. Ziel fast jeder Kommunikation wird es, neue Daten zu gewinnen. Kommunikative Prozesse und somit auch soziale Beziehungen werden monetarisiert. Die sich daraus ergebenden Aktionen der Anbieter haben also auch Kommunikation zum Ziel - doch diese muss nicht zwangsläufig Demokratie befördern. Schließlich können die Daten dazu genutzt werden, vorhandene Sichtweisen zu verstärken oder gegenläufige Informationen und Argumente auszublenden, wenn das die Nutzer*innen länger auf der Plattform hält.

Was folgt daraus für die bisher etablierten Medienunternehmen? Die Konsequenz ist, dass diese nur dann relevant bleiben können, wenn auch sie mit ihren Angeboten Nutzer*innendaten akquirieren. Nur so sind sie in der Lage, personenspezifische Angebote zu unterbreiten und auf die Interessen der Nutzer*innen einzugehen.

Was bedeutet es, wenn gefordert wird, dass die Sender über ihre digitalen Plattformen keine Daten sammeln dürfen? Das käme der Verbannung in eine Nische gleich, gefolgt von rasch einsetzender gesellschaftlicher Irrelevanz. Wenn alle anderen Anbieter Daten erheben, um damit ihre Angebote zu optimieren und zu individualisieren, wäre ein öffentlich-rechtliches Angebot, das keine Daten erheben darf, nicht mehr konkurrenzfähig.

Die entscheidende Frage ist nicht mehr, ob Daten erhoben werden dürfen oder nicht, sondern unter welchen Bedingungen und mit welchen Zielen dies geschieht und ob Nutzer*innen die Möglichkeit haben, nicht nur ihr Einverständnis zur Datenspeicherung zu geben, sondern auch zu verlangen, dass alle ihre Daten wieder gelöscht beziehungsweise zurückgegeben werden. Dabei haben die öffentlich-rechtlichen Sender zudem den Vorteil, dass sie über Beiträge finanziert sind und personenspezifische Daten nicht weiterverkaufen müssen.

Datenschutz und -sparsamkeit werden für einen Teil der Bürger*innen ein relevantes Entscheidungskriterium sein, um Angebote zu nutzen oder abzulehnen. Das macht sie potenziell zu einem wichtigen 
Differenzierungsmerkmal von digitalen Angeboten in der Zukunft. Allerdings müssen die Bürger*innen überhaupt erst einmal die Wahl dazu haben. Und diese sollte auch bei allen anderen digitalen Anbietern möglich sein, vom Pizzaservice über den Buchhändler bis zur Bank.

\section{Neue Perspektiven für die öffentlich-rechtlichen Sender}

Für die öffentlich-rechtlichen Sender ergeben sich darüber hinaus ganz neue Perspektiven und gesellschaftliche Aufgaben, wenn man die neuen technischen Möglichkeiten unter den oben geschilderten Rahmenbedingungen weitergehend nutzt und Datenschutz nicht darauf verkürzt, keine Daten zu erheben. Die Nutzer*innen können selbst entscheiden, welche Daten die Sender von ihnen haben dürfen oder löschen müssen. Angesichts des umfangreichen inhaltlichen Angebots von ARD, ZDF und Deutschlandradio in fast allen Genres wäre es auch möglich, jeder Beitragszahlerin ein auf sie zugeschnittenes individuelles und doch redaktionell gestaltetes Angebot zu unterbreiten. Wenn die Sender wissen, dass sich ein Nutzer oder eine Nutzerin etwa für Radball, Kriminalhörspiele, Kurzfilme und Asien interessiert, könnten sie ihn oder sie täglich über die aktuell laufenden Angebote zu diesen Themen auf ihren Sendern informieren. Dadurch wäre es möglich, für jedes spezifische »Interessenportfolio« ein eigenes Angebot entwickeln.

Über eine App könnte man ein personenspezifisches Programm zusammenstellen, in dem, redaktionell gestaltet, den Nutzer*innen Beiträge und Musik entsprechend der eigenen Interessengebiete zur Verfügung stehen. Wenn diese dann ein Beitrag oder Angebot nicht interessiert, könnten sie es wegwischen und neue Inhalte angezeigt bekommen. Der Vorteil: Dieses »Wegschalten« würde nicht zum Verlassen des Angebots führen, sondern die Nutzer*innen auf dem Kanal behalten. Die App könnte zudem so lernen, was ihnen gefällt. Allerdings müsste redaktionell abgesichert werden, dass sich die Nutzer*innen auf diesem Weg keine eigene Filterblase schaffen. Immer wieder sollte die App ihnen über die eigenen Interessen hinaus redaktionell als relevant erkannte Themen und Genres anbieten. Neben ihren anderen Programmen und Angeboten könnten so ARD, ZDF und Deutschlandradio ihre breit gefächerten Inhalte zielgerichtet jenen offerieren, die diese gern nutzen würden, jedoch in der digitalen Welt bisher nicht 
auf diese Vielfalt aufmerksam gemacht wurden. Schließlich verfügen sie über 18 öffentlich-rechtliche Fernsehsender und mehr als 70 Radioangebote. Auch wenn nicht alle Angebote rund um die Uhr originäre Inhalte bieten, so ist doch das Angebot so groß, dass eine Einzelperson dieses allein kaum überblicken und in seiner Gänze nutzen kann.

Noch haben ARD, ZDF und Deutschlandradio das Potenzial und die gesellschaftliche Relevanz, um Kern der datensparsamen Säule des neuen dualen Systems zu sein. Sie könnten damit indirekt weitere Anbieter unterstützen, die sich an die Datenschutzkriterien halten, wie Medienanbieter, aber auch Onlineverkaufsportale bis hin zum Pizzaservice oder Blumenladen. Doch irgendwann wird die Zeit dafür vorbei sein, denn dann haben andere Instanzen bereits Tatsachen geschaffen. Die Sender könnten zum Technologietreiber für datensparsame Angebote werden und dadurch öffentliche Standards und auch andere Anbieter unter Druck setzen. Unsere Medienpolitik ist gefordert, den Sendern diese Entwicklungsperspektive zu eröffnen.

Der vor 30 Jahren geschlossene Rundfunkstaatsvertrag wurde im Zuge der technologischen Entwicklung 22 Mal geändert. Im Herbst letzten Jahres trat ein neuer Medienstaatsvertrag in Kraft, der wesentliche Regelungen des Rundfunkstaatsvertrages übernommen hat. So unterscheidet man noch immer in Radio, Fernsehen und Telemedien. Es gelten weiterhin unterschiedliche Regelungen für die Unternehmen, die schon immer Radio und Fernsehen angeboten haben, und solchen, die allein im Internet mediale Angebote unterbreiten. Doch die Ziele und die Notwendigkeit der Vielfaltssicherung bestehen in der digitalen Welt unverändert weiter. Viele Instrumente können übernommen werden. Allerdings gibt es eine notwendige Erweiterung: Die Anforderung zur Sicherung der Vielfalt darf sich nicht mehr nur an die Rundfunkunternehmen richten. Sie muss auf alle Unternehmen erweitert werden, die in Medienmärkten agieren und damit zur Meinungsbildung beitragen: Telekommunikationsunternehmen, Plattformbetreiber, Suchmaschinen und soziale Netzwerke. Zudem stehen wir vor der Frage, ob nicht ein wesentlich größerer Teil der Mittel aus dem Rundfunkbeitrag auch zur Finanzierung von Angeboten genutzt werden sollte, die nicht von öffentlich-rechtlichen Anbietern erstellt werden, aber wesentlich zur Meinungs- und Willensbildung in der Gesellschaft beitragen. So brachte der Senator der Behörde für Kultur und Medien, Dr. Carsten Brosda, ins Gespräch, statt Institutionen stärker journalistisch-redaktionelle Inhalte zu fördern. Es gehe um die journalistische Leistung, nicht um die Verbreitungsform (Brosda und Schulz 2020). Schon 2011 hatte 
die AG Dokumentarfilm angesichts der sich abzeichnenden Mehreinnahmen aus dem Rundfunkbeitrag vorgeschlagen, dass die Beitragszahler*innen zehn Prozent ihres Rundfunkbeitrags selbst auf verschiedene Medienangebote verteilen dürfen (AG Dokumentarfilm 2011). Diese neuen Angebote können sich dann an den Datenschutzstandards der großen Anbieter orientieren und deren Praxis übernehmen.

Es dient der gesellschaftlichen Meinungs- und Willensbildung, wenn es mehr Angebote gibt, die frei und unabhängig von den Interessen Dritter erstellt werden. Dabei geht es nicht nur um die Unabhängigkeit von direktem politischem oder wirtschaftlichem Einfluss. Es ist auch vielfaltsverengend, wenn man mit den eigenen Angeboten Geld verdienen muss und sie dafür zielgruppenorientiert optimiert. Dies schränkt die Freiheit des jeweiligen Medienunternehmens ein. Die Presse- beziehungsweise Medienfreiheit folgt eben anderen Regeln und Zielen als die Gewerbefreiheit. Ein beitragsfinanziertes Angebot kann anders agieren als eines, das sich auf dem Werbe-, Publikums- oder Datenmarkt behaupten muss. Deshalb sollte das Prinzip der Beitragsfinanzierung auch auf Angebote weiterer Mediengattungen ausgedehnt werden, wenn diese öffentlich-rechtlichen Standards genügen. So würden die Sender den Beitragszahler*innen, dem Datenschutz, der Vielfalt in der Gesellschaft und der öffentlichen Meinungs- und Willensbildung dienen.

Diese Idee wurde in ihren Grundzügen erstmals im Frühjahr 2014 veröffentlicht (Hilker und Kamann 2014). So blieben die Daten sowie auch die Spielregeln unter eigener Kontrolle und es könnte digitale Souveränität aufgebaut werden. Dazu sei eine »EU-weite technologische Lösung mit jeweils nationalen Ausgestaltungen « am sinnvollsten. Doch dürfe man die rechtlichen Hürden nicht unterschätzen. Vergleichbare Plattformvorhaben scheiterten in der Vergangenheit am Kartellrecht. So wurden sowohl die »Amazonas«-Plattform von ProSieben, Sat.1 und RTL als auch die öffentlich-rechtliche Plattform »Germany's Gold« von ARD und ZDF durch das Bundeskartellamt untersagt. Der Medienrechtler Tobias Gostomzyk (2018) fordert deshalb, »das Kartellrecht $[\ldots]$ als publizistisches Kartellrecht an die Bedingungen der Plattformökonomie anzupassen: Plattformbezogene Kooperation müsste möglich sein, wenn sie dem publizistischen Wettbewerb nicht schadet, aber wirtschaftliche Vorteile bringt.«

An dieser Stelle ist der Gesetzgeber gefordert. Der Bund muss das Wettbewerbsrecht entsprechend novellieren und gemeinsam mit den Ländern die Datenschutzstandards so anpassen, dass die öffentlich- 
rechtlichen Sender ihren Auftrag zur öffentlichen und individuellen Meinungs- und Willensbildung bestmöglich erfüllen können. Wenn der Gesetzgeber die Sender weiter im bisherigen Rahmen gefangen hält, werden diese bei der Erfüllung ihres demokratischen Auftrags zunehmend scheitern.

\section{Literatur}

AG Dokumentarfilm. 2011. Von der Rundfunkgebühr zur Haushaltsabgabe: Die historische Chance für Demokratie, Pluralismus und kulturelle Vielfalt!

Presseerklärung vom 20. Oktober, https://agdok.de/de_DE/von-der-rundfunkgebuehr-zur-haushaltsabgabe. Zugegriffen: 9. März 2021.

Arlt, Hans Jürgen, und Wolfgang Storz. 2010. Wirtschaftsjournalismus in der Krise. Zum massenmedialen Umgang mit Finanzmarktpolitik. Frankfurt am Main: OttoBrenner-Stiftung.

ARD. 2017. Auftrag und Strukturoptimierung des öffentlich-rechtlichen Rundfunks im digitalen Zeitalter. https://www.horizont.net/news/media/22/ARD-Bericht-218216.pdf. Zugegriffen: 9. März 2021.

Boehme-Neßler, Volker. 2018. Sie haben wirklich nichts zu verbergen? Die Zeit vom 31. Dezember, https://www.zeit.de/politik/2018-12/datenschutz-sicherheitueberwachung-privatsphaere-voraussetzungen-demokratie/komplettansicht. Zugegriffen: 9. März 2021.

Brosda, Carsten, und Wolfgang Schulz. 2020. Wir brauchen eine neue Medienpolitik. Faz.net vom 10. Juni, https://www.faz.net/aktuell/feuilleton/medien/aufruf-an-die-bundeslaender-wir-brauchen-eine-neue-medienpolitik-16808016. html. Zugegriffen: 9. März 2021.

BVerfG. 1966. Spiegel-Urteil des Bundesverfassungsgerichts. BVerfGE 20, 162. 05.08.1966. https://www.servat.unibe.ch/dfr/bv020162.html. Zugegriffen: 9. März 2021.

BVerfG. 1991. WDR-Urteil des Bundesverfassungsgerichts. BVerfGE 83, 238. 05.02.1991. https://www.servat.unibe.ch/dfr/bv083238.html. Zugegriffen: 9. März 2021.

BVerfG. 2007. Gebührenurteil II des Bundesverfassungsgerichts. BVerfGE 119, 181. 11.09.2007. https://www.bundesverfassungsgericht.de/SharedDocs/Entscheidungen/DE/2007/09/rs20070911_1bvr227005.html. Zugegriffen: 9. März 2021.

BVerfG. 2014. ZDF-Urteil des Bundesverfassungsgerichts. BVerfGE 136, 9. 25.03.2014. https://www.bundesverfassungsgericht.de/SharedDocs/Entscheidungen/DE/2014/03/fs20140325_1bvf000111.html. Zugegriffen: 9. März 2021.

BVerfG. 2018. Rundfunkbeitragsurteil des Bundesverfassungsgerichts. BVerfGE 149, 222. 18.07.2018. https://www.bundesverfassungsgericht.de/SharedDocs/ 
Entscheidungen/DE/2018/07/rs20180718_1bvr167516.html. Zugegriffen: 9. März 2021.

Giani, Paul Leo. 2013. Anreizsysteme fortentwickeln. In: Medien, Netz und Öffentlichkeit. Impulse für eine digitale Gesellschaft, herausgegeben von Marc Jan Eumann, Frauke Gerlach, Tabea Rößner und Martin Stadelmeier, 286-289. Essen: Klartext.

Gostomzyk, Tobias. 2020. Europas Traum von der Digitalmacht. Süddeutsche Zeitung vom 18. September, https://www.sueddeutsche.de/digital/europa-medienpolitik-gastbeitrag-gostomzyk-1.5034951. Zugegriffen: 9. März 2021.

Hilker, Heiko, und Uwe Kammann. 2014. Zeit für einen großen Wurf. Vocer.org vom 12. März, http://www.vocer.org/es-ist-zeit-fuer-den-grossen-wurf/. Zugegriffen: 9. März 2021.

Marx, Karl. 1842. Debatten über Preßfreiheit und Publikation der Landständischen Verhandlungen. Rheinische Zeitung Nr. 139 vom 19. Mai, http://www.mlwerke. de/me/me01/me01_028.htm. Zugegriffen: 9. März 2021.

Vaunet. 2019. Vaunet-Prognose zum Medienmarkt in Deutschland 2019. https:// www.vau.net/pressemitteilungen/content/vaunet-prognose-medienmarktdeutschland-2019-0. Zugegriffen: 9. März 2021.

\section{Open Access}

Dieser Beitrag erscheint unter der Creative-Commons-Lizenz CC BY-ND 3.0 DE: https://creativecommons.org/licenses/by-nd/3.0/de/. 


\title{
Gegen die Zwänge des Marktes: Konturen eines demokratischeren Mediensystems
}

\author{
Florian Zollmann
}

Keywords: Medienreformen, Krise des Journalismus, Demokratie, Markt, Kapitalismus

\section{Abstract}

Finanzeinbrüche, Redaktionsverschlankungen, Zusammenschlüsse: Auf lokaler Ebene gibt es kaum noch eigenständige Berichterstattung und der überregionale Journalismus hat seine pluralistische Vielfalt eingebüßt. Der Rundfunk ist durch eine zunehmende Boulevardisierung und Entpolitisierung gekennzeichnet. Das hat Folgen für die Demokratie: Von der Gesellschaft gewünschte Funktionen der Medien, wie Abbildung unterschiedlicher Meinungen, Wahrheitssuche oder objektive Informationsvermittlung, können kaum noch gewährleistet werden. Die Nachrichtenbranche befindet sich in einer Krise, deren Ursache in den Institutionen des kapitalistischen Marktsystems zu finden ist. Medienreformen sind daher dringend nötig. Ziel dieses Beitrages ist - neben einer kritischen Bestandsaufnahme des Journalismus - Visionen und Strategien für Medienreformen herauszuarbeiten, die von einer sozialen Bewegung eingeleitet und mit Blick auf die deutsche Medienlandschaft realisiert werden können. Darunter fallen folgende Aspekte: Konzentrationskontrolle, unabhängige Aufsicht und Überwachung journalistischer Standards, Demokratisierung der Presse- und Rundfunkräte, Aufbau und Finanzierung unabhängiger Nachrichtenmedien, öffentliche Kontrolle und journalistische Selbstverwaltung. Medienreform wird außerdem als Mediengerechtigkeit verstanden, die durch Prinzipien wie Egalitarismus und Demokratie sowie finanzieller und ökologischer Nachhaltigkeit charakterisiert sein sollte. 
Der Autor bedankt sich bei Nils S. Borchers, Kerem Schamberger und Werner Eiermann für konstruktive Kritik und wertvolles Feedback zu einer früheren Version dieses Textes.

Florian Zollmann: Gegen die Zwänge des Marktes: Konturen eines demokratischeren Mediensystems. In: Nils S. Borchers, Selma Güney, Uwe Krüger und Kerem Schamberger (Hrsg.): Transformation der Medien - Medien der Transformation. Verhandlungen des Netzwerks Kritische Kommunikationswissenschaft. Frankfurt am Main: Westend 2021. DOI: https://doi. org/10.53291/BQPE5410.

Dr. Florian Zollmann I Newcastle University, UK I florian.zollmann@ newcastle.ac.uk

\section{Einführung}

Natalie Fenton et al. $(2020,84)$ schreiben in ihrem Manifest für eine Medienreform, die Aufgabe von emanzipatorischen Sozialwissenschaften sei es, auf der Basis einer systematischen und kritischen Untersuchung des gegenwärtigen Gesellschaftszustands Alternativen zu entwickeln. ${ }^{1}$ Ihnen geht es darum, zunächst die Handlungslogiken von existierenden Medienorganisationen sowie die Funktionen der wesentlichen Institutionen innerhalb der politischen Ökonomie der Medienindustrie zu erfassen und ihre Defizite herauszuarbeiten (ebd.). Aufbauend auf dieser Kritik des Status quo, welche die Legitimität von Medienmacht in Frage stellt, können dann die Strukturen eines neuen Mediensystems und Strategien der Medienreform entwickelt werden (ebd.). In diesem Sinn beleuchtet der anschließende Abschnitt zunächst die Ursachen der Krise des Journalismus in Deutschland. Darauf folgt eine kritische Analyse der Institutionen der kapitalistischen Medienindustrie. Der Hauptteil stellt im Anschluss kurz-, mittel-, und langfristig realisierbare Visionen und Strategien für Medienreformen vor. Abschließend werden die Konturen eines demokratischeren Mediensystems, das vielfältigen Akteur*innen der Zivilgesellschaft Zugang zu Medien gewährt und von der Gesellschaft gewünschte Funktionen der Nachrichtenmedien wie Meinungsvielfalt, Wahrheitssuche oder objektive Politik- und Informationsvermittlung leisten kann, aufgezeigt.

1 Fenton et al. $(2020,84)$ beziehen sich hier insbesondere auf Erik Olin Wright. 


\section{Die Krise des Journalismus}

In seiner Festrede zur Verleihung der Otto-Brenner-Preise für kritischen Journalismus am 19. November 2018 in Berlin warnte Armin Wolf, stellvertretender ORF-Chefredakteur, vor einer »Krise des Journalismus«, die ein Symptom darstelle »für etwas noch viel Bedrohlicheres, für eine Krise der Demokratie« (2019). Er verwies auf das traditionelle Geschäftsmodell des Journalismus, das darauf beruht, Publikum an die Werbeindustrie zu verkaufen sowie auf einen zunehmenden Einfluss der Politik auf die Pressefreiheit. Dieses System Journalismus sei durch die Digitalisierung und durch Einschnitte in die Pressefreiheit in seinen Grundfesten erschüttert worden (ebd.).

Das Internet hat den bereits durch Kürzungen gebeutelten Zeitungsunternehmen die Existenzgrundlage weiter entzogen. Denn die werbetreibende Industrie bucht Werberaum und -zeit immer weniger in Nachrichtenmedien, sondern auf digitalen Plattformen wie Facebook und Google (Barthel 2018). Um ein Beispiel zu nennen: 1999 verdienten deutsche Tageszeitungen netto noch etwa sechs Milliarden Euro an Werbeschaltungen, 2019 waren es nur noch knapp über zwei Milliarden Euro (Röper 2020, 333). Solche Einnahmeverluste erhöhen den wirtschaftlichen Druck auf Zeitungsunternehmen und müssen mittels Verkaufserlösen, Mehrfachverwertung von Inhalten und Redaktionsabbau kompensiert werden. »Die stetig sinkenden Gesamteinnahmen führen seit Jahren zu Einsparungen in allen Bereichen«, schreibt Horst Röper (ebd.) im aktuellen Bericht zur Konzentration der Tagespresse. Demnach gibt es eine voranschreitende »Ausdünnung des lokalen Zeitungsangebots«, die zur Folge hat, dass »die Pressevielfalt mehr und mehr « eingeschränkt wird (ebd., 331). Auf überregionaler Ebene gestaltet sich die Zeitungsberichterstattung des Weiteren »immer uniformer, «enn Verlage verzichten auf eigenständige Hauptredaktionen zugunsten von Gemeinschaftsredaktionen, Mantelproduktionen oder Zulieferungen anderer Verlagshäuser (ebd., 332-333).

Das deutsche Rundfunksystem ist von den ökonomischen Folgen der Digitalisierung bisher weniger stark betroffen als die Zeitungsverlage: Die jährlichen Nettowerbeumsätze, die hauptsächlich dem privaten Fernsehen zugutekommen, liegen seit 2007 relativ gleichbleibend bei etwa vier Milliarden Euro (Ferschli, Grabner und Theine 2019, 10); die Finanzierung der Öffentlich-Rechtlichen ist durch den Rundfunkstaatsvertrag gewährleistet. Aber auch der Rundfunk ist dem ökonomischen Diktat der Wirtschaft unterworfen, mit Folgen für die Programmstruk- 
tur und Inhalte. Zahlreiche Studien belegen übereinstimmend, dass die öffentlich-rechtlichen Fernsehnachrichten die Qualität der Privaten in Sachen Umfang und gesellschaftspolitischer Relevanz deutlich übersteigen (für einen Überblick Daschmann 2009, 260-264; vgl. Betz 2015). Der Journalismus der privaten Vollprogramme legt mehr Wert auf Unterhaltung und Emotionen, tendenziell lässt sich eine »Marginalisierung der politischen Nachrichtengebung « konstatieren (Weiß 2007, 61). Gregor Daschmann $(2009,264)$ ist daher der Auffassung, dass ohne öffentlich-rechtliche Nachrichtenprogramme »derzeit die von der Gesellschaft eingeforderte Qualität des Fernsehnachrichtenangebotes in Deutschland nicht mehr gewährleistet« ist. Allerdings sollten Vergleiche nicht darüber hinwegtäuschen, dass sich der Journalismus des öffentlich-rechtlichen Rundfunks seit der Einführung des »dualen Systems « dem der Privaten annähert. Wolfgang Donsbachs und Katrin Büttners $(2005,34)$ Untersuchung der öffentlich-rechtlichen und privaten Fernsehnachrichten von ARD, ZDF, Sat1 und RTL aus den Jahren 1983, 1990 und 1998 kommt zu dem Ergebnis:

Tendenzen zu einer stärker boulevardesken Darstellung der Politik in den Fernsehnachrichten sind unverkennbar. Sie zeigen sich auf allen Ebenen der Boulevardisierung, also in den Inhalten, dem Stil und der Aufmachung. In einzelnen Dimensionen haben sich sogar dramatische Entwicklungen vollzogen, zum Teil bei allen Anbietern, zum Teil nur bei den Privaten.

Demnach ist das Volumen politischer Themen stark gesunken und die Berichterstattung enthält zunehmend personenbezogene, emotionale, skandalträchtige, sensationelle und spekulative Elemente (ebd., 34). Diese Merkmale sind zwar einerseits bei den privaten stärker ausgeprägt als bei den öffentlich-rechtlichen Sendern, andererseits sind die Befunde der Studie von Donsbach und Büttner aber »eher pessimistisch «, was die »Qualität medialer Vermittlung von politischer Wirklichkeit« sowie die »Erfüllung öffentlicher Aufträge durch die Fernsehsender« angeht (ebd., 34-35):

Politik wird offensichtlich immer seltener Gegenstand von Nachrichten, und sie wird, wenn sie vorkommt, zunehmend in einer Art und Weise präsentiert, die sie möglicherweise dem breiten Publikum schmackhafter und konsumierbarer macht, die aber immer weniger in der Lage ist, ein kohärentes und wirklichkeitsadäquates Bild zu zeichnen. (ebd., 35)

Ein Gutachten für die Linke-Fraktion im Bundestag von Jörg Becker et al. (2007) bilanziert dann auch einen allgemeinen Qualitätsverlust bei 
den Öffentlich-Rechtlichen. Demnach verzeichneten ARD und ZDF schon seit Beginn ihres Sendestarts einen Rückgang bei den Informationssendungen (ebd., 12). Die Forscher stellen außerdem eine Abnahme von Sendungen mit politischen Themen zugunsten eines "Anstiegs an Boulevardisierung « (ebd.) fest. Ähnlich wie Donsbach und Büttner kommen Becker et al. zu dem Schluss, dass diese Entwicklungen eine »erhebliche Relevanz für den Grundversorgungsauftrag des öffentlich-rechtlichen Rundfunks« haben (ebd.).

Dazu kommt eine Politisierung der für Programmkontrolle und Rundfunkaufsicht zuständigen Rundfunk- und Fernsehräte (ebd., 3031). Den Gremien mangelt es oft an professioneller Fachkompetenz, Effektivität und externer Kontrolle; des Weiteren haben die politischen Parteien überproportionalen Einfluss, sodass viele Rundfunk- und Fernsehräte ihrer Kontrollfunktion kaum noch nachkommen können (ebd.; Deutscher Bundestag 2009, 9-10). Letzteres bestätigt auch eine Studie zur Zusammensetzung der Rundfunkräte des Rundfunks BerlinBrandenburg (RBB), des Bayerischen Rundfunks (BR) und von Radio Bremen (RB) durch die Zeitschrift Liberal, die von der FDP-nahen Friedrich-Naumann-Stiftung herausgegeben wird. Die Mehrheit aller Mitglieder (zwischen 58 und 67 Prozent) der untersuchten Rundfunkräte waren entweder Staatsvertreter*innen und Vertreter*innen von Kommunen sowie staatlichen Einrichtungen oder Entsandte von Institutionen, die staatliche Finanzhilfe empfangen (Eichler 2013, 84-87). »Der Rundfunk in Deutschland ist vom Ziel der Staatsferne weiter entfernt denn je«, heißt es in der Studie, »[d]enn die unabhängigen Vertreter der sogenannten sgesellschaftlich relevanten Gruppen werden oft von Institutionen entsandt, die von staatlicher Finanzierung abhängig sind« (ebd., 84).

Zusammenfassend kann festgehalten werden: Der Substanzverlust des Zeitungssektors sowie die Boulevardisierung und Instrumentalisierung des Rundfunks haben auf allgemeiner Ebene zu einer Synchronisierung des Journalismus geführt. Wie Marcus Klöckner $(2019,158)$ beobachtet, »erblinden die Wächter der Demokratie zunehmend und werden immer unfähiger, zentrale politische Weichenstellungen mit dem notwendigen Druck und auch mit der notwendigen Schärfe zu kritisieren«.

Der zunehmende Qualitätsverlust der Nachrichten ist auch ein Resultat der Triebkräfte und Einflusselemente der kapitalistischen Produktionsweise $(\mathrm{kPw})$, denen Journalist*innen und Nachrichtenmedien genauso wie Werbetreibende, Manager*innen und Medieneigen- 
tümer*innen als Teil der Industrie unterworfen sind (Knoche 2013, 91). Nach Manfred Knoche fallen darunter »die strukturell bedingten Mechanismen « der kapitalistischen Medienproduktion: Profitmaximierung auf Basis von Privateigentum an Produktionsmitteln, Mehrwertproduktion, Konkurrenz und Kapitalakkumulation (ebd.). Sie begrenzen den Handlungsspielraum von Medienorganisationen und ziehen auch die öffentlich-rechtlichen Sender in ihr Einflussfeld (ebd.). Knoche (ebd., 92) hat diesen Prozess wie folgt beschrieben:

Aus der Sicht der Kapitaleigner kommt es deshalb auch elementar darauf an, durch geeignete Modifikationen der kPw gegen ihre Interessen gerichtete Transformationen zu verhindern. Sie initiieren stattdessen grundsätzlich nur Restrukturierungen und Transformationen, mittels derer die Kapitalverwertung optimiert sowie das Kapitalverhältnis und die kapitalistische Gesellschaftsformation gesichert werden. Vorangetrieben wird damit der Prozess der formellen und reellen Subsumtion der Gesellschaft unter das Kapital. (Hervorhebung im Original)

Das heißt: Kapitalverschiebungen durch die Werbetreibenden weg von Nachrichtenmedien hin zu Internetmonopolisten machen aus unternehmerischer Perspektive Sinn, da Google und Facebook einen direkteren Zugang zu klar definierten Zielgruppen bieten. Eigentümer*innen und Leiter*innen von Zeitungsunternehmen sind dazu gezwungen, Werbeverluste auch durch Redaktionsverschlankung und Rationalisierung der journalistischen Arbeitsweise zu kompensieren. Die Boulevardisierung und Entpolitisierung der Fernsehnachrichten resultieren ebenfalls aus dem Wettbewerb zwischen öffentlich-rechtlichen und privaten Rundfunkanstalten, bei dem es für die Manager*innen und Kapitaleigner*innen um Reichweiten geht. Obwohl die Politisierung der Rundfunkräte kein direktes Resultat der $\mathrm{kPw}$ darstellt, führt sie auch zu einer weiteren Entfesselung der kapitalistischen Handlungslogik innerhalb des öffentlich-rechtlichen Rundfunks. Denn die bürgerlichen Parteien, die dort einen überproportionalen Einfluss ausüben, befinden sich im Griff der $\mathrm{kPw}$. Das zeigt ein Blick auf die derzeitige Medien- und Wirtschaftspolitik, die sich vor allem durch Privatisierung, Deregulierung und Konzentrationsförderung kennzeichnet (vgl. Knoche 2013, 91).

Was bei diesen Prozessen auf der Strecke bleibt, ist das von der Gesellschaft geforderte öffentliche Gut: Für den Journalismus sind nur noch unzureichend Ressourcen und Anreize vorhanden. Der britische Journalist Nick Davies hat in einer Studie gezeigt, wie die Realität im Geburtsland des Kapitalismus heute aussieht: Journalist*innen müssen im 
Durchschnitt 48 Berichte pro Woche schreiben, das sind 9,6 an einem Tag $(2009,59)$. Die Arbeit wird hauptsächlich vom Schreibtisch aus erledigt: Von 45,5 Arbeitsstunden pro Woche entfallen lediglich drei auf Recherchen »außer Haus«, während denen sich Journalist*innen im Durchschnitt mit vier Interviewpartnern*innen treffen (ebd.). Als Ergebnis dieser Arbeitsverhältnisse bestehen 60 Prozent aller Nachrichtenbeiträge der Qualitätsmedien hauptsächlich aus Agentur- oder PR-Material (ebd., 52). Davies (2008) macht eine fortschreitende Kommerzialisierung für diesen Zustand verantwortlich: Kürzungen in den Redaktionen durch die Finanzplaner*innen der Konzerne hätten Journalist*innen zu passiven Verarbeiter*innen von Informationen aus zweiter Hand gemacht. Daher fänden sich heute selbst die besten und anständigsten ihrer Zunft in einer Art Käfig gefangen (ebd.). Medienökonomisch gesprochen ist diese Aushöhlung des Journalismus, die auch in Deutschland weit vorangeschritten ist, als ein externer Effekt des Marktes anzusehen.

\section{Institutionen der kapitalistischen Medienindustrie}

In diesem Abschnitt werden auf Basis der kritischen politischen Ökonomie der Medien (Curran 2002; Ferschli, Grabner und Theine 2019; Herman 1995; 1999; Knoche 2013; McChesney 2008; Zollmann 2009; 2017) und der Medienökonomie (Heinrich 2002; Kiefer 2001) die relevanten Institutionen aufgezeigt und deren Probleme für die Nachrichtenproduktion veranschaulicht. Diese Vorgehensweise verdeutlicht den Zusammenhang zwischen der Krise des Journalismus und den kapitalistischen Strukturen der Nachrichtenmedien.

\section{1 Privateigentum/Konzernstruktur/Profit}

Die zehn größten deutschen Medienunternehmen sind als privatwirtschaftlich agierende Medienkonzerne (Kapitalgesellschaften) organisiert, die von einzelnen Familien oder einem Familiengeflecht kontrolliert werden. Die beiden einzigen Ausnahmen bilden die ProSiebenSat.1-Gruppe, deren Anteile verschiedenen internationalen Finanzinvestoren gehören, und der gebührenfinanzierte, öffentlichrechtliche Rundfunk (Ferschli et al. 2019, 23-24). Die meisten Zeitungsverlage außerhalb der Top 10 der Medienunternehmen sind ebenfalls als private Konzerne organsiert. 
Auf einer allgemeinen Ebene sind Konzerne im Kapitalismus als Institution juristisch dazu verpflichtet, ihrem eigenen organisatorischen und nicht etwa dem gesellschaftlichen Gemeinwohl zu dienen (Bakan 2005, 1-2). Das bedeutet: Medienkonzerne müssen in erster Linie, und im Sinne ihrer Anteilseigner*innen, Profite maximieren. Journalistische und andere von der Gesellschaft an die Medien gestellte Imperative sind nicht Teil der Handlungslogik und bestenfalls als sekundär zu betrachten. Wenn Medienunternehmen zu Konglomeraten fusionieren, Redaktionen zusammenschließen, auf Mantelproduktion umsteigen, Arbeitsabläufe rationalisieren oder Personal abbauen, ist das aus unternehmerischer Perspektive sinnvoll, weil dabei gemäß der institutionellen Handlungslogik Profite generiert werden (für eine allgemeine Diskussion dieser Sachverhalte mit Blick auf die Handlungslogik von Konzernen vgl. Bakan 2005; Zollmann 2017).

Konzerneigentümer*innen und Manager*innen sind außerdem Teil der Wirtschaftsgemeinde, sie verkehren in gemeinsamen Gremien und sozialen Kreisen. Durch Anteilseignung und Kreditvergabe nehmen andere Unternehmen und Banken Einfluss auf Medienkonzerne. Interessenkonflikte werden durch solche Verflechtungen institutionalisiert (Zollmann 2009, 112).

\subsection{Markt und Wettbewerb}

Konzernmedien verkaufen ihre Medienprodukte auf zwei Märkten: an die Werbeindustrie und an Rezipient*innen. Diese nehmen auf verschiedenen Ebenen Einfluss auf die Nachrichtenproduktion:

\section{Kosteneffizienz}

Einerseits stehen Nachrichtenmedien konstant unter Druck, möglichst kostengünstig zu produzieren, und sind ökonomischen Schwankungen wie auch Krisen ausgesetzt. Andererseits kosten journalistische Recherchen zu politischen oder wirtschaftlichen Themen teures Geld: Personal-, Zeit- und Rechercheaufwand sowie das Risiko, verklagt zu werden, müssen einkalkuliert werden. Marktwirtschaftliche Zwänge veranlassen die Eigentümer*innen und Manager*innen von Nachrichtenorganisationen dazu, eine publizistische Strategie zu wählen, die es ermöglicht, die Kosten zu minimieren. Diese Tendenz wird durch das in Medienkonzernen institutionali- 
sierte Profitimperativ verstärkt. PR- und Agenturmaterial erhält daher Vorrang vor investigativen Recherchen zu sensiblen Themen (Zollmann 2017, 40).

Die im letzten Abschnitt angesprochenen Einbrüche im Werbemarkt haben den ökonomischen Wettbewerb um Werbekund*innen und Leser*innen verschärft. Viele Zeitungsverlage mussten ihre Verkaufspreise anheben, um Verluste zu kompensieren, was wiederum die Gefahr, Käufer*innen zu verlieren, nach sich zog (Röper 2020, 333). Gleichzeitig haben sie seit Jahren mit Auflagenrückgang und sinkenden Gesamteinnahmen zu kämpfen (ebd., 331-333). Das alles begünstigt weitere Einsparungen, die zu Lasten der journalistischen Qualität gehen. Die Gravitation des Marktes und der Wettbewerb mit den Privaten beeinflussen auch die öffentlich-rechtlichen Sender. Die in Abschnitt 2 untersuchte Boulevardisierung und Entpolitisierung der Fernsehnachrichten sind ebenfalls auf Marktzwänge zurückzuführen, denn boulevardeske Nachrichten sind kostengünstig und versprechen hohe Reichweiten.

\section{Konzentration}

Eine weitere durch Marktzwang begünstigte Strategie von Medienkonzernen ist, über Zusammenschlüsse und Fusionen Größenvorteile zu erlangen. Das erlaubt es, Inhalte mehrfach zu verwerten und anderen Anbietern den Zutritt zum Werbe- und Publikumsmarkt zu erschweren.

Die Struktur aller deutschen Medienmärkte weist ein hohes Maß an Konzentration auf und kann als ein Oligopol bezeichnet werden. Auf lokaler und regionaler Ebene gibt es sogar Monopole im Zeitungssektor. Das bedeutet: Wenige große Unternehmen beherrschen die Medienmärkte im Presse-, Rundfunk- und Onlinesektor auf Seite der Anbieter und Rezipient*innen (Ferschli et al. 2019, 12). Diese so gut wie alle kapitalistischen Mediensysteme kennzeichnende Konzentration hat schwerwiegende Folgen für die publizistische Vielfalt (Fenton et al. 2020, 85; Leidinger 2003). Liberale Pressetheorien gehen davon aus, dass eine freie Meinungsbildung nur dann möglich ist, wenn Rezipient*innen vielfältige Meinungen und Informationen zur Verfügung stehen (Alexander 1981). Dieses Prinzip wird durch Medienkonzentration ausgehebelt, denn die als Oligopolisten agierenden Konzerne bieten lediglich eine ideologisch begrenzte Menge von »Meinungsoptionen « zur Auswahl (Herman 1999, 295). Dadurch fallen eine Vielzahl von Positionen unter den Tisch und der freie Austausch von Informationen wird behindert. 
Auch agieren Oligopolisten durch ihre Werbereichweiten und crossmedial aufgebauten Portfolios als Marktschranken. Ein wichtiges Beispiel ist das Internet, in dem professionelle journalistische Angebote überwiegend von traditionellen Medienunternehmen erstellt werden (siehe Lobings und Neuberger 2018, 65, 160). Dort gibt es also so gut wie keine relevanten und reichweitenstarken journalistischen Anbieter, die nicht Teil der krisenhaften, oligopolistischen Struktur der Nachrichtenmedien sind (siehe Abschnitt 2).

\section{Ausgrenzung von Zielgruppen}

Marktabhängigkeit hat auch direkte ideologische Effekte für die Medieninhalte. Auf dem Zuschauer*innenmarkt werden eher wohlhabendere Zielgruppen, insbesondere Akademiker*innen und professionelle Eliten, anvisiert. Diese Marktsegmente können sich den Verkaufspreis leisten und werden von der Werbeindustrie wegen ihrer Kaufkraft bevorzugt. Die Lebenswelten von Arbeiter*innen, Minderheiten oder Geflüchteten finden daher kaum Berücksichtigung.

Die Werbeindustrie fungiert außerdem als indirekte Lizensierungsaufsicht der privaten Medien (Curran 2002, 96), da Werbekund*innen nur in solchen Nachrichtenmedien Werbung schalten, deren Medieninhalte ihren ideologischen Präferenzen entsprechen (Herman 1995, 169). Historisch hatte das zur Folge, dass Medienunternehmen, die inhaltlich die Interessen der Arbeiterklasse vertraten und ein großes Publikum ansprachen, vom Markt verdrängt wurden, weil sie nicht genug Werbeeinnahmen akquirieren konnten (Curran 2002, 81-103).

\section{Externe Effekte}

Nachrichten sind sogenannte öffentliche oder meritorische Güter, deren Allokation über Märkte zu externen Effekten führt. Diese umfassen, was die Medien angeht, Boulevardisierung, Entpolitisierung oder Fehlinformierung.

Idealtypisch sollten Angebot und Nachfrage die Produkte an die Präferenzen der Rezipient*innen anpassen und eine optimale Versorgung bieten. Weil Nachrichten aber ständig neu produziert werden, fehlt den Rezipient*innen das relevante Wissen, um die Qualität und Richtigkeit der Nachrichten überprüfen zu können (Kiefer 2001, 136-139). Anders ausgedrückt: Wenn Nachrichten eine bestimmte ideologische Sichtweise hervorheben, über wichtige Ereignisse überhaupt nicht berichten oder zu wenig Informationen liefern, ist das als Rezipient*in nur schwer nachvollziehbar. Diese Mängel führen bei öffentlichen Gütern 
dazu, dass keine ausreichende Bandbreite an relevanten Informationen angeboten wird. Daher kommt es zu externen Effekten, im Zuge derer die Rezipient*innen nur ungenügend oder sogar fehlinformiert werden. Deshalb ist es in der Medienökonomie unumstritten, dass ein Marktsystem nicht in ausreichendem Maße die Produktion und Konsumption meritorischer Güter wie Nachrichten gewährleisten kann (Heinrich 2002, 46; Kiefer 2001, 136-148). Jürgen Heinrich (2002, 46) argumentiert beispielsweise, dass die Produktion von Öffentlichkeit, Meinungsvielfalt, Wahrheit und gesellschaftlicher Normen »nicht dem Markt überlassen« werden sollte. Denn diese Bereiche »sind nur jenseits der Kategorien von Gebrauchswert und Tauschwert zu bewerten «, liegen »mithin normativ jenseits der Wirkungsweise des Wettbewerbs « und sind seiner theoretisch fundierten ökonomischen Analyse im Grunde nicht zugänglich« (ebd.).

Die Gesellschaft muss daher eingreifen, um eine Grundversorgung mit Nachrichten oder politischen Themen zu gewährleisten.

\subsection{Produktionsverhältnisse und professioneller Journalismus}

Die hier dargelegten Institutionen und Tendenzen definieren die Produktionsverhältnisse in der kapitalistischen Medienindustrie. Die kritische politische Ökonomie sieht des Weiteren diese »Produktionsverhältnisse als Herrschaftsverhältnisse und darauf basierendes Handeln im Interesse der Kapitaleigner als bestimmende Triebkraft für die Entwicklung der Produktivkräfte (Produktionsmittel und Arbeit)« (Knoche 2013, 94).

Das heißt: Professionelle Journalist*innen müssen sich diesen institutionellen Zwängen anpassen. Die Unabhängigkeit und Integrität des Journalismus sollen zwar durch eine Berufsethik und einen professionellen Kodex gewährleistet werden, aber - wie zahlreiche Studien belegen - ist es in der Realität kaum möglich, der Marktlogik zu entkommen (Zollmann 2009; 2017 für einen Überblick). Daher muss eine Reform an den Wurzeln ansetzen und die Strukturen der Medien verändern. 


\section{Visionen und Strategien der Medienreform}

Im Folgenden wird erläutert, von welchen normativen Werten eine Medienreformbewegung geleitet sein sollte und mit was für kurz-, mittel-, und langfristigen Maßnahmen sich strukturelle Reformen umsetzen lassen. ${ }^{2}$ Eine Transformation der Medien ist notwendig, damit von der Gesellschaft gewünschte Funktionen des Journalismus, wie Meinungsvielfalt, Wahrheitssuche oder objektive Informationsvermittlung, gewährleistet werden können.

\subsection{Normativer Werterahmen: Medienreform bedeutet Mediengerechtigkeit}

Der Begriff »Reform « sollte zum weiteren Verständnis kurz beleuchtet werden. Denn die hier vorgestellten Werte und Maßnahmen haben nichts mit den in den letzten Jahrzehnten in vielen Demokratien durchgeführten neoliberalen »Reformen«, die einen technokratischen Charakter hatten mit dem Ziel, kosmetische Veränderung oder Privatisierungen von Medien durchzuführen, zu tun (Fenton et al. 2020, 28). Fenton et al. schlagen daher vor, nicht von Medienreform, sondern von Mediengerechtigkeit zu sprechen. Darunter fallen »underlying struggles of class, gender and race that are at stake when we talk about the need for more balanced, pluralistic, representative, accurate and accountable sources of news and information, or a more accessible, diverse and participatory system of cultural production « (ebd.).

Diese Sichtweise impliziert, dass auf marktwirtschaftlichen Annahmen basierende Ansätze der Transformation der Medien fehlgeschlagen sind und nicht einmal in der Lage waren, liberale Basisziele wie die Gewährleistung von Wettbewerb und Privatsphäre oder Vielfalt und Freiheit zu erreichen (ebd.). Mediengerechtigkeit versucht demnach,

2 Hier wird im Wesentlichen auf eine Reform der Nachrichtenmedien und des Journalismus eingegangen. Reformen von nichtjournalistischen Medien insbesondere im Internet (Soziale Medien, Suchmaschinen, Buchhandel und weitere) werden hier aus forschungsökonomischen Gründen nicht direkt berücksichtigt. Sicherlich sollte eine umfassende Medienreform auch bei den Internetkonzernen ansetzen, die quasi als Monopolisten agieren und bei der Nachrichtenverbreitung eine Rolle spielen. Einige der hier vorgeschlagenen Reformmaßnahmen (zum Beispiel die Konzentrationskontrolle und Besteuerung von Werbung) könnten dort ebenfalls angewandt werden. 
nicht nur Abhilfe gegen die in Abschnitt 2 beschriebene Aushöhlung des Journalismus zu schaffen, sondern auch Machtungleichheiten zu beseitigen, die auf Kosten von Arbeitern*innen, Frauen und Minderheiten gehen. Die sich aus Kapitalismus und Marktlogik ergebene Akkumulation von Macht in der Hand weniger Konzerne und Eigentümer*innen ist aus dieser Perspektive ein Kernproblem der Medien (ebd., 28-29). Daher müssen, wie Fenton et al. abschließend argumentieren, Strategien der Medienreform von Prinzipien wie Egalitarismus, Gerechtigkeit und Demokratie sowie finanzieller und ökologischer Verantwortung geleitet werden und als Teil von visionären und emanzipatorischen Bewegungen der Zivilgesellschaft, die für soziale, politische, wirtschaftliche und ökologische Transformation einstehen, ablaufen (ebd., 84).

\subsection{Verzahnung von Visionen und Strategien des Medienwandels}

Zusätzlich zu visionären Überlegungen bezüglich der institutionellen Basis eines reformierten Mediensystems brauchen Reformbestrebungen eine Strategie, wie Veränderungen realistisch erreicht werden können. Außerdem gilt es zu evaluieren, welche bewährten Aspekte des Mediensystems beizubehalten und welche zu verändern oder auszutauschen sind (McChesney 2008, 491). Medienreformbestrebungen enthalten daher ein Bündel von kurz-, mittel- und langfristig durchsetzbaren transformativen, visionären und strategischen Elementen. Darauf aufbauend sollten die Konturen neuer Institutionen entwickelt und in die Langzeitstrategie für Medienwandel integriert werden. Auch muss die Medienreformbewegung kontinuierlich ihre Visionen und Strategien evaluieren und gegebenenfalls revidieren und erneuern.

Die hier vorgeschlagene Medienreform hat zum Ziel, positive Aspekte des bestehenden Fundaments der Medien zu stärken und nicht einzureißen. Sie baut auf existierende normative und gesetzliche Rahmenbedingungen der Presse und des Rundfunks auf. Dazu gehören beispielsweise die ethischen Standards des Journalismus wie der vom Presserat erstellte Pressekodex, die beibehalten und erweitert werden sollten. Gleiches gilt für den Auftrag des öffentlich-rechtlichen Rundfunks, der sich aus dem Grundgesetz und Rundfunkstaatsvertrag ergibt und wichtige Momente wie »Grundversorgung «, »Ausgewogenheit« oder »Überparteilichkeit« enthält. 
Die Medienreform vollzieht sich, ähnlich wie andere gesellschaftliche Transformationen, als ein langfristiger Prozess, der von sozialen Bewegungen, Zivilgesellschaft, Wissenschaft und Regulierungsbehörden mit dem Ziel vorangetrieben werden muss, die Politik zum Handeln zu bewegen (McChesney et al. 2005). Wie die Arbeit von Mandy Tröger $(2019,117,133)$ zeigt, folgt die ordnungspolitische Regulierung (und die Kommunikationswissenschaft) in Deutschland allerdings einem ideologischen Mantra, das Pressefreiheit mit privatwirtschaftlicher Organisation gleichsetzt. Demnach ermöglicht Medienpolitik Transformationen, wenn diese mit Privatisierung und Kommerzialisierung einhergehen. Auf der anderen Seite stoßen Reformvorschläge, die mehr öffentliche Kontrolle der Medien fordern, auf Widerstand. Denn Ordnungspolitik wird von der neoliberalen Doktrin geleitet und Medienkonglomerate sind in der Lage, die Politik in ihrem Interesse zu beeinflussen und mitzugestalten.

Daher können die hier vorgeschlagenen Reformmaßnahmen, die öffentlich finanzierte Medien substanziell stärken möchten, nur durch Unterstützung einer starken Medienreformbewegung umgesetzt werden. Um substantielle Veränderungen zu erreichen, muss ein öffentliches Bewusstsein dafür geschaffen werden, warum eine Reform nötig ist (Stichwort: Krise des Journalismus) und welche Strategien dabei helfen, diese politisch umzusetzen (McChesney 2005, 12-13). Zivilgesellschaftliche Akteur*innen, die als Vermittler*innen der Medienreform auftreten, sollten außerdem in der Lage sein, Debatten zu framen und medienpolitische Entscheidungen anzustoßen. Das muss insbesondere auf Länderebene geschehen, weil dort wichtige Aspekte der Mediengesetzgebung stattfinden, sollte aber auch auf Bundesebene ablaufen, damit Kernreformen länderübergreifend umgesetzt werden können.

Grundsätzlich sollten die Reformbestrebungen auch im Medienrecht verankerte Anweisungen von Regulierungsstellen zur Hilfe nehmen. Denn wichtige Normen, zum Beispiel zur Vielfaltssicherung, sind bereits durch das Bundesverfassungsgericht, den Europäischen Gerichtshof und in Rundfunkstaatsverträgen kodifiziert (KEK 2018, 46-48). Die Kommission zur Ermittlung der Konzentration im Medienbereich (KEK) hat Gutachten zur Konzentrationskontrolle inklusive zeitgemäßer Reformanweisungen verfasst, welche die Gesetzgeber*innen aber bestenfalls schwerfällig umsetzen (ebd., 488-498). Eine entsprechende Bewegung kann sich diese Instrumente zu eigen machen: Wenn es gelingt, genug öffentlichen Druck auf die Politik aufzubauen, kön- 
nen die von diesen Institutionen bereits vorgebrachten Reformansätze realisiert werden. ${ }^{3}$

\subsection{Kurz- und mittelfristige Medienreformmaßnahmen}

Im Folgenden werden Reformmaßnahmen aus ausgewählten Studien (Becker et al. 2007; Beiler und Krüger 2018; Fenton et al. 2020; Herman 1999; KEK 2018) herausgearbeitet, die kurz- und mittelfristig eingeleitet und mit Blick auf die deutsche Medienlandschaft realisiert werden können. Medienreformen werden demnach unter den folgenden Aspekten zusammengefasst: Konzentrationskontrolle, unabhängige Aufsicht und Überwachung journalistischer Standards, Demokratisierung der Rundfunkräte sowie Aufbau und Finanzierung unabhängiger Nachrichtenmedien.

\section{Konzentrationskontrolle}

Die Schaffung einer medienübergreifenden Konzentrationskontrolle (Gesamtmarktmodell) unter Aufsicht der KEK ist dringend erforderlich. Sie bemerkte diesbezüglich in ihrem letzten Gutachten, dass die derzeitige Umsetzung lediglich am Zuschauer*innenmarkt des privaten Fernsehens ansetze, es aber einer Betrachtung des Gesamtmedienmarktes bedürfe, um allen »meinungsbildenden Faktoren Genüge zu tun« und die »adäquate Erfassung und Bewertung von Verflechtungen« zu ermöglichen (KEK 2018, 492-493). Die in Abschnitt 3.2 angesprochenen Konzentrationstendenzen, die sich auf alle Mediensektoren übergreifend erstrecken, müssen in diesem Sinne entschärft werden. Dafür bedarf es auch der Erstellung neuer Richtlinien, ab welchem Grad Verflechtungen der Meinungsbildung abträglich sind. Denn die

3 Natürlich sollten Akteur*innen der Medienreformbewegung die rechtlich und regulativ kodifizierten Medienreformvorschläge auch evaluieren und gegebenenfalls Debatten anstoßen, wie diese im Sinne von Mediengerechtigkeit zu verbessern wären. Ein Beispiel einer Reformbewegung ist die britische »Media Reform Coalition« (MRC), ein Zusammenschluss aus Wissenschaftler*innen, politischen Aktivist*innen und Gruppen der Zivilgesellschaft, der das gemeinsame Ziel einer progressiven Medienreform verfolgt (Fenton et al. 2020, 7). Die MRC erstellt Analysen zur Medienkonzentration, engagiert sich bei öffentlichen Veranstaltungen, bietet Lageberichte für parlamentarische Untersuchungen und entwickelt Vorschläge, wie die Medien im öffentlichen Interesse verbessert werden können. 
Instrumente und Richtwerte der derzeitigen Konzentrationskontrolle können im Licht des realen Ausmaßes kaum als ausreichend bezeichnet werden. ${ }^{4}$

Konzentrationskontrolle ist des Weiteren unzureichend, wenn sie nur "passiv«, also bei zu hohen Konzentrationswerten, greift. Das heißt: Vielfalt sollte nicht nur im Hinblick auf die Zahl der Anbieter gesichert werden; Konzentrationskontrolle muss auch »aktiv« eine reichhaltige Medienlandschaft fördern. Das kann durch die Etablierung neuer öffentlich-rechtlicher, unabhängiger (gemeinnütziger) und privater Anbieter auf lokaler, regionaler und nationaler Ebene geschehen (Fenton et al. 2020, 86). Auch hierzu sagte die KEK (2018, 493): »Effektive Vielfaltsicherung ist gleichermaßen negativ abwehrend und positiv gestaltend anzulegen und am Verfassungsgebot des Art. 5 Abs.1 GG auszurichten.« Allerdings beschränke sich die derzeitig gesetzlich vorgeschriebene Konzentrationskontrolle lediglich auf defensive, negative Vielfaltssicherung (ebd.). Eine Änderung des Staatsvertrags dahingehend, dass die KEK auch strukturgestaltend tätig werden darf, gilt es bei den Gesetzgeber*innen durchzusetzen. So könnte sie Befugnisse erhalten, Medieneinheiten ab einer gewissen Konzentrationsschwelle zu spalten und in kleinere, voneinander unabhängige Organisationen aufzuteilen. Im Dienste einer positiven Gestaltungsfunktion muss die KEK außerdem das Mandat und die Mittel erhalten, den Aufbau neuer Medienorganisationen voranzutreiben. Dann könnte sie zum Beispiel mittels Ausschreibeverfahren für Lizenzen und der Vergabe kompetitiver Fördermittel die Medienlandschaft aktiv mitgestalten.

4 Daten für die Auflagen von Tageszeitungen werden beispielsweise lediglich bundesweit veranschlagt (Ferschli, Grabner und Theine 2019, 13). Die nationalen Konzentrationsmessungen sind also blind gegenüber einer erheblichen Zahl von lokalen oder regionalen Zeitungsmonopolen (ebd.). Laut dem Rundfunkstaatsvertrag könnte eine vorherrschende Meinungsmacht im Fernsehsektor bestehen, wenn auf die Programme einer Sendergruppe ein Zuschauer*innenanteil von 30 Prozent oder mehr entfällt (KEK 2018, 48). Demnach werden die Verhältnisse deutscher Fernsehsender als angemessen eingestuft. Dabei dominierte 2018 ein Oligopol bestehend aus den öffentlich-rechtlichen Sendern mit insgesamt 48,2 Prozent (ARD: 11,5; ZDF: 13,9; andere Öffentlich-Rechtliche: 22,8), der RTL Group mit 22,0 Prozent und der ProSiebenSat.1 Media AG mit 17,9 Prozent den Markt der Fernsehzuschauer*innen in Deutschland (Ferschli, Grabner und Theine 2019, 15). Die Richtwerte der Konzentrationskontrolle ermöglichen damit ein mächtiges Rundfunkoligopol. 
Unabhängige Aufsicht und Überwachung journalistischer Standards Von der Industrie und Regierung unabhängige Rundfunk- und Presseräte sollten dafür zuständig sein, die Kodifizierung und Einhaltung von Rundfunk- und Pressestatuten zu überprüfen, ethische Standards aufrechtzuerhalten, öffentliche Beschwerden abzuwickeln und gegebenenfalls Sanktionen bei Fällen einer Fehlberichterstattung auszusprechen, damit die Integrität des Journalismus gewährleistet bleibt (Fenton et al. 2020, 89). Hier könnte die Medienreformbewegung bei den bestehenden Rundfunk- und Presseräten sowie Landesmedienanstalten (zuständig für die privaten Sender) ansetzen, die im derzeitigen System für Beschwerden zuständig sind. Wie schon in Abschnitt 2 besprochen, werden die Rundfunkräte von den politischen Parteien dominiert. Die Organe des Presserats setzen sich im Wesentlichen aus Vertreter*innen der Organisationen Bundesverband Digitalpublisher und Zeitungsverleger (BDZV), Deutscher Journalisten-Verband (DJV), Deutsche Journalistinnen- und Journalisten-Union (dju) in ver.di und Verband Deutscher Zeitschriftenverleger (VDZ) zusammen. ${ }^{5}$ Es fehlt daher die nötige Unabhängigkeit von der Industrie. Rundfunk- und Presseräte sowie die Räte der Landesmedienanstalten müssen daher im Sinne einer repräsentativen Bürger*innenbeteiligung reformiert werden.

Auch gilt es, die Befugnisse und Sanktionsmittel dieser Organe auszuweiten. Denkbar wäre beispielsweise eine aktivere Rolle der Behörden: So könnten Medieninhalte in Bezug auf die Einhaltung journalistischer Standards regelmäßig überprüft und Ergebnisse dieser Untersuchungen in kontinuierlichen Abständen veröffentlicht werden. Dies ließe sich auch über eine Bürger*innenbeteiligung, beispielsweise durch die Errichtung einer Stiftung Mediawatch, die Gutachten zur Berichterstattung für die Rundfunk- und Presseräte erstellt, umsetzen (Becker et al. 2007, 52). Was Sanktionen angeht, sollten Medienorganisationen bei aufgedeckten Verletzungen journalistischer Standards dazu verpflichtet werden, einen größeren und prominenteren Raum ihrer Berichterstattung für Richtigstellungen und Gegendarstellungen zur Verfügung zu stellen. Auch müssen die Rundfunk- und Presseräte Fehlverhalten öffentlich thematisieren und missbilligen. Um die Pressefreiheit zu wahren, sollten allerdings keine Sanktionsbefugnisse erteilt werden, die direkt in die Redaktionen eingreifen.

5 https://www.presserat.de/aufgaben-organisation.html. Zugegriffen: 10. November 2020. 
Ein wichtiger Teil der Medienreform bestünde außerdem in einer Erweiterung der ethischen Standards des Journalismus: So könnten redaktionelle Statuten ein Element des Konstruktiven Journalismus enthalten (Beiler und Krüger 2018; Krüger in diesem Band). Dieser fokussiert auf die Lösung von Problemen und vermittelt Strategien, wie Menschen positive gesellschaftliche Veränderungen erreichen können (Beiler und Krüger 2018, 185). Das erscheint auch mit Blick auf den menschengemachten Klimawandel von Bedeutung: Hier könnte Konstruktiver Journalismus eine wesentliche Rolle spielen, indem er »Bürgerinnen und Bürger über Problemlösungsversuche informiert und damit gleichzeitig ermächtigt, gegebenenfalls selbst zielgerichtet tätig zu werden« (ebd., 180). Um solche Reformen politisch umzusetzen, schlagen Beiler und Krüger (ebd., 185) vor, durch neue Vorgaben im Rundfunkstaatsvertrag »den Programmauftrag für die öffentlich-rechtlichen Sender um eine konstruktive Komponente « zu ergänzen. Auf ähnliche Weise könnte man den vom Presserat herausgegebenen Pressekodex, der von den meisten Verlagen anerkannt wird, um eine konstruktive Richtlinie erweitern.

Demokratisierung des öffentlich-rechtlichen Rundfunks

Eine strukturelle Reform der Rundfunkräte kann eine demokratischere Kontrolle- und Programmplanung der öffentlich-rechtlichen Sender ermöglichen: Rundfunkräte und -vorstände aller öffentlich-rechtlicher Medien sollten daher von der Gesellschaft gewählt werden und Vertreter*innen aus der Belegschaft enthalten; auch müssen Quotenregelungen absichern, dass alle relevanten Gruppen inklusive der Arbeiter*innen und neuen sozialen Bewegungen in den Rundfunkräten repräsentiert sind. Damit die Vielfalt der Mitarbeiter*innen des Rundfunks gewährleistet bleibt, sollten Daten zur sozialen Zusammensetzung der Arbeitskräfte regelmäßig im Sinne eines Gleichstellungsmonitorings (das auch sozioökonomische Faktoren miteinbezieht) veröffentlicht und überprüft werden. Schließlich sind Grundsatzentscheidungen zur Programmplanung und zur Einführung neuer Dienste unter Berücksichtigung regelmäßiger, repräsentativer Befragungen der Rezipient*innen zu treffen (Becker et al. 2007, 52; Fenton et al. 2007, 88-89).

Die innere Pressefreiheit sollte durch interne Statuten gewährleistet werden, die Journalist*innen »gegen hierarchischen Druck von oben und kurzfristiges Quotendenken absichern« (Becker et al. 2007, 52). Ein möglichst hoher Grad an gewerkschaftlicher Organisation ist dabei 
nötig, um ihre Verhandlungsmacht gegenüber dem Rundfunkmanagement zu stärken. Des Weiteren wird ein Mechanismus benötigt, der es Journalist*innen erlaubt, auf unethisches Verhalten innerhalb der Organisation aufmerksam zu machen, ohne Sanktionen fürchten zu müssen (Fenton et al., 2020, 89). Das Rundfunkmanagement sollte darüber hinaus dezentralisiert und demokratisch aus der Belegschaft für einen befristeten Zeitraum gewählt werden. Über Vollversammlungen ließe sich eine Plattform schaffen, um über wichtige Belange des Rundfunks zu debattieren und abzustimmen. Diese Maßnahmen könnten den Rundfunk aus dem Klammergriff der Politik und Funktionäre befreien und mehr »Aufklärung, Emanzipation, Partizipation und Demokratisierung« ermöglichen (Becker et al. 2007, 51).

Reformmaßnahmen müssen auch dazu führen, dass finanzielle Ressourcen mit Blick auf das öffentliche Interesse und nicht auf Quoten verteilt werden. Das könnte mit einer Stärkung der Finanzkontrolle des öffentlich-rechtlichen Rundfunks durch den Bundesrechnungshof und die Landesrechnungshöfe einhergehen (ebd., 51). Gleichzeitig sollte der öffentlich-rechtliche Rundfunk komplett auf Werbeeinnahmen, Produktplatzierungen und Outsourcing redaktioneller Arbeit verzichten, damit Interessenkonflikte ausgeschlossen bleiben; betriebswirtschaftliche Imperative des Rundfunkmanagements müssen gesellschaftlichen Zielsetzungen weichen (ebd., 51-52). Schließlich wäre eine Veröffentlichung der Honorare von Manager*innen, Führungspersonen und »Stars" der Unterhaltungssendungen sowie Sitzungsprotokolle der Rundfunkräte und Lizensierungsverfahren zur besseren Transparenz geboten (ebd.).

\section{Aufbau und Finanzierung unabhängiger Nachrichtenmedien}

Neben der Stärkung des bestehenden Rundfunk- und Pressesystems sollte die Entwicklung eines gemeinnützigen, unabhängigen Mediensektors mit alternativen Organisations- und Eigentumsstrukturen (zum Beispiel Kooperativen, Stiftungen oder auf Selbstbestimmung basierende Organisationsformen), geleitet von Imperativen wie Gleichheit, Vielfalt, Mitbestimmung, Kollektivismus und Nachhaltigkeit, gefördert werden (Fenton et al. 2020, 87-90). Die KEK oder eine noch zu gründende Behörde für unabhängige Nachrichtenmedien, deren Gremien die Bevölkerung per Wahl bestimmt, könnte die Befugnisse erhalten, diesen Sektor über Lizenzausschreibungen und Fördermittelvergaben mitzugestalten. Gesellschaftliche Gruppen sollten dabei auch in die Lage versetzt werden, mit neuen Organisationsformen und Medienfor- 
maten zu experimentieren. Der Aufbau und Betrieb eines vielfältigen und lebhaften alternativen Mediensektors benötigt allerdings erhebliche Ressourcen. Nach Edward S. Herman $(1999,303)$ besteht ein wichtiger Aspekt der Medienreformstrategie darin, Lösungen zu finden, wie eine stabile und substantielle Finanzierung unabhängiger Nachrichtenmedien ermöglicht werden kann. Die beiden Hauptquellen dafür seien Besteuerung der Einnahmen kommerzieller Medienunternehmen sowie staatliche Zuschüsse und Subventionen.

So wäre eine Finanzierung der reformierten deutschen Medienlandschaft über folgende Modelle möglich: die Landesmedienanstalten könnten Steuern bei den Privaten abschöpfen und damit beispielsweise die durch Werbeeinbrüche geschrumpfte Presse revitalisieren und neue öffentliche oder alternative Medien aufbauen und fördern; alternativ erhielten alle Rezipient*innen einen festgelegten Betrag von den Landesmedienanstalten, der nur für von gemeinnützigen Anbietern produzierte Nachrichten ausgegeben werden darf (Coupon-System). Finanzielle Mittel für diese Subventionssysteme ließen sich über eine Besteuerung von Firmen generieren, deren Marktanteil auf nationalen Medien-, Suchmaschinen- oder Netzwerkplattformmärkten jenseits der 20 Prozent liegt (Fenton et al. 2020, 87-90). Werbekosten, die in Unternehmen fließen, die keine journalistischen Produkte herstellen, könnten, was die steuerliche Abzugsfähigkeit betrifft, anders eingestuft werden als solche, die journalistischen Angeboten zugutekommen. Auch eine Besteuerung von PR-Ausgaben wäre denkbar, denn oftmals bedient sich und profitiert Öffentlichkeitsarbeit vom Journalismus (Kiefer 2011, 17). Darüber hinaus könnten unabhängige Nachrichtenmedien mit eigener journalistischer Redaktion Steuererleichterungen für ihre kultur-gesellschaftliche Leistung erhalten (ebd.). Auch wären die Landesmedienanstalten in der Lage, eine Gebrauchssteuer auf die Nutzung der Übertragungswege Kabel, Satellit, DVBT und IPTV sowie auf Mobil- und andere Telefonverbindungen zu veranschlagen, die private Anbieter nach der Lizensierung zu entrichten haben; denn bei diesen Kommunikationsinfrastrukturen handelt es sich um öffentliche Ressourcen, deren Besteuerung legitim ist (Herman 1999, 303). Schließlich rechtfertigt die gesellschaftliche Bedeutung unabhängiger Nachrichtenmedien mit Blick auf die demokratische Meinungsbildung und Informationsvermittlung die Verwendung allgemeiner Steuern als Mittel der Subvention (ebd.). 


\subsection{Konturen eines reformierten Mediensystems: \\ Langfristige Medienreform bedeutet öffentliche Kontrolle und journalistische Selbstbestimmung}

Die in Abschnitt 3 vorgenommene Analyse der Institutionen der kapitalistischen Medien legt nahe, dass die Nachrichtenproduktion größtenteils von einem System geleistet werden muss, das von wirtschaftlichen und staatlichen Interessen unabhängig zu organisieren ist. Im Umkehrschluss sollten daher Privateigentum, Konzernorganisation, Profit, Markt und Wettbewerb langfristig keine wesentliche Rolle für die Nachrichtenmedien spielen. Robert W. McChesney $(1997,66)$ argumentiert daher, ein Großteil der Nachrichtenmedien müsse unter öffentliche Kontrolle gestellt werden und dürfe nicht von Wirtschaftsunternehmen oder Werbefinanzierung abhängig sein. Um das zu erreichen, können die im vorherigen Abschnitt beschriebenen Besteuerungs- und Subventionierungsinstrumente eingesetzt werden. Daher muss die Reformbewegung eine Medienpolitik forcieren, welche die Entstehung eines gemeinnützigen, nichtgewerblichen und vom Staat unabhängigen Journalismus vorantreibt (ebd.).

Konkret bedeutet das für die deutsche Medienlandschaft: Der öffentlich-rechtliche Rundfunk sollte als eine zentrale Säule des neuen Mediensystems mittels demokratischer Reformen gestärkt und erweitert werden. Gleichzeitig muss ein neuer, nichtkommerzieller Mediensektor entstehen, der sich insbesondere der Journalismus- und Nachrichtenproduktion widmet. James Curran (2002, 239-241) schlägt vor, diesen Sektor in verschiedene Sphären zu unterteilen, in denen unterschiedliche Gruppierungen der Zivilgesellschaft (insbesondere außerhalb der privilegierten Schichten) eigene Nachrichtenmedien unterhalten können. Das erlaube ihnen, vorherrschende ideologische Annahmen in Frage zu stellen, gemeinsame Interessen zu identifizieren und alternative Sichtweisen auszuloten. Curran (ebd., 239) argumentiert des Weiteren, die Fokussierung von Gruppeninteressen dürfe nicht dem Allgemeininteresse schaden oder gesellschaftliche Konfliktlinien vertiefen: »Mutualism should coexist with freedom and equality as general societal objectives.« Er schlägt daher den Aufbau eines zweigleisigen Mediensystems vor, das einerseits in der Lage sein soll, marginalisierten Gruppen und deren Anliegen, Werten und Identitäten Macht zu verleihen, indem es diesen ermöglicht, ihre eigenen, auf vielfältige Weise organisierten und ideologisch ausgerichteten Nachrichtenmedien zu 
betreiben (ebd., 239-240). Neben diesen Medien der Zivilgesellschaft könnte auch die traditionelle Presse eine Sphäre dieses Teilsystems als privatwirtschaftlich organisierter Nachrichtensektor einnehmen. Anderseits soll das Kernelement der Medien, hier repräsentiert durch den öffentlich-rechtlichen Rundfunk, die Gesellschaft durch die Vermittlung gemeinsamer kultureller Erfahrungen, Werte und Erinnerungen sowie durch die Formierung allgemeiner politischer Debatten zusammenhalten (ebd.).

Auch wäre es denkbar, eine professionell-journalistische Sphäre des Mediensystems im Sinne der von Marie Luise Kiefer (2011) vorgeschlagenen Selbstverwaltung des Journalismus als Commons zu organisieren. Demnach würde er als eine selbstorganisierte Profession institutionalisiert und öffentlich finanziert (ebd., 13-14). Laut Kiefer bedürfe es neben gesellschaftlichen auch »wissenschaftliche, politische und gesetzgeberische Initiativen «, um für dieses Ressourcensystem den relevanten Personenkreis und Regelrahmen sowie Kontroll-, Sanktionsund Konfliktlösungsmechanismen zu etablieren (ebd.). Sie argumentiert, dass die Bildung einer Commons nicht frei von Risiko sei; allerdings spreche vieles dafür, dass professionelle Journalist*innen ihre selbstorganisierte Commons "gemäß den via Ausbildung vermittelten professionellen Regeln und Verpflichtungen pflegen « würden, »wobei die gewonnene Reputation des Berufstandes die quasi-freiwillige Kooperation zusätzlich abstützen dürfte« (ebd., 14). Ihr zufolge könnte dieser Ansatz der Selbstorganisation der einzige Ausweg aus der gegenwärtigen Krise sein, der dem Journalismus die nötige wirtschaftliche Unabhängigkeit und Staatsferne ermöglicht.

\section{$5 \quad$ Zusammenfassung}

Zunächst wurde gezeigt, dass die Krise des Journalismus in Deutschland auf die Institutionen der kapitalistischen Medienindustrie zurückzuführen ist. Daher sind umfangreiche strukturelle Reformen, die in einer Demokratisierung, Neuordnung und Erweiterung des Mediensektors münden, erforderlich. Journalismus und Nachrichtenmedien müssen von den Zwängen des Marktes und der konzernkapitalistischen Institutionen befreit und unter öffentliche Kontrolle gestellt werden. Um das zu erreichen, wurden Visionen und Strategien für Medienreformen sowie ein Katalog konkreter Reformmaßnahmen vorgestellt wie auch, darauf aufbauend, die Konturen eines neuen Mediensystems gezeichnet, das neben 
einer Stärkung und Demokratisierung des Journalismus mehr gesellschaftliche Beteiligung an der Nachrichtenproduktion ermöglichen soll. Medienreform ist ein Prozess, der alle Gesellschaftsgruppen einbeziehen muss. Das kann nur durch die Schaffung einer breitangelegten Bewegung, die von Akteur*innen der Zivilgesellschaft, Wissenschaft, und Regulierungsbehörden getragen wird, passieren. Diese Gruppierungen müssen sich auf lokaler, regionaler und länderübergreifender Ebene vernetzen und ein Programm für eine Medienreform ausarbeiten, das parallel auf die öffentliche Agenda gesetzt werden sollte. Denn eine Medienreform benötigt öffentliche Zustimmung und Partizipation. Nur so können die Gesetzgeber*innen dazu verpflichtet werden, Veränderungen auf politischer Ebene einzuleiten. Die hier vorgestellten Reformen, die überwiegend von einer britisch-amerikanischen Forschungstradition inspiriert sind (Curran 2002; Fenton et al. 2020; Herman 1999; McChesney 1997; 2005; 2008; McChesney et al. 2005), verweisen auf eine mögliche Route, die sicherlich noch einer Verfeinerung bedarf. Denn letztendlich müssen gesellschaftliche Transformationen von der Zivilgesellschaft angestoßen werden. Auch sollten Maßnahmen für umfassende Restrukturierungen des Internet-Sektors, der für die Nachrichtenselektion und -verbreitung zunehmend an Bedeutung gewinnt, Einzug in das Programm der Bewegung halten. In jedem Fall müssen weitere Reformprogramme von Wissenschaft und Zivilgesellschaft erörtert und möglichst bald umgesetzt werden.

\section{Literatur}

Alexander, Jeffrey C. 1981. The Mass News Media in Systemic, Historical, and Comparative Perspective. In: Mass Media and Social Change, herausgegeben von Elihu Katz und Tamás Szecskö, 17-51. London: Sage.

Bakan, Joel. 2005. The Corporation: The Pathological Pursuit of Profit and Power. Überarbeitete und erweiterte Auflage. London: Constable.

Barthel, Michael. 2018. 5 facts about the state of the news media in 2017. http:// www.pewresearch.org/fact-tank/2018/08/21/5-facts-about-the-state-of-thenews-media-in-2017/. Zugegriffen: 9. September 2020.

Becker, Jörg, Frank Götz, und Ulrich Meyerholt. 2007. Der öffentlich-rechtliche Rundfunk zwischen Wettbewerb und Kultur: Gutachten zur Situation und Zukunft der Medien, des Medienrechts und der Medienpolitik in Deutschland und der EU, insbesondere des Öffentlich-rechtlichen Rundfunks. Berlin: Fraktion Die Linke im Deutschen Bundestag.

Beiler, Markus, und Uwe Krüger. 2018. Mehr Mehrwert durch Konstruktiven Journalismus? Idee des Konzepts und Implikationen zur Steigerung des Public Va- 
lues von Medien. In: Der öffentliche (Mehr-)Wert von Medien, herausgegeben von Nicole Gonser, 167-191. Wiesbaden: Springer VS.

Betz, Jürgen. 2015. Der Auftrag des öffentlich-rechtlichen Rundfunks: Anmerkungen zu einem Gutachten. Media Perspektiven 2: 58-65.

Curran, James. 2002. Media and Power. London: Routledge.

Daschmann, Gregor. 2009. Qualität von Fernsehnachrichten: Dimensionen und Befunde. Media Perspektiven 5: 257-266.

Davies, Nick. 2009. Flat Earth News. London: Vintage.

Davies, Nick. 2008. Nick Davies: „Churnalism has taken the place of what we should be doing: Telling the truth«. PressGazette vom 4. Februar, https://www. pressgazette.co.uk/nick-davies-churnalism-has-taken-the-place-of-what-weshould-be-doing-telling-the-truth-40117/. Zugegriffen: 8. September 2020.

Deutscher Bundestag. 2009. Die Staatsferne der Aufsichtsgremien öffentlich-rechtlicher Rundfunkanstalten: Sachstand und Reformansätze in vergleichender Perspektive. WD 10 - 3000 - 044/09, Wissenschaftliche Dienste des Deutschen Bundestages.

Donsbach, Wolfgang, und Katrin Büttner. 2005. Boulevardisierungstrend in deutschen Fernsehnachrichten: Darstellungsmerkmale der Politikberichterstattung vor den Bundestagswahlen 1983, 1990 und 1998. Publizistik 50 (1): 21-38.

Eichler, Boris. 2013. Der graue Block: Der Rundfunk in Deutschland hat staatsfern zu sein. Doch die vermeintlich unabhängigen Vertreter in den Rundfunkräten werden oft von staatlich finanzierten Institutionen entsandt. Liberal 4: 84-87.

Fenton, Natalie, Des Freedman, Justin Schlosberg, und Lina Dencik. 2020. The Media Manifesto. E-Book. Cambridge: Polity Press.

Ferschli, Benjamin, Grabner, Daniel, und Hendrik Theine. 2019. Zur Politischen Ökonomie der Medien in Deutschland: Eine Analyse der Konzentrationstendenzen und Besitzverhältnisse. ISW Report Nr. 118. München: Institut für sozial-ökologische Wirtschaftsforschung.

Heinrich, Jürgen. 2002. Medienökonomie. Band 2: Hörfunk und Fernsehen. 2. Auflage. Wiesbaden: Westdeutscher Verlag.

Herman, Edward S. 1999. The Myth of the Liberal Media: An Edward Herman Reader. New York: Peter Lang.

Herman, Edward S. 1995 Triumph of the Market: Essays on Economics, Politics and the Media. Boston: South End Press.

KEK. 2018. Sicherung der Meinungsvielfalt im digitalen Zeitalter: Bericht der Kommission zur Ermittlung der Konzentration im Medienbereich (KEK) über die Entwicklung der Konzentration und über Maßnahmen zur Sicherung der Meinungsvielfalt im privaten Rundfunk. Schriftenreihe der Landesmediananstalten 52. Berlin: Die Medienanstalten.

Kiefer, Marie Luise. 2011. Die schwierige Finanzierung des Journalismus. Medien \& Kommunikationswissenschaft 59 (1): 5-22.

Kiefer, Marie Luise. 2001. Medienökonomik: Einführung in eine ökonomische Theorie der Medien. München: Oldenbourg.

Klöckner, Marcus B. 2019. Sabotierte Wirklichkeit: Oder: Wenn Journalismus zur Glaubenslehre wird. Frankfurt am Main: Westend. 
Knoche, Manfred. 2013. Krisenhafte kapitalistische Produktionsweise als Triebkraft für Restrukturierungen und Transformationen (in) der Medienindustrie: Erklärende Theorieelemente einer Kritik der politischen Ökonomie der Medien. In: Langfristiger Wandel von Medienstrukturen. Theorie, Methoden, Befunde, herausgegeben von Wolfgang Seufert und Felix Sattelberger, 87-111. Baden-Baden: Nomos.

Leidinger, Christiane. 2003. Medien - Herrschaft - Globalisierung: Folgenabschätzung zu Medieninhalten im Zuge transnationaler Konzentrationsprozesse. Münster: Westfälisches Dampfboot.

Lobings, Frank, und Christoph Neuberger. 2018. Meinungsmacht im Internet und die Digitalstrategien von Medienunternehmen: Neue Machtverhältnisse trotz expandierender Internet-Geschäfte der traditionellen Massenmedien-Konzerne. Leipzig: Vistas.

McChesney, Robert W., Newman, Russell, und Ben Scott. 2005. The Future of Media: Resistance and Reform in the 21st Century. New York: Seven Stories Press.

McChesney, Robert W. 2008. The Political Economy of Media: Enduring Issues, Emerging Dilemmas. New York: Monthly Review Press.

McChesney, Robert W. 2005. The emerging struggle for a free press. In: The Future of Media: Resistance and Reform in the 21st Century, herausgegeben von Robert W. McChesney, Russell Newman und Ben Scott, 9-20. New York: Seven Stories.

McChesney, Robert W. (1997) Corporate Media and the Threat to Democracy. New York: Seven Stories.

Röper, Horst. 2020. Daten zur Konzentration der Tagespresse im I. Quartal 2020. Tageszeitungen 2020: Schrumpfender Markt und sinkende Vielfalt. Media Perspektiven 6: 331-352.

Tröger, Mandy. 2020. Eine Kritik der Ideologie der »freien Presse« zur Wendezeit 1989/1990. In: Ideologie, Kritik, Öffentlichkeit - Verhandlungen des Netzwerks Kritische Kommunikationswissenschaft, herausgegeben von Uwe Krüger und Sebastian Sevignani, 115-135. Frankfurt am Main: Westend.

Weiß, Hans-Jürgen. 2007. Private Fernsehvollprogramme 1998-2007. In: ALM Programmbericht 2007, herausgegeben von Arbeitsgemeinschaft der Landesmedienanstalten in der Bundesrepublik Deutschland, 37-66. Berlin: Vistas.

Wolf, Armin. 2019. Zwischen Propaganda und Paywall: Journalismus in der Krise. Blätter für deutsche und internationale Politik, Januar. https://www.blaetter.de/ ausgabe/2019/januar/zwischen-propaganda-und-paywall-journalismus-inder-krise. Zugegriffen: 8. September 2020.

Zollmann, Florian. 2017. Media, Propaganda and the Politics of Intervention. New York: Peter Lang.

Zollmann, Florian. 2009. Is it Either Or? Professional Ideology vs. Corporate-Media Constraints. Westminster Papers in Communication and Culture 6 (2): 97-118.

\section{Open Access}

Dieser Beitrag erscheint unter der Creative-Commons-Lizenz CC BY-ND 3.0 DE: https://creativecommons.org/licenses/by-nd/3.0/de/. 


\section{Kurzbiographien}

Hanan Badr, Prof. Dr., ist Kommunikationswissenschaftlerin mit Schwerpunkt auf internationalen Mediensystemen, Öffentlichkeiten und Transformation. Zurzeit ist sie Associate Professor an der Gulf University for Science and Technology. Sie hat Forschungsexpertise an deutschen und arabischen Institutionen wie der Freien Universität Berlin, dem Orient-Institut Beirut und der Kairo Universität. Ihre Forschung beschäftigt sich mit Fragen nach Kommunikation und Ungleichheit, gegenseitigen Bildern zwischen dem Westen und muslimischen Ländern, Journalismus sowie Internet und digitaler Öffentlichkeit. Badr hat in Digital Journalism, International Communication Gazette, Media, War \& Conflict, Publizistik, Medien und Kommunikation, Égypte/ Monde arabe, Zeitschrift für Internationale Beziehungen und in mehreren internationalen Sammelbänden veröffentlicht.

Natalie Berner, M.A., ist seit 2017 wissenschaftliche Mitarbeiterin und Doktorandin am Institut für Kommunikationswissenschaft und Medienforschung an der Ludwig-Maximilians-Universität München. Ihre Forschungsschwerpunkte sind qualitative Methoden, Diskursanalysen sowie die Zusammenführung von Gesellschafts- und Medientheorie. In ihrem Dissertationsprojekt beschäftigt sie sich mit der Verhandlung von Mutterschaft auf verschiedenen gesellschaftlichen und medialen Ebenen. Sie ist seit der Gründungstagung in München Teil des Netzwerks.

Nils S. Borchers, Dr., ist Akademischer Rat auf Zeit am Lehrstuhl für Empirische Medienforschung am Institut für Medienwissenschaft an der Eberhard Karls Universität Tübingen. 2017 hat er das Netzwerk Kritische Kommunikationswissenschaft mitgegründet. Er ist ehemaliger Sprecher der Fachgruppe Werbekommunikation in der Deutschen Gesellschaft für Publizistik und Kommunikationswissenschaft sowie 
Mitglied des Wissenschaftsnetzwerks des Kompetenzzentrums Kulturund Kreativwirtschaft des Bundes.

Moritz Clauß, M. A., ist Multimedia-Redakteur in der Regionalredaktion der Südwest Presse in Ulm. Nach seinem Bachelorstudium der Sozialwissenschaften an der Universität Augsburg absolvierte er dort den Master Sozialwissenschaftliche Konfliktforschung und schrieb unter anderem für die Stuttgarter Zeitung und die Tageszeitung taz. Während seiner journalistischen Ausbildung bei der Südwest Presse produzierte er gemeinsam mit seinen Kolleg*innen das Magazin Ein Land zu 30 Jahren Mauerfall - das Projekt wurde von der Konrad-AdenauerStiftung mit dem Deutschen Lokaljournalistenpreis für Volontäre ausgezeichnet.

Klaus Dörre, Prof. Dr., ist seit 2005 Professor für Arbeits-, Industrieund Wirtschaftssoziologie an der Friedrich-Schiller-Universität Jena. Er ist einer der Direktoren des DFG-Kollegs »Postwachstumsgesellschaften« und Mitherausgeber des Berliner Journals für Soziologie und des Global Dialogue. Seine Forschungsschwerpunkte sind Kapitalismustheorie, Prekarisierung von Arbeit und Beschäftigung, Arbeitsbeziehungen, soziale Folgen der Digitalisierung sowie Rechtspopulismus. Aktuelle Bücher: In der Warteschlange - Arbeiter*innen und die radikale Rechte (2020); Abschied von Kohle und Auto? Sozial-ökologische Transformationskonflikte um Energie und Mobilität (2020, mit M. Holzschuh, J. Köster und J. Sittel); Neosozialismus - Solidarität, Demokratie und Ökologie vs. Kapitalismus (2019, mit C. Schickert).

Johannes Gemkow, Dr., ist wissenschaftlicher Mitarbeiter am Forschungsinstitut Gesellschaftlicher Zusammenhalt (FGZ), Teilstandort Leipzig. Am FGZ forscht Johannes Gemkow über den Zusammenhang zwischen gesellschaftlichem Zusammenhalt und (teil-)öffentlicher Kommunikation populistischer Gruppierungen und Jugendlicher auf Social-Media-Plattformen.

Antje Glück, Dr., ist Lecturer in Multimedia-Journalismus an der Bournemouth University in England. In ihrer Promotion untersuchte sie, wie Fernsehjournalist*innen in Indien und Großbritannien Emotionen und Empathie in ihrer Arbeitspraxis wahrnehmen und reflektieren. Antje Glück forscht und publiziert außerdem zu den Themen De-Westernisierung, Internationaler Journalismus, Datenjournalismus, Terro- 
rismus sowie mediale Repräsentationen. Vor ihrer wissenschaftlichen Karriere studierte und arbeitete sie als freie Journalistin in Deutschland, Ägypten, Indien und Frankreich.

Selma Güney, B.A., studiert Kommunikationswissenschaft im Master an der Westfälischen Wilhelms-Universität Münster, wo sie zuvor Politikwissenschaft, Islamische Theologie, Philosophie und Kunstgeschichte studiert hat. Seit 2011 ist sie in politischen Initiativen aktiv, zuletzt als Mitbegründerin des Projekts »Muslima Empowerment«. Bis 2019 war Selma Güney studentische Hilfskraft bei Prof. Christopher Jon Sprigman am Engelberg Center for Innovation Law and Policy, New York University Law School. Seit 2019 ist sie Mitglied im Organisationsteam des Netzwerks Kritische Kommunikationswissenschaft.

Michael Haller, Prof. Dr., leitet das Europäische Institut für Journalismus- und Kommunikationsforschung (EIJK) in Leipzig. Bis zu seiner Emeritierung 2010 lehrte er an der Universität Leipzig, wo er den 1993 reformierten Diplomstudiengang Journalistik aufgebaut hat. Vor seiner wissenschaftlichen Laufbahn war Michael Haller als Reporter und Redakteur in verschiedenen Pressemedien tätig, darunter zehn Jahre bei Zeitungen, 13 Jahre beim Spiegel, dann als Ressortleiter bei der Zeit. Er hat mehrere Standardwerke des Journalismus verfasst, darunter Recherchieren (aktuell in der 8. Auflage) und Die Reportage (7. Auflage) und forscht zur gesellschaftlichen Funktion des Journalismus.

Heiko Hilker, Dipl.-Ing., ist seit 2009 einer der beiden Geschäftsführer des von ihm mit gegründeten Dresdner Instituts für Medien, Bildung und Beratung (DIMBB). Geboren 1966 in Eberswalde, arbeitete er nach dem Abitur ein Jahr als Hilfselektriker in der VEB Filmfabrik Wolfen, wo er in der Abendschule den Berufsabschluss eines Elektromonteurs erwarb. Von 1986 bis 1991 studierte er an der TU Dresden Informationstechnik. 1991 bis 1993 war er einer der bundesweiten Koordinatoren der DT64-Freundeskreise. Im Herbst 1993 startete das von ihm mitinitiierte Jugendmedienzentrum, das handlungsorientierte Medienarbeit (Radio, Foto, Video, Zeitung, Internet) anbot. Als Parteiloser war er von 1994 bis 2009 Landtagsabgeordneter der PDS in Sachsen. Seit 1997 ist er Mitglied im MDR-Rundfunkrat.

Sebastian Jürss, M.A., ist wissenschaftlicher Mitarbeiter am SOCIUM Forschungszentrum Ungleichheit und Sozialpolitik der Universität 
Bremen. Zuvor war er wissenschaftlicher Mitarbeiter am Institut für Kommunikations- und Medienwissenschaft der Universität Leipzig und hat dort unter anderem zu Sharing Economy, digitaler Ungleicheit und Future Imaginaries geforscht.

Sigrid Kannengießer, Prof. Dr., ist Vertretungsprofessorin für Kommunikations- und Medienwissenschaft mit dem Schwerpunkt Mediengesellschaft am Zentrum für Medien-, Kommunikations- und Informationsforschung der Universität Bremen und Mitglied des artec Forschungszentrums Nachhaltigkeit derselben Universität. Sie ist ehemalige Sprecherin der Fachgruppe "Soziologie der Medienkommunikation« der Deutschen Gesellschaft für Publizistik und Kommunikationswissenschaft.

Sebastian Köhler, Prof. Dr., arbeitet seit 2010 als Professor für Publizistik an der Hochschule für Medien, Kommunikation und Wirtschaft am Standort Berlin und ist dort seit 2020 Fachbereichsleiter für Journalismus und Kommunikation. Geboren 1967 und aufgewachsen in Erfurt, volontierte er im Wendejahr 1989/1990 in Erfurt, Sömmerda und Böblingen. Seitdem bis heute auch als Journalist tätig. Ab 1990 Magisterstudium der Philosophie und Publizistik/Kommunikationswissenschaft an HU und FU Berlin. Anschließend berufsbegleitendes Aufbaustudium »Audiovisueller Journalismus/Digitale Medien« an der FH Kiel. 1998 bis 2001 als Stipendiat der Studienstiftung des deutschen Volkes, Promotion an der Universität Potsdam zu »Potenzialen neuer Medien für gesellschaftliche Kommunikation«. 2002 bis 2008 wissenschaftlicher Mitarbeiter der Abteilung Journalistik der Universität Leipzig. Seit 2013 Vertrauensdozent der Hans-Böckler-Stiftung.

Judith Kretzschmar, Dr., ist wissenschaftliche Mitarbeiterin am Zentrum Journalismus und Demokratie der Universität Leipzig (JoDem) und Leitung des Leipziger Instituts für Heimat- und Transformationsforschung (LIHT). Magister in Kommunikations- und Medienwissenschaft sowie Theaterwissenschaft an der Universität Leipzig, anschließend wissenschaftliche Mitarbeiterin im DFG-Projekt »Programmgeschichte des DDR-Fernsehens « und am Institut für Kommunikations- und Medienwissenschaft der Universität Leipzig. Promotion über Repräsentation von »Heimat « im DDR-Fernsehen und Anschlussforschung "Sächsisches Lokalfernsehen in der Nachwendezeit«. Sie ist außerdem Projektleiterin der Oral-History-Fachgruppe »Zeitzeugen des Rund- 
funks« und stellvertretende Vorsitzende des Studienkreises Rundfunk und Geschichte e.V. und war die letzten zwölf Jahre Vize-Vorsitzende des Zentrums für Wissenschaft und Forschung | Medien e.V.

Uwe Krüger, Dr., ist wissenschaftlicher Mitarbeiter am Institut für Kommunikations- und Medienwissenschaft und Forschungskoordinator des Zentrums Journalismus und Demokratie der Universität Leipzig. Für seine Bücher Mainstream - Warum wir den Medien nicht mehr trauen (C. H. Beck 2016) und Meinungsmacht. Der Einfluss von Eliten auf Leitmedien und Alpha-Journalisten - eine kritische Netzwerkanalyse (Halem 2013) erhielt er den Günter-Wallraff-Preis für Journalismuskritik der Initiative Nachrichtenaufklärung. 2017 hat er das Netzwerk Kritische Kommunikationswissenschaft mitgegründet und gehört seitdem dessen Organisationsteam an. 2018 bis 2019 Mitglied des MDR-Rundfunkrates, entsandt vom Deutschen Journalisten-Verband Sachsen.

Stella Lorenz, M. A., arbeitet für die Frankfurter Neue Presse als Lokalredakteurin beim Rüsselsheimer Echo und promoviert seit 2019 an der Albert-Ludwigs-Universität Freiburg und der Hochschule Darmstadt zu alternativen Erzählformen für Nachhaltigkeitsjournalismus in Printmagazinen. Nach ihrem Bachelor-Studium in Kunst, Musik und Medien an der Philipps-Universität Marburg absolvierte sie 2017 den Masterstudiengang Medienentwicklung an der Hochschule Darmstadt, wo sie außerdem als Lehrbeauftragte für journalistisches Schreiben tätig war. Schwerpunkte ihrer Arbeit sowie ihres Lebens abseits des Schreibtisches sind Kultur, Musik, Literatur, grüne und gesellschaftliche Trends.

Melanie Malczok, M. A., ist wissenschaftliche Mitarbeiterin im »Zukunftslabor Gesellschaft und Arbeit« des ZDIN an der Hochschule Osnabrück und freiberuflich als Dozentin und Kommunikationsberaterin tätig. Ihre Arbeitsschwerpunkte sind die interne Organisationskommunikation und der Einfluss technologischer Transformationsprozesse auf Arbeit und Gesellschaft. Vor ihrem Studium in Strategischer Kommunikation an der Westfälischen Wilhelms-Universität Münster und Kommunikationsmanagement in Osnabrück implementierte sie E-Learning und blended Learning als neue Lehrmethoden beim Bildungs- und Wissenschaftszentrum der Bundesfinanzverwaltung.

Lea Matusiak, B. A., arbeitet als Marketing-Managerin in Darmstadt. 2020 absolvierte sie ihr Studium der Onlinekommunikation an der 
Hochschule Darmstadt. Sie übernahm während des Studiums ein Jahr lang die Redaktionsleitung des studentischen PR-Blogs »PR Fundsachen $\ll$.

Sandra Müller, Dipl.-Informationsw. (FH), ist verantwortlich für das Kommunikations- und Wissensmanagement im Projekt »Systeminnovation für Nachhaltige Entwicklung (s:ne)« an der Hochschule Darmstadt. Nach dem Studium Informations- und Wissensmanagement an der Hochschule Darmstadt war sie Mitarbeiterin bei der MLP Finanzdienstleistungen AG. Dort arbeitete sie von 2008 bis 2018 in verschiedenen Themenfeldern - im Wissensmanagement, in der Internen Kommunikation sowie im Tagungs- und im Vertriebsmanagement.

Thomas Pleil, Prof. Dr., ist Professor für Public Relations mit Schwerpunkt Online-PR an der Hochschule Darmstadt. Dort ist er Sprecher des Direktoriums des Instituts für Kommunikation und Medien (ikum) und hat den Studiengang Onlinekommunikation (B.Sc.) aufgebaut. Zuvor war er mehr als zehn Jahre als PR-Praktiker und Journalist tätig. Seine aktuellen Arbeitsschwerpunkte sind Onlinekommunikation, Social Media, Nachhaltigkeitskommunikation und Lebenslanges Lernen.

Holger Pötzsch, $\mathrm{PhD}$, ist Professor für Medienwissenschaften am Institut für Sprachen und Kultur an der Universität Troms $\emptyset$ - Norwegens Arktischer Universität. Seine Forschungsschwerpunkte sind kritische Medienkompetenz, das Verhältnis von Medien, Gedächtnis und Krieg (vor allem Kriegsfilme und -spiele) sowie der Einfluss digitaler Technologien auf Identität und Politik. Seine Arbeiten sind in einer Reihe von Fachzeitschriften erschienen, darunter EPD: Society \& Space, TripleC, New Media \& Society, Memory Studies, Game Studies und Games \& Culture. Zuletzt hat er zusammen mit Phil Hammond den Sammelband War Games: Memory, Militarism and the Subject of Play (Bloomsbury Academic 2019) herausgegeben.

Torsten Schäfer, Prof. Dr., ist Professor für Journalismus und Textproduktion an der Hochschule Darmstadt, freier Autor sowie Medientrainer. Seine Arbeitsschwerpunkte liegen neben dem Umwelt- und Klimajournalismus im Storytelling, der Stilistik und der EU-Berichterstattung. Für Journalismus und Forschungen erhielt er mehrere Preise und Stipendien. Von 2009 bis 2013 war Schäfer Redakteur der internationalen GEO-Ausgabe und zuvor Chef vom Dienst und Planer in der 
Onlineredaktion der Deutschen Welle. Stationen davor: Politik-Promotion zur EU-Berichterstattung sowie Master in European Studies an der RWTH Aachen, Diplom-Studium der Journalistik an der TU Dortmund mit integriertem Zeitungsvolontariat. Freier Journalist jeweils über mehrere Jahre für GEO, taz, Süddeutsche Zeitung und dpa.

Kerem Schamberger, Dr., ist wissenschaftlicher Mitarbeiter am Institut für Kommunikationswissenschaft und Medienforschung der Ludwig-Maximilians-Universität München. Sein Forschungsschwerpunkt liegt in der Analyse von Mediensystemen. In seinem Dissertationsprojekt beschäftigte er sich mit dem transnationalen Netzwerk kurdischer Medien. 2017 hat er das Netzwerk Kritische Kommunikationswissenschaft mitgegründet und gehört seitdem dessen Organisationsteam an. 2018 erschien im Westend Verlag sein Buch Die Kurden - ein Volk zwischen Unterdrückung und Rebellion (zusammen mit Michael Meyen). Er ist zudem im Vorstand des Instituts für sozial-ökologische Wirtschaftsforschung (isw) und des Instituts Solidarische Moderne.

Rüdiger Steinmetz, Prof. Dr., war von 1992 bis 2018 Inhaber des Lehrstuhls Medienwissenschaft und Medienkultur am Institut für Kommunikations- und Medienwissenschaft (IfKMW) der Universität Leipzig, jetzt Emeritus. Seit 2010 Medienrat der Sächsischen Landesmedienanstalt. Leitung des Leipziger Instituts für Heimat- und Transformationsforschung (LIHT). Publikationen zu Mediengeschichte Ost-West, Filmtheorie, Medienpolitik, Digitalisierung, anwendungsorientierter Medienausbildung und Media Literacy. Ab 1992 Aufbau des IfKMW (Gründungsdirektor) und des Lokalradios der Uni Leipzig, mephisto 97.6. Zuvor: Staatsexamen Uni Göttingen (Politik-, Kommunikationsund Erziehungswissenschaft sowie Germanistik), Zeitungsredakteur mit Volontariat, Wissenschaftlicher Assistent an der Hochschule für Fernsehen und Film München, Promotion LMU München und Habilitation Uni Marburg.

Mandy Tröger, $\mathrm{PhD}$, ist wissenschaftliche Mitarbeiterin am Institut für Kommunikationswissenschaft und Medienforschung der Ludwig-Maximilians-Universität München. Sie hat am Institute of Communications Research der Universität Illinois (USA) studiert und wurde dort 2018 promoviert. Ihre Forschungsschwerpunkte liegen in der Kritischen Theorie und deutsch-deutscher Mediengeschichte. Für Ihre Masterarbeit »Dallas in East Germany« an der Universität Amsterdam erhielt 
sie den Theodore Roosevelt History Award. Sie war Promotionsstipendiatin der Heinrich-Böll-Stiftung und ist Autorin des Buches Pressefrühling und Profit: Wie westdeutsche Verlage 1989/1990 den Osten eroberten (Halem 2019). 2020 erhielt sie für ihre Dissertation den Nachwuchsförderpreis der Fachgruppe Kommunikationsgeschichte der Deutschen Gesellschaft für Publizistik- und Kommunikationswissenschaft (DGPuK). Seit 2017 gehört sie dem Organisationsteam des Netzwerks Kritische Kommunikationswissenschaft an.

Thomas Wiedemann, Dr., ist wissenschaftlicher Mitarbeiter am Institut für Kommunikationswissenschaft und Medienforschung der Ludwig-Maximilians-Universität München. Er promovierte 2012 mit einer fachgeschichtlichen Arbeit über Walter Hagemann und die Neugründung der Publizistikwissenschaft nach dem Zweiten Weltkrieg. Gegenwärtig leitet er das von der Deutschen Forschungsgemeinschaft geförderte Projekt »Diskursive Wirklichkeitskonstruktion im deutschen Kinospielfilm«. Forschungsschwerpunkte: Medienkultur, Filmsoziologie, Fach- und Theoriegeschichte der Kommunikationswissenschaft, Sozialtheorien, Qualitative Methoden.

Florian Zollmann, Dr., ist Senior Lecturer in Journalism an der Newcastle University in England. Zu seinen Schwerpunkten gehören Kriegs- und Krisenberichterstattung, kritische politische Ökonomie, internationale Beziehungen und Propaganda. 2017 erschien bei Peter Lang (New York) sein Buch Media, Propaganda and the Politics of Intervention, das Doppelstandards in der deutschen, englischen und US-amerikanischen Medienberichterstattung zu internationalen Konflikten untersucht. Florian Zollmann ist außerdem Autor der zweimonatlich in dem Magazin Publik-Forum Extra Leben erscheinenden Medienkritik »Unterm Brennglas ...« 


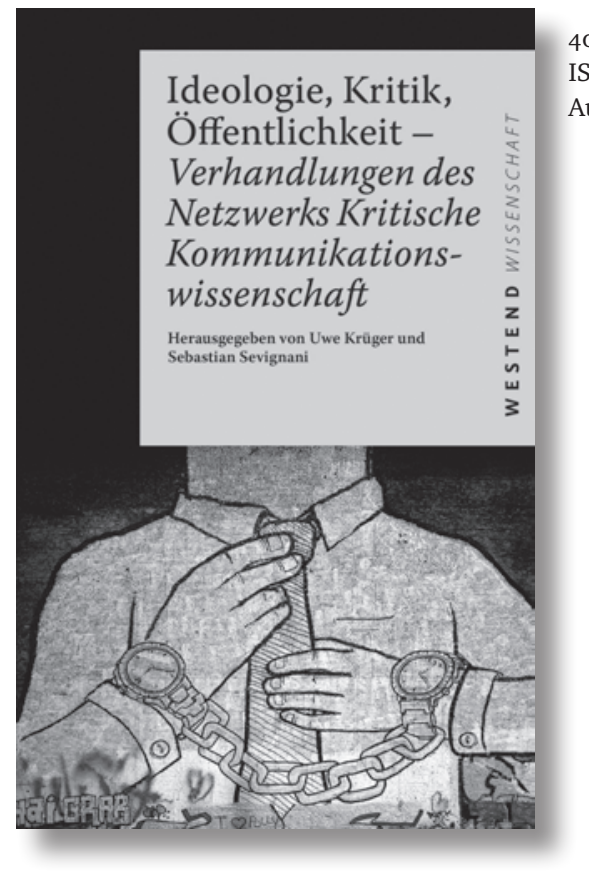

Aus dem Mainstream der wissenschaftlichen Debatte über Medien, Journalismus und Öffentlichkeit sind seit Jahrzehnten wichtige Begriffe praktisch verschwunden: »Herrschaft«, »Propaganda « und auch »Ideologie«.

Dieses Buch übt Ideologiekritik an den Kommunikationsverhältnissen in westlich-kapitalistischen Demokratien. Seine Autorinnen und Autoren sind Forscher aus dem Netzwerk Kritische Kommunikationswissenschaft und beleuchten Ideologien in der massenmedialen Berichterstattung, der Medienpolitik, der Medienindustrie und der Medienwissenschaft. Mit Beiträgen von Floris Biskamp, Nils S. Borchers, Michael Haller, Sebastian Jürss, Manfred Knoche, Patrick Körner, Uwe Krüger, Kim Kristin Mauch, Birgit Peuker, Juliane Pfeiffer, Holger Pötzsch, Renatus Schenkel, Armin Scholl, Sebastian Sevignani, Martina Thiele, Mandy Tröger und Florian Zollmann. 